\title{
DIVERSIDADE ZOOPLANCTÔNICA E VARIÁVEIS LIMNOLÓGICAS DAS REGIÕES LIMNÉTICA E LITORÂNEA DE CINCO LAGOAS DO VALE DO RIO DOCE - MG, E SUAS RELAÇões COM O ENTORNO
}

EVANDRo Mateus MORETto

Dissertação apresentada à Escola de Engenharia de São Carlos, Universidade de São Paulo, como parte dos requisitos para obtenção do grau de Mestre em Ciências da Engenharia Ambiental.

Orientadora: Prof ${ }^{\text {a. }}$ Dr $^{\text {a. }}$ Odete Rocha 
Ficha catalográfica preparada pela Seção de Tratamento da Informação do Serviço de Biblioteca - EESC/USP

Moretto, Evandro Mateus

M845d Diversidade zooplanctônica e variáveis limnológicas das regiões limnética e litorânea de cinco lagoas do Vale Do Rio Doce - MG, e suas relações com o entorno / Evandro Mateus Moretto. -- São Carlos, 2001.

Dissertação (Mestrado) -- Escola de Engenharia de São Carlos-Universidade de São Paulo, 2001.

Área: Ciências da Engenharia Ambiental.

Orientador: Prof ${ }^{a}$. Dra . Odete Rocha.

1. Diversidade do zooplâncton. 2. Limnologia.

3. Lagos brasileiros. 4. Vale do Rio Doce.

5. Copepoda. 6. Cladocera. 7. Rotifera. I. Título. 


\section{FOLHA DE APROVAÇÃO}

Autor: Bacharel em Ciências Biológicas EVANDRo MATEUs MORETTO

Título: Diversidade zooplanctônica e variáveis limnológicas das regiões limnéticas e litorâneas de cinco lagoas do Vale do Rio Doce - MG, e suas relações com o entorno

Dissertação apresentada e aprovada em 22 de junho de 2001.

pela Comissão Julgadora:

Profa. Titular OdETE RoCHA (Orientadora)

(Universidade Federal de São Carlos - UFSCar)

Prof. Dr. EVALDO LUIZ GAETA ESPÍNDOLA

(Universidade de São Paulo - USP)

Prof. Dr. MARCOS GOMES NOGUEIRA

(Universidade Estadual Paulista - UNESP)

Prof. Dr. EVALDO LUIZ GAETA ESPÍNDOLA

Coordenador da Área de Ciências da Engenharia Ambiental

Prof. Dr. José Carlos Ângelo Cintra

Presidente da Comissão de Pós-Graduação da EESC 
Dedico este trabalho aos meus pais, Pedro e Deolinda, ao meu irmão, Sandro, e à minha namorada, Mercia, pela confiança e apoio incondicionais que me conferiram em todos os momentos. 


\section{AGRADECIMENTOS}

À Profa. Dra. Odete Rocha, pela amizade e orientação ao longo dos últimos três anos, e pela contribuição para o meu aperfeiçoamento profissional e dos valores científicos.

Ao Centro de Recursos Hídricos e Ecologia Aplicada - EESC / USP, por ter propiciado a oportunidade da convivência com profissionais de diversos segmentos relacionados às Ciências da Engenharia Ambiental.

Ao Departamento de Ecologia e Biologia Evolutiva - USFCar, pela disponibilização de apoio técnico, logístico e estrutural, fundamentais na execução de todas as etapas deste trabalho.

Ao Conselho Nacional de Desenvolvimento Científico e Tecnológico pela concessão de bolsa de estudos durante o período de vigência do mestrado.

Ao Ministério do Meio Ambiente - Programa Probio, do qual este trabalho é integrante, pelo fornecimento de apoio técnico e financeiro.

À Companhia Agrícola Florestal de Minas Gerais (CAF) e ao Instituto Estadual de Florestas (IEF-MG) pela permissão de acesso à área de estudos, pela disponibilização das instalações, suporte de pessoal técnico e informações, fundamentais na execução dos trabalhos de campo.

Ao Prof. Dr. Marcos Gomes Nogueira, pela enorme contribuição para minha formação acadêmica, pelo apoio nas minhas decisões profissionais, pela grande amizade, e pelas sugestões e críticas que ajudaram a delinear o presente trabalho.

Ao Prof. Dr. Evaldo Luiz Gaeta Espíndola, pelas avaliações e sugestões atribuídas ao presente trabalho e no decorrer do curso de mestrado, e pela convivência oferecida no Centro de Recursos Hídricos e Ecologia Aplicada.

Ao auxiliar acadêmico e companheiro de turma de mestrado José Valdecir de Lucca, pelos gratificantes trabalhos desenvolvidos em parceria ao longo dos últimos três anos, e pela sua colaboração fundamental nos meus trabalhos de campo e laboratoriais.

Aos auxiliares acadêmicos Airton Santo Soares, do Departamento de Biologia e Ecologia Evolutiva - UFSCar, e ao Valdomiro Antônio Filho, do Centro de Recursos Hídricos e Ecologia Aplicada - USP, pela amizade e pela pronta colaboração nas atividades de campo.

Ao Caio Augusto de Almeida e Glória Tanigushi pelo auxílio nas atividades de campo. 
Ao Magno Botelho Castelo Branco pelo auxílio nas atividades de campo, pelo levantamento do acervo fotográfico deste trabalho e pelo posterior processamento computacional deste material.

Aos alunos de pós-graduação da UFSCar Adriana Güntzel, Irineu Francisco Neves, Maria José dos Santos Wisniewiski e Paulo Augusto Zaitune Pamplin, do Laboratório de Limnologia do DEBE - UFSCar, pela colaboração nas atividades laboratoriais e sugestões oferecidas.

Ao Carlos Eduardo Marinelli pela contribuição teórica oferecida por discussões e material bibliográfico, pela parceria em diversas atividades acadêmicas (curriculares e extra-curriculares), pelo intenso convívio durante todo o período de mestrado, e pela grande amizade conquistada durante nosso convívio em república.

Ao Prof. Xavier Lazaro e ao Welber Smith pelas orientações no tratamento dos dados.

A Fernanda Teixeira Marciano pelo auxílio no tratamento estatístico e pelas inúmeras conversas informais, prova de nossa grande amizade.

Ao Éliton Rodrigo Silveira, pela vivência ao longo do curso de mestrado em infindáveis discussões, eventos gastronômicos e festivos, cuja satisfação e alegria levarei como um agradável cenário lúdico de minha vida em São Carlos.

Ao Rinaldo Ribeiro Filho, pelo apoio teórico no presente trabalho e pela confiança e amizade conquistadas durante o hilariante período em que moramos em república.

Aos também companheiros de república José Luiz Müller, Fabiano Botta Tonisi e Rosa Maria Toro pela amizade e convivência agradável.

Aos amigos Adeíldo, Ana Paola, André Luiz de Oliveira, Andréia, Celina, Camila Pereira Sitônio, Conceição, Dirlane Fátima do Carmo, Gunther Brucha, Isabel Sakamoto, Kênia Mara da Rocha, Luana Maria Marelli, Maurício Augusto Leite, Patrícia Aparecida Souza, pelos momentos de descontração.

Aos grandes amigos Alexandre Dal Pai, Alexandre Baaklini Gomes Coelho, Mathias Schelp, Paulo Malagutte, Rodrigo Maia e Silmar Antônio Travain pela grande amizade e por terem me recebido no primeiro ano em São Carlos.

Aos amigos Hélio César Fernandes Marques e Mauro Sérgio Vianello Pinto que, embora não tenham participado diretamente do presente trabalho, contribuíram de forma determinante na formação de meus ideais e nas minhas decisões profissionais. 
Em especial à minha namorada Mercia Regina Domingues pela alegria, pelo apoio e conforto nos momentos de incertezas, e pela felicidade que encontramos nestes dois últimos anos.

E aos meus pais, Pedro Ramos Moretto e Deolinda Aparecida Saltarelli Moretto, e ao meu irmão Sandro Marcelo Moretto, pelo confiança, apoio e paciência que disponibilizaram ao longo da realização deste trabalho e de todos os outros já realizados. 


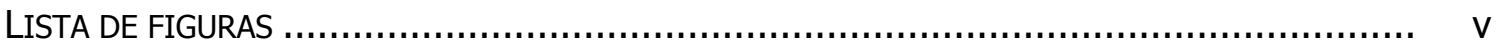

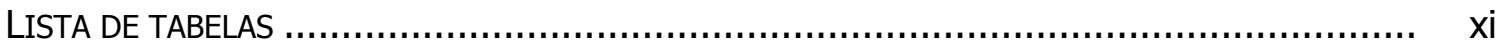

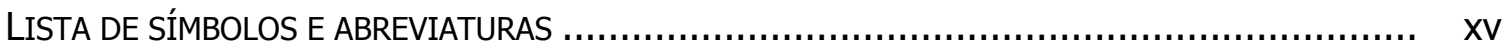

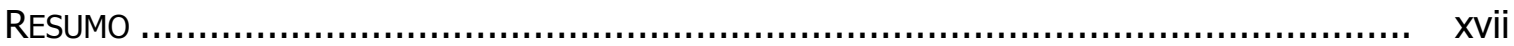

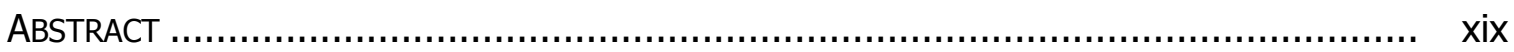

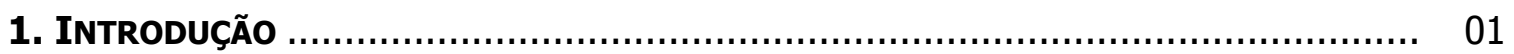

1.1. O PRESENTE ESTUDO NO CONTEXTO AMBIENTAL ...................................... 02

1.2. ELEMENTOS NATURAIS VERSUS RECURSOS NATURAIS .................................. 05

1.3. OS EFEITOS DOS DISTÚRBIOS NA BIODIVERSIDADE ................................... 07

1.4. A DIVERSIDADE BIOLÓGICA NOS ECOSSISTEMAS LACUSTRES $\ldots \ldots \ldots \ldots \ldots \ldots \ldots \ldots \ldots \ldots \ldots$

1.5. CARACTERÍSTICAS E GÊNESE DOS LAGOS NATURAIS BRASILEIROS ....................... 14

1.6. COMPARTIMENTOS HORIZONTAIS EM SISTEMAS LACUSTRES NATURAIS $\ldots \ldots \ldots \ldots \ldots \ldots . .17$

1.7. A DIVERSIDADE ZOOPLANCTÔNICA NOS SISTEMAS LACUSTRES:

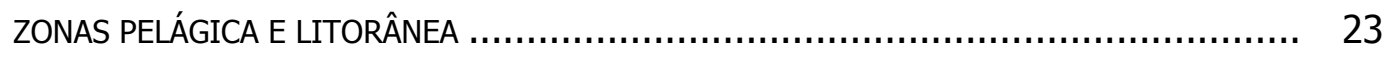

1.8. ZOOPLÂNCTON COMO INDICADOR DA QUALIDADE DA ÁGUA ............................. 26

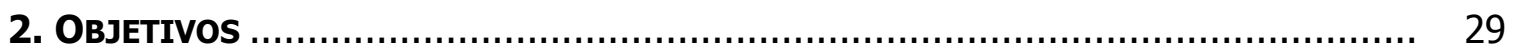

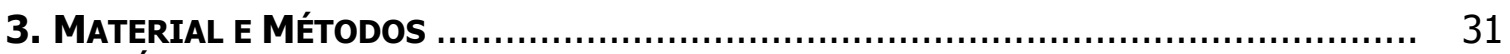

3.1. ÁREA DE ESTUDOS: O SISTEMA DE LAGOS DO VALE DO RIO DOCE ..................... 31

3.1.1. REGIÃO POLÍTICO-ADMINISTRATIVA ............................................. 31

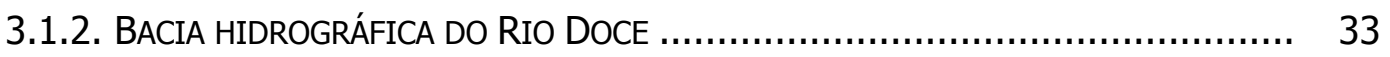

3.1.3. ASPECTOS ECONÔMICOS DA BACIA DO RIO DOCE ............................. 35

3.1.4. SISTEMA DE LAGOS DO VALE DO RIO DOCE .................................. 38

3.1.5. PARQUE ESTADUAL DO RIO DOCE (PERD) ...................................... 42

3.1.6. AS LAGOAS ESTUDADAS ........................................................... 44

3.1.7. OS ESTUDOS REALIZADOS NA REGIÃO ........................................... 57

3.2. DELINEAMENTO LÓGICO DO TRABALHO ............................................... 59

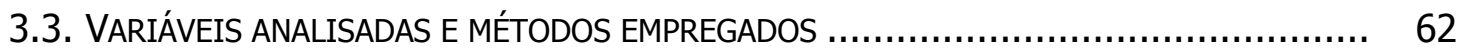

3.3.1. VARIÁVEIS MORFOMÉTRICAS .................................................. 62

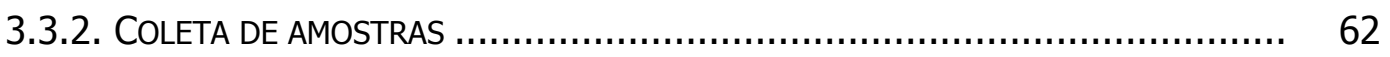

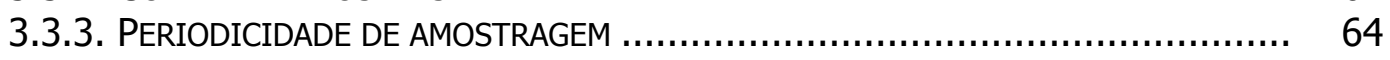

3.3.4. VARIÁVEIS LIMNOLÓGICAS ....................................................... 64

- PROFundidAde, TRANSPARÊNCIA da ÁGUa E EXTENSÃO DA ZONA EUFÓTICA ................................................ 64

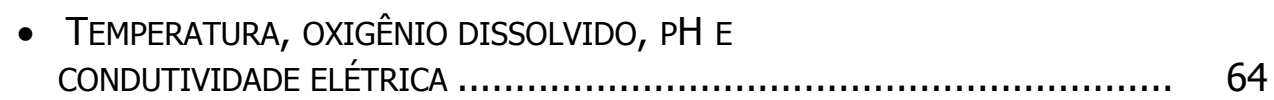

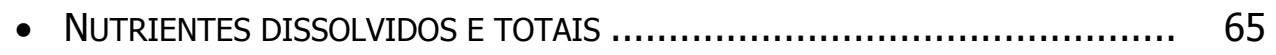

- MATERIAL eM SUSPENSÃo (FRAÇÕES ORGÂNICA E INORGÂNICA) …...................................... 65

• CONCENTRAÇÃO DE CLOROFILA ............................................. 65

3.3.5. COLETA E ANÁLISE DO ZOOPLÂNCTON ........................................... 66

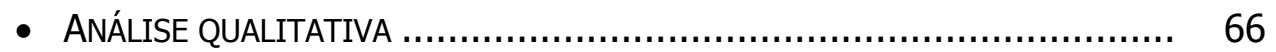

- ANÁLISE QUANTITATIVA ....................................................... 66

3.3.6. AVALIAÇÃO DAS LAGOAS QUANTO AO GRAU DE TROFIA ........................... 67

3.3.7. AVALIAÇÃO DA DIVERSIDADE ZOOPLANCTÔNICA .................................... 68

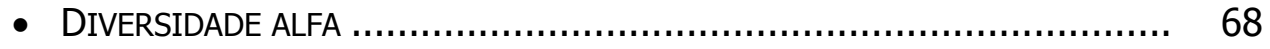

- DIVERSIDADE BETA .......................................................... 70

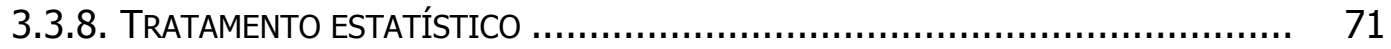




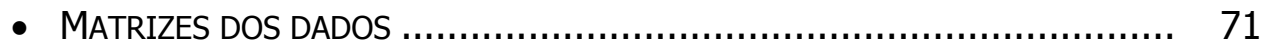

- ANÁLISE DE VARIÂNCIA MULTIVARIAdA (MANOVA) ......................... 72

- ANÁLISE DE COMPONENTES PRINCIPAIS (ACP) ............................. 72

- ANÁLISE DE AGRUPAMENTO (CLUSTER) ...................................... 73

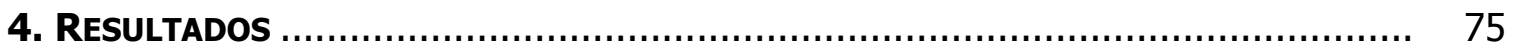

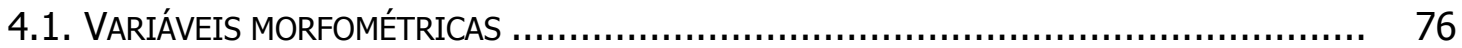

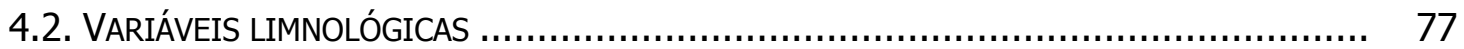

4.2.1. PROFUNDIDADE DA COLUNA DA ÁGUA ......................................... 77

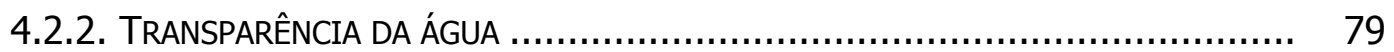

4.2.3. EXTENSÃO DA ZONA EUFÓTICA ................................................... 81

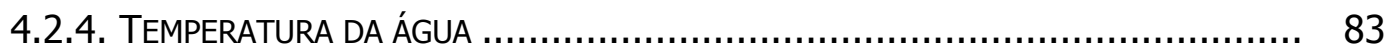

4.2.5. OXIGÊNIO DISSOLVIDO ...................................................... 91

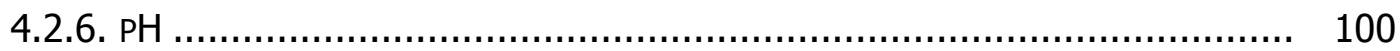

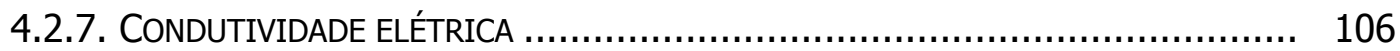

4.2.8. NUTRIENTES DISSOLVIDOS ................................................... 112

- NITRITO ..................................................................... 112

• NITRATO ...................................................................... 114

• AMÔNIO ...................................................................... 117

- FOSFATO DISSOLVIDO TOTAL ................................................. 120

- FOSFATO INORGÂNICO ....................................................... 122

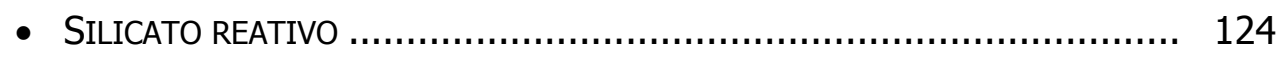

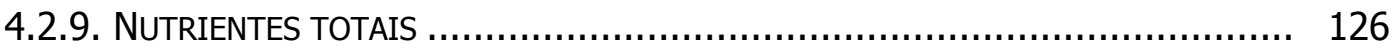

- NITROGÊNIO ORGÂNICO TOTAL ........................................... 126

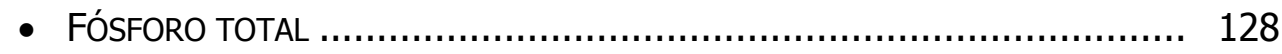

4.2.10. MATERIAL EM SUSPENSÃO .................................................... 130

- FRAÇÕES ORGÂNICA E INORGÂNICA ........................................ 130

- MATERIAL EM SUSPENSÃO TOTAL ............................................ 132

4.2.11. CONCENTRAÇÃO DE CLOROFILA ............................................ 134

4.3. ANÁLISE DO ZOOPLÂNCTON ......................................................... 135

4.3.1. ANÁLISE QUALITATIVA ......................................................... 135

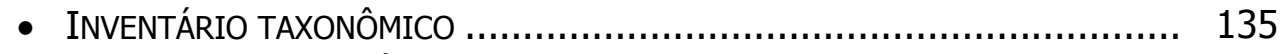

• COMPOSIÇÃO DE ESPÉCIES DAS LAGOAS ....................................... 139

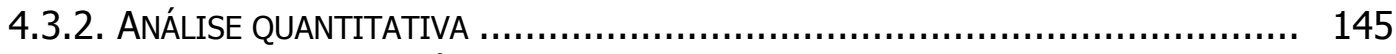

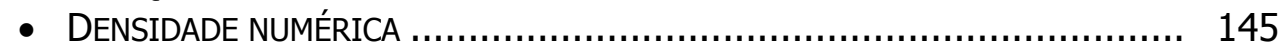

- ABUNDÂNCIA RELATIVA .................................................... 156

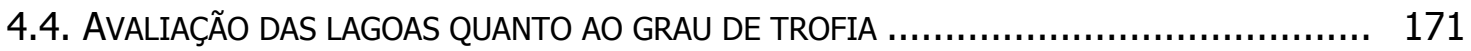

4.4.1. MODELO DE CARLSON MODIFICADO POR TOLEDO JR. .......................... 171

4.4.2. MODELO DE SALAS \& MARTINO ................................................. 172

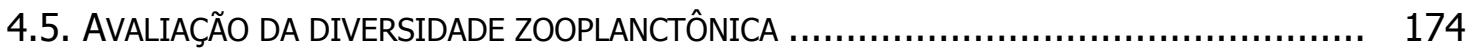

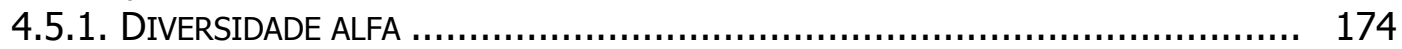

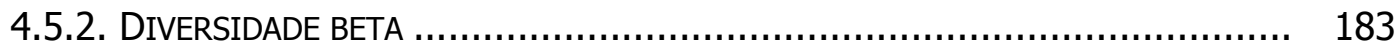

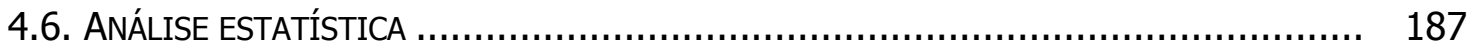

4.6.1. CARACTERÍSTICAS LIMNOLÓGICAS ........................................... 187

- ANÁLISE DE VARIÂNCIA MULTIVARIADA (MANOVA) ........................ 187

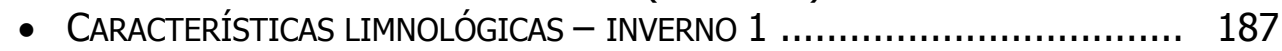

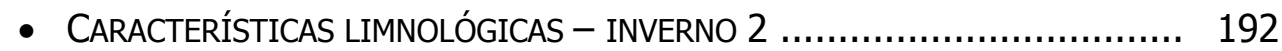

- CARACTERÍSTICAS LIMNOLÓGICAS - VerÃO ................................... 196

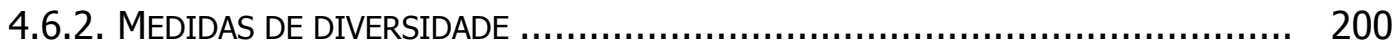

- ANÁLISE DE VARIÂNCIA MULTIVARIADA (MANOVA) ......................... 200

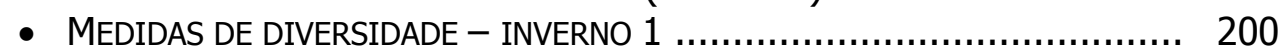

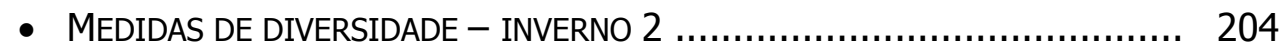




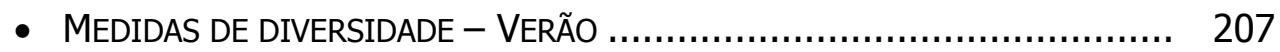

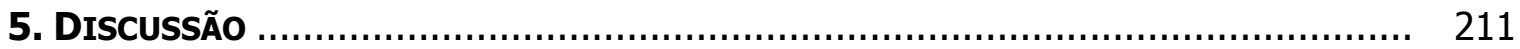

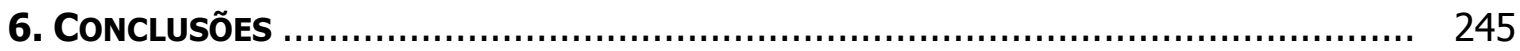

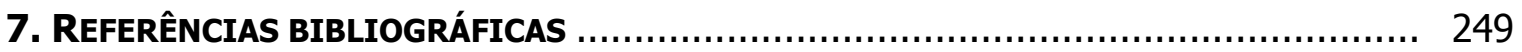

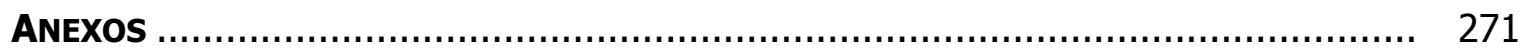




\section{LISTA DE FIGURAS}

Pág.

Figura 1. Seis principais problemas (delimitados por linha simples) em lagos e reservatórios do planeta

Figura 2. Zonação de um sistema lacustre

Figura 3. Representação simplificada do fluxo da produção das macrófitas nos lagos

Figura 4. Graus de sinuosidade do ecótono (zona litorânea em tons de cinza) entre ambiente terrestre (em preto) e zona limnética (em branco). Adaptado de KoLASA \& ZALEWSKI (1995)

Figura 5. Delimitação político-administrativa do Vale do Rio Doce. Adaptado de: Mapa Geopolítico de Minas Gerais - IGA / CETEC (1994). Digitalização: Assessoria da Secretaria Geral do Governador

Figura 6. Bacia de drenagem do Rio Doce e principais municípios. Adaptado de MELLO (1997)

Figura 7. Áreas críticas e problemas prioritários da Bacia do Rio Doce. Adaptado de DNAEE (1948) apud SETTI (1996)

Figura 8. Visão geral, em imagem de satélite (TM-Landsat, escala original $1: 250.000)$, do sistema de lagos do médio vale do Rio Doce (MG), destacando a porção de maior concentração de lagos. Adaptado de MelLo (1997)

Figura 9. Foto aérea destacando algumas atividades desenvolvidas dentro da área da CAF, no sistema de lagos. Retirado de: Levantamento Aerofotométrico, Coronel Fabriciano - 4. Folha 36-22-07, CEMIG (1989)

Figura 10. Parque Estadual do Rio Doce. Adaptado de GodinHo (1996)

Figura 11. Agrupamentos das lagoas estudadas segundo a vegetação do entorno

Figura 12. Ilustração dos compartimentos lacustres abordados neste trabalho

Figura 13. Batimetria da lagoa Carioca. Retirado de MEIS \& TUNDISI (1997) 
Figura 14. Foto aérea da Lagoa Carioca. Adaptado de: Levantamento Aerofotométrico, Coronel Fabriciano - 4. Folha 36-22-03, CEMIG (1989)

Figura 15. Foto aérea da Lagoa Aguapé. Adaptado de Levantamento Aerofotométrico, Coronel Fabriciano - 4. Folha 36-22-10, CEMIG (1989)

Figura 16. Foto aérea da Lagoa Águas Claras. Adaptado de: Levantamento Aerofotométrico, Coronel Fabriciano - 4. Folha 36-22-07, CEMIG (1989)

Figura 17. Foto aérea da Lagoa Ariranha. Adaptado de: Levantamento Aerofotométrico, Coronel Fabriciano - 4. Folha 36-22-07, CEMIG (1989)

Figura 18. Foto aérea da Lagoa Amarela. Adaptado de: Levantamento Aerofotométrico, Coronel Fabriciano - 4. Folha 36-22-07, CEMIG (1989)

Figura 19. Valores da profundidade da coluna d'água nas diferentes lagoas, medidos nos diferentes pontos de amostragens

Figura 20. Variação dos valores da transparência da água entre os pontos de amostragem das cinco lagoas, para os três períodos climáticos estudados

Figura 21. Variação dos valores da extensão da zona eufótica entre os pontos de amostragem das cinco lagoas, para os três períodos estudados

Figura 22. Perfis da temperatura da água dos pontos de amostragem das cinco lagoas, para os três períodos estudados

Figura 23. Perfis de oxigênio dissolvido na água dos pontos de amostragem das cinco lagoas, para os três períodos estudados

Figura 24. Perfis de $\mathrm{pH}$ da água dos pontos de amostragem das cinco lagoas, para os três períodos estudados $101-105$

Figura 25. Perfis da condutividade elétrica da água dos pontos de amostragem das cinco lagoas, para os três períodos estudados $107-111$

Figura 26. Concentração de nitrito nos pontos de amostragem das cinco lagoas, para os três períodos estudados

Figura 27. Concentrações de nitrato nos pontos de amostragem das cinco lagoas, para os três períodos estudados 
Figura 28. Concentração de amônio nos pontos de amostragens das cinco lagoas, para os três períodos estudados

Figura 29. Concentrações de fosfato dissolvido total nos pontos de amostragem das cinco lagoas, para os três períodos estudados ...

Figura 30. Concentrações de fostato inorgânico nos pontos de amotragem das cinco lagoas, para os três períodos estudados

Figura 31. Concentrações de silicato reativo nos pontos de amotragem das cinco lagoas, para os três períodos estudados

Figura 32. Concentrações de nitrogênio orgânico total nos pontos de amostragem das cinco lagoas, para os três períodos estudados ....

Figura 33. Concentrações de fósforo total nos pontos de amostragem das cinco lagoas, para os três períodos estudados

Figura 34. Valores do material em suspensão total nos pontos de amostragem das cinco lagoas, para os três períodos estudados ...

Figura 35. Fração orgânica do material em suspensão nos pontos de amostragem das cinco lagoas, para os três períodos estudados ...

Figura 36. Abundância relativa entre os principais grupos zooplanctônicos, nas zonas limnéticas e litorâneas das lagoas estudadas, nos três períodos de estudo

Figura 37. Abundância relativa entre os Lecanidae, Brachionidae e as demais famílias de Rotifera, nas zonas limnética e litorânea das lagoas estudadas, nos três períodos estudados

Figura 38. Abundância relativa entre as famílias de Cladocera, nas zonas pelágica e litorânea das lagoas estudadas, nos três períodos estudados

Figura 39. Abundância relativa entre os Copepoda Calanoida e Cyclopoida, nas zonas pelágicas e litorâneas das lagoas Ariranha e Amarela, nos três períodos estudados

Figura 40. Abundância relativa de Notodiaptomus isabelae, entre as zonas limnética e litorânea das lagoas Ariranha e Amarela, nos três períodos estudados

Figura 41. Abundância relativa de Thermocyclops minutus, entre as zonas limnética e litorânea das cinco lagoas, nos três períodos estudados 
Figura 42. Abundância relativa de Mesocyclops brasilianus, entre as zonas limnética e litorânea nas cinco lagoas, nos três períodos estudados

Figura 43. Abundância relativa entre náuplios de Calanoida e Cyclopoida, nas zonas limnética e litorânea das lagoas Ariranha e Amarela, nos três períodos estudados

Figura 44. Abundância relativa dos copepoditos de Copepoda Calanoida e Cyclopoida, entre as zonas limnética e litorânea das lagoas Ariranha e Amarela, nos três períodos estudados

Figura 45. Abundância relativa das formas jovens de Copepoda, entre as zonas limnética e litorânea nas cinco lagoas, nos três períodos estudados

Figura 46. Abundância relativa entre os outros grupos zooplanctônicos, nas zonas limnética e litorânea das cinco lagoas, nos três períodos estudados

Figura 47. Dendrograma representando a diversidade beta entre as cinco lagoas no período de inverno 1 (junho de 1999)

Figura 48. Dendrograma representando a diversidade beta entre as cinco lagoas no período de inverno 2 (agosto de 1999)

Figura 49. Dendrograma representando a diversidade beta entre as cinco lagoas no período de verão (fevereiro de 1999)

Figura 50. Ordenação dos pontos de amostragem no período de inverno 1, pela análise de componentes principais para as varáveis limnológicas, segundo os fatores 1 e 2

Figura 51. Dendrograma dos pontos de amostragem a partir da análise de agrupamento do tipo Cluster para valores dos coeficientes dos fatores da ACP para valores das variáveis limnológicas no período de inverno 1, com distância euclidiana média e método de ligação do tipo UPGMA

Figura 52. Ordenação dos pontos de amostragem no período de inverno 2, pela análise de componentes principais para as varáveis limnológicas, segundo os fatores 1 e 2 
Figura 53. Dendrograma dos pontos de amostragem a partir da análise de agrupamento do tipo Cluster para valores dos coeficientes dos fatores da ACP para valores das variáveis limnológicas no período de inverno 2, com distância euclidiana média e método de ligação do tipo UPGMA

Figura 54. Ordenação dos pontos de amostragem no período de verão, pela análise de componentes principais para as varáveis limnológicas, segundo os fatores 1 e 2

Figura 55. Dendrograma dos pontos de amostragem a partir da análise de agrupamento do tipo Cluster para valores dos coeficientes dos fatores da ACP para valores das variáveis limnológicas no período de verão, com distância euclidiana média e método de ligação do tipo UPGMA

Figura 56. Ordenação dos pontos de amostragem no período de inverno 1, pela análise de componentes principais para as medidas de diversidade, segundo os fatores 1 e 2

Figura 57. Dendrograma dos pontos de amostragem a partir da análise de agrupamento do tipo Cluster para valores dos coeficientes dos fatores da ACP para valores das medidas de diversidade no período de inverno 1, com distância euclidiana média e método de ligação do tipo UPGMA

Figura 58. Ordenação dos pontos de amostragem no período de Inverno 2, pela análise de componentes principais para as medidas de diversidade, segundo os fatores 1 e 2

Figura 59. Dendrograma dos pontos de amostragem a partir da análise de agrupamento do tipo Cluster para valores dos coeficientes dos fatores da ACP para valores das medidas de diversidade no período de inverno 2, com distância euclidiana média e método de ligação do tipo UPGMA

Figura 60. Ordenação dos pontos de amostragem no período de verão, pela análise de componentes principais para as medidas de diversidade, segundo os fatores 1 e 2 
Figura 61. Dendrograma dos pontos de amostragem a partir da análise de agrupamento do tipo Cluster para valores dos coeficientes dos fatores da ACP para valores das medidas de diversidade no período de verão, com distância euclidiana média e método de

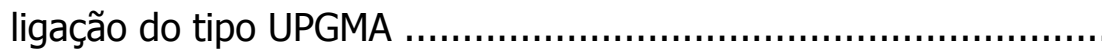




\section{LISTA DE TABELAS}

Tabela 1. Distribuição dos pontos de amostragem nas lagoas, segundo os

Pág. compartimentos e número total de pontos amostrados

Tabela 2. Nomenclatura adotada, compartimento onde se localiza e presença ou ausência de macrófitas para os pontos de amostragem

Tabela 3. Classificação e nomenclatura dos períodos de amostragem

Tabela 4. Métodos utilizados nas análises dos nutrientes químicos e referências onde os métodos se encontram descritos

Tabela 5. Valores de algumas variáveis morfométricas para as lagoas estudadas: Carioca, Aguapé, Águas Claras, Ariranha e Amarela

Tabela 6. Concentrações de clorofila (mg/l) nos diferentes pontos de amostragem, nas cinco lagoas para os três períodos estudados

Tabela 7. L Lista dos táxons presentes nas zonas limnética e litorânea da lagoa Carioca

Tabela 8. Lista dos táxons presentes nas zonas limnética e litorânea da lagoa Aguapé

Tabela 9. Lista dos táxons presentes nas zonas limnética e litorânea da lagoa Águas Claras

Tabela 10. Lista dos táxons presentes nas zonas limnética e litorânea da lagoa Ariranha

Tabela 11. Lista dos táxons presentes nas zonas limnética e litorânea da lagoa Amarela

Tabela 12. Densidade numérica dos táxons encontrados na lagoa Carioca, nos três períodos estudados

Tabela 13. Densidade numérica para os principais grupos taxonômicos e fases de desenvolvimento de Copepoda encontrados na lagoa Carioca, nos três períodos estudados

Tabela 14. Densidade numérica dos táxons encontrados na lagoa Aguapé, nos três períodos estudados

Tabela 15. Densidade numérica dos principais grupos taxonômicos e fase de desenvolvimento de Copepoda encontrados na lagoa Aguapé, nos três períodos estudados

Tabela 16. Densidade numérica dos táxons encontrados na lagoa Águas Claras, nos três períodos estudados 
Tabela 17. Densidade numérica dos principais grupos taxonômicos e fase de desenvolvimento de Copepoda encontrados na lagoa Águas Claras, nos três períodos de estudo

Tabela 18. Densidade numérica dos táxons encontrados na lagoa Ariranha, nos três períodos estudados

Tabela 19. Densidade numérica dos principais grupos taxonômicos e fases de desenvolvimento de Copepoda encontrados na lagoa Ariranha, nos três períodos estudados

Tabela 20. Densidade numérica dos táxons encontrados na lagoa Amarela, nos três períodos estudados

Tabela 21. Densidade numérica dos principais grupos taxonômicos e fases de desenvolvimento de Copepoda encontrados na lagoa Amarela, nos três períodos estudados

Tabela 22. Valores do índice e classificação do estado trófico, segundo modelo proposto por CARLSON (1977) e modificado por TOLEDO Jr. et al. (1983)

Tabela 23. Valores do índice e classificação do estado trófico, segundo modelo proposto por SALAS e MARTINO (1990)

Tabela 24. Valores da riqueza de espécies para o zooplâncton dos pontos de amostragem das cinco lagoas, nos três períodos estudados

Tabela 25. Valores do índice de diversidade de Margalef para o zooplâncton dos pontos de amostragem das cinco lagoas, nos três períodos estudados

Tabela 26. Valores do índice de diversidade de Shannon-Wiener para para o zooplâncton os pontos de amostragem das cinco lagoas, nos três períodos estudados

Tabela 27. Valores do índice de diversidade de Simpson para o zooplâncton dos pontos de amostragem das cinco lagoas, nos três períodos estudados

Tabela 28. Valores do índice de dominância de Simpson para o zooplâncton dos pontos de amostragem das cinco lagoas, nos três períodos estudados

Tabela 29. Valores do índice de equidade de Pielou para o zooplâncton dos pontos de amostragem das cinco lagoas, nos três períodos estudados

Tabela 31. Correlação (coeficiente de correlação>0.700) das variáveis limnológicas com os componentes principais 1 e 2, "Eigenvalue" e variância explicada, no período de inverno 1 (junho de 1999) 
Tabela 32. Correlação (coeficiente de correlação>0.700) das variáveis limnológicas com os componentes principais 1 e 2, "Eigenvalue" e variância explicada, no período de inverno 2 (agosto de 1999)

Tabela 33. Correlação (coeficiente de correlação>0.700) das variáveis limnológicas com os componentes principais 1 e 2, "Eigenvalue" e variância explicada, no período de verão (fevereiro de 2000)

Tabela 34. Correlação (coeficiente de correlação>0.700) das medidas de diversidade com os componentes principais 1 e 2, "Eigenvalue" variância explicada, no período de inverno 1 (junho de 1999)

Tabela 35. Correlação (coeficiente de correlação>0.700) das medidas de diversidade com os componentes principais 1 e 2, "Eigenvalue" e variância explicada, no período de inverno 2 (agosto de 1999)

Tabela 36. Correlação (coeficiente de correlação>0.700) das medidas de diversidade com os componentes principais 1 e 2, "Eigenvalue" e variância explicada, no período de verão (fevereiro de 2000)

Tabela 37. Comparação entre os valores de algumas variáveis limnológicas de lagos naturais do Pantanal, do Vale do Rio Doce e da Represa de Barra Bonita 


\section{LISTA DE SÍMBOLOS E ABREVIAÇõES}

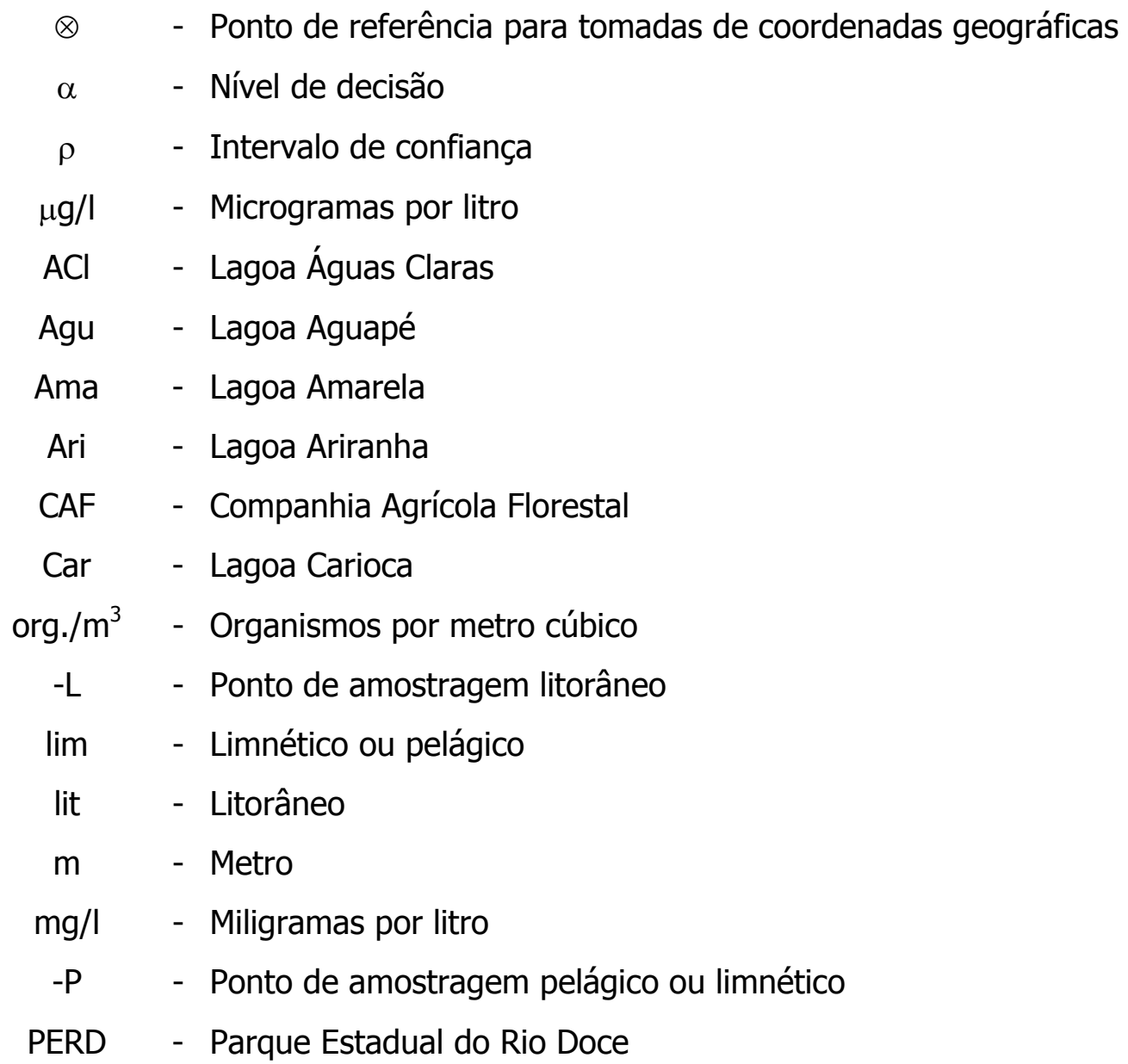




\section{RESUMO}

MORETTO, E. M. (2001). Diversidade zooplanctônica e variáveis limnológicas das regiões limnética e litorânea de cinco lagoas do Vale do Rio Doce - MG, e suas relações com o entorno. Dissertação de mestrado. Escola de Engenharia de São Carlos, Universidade de São Paulo.

Nos sistemas lacustres, ocorrem diferenças naturais entre os compartimentos limnético e litorâneo num mesmo lago (hábitats, recurso trófico, ciclos biogeoquímicos e processos hidrológicos) e entre lagos que se encontram em regiões de diferentes coberturas vegetais. Tais diferenças podem determinar variações na diversidade zooplanctônica e nas características químicas e físicas da água. Pelo presente trabalho objetivou-se verificar a ocorrência destas diferenças entre as regiões limnética e litorânea de cinco lagoas (Carioca, Aguapé, Águas Claras, Ariranha e Amarela) pertencentes ao sistema de lagos do Vale do Rio Doce (MG), além de uma comparação destes resultados com os diferentes tipos de vegetação que ocorrem no entorno. Situado a sudoeste do estado de Minas Gerais, o sistema de lagos do Vale do Rio Doce é composto, principalmente, por dois tipos de vegetação terrestre: a floresta secundária de Mata Atlântica que está restrita ao Parque Estadual do Rio Doce; e o cultivo de eucalipto que ocupa grande área da região. As lagoas abordadas no presente estudo foram reunidas em três grupos distintos, segundo o tipo de vegetação que ocorre no seu entorno: lagoa Carioca (floresta de Mata Atlântica); lagoas Aguapé e Águas Claras (cultivo de eucalipto com manejo mais intensivo e com freqüente retirada de espécies nativas do sub-bosque); e lagoas Ariranha e Amarela (cultivo de eucalipto com presença de sub-bosque de espécies nativas da Mata Atlântica). Foram realizadas amostragens nos períodos climáticos de inverno de 1999 (estiagem) e verão de 2000 (chuvas), para as variáveis físicas e químicas da água e para a comunidade zooplanctônica. Pelos resultados obtidos, ficaram claras as diferenças entre os compartimentos limnético e litorâneo em função das variáveis físicas e químicas no período de inverno de 1999, e em função da riqueza de espécies zooplanctônicas em ambos os períodos climáticos estudados. A principal diferença da riqueza de espécies entre os compartimentos foi devida ao maior número de táxons na região litorânea, em função da ocorrência de espécies da família Chydoridae e Macrothricidae (Cladocera), e da família Lecanidae (Rotifera). Por outro lado, não ficaram evidentes as diferenças entre os grupos de lagoas segundo a vegetação do entorno, em função das variáveis limnológicas e dos indicadores de diversidade. Ainda assim, é importante destacar as diferenças entre a lagoa Carioca para as demais lagoas, principalmente, em relação ao seu maior grau de trofia e menor disponibilidade de habitats litorâneos, que determinam uma menor riqueza de espécies. Assim, na lagoa Carioca não ocorreram organismos filtradores e herbívoros pertencentes aos Cladocera, com exceção da espécie Diaphanosona birgei. Foi possível verificar também que as espécies de Copepoda Cyclopoida Thermocyclops minutus e Tropocyclops prasinus ocuparam preferencialmente as regiões limnéticas das lagoas, enquanto que Mesocyclops brasilianus ocorreu de forma mais marcante na litorânea. De forma geral, foi possível verificar que os tipos de vegetação não determinaram diferenças nas condições limnológicas e na diversidade zooplanctônica, uma vez que não se observaram padrões semelhantes nos valores das variáveis analisadas dentro de cada grupo de lagoas.

Palavras-chave: diversidade do zooplâncton, limnologia, lagos brasileiros, Vale do Rio Doce, Copepoda, Cladocera, Rotifera. 


\section{ABSTRACT}

Moretto, E. M. (2001). ZOOPLANKTON DIVERSITY AND LIMNOLOGICAL VARIABLES IN THE LIMNETIC AND LITTORAL REGIONS OF FIVE LAKES IN RIO DOCE VALLEY - MG, AND THE RELATIONSHIP WITH THE SURROUNDING BASIN. DisSERTAÇÃo DE MESTRADO. EsCOLA DE Engenharia de São Carlos, UniVersidade de São PaUlo.

In lacustrine systems there are natural differences among the limnetic and littoral region in the same lake (habitat, food resources, biogeochemical cycles and hydrological processes) as well as between lakes that are located in regions with different vegetation cover. Such differences can determine defferences in the physical and chemical characteristics of the water as well as in the zooplankton diversity. The present work had the objective of verify the existence of these differences among limnetic and littoral region of five lakes (Carioca, Aguapé, Águas Claras, Ariranha e Amarela) belonging to the ake system of Rio Doce Valley (MG), and to analyse these results regarding the different vegetation cover existing in the lake surroundings. Located at the Southeast of Minas Gerais State, the Rio Doce Valley Lake System is covered by two main types of vegetation: secondary atlantic forest, restricted to the area of the State Park of Rio Doce, and Eucalyptus plantation covering the largest portion of the region. The lakes analysed in the present study were grouped in three distinct categories, according to the type of plant coverage in the surroundings: lake Carioca (atlantic forest); lakes Aguapé and Aguas Claras (Eucalyptus, without native forest layer) and lakes Ariranha and Amarela (mixed formation of Eucalyptus and native forest species). Samplig was carried out in the winter (dry period) of 1999 and summer (wet period) of 2000, for both physical and chemical water analysis and zooplankton community studies. There were clear differences among limnetic and littoral regions, regarding physical and chemical characteristics in the winter, and regarding zooplankton richness in both, dry and wet seasons. Major differences in species richness among these compartments were determined by the large number of taxa found in the littoral region, particularly due to the occurrence of species of Chydoridae and Macrothricidae (Cladocera) and Lecanidae (Rotifera). On the other hand, differences among the groups of lakes, according to the type of plant cover around the lake, were not evident, considering the limnological variables and diversity indices. There were, nevertheless, differences between Lake Carioca and the other lakes, mainly related to its higher trophic state, which combined with a small littoral development determines a low zooplankton species richness. Thus, in Lake Carioca filter-feeding Cladocera does not occur, except for Diaphanosoma birgei. It was also possible to verify that the species of Copepoda Cyclopoida Thermocyclops minutus, and Tropocyclops prasinus preferentiatly occupied the limnetic region of the lakes, whereas Mesocyclops brasilianus had a marked occurrence in the littoral region. In general, it was possible to conclude that the type of plant covering did not influence limnological conditions and zooplankton diversity since it was not possible to find a pattern regarding the variables here analysed, if considering those group of lakes.

Key-words: limnology, zooplankton diversity, Brazilian lakes, Rio Doce Valley, Copepoda, Cladocera, Rotifera. 


\section{INTRODUÇÃO}

Nas últimas décadas o modelo de crescimento urbano e industrial, como regra, não tem considerado a realidade ambiental nos modos de produção, acarretando como conseqüência uma série de fatores interferentes na estabilidade dos ecossistemas, os quais acabaram-se tornando progressivamente alterados e suscetíveis.

Em relação ao elemento água, apenas recentemente concebeu-se que não só a quantidade, mas principalmente a sua qualidade é fundamental para a manutenção da vida, inclusive a humana. Vale lembrar, que a maior parte da população mundial não apresenta um boa qualidade de vida em função do estado qualitativo em que se encontra a água utilizada para o abastecimento público.

Dessa forma, torna-se cada vez mais necessária a elaboração de programas de gerenciamento ambiental, não de cunho essencialmente normativo, mas principalmente com o objetivo de gerar alternativas para as práticas econômicas e políticas em vigência.

Porém, para a elaboração destes, faz-se necessário a investigação e compreensão prévias dos processos ecológicos e suas alterações frente aos impactos antrópicos.

É sob este prisma que o presente trabalho foi desenvolvido, principalmente como uma proposta de evidenciar a relevância das investigações ecológicas, desde que analisadas de forma integrada com os demais atributos ambientais e sócioeconômicos.

Além disso, o presente trabalho visa complementar e dar continuidade a uma série de estudos que vem sendo realizados no Vale Médio do Rio Doce desde a década de 70. 


\subsection{O PRESENTE ESTUDO NO CONTEXTO AMBIENTAL}

As massas continentais de água doce representam um porção muito pequena do total do componente hídrico do planeta. Essa fração é de apenas 1,2\% do total, segundo REBOUÇAS (1999), quando são consideradas apenas as águas superficiais disponíveis para uso imediato pelo homem, excluindo-se aquelas que se encontram congeladas na superfície da crosta terrestre e no interior dos solos "permafrost", e aquelas que já sofreram fortes impactos antropogênicos.

Sabe-se que as atividades humanas dependem cada vez mais da disponibilidade das águas continentais, principalmente para o abastecimento urbano e industrial (ESTEVES, 1988). Por outro lado, o processo de desenvolvimento humano é o principal fator responsável pela alteração da qualidade da água, o que diminui aceleradamente a sua disponibilidade para o uso humano.

Segundo TUNDISI (1999), os principais fatores que tem gerado distúrbios de origem antrópica, a partir das últimas décadas, nos sistemas aquáticos continentais, são:

- aumento da carga nas concentrações de fósforo e nitrogênio, que geram processos de eutrofização de longa duração nos sistemas;

- aumento da descarga de substância tóxicas e produção de toxinas por cianobactérias, da concentração de metais pesados e da contaminação radioativa;

- introdução voluntária ou involuntária de espécies exóticas, levando à drástica reorganização das cadeias alimentares, alterações na produção orgânica e na dominância de espécies.

Deve-se lembrar, também, da existência de distúrbios de origem natural, próprios dos processos ecológicos, que causam continuamente alterações qualitativas e quantitativas nas massas de águas e que fazem parte dos processos ecológicos.

Porém, não se pode analisar as condições dos sistemas aquáticos apenas do ponto de vista do seu uso pelo homem (visão antropocêntrica), necessitando-se contemplar a saúde do ecossistema pelos seus atributos intrínsecos, como a biodiversidade e estabilidade, sob uma visão evolucionista. 


\section{O CONCEITO DE ESTABILIDADE}

Durante muito tempo, o meio acadêmico tem discutido as relações entre a diversidade biológica e a estabilidade dos sistemas, buscando estabelecer uma relação de causa e conseqüência.

A tradição naturalista pautou-se sempre na conclusão de que a diversidade determina a estabilidade. Sob esta visão, sistemas com alta diversidade deveriam apresentar maior estabilidade, ou seja, uma resposta mais rápida no sentido de uma reorganização estrutural e funcional a partir do momento em que um distúrbio é instaurado (MARGALEF, 1993).

O mesmo autor caracteriza este paradigma (diversidade/causa=> estabilidade/conseqüência) como uma boa intenção pedagógica, porém, inadequada à racionalidade científica, refutando esta hipótese naturalista segundo uma análise lógica baseada nas seguintes premissas (exemplos reais análogos):

- O mar Mediterrâneo apresenta baixa diversidade e alguma estabilidade, não estando "morto" ou agonizando;

- As diferenças genéticas dentro da espécie humana não garantem que ela tenha uma alta estabilidade. O que permite esta estabilidade é o senso de justiça inerente da sociedade.

Pela análise da primeira premissa, o autor sugere que apenas a diversidade de espécies não é suficiente para determinar a estabilidade de um ecossistema como um todo, mas sim a complexidade das inter-relações entre os organismos e os meios físico e químico, que se mantém e se reorganizam ao longo do tempo

Analisando a segunda, admite-se que o fator que pode garantir a estabilidade da espécie humana e de suas relações não é a sua alta diversidade genética, mas seus valores sociais, como o senso de justiça. Conclui-se, então, que a maneira mais apropriada é admitir que a estabilidade não é conseqüência da diversidade. $\mathrm{O}$ autor atribui como fator responsável pela estabilidade, o grau de conectância dos sistemas naturais, ou seja, o nível de complexidade de relações entre os diversos elementos ambientais, sejam eles de natureza biológica, física ou química.

A presença de um distúrbio afeta diretamente as relações entre todos os elementos do sistema, pelo desaparecimento de algumas, surgimento de outras ou ainda, a reorganização das mesmas. Porém, o nível de complexidade destas interrelações pode permanecer inalterado. 
De forma geral, o processo citado está baseado na resiliência de um ecossistema, ou seja, no potencial de reorganização deste frente a um distúrbio.

A estabilidade será efetivamente afetada se o distúrbio apresentar intensidade e continuidade suficientes para alterar o conjunto das características físicas, químicas e biológicas do sistema, e suas inter-relações, mas não apenas em função de mudanças na diversidade, isoladamente.

Segundo MARGALEF (1993), o que torna relevante o estudo e a conservação da diversidade biológica é o entendimento dos processos ecológicos dos ecossistemas, fundamental para a manutenção da sua funcionalidade e flexibilidade, garantindo a estabilidade. Esta nova perspectiva está pautada nas características evolutivas dos sistemas ecológicos, analisadas e sintetizadas por MARGALEF (op. cit.) em "Teoria dos ecossistemas ecológicos".

É por este prisma que o presente trabalho é conduzido, ou seja, uma análise da biodiversidade de um determinado grupo de organismos de água doce, segundo suas inter-relações e da interação com os elementos físicos e químicos dos sistemas aquático e terrestre, culminando numa contribuição para o entendimento dos processos ecológicos de lagos naturais.

Optou-se por esta perspectiva ecológica pelo fato da realidade ambiental da atualidade necessitar cada vez mais de informações integradas dos processos ecológicos que ocorrem nos ecossistemas, como base de dados para a formulação de políticas de gestão e manejo ambientais. 


\subsection{ELEMENTOS NATURAIS VERSUS RECURSOS NATURAIS}

Muitas são as justificativas para a conservação ambiental e, de maneira geral, todas devem conduzir a um gerenciamento adequado.

Aquela que é mais defendida atualmente no meio acadêmico e nos órgãos públicos de decisão está pautada na premissa de que o cenário ambiental deve ser conservado por ser fonte de recursos essenciais à manutenção e desenvolvimento da população humana, seus processos urbanísticos, sócio-culturais e industriais.

Para isso são criados mecanismos econômicos para a valoração da água baseados, principalmente, na análise custo-benefício pela agregação dos valores que os indivíduos da sociedade lhe atribuem e na disposição destes no pagamento pela água (LANNA, 1995).

Assim, a utilização freqüente do termo "recurso" natural e hídrico nos discursos técnicos demonstra a abordagem econômica do meio ambiente, pela qual a natureza é um estoque de matéria-prima e energia para os processos de desenvolvimento humano.

A análise deste prisma revela que seus atributos são de natureza essencialmente econômica, não levando diretamente em consideração os processos naturais dos níveis físicos, químicos e biológicos do planeta, que contemplam a estabilidade dos sistemas, fundamentais para a manutenção da vida, inclusive a da população humana.

Segundo o Glossário de Ecologia (ACIESP, 1997), o termo recurso, quando utilizado isoladamente, apresenta uma conotação ecológica e natural por representar qualquer componente do ambiente que pode ser utilizado e potencialmente esgotado por um organismo. Porém, quando associado ao termo natural (recurso natural), assume uma conotação estritamente econômica, representando qualquer recurso ambiental que pode ser utilizado pelo homem na mesma proporção.

Assim, o termo recurso assume uma característica finalista pelo fato de atribuir aos sistemas naturais a função primeira de sustentar a sobrevivência da espécie humana, baseada nos artifícios econômicos próprios da civilização.

Pode ser, também, permissivo no sentido de possibilitar, num futuro próximo, a deterioração paulatina do meio ambiente, deixando a posteriori a elaboração de soluções paleativas que supram as necessidades humanas.

Dessa forma, o termo elemento natural ou hídrico revela-se mais adequado por se basear numa premissa que considera a história natural dos processos ambientais 
que geraram, numa escala geológica, a atual complexidade de formas abióticas e bióticas do planeta, responsáveis pela manutenção da estabilidade dos ecossistemas. Exclui-se, neste momento, a visão puramente econômica que contempla apenas o benefício da espécie humana.

Porém, esta visão, muitas vezes, não é compreendida pelas autoridades governamentais, pelo setor privado e acadêmico, mesmo entre muitos dos profissionais da área ambiental. 


\subsection{OS EFEITOS DOS DISTÚRBIOS NA BIODIVERSIDADE}

De uma maneira geral, os distúrbios ambientais de origem natural ou antrópica afetam diretamente a biodiversidade dos ecossistemas, por alterações na composição e dinâmica das populações que, muitas vezes, são irreversíveis.

KIRA (1998) apud TUNDISI (1999), apresenta as causas e os efeitos de um desastre ecológico de grandes proporções no Mar de Aral na Ásia Central, e que acomete muitos sistemas aquáticos continentais, fruto de um gerenciamento inadequado associado a práticas que acabaram diminuindo a quantidade da água, como megaprojetos de irrigação que produziram alterações no ciclo hidrológico, na salinização do solo e na saúde do sistema.

A Figura 1 apresenta um fluxograma com os problemas mais encontrados nos sistemas aquáticos, principalmente em lagos e reservatórios, elaborado a partir de uma pesquisa realizada pelo Comitê Internacional do meio ambiente lacustre - ILEC (KIRA, 1998 apud TUNDISI, 1999) em 600 lagos de todo o planeta, que serve como modelo para a situação de muitos ecossistemas ameaçados.

Pelo esquema apresentado, pode-se verificar que o crescimento acelerado da população humana associado a mudanças dos paradigmas econômicos, levam à necessidade de aumento da produção agrícola e industrial, que por sua vez, alteram as características físicas e biológicas da paisagem, culminando em alterações drásticas da biodiversidade.

Dessa forma, é indiscutível a importância da conservação e utilização racional dos sistemas aquáticos que ainda apresentam níveis consideráveis de qualidade da água - pressupostos centrais da Limnologia moderna (ESTEVES, 1988).

E qual seria o padrão ambiental que se deseja atingir com os programas de gerenciamento, manejo e conservação dos sistemas hídricos?

Esta questão é bastante discutida em diversos segmentos da sociedade, mas pode-se presumir que este padrão deva estar o mais próximo possível daqueles anteriores aos processos de urbanização e industrialização, os quais foram os principais responsáveis pela alteração drástica na estrutura e funcionamento dos sistemas naturais em uma escala temporal muito reduzida, os quais em alguns casos já apresentam sua estabilidade alterada. 


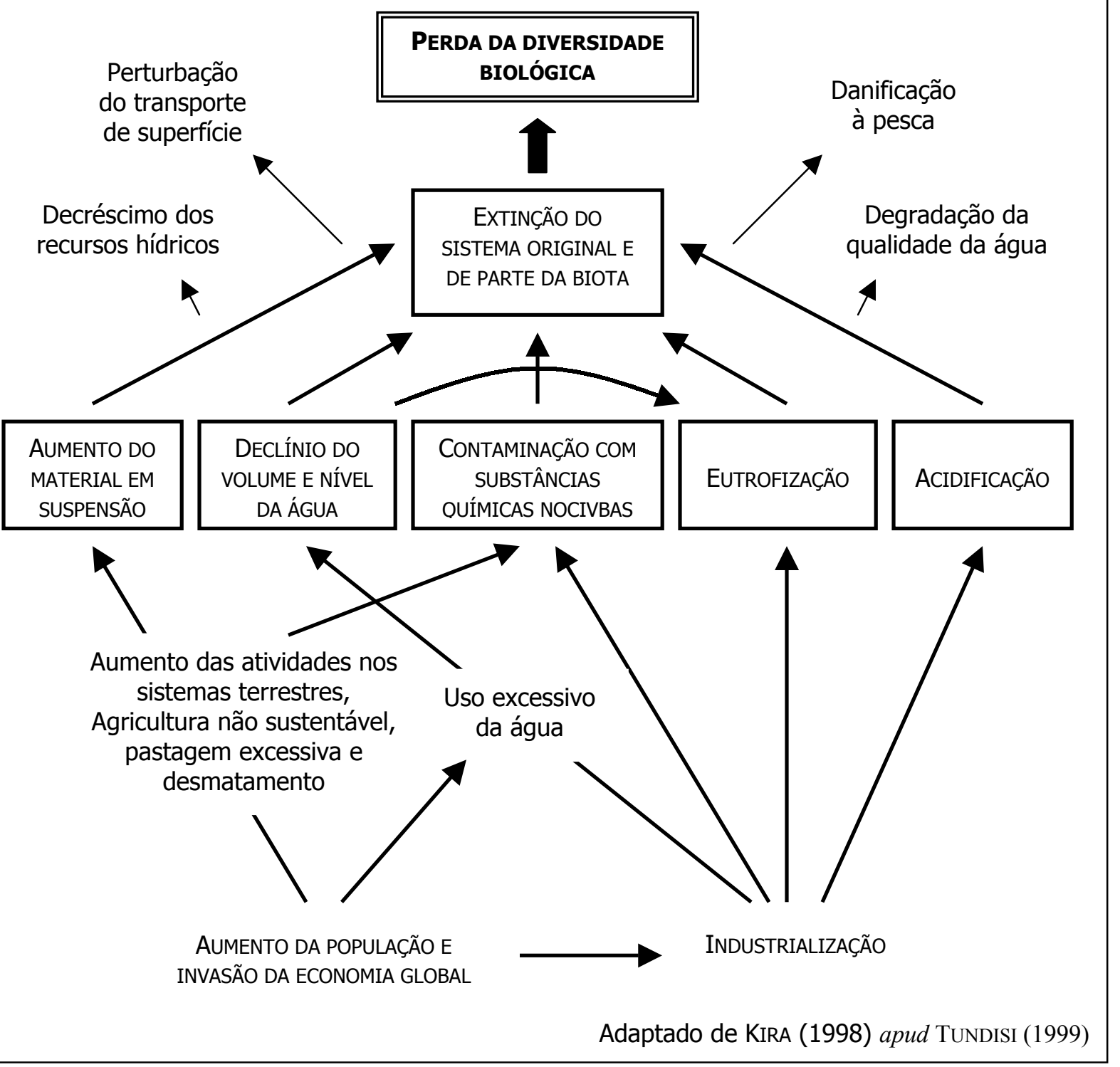

Figura 1. Seis principais problemas (delimitados por linha simples) em lagos e reservatórios do planeta.

Está claro que este retorno às características originais dos sistemas naturais na sua totalidade é sumamente ideológica, se não impossível em função do paradigma expansionista do neoliberalismo. Porém, a busca constante de uma reformulação dos conceitos econômicos do desenvolvimento humano no sentido da menor interferência possível no meio ambiente, é imprescindível.

TUNDISI (1999) afirma que o desenvolvimento de um país, nos campos social e econômico, está baseado na disponibilidade hídrica de boa qualidade, e na capacidade de proteção e conservação deste elemento natural. 
RICKLEFS (1993) atribui dois principais efeitos ao consumo excessivo dos elementos naturais e da grande produção de rejeitos gerados pelo desenvolvimento humano:

- impacto nos sistemas naturais, incluindo as alterações nos processos ecológicos e extinção de espécies;

- forte deterioração do meio ambiente humano, à medida que se ultrapassa os limites do desenvolvimento sustentável.

Em ambos os casos, fica clara a importância da compreensão dos processos ecológicos não só para a manutenção do desenvolvimento humano, dos sistemas produtivos, mas sobretudo do processos naturais e, portanto, da estabilidade dos ecossistemas naturais.

É por este prisma que se torna importante quaisquer estudos que contemplem os processos relacionados com a diversidade nos níveis biológico, genético, da cultura humana e das características climáticas e paisagísticas (físicas) dos sistemas naturais. Isto, desde que estas investigações estejam inseridas no contexto dos processos ecológicos e sociais, extrapolando os limites acadêmicos.

MARGALEF (1997) apud TUNDISI (1999) afirma que as complexas características dos ecossistemas aquáticos devem ser permanentemente investigadas analiticamente, sintetizadas e comparadas, devido ao fato de cada sistema aquático ser único em função de suas relações internas e externas com a bacia de drenagem.

O mesmo autor considera que as práticas científicas no estudo das interfaces entre os sistemas terrestre-aquático, e entre os compartimentos sedimento-água e organismos/água, conformam os novos desafios e perspectivas para o gerenciamento do elemento água e uso da Limnologia.

Dessa forma, os estudos que visam a investigação sobre a diversidade biológica em qualquer nível de organização, seus processos ecológicos e suas implicações no sistema natural, são de suma importância, não só para a espécie humana, mas para a homeostase de toda a biosfera. 


\subsection{A DIVERSIDADE BIOLÓGICA NOS ECOSSISTEMAS LACUSTRES}

A diversidade de espécies constitui um dos atributos mais importantes de um sistema biológico (RICKLEFS, 1993), devido, principalmente, ao processo de especiação que presume o surgimento de uma determinada espécie apenas uma única vez no tempo e no espaço.

Assim, a diminuição da biodiversidade fruto de alterações de origem antropogênica nos sistemas naturais não significa apenas redução das complexidades de formas dos organismos no planeta, mas também a extinção dos processos históricos de surgimento das espécies, e a possibilidade de sucesso de um determinado grupo taxonômico.

De maneira geral, é encontrada uma alta riqueza de espécies nos trópicos em contraste com uma menor diversidade de formas das regiões temperadas e polares (RoCHA, et al., 1994). Esta relação também é valida para os sistemas aquáticos.

Em escala global, o Brasil é considerado como o detentor da maior diversidade biológica do planeta, sendo também o primeiro signatário da Convenção sobre a Diversidade Biológica, onde se estabelece que a biodiversidade mundial deve ser tratada em toda a sua amplitude (BRASIL, 1998).

No Brasil, o maior número de trabalhos descrevem a biodiversidade nas regiões onde estão mais concentrados os núcleos de pesquisa, como as regiões Sul e Sudeste, enquanto que as Centro-Oeste e Nordeste continuam pouco estudadas.

Em se tratando dos estudos que têm como enfoque a biodiversidade dos corpos de água doce, pode-se dizer que no Brasil a grande maioria referem-se aos reservatórios, por estes serem numerosos e apresentarem importância econômica na geração de energia elétrica e transporte fluvial, principalmente.

Geralmente, quando são realizados estudos sobre a diversidade biológica em outros tipos de sistemas aquáticos brasileiros, como em lagos naturais interiores e costeiros, o enfoque restringe-se apenas a grupos de vertebrados e às macrófitas.

Dessa forma, pode-se dizer que o conhecimento acerca da diversidade biológica em ecossistemas aquáticos naturais brasileiros, como lagos, ainda é incompleto, principalmente em relação aos grupos de invertebrados.

Os corpos de águas pertencentes aos sistemas continentais de água doce têm como características principais o baixo e variável grau de mineralização e um tamanho menor em relação às massas de água marinhas (MARGALEF, 1983). 
Devido a isto e ao fato da maioria das espécies de invertebrados aquáticos Ter sua origem marinha, as pressões seletivas que atuaram sobre os organismos aquáticos ao longo do tempo, em escala geológica, favoreceram a permanência de estratégias oportunistas, o que culminou num quadro atual de poucas formas taxonômicas nos ecossistemas aquáticos continentais em relação ao ambiente marinho. Entretanto, o mesmo autor afirma que, relacionando-se o número de espécies com o volume de água, pode-se considerar que a razão resultante é muito maior na água doce do que no ambiente marinho.

A biota de água doce é composta, principalmente, pelas comunidades planctônicas (fitoplâncton e zooplâncton), bentônica (fauna e flora associadas ao sedimento), perifítica (algas e animais associados a um substrato orgânico ou mineral), de macrófitas (vegetação aquática macroscópica de importante papel na dinâmica dos nutrientes) e nectônica (representada principalmente pelos peixes e outros vertebrados aquáticos).

Em se tratando de sistemas de lagos de uma mesma bacia geológica, muitas vezes, é possível encontrar uma grande variabilidade de características e também de biodiversidade de um lago para outro pelo fato destes estarem usualmente isolados (PAYNE, 1986). Por outro lado, considerando os fluxos biogeoquímicos e hidrológicos, os lagos, no geral, são dependentes dos sistemas terrestres que os circundam, por receberem as águas que escoam das bacias de captação e de ribeirões emissários (KIRA \& SAZANAMI, 1995). Isto faz com que a diversidade biológica e os aspectos físicos e químicos de um sistema lacustre sejam extremamente sensíveis aos processos que ocorrem na sua bacia de drenagem.

Os principais impactos antropogênicos na bacia de drenagem que determinam alterações na biodiversidade aquática referem-se à introdução de efluentes domésticos e industriais, às mudanças nas características paisagísticas (vegetação e características pedológicas), às alterações no fluxo hídrico pelo barramento de rios e introdução de espécies exóticas nas massas d'água.

De maneira geral, estes impactos têm efeitos contínuos na reinicialização das sucessões ecológicas (MARGALEF, 1993), aumentando-se a taxa de reprodução das populações e diminuindo-se a diversidade de toda a biosfera. 


\section{SISTEMA TERRESTRE E DIVERSIDADE AQUÁTICA}

Segundo KIRA \& SAZANAMI (1995), um dos principais fatores que garantem a estabilidade dos ecossistemas de lagos são as condições ecológicas da bacia de drenagem, que envolvem os aspectos físicos, químicos e biológicos.

O tipo de vegetação é um dos atributos mais importantes dos sistemas terrestres que podem afetar a composição de organismos e a qualidade da água em corpos lacustres, pela diferença qualitativa e quantitativa na entrada do "litter" ou serrapilheira e dos nutrientes no corpo lacustre.

ABELHO \& GRAÇA (1996) afirmam que corpos d'água que apresentam florestas decíduas naturais no entorno contêm maior número de invertebrados do que aqueles que são constituídos por agroecossistemas, como florestas de eucalipto.

Portanto, as alterações geradas pelo cultivo do eucalipto (vegetação exótica) nos sistemas lacustres atuam inicialmente como um distúrbio que pode ser assimilado pelos processos ecológicos ao longo do tempo, pela alteração das inter-relações entre os elementos biológicos (diversidade), físicos e químicos, podendo alterar a estabilidade dos lagos.

Porém, os distúrbios que os sistemas agrícolas artificiais acarretam nos corpos d'água não se resumem apenas ao momento em que o cultivo já está estabelecido, mas também aos processos que envolvem a retirada da mata nativa para o plantio.

No caso da monocultura do eucalipto, as alterações da bacia de drenagem e, consequentemente, na qualidade da água, são desencadeadas desde o início com a retirada da cobertura natural que elimina praticamente toda a diversidade biológica da região. Além disso, a construção de estradas, o preparo do solo com adubação, uso rotineiro do fogo, combate às formigas e o estabelecimento de vilas de trabalhadores (BARBIERI et al., 1997) são forças que incrementam o nível do impacto antropogênico.

Segundo os mesmos autores, os principais efeitos desta atividade de monocultura referem-se ao grande consumo de água e nutrientes, alterações nas propriedades do solo que podem ocasionar erosão, e eventuais efeitos alelopáticos próprios da vegetação de eucalipto sobre outras espécies vegetais.

Segundo MARGALEF (1993), a composição química das águas epicontinentais pode indicar a saúde dos sistema terrestres pertencentes à bacia de drenagem.

É esperado, portanto, que a alteração da paisagem do entorno dos lagos acarretará efeitos na qualidade de água destes sistemas, principalmente pelo escoamento superficial que carreia o excedente de fertilizantes e agrotóxicos 
empregados, além de alterações nos ciclos hidrológico e biogeoquímicos, e entrada de substâncias alelopáticas que poderão ter efeito inibidor para o crescimento de formas vegetais e animais aquáticas.

Além destes, a introdução de espécies exóticas nos sistemas lacustres pode acarretar, dependendo dos aspectos biológicos da espécie introduzida e dos processos ecológicos do local de destino, a diminuição quantitativa das populações nativas, bem como extinções locais em decorrência das seguintes alterações citadas por WELCOMME (1988):

- mudança na estrutura dos habitats no sistema no qual a espécie é introduzida;

- alterações das pressões de predação e competição;

- ocorrência de novos parasitas e patógenos.

Dessa forma, o entendimento dos processos ambientais associados aos aspectos sócio-econômicos de uma determinada região, que contemplam, por exemplo, o uso da bacia de drenagem para o estabelecimento de agroecossistemas, são fundamentais para a contextualização do quadro em que se encontram os ecossistemas aquáticos brasileiros, e para a definição de políticas e estratégias de conservação e manejo desses ambientes (TUNDISI \& BARBOSA, 1995). 


\subsection{CARACTERÍSTICAS E GÊNESE DOS LAGOS NATURAIS BRASILEIROS}

De maneira geral, os ecossistemas lacustres são definidos como corpos d'água continentais lênticos, sem contato direto com o mar, que apresentam baixos teores de íons dissolvidos e curta duração em escala geológica, devido ao acúmulo de sedimentos transportados, principalmente pelo carreamento de material alóctone da bacia de drenagem (ESTEVES, 1988).

Embora possam estar isolados de outros sistemas aquáticos, os lagos são diretamente dependentes das interações com o sistema terrestre, podendo apresentar respostas às atividades antrópicas que ocorrem no entorno (LIKENS, 1992).

Quanto mais antigos e isolados são os corpos lacustres, maior a tendência de se encontrar uma "biota" altamente especializada, com uma comunidade biológica formada por espécies endêmicas (KIRA \& SAZANAMI, 1995). Ou seja, de maneira geral, quanto maior o tempo de isolamento de uma massa de água, maior a estabilidade de suas condições (MARTENS, 1997) e, consequentemente, maior a chance de se encontrar uma comunidade biológica com espécies únicas e dinâmica particular, em relação a outros corpos d'água.

Segundo o mesmo autor (MARTENS, 1997), a formação dos lagos pode envolver diferentes processos: movimentos tectônicos e vulcânicos (fenômenos endógenos), glaciações, erosão e sedimentação (fenômenos exógenos).

No Brasil, a origem da grande maioria dos lagos está relacionada a processos erosivos e sedimentológicos dos rios, do mar, do vento, dos recifes de corais e das águas pluviais (TRINDADE, 1984). Isso fez com que, atualmente, estes sistemas aquáticos estejam localizados em regiões costeiras ou em regiões que, no passado, foram regadas por bacias hidrográficas de grande porte e que mudaram o seu curso ao longo tempo.

Em relação aos aspectos ecológicos, LEWIS (1996) apud TUNDISI (1999) afirma que os lagos de regiões tropicais apresentam cadeias alimentares com as mesmas complexidades daquelas de lagos temperados, um contraste em relação às comunidades terrestres que apresentam maior heterogeneidade em região tropical.

TUNDISI (1999) relata que os lagos tropicais apresentam a tendência de uma eficiência menor na transferência da energia na cadeia trófica e uma resposta mais rápida à entrada de nitrogênio e fósforo (processo de eutrofização mais acelerado) em relação aos lagos temperados. 
Os processos de eutrofização, geralmente, são associados à entrada de grandes cargas de efluentes dométicos e industriais (MARGALEF, 1983). Porém, é importante destacar a eutrofização natural relacionada ao processo de sedimentação de partículas em suspensão de origem terrestre ao longo do tempo, diminuindo a extensão da coluna da água, e disponibilizando crescentes quantidades de nutrientes para o metabolismo de produção do sistema aquático.

Está claro que, devido à intensidade na entrada do material alóctone, os processos de eutrofização natural ocorrem muito mais lentamente do que aqueles forçados pela ação antrópica.

MARGALEF (1993) afirma que o sedimento acumulado no fundo de lagos contém o registro das alterações ambientais que ocorreram ao longo do tempo, incluindo aspectos da evolução das espécies, como endemismos e extinções.

Segundo TRINDADE (1984), como a maior parte dos lagos permanentes brasileiros encontram-se em região costeira (lagoas e lagunas de barragem), originados por processos sedimentológicos e erosivos do mar, são raros os lagos interiores originados somente pela ação fluvial, como os lagos amazônicos, do vale do Rio Doce e dos Pantanais do centro-oeste do Brasil.

MARGALEF (1983) afirma que regiões de baixa altitude, mas com relevo montanhoso, favorecem o surgimento de lagos isolados ou independentes, pelo processo de ação das águas fluviais. Como exemplo, pode-se citar os lagos formados pelo rio Columbia nos Estados Unidos, e os lagos do Vale do Rio Doce no sudeste brasileiro.

Por outro lado, no Brasil não ocorrem lagos de altitude devido ao fato dos processos geológicos não terem favorecido a formação de montanhas com grandes altitudes, como em outras partes do continente americano (região dos Andes e das Montanhas Rochosas), do continente europeu (Alpes) e Asiático (Himalaia), (TRINDADE, 1984).

De acordo com o mesmo autor, os lagos glaciares também não fazem parte da fisionomia do território brasileiro, pois aqueles que existiram no passado, hoje apresentam-se como bacias extintas, formadas por rochas sedimentares. Pelo mesmo motivo, as fossas tectônicas profundas não abrigam lagos de grande profundidade, devido aos processos sedimentológicos que levaram a uma diminuição da coluna da água ao longo do tempo.

No Brasil existem poucos registros da ocorrência de lagos de origem vulcânica, os quais estão relacionados, sobretudo, a fontes termais. 
Dessa forma, os lagos brasileiros diferem dos lagos existentes em outras regiões do mundo não só pela localização geográfica, mas também pela geomorfologia e geologia. 


\subsection{COMPARTIMENTOS HORIZONTAIS EM SISTEMAS LACUSTRES NATURAIS}

No sentido horizontal, um lago pode ser dividido em dois compartimentos principais, para o melhor entendimento da sua dinâmica e estrutura: as zonas limnética ou pelágica, e a litorânea (Figura 2).

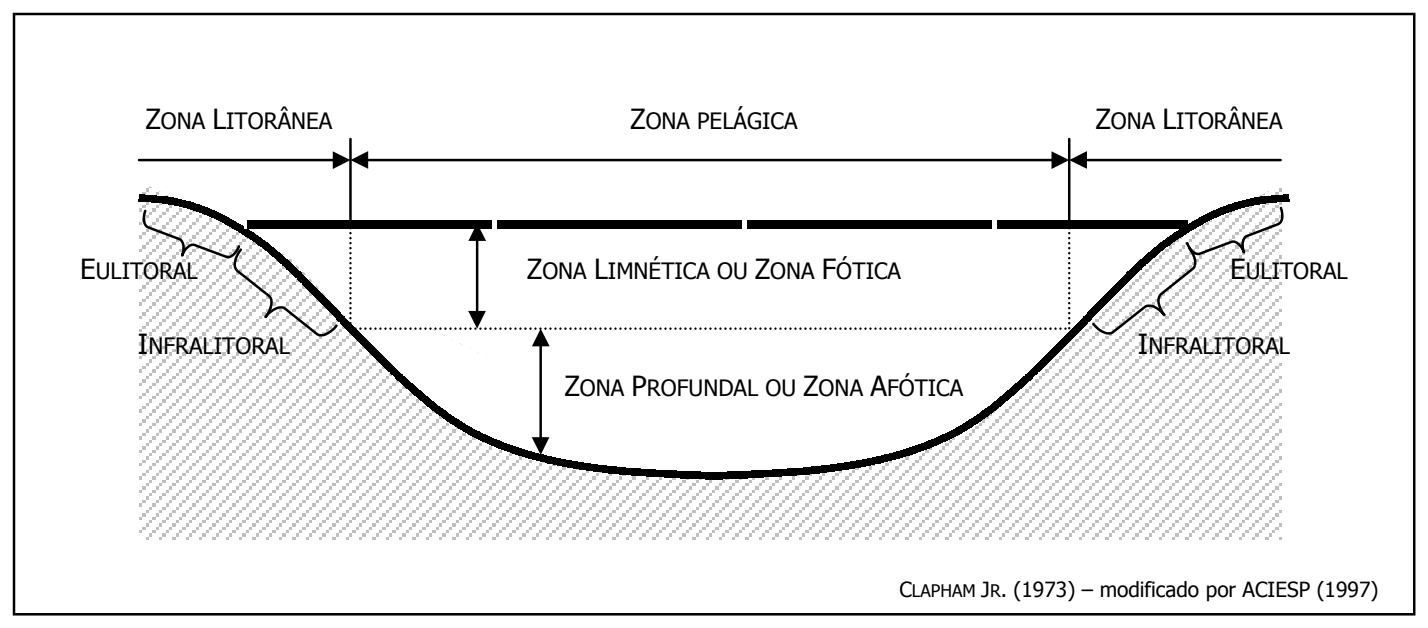

Figura 2. Zonação de um sistema lacustre.

Estas regiões são distintas não apenas pelas características morfológicas, mas também por apresentarem condições ambientais e comunidades biológicas bastante diferenciadas.

O compartimento limnético ou pelágico é aquele localizado na região central e aberta de um corpo lacustre, com profundidades que, geralmente, proporcionam a formação de gradientes verticais nas variáveis limnológicas.

Tais gradientes podem ser estabelecidos com base nos estratos de luz (zona fótica e afótica) dependentes da transparência da água, e pela estratificação química e térmica que são dependentes da sazonalidade na região em que o sistema se encontra e de características geomorfológicas no entorno do lago.

Os grupos de organismos mais característicos da região limnética são o nécton, representados principalmente por peixes, e o plâncton, composto pelo bacterioplâncton, protozooplâncton, fitoplâncton e zooplâncton (ESTEVES, 1988).

O fluxo biogeoquímico nesta região do lago é regido, principalmente, pela interação entre o sedimento e a água, e pela relações ecológicas entre as diferentes comunidades. 
Atualmente, encontra-se um grande número de estudos no Brasil para a região limnética, principalmente em reservatórios construídos para a geração de energia elétrica.

As regiões litorâneas podem ser caracterizadas como uma região de ecótono ou transição entre as águas abertas (zona pelágica) de um corpo d'água e os ecossistemas terrestres da bacia de drenagem (WETZEL \& LIKENS, 1991; JØRGENSEN,1995).

Dessa forma, atuam como um tampão ou filtro das interferências do ecossistema terrestre nas condições lacustres, podendo reter grande parte da matéria orgânica e inorgânica que flui do sistema terrestre, evitando que eventuais substâncias tóxicas e excesso de nutrientes cheguem à região limnética (JØRGENSEN, 1995), o que Ihe confere um papel determinante no metabolismo aquático, principalmente em se tratando de sistemas lacustres rasos (PIECZYNSKA, 1995). Esta função da região litorânea, de amortizadora dos impactos terrestres, é influenciada pela mudança na frequência das forças e na natureza das substâncias que vêm do sistema terrestre.

Este é o motivo que faz da zona litorânea uma região importante a ser considerada nos estudos limnológicos que podem servir de base para programas de manejo e gestão dos ecossistemas aquáticos, principalmente quando se considera a vegetação de macrófitas.

Um exemplo prático do estudo das zonas litorâneas associadas à vegetação de macrófitas, citado por GRANÁLI \& SOLANDER (1988), é a sua função de retenção do aporte de nutrientes nos processos de eutrofização.

Diferentemente das áreas abertas de um sistema lacustre, a região litorânea, geralmente, recebe radiação solar incidente em toda a extensão da coluna da água, o que proporciona uma importante área de produção de matéria orgânica e de retenção de energia pela atividade fotossintética de organismos vegetais.

Devido ao tipo de vegetação e profundidade, esta região pode ser subdividida em duas zonas: eulitoral, com macrófitas emergentes, e neste caso WETZEL \& LIKENS, (1991) a considera como um dos habitats aquáticos de maior produtividade de toda a biosfera; e infralitoral, caracterizado pela ocorrência de macrófitas submersas.

Em ambos os casos pode ocorrer uma rica comunidade de perifíton associada às próprias macrófitas e a outros tipos de substrato, cujas algas desempenham importante papel na produção de matéria orgânica para o ecossistema.

Além destes tipos, existe uma formação litorânea onde não predomina a vegetação de macrótitas. Isto ocorre, geralmente, quando a vegetação terrestre de 
grande porte faz sombra no litoral, impossibilitando a ocorrência desta comunidade aquática. Por exemplo, é o caso da maioria dos lagos de origem vulcânica e de represas construídas para a geração de energia elétrica (ESTEVES, 1988)

A vida na região litorânea depende muito da vegetação presente e, particularmente, quando ocorrem extensos bancos de macrófitas, as zonas litorais podem ser consideradas como as regiões mais produtivas do sistema lacustre com uma comunidade bastante diferente daquelas dos sistemas adjacentes (JØRGENSEN, 1995) devido, principalmente, a um grande número de hábitats e cadeias tróficas.

Segundo ESTEVES (1988), as cadeias tróficas na região litorânea podem ser de dois tipos:

- Cadeia trófica de herbivoria, na qual a fonte de energia para os heterótrofos é a biomassa vegetal viva representada, principalmente, pelas macrófitas e algas perifíticas.

- Cadeia trófica de detritos, na qual os heterótrofos utilizam como fonte de energia a biomassa morta autóctone (de origem na vegetação de macrófitas, principalmente) ou alóctone (de origem na bacia de drenagem).

O mesmo autor atribui à cadeia de detritos a maior eficiência na retenção de energia na zona litorânea.

Em ambos os tipos de cadeia estão representados vários grupos de invertebrados zooplanctônicos, perífíticos e bentônicos, como espécies de crustáceos, oligoquetas, moluscos e fases larvais de insetos. Dessa forma, pode-se considerar que esta região lacustre apresenta uma rede trófica formada por todos os níveis possíveis: produtores, consumidores e decompositores.

A zona litorânea também apresenta um papel central na qualidade da água dos sistemas lacustres, principalmente em função das seguintes características, apresentadas por KURATA \& KIRA (1995):

- Interação entre água e sedimento: geralmente, as regiões litorâneas apresentam baixa profundidade, o que favorece a deposição de material em suspensão alóctone para o sedimento e a disponibilização de substâncias solúveis deste para a coluna da água. Esta interação sedimento-água constitui num elemento fundamental para o ritmo acelerado da ciclagem de nutrientes que ocorre nas zonas litorâneas;

- Elevada atividade biológica: os bancos de macrófitas nas zonas litorâneas proporcionam substrato para o crescimento de uma grande massa de microorganismos que acabam sustentando grandes populações de 
consumidores. A atividade biológica destes organismos é muito acelerada nas zonas litorâneas, contribuindo para o processo mais rápido de ciclagem de nutrientes e outras substâncias, o que altera de forma contínua a qualidade da água.

Como retratam GRANÁLI \& SOLANDER (1988), a vegetação litorânea, quando enraizada, atua como uma eficiente rede de transporte de nutrientes, podendo mediar a alocação destes compostos do sedimento para a água e vice e versa.

Essas duas características associadas revelam a importância de zonas litorâneas com presença de bancos de macrófitas no metabolismo dos sistemas aquáticos, principalmente como região amortizadora dos impactos que ocorrem na bacia de drenagem. Devido a esse fator, KURATA \& KIRA (1995) consideram essas regiões fundamentais para o programas de gestão ambiental.

A Figura 3, elaborada por PIECZYNSKA (1995), apresenta um diagrama com os fluxos de matéria e de energia produzidas pelas macrófitas nos lagos.

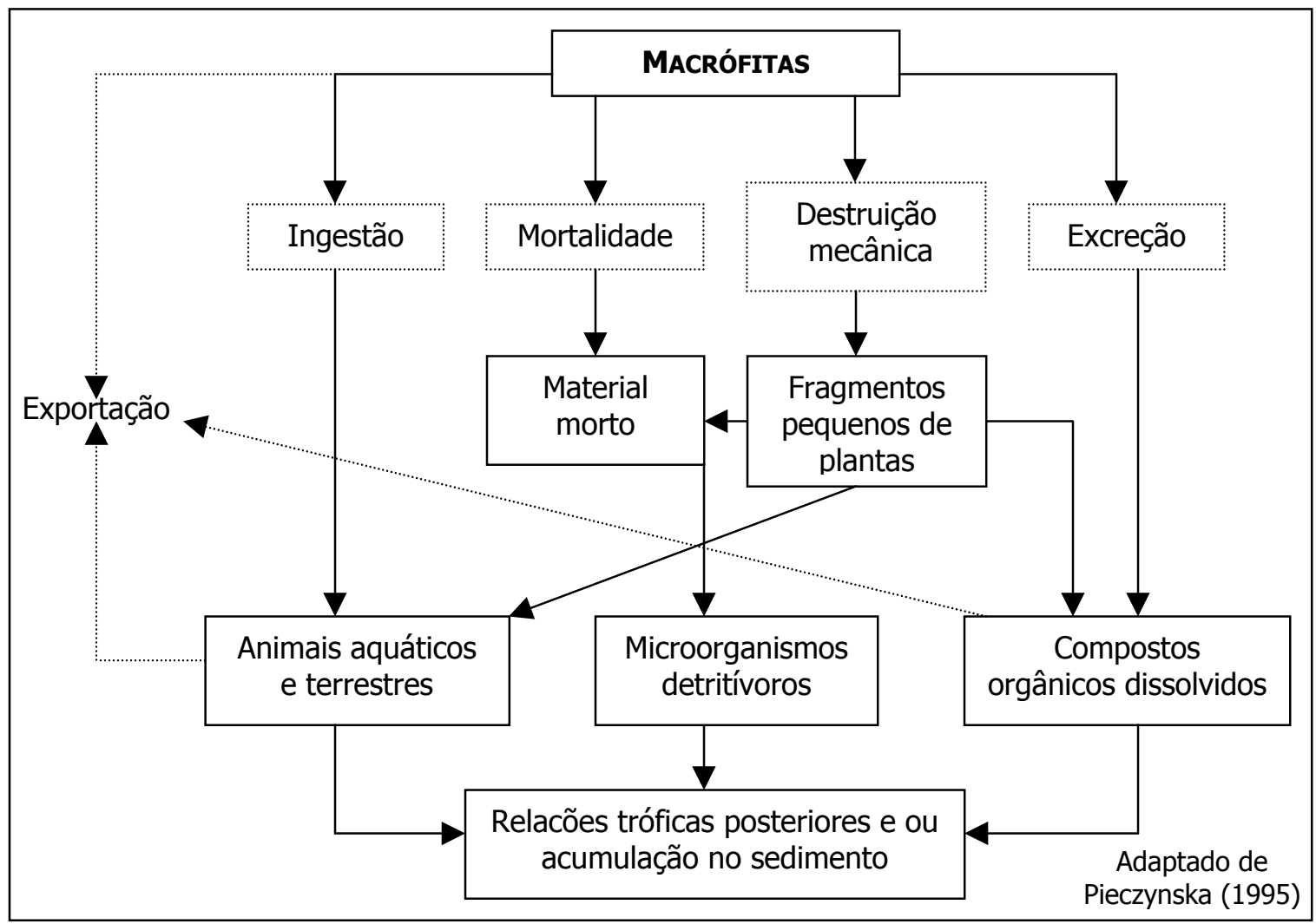

Figura 3. Representação simplificada do fluxo da produção das macrófitas nos lagos. 
Mesmo assim, este compartimento lacustre ainda é pouco estudado, principalmente em relação aos processos biogeoquímicos associados à vegetação de macrófitas, quando comparado, por exemplo, às investigações comumente realizadas na interface sedimento/água de regiões limnéticas.

De maneira geral, o grande número de espécies de invertebrados que habitam as zonas litorâneas está relacionado com o sedimento, com as macrófitas e com outros substratos sólidos. KURATA \& KIRA (1995) atribuem as mudanças na estrutura e na dinâmica das comunidades de invertebrados como um reflexo das variações no meio físico, da distribuição das macrófitas e dos ciclos de vida particulares de cada espécie.

Os mesmos autores relatam a tendência de se encontrar uma grande quantidade de animais e diversidade de espécies em zonas litorâneas que apresentam densa vegetação de macrófitas, também em função da grande quantidade de detritos orgânicos na água e sedimento.

Em suma, para um melhor entendimento da ecologia de qualquer comunidade aquática os estudos devem abranger os diferentes compartimentos de um corpo d'água, uma vez que a riqueza de táxons pode variar significativamente entre os mesmos. Dessa forma, pode-se admitir que os invertebrados litorâneos, principalmente em relação aos organismos zooplanctônicos, tendem a apresentar diversos tipos de hábitos alimentares, como consumidores primários e secundários, filtradores e detritívoros.

Uma zona litorânea bem desenvolvida com a presença de macrófitas aquáticas emergentes e ou submersas favorece, geralmente um maior número de táxons zooplanctônicos devido à alta produtividade (LEMLY \& DIMMICK, 1982; MARGALEF, 1983) e à presença de refúgios contra a predação e menor circulação da massa d'água.

De acordo com KolASA \& ZALEWSKI (1995), as relações que se estabelecem entre a zona litorânea e a limnética são bastantes complexas e dependentes, principalmente, do grau de sinuosidade da margem ou borda, representado pelo seu contorno e fragmentação.

Os mesmos autores afirmam que, como apresentado na Figura 4, com 0 aumento da sinuosidade da borda do ecótono (de 1 para 3) aumenta também o comprimento da borda e, consequentemente, a disponibilidade de habitats. No caso de haver um grau de sinuosidade muito elevado, podem ocorrer novos ecótonos entre a região de transição e as águas abertas, como representado em 4 na mesma figura. 


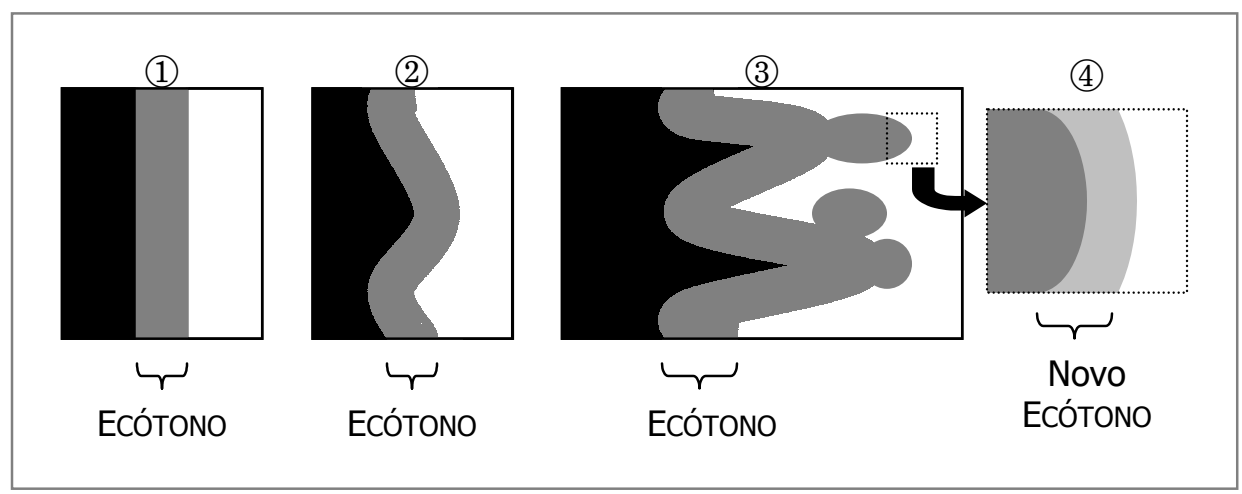

Figura 4. Graus de sinuosidade do ecótono (zona litorânea em tons de cinza) entre ambiente terrestre (em preto) e zona limnética (em branco). Adaptado de KolASA \& ZALEWSKI (1995).

Esta relação de sinuosidade da borda do sistema aquático pode ser representada pelo índice de desenvolvimento de margem ou borda. Tal índice consiste numa característica morfométrica importante para se inferir a influência do sistema terrestre na zona limnética de corpos lacustres, e é definida pela razão entre o perímetro do lago e o perímetro da circunferência calculada a partir do maior comprimento do lago. 
1.7. A DIVERSIDADE ZOOPLANCTÔNICA NOS SISTEMAS LACUSTRES: ZONAS PELÁGICAS E LITORÂNEAS

A maior parte dos estudos brasileiros que abordam aspectos ecológicos do zooplâncton refere-se às regiões limnéticas de reservatórios construídos para a finalidade de geração de energia elétrica.

Nestes sistemas artificiais o regime hidrológico é regido pela dinâmica de operações da barragem, como tempo de residência, fluxo de água vertida e turbinada e correntes de advecção, o que leva a padrões de circulação que podem determinar a ocorrência de padrões, horizontais e temporais, variáveis em diferentes comunidades e, entre elas, no zooplâncton (TUNDISI, 1990).

Por outro lado, os lagos naturais que não recebem aporte de tributários, como por exemplo aqueles do sistema do Vale do Rio Doce, não apresentam estas forças, o que ocasiona uma maior estabilidade temporal e espacial na estrutura e funcionamento dos grupos de organismos, como aqueles componentes do zooplâncton.

Ao contrário do fitoplâncton, a comunidade zooplanctônica, de maneira geral, apresenta menor diversidade de formas nos sistemas lacustres de água doce, em relação ao ambiente marinho (PENNAK, 1991), de tal forma que em alguns lagos africanos a riqueza de espécies de invertebrados zooplanctônicos chega a ser menor do que a de peixes (MARGALEF, 1983).

Os organismos zooplanctônicos que habitam as regiões abertas dos corpos lacustres apresentam adaptações à vida em suspensão na coluna da água, podendo ocupar os diferentes estratos desta. Segundo ESTEVES (1988), o zooplâncton limnético apresenta papel central na dinâmica de um ecossistema aquático.

Dentre os principais grupos zooplanctônicos, o mais investigado é o filo Rotifera. Este grupo está presente em quase todos os tipos de hábitats de água doce, tendo sido descritas cerca de 457 espécies com ocorrência no Brasil, segundo OLIVEIRANETO \& MORENO (1999).

As espécies de Rotifera apresentam grande importância na ecologia do plâncton de água doce, principalmente pelo fato de ocuparem o nicho dos pequenos filtradores, embora existam espécies suspensívoras (MARGALEF, 1983) e algumas carnívoras.

Segundo SEgERS \& DUMONT (1994), a maioria das espécies de Rotifera são típicas de regiões litorâneas, sendo encontradas em menor número na limnética. Muitos são os fatores que determinam esse padrão de ocorrência, sendo destacados, pelo mesmo autor, a biogeografia, temperatura, luminosidade, oxigênio dissolvido, pH 
e disponibilidade de habitats. Além disso, forças de predação, competição e disponibilidade de recursos podem determinar a dinâmica das populações.

Os microcrustáceos de água doce são representados, principalmente, pelos Cladocera e Copepoda. Dentre estes, os Cladocera apresentam grande grau de endemismo em águas continentais, o que poderá ser melhor evidenciado quando o grupo for estudado de forma mais intensiva. No Brasil já foram registradas cerca de 86 espécies de Cladocera (RochA \& GüNTZEL, 1999), e 76 espécies de Copepoda (MATSUMURA-TUNDISI \& SILVA, 1999).

De maneira geral, a região limnética de um corpo lacustre apresenta menor riqueza de espécies de Cladocera em relação à litorânea. Nesta última, é comum encontrar a grande maioria dos representantes do grupo, principalmente entre a vegetação litorânea (ELMOOR-LOUREIRO, 1997).

Os grupos de Cladocera típicos da região litorânea são representados pelas famílias Chydoridae, Macrothricidae e Ilyocryptidae, que apresentam adaptações à utilização de partículas do sedimento e em suspensão, como recurso trófico (FRYER, 1968 apud ELMOOR-LOUREIRO, 1997; e FRYER, 1974 apud ELMOOR-LOUREIRO, 1997).

Por outro lado, os grupos típicos da região limnética, como as famílias Daphnidae e Sididae (ELMOOR-LOUREIRO, 1997), geralmente não apresentam estas características, estando mais adaptadas à filtração de partículas em suspensão.

As espécies de Copepoda encontradas no Brasil estão divididas, principalmente, nas seguintes sub-ordens: Cyclopoida (102 espécies), Calanoida (58 espécies), Harpacticoida (56) e Poecilostomatoida (57), segundo BRASIL (1998) e YOUNG (1999).

As espécies de Copepoda ocupam, praticamente, todos os habitats de um sistema lacustre. Segundo WiLSON \& YEATMAN (1959) apud REID (1985), a distribuição das principais sub-ordens nos habitats é a seguinte:

- Calanoida: habitam, geralmente, as regiões limnéticas;

- Cyclopoida: a maioria das espécies são litorâneas ou bentônicas, podendo haver também aquelas limnéticas;

- Harpacticoida: a maioria das espécies são litorâneas ou bentônicas, havendo também as semi-terrestres.

No caso de lagoas, é comum encontrar uma menor quantidade de táxons zooplanctônicos na zona limnética, o que torna também necessário o envolvimento da zona litorânea nos estudos para uma caracterização mais efetiva do grupo. 
A região litorânea de um sistema lacustre difere da limnética não apenas pela presença de macrófitas que fornecem alimento e refúgio contra predadores, diferenças nas características físicas e químicas, mas também pela comunidade de heterótrofos, devido à maior disponibilidade de habitats e de recursos tróficos, além de outras características como conforto térmico e áreas de pouca luminosidade.

Embora a comunidade zooplanctônica, de uma forma geral, tenha sido objeto de estudos bem detalhados, ainda existem aspectos sobre a ecologia e a diversidade deste grupo em lagos da região neotropical que necessitam de investigações mais aprofundadas, devido à grande variabilidade de formas e hábitos destes animais.

Isto se torna mais evidente quando se considera que a maioria dos estudos sobre a comunidade zooplanctônica concentram-se na zona limnética, tendo até o momento sido dada pouca ênfase às zonas litorâneas, região de maior riqueza de táxons. Para uma caracterização global da comunidade zooplanctônica de um corpo lacustre é necessário que se envolva no estudo, ambas as regiões, limnética e litorânea. 


\subsection{ZOOPLÂNCTON COMO INDICADOR DA QUALIDADE DA ÁGUA}

Devido aos impactos antrópicos nos sistemas aquáticos, a conseqüente diminuição na qualidade da água tem gerado muitos problemas para o metabolismo dos corpos d'água e para o abastecimento das atividades humanas.

Dessa forma, um dos papeis fundamentais da Limnologia é o estabelecimento de critérios biológicos (indicadores biológicos), físicos e químicos que colaborem com a implementação dos mecanismos de identificação e controle da qualidade da água (ESTEVES, 1988).

Um aspecto importante nas relações ecológicas do zooplâncton, e ainda pouco estudado, são as respostas ou alterações na composição e abundância dos organismos em decorrência de alterações da qualidade da água que, por outro lado, são conseqüência dos impactos que ocorrem na bacia de drenagem.

De uma maneira geral, observa-se que a biota dos lagos ou lagoas é dominada numericamente por uma ou mais populações, dentro de cada grupo taxonômico ou de uma comunidade.

Estas relações de dominância podem apresentar um caráter importante na identificação de alterações da qualidade água, devido à existência de adaptações nos organismos que favorecem a eficiência na exploração de determinados nichos.

Devido a isso, o grupo zooplanctônico apresenta grande sensibilidade em relação às mudanças nas características ambientais do sistema, respondendo à freqüência das forças físicas periódicas e à amplitude de variação dos fatores ambientais (LEGENDRE \& DEMMERS, 1984), podendo ser considerados sensores refinados (indicadores ambientais) das características ambientais, melhores do que artefatos tecnológicos de análise indireta (MARGALEF, 1983).

PEnNAK (1991) relaciona a eficiência na exploração das diferentes condições físicas e químicas dos hábitats, às características genéticas, morfológicas, fisiológicas e ecológicas das populações.

As alterações nas características limnológicas podem afetar qualitativamente e quantitativamente a disponibilidade de recursos tróficos para o zooplâncton. Um processo importante que acarreta estes efeitos é a eutrofização, atuando indiretamente na sucessão zooplanctônica (SLÁDECEK, 1983; CHAPMAN et al., 1985).

PEJLER (1983) faz uma análise, baseada na literatura, da ocorrência de populações zooplanctônicas em relação ao estado trófico, discutindo que o aumento do grau de trofia favorece populações especialistas no aproveitamento de pequenas 
partículas como recurso trófico, e desfavorece aquelas de macrofiltradores. Já BËRZINS \& BERTILSSON (1988), pela análise do material de diferentes tipos de sistemas aquáticos suecos, relacionam espécies planctônicas, perifíticas e bentônicas com o estado trófico, mostrando suas relações com diferentes concentrações de fósforo total e com amplitudes de variação da condutividade da água. Com o mesmo material, BERTILSSON et al. (1995) relacionam a ocorrência de microcrustáceos com espectros de temperatura da água e oxigênio dissolvido.

Outros autores, como McNaught (1975), SLAdecek (1983), OrCutt \& PACE (1984), ChAPMAN et al. (1985), MATSUMURA-TUNDisi et al. (1990), também discutem os efeitos dos processos de eutrofização na estrutura e dinâmica sucessional do zooplâncton, tendo como foco a alteração na qualidade do recurso trófico.

MARGALEF (1983) associa a ocorrência de espécies de copépodos nas águas epicontinentais com o grau de trofia relativamente próximo ao de áreas marinhas litorâneas ou de ressurgência, embora nestas últimas o número de espécies ainda seja maior.

Dessa forma, as respostas do zooplâncton às variações dos fatores ambientais ressaltam a importância de estudos sobre a sua estrutura e dinâmica para programas de monitoramento da qualidade da água (GANNON \& STEMBERGER, 1978; SLÁDECEK, 1983).

Geralmente, a abordagem mais difundida nos estudos que envolvem 0 zooplâncton refere-se à investigação de fatores, muitas vezes isolados, que determinam alterações na estrutura e dinâmica das populações, não contemplando a interação destes fatores com os processos que ocorrem na bacia de drenagem.

Neste contexto atual, estudos sobre a composição específica, a proporção entre as populações e a diversidade do zooplâncton em resposta às características da bacia de drenagem são de suma importância para gerar informações sobre os processos ecológicos dos sistemas, buscando relações e bioindicadores que permitam inferir sobre as condições da qualidade da água de ecossistemas aquáticos. 


\section{OBjetivos}

\section{ObJetivo Geral}

O presente estudo objetiva realizar uma caracterização limnológica comparativa de cinco lagoas (Carioca, Amarela, Aguapé, Águas Claras e Ariranha) do sistema de lagos do Vale do Rio Doce, em duas épocas do ano (período chuvoso-verão e período de estiagem-inverno), buscando identificar as diferenças na diversidade do zooplâncton e nas características limnológicas entre as zonas limnéticas e litorâneas das lagoas que se encontram inseridas na área de reflorestamento da Companhia Agrícola Florestal e da Lagoa Carioca, localizada dentro de uma área de floresta de Mata Atlântica do Parque Estadual do Rio Doce. 


\section{OBJETIVOS ESPECÍfICOS}

1. Caracterizar a composição e abundância relativa do zooplâncton, e as variáveis físicas e químicas, das regiões limnética e litorânea das lagoas, nos períodos estudados, visando identificar a ocorrência de diferenças na diversidade zooplanctônica e/ou na estrutura física e química entre as zonas limnéticas e litorâneas, comparando-se as lagoas que se encontram em área de cultivo de eucalipto com uma lagoa com floresta de Mata Atlântica no entorno;

2. Identificar os principais fatores responsáveis pelas possíveis diferenças citadas em 1 ;

3. Estimar as diversidades alfa $(\alpha)$ e beta $(\beta)$ do zooplâncton, relacionando-as com o tipo de compartimento lacustre (limnético ou litorâneo) e com o tipo de vegetação no entorno das lagoas;

4. Determinar o estado trófico das lagoas, associando esses dados com as características de uso e ocupação do solo no entorno das lagoas estudadas; 


\section{MATERIAL e MÉtodos}

\section{1. Área de estudos: o sistema de lagos do Vale do Rio Doce}

\subsubsection{REGIÃO POLÍTICO-ADMINISTRATIVA}

A área investigada neste trabalho pertence à região político-administrativa do Vale do Rio Doce (Figura 5) e está situada na "Depressão Interplanáltica do Vale do Rio Doce" (CETEC, 1981).

Esta região é de grande importância para o desenvolvimento econômico do Estado de Minas Gerais,por possuir um extenso pólo industrial denominado Zona Metalúrgica ou "Vale do Aço", onde se encontram importantes usinas siderúrgicas, como a Usina Siderúrgica de Minas Gerais (USIMINAS), a Aços Especiais Itabira S.A. (Acesita) e a Companhia Siderúrgica Belgo-Mineira (MelLo, 1997).

Outra área importante desta região é a denominada Zona da Mata, onde está localizada a Zona Geográfica do Rio Doce, constituída por uma rica rede de drenagem e por remanescentes de Mata Atlântica. É nesta zona que se encontra inserido o sistema de lagos do Vale do Rio Doce, constituído por cerca de 160 corpos lacustres preservados, sendo que cerca de 50 situam-se dentro do Parque Estadual do Rio Doce (PERD). 


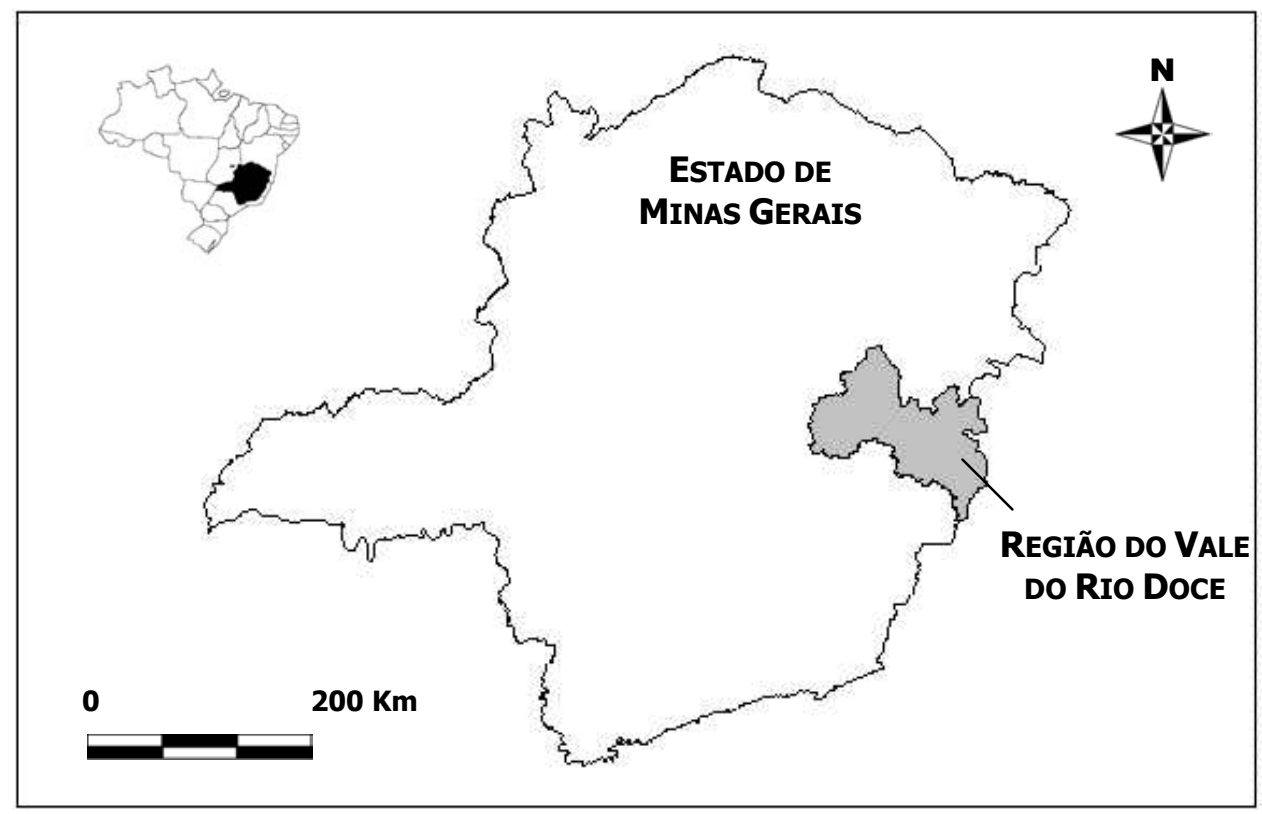

Figura 5. Delimitação político-administrativa do Vale do Rio Doce. Adaptado de: Mapa Geopolítico de Minas Gerais - IGA / CETEC (1994). Digitalização: Assessoria da Secretaria Geral do Governador. 


\subsubsection{BACIA HIDROGRÁFICA DO RIO DOCE}

A Bacia Hidrográfica do Rio Doce está localizada a sudeste de Minas Gerais (Figura 6), e compreende uma área de drenagem de $83.400 \mathrm{Km}^{2}$, dos quais $86 \%$ pertencem ao Estado de Minas Gerais e 14\% ao Estado do Espírito Santo, abrigando uma população de 3,1 milhões de habitantes, distribuídos em de 222 municípios (MeLLo, 1997).

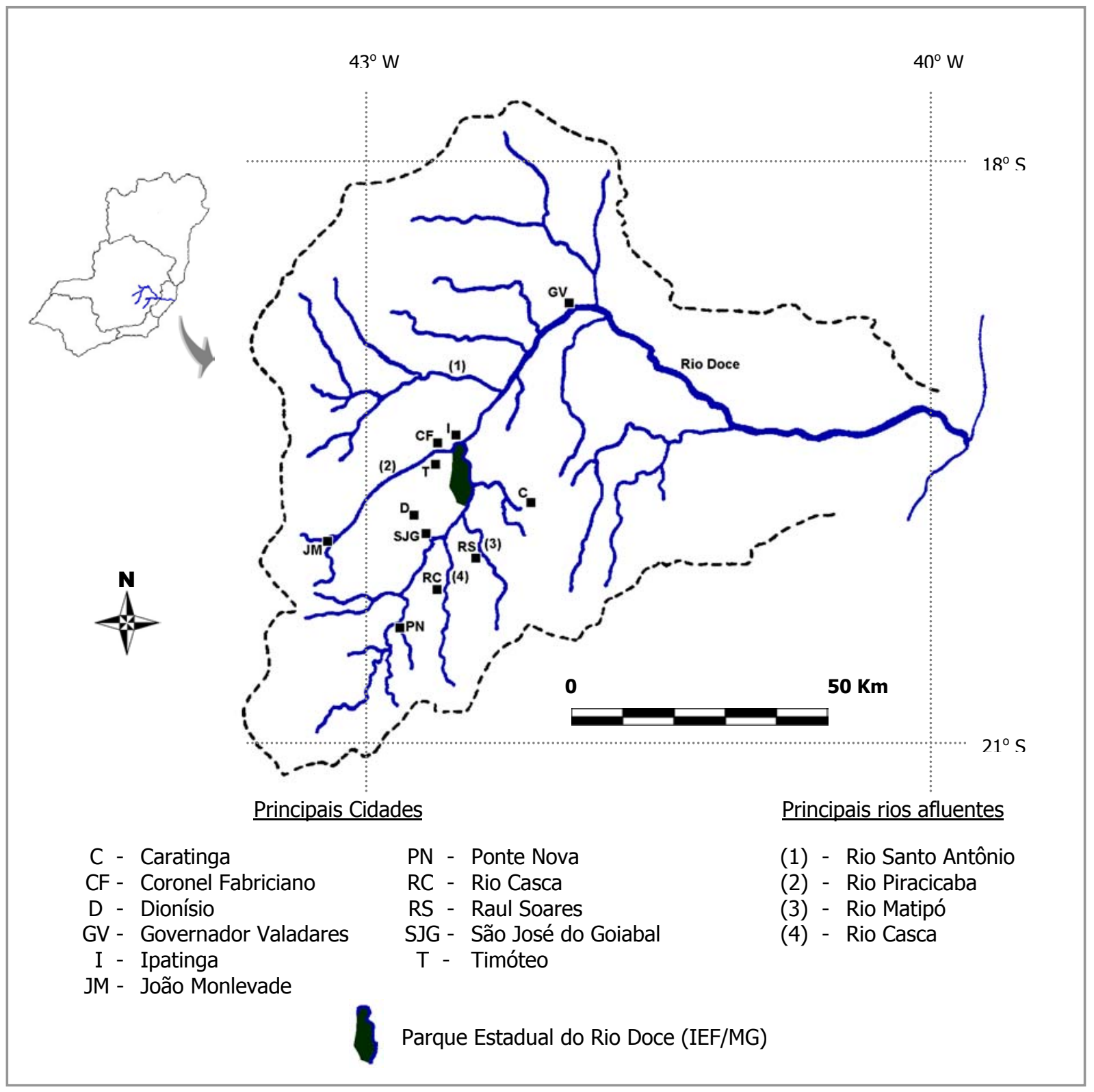

Figura 6. Bacia de drenagem do Rio Doce e principais municípios. Adaptado de Mello (1997). 
Ao longo de sua bacia de drenagem, o Rio Doce recebe um grande número de tributários, sendo os mais importantes os rios Santo Antônio, Piracicaba, Matipó e Casca.

Originalmente, esta bacia era quase toda coberta por floresta tropical úmida de Mata Atlântica, compondo um dos maiores biomas tropicias da Terra, comparável apenas à floresta Amazônica. Porém, o intenso desmatamento desta cobertura vegetal, iniciado nas primeiras décadas do século $\mathrm{XX}$, acabou restringindo a floresta a pequenos fragmentos espalhados ao longo da bacia, tendo sua área geográfica e biodiversidade animal e vegetal consideravelmente diminuída, restando apenas $7 \%$ da cobertura inicial (FONSECA, 1983, 1985 apud PAULA et al., 1997). 


\subsubsection{ASPECTOS ECONÔMICOS DA BACIA DO RIO DOCE}

Ao longo de toda a Bacia Hidrográfica do Rio Doce, a economia é bastante diversificada:

- Alto Rio Doce: grandes projetos de mineração (minério de ferro), agricultura e pecuária;

- Médio Rio Doce: está localizado o maior pólo siderúrgico da América Latina, além de indústria de celulose, carvão vegetal, agropecuária e hidroelétricas de médio porte nos rios Piracicaba e Santo Antônio;

- Baixo Rio Doce: cultura de café e agropecuária.

A Figura 7 mostra as principais áreas de mineração e siderurgia do Vale do Rio Doce, além das áreas críticas e problemas prioritários quanto à disponibilidade dos recursos hídricos (SETTI, 1996):

- Área crítica 1 e 2: caracterizadas por grandes retiradas de água, associadas ao lançamento de elevadas cargas poluidoras. Tem como problema prioritário a baixa qualidade das águas da rede de drenagem;

- Área crítica 3: compreende a região do Vale do Aço e de áreas de mineração que, segundo o DNAEE (1984) apud SETTI (1996), são responsáveis por elevadas demandas de água e alto potencial poluidor com substâncias inorgânicas. O maior problema que esta região vem apresentando, recentemente, são as enchentes.

- Área crítica 4: compreende cidades de grande porte como Governador Valadares, o que ocasiona uma considerável diminuição na qualidade da água pelo aporte de efluentes domésticos e industriais, comprometendo até mesmo os pontos de captação.

Além destas atividades, vale ressaltar a presença de indústrias de celulose e carvão vegetal que, ao longo dos anos, substituiu grande parte da floresta de Mata Atlântica por maciços florestais de eucalipto às margens do Rio Doce e imediatamente após a confluência com o Rio Piracicaba. 


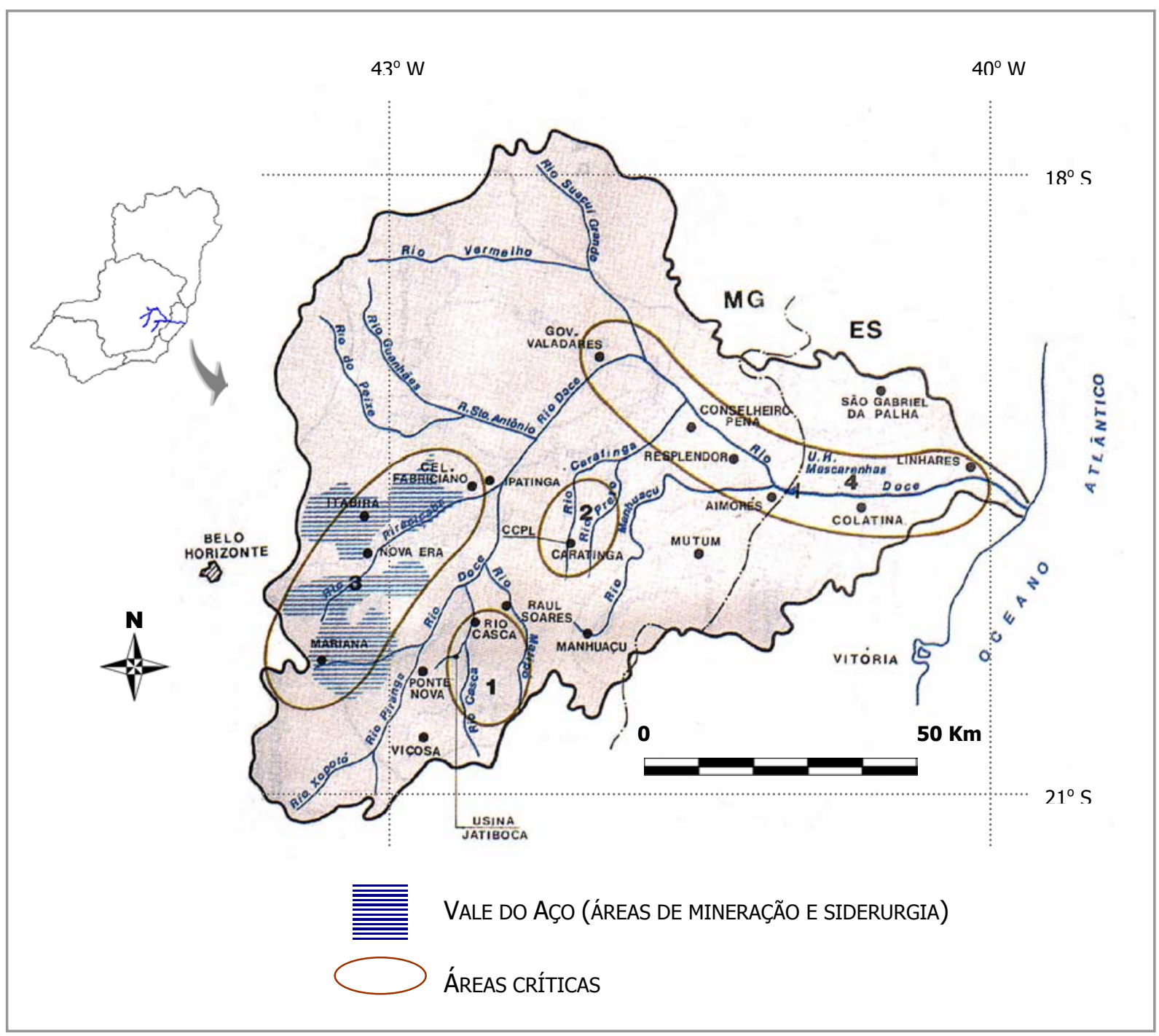

Figura 7. Áreas críticas e problemas prioritários da Bacia do Rio Doce. Adaptado de DNAEE (1948) apud SETTI (1996).

De maneira geral, o sistema de drenagem desta bacia apresenta um papel fundamental na economina do leste brasileiro, principalmente no leste do Estado de Minas Gerais e nordeste do Espírito Santo, uma vez que além de fornecer água para fins doméstico, agropecuário, industrial e geração de energia; recebe esgotos, rejeitos e efluentes produzidos pelos centros urbanos e pelas atividades industriais.

Tendo em vista o grau de devastação, conclui-se que a Bacia do Rio Doce é considerada um ecossistema tropical bastante ameaçado, pois apesar de possuir uma rica rede de drenagem, encontra-se associada a uma extensa área industrial. 
Outro problema derivado da atividade econômica estabelecida na região é a alta taxa de perda da cobertura vegetal, o que ameaça muitas espécies de extinção. Vale lembrar que a região é considerada um pólo de endemismo de espécies. FONSECA (1997) relata que das 10.000 espécies vegetais (terrestres) estimadas para a região, $53 \%$ das formas arbóreas, $64 \%$ das palmeiras e $74 \%$ das bromélias são consideradas endêmicas. Em relação à fauna, o mesmo autor afirma que 214 espécies de aves (de um total de 940 registradas) e 73 espécies de mamíferos (de um total de 260 registrados) também apresentam distribuição restrita à região.

Dentre os grandes fragmentos florestais naturais que restam hoje na região da Bacia do Rio Doce, pode-se destacar o Parque Estadual do Rio Doce como sendo o maior deles, o qual abriga um vasto sistema de lagos naturais (GODINHO, 1996), único no Brasil por se tratarem de lagos muito antigos. 


\subsubsection{Sistema de LAGOS do VAle do Rio Doce}

Na região compreendida entre os rios Piracicaba e Doce, ocorre um sistema hídrico preservado com cerca de 160 lagos de dimensões variáveis, não excedendo 6 Km de comprimento e 0,5 Km de largura (MelLo, 1997).

A origem deste sistema de lagos data do período Pleistocênico-Holocênico, por depósitos de material carreado pelo Rio Doce que formaram barragens naturais no seu curso, possibilitando o acúmulo de água dos seus afluentes, principalmente nos vales do relevo de "Mares de morros", formação geológica predominante na região.

A maioria das lagoas que ocorrem neste sistema não se localizam às margens do Rio Doce, devido ao fato de seu leito ter sido abandonado várias vezes ao longo do tempo. Hoje, por estudos geomorfológicos, pode-se observar dois leitos antigos com várias lagoas associadas (GodiNHO, 1996).

Segundo o mesmo autor, no período das chuvas, eventualmente, .2/podem ocorrer comunicações de algumas lagoas entre si, com o Rio Doce e com outros tributários desta bacia, possibilitando a formação de "pontes" por onde podem passar peixes e outros organismos aquáticos. Este parece ser o motivo pelo qual grande parte das lagoas deste sistema apresentam as mesmas espécies exóticas de peixes e invertebrados aquáticos.

A paisagem que domina a região onde se encontra o sistema de lagos do Vale do Rio Doce é caracterizada por montanhas com escalonamento de faixas ecológicas e morfoclimáticas (de acordo com a altitude e latitude) e paisagens sazonais de setorização complexa, segundo AB'SABER (1972).

Como os lagos desse sistema são, predominantemente, permanentes e fechados, ou seja, não recebem e nem exportam água de tributários, o ciclo hidrológico é regido pelo aporte de água das chuvas diretamente ou pelo escoamento na bacia de drenagem e do lençol freático, e pela perda de água pelo processo físico de evaporação e pela transpiração das macrófitas. Dessa forma, as principais alterações na qualidade destes sistemas ocorrem devido a variações nas características físicas, químicas e biológicas do material alóctone que é carreado do sistema terrestre.

A Figura 8 apresenta uma imagem de satélite com a área de maior concentração das lagoas, tendo em destaque o Parque Estadual do Rio Doce, e as regiões onde se encontram as lagoas estudadas neste trabalho. 
Dentro deste sistema de lagos ocorrem muitas vilas e pequenas cidades, cuja população utiliza-se do recurso hídrico oferecido pelas lagoas para a pesca, lazer e abastecimento.

A atividade econômica que ocorre de forma mais concentrada na região do sistema de lagos é a cultura intensiva do eucalipto para a produção de carvão vegetal. Para isso, ao longo das últimas décadas a maior parte da vegetação nativa do sistema de lagos foi retirada.

Hoje, este cultivo encontra-se bastante implantado na região, e observando-se ainda baterias de fornos para a produção do carvão vegetal pertencentes à Companhia Agrícola Florestal (CAF), o qual é destinado às indústrias siderúrgica do Vale do Aço. $\mathrm{A}$ utilização do carvão vegetal tem sido gradualmente substituída pelo carvão mineral, resultando no abandono de algumas plantações e formação de bosques mistos pelo crescimento do subbosque de espécies nativas.

Na Figura 9, que apresenta uma aerofoto com algumas atividades econômicas da região, pode-se observar uma bateria de fornos atualmente desativada pertencente à Companhia Agrícola Florestal, e um extenso tabuleiro de secagem de arroz. O cultivo do arroz é desenvolvido, principalmente, em áreas alagadas e em lagoas que se apresentam assoreadas por processos sedimentológicos. 


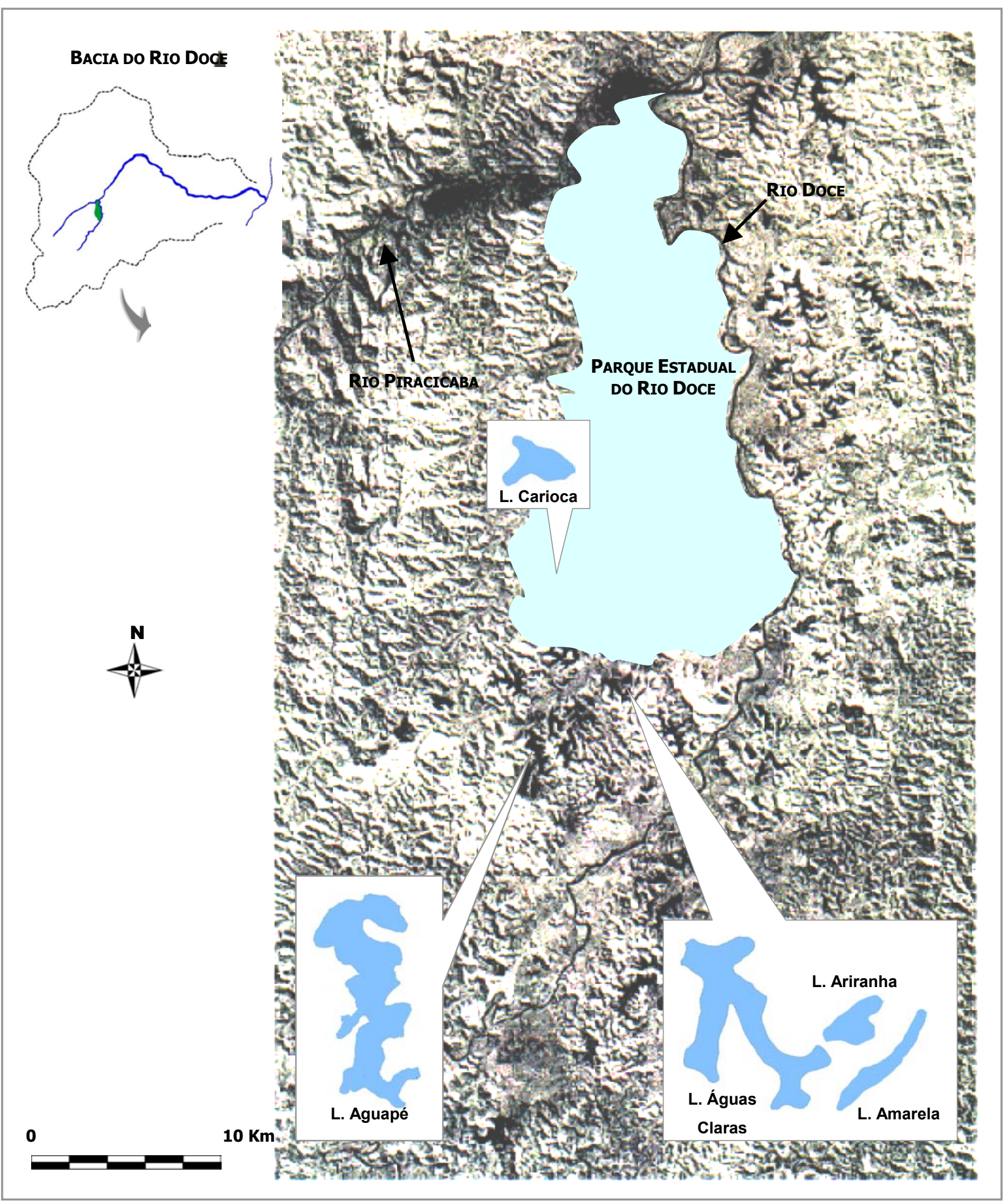

Figura 8. Visão geral, em imagem de satélite (TM-Landsat, escala original 1:250.000), do sistema de lagos do médio vale do Rio Doce (MG), destacando a porção de maior concentração de lagos. Adaptado de Mello (1997). 


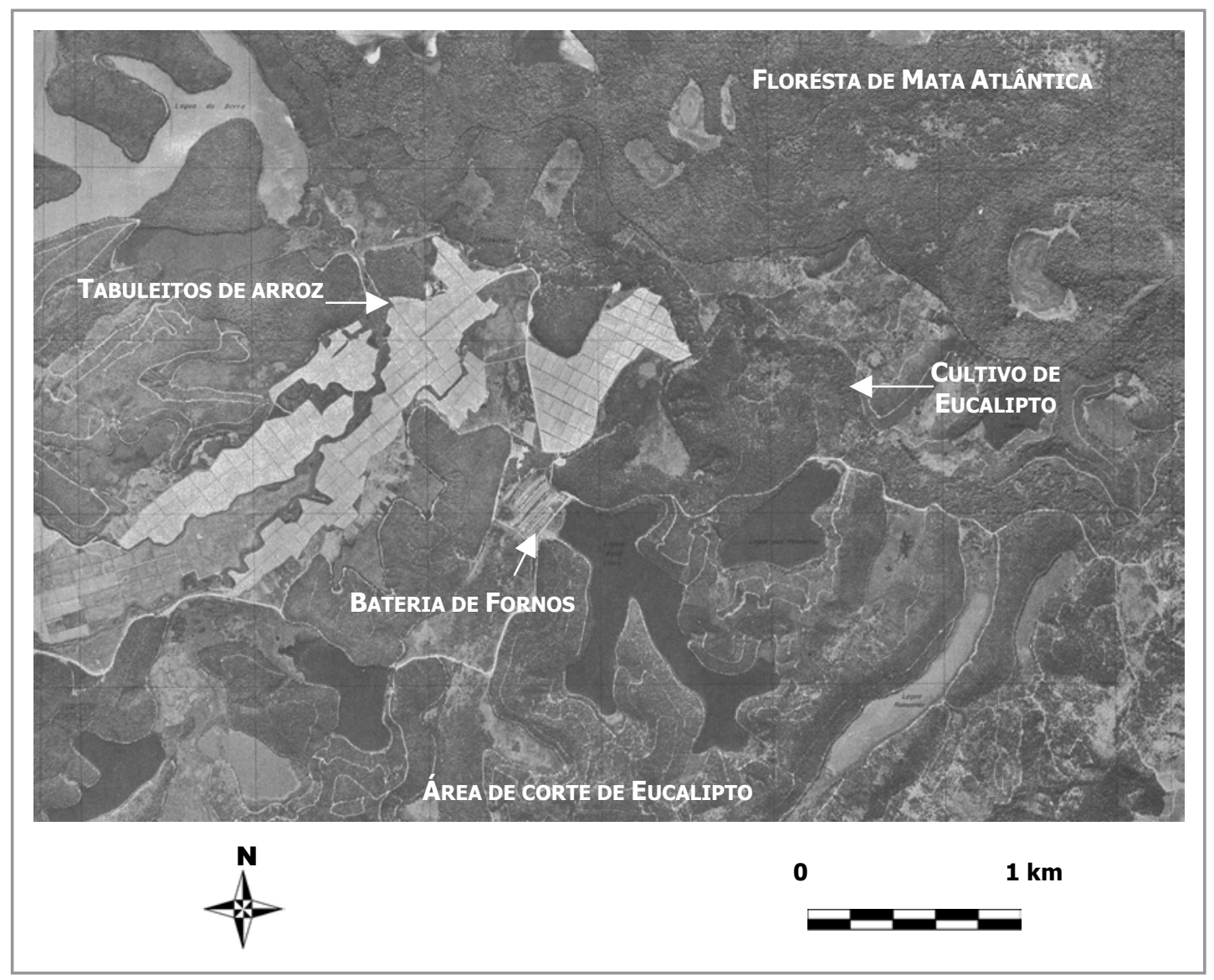

Figura 9. Foto aérea destacando algumas atividades desenvolvidas dentro da área da CAF, no sistema de lagos. Retirado de: Levantamento Aerofotométrico, Coronel Fabriciano - 4. Folha 36-22-07, CEMIG (1989). 


\subsubsection{PARQUe Estadual do Rio Doce (PERD)}

Localizado a sudeste do Estado de Minas Gerais, próximo à região conhecida como Vale do Aço e dentro do sistema de lagos, o Parque Estadual do Rio Doce abrange parte dos municípios de Marliéria, Timóteo e Dionísio (Figura 10). Constitui uma reserva de Floresta Tropical Úmida com uma área de 35.974 ha. (ANDRADE et al., 1997).

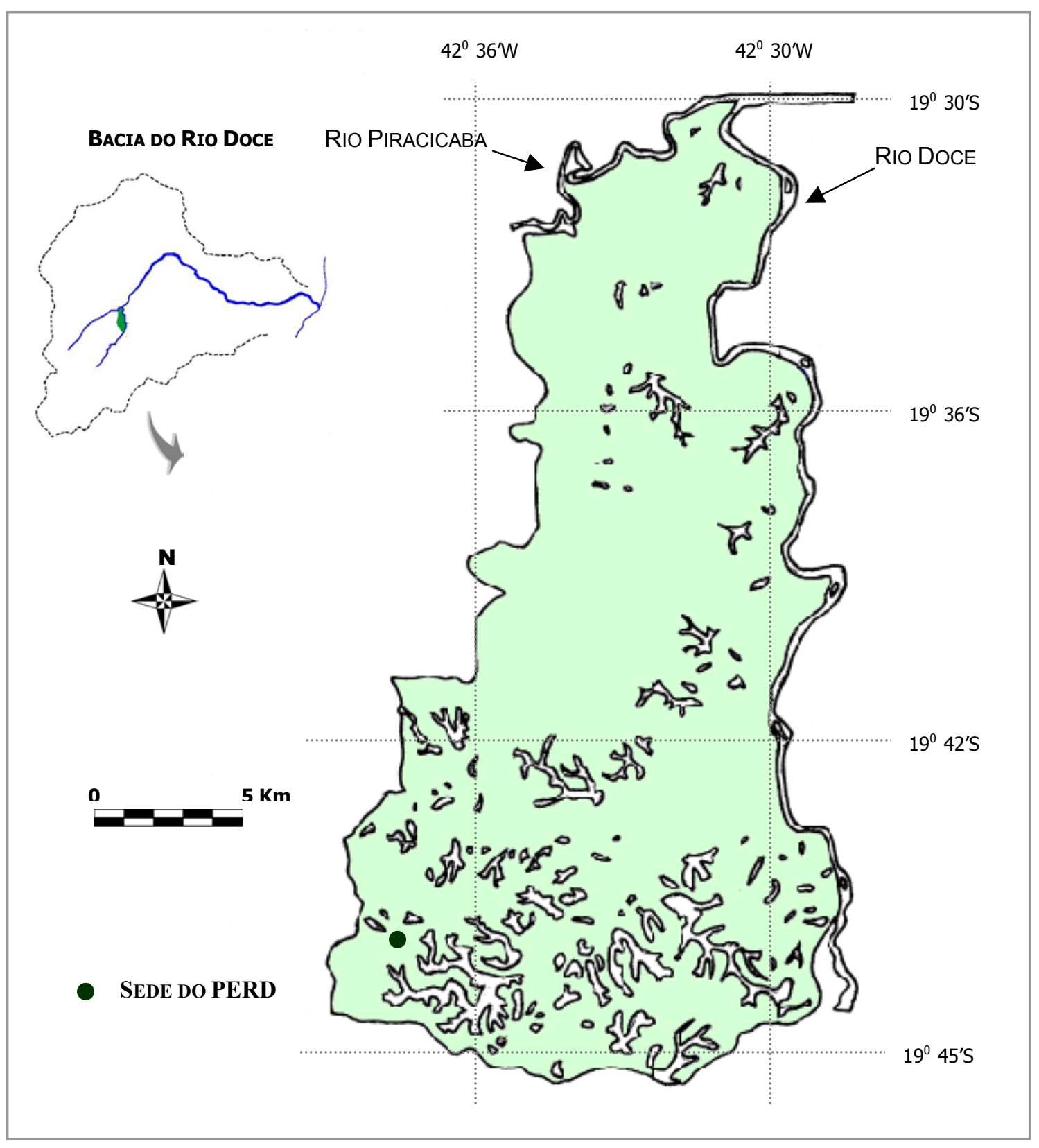

Figura 10. Parque Estadual do Rio Doce. Adaptado de GodinHo (1996). 
No início dos anos 30 o arcebispo da cidade de Mariana, Dom Helvécio Gomes de Oliveira, apresentou as primeiras iniciativas no sentido de preservar a região. Porém, só em 1944 o governador de Minas Gerais, Benedito Valadares, assinou o decreto-lei 1.119 que o criou oficialmente (GodiNHO, 1996). Atualmente, o parque é administrado pelo Instituto Estadual de Floresta de Minas Gerais (IEF-MG). Vale ressaltar que alguns trabalhos, como os de GiLHUIS (1986), ROCHA \& MATSUMURATUNDISI (1997) e TUNDISI (1997), referem-se ao parque como "Parque Florestal do Rio Doce", porém, de acordo com a lei anteriormente citada o nome mais apropriado é "Parque Estadual do Rio Doce", estando sob a administração do governo do Estado de Minas Gerais.

O sistema hídrico do parque é formado pelo conjunto de cerca de 50 lagoas (6\% de sua área), sendo 21 já totalmente assoreadas por processos naturais. Além das lagoas, ocorrem pequenos tributários dos Rios Piracicaba e Doce. A área faz fronteiras a centros urbanos, áreas agropastoris e extensos cultivos de eucalipto da Companhia Agrícola Florestal (CAF).

Por estar inserida na "Depressão Interplanáltica do Rio Doce", esta região está sujeita a massas de ar oriundas do sul, oeste e leste, o que ocasiona um clima com características secas de maio a agosto e úmidas de outubro a março, onde se pode evidenciar um verão de fato. As temperaturas variam entre 28 e $39^{\circ} \mathrm{C}$ nos meses mais quentes e entre 7 e $20^{\circ} \mathrm{C}$ nos meses mais frios. A precipitação anual varia de 1.350 a 1.900 milímetros (GODINHO, 1996).

De maneira geral, grande parte dos corpos de água que compõem o sistema de lagos tem sofrido algum tipo de impacto, seja pelo uso da água ou pela modificação da paisagem. Apenas na área onde se encontra o Parque Estadual do Rio Doce as lagoas estão preservadas, e a paisagem no entorno praticamente inalterada. 


\subsubsection{As LAGOAS ESTUDADAS}

Foram escolhidas 5 lagoas para o estudo sobre a estrutura da comunidade zooplanctônica: Lagoa Carioca, Aguapé, Águas Claras, Ariranha e Amarela.

Segundo a paisagem do entorno das lagoas, estas podem ser subdivididas em três grupos (Figura 11):

- Grupo 1: formado pela lagoa Carioca, localizada dentro dos limites do Parque Estadual do Rio Doce. Este grupo é caracterizado pela presença de floresta de Mata Atlântica preservada;

- Grupo 2: formado pelas lagoas Aguapé e Águas Claras, localizadas em área de propriedade particular da Companhia Agrícola Florestal. O grupo é caracterizado pelo cultivo de eucalipto em atividade, com extensas áreas de corte.

- Grupo 3: formado pelas lagoas Ariranha e Amarela, também localizadas em área de propriedade particular da Companhia Agrícola Florestal. Este terceiro grupo é caracterizado pela cultivo de eucalipto abandonado, entremeado por espécies nativas oportunistas.

\begin{tabular}{|c|c|c|c|c|}
\hline $\begin{array}{l}\text { GRUPO } 1 \\
\text { (PERD) }\end{array}$ & GRUP & (CAF) & \multicolumn{2}{|c|}{ GRUPO 3 (CAF) } \\
\hline $\begin{array}{l}\text { Lagoa } \\
\text { Carioca }\end{array}$ & $\begin{array}{l}\text { Lagoa } \\
\text { Aguapé }\end{array}$ & $\begin{array}{l}\text { Lagoa } \\
\text { Águas Claras }\end{array}$ & $\begin{array}{l}\text { Lagoa } \\
\text { Ariranha }\end{array}$ & $\begin{array}{c}\text { Lagoa } \\
\text { Amarela }\end{array}$ \\
\hline
\end{tabular}

Figura 11. Agrupamentos das lagoas estudadas segundo a vegetação do entorno.

Outro aspecto relevante neste trabalho é a abordagem de dois compartimentos importantes das lagoas: as zonas limnética e litorânea; com a finalidade de abranger de forma mais efetiva a comunidade zooplanctônica. 
Para isso os pontos de amostragem foram divididos em dois grupos, segundo a localização dentro da lagoa (Figura 12):

- zona pelágica;

- zona litorânea (com e sem bancos de macrófitas).

De acordo com IKUSIMA \& GENTIL (1977) a vegetação de macrófitas que compõe as lagoas do Vale do Rio Doce, estudadas no presente trabalho, especialmente nas regiões litorâneas, é composta pelas seguintes espécies:

- Macrófitas enraizadas emergentes: Typha domingensis, Eleocharis interstincta, Dryopteris gongylodes, Eichornia azurea;

- Macrófitas enraizadas submersas: Cabomba piauhyensis, Najas conferta, Mayaca fluviatilis, Utricularia sp.;

- Macrófitas livre-flutuantes: Salvinia auriculata, Nymphoides indica, Nymphaea elegans. 


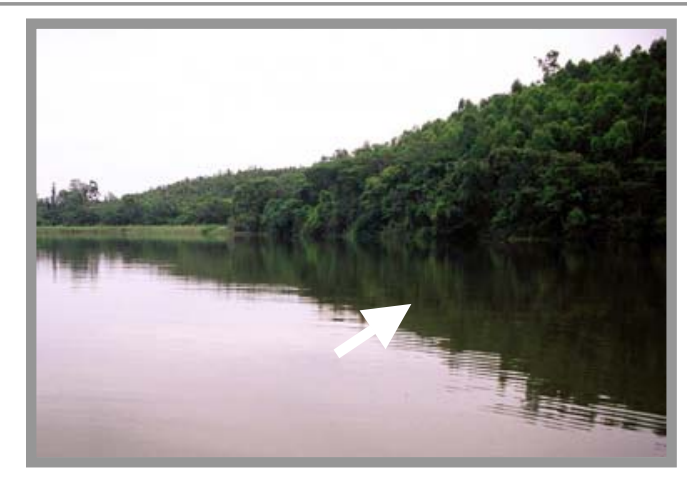

ZONA LITORÂNEA SEM BANCO DE MACRÓFITAS

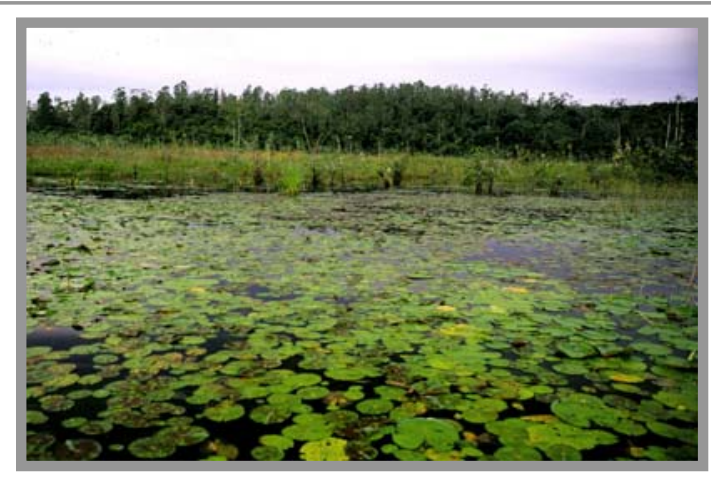

ZONA LITORÂNEA COM BANCO DE MACRÓFITAS

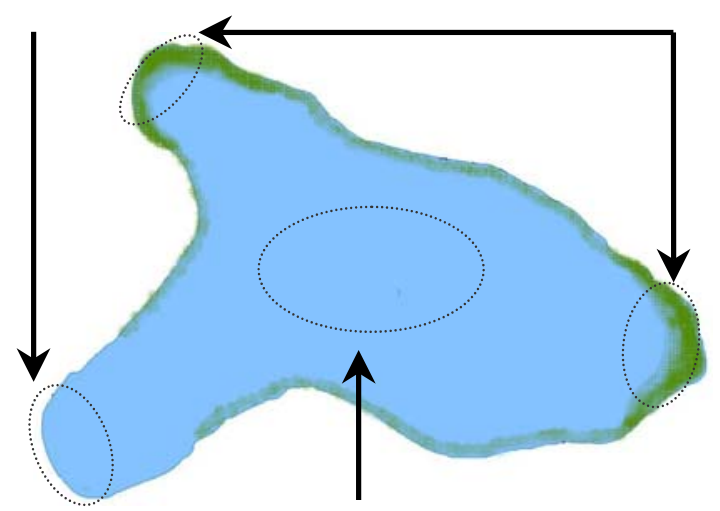

ZONA LIMNÉTICA

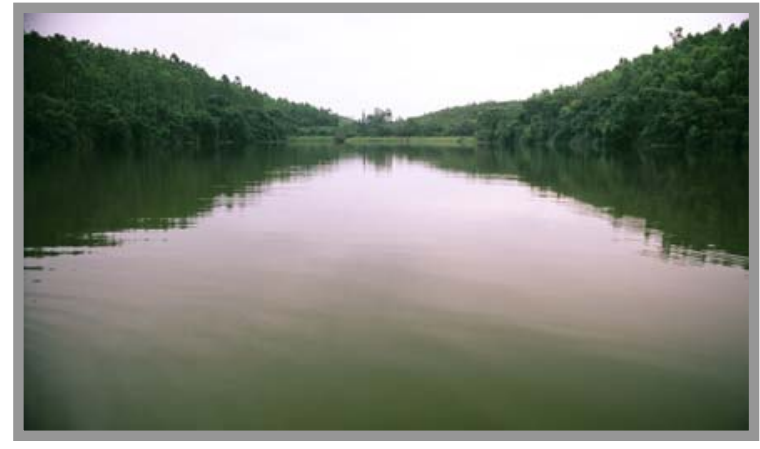

Figura 12. Ilustração dos compartimentos lacustres abordados neste trabalho. 


\section{- LAGOA CARIOCA (GRUPO 1)}

Por estar inserida no Parque Estadual do Rio Doce, a lagoa Carioca é tratada neste trabalho como uma "lagoa controle" pois é a única que apresenta os aspectos fisionômicos naturais inalterados, como uma extensa floresta de Mata Atlântica no seu entorno.

Porém, devido à sua comunicação temporária com outros corpos lacustres no período da cheia, também apresenta espécies exóticas de peixes, como o "Tucunaré" (Cichla ocellaris) e a "Piranha" (Pygocentrus sp.). Segundo GodinHo (1996), após 10 anos da detecção destas espécies na lagoa Carioca, o número de espécies nativas de peixes se reduziu à metade.

A Figura 13 apresenta o perfil de fundo da lagoa Carioca, evidenciando a forma em "V" do fundo do lago, e a Figura 14 mostra a localização dos quatro pontos de amostragem da Lagoa Carioca, que apresentam as seguintes características:

- Estação Car-P1: região pelágica com profundidade de cerca de 12 m;

- Estações Car-L1, Car-L2: regiões litorâneas típicas, com presença de bancos de macrófitas;

- Estação Car-L3: região litorânea sem macrófitas;

- $(\otimes)$ Tomada de coordenadas: $19^{\circ} 45^{\prime} 20^{\prime \prime} \mathrm{S} 42^{\circ} 37^{\prime} 12^{\prime \prime}$ WO;

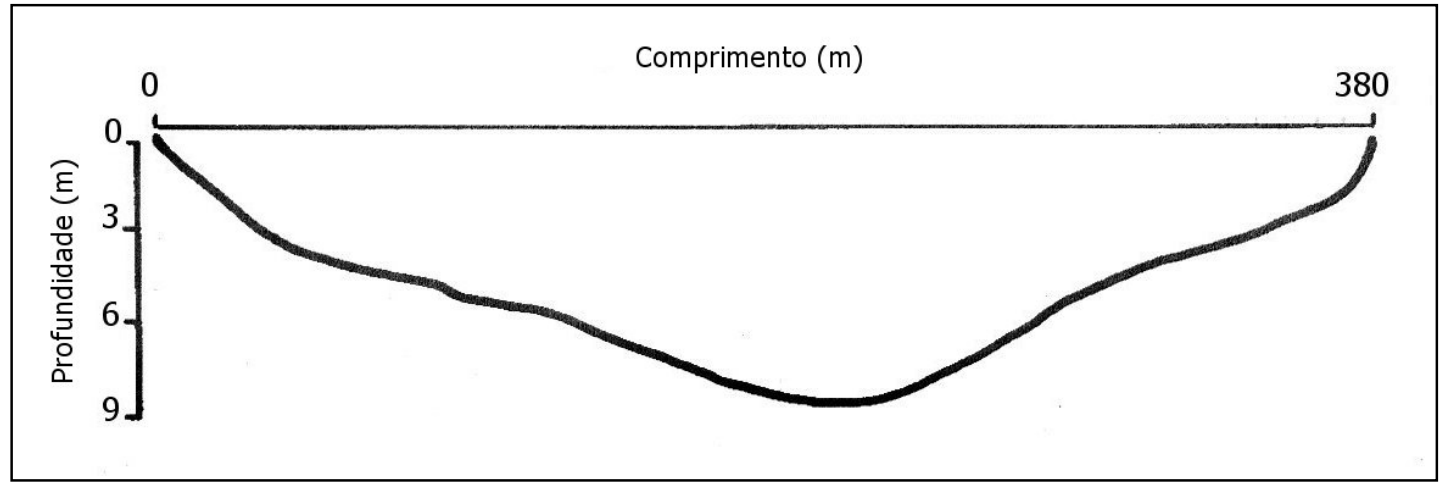

Figura 13. Batimetria da lagoa Carioca. Retirado de MEIs \& TUNDISI (1997). 


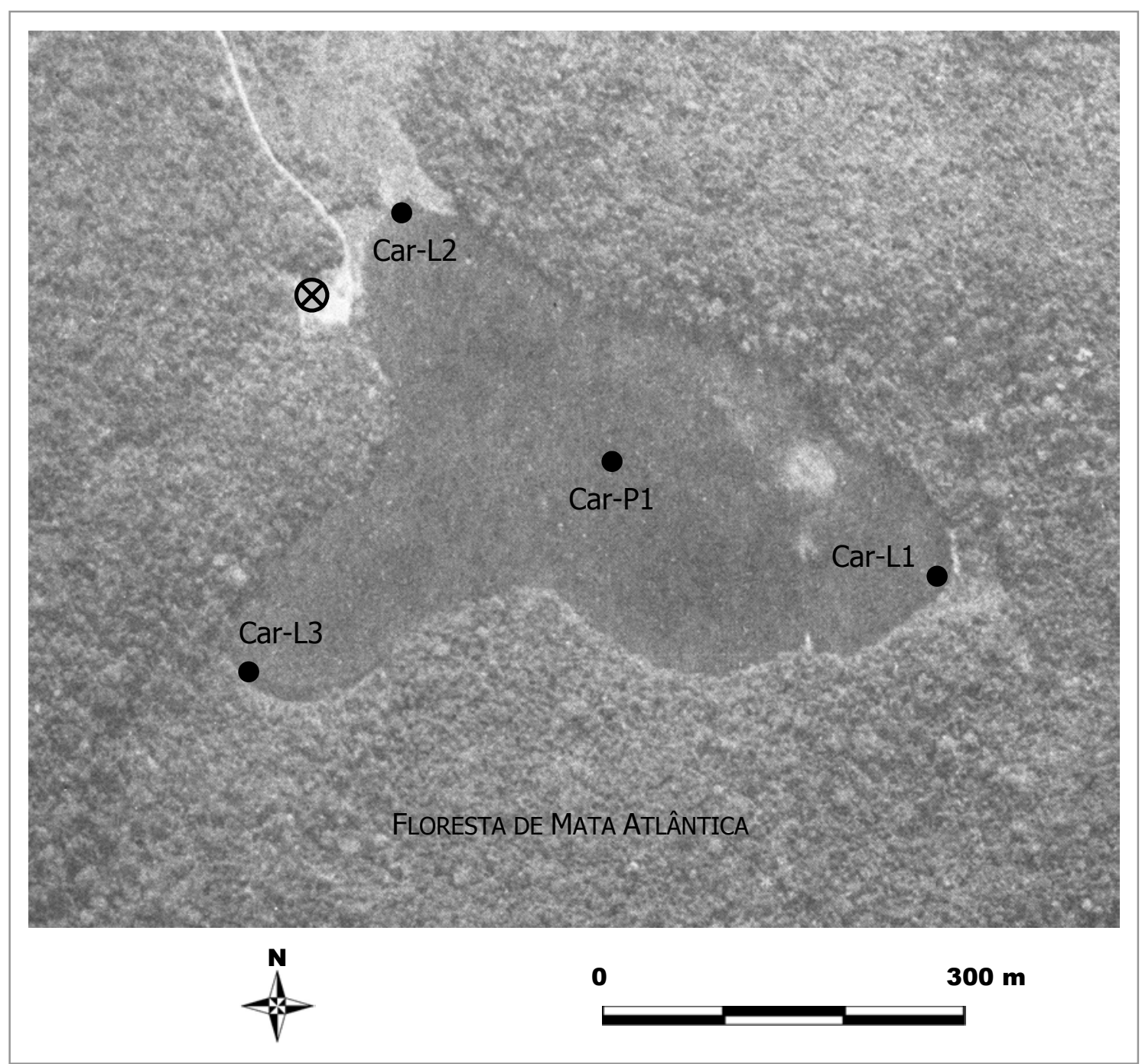

Figura 14. Foto aérea da Lagoa Carioca. Adaptado de: Levantamento Aerofotométrico, Coronel Fabriciano - 4. Folha 36-22-03, CEMIG (1989). 
- LAGOA Aguapé (GRUPO 2)

Já fora dos limites do PERD, e em área de cultivo de eucalipto pela Companhia Agrícola Florestal (CAF), a lagoa Aguapé constitui o maior corpo lacustre investigado neste trabalho.

O cultivo de eucalipto no seu entorno encontra-se em atividade, tendo sido observados cortes durante os trabalhos de campo (Fevereiro de 2000) e em fotos aéreas de 1989 (Figura 15).

Outra importante atividade que ocorreu durante cerca de 30 anos, nesta lagoa, foi o despejo de efluentes domésticos pelas comunidades da região. Esta atividade está suspensa a 3 anos, e hoje existem clubes de recreação no seu entorno.

Vale ressaltar que um trabalho sobre a limnologia de 15 lagoas da região realizado por TUNDISI et al. (1997b) faz referência a esta lagoa como "Recreio". Porém, de acordo com os registros do Parque Estadual do Rio Doce e com o conhecimento tradicional das populações da região, a denominação seria "Lagoa Aguapé".

Durante os trabalhos de campo, pode ser observada também uma grande área com atividade de apicultura.

Os pontos de amostragem da Lagoa Aguapé podem ser observados também na Figura 15:

- Estações Agu-P1, Agu-P2 e Agu-P3: regiões pelágicas com profundidade de cerca de $4 \mathrm{~m}$;

- Estações Agu-L1 e Agu-L3 : regiões litorâneas típicas, com presença de banco de macrófitas;

- Estação Agu-L2: região litorânea sem macrófitas.;

- $(\otimes)$ Tomada de coordenadas: $19^{\circ} 51^{\prime} 00^{\prime \prime} \mathrm{S} 42^{\circ} 38^{\prime} 39^{\prime \prime} \mathrm{WO}$; 


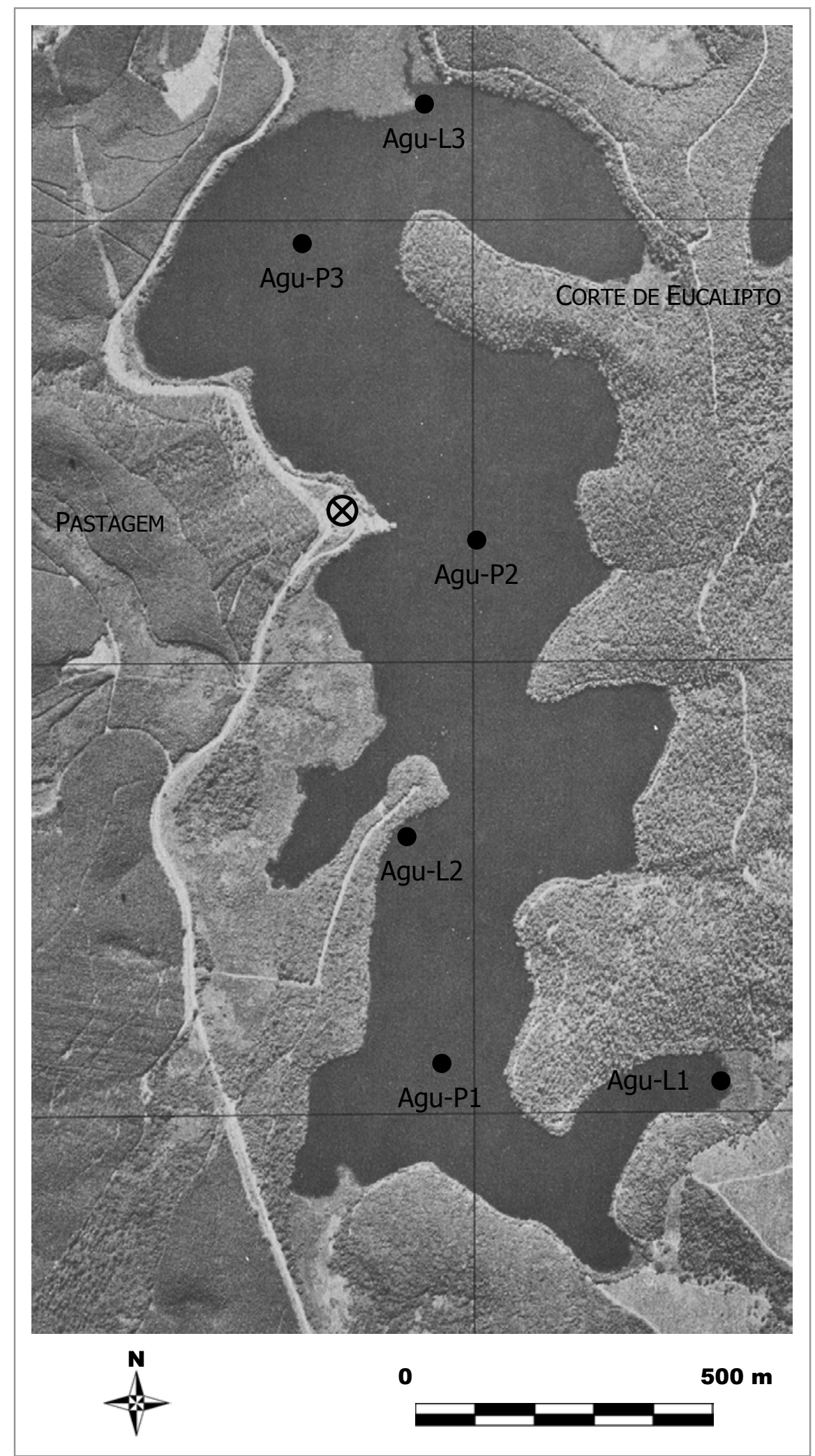

Figura 15. Foto aérea da Lagoa Aguapé. Adaptado de Levantamento Aerofotométrico, Coronel Fabriciano - 4. Folha 36-22-10, CEMIG (1989). 
- $\quad$ lagoa Águas Claras (Grupo 2)

No entorno desta lagoa, assim como na lagoa Aguapé, ainda ocorrem cultivo e corte de eucalipto.

A lagoa Águas Claras possui toda a zona litorânea ocupada por bancos de macrófitas.

A localização dos pontos de amostragem descritos abaixo está apresentada na Figura 16:

- Estações ACl-P1 e ACl-P2: regiões pelágicas com profundidade de cerca de 7 m;

- Estações ACl-L1, ACl-L2 e ACl-L3: regiões litorâneas típicas;

- $(\otimes)$ Tomada de coordenadas: $19^{\circ} 49^{\prime} 02^{\prime \prime} \mathrm{S} 42^{\circ} 35^{\prime} 47^{\prime \prime} \mathrm{WO}$; 


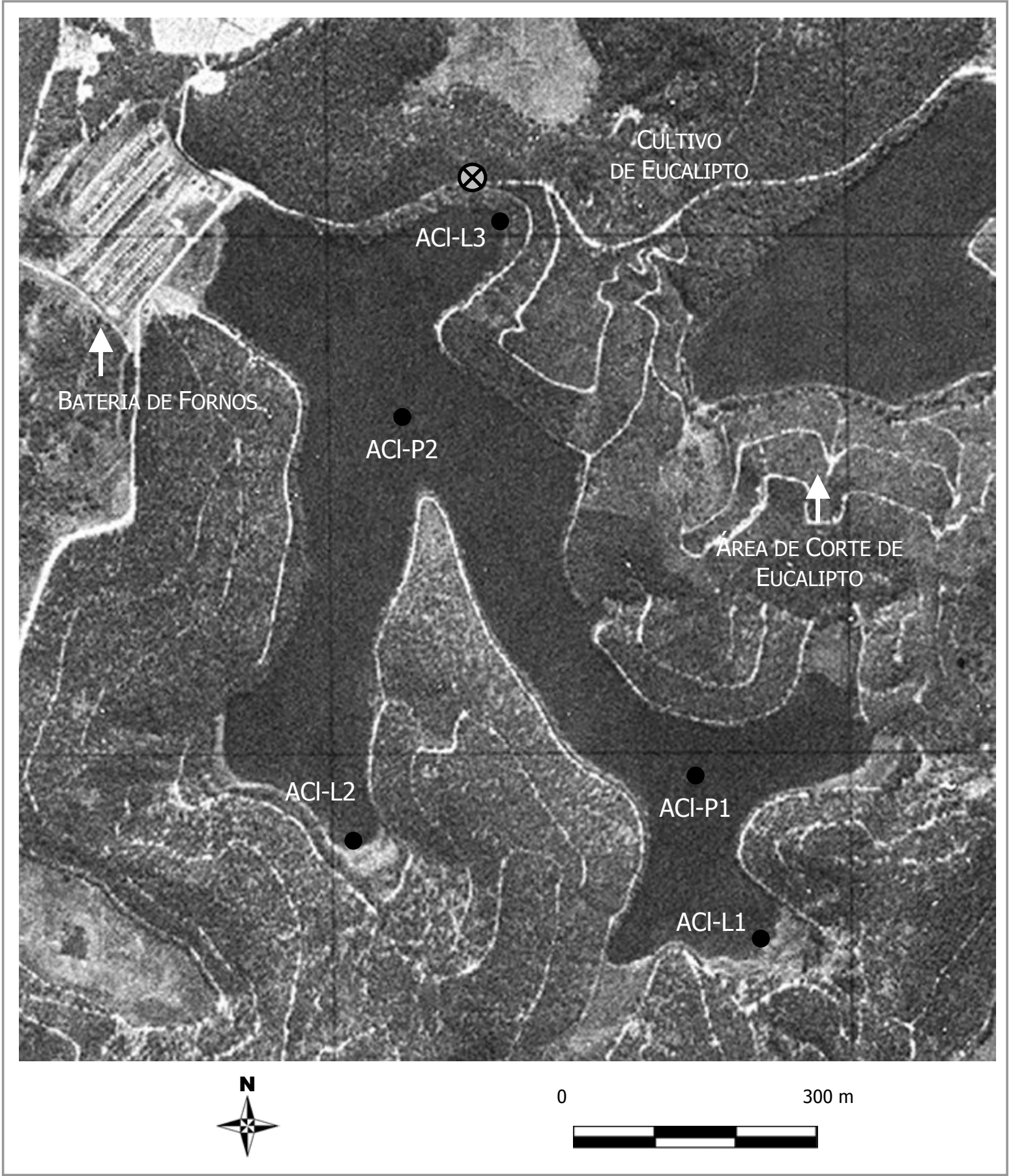

Figura 16. Foto aérea da Lagoa Águas Claras. Adaptado de: Levantamento Aerofotométrico, Coronel Fabriciano - 4. Folha 36-22-07, CEMIG (1989). 
- $\quad$ LagOa ARiranha (GRUPO 3)

Grande parte da mata de eucalipto localizada no entorno desta lagoa está invadida por espécies nativas oportunistas.

$\mathrm{Na}$ lagoa Ariranha a pesca é proibida no período das cheias, quando os afluentes da Bacia do Rio Doce transbordam e ela se transforma em uma lagoa marginal.

Vale ressaltar que como ocorre para a Lagoa Aguapé, no trabalho de TUNDISI et al. (1997b) sobre a limnologia de 15 lagoas, esta lagoa foi registrada como "Palmerinha". Porém, de acordo com as informações do Parque Estadual do Rio Doce e com o conhecimento tradicional das populações da região, a denominação seria "Lagoa Ariranha".

Os pontos de amostragem da lagoa Ariranha podem ser observados na Figura 17:

- Estação Ari-P1: região pelágica com profundidade de cerca de 5 m;

- Estações Ari-L1 e Ari-L3: regiões litorâneas típicas;

- Estação Ari-L2: região litorânea sem banco de macrófitas;

- $(\otimes)$ Tomada de coordenadas: $19^{\circ} 49^{\prime} 07^{\prime \prime} \mathrm{S} 42^{\circ} 34^{\prime} 05^{\prime \prime}$ WO; 


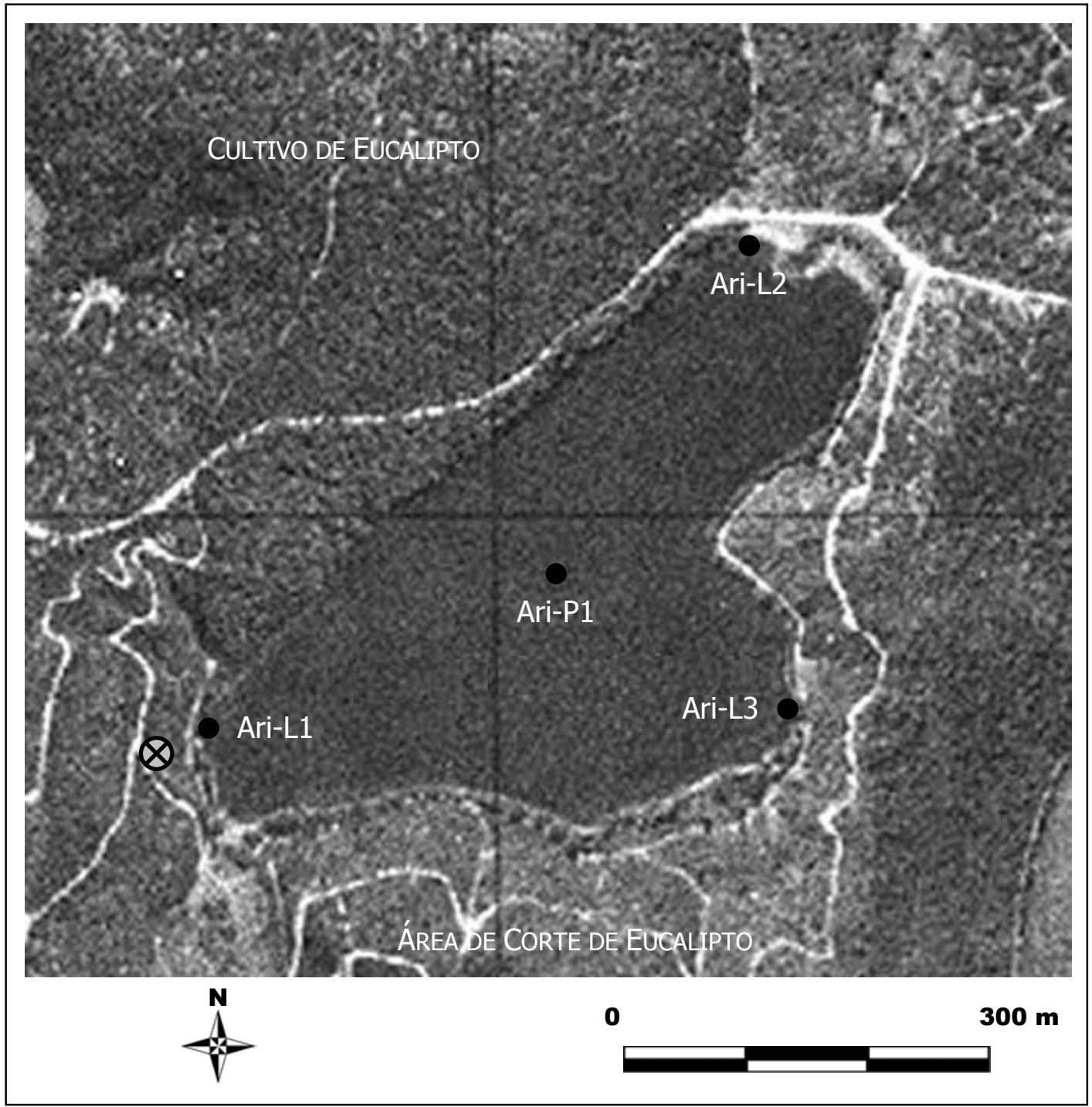

Figura 17. Foto aérea da Lagoa Ariranha. Adaptado de: Levantamento Aerofotométrico, Coronel Fabriciano - 4. Folha 36-22-07, CEMIG (1989). 
- LAGOA AMARELA (GRUPO 3)

A lagoa Amarela diferencia-se das demais lagoas por estar em estágio final de "evolução" natural. Dessa forma, há ocorrência de macrófitas por toda a lâmina de água da lagoa.

Assim como a lagoa Ariranha, a vegetação no entorno desta é formada por mata de eucalipto que está invadida por espécies nativas oportunistas.

A Figura 18 apresenta a localização dos pontos de amostragem:

- Estação Ama-P1: região pelágica com profundidade de cerca de 3 m;

- Estação Ama-L1 : região litorânea típica com bancos de macrófitas;

- $(\otimes)$ Tomada de coordenadas: $19^{\circ} 49^{\prime} 16^{\prime \prime} \mathrm{S} 42^{\circ} 34^{\prime} 35^{\prime \prime} \mathrm{WO}$; 


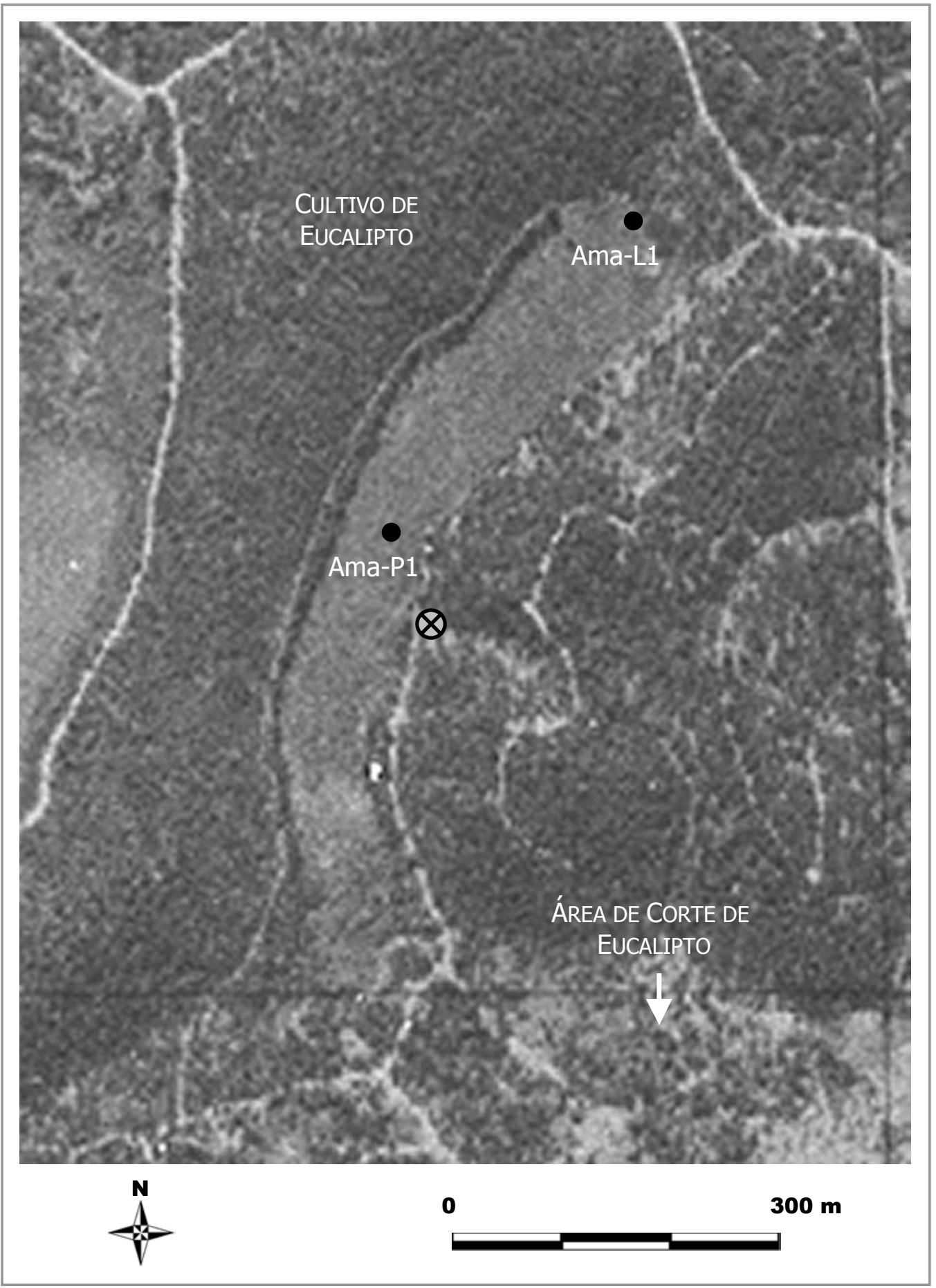

Figura 18. Foto aérea da Lagoa Amarela. Adaptado de: Levantamento Aerofotométrico, Coronel Fabriciano - 4. Folha 36-22-07, CEMIG (1989). 


\subsubsection{OS ESTUDOS REALIZADOS NA REGIÃO}

Os estudos nesta região iniciaram-se efetivamente no ano de 1976, após a $1^{\text {a }}$ Conferência Brasileira sobre Limnologia e Aquicultura em Belo Horizonte (MG). Porém, em 1974 estabeleceu-se um convênio de cooperação entre Japão e Brasil, quando N. Nakamoto da Universidade Shinshu (Japão), visitou a região (TUNDISI \& SAIJo, 1997a).

Devido a esta cooperação internacional, nos anos de 1983, 1985 e 1987 foram publicadas três revistas que reuniram os principais trabalhos realizados até então, com o nome de "Limnological studies in Central Brazil: Rio Doce Valley lakes and Pantanal wetland, Brazil", de autoria de SAIJo \& TUNDISI (1983, 1985 e 1987), pelo Instituto de Pesquisa Aquática da Universidade de Nagoya, Japão.

Em 1997, foi publicado uma revisão mais ampla dos trabalhos realizados no Vale do Rio Doce intitulada "Limnological Studies on the Rio Doce Valley Lakes, Brazil" (TUNDISI \& SAIJO, 1997a), pelo convênio entre a Academia Brasileira de Ciências e o Centro de Recursos Hídricos e Ecologia Aplicada, Escola de Engenharia de São Paulo (USP-São Carlos).

Esta região tem sido investigada desde a década de 70 com diversos enfoques:

- Caracterização geológica e geomorfológica: PfLUGg (1969), MEIS (1977), Meis \& Monteiro (1979), LemOs et al. (1981), MeIs (1986) e Mello (1997);

- Aspectos da vegetação e uso e ocupação: NAKAMOTO et al. (1979), CETEC (1981), CARVALHO et al. (1983) e GILHUIS (1986); TUNDISI et al. (1997c)

- $\quad$ Meteorologia: MEIS \& MonTEIRo (1979) e NAKAMOTO et al. (1979);

- Vertebrados em geral: SunAga \& Verani (1991), Godinho \& Formagio (1992), Godinho et al. (1994), Vieira (1994), POMPEU (1995), GOdinHo (1996) e FEIO et al. (1998).

- Limnologia: BARBOSA \& TUNDISI (1980), OKANO (1980), BARBOSA (1981), BARBOSA et al. (1981), TUNDISI \& MATSUMURA-TUNDISI (1981), TUNDISI et al. (1981), TUNDISI (1983), HiNo et al. (1986), MATSUMURA-TUNDISI \& TUNDISI (1986), HENRY et al. (1987), IKUSIMA \& GENTIL (1987), TUNDISI (1987), 
BARBOSA \& TUNDISI (1988), HENRY et al. (1989a,b), FUKUHARA (1989), ROCHA et al. (1989), HENRY et al. (1997), FUKUHARA et al. (1997a,b) e TUNDISI et al. (1997a, b);

Os estudos que abordam aspectos da limnologia da região concentram-se mais nas lagoas pertencentes ao Parque, como a lagoa Carioca e a Dom Helvécio. Esta última é a maior de todo o sistema de lagos. 


\subsection{Delineamento lógico do trabalho}

De forma geral, o delineamento de uma investigação científica deve estar pautada em um método lógico que conduz o raciocínio para uma abordagem final e conclusiva.

O presente capítulo propõe-se a apresentar a estrutura lógica delineada neste trabalho, fundamentada nas informações apresentadas anteriormente. Tal método foi adotado por uma seqüência de elementos lógicos que se inter-relacionam, a partir da visualização de duas questões, apresentadas a seguir:

I - DIFERENÇA ENTRE ZONAS LIMNÉTICA E LITORÂNEA DE SISTEMAS LACUSTRES NATURAIS: DIVERSIDADE ZOOPLANCTÔNICA, CARACTERÍSTICAS MORFOMÉTRICAS E LIMNOLÓGICAS

a) Visualização do problema e seu contexto teórico: Como já apresentado anteriormente, é provável haver diferenças na diversidade zooplanctônica e nas características físicas e químicas da água, entre as zonas limnética e litorânea de ecossistemas lacustres naturais como o sistema de lagos do Vale do Rio Doce.

b) Pergunta: Existem diferenças na diversidade zooplanctônica e nas características físicas e químicas da água, entre as zonas limnética e litorânea de algumas lagoas do Vale do Rio Doce?

c) Premissas:

1 - Existem diferenças naturais entre zonas limnéticas e litorâneas, em relação à estrutura de hábitats, à disponibilidade de recurso trófico, aos ciclos biogeoquímicos, às características morfométricas e aos processos hidrológicos.

2 - A estrutura de hábitats, a disponibilidade de recurso trófico, os ciclos biogeoquímicos, as características morfométricas e os processos hidrológicos determinam variações na diversidade zooplanctônica e nas características químicas e físicas da água. 
d) Hipóteses a serem testadas pelo presente trabalho:

\section{CARACTERÍSTICAS MORFOMÉTRICAS E LIMNOLÓGICAS}

H0 (hipótese de nulidade): As diferenças naturais entre zonas limnética e litorânea de alguns lagos do Vale do Rio Doce não determinam diferenças significativas nas características limnológicas.

H1 (hipótese alternativa): As diferenças naturais entre zonas limnética e litorânea de ecossistemas lacustres determinam diferenças significativas nas características limnológicas.

DIVERSIDADE ZOOPLANCTÔNICA

H0 (hipótese de nulidade): As diferenças naturais entre zonas limnética e litorânea de alguns lagos do Vale do Rio Doce não determinam diferenças significativas na diversidade zooplanctônica.

H1 (hipótese alternativa): As diferenças naturais entre zonas limnética e litorânea de ecossistemas lacustres determinam diferenças significativas na diversidade zooplanctônica.

II - DIFERENÇA ENTRE LAGOS INSERIDOS EM ÁREAS COM VEGETAÇÃO DE FLORESTA DE MATA ATLÂNTICA E EM ÁREAS DE CULTIVO DE EUCALIPTO: DIVERSIDADE ZOOPLANCTÔNICA, CARACTERÍSTICAS MORFOMÉTRICAS E LIMNOLÓGICAS

a) Visualização do problema e seu contexto teórico: Como já apresentadas anteriormente, é provável haver diferenças na diversidade zooplanctônica e nas características físicas e químicas da água, entre lagos que se encontram em região de vegetação de Mata Atlântica e de cultivo de eucalipto.

b) Pergunta: Existem diferenças na diversidade zooplanctônica e nas características físicas e químicas da água, entre lagos que se encontram em região de vegetação de Mata Atlântica e naqueles em região de cultivo de eucalipto, utilizando-se o caso de algumas lagoas do Vale do Rio Doce? 
c) Premissas:

1 - Existem diferenças naturais entre lagos que se encontram em região de vegetação de Mata Atlântica e de cultivo de eucalipto, em relação às características quantitativas e qualitativas do material alóctone que é carreado da bacia de drenagem para dentro dos ecossistemas lacustres.

2 - As diferenças quantitativas e qualitativas do material alóctone que é carreado da bacia de drenagem para dentro dos ecossistemas lacustres determinam variações na diversidade zooplanctônica e nas características químicas e físicas da água.

d) Hipóteses a serem testadas pelo presente trabalho:

\section{CARACTERÍSTICAS MORFOMÉTRICAS E LIMNOLÓGICAS}

HO (hipótese de nulidade): As diferenças naturais entre lagos que se encontram em região de vegetação de Mata Atlântica e de cultivo de eucalipto não determinam diferenças significativas nas características limnológicas.

H1 (hipótese alternativa): As diferenças naturais entre lagos que se encontram em região de vegetação de Mata Atlântica e de cultivo de eucalipto determinam diferenças significativas nas características limnológicas.

DIVERSIDADE ZOOPLANCTÔNICA

HO (hipótese de nulidade): As diferenças naturais entre lagos que se encontram em região de vegetação de mata atlântica e de cultivo de eucalipto não determinam diferenças significativas na diversidade zooplanctônica.

H1 (hipótese alternativa): As diferenças naturais entre lagos que se encontram em região de vegetação de mata atlântica e de cultivo de eucalipto determinam diferenças significativas na diversidade zooplanctônica. 


\subsection{VARIÁVEIS ANALISADAS E MÉTODOS EMPREGADOS}

\subsubsection{VARIÁVEIS MORFOMÉTRICAS}

Foram estimados os seguintes dados morfométricos das lagoas, de acordo com a metodologia descrita em WETZEL e LIKENS (1991):

- Área superficial (A), perímetro ( $P$ ) e comprimento máximo (I max): a partir das aerofotos, utilizando o programa computacional AutoCAD R14;

- $\quad$ Profundidade máxima (P max);

- Índice de desenvolvimento de margem (IDM): a partir da razão entre perímetro ( $P$ ) da lagoa e perímetro da circunferência formada pelo comprimento máximo, segundo a seguinte equação:

$$
\operatorname{IDM}=\mathrm{P} /\{2 \times[\operatorname{RAIZ}(\pi \times A)]\}
$$

\subsubsection{COLETA DE AMOSTRAS}

As coletas das amostras de água e tomada de medidas ambientais foram realizadas em cinco lagoas (Carioca, Aguapé, Águas Claras, Ariranha e Amarela) pertencentes ao sistema de lagos do Vale do Rio Doce (MG).

Os pontos de amostragem foram divididos em zona pelágica e zona litorânea (com ou sem banco de macrófitas) para melhor caracterização da qualidade da água e da diversidade zooplanctônica das lagoas.

O número de pontos pelágicos e litorâneos amostrados foi estabelecido de acordo com a relação de tamanho entre as lagoas:

AGUAPÉ $>$ ÁGUAS CLARAS $>$ CARIOCA $\approx$ ARIRANHA $>$ AMARELA

Na Tabela 1 são mostrados o número de pontos de amostragem utilizados em cada lagoa e suas classificações segundo o compartimento, enquanto na Tabela 2 são apresentadas a nomenclatura adotada neste trabalho para os pontos de amostragem. 
Tabela 1. Distribuição dos pontos de amostragem nas lagoas, segundo os compartimentos e número total de pontos amostrados.

\begin{tabular}{cccc}
\hline \hline Lagoa & Zona pelágica & $\begin{array}{c}\text { Zona } \\
\text { litorânea }\end{array}$ & $\begin{array}{c}\text { Total de pontos } \\
\text { por lagoa }\end{array}$ \\
\hline CARIOCA & 1 & 3 & 4 \\
AGUAPÉ & 3 & 3 & 6 \\
ÁGUAS CLARAS & 2 & 3 & 5 \\
AMARELA & 1 & 1 & 2 \\
ARIRANHA & 1 & 3 & 4 \\
\hline $\begin{array}{c}\text { Total de pontos por } \\
\text { compartimento }\end{array}$ & $\mathbf{8}$ & $\mathbf{1 3}$ & $\mathbf{2 1}$ \\
\hline \hline
\end{tabular}

Tabela 2. Nomenclatura adotada, compartimento onde se localizam e presença ou ausência de macrófitas, para os pontos de amostragem.

\begin{tabular}{ccc}
\hline \hline Lagoa & Nomenclatura & Descrição \\
\hline \multirow{4}{*}{ Carioca } & Car-P1 & zona pelágica \\
& Car-L1 & zona litorânea (com macrótifas) \\
& Car-L2 & zona litorânea (sem macrófitas) \\
& Car-L3 & zona litorânea (com macrótifas) \\
& Agu-P1 & zona pelágica \\
Aguapé & Agu-P2 & zona pelágica \\
& Agu-P3 & zona pelágica \\
& Agu-L1 & zona litorânea (com macrótifas) \\
& Agu-L2 & zona litorânea (sem macrófitas) \\
& Agu-L3 & zona litorânea (com macrótifas) \\
Águas Claras & ACl-P1 & zona pelágica \\
& ACl-P2 & zona pelágica \\
& ACl-L1 & zona litorânea (com macrótifas) \\
& ACl-L2 & zona litorânea (com macrótifas) \\
& ACl-L3 & zona litorânea (com macrótifas) \\
Ariranha & Ari-P1 & zona pelágica \\
& Ari-L1 & zona litorânea (com macrótifas) \\
& Ari-L2 & zona litorânea (sem macrófitas) \\
Amarela & Ari-L3 & zona litorânea (com macrótifas) \\
& Ama-P1 & zona pelágica (com macrótifas) \\
& Ama-L1 & zona litorânea (com macrótifas) \\
\hline \hline
\end{tabular}




\subsubsection{PERIOdicidade DE AMOSTRAGEM}

Foram realizadas três coletas de amostras de água e tomadas de medidas ambientais, sendo duas no período de estiagem e uma no período das chuvas.

A primeira coleta foi realizada em junho de 1999, caracterizando o fim do período de estratificação térmica da coluna da água das lagoas desta região. A segunda foi em agosto de 1999, no período de isotermia da coluna da água. Em fevereiro de 2000, período das chuvas com típica estratificação térmica e química, foi realizada a terceira coleta. A Tabela 3 sumariza as informações sobre a data de amostragem, a condição térmica, a estação climática e a nomenclatura dos períodos de amostragem adotada no decorrer da apresentação dos resultados.

Tabela 3. Classificação e nomenclatura dos períodos de amostragem.

\begin{tabular}{cccc}
\hline \hline Período & Condição térmica & Regime Climático & Nomenclatura \\
\hline JUNHO DE 1999 & Início da desestratificação & Estiagem & Inverno 1 \\
AGOSTO DE 1999 & Isotermia & Estiagem & Inverno 2 \\
FEVEREIRO DE 2000 & Estratificação & Chuvas & Verão \\
\hline \hline
\end{tabular}

\subsubsection{VARIÁVEIS LIMNOLÓGICAS}

- Profundidade, tRanSParÊnCia da ÁGUa e EXTENSÃo da ZONA EUFÓtica

A transparência da água foi estimada pela medida da profundidade média de desaparecimento e reaparecimento visual do Disco de Secchi. Com o mesmo aparelho foi medida a profundidade da coluna da água.

A extensão da zona eufótica foi calculada pela multiplicação do valor da leitura do Disco de Secchi pelo fator 2,7, segundo descrito em MARGALEF (1983).

- Temperatura da ÁGUa, OXigênio dissolvido, PH E CONDUTIVIDADE ElÉtrica

As medidas foram feitas ao longo de toda a coluna de água (de 0,5 em 0,5 metro) utilizando-se um aparelho do tipo sensor múltiplo da marca HORIBA U-10 "water quality checker". 
- NUTRIENTES DISSOLVIDOS E TOTAIS

Para a análise dos nutrientes, as amostras de água foram coletadas integrando toda a coluna de água, com coleta com motobomba Stihl em baixa rotação, acoplada a uma mangueira que foi movimentada verticalmente da superfície ao fundo. Após, as amostras foram armazenadas em frascos de polietileno e congeladas para análise posterior em laboratório.

Para a determinação de nitrogênio orgânico total e fósforo total, as amostras não foram filtradas. Já para os nutrientes dissolvidos (amônio, nitrato, nitrito, fosfato dissolvido total, fostato inorgânico e silicato reativo) as amostras foram filtradas utilizando-se filtros de fibra de vidro do tipo GF/C da marca "Whatman".

Os nutrientes foram determinados em laboratório utilizando-se os métodos espectrofotométricos, apresentados na Tabela 4.

\section{Tabela 4. Métodos utilizados nas análises dos nutrientes químicos e referências onde os métodos se encontram descritos.}

\begin{tabular}{cc}
\hline \hline Nutrientes analisados & Referências \\
\hline Nitrito & $\begin{array}{c}\text { BENDCHREIDER \& ROBINSON (1952), } \\
\text { apud GOLTERMAN et al. (1978) } \\
\text { Nitrato } \\
\text { Amônio } \\
\text { MACKRETH et al. (1978) } \\
\text { Fosfato dissolvido, } \\
\text { inorgânico e fósforo total } \\
\text { Silicato reativo } \\
\text { Kitrogênio e Fósforo Totais }\end{array}$ \\
\hline \hline
\end{tabular}

- MATERIAL EM SUSPENSÃO (FRAÇÕES ORGÂNICA E INORGÂNICA)

A concentração do material em suspensão total e suas frações orgânica e inorgânica foram determinadas por gravimetria, segundo o método descrito por COLE (1979).

- concentração de CLOROFila-A

A determinação da clorofila-a total foi realizada pelo método de extração com etanol 90\% a quente, segundo método descrito em NuSCH (1980). 


\subsubsection{COLETA E ANÁLISES DO ZOOPLÂNCTON}

- ANÁlise QUALITATIVA

As amostras do zooplâncton para a análise qualitativa foram coletadas através de arrastos horizontais e verticais com uma rede de $68 \mu \mathrm{m}$ de abertura de malha, em cada ponto de amostragem.

Em laboratório, a identificação dos organismos foi feita feita utilizando-se microscópio óptico estereoscópico da marca Zeiss modelo Stemi SV6 com "zoom" e aumento de até 100 vezes, e microscópio óptico comum da marca Zeiss modelo Standard 25 com câmara clara acoplada e aumento de até 1000 vezes.

Procurou-se identificar todos os organismos presentes na amostra, no nível específico, com ênfase para os grupos de Copepoda, Cladocera e Rotifera.

Bibliografia consultada: EDMONDSON (1959); ROCHA \& MATSUMURA-TUNDISI (1976); BRANDlova et al. (1972); KOSTE (1978a, 1978b); PAGGI (1978); KORINEK (1981); MATSUMURA-TUNDiSI (1984); VAN DE VELDE (1984); MATSUMURA-TUNDISI (1986); MONTÚ \& Goeden (1986); Reid, (1985, 1988); Elmor-Loureiro (1988); Pennak (1991); Segers \& DUMONT (1994); SEGERS (1995-1996).

\section{- ANÁLISE QUANTITATIVA}

As amostras para a análise quantitativa do zooplâncton foram obtidas coletando-se um volume de 200 litros de água, integrando-se a coluna da água com motobomba de sucção Stihl, em baixa rotação, filtrando-se o zooplâncton em uma rede de $68 \mu \mathrm{m}$ de abertura de malha. As amostras foram fixadas em formol a uma concentração final de $4 \%$.

O volume filtrado de 200 I foi adotado, pois estudos preliminares demonstraram que este volume permite uma representatividade de forma significativa da composição e abundância da comunidade zooplanctônica das lagoas estudadas.

A análise quantitativa foi feita pela contagem de toda a amostra para Rotifera e náuplios de Copepoda, e entre 40 a $80 \mathrm{ml}$ os organismos de maior tamanho (outros microcrustáceos, nemátodos e turbelários).

Os organismos de maior tamanho como copépodos (adultos e copepoditos), cladóceros, larvas de Díptera, nemátodos, turbelários, etc., foram contados em câmaras de acrílico com fundo quadriculado, sob microscópio estereoscópico. Já os 
rotíferos e náuplios de copépodos, em lâmina Sedgwick-Rafter sob microscópio óptico comum.

\subsubsection{AVALIAÇÃO DAS LAGOAS QUANTO AO GRAU DE TROFIA}

Para a classificação segundo o grau de trofia dos pontos de amostragens e das lagoas estudadas, foram adotados dois índices de estado trófico: de CARLSON (1977), modificado por TOLEDO JR et al. (1983) e o de SALAS \& MARTINo (1988) para lagos e reservatórios tropicais.

Para a estimativa do grau de trofia pelo índice de CARLSON, foram utilizados os valores das concentrações de fósforo total, fosfato dissolvido orgânico e clorofila. Não foram utilizados os valores de transparência da coluna da água devido à sua discrepância entre os compartimentos litorâneos (com transparência total) e pelágicos (de 0,8 a 2,5m).

As equações utilizadas para a estimativa do índice de estado trófico, e os intervalos para a classificação do grau de trofia, segundo método de Carlson, foram:

Os valores de fósforo total também foram utilizados para a estimativa do índice

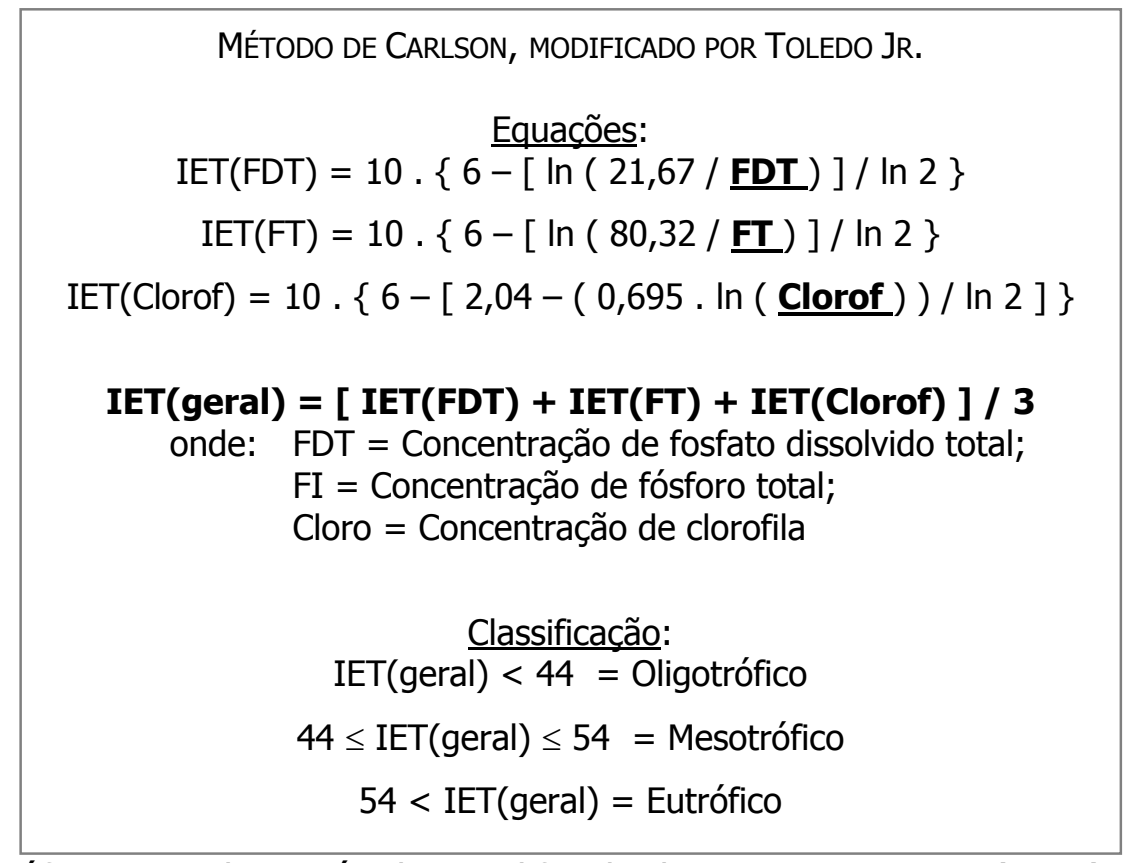

de estado trófico segundo o método simplificado de SALAS \& MARTINO (1988) para lagos tropicais. 
As equações utilizadas para a estimativa do índice de estado trófico, e os intervalos para a classificação do grau de trofia, segundo método simplificado de SALAS \& MARTINO (1988), foram:

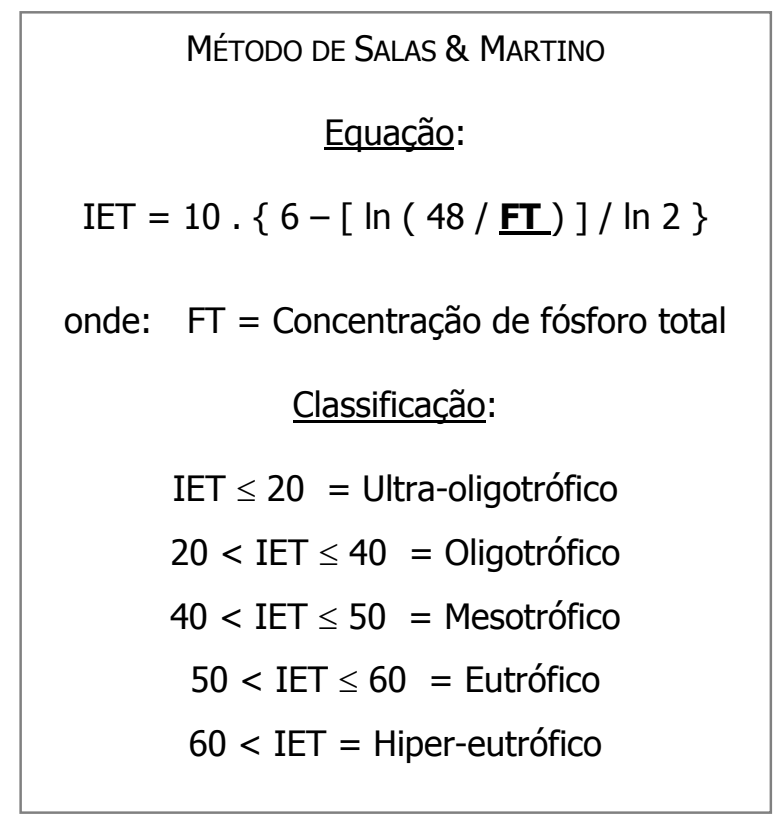

\subsubsection{AVALIAÇÃO DA DIVERSIDADE ZOOPLANCTÔNICA}

- Diversidade AlFa $(\alpha)$

Para a estimativa da diversidade alfa (diversidade em cada ponto de amostragem) ....do zooplâncton, assumiu-se cada ponto de amostragem como unidade de medida da diversidade alfa.

Com o intuito de contemplar da melhor maneira possível a diversidade, foram utilizados vários índices conforme descritos em MAGURRAN (1989) e sumarizados a seguir:

- RIQUEZA DE ESPÉCIES

A riqueza de espécies foi representada pelo número total de espécies encontradas na amostra.

- ÍNDICE DE MARGALEF 
O índice de Margalef foi adotado por apresentar a mesma sensibilidade a todas as espécies da amostra, sem levar em consideração as proporções em que aparecem.

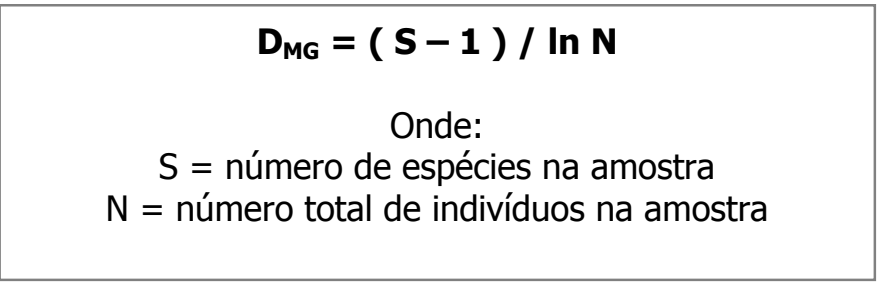

- INDICE DE SHANNON

O índice de Shannon considera que todas as espécies estão presentes na mesma proporção na amostra. Embora seja um bom indicador da diversidade, está baseado nas proporções entre as espécies e dá ênfase, em seu cálculo, às espécies mais abundantes.

$\mathbf{H}=-\sum \mathbf{p} \boldsymbol{i} \cdot \mathbf{I n} \mathbf{p} \boldsymbol{i}$
Onde:
pi = abundância relativa da i-ésima espécie

- ÍNDICE DE SIMPSON

Assim como o Índice de Shannon, o de Simpson representa as espécies mais abundantes e é pouco sensível a riqueza. Na verdade, é uma medida mais relacionada com a dominância de espécies.

$$
\begin{gathered}
\mathbf{D}=\sum\left(\mathbf{p} \mathbf{I}^{2}\right. \\
\text { Onde: } \\
\text { pi = abundância relativa da i-ésima espécie }
\end{gathered}
$$

- INVERSO DO ÍNDICE DE SIMPSON

Para contrapor a força do índice de Simpson, MAGURRAN (1989) orienta o cálculo do seu inverso, como uma medida da diversidade, contrária à força de dominância na amostra.

\section{$1 / D$}

- ÍNDICE DE PIELOU 
Este índice foi adotado por representar a equidade (uniformidade) da amostra, quando se supõe que todas as espécies encontram-se na mesma proporção.

E = H / In S
Onde:
$\mathrm{H}=$ Valor do índice de Shannon da amostra
$\mathrm{S}=$ Número total de espécies da amostra

- DIVERSIDADE BETA $(\beta)$

A diversidade beta (entre ecossistemas lacustres próximos) foi calculada para 0 conjunto das cinco lagoas a partir das matrizes do tipo presença/ausência de espécies de cada lagoa, em cada período climático, utilizando-se a análise de agrupamento do tipo cluster, com a medida de dissimilaridade de SORENSEN (MAGURRAN, 1989) para dados qualitativos (valores de riqueza de espécies) como coeficiente de associação, e método de ligação do tipo UPGMA (média de grupo).

Foi calculado também o coeficiente de correlação cofenética, para se verificar a proporção expressa com que os resultados representam os dados originais.

Para isso, foram utilizados programas computacionais.

A medida de dissimilaridade de SORENSEN para dados qualitativos é representada pela equação abaixo:

$\mathbf{C}_{\mathbf{s}} \mathbf{=} \mathbf{2} \cdot \mathbf{j} \cdot(\mathbf{a}+\mathbf{b})$
Onde:
$\mathrm{j}=$ Número de espécies comuns entre as amostras a e b
$a=$ Número de espécies da amostra $a$
$b=$ Número de espécies da amostra $b$




\subsubsection{TRATAMENTO ESTATÍSTICO}

O tratamento estatístico realizado teve como objetivo verificar a existência de diferenças nas características gerais e limnológicas, e nas medidas de diversidade, espacialmente, entre as lagoas, e temporalmente entre os períodos climáticos amostrados.

- MATRIZES DOS DADOS

As matrizes foram montadas de forma multivariada, com s linhas representando os pontos de amostragem (objetos), e $\mathrm{n}$ colunas representando as variáveis (descritores).

Para a montagem das matrizes os dados obtidos foram divididos em duas categorais:

- $\quad 1^{a}$ CATEGORIA - Características limnológicas: tipo de habitat (zona pelágica ou litorânea), profundidade da coluna da água, transparência da água, temperatura da água (média do perfil), concentração do oxigênio dissolvido (média do perfil), condutividade elétrica (média do perfil), pH (média do perfil), concentração de nitrato, nitrito, amônio, nitrogênio orgânico total, fosfato orgânico total, fosfato inorgânico, fósforo total, silicato reativo, fração orgânica e fração inorgânica do material em suspensão, material em suspensão total, concentração de clorofila, índice de estado trófico de Carlson (para dados de transparência, fosfato orgânico total e fósforo total) e índice de estado trófico de Salas \& Martino (para dados de fósforo total).

- $\quad 2^{\mathrm{a}}$ CATEgORIA - Medidas de diversidade: riqueza de espécies, índice de Margalef (diversidade), índice Shannon (diversidade), índice de Simpson (dominância), inverso do índice de Simpson (diversidade) e índice de Pielou (equidade). 
- ANÁLISE DE VARIÂNCIA MULTIVARIADA (MANOVA)

Esta análise foi realizada com o objetivo de se testar a influência da sazonalidade na distribuição dos dados, para as duas categorias (características gerais e llimnológicas, e medidas de diversidade) separadamente.

Para a aplicação desse teste, o número de objetos (pontos de amostragem) nunca foi menor ou igual ao número de descritores (variáveis), ou seja, a condição para a aplicação foi $\mathrm{s}>\mathrm{n}$.

O nível de decisão admitido para o teste foi de $5 \%(\alpha=0,05)$.

PROCEDIMENTO:

Nível de decisão: $5 \%(\alpha=0.05)$

Pergunta: Há efeito da sazonalidade na distribuição dos dados?

Hipóteses:

H0: Não há efeito da sazonalidade na distribuição dos dados;

H1: Há efeito da sazonalidade na distribuição dos dados.

\section{Conclusão:}

- $\rho>\alpha=$ não se rejeita $\mathrm{H} 0$ e rejeita-se H1.

Não há efeito da sazonalidade na distribuição dos dados.

Neste caso, dá-se seguimento à análise utilizando-se uma matriz com os três períodos amostrados.

- $\rho<\alpha=$ rejeita-se $\mathrm{H} 0$ e não se rejeita $\mathrm{H} 1$.

Há efeito da sazonalidade na distribuição dos dados.

Neste caso, há prosseguimento dos testes, utilizando-se uma matriz para cada período amostrado.

- ANÁLISE DE COMPONENTES PRINCIPAIS (ACP)

Esta análise foi aplicada separadamente para as duas categorias de dados (características limnológicas e medidas de diversidade), a partir de uma matriz de correlação.

A análise de componentes principais é realizada por combinações lineares do conjunto de dados, visando identificar quais variáveis são responsáveis pela maior proporção da variância dos dados. De maneira geral, esta análise foi aplicada para hierarquizar os pontos de amostragem segundo as variáveis que compunham as matrizes de dados iniciais. 
Após uma análise inicial com todas as variáveis, foram descartadas aquelas que apresentaram correlação (carga), em módulo, menor que 0.500 , com o objetivo de aumentar a variância explicada dos componentes 1 e 2 .

Foram consideradas variáveis importantes para a análise dos resultados do teste, aquelas que apresentaram coeficiente de correlação maior que 0.700 , em módulo, nos componentes 1 e 2 . O número mínimo de fatores foi estabelecido segundo MANLY (1986).

- ANÁlise de AGRUPAMENTo (CLUSTER)

A partir dos coeficientes dos fatores gerados pelas análises de componentes principais, foi realizada a análise de agrupamento do tipo Cluster, utilizando-se a distância euclidiana média como índice de correlação e a média de grupo (UPGMA) como método de ligação.

Foi calculado o coeficiente de correlação cofenético para estimar a resposta das análises em relação aos dados originais, admitindo-se serem estas significativas quando o coeficiente fosse superior a $70 \%$. 


\section{Resultados}

A seguir estão apresentados os dados obtidos no presente trabalho, divididos em cinco categorias de resultados: variáveis morfométricas das lagoas, variáveis limnológicas, análise do zooplâncton, tratamento dos dados e tratamento estatístico. 


\subsection{VARIÁVEIS MORFOMÉTRICAS}

Os valores das variáveis morfométricas das lagoas estão apresentados na Tabela 5. Com exceção dos dados da lagoa Carioca que foram obtidos por HENRY et al. (1997), os demais resultados apresentados foram determinados pelo presente trabalho.

As lagoas analisadas apresentam valores da profundidade bastante variáveis entre si, sendo o maior de 9,50 metros encontrado na lagoa Carioca, e o menor de 2,25 metros na lagoa Amarela. A lagoa Águas Claras possui a segunda maior profundidade, com 8,00 metros. Já para as lagoas Aguapé e Ariranha os valores de profundidade são próximos entre si e intermediários aos das lagoas citadas anteriormente, sendo, respectivamente, 5,00 e 5,50 metros.

Em relação aos valores do comprimento máximo, pode-se observar a seguinte ordem de magnitude das lagoas no sentido decrescente: Aguapé, Águas Claras (Grupo 2), Carioca (Grupo 1), Ariranha e Amarela (Grupo 3). A mesma ordem apresentada acima também foi observada para os valores do perímetro e da área das lagoas.

Na lagoa Aguapé foi verificado o maior valor (7,45 metros) para o índice de desenvolvimento de margem, o que refletiu o seu contorno marginal mais dendrítico, seguido da lagoa Águas Claras com 5,36 metros para este índice, ambas pertencentes ao segundo grupo de lagoas estipulado neste trabalho com base na vegetação do entorno. Nas demais lagoas foram observados valores relativamente baixos para este índice, o que mostrou um aspecto pouco dendrítico destas, com 2,20 metros para a lagoa Ariranha, 1,90 metros para a Amarela (Grupo 3) e 1,29 metros para a Carioca (Grupo 1), sendo este último o menor valor encontrado para este índice.

Tabela 5. Valores de algumas variáveis morfométricas para as lagoas estudadas: Carioca, Aguapé, Águas Claras, Ariranha e Amarela.

\begin{tabular}{lccccc}
\hline \hline Lagoa & $\begin{array}{c}\text { Profundidade } \\
(\mathbf{m})\end{array}$ & $\begin{array}{c}\text { Comprimento } \\
\text { máximo } \mathbf{( m )}\end{array}$ & $\begin{array}{c}\text { Perímetro } \\
(\mathbf{m})\end{array}$ & $\begin{array}{c}\text { Área } \\
\left(\mathbf{m}^{\mathbf{2}}\right)\end{array}$ & $\begin{array}{c}\text { Índice de desenv. } \\
\text { de margem }\end{array}$ \\
\hline Carioca & 9,50 & 611 & 1676 & 133300 & 1,29 \\
Aguapé & 5,00 & 1784 & 6813 & 662942 & 7,45 \\
A.Claras & 8,00 & 1176 & 4089 & 271818 & 5,36 \\
Ariranha & 5,50 & 562 & 1381 & 101754 & 2,20 \\
Amarela & 2,25 & 513 & 1094 & 34155 & 1,90 \\
\hline \hline
\end{tabular}




\subsection{VARIÁVEIS LIMNOLÓGICAS}

As variáveis limnológicas analisadas neste trabalho estão apresentadas a seguir. Para isso foi seguida a nomenclatura apresentada, anteriormente, na Tabela 2, para os pontos de amostragem, com a finalidade de facilitar a interpretação dos dados.

\subsubsection{PROFUNDIDADE DA COLUNA D'ÁGUA}

Os valores da profundidade da coluna da água, apresentados na Figura 19, foram os mesmos em todos os períodos de estudo para cada ponto de amostragem, ou seja, não apresentaram variação sazonal.

Todos os pontos de amostragem limnéticos de todas a lagoas estudadas apresentaram valores de profundidade da água superiores aos encontrados nos pontos litorâneos. A menor diferença nos valores desta variável entre os compartimentos limnético e litorâneo ocorreu na lagoa Amarela, com uma diferença de apenas 1,00 metro entre os pontos do compartimento limnético e litorâneo.

Para as lagoas Carioca, Aguapé e Ariranha, os valores da profundidade da coluna da água dos pontos litorâneos foram de 0,75 metros. Já nas lagoas Águas Claras e Amarela foi observado o valor de 1,25 metros para esta variável, nos pontos litorâneos.

Quando, numa mesma lagoa, foi amostrado mais de um ponto na região limnética, ou seja, nas lagoas Aguapé e Águas Claras (Grupo 2), a variação dos valores da profundidade da coluna da água neste compartimento foi de 0,50 metros. Dessa forma, os valores da profundidade das zonas limnéticas amostradas da lagoa Aguapé variaram de 4,50 a 5,00 metros, e da lagoa Águas Claras de 7,50 a 8,00 metros.

O maior valor de profundidade da água dentre todos os pontos de amostragens, de todas as lagoas, foi verificado no ponto limnético da lagoa Carioca (Grupo 1), com 9,50 metros. Na lagoa Amarela (Grupo 3) foi encontrada a menor profundidade no ponto limnético, com 2,25 metros. Na região limnética da lagoa Ariranha (Grupo 3) a profundidade foi de 5,50 metros, intermediário entre os pontos limnéticos das demais lagoas.

Dessa forma, pode-se concluir que a ordem decrescente das lagoas em relação aos valores da profundidade do compartimento limnético foi a seguinte: Carioca, Águas Claras, Ariranha, Aguapé e Amarela. 


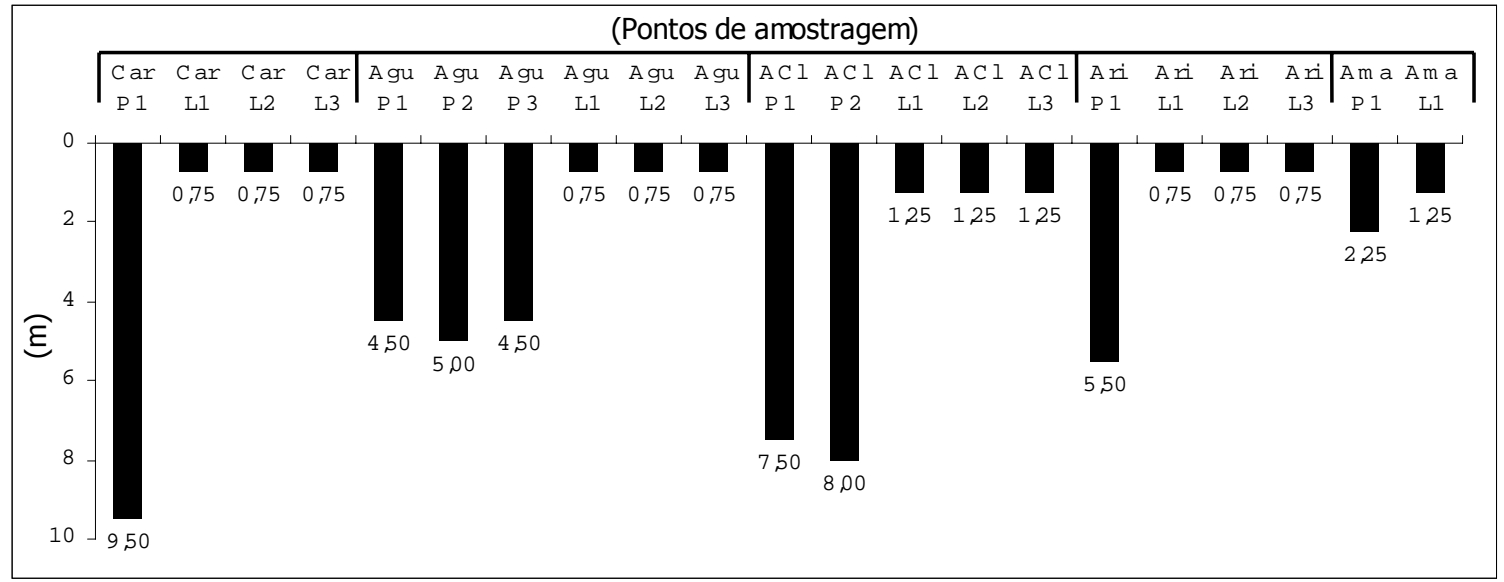

Figura 19. Valores da profundidade da coluna d'água nas diferentes lagoas, medidos nos diferentes pontos de amostragens. 


\subsubsection{TRANSPARÊNCIA DA ÁGUA}

Na Figura 20 estão apresentados os valores da transparência da água dos pontos limnéticos e litorâneos das lagoas, nos três períodos estudados.

Em todos os períodos amostrados, a transparência da água foi total nos pontos litorâneos de todas as lagoas, ou seja, os valores desta variável foram iguais aos da profundidade.

De maneira geral, os valores encontrados nos pontos limnéticos tiveram um decréscimo de 0,10 a 0,40 metros comparando-se o mês de junho de 1999 (inverno 1) com o mês de agosto de 1999 (inverno 2). Nestes mesmos compartimentos, com exceção aos da lagoa Ariranha e Amarela, observou-se um acréscimo de transparência comparando-se ambos os períodos de Inverno com o de verão (fevereiro de 2000).

$\mathrm{Na}$ lagoa Águas Claras foram verificados os maiores valores para a transparência da água nos três períodos de amostragem, com um máximo de 3,10 metros (ACl-P1 e ACL-P2) em fevereiro de 2000 (verão), e um mínimo de 1,80 metros (ACl-P1) em junho de 1999 (inverno 1).

Para as demais lagoas foram encontrados valores nos períodos de amostragem na zona limnética, entre o mínimo de 0,90 na lagoa Carioca (Car-P1) no período de inverno 2, e o máximo de 1,80 metros na mesma lagoa (Car-P1) no período de verão.

No período de inverno 1 , foram observados valores iguais (1,40 metros) para os pontos limnéticos da lagoa Aguapé. O descréscimo no valor desta variável do inverno 1 para o 2 foi mais expressivo no ponto Agu-P2, onde foi observado o valor de 0,80 metros para a transparência da água segundo período de Inverno. Já no verão, foi verificado neste mesmo ponto o maior valor dentre as amostragens limnéticas nesta lagoa, com um valor máximo de 1,50 metros. 


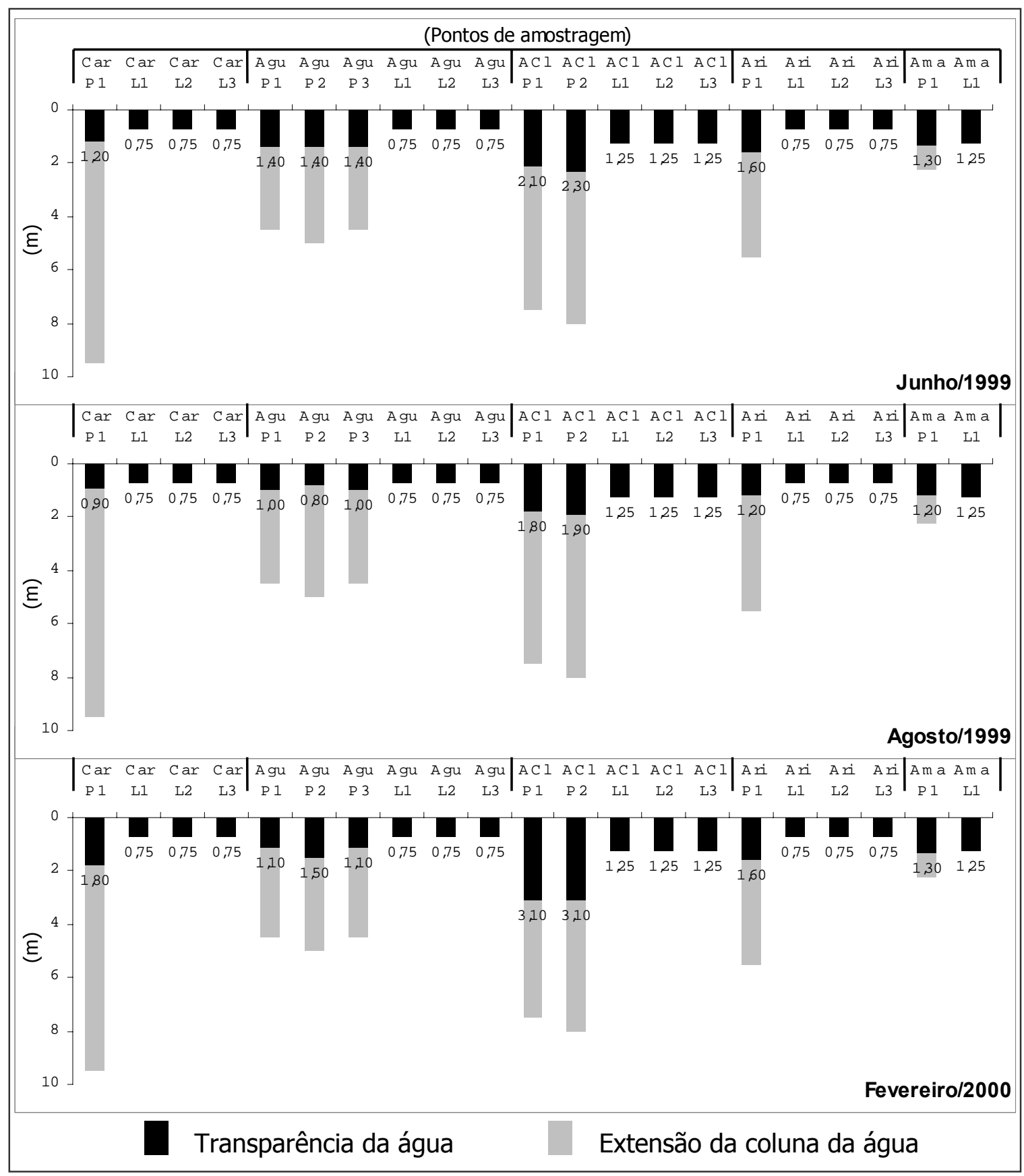

Figura 20. Variação dos valores da transparência da água entre os pontos de amostragem das cinco lagoas, para os três períodos climáticos estudados. 


\subsubsection{EXTENSÃO DA ZONA EUFÓTICA}

Na Figura 21 estão apresentados os valores da extensão da zona eufótica, lembrando que nos pontos de coleta litorâneos ocorreu transparência total e, portanto, zona eufótica em toda a extensão da coluna d'água.

Dentre os valores apresentados, aqueles dos pontos pelágicos da lagoa Amarela, em todos os períodos de amostragem, e da lagoa Águas Claras no período de verão (fevereiro de 2000), também apresentaram zona eufótica em toda a extensão da coluna da água.

Os valores da zona eufótica apresentam variações similares aos da transparência, já que seu cálculo tem como base os valores desta última.

Nos pontos pelágicos das lagoas Carioca, Aguapé e Águas Claras verificou-se uma diminuição nos valores da extensão da zona eufótica do período de inverno 1 (junho de 1999) para o 2 (agosto de 1999).

Nos pontos limnéticos das lagoas Carioca e Águas Claras, observou-se um aumento nos valores desta variável dos períodos de inverno para o de verão. O mesmo foi observado para apenas um ponto limnético (Agu-P2) da lagoa Aguapé. 


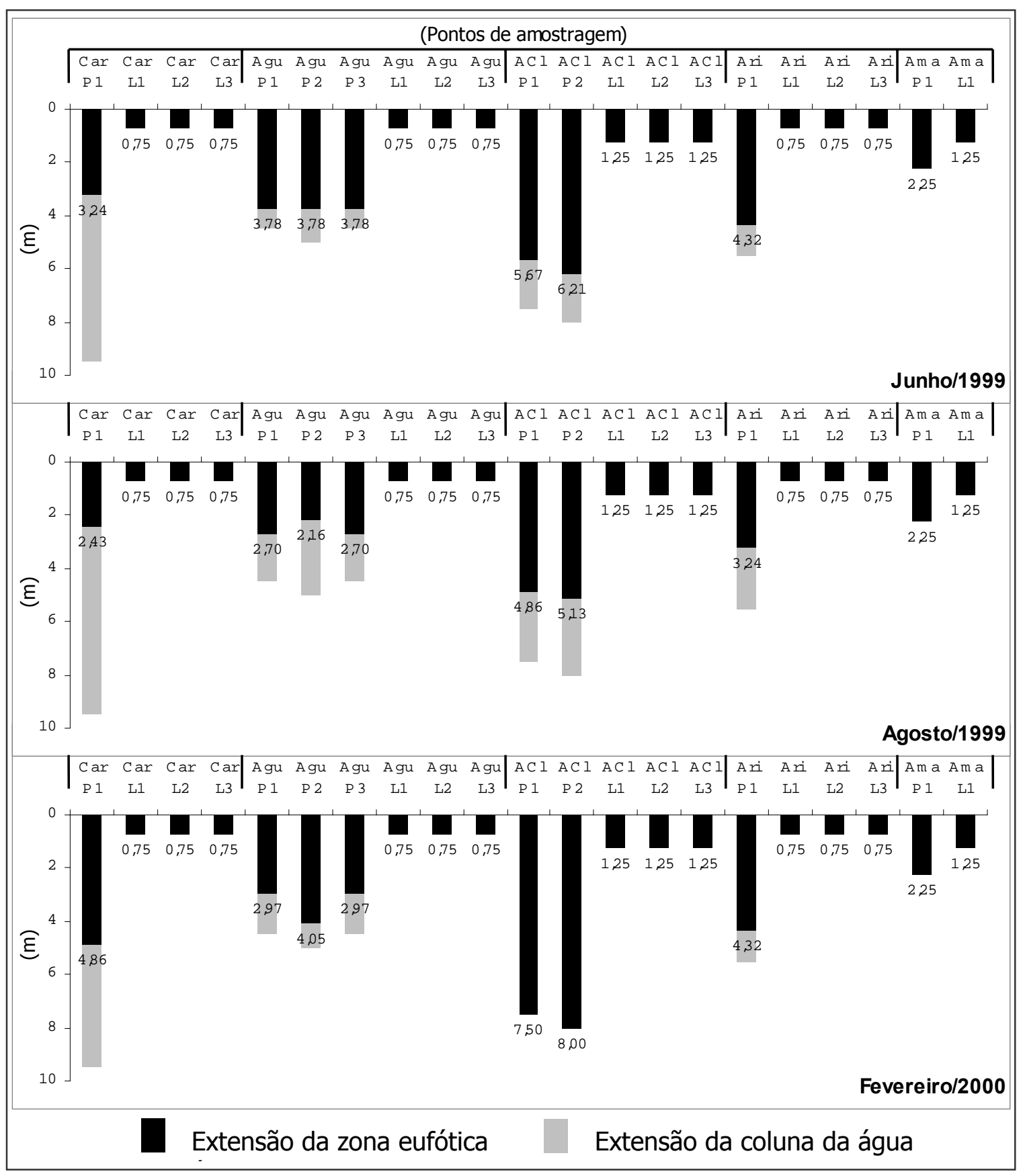

Figura 21. Variação dos valores da extensão da zona eufótica entre os pontos de amostragem das cinco lagoas, para os três períodos estudados. 


\subsubsection{TEMPERATURA DA ÁGUA}

Os perfis térmicos dos pontos de amostragem representantes dos compartimentos litorâneos e limnéticos, nos três períodos de, estudo estão apresentados nas Figuras 22.

\section{LAGOA CARIOCA}

De maneira geral, considerando o primeiro metro da coluna da água, os valores da temperatura da água nos pontos de amostragem da lagoa Carioca (Figura 22) diminuiram do período de inverno 1 para o inverno 2 , e aumentaram deste último para o verão.

No ponto limnético Car-P1 da lagoa Carioca lagoa, foi observada isotermia nos períodos de inverno, sendo mais evidente no inverno 2 , quando as variações da temperatura ao longo do perfil da coluna da água foram menores. Neste mesmo ponto, no Inverno 1 , os valores da temperatura da água variaram de $22^{\circ} \mathrm{C}$, na profundidade máxima, até $23,4^{\circ} \mathrm{C}$ na superfície da água, ou seja, um espectro de variação térmica de $1,4^{\circ} \mathrm{C}$. No período de inverno 2 , foi observada uma variação de $0,2^{\circ} \mathrm{C}$, menor que a do inverno 1 , nos valores desta variável neste mesmo ponto da lagoa Carioca, com um mínimo de $21,6^{\circ} \mathrm{C}$ a partir da profundidade de 6,5 metros e máximo de $21,8^{\circ} \mathrm{C}$ de 0 a 1 metros de profundidade.

No verão, foi possível identificar o estabelecimento de estratificação térmica bem definida no ponto limnético da lagoa Carioca entre as profundidades de 5,5 a 6,5 metros, com um decaimento de $2,6^{\circ} \mathrm{C}$ na temperatura.

Em todos os pontos litorâneos da lagoa Carioca observou-se uma homogeneidade térmica, em cada período de amostragem, com variações de no máximo $0,3^{\circ} \mathrm{C}$ entre a superfície e a maior profundidade. Em geral, o decréscimo da temperatura da água, entre os compartimentos litorâneos do período de inverno 1 para o inverno 2 , foi de cerca de $1,8^{\circ} \mathrm{C}$, e deste último para o período de verão foi de cerca de $8,8^{\circ} \mathrm{C}$.

\section{LAGOA AGUAPÉ}

Na lagoa Aguapé, os valores da temperatura da água mantiveram-se bastante próximos comparando-se os períodos de inverno 1 e 2, com exceção para o ponto litorâneo (Ag-L3) onde houve um aumento de cerca de $2^{\circ} \mathrm{C}$ do período de inverno 1 
para o 2. Do segundo período amostrado (inverno 2) para o período de verão houve um aumento de cerca de $6^{\circ} \mathrm{C}$ em todos os pontos de amostragem.

A estrutura térmica da coluna da água caracterizou-se por isotermia nos períodos de inverno e uma tendência à estratificação no verão, o que foi melhor evidenciado nos pontos Agu-P2 e Agu-P3.

No período de inverno 1, foi verificada uma grande homogeneidade térmica na coluna da água nos pontos limnéticos da lagoa Aguapé, com uma variação máxima 0,5 ${ }^{\circ} \mathrm{C}$ da superfície até a maior profundidade. $\mathrm{O}$ ponto limnético Agu-P2, considerado o ponto mais central da lagoa, foi aquele onde se verificou a menor variação $\left(0,1^{\circ} \mathrm{C}\right)$ da temperatura da água da superfície até a maior profundidade. Neste período a maior temperatura encontrada foi de $23{ }^{\circ} \mathrm{C}$, e a menor de $22,5^{\circ} \mathrm{C}$.

No segundo período de inverno amostrado, observou-se um aumento da temperatura da água no primeiro metro da coluna da água dos pontos limnéticos. Dessa forma, as variações nos valores desta variável dentro de cada perfil térmico foram maiores do que as do período anterior, ou seja, uma menor homogeneidade térmica da coluna da água, com variação de até $1,4{ }^{\circ} \mathrm{C}$ da superfície para o fundo.

No verão, foi possível identificar apenas uma tendência à estratificação térmica nos pontos limnéticos Agu-P2 e Agu-P3. Em todos os pontos limnéticos, observou-se variações de cerca de $0,8{ }^{\circ} \mathrm{C}$ entre as profundidades de 2,5 a 3,5 metros, onde se estabeleceu a termoclina. Neste período o valor máximo desta variável foi de $29,4{ }^{\circ} \mathrm{C}$ e o mínimo de $28,2{ }^{\circ} \mathrm{C}$, com diferença de apenas $1,2{ }^{\circ} \mathrm{C}$ entre superfície e fundo.

No pontos litorâneos observou-se uma grande homogeneidade da temperatura na coluna da água, com variações máximas de $0,1{ }^{\circ} \mathrm{C}$, exceção feita ao ponto Agu-L3 (com 0,75 metros de profundidades), onde a variação da superfície para o fundo foi de $0,9^{\circ} \mathrm{C}$.

\section{LAGOA ÁGUAS CLARAS}

De maneira geral, os valores desta variável na lagoa Águas Claras foram semelhantes entre os períodos de inverno, com exceção feita ao ponto litorâneo ACl$\mathrm{L} 1$, onde a diferença foi de cerca de $1,5{ }^{\circ} \mathrm{C}$ do período de Inverno 1 para o 2 . Observou-se aumento em torno de $5{ }^{\circ} \mathrm{C}$ nos valores da temperatura da água dos períodos de inverno para o de verão.

Nos pontos limnéticos, foi observada uma tendência a estratificação nos períodos de inverno, com valor máximo de $24,8{ }^{\circ} \mathrm{C}$ na superfície do ponto $\mathrm{ACl}-\mathrm{P} 1$ e $\mathrm{ACl}-$ 
P2 no período de inverno 2 , e mínimo de $22,9^{\circ} \mathrm{C}$ nos mesmos pontos no mesmo período, com uma diferença de apenas $1,9^{\circ} \mathrm{C}$.

Nestes mesmos pontos, foi verificada apenas uma tendência ao estabelecimento de estratificação térmica, com declínio dos valores de temperatura nas camadas mais profundas da coluna da água. No verão, os valores da temperatura da água dos pontos limnéticos variaram de $29,5^{\circ} \mathrm{C}$, na superfície, a $27,4^{\circ} \mathrm{C}$ na maior profundidade da coluna da água.

Nos pontos litorâneos foram verificados valores próximos desta variável entre as profundidades, com uma grande homogeneidade térmica.

\section{LAGOA ARIRANHA}

Os valores da temperatura da águas dos pontos da lagoa Ariranha mantiveramse próximos quando considerados os períodos de inverno 1 e 2 . Porém, quando estes são comparados com o período de verão, pode-se observar que houve um aumento de cerca de $6^{\circ} \mathrm{C}$.

No ponto limnético desta lagoa, foi verificada uma maior homogeneidade (isotermia) nos valores da temperatura da água ao longo da coluna da água no período de inverno 1 , com um mínimo de $22,9^{\circ} \mathrm{C}$ e máximo de $23,0^{\circ} \mathrm{C}$, ou seja, uma variação de apenas $0,1^{\circ} \mathrm{C}$, em 5,50 metros de profundidade. De forma mais atenuada, no inverno 2 também foi observada a ocorrência de termoclina neste ponto, com uma variação de $0,8^{\circ} \mathrm{C}$ entre a superfície $\left(23,5^{\circ} \mathrm{C}\right)$ e o fundo da coluna da água $\left(22,6^{\circ} \mathrm{C}\right)$.

No Verão, a variação nos valores desta variável no ponto limnético da lagoa Ariranha foi de $0,7^{\circ} \mathrm{C}$, menor que o encontrado para o inverno 2. Ainda assim, pode-se inferir que a partir do quarto metro da coluna da água formou-se a estratificação térmica.

Verificaram-se valores menores de temperatura no ponto Ari-L2, tanto no período de inverno 1 quanto no inverno 2 . No verão, foram verificados valores de temperatura similares entre os três pontos litorâneos da lagoa Ariranha.

\section{LAGOA AMARELA}

Em ambos os compartimentos amostrados na lagoa Amarela, litorâneo e limnético, pôde-se observar uma diminuição nos valores da temperatura da água de cerca de $1^{\circ} \mathrm{C}$ do período de inverno 1 para o 2 , e um aumento de cerca de $6^{\circ} \mathrm{C}$ deste último para o período de verão. 
No ponto limnético, foi possível verificar uma certa homogeneidade térmica da coluna da água nos períodos de inverno 1 e 2, e um decaimento nos valores da temperatura da superfície para o fundo no verão.

De maneira geral, os valores da temperatura entre as profundidades do ponto litorâneo mantiveram-se bastante próximos, com exceção para o período de inverno 1, quando a variação térmica da superfície para o fundo foi de $1,4^{\circ} \mathrm{C}$.

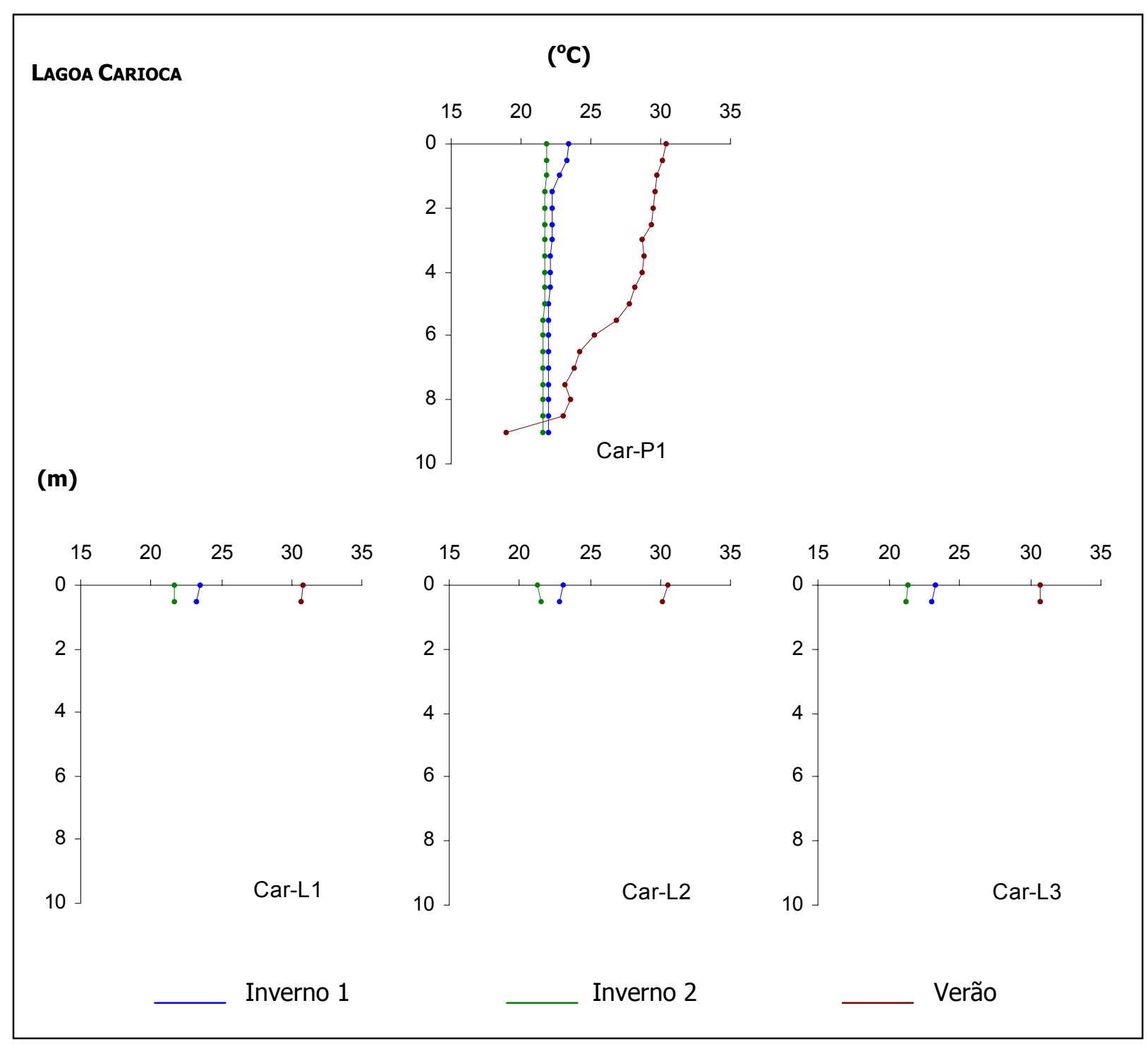

Figura 22. Perfis da temperatura da água dos pontos de amostragem das cinco lagoas, para os três períodos estudados. 


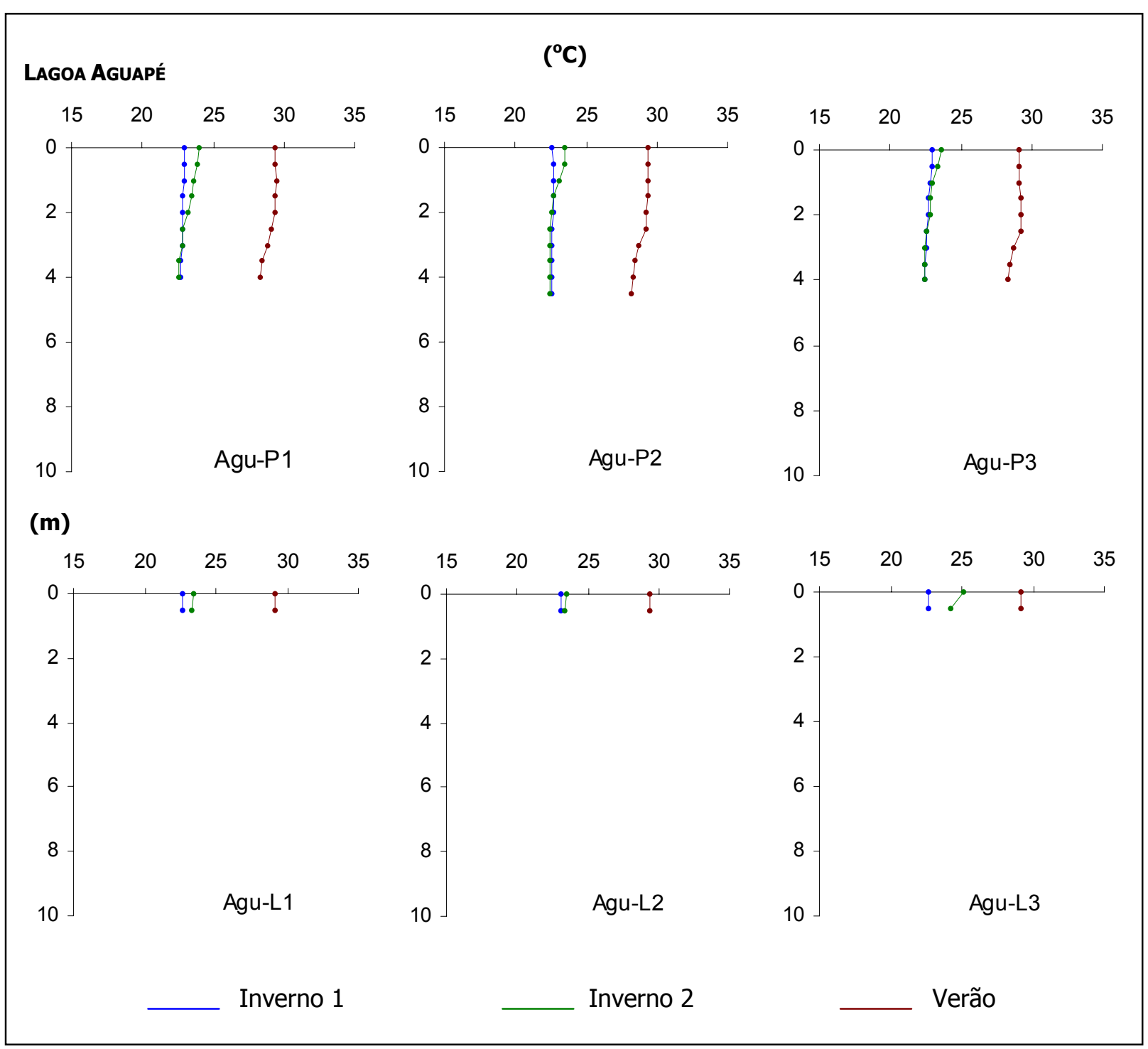

Continuação da Figura 22. Perfis da temperatura da água dos pontos de amostragem das cinco lagoas, para os três períodos estudados. 


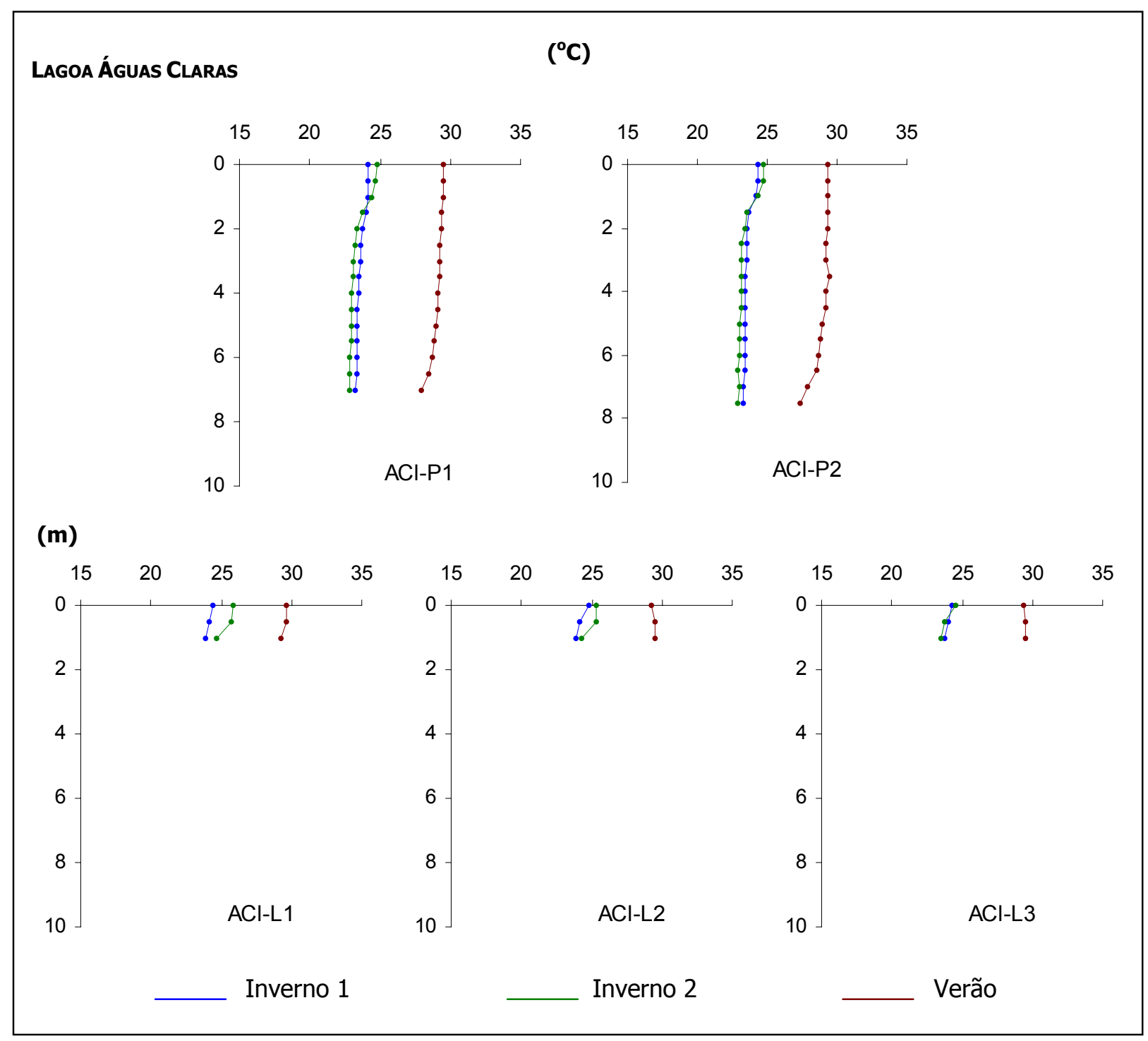

Continuação da Figura 22. Perfis da temperatura da água dos pontos de amostragem das cinco lagoas, para os três períodos estudados. 


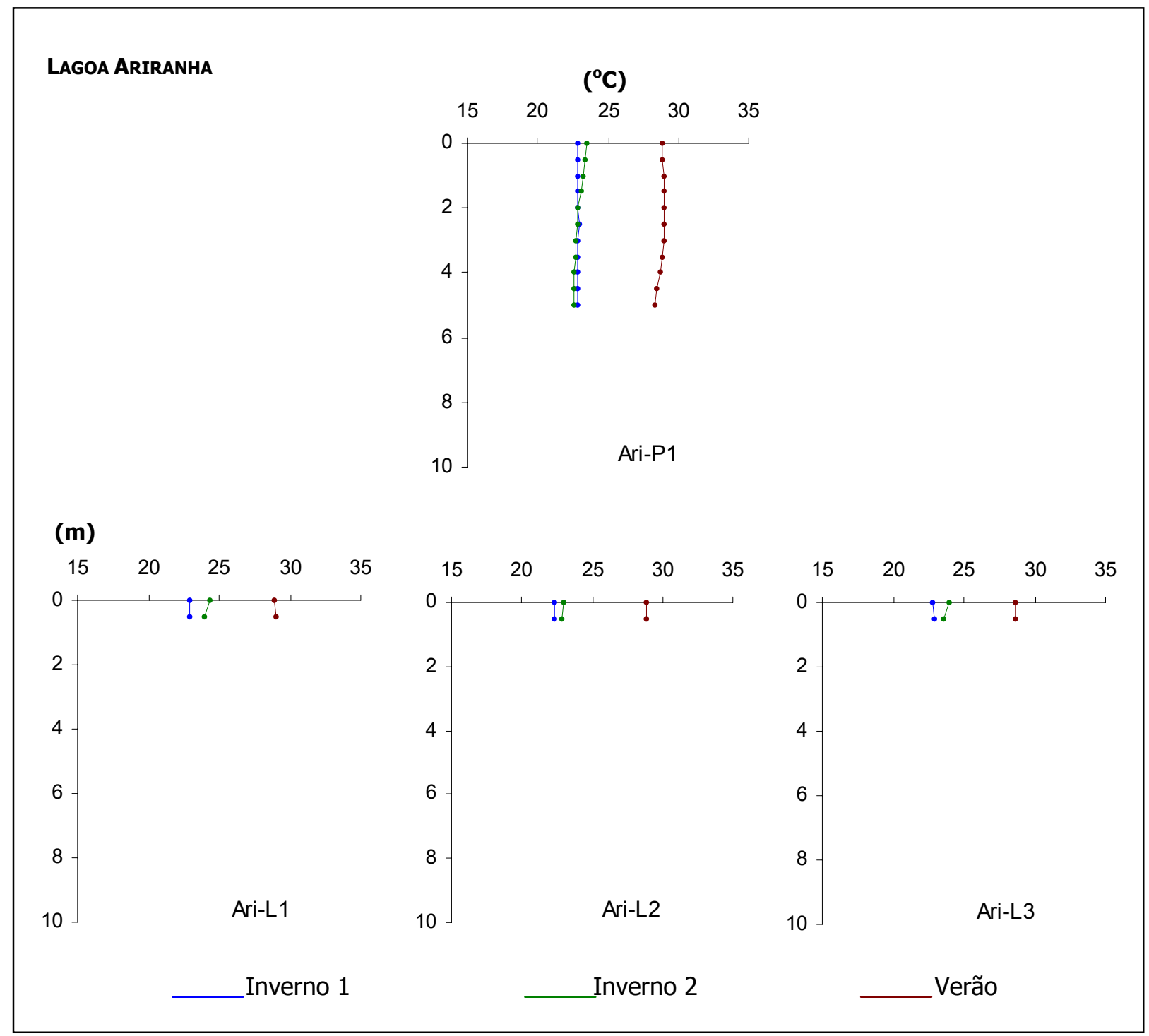

Continuação da Figura 22. Perfis da temperatura da água dos pontos de amostragem das cinco lagoas, para os três períodos estudados. 


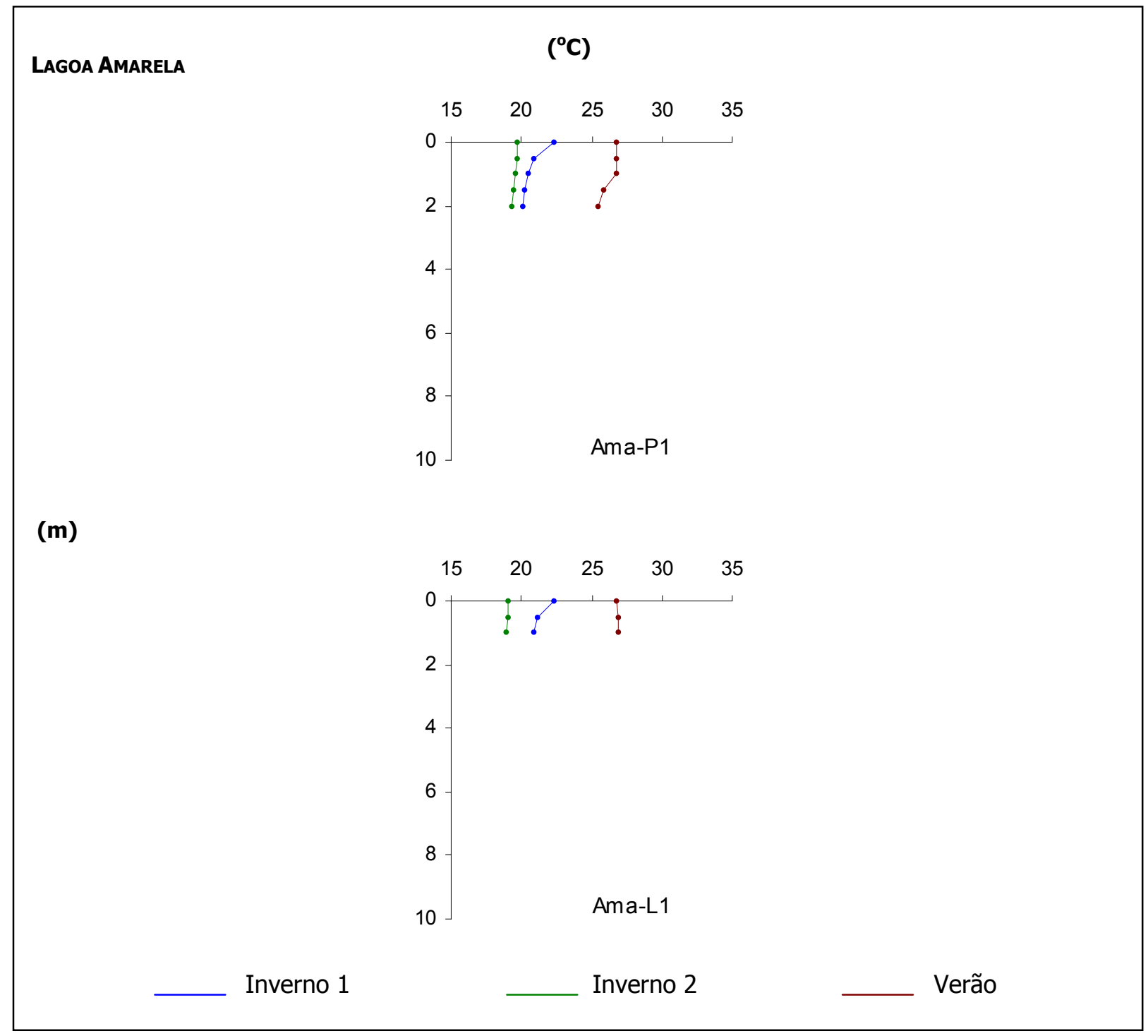

Continuação da Figura 22. Perfis da temperatura da água dos pontos de amostragem das cinco lagoas, para os três períodos estudados. 


\subsubsection{OXIGÊNIO DISSOLVIDO}

Os perfis de oxigênio dissolvido dos compartimentos litorâneos e limnéticos das lagoas estudadas, nos três períodos amostrados, estão apresentados na Figura 23.

Pela análise destes, pode-se dizer que, de maneira geral, observou-se uma tendência a uma homogeneidade nos valores desta variável entre as profundidades da coluna da água dos pontos limnéticos de todas as lagoas nos períodos de inverno $1 \mathrm{e}$ 2, e uma tendência à estratificação química, chegando à anoxia nas últimas profundidades dos mesmos pontos no verão. Esta tendência observada seguiu os padrões de isotermia e estratificação térmica descritos anteriormente.

\section{LAGOA CARIOCA}

No ponto limnético da lagoa Carioca, foram observadas concentrações de oxigênio dissolvido similares entre os períodos de inverno 1 e 2 . 0 maior valor encontrado no Inverno 1 foi de 7,43 mg/L na superfície da coluna da água e o menor foi de $4,14 \mathrm{mg} / \mathrm{L}$, encontrado na profundidade de 8,5 metros. Neste mesmo ponto, no inverno 2 , os valores desta variável estiveram entre $6,98 \mathrm{mg} / \mathrm{L}$ na superfície e 4,23 $\mathrm{mg} / \mathrm{L}(8,5$ metros$)$.

Já no verão, observou-se um decaimento na concentração de oxigênio dissolvido da superfície para o fundo, no ponto limnético da lagoa Carioca, com um máximo de 7,42 mg/L a 0,0 metros, para uma anoxia quase total nas profundidades de 7,0 e 7,5 metros. O maior decréscimo foi observado a partir dos 4,5 metros de profundidade, sendo que o sistema tornou-se praticamente anóxico a partir dos 6,0 metros, caracterizando a ocorrência de oxiclina.

Nos pontos litorâneos desta lagoa, nos três períodos de amostragem, não foi possível estabelecer um padrão de decréscimo nas concentrações do oxigênio dissolvido entre superfície e fundo. Nestes pontos, os valores desta variável entre as profundidades, estiveram sempre próximos e semelhantes aqueles encontrados na superfície do ponto limnético, considerando-se os três períodos de amostragem.

\section{LAGOA AGUAPÉ}

No inverno 1 as concentrações de oxigênio dissolvido entre os pontos limnéticos estiveram mais próximas do que na lagoa Carioca, com um valor máximo de 7,91 mg/l a 0,0 metro do ponto Agu-P3, e um mínimo de 4,84 mg/l na profundidade de 4,0 metros do ponto Agu-P1. Neste último ponto foi observado o maior decaimento dos 
valores desta variável, para o inverno 1 , com uma variação de $2,58 \mathrm{mg} / \mathrm{L}$ entre superfície e fundo.

No geral, do período de inverno 1 para 0 2, as concentrações de oxigênio dissolvido nos pontos limnéticos aumentaram. No inverno 2 foi observado um valor máximo de 8,20 mg/L na superfície do ponto Agu-P3, e um mínimo de 6,04 mg/L na profundidade máxima (4,0 metros) do ponto Agu-P1.

Pode-se dizer, ainda, que no ponto Agu-P2 (ponto limnético mais central) foi verificada uma maior homogeneidade nos valores desta variável entre as profundidades amostradas, no período de inverno 1.

No período de verão, observou-se uma grande diminuição nas concentrações de oxigênio dissolvido da superfície para o fundo dos pontos limnéticos, tendendo a uma anoxia nas últimas profundidades, com exceção feita ao ponto Agu-P3, onde foram verificadas concentrações relativamente altas de oxigênio dissolvido no fundo. Neste período, a maior concentração desta variável foi de $7,96 \mathrm{mg} / \mathrm{l}$, encontrada na profundidade de 0,0 metro do ponto Agu-P2, e a menor de 0,95 mg/L na última profundidade (4,5 metros) deste mesmo ponto.

Em relação aos pontos litorâneos, nos três períodos estudados, as concentrações de oxigênio dissolvido estiveram próximas entre as profundidades da coluna da água.

\section{LAGOA ÁGUAS CLARAS}

Em ambos os pontos limnéticos da lagoa Águas Claras, no período de inverno 1, foi observada uma certa homogeneidade nas concentrações de oxigênio dissolvido entre as profundidades amostradas. Nos dois pontos verificou-se um decaimento de $0,5 \mathrm{mg} / \mathrm{L}$ por metro nos valores dessa variável, a partir da profundidade de 2,5 metros. Os valores mantiveram-se menores até a profundidade de 5,5 metros para ACl-P1 e de 5,0 metros para ACl-P2, a partir das quais as concentrações desta variável aumentaram e tornaram a decair até atingir o fundo. Neste período, o maior valor para a concentração de oxigênio dissolvido entre os pontos limnéticos foi de 8,58 mg/L na profundidade de 1,5 metros do ponto $\mathrm{ACl}-\mathrm{P} 1$, e o menor de $6,55 \mathrm{mg} / \mathrm{L}$ na última profundidade (7,0 metros) do mesmo ponto.

No período de inverno 2, os pontos limnéticos desta lagoa apresentaram perfis de concentração de oxigênio dissolvido diferentes. No ponto $\mathrm{ACl}-\mathrm{P} 1$, observou-se um decréscimo nos valores desta variável a partir da profundidade de 2,0 metros. Já no ponto ACl-P2 (ponto limnético mais central), os valores mantiveram-se relativamente 
próximos ao longo da coluna da água. Neste período, a maior concentração de oxigênio dissolvido foi de 7,58 mg/L, encontrada na profundidade de 0,5 metro do ponto $\mathrm{ACl}-\mathrm{P} 1$, e a menor de $4,38 \mathrm{mg} / \mathrm{L}$ na profundidade de 5,5 metros do mesmo ponto.

No verão, o padrão de variação das concentrações de oxigênio dissolvido entre as profundidades dos pontos limnéticos foi semelhante, com valores altos na superfície, e forte decaimento das concentrações deste gás a partir da profundidade de 4,0 metros, atingindo valores relativamente baixos nas últimas profundidades, o que caracterizou ocorrência de anoxia no fundo. Neste período, o maior valor para esta variável na região limnética foi de $7,63 \mathrm{mg} / \mathrm{L}$, encontrado na profundidade de 1,0 metro do ponto ACl-P1, e o menor de $0,05 \mathrm{mg} / \mathrm{l}$, verificado no fundo (7,5 metros) do ponto ACL-P2.

Nos pontos litorâneos, as concentrações de oxigênio dissolvido, entre as profundidades amostradas, mantiveram-se próximas e semelhantes àquelas encontradas na superfície dos pontos limnéticos, dentro de cada período de amostragem.

\section{LAGOA ARIRANHA}

Em ambos os períodos de inverno, no ponto limnético da lagoa Ariranha, verificou-se uma tendência a homogeneidade nas concentrações de oxigênio dissolvido entre as profundidades amostradas, valendo destacar um descréscimo nos valores desta variável a partir dos 2,0 metros de profundidade. De maneira geral, os valores encontrados para o inverno 2 foram maiores do que aqueles verificados o inverno 1. Neste último período, a maior concentração verificada no ponto limnético foi de 6,89 $\mathrm{mg} / \mathrm{L}$ observada na superfície (0,0 metro), e a menor de 5,36 mg/L na última profundidade. No período de inverno 2, os valores desta variável estiveram entre 0 máximo de 8,36 mg/L, verificado nas profundidades de 1,5 e 2,0 metros, e o mínimo de $6,98 \mathrm{mg} / \mathrm{L}$ das profundidades de 3,5 e 5,0 metros.

No verão, as concentrações mantiveram-se em torno dos 7,60 mg/L até a profundidade de 3,5 metros, a partir da qual ocorreu uma diminuição acentuada nos valores desta variável, porém, sem atingir uma anoxia no fundo, onde foi encontrado o menor valor de 3,49 mg/L. Neste período, o maior valor para oxigênio dissolvido no ponto limnético foi de $7,77 \mathrm{mg} / \mathrm{L}$, na superfície (0,0 metro).

No pontos litorâneos, dentro de cada período, as concentrações mantiveram-se semelhantes entre as profundidades e próximas àquelas encontradas no ponto 
limnético, com exceção aos pontos Ari-L2 e Ari-L3 no período de inverno 1, onde foram verificados valores relativamente baixos na concentração deste gás, ressaltando-se, principalmente, este último ponto.

\section{LAGOA AMARELA}

No ponto limnético da lagoa Amarela, em todos os períodos estudados, pôde-se verificar um descréscimo bastante expressivo nas concentrações de oxigênio dissolvido no sentido da superfície para o fundo. Vale destacar que nos períodos de inverno $1 \mathrm{e}$ Verão, este descréscimo foi mais expressivo, uma vez que se atingiu um padrão de anoxia no fundo ( 2,0 metros).

Neste ponto de amostragem, o maior valor encontrado para a concentração de oxigênio dissolvido foi de $5,04 \mathrm{mg} / \mathrm{L}$ a 0,0 metro de profundidade no período de inverno 1 , e o menor foi de $0,08 \mathrm{mg} / \mathrm{L}$ na profundidade máxima (2,0 metros) no Verão.

No inverno 1, observou-se um acrescécimo de cerca de $3 \mathrm{mg} / \mathrm{L}$ nos valores de oxigênio dissolvido da superfície para o fundo do ponto litorâneo. Nos demais períodos, foi observada uma certa homogeneidade nos valores desta variável, comparando-se as profundidades amostradas. 


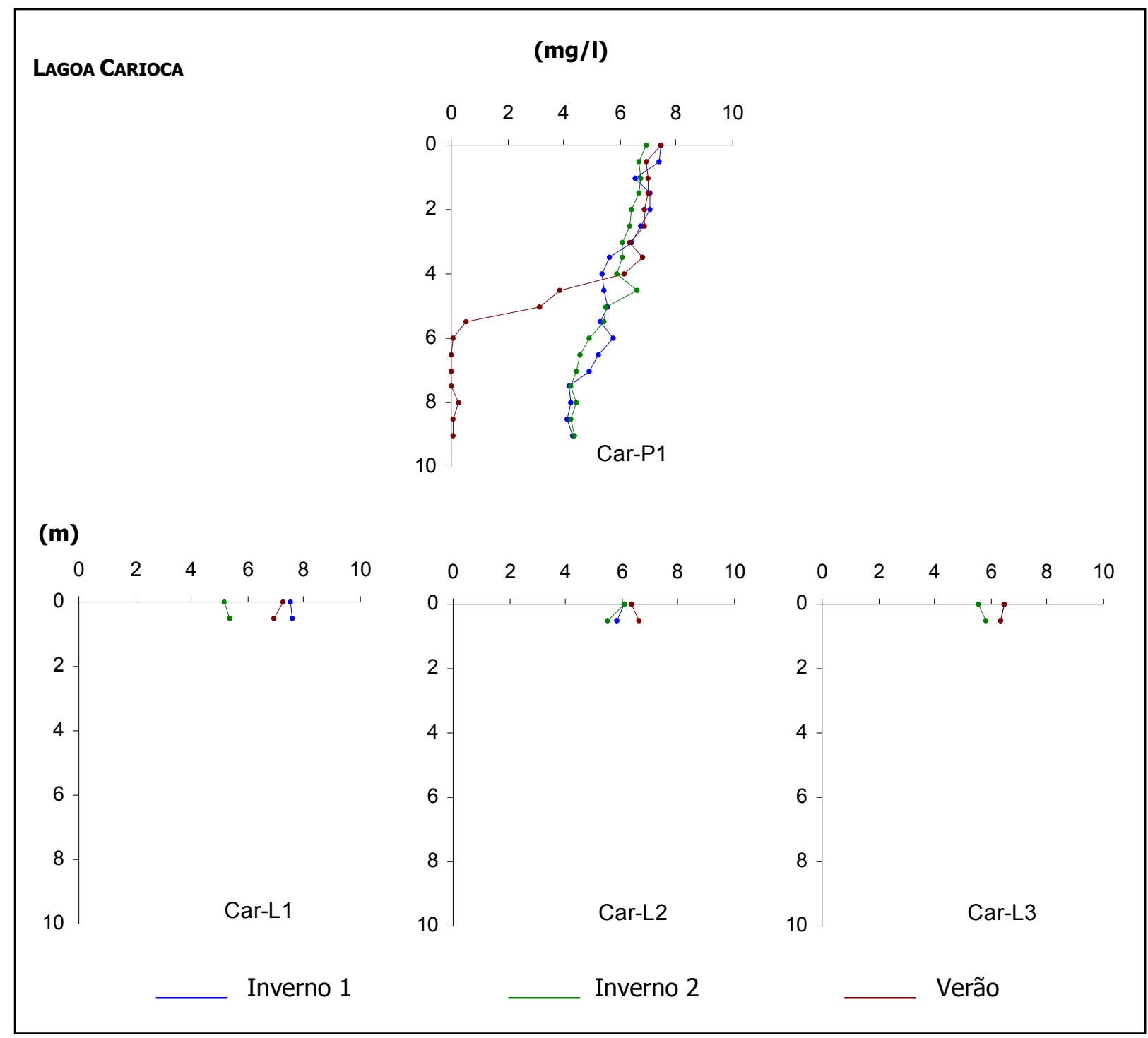

Figura 23. Perfis de oxigênio dissolvido na água dos pontos de amostragem das cinco lagoas, para os três períodos estudados. 


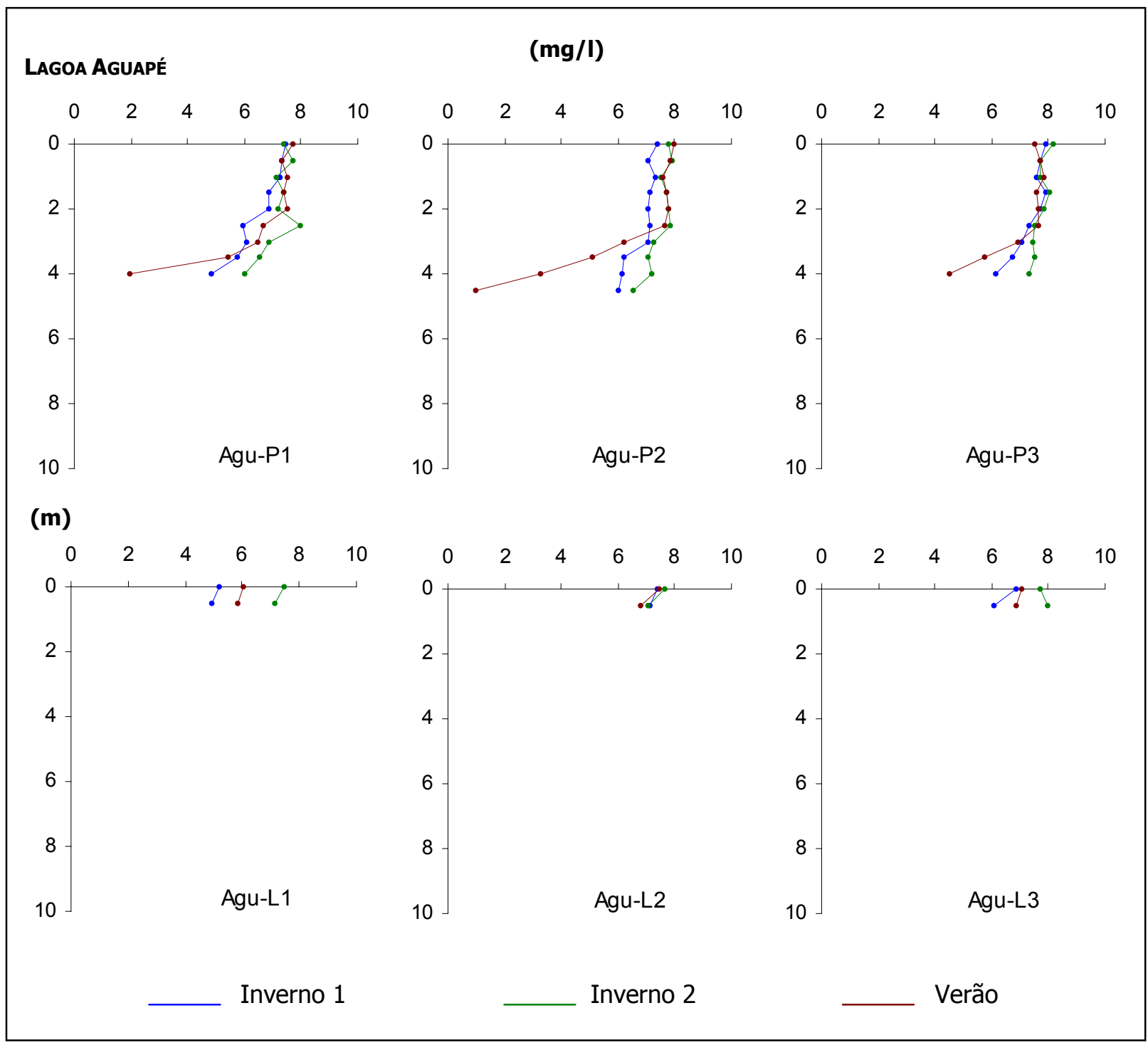

Continuação da Figura 23. Perfis de oxigênio dissolvido na água dos pontos de amostragem das cinco lagoas, para os três períodos estudados. 


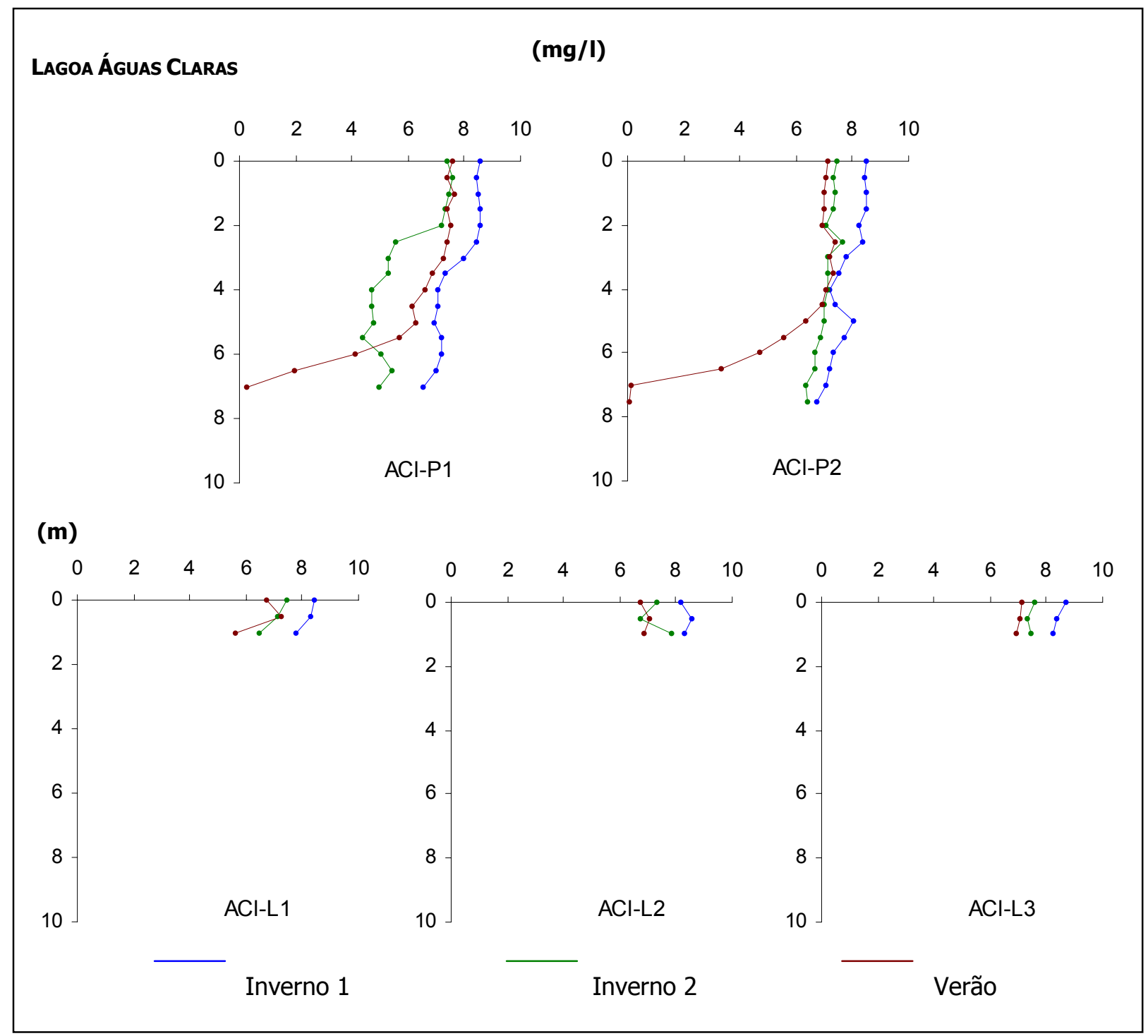

Continuação da Figura 23. Perfis de oxigênio dissolvido na água dos pontos de amostragem das cinco lagoas, para os três períodos estudados. 


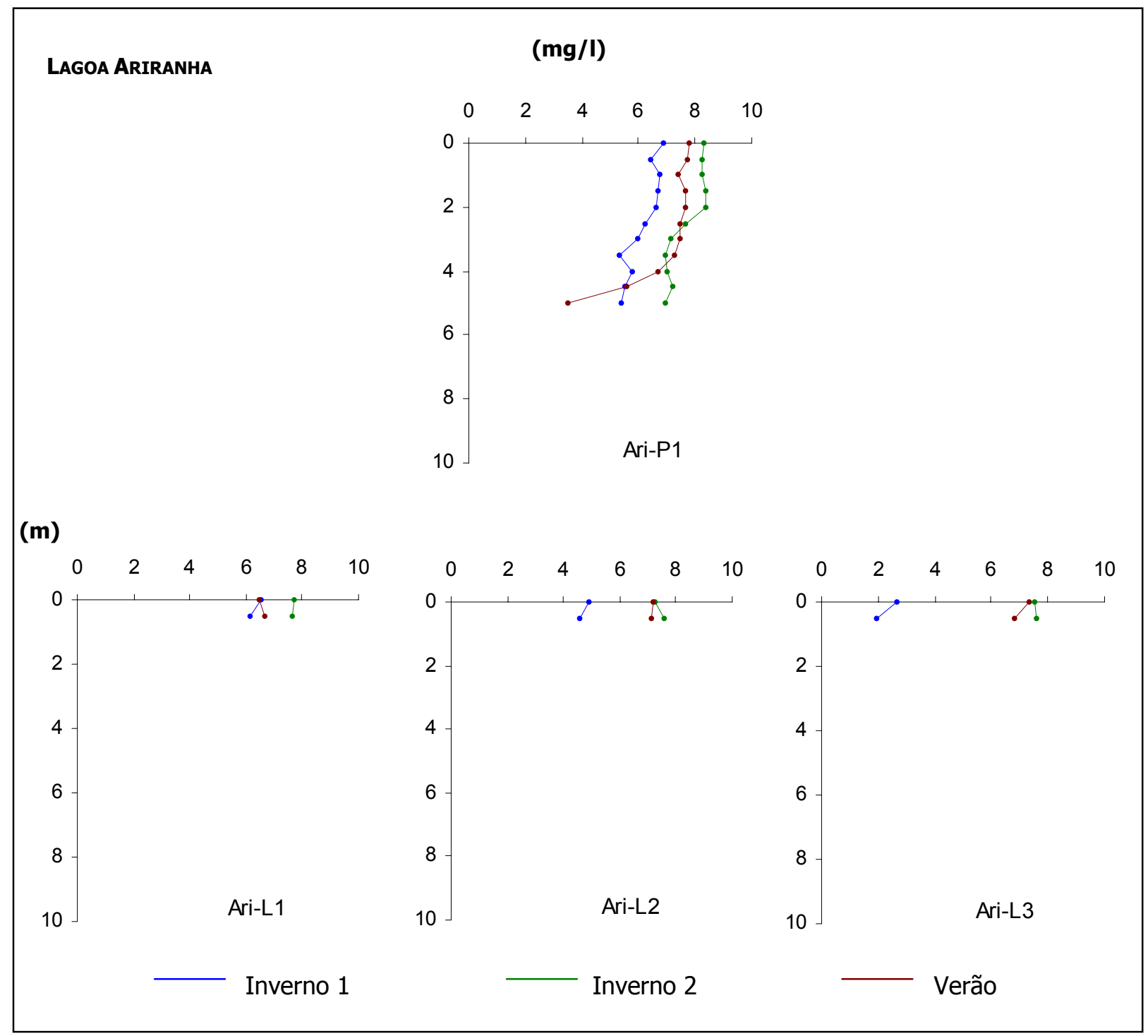

Continuação da Figura 23. Perfis de oxigênio dissolvido na água dos pontos de amostragem das cinco lagoas, para os três períodos estudados. 


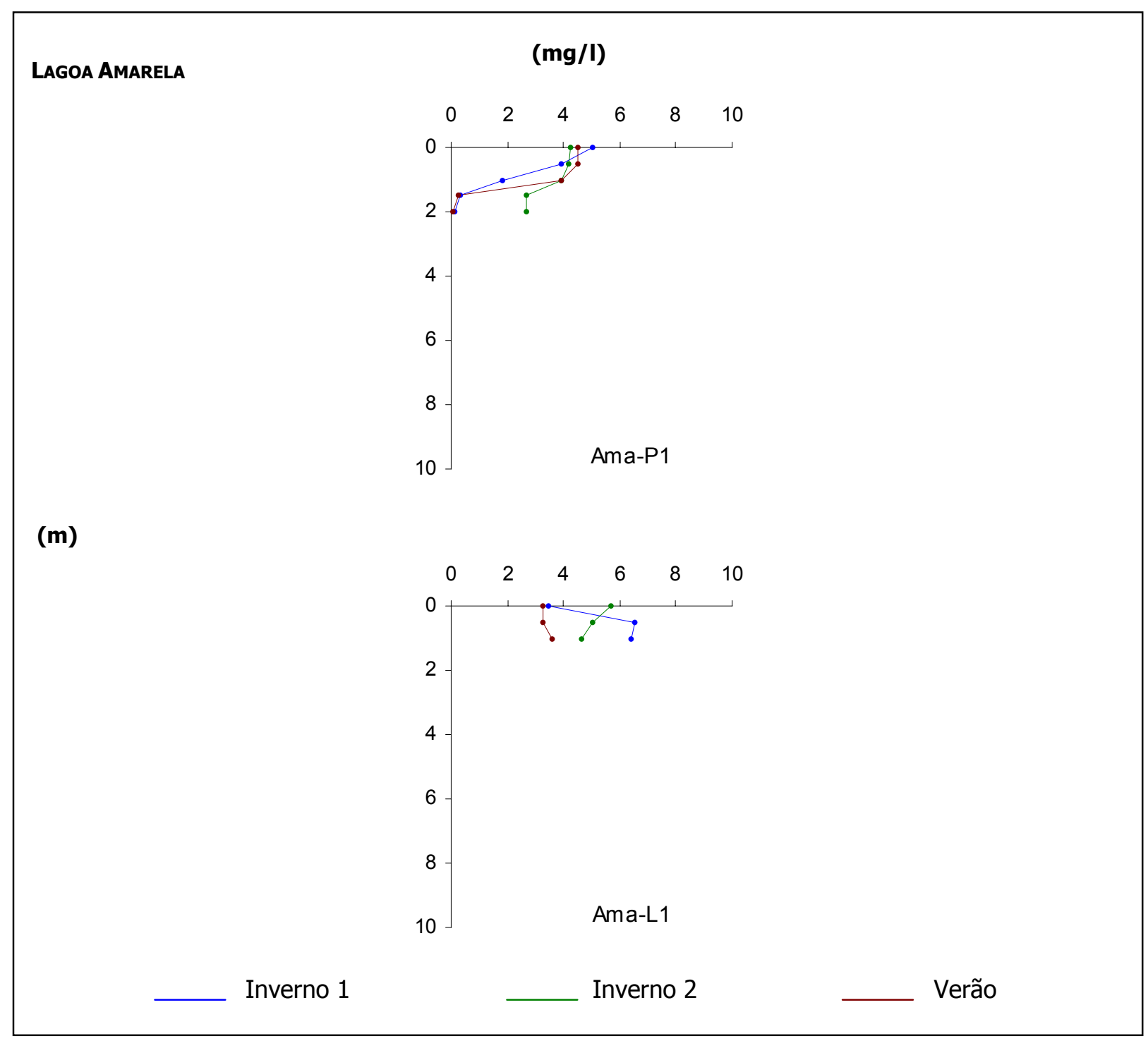

Continuação da Figura 23. Perfis de oxigênio dissolvido na água dos pontos de amostragem das cinco lagoas, para os três períodos estudados. 


\subsection{6. $\mathrm{PH}$}

A Figura 24 apresenta os perfis de $\mathrm{pH}$ dos compartimentos litorâneos e limnéticos das lagoas estudadas nos três períodos amostrados.

De maneira geral, os valores de pH nos pontos litorâneos e nas profundidades mais superficiais dos pontos limnéticos estiveram entre 6 e 8 em todos os períodos analisados.

Nos pontos limnéticos, pôde-se observar também diminuições nos valores de $\mathrm{pH}$, no sentido da superfície para o fundo, nos três períodos. Ou seja, ocorreu uma acidificação da água nas últimas profundidades amostradas. A exceção a este padrão foi feita para o ponto limnético da lagoa Carioca (Car-P1) no período de verão.

Pôde-se observar valores próximos de $\mathrm{pH}$ entre as profundidades amostradas nos pontos litorâneos em todos os períodos analisados.

É importante destacar que em todos as profundidades dos pontos amostrados na lagoa Carioca, nos três períodos de análise, a água sempre apresentou um caráter levemente ácido, com valores de $\mathrm{pH}$ inferiores a 7,0.

Os valores de $\mathrm{pH}$ ao longo de toda a coluna da água do ponto limnético (CarP1) da lagoa Carioca mantiveram-se semelhantes entre os períodos de inverno 1 e 2, seguindo a tendência de uma diminuição no sentido da superfície para o fundo. Este padrão não foi observado no mesmo ponto, no período de Verão, quando os valores decaíram a partir da profundidade de 1,5 metros, voltando a subir a partir dos 6,0 metros.

De maneira geral, nas profundidades mais superficiais dos pontos limnéticos e nos pontos litorâneos da lagoa Aguapé, os valores de pH encontrados no período de inverno 2 estiveram levemente básicos, isto é, acima de 7.

No pontos limnéticos, observou-se um decaimento nos valores desta variável no sentido da superfície para o fundo da coluna da água, em todos os períodos analisados, com mais destaque para os pontos Agu-P1 e Agu-P2 período de verão, onde este padrão foi mais acentuado.

O padrão decrescente nos valores de $\mathrm{pH}$ da superfície para o fundo foi interrompido na profundidade de 4,5 metros do ponto limnético ACl-P2 da lagoa Águas Claras, onde foi observado o valor de 7,12, levemente básico.

Nas lagoas Ariranha e Amarela, deve-se destacar o acentuado descréscimo dos valores desta variável nos pontos limnéticos, Ari-P1 e Ama-P1, no Verão. 


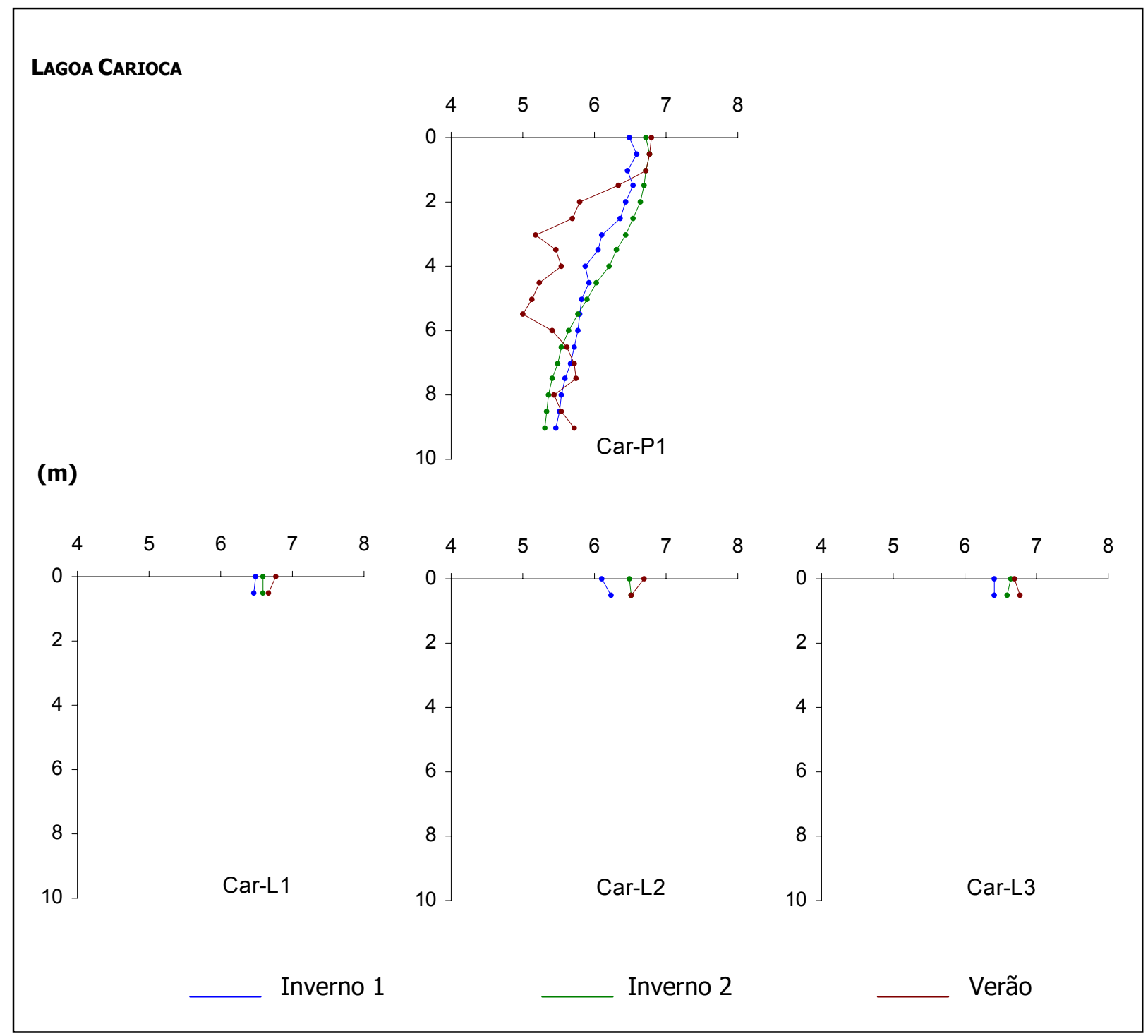

Figura 24. Perfis de pH da água dos pontos de amostragem das cinco lagoas, para os três períodos estudados. 


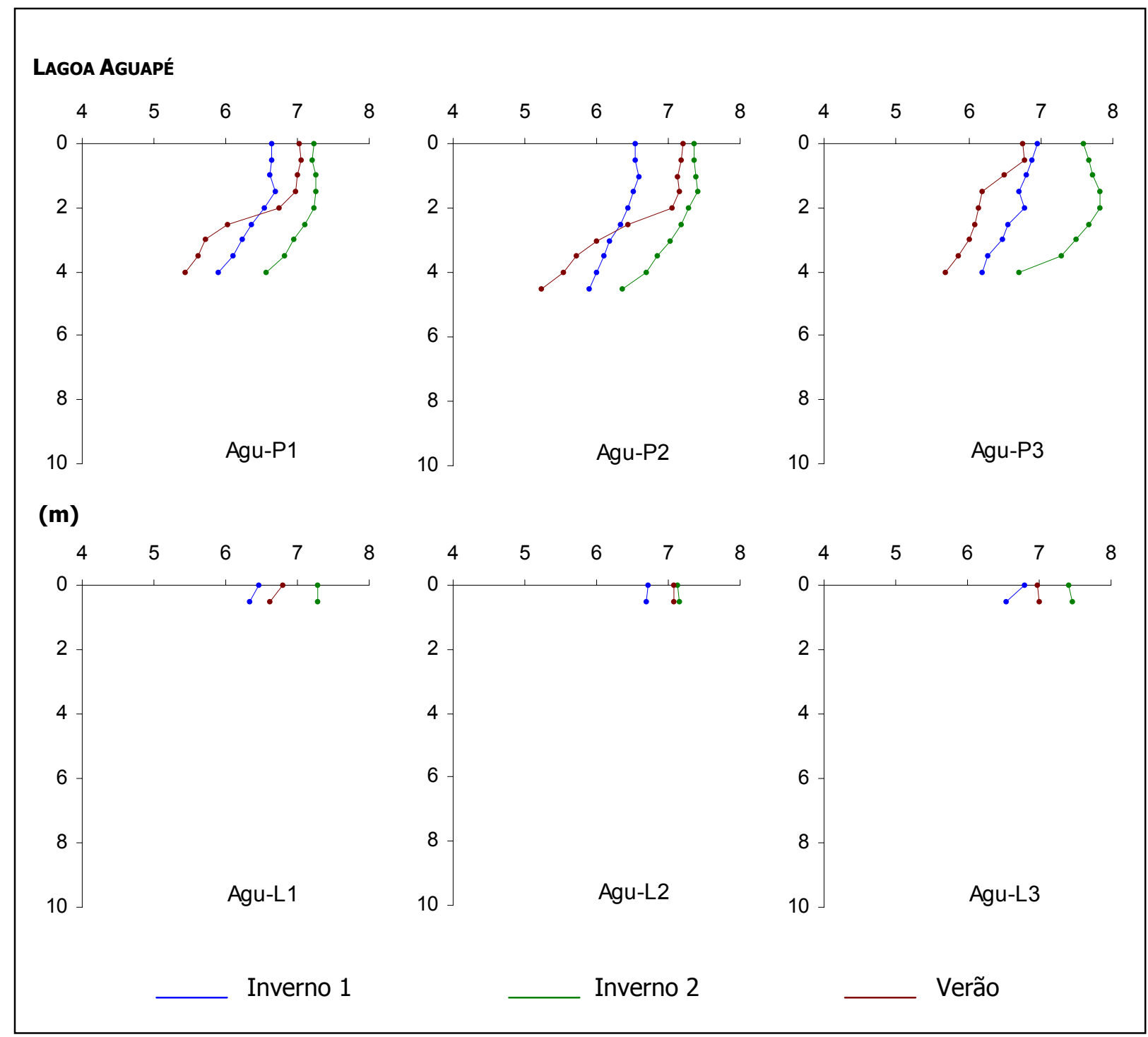

Continuação da Figura 24. Perfis de pH da água dos pontos de amostragem das cinco lagoas, para os três períodos estudados. 


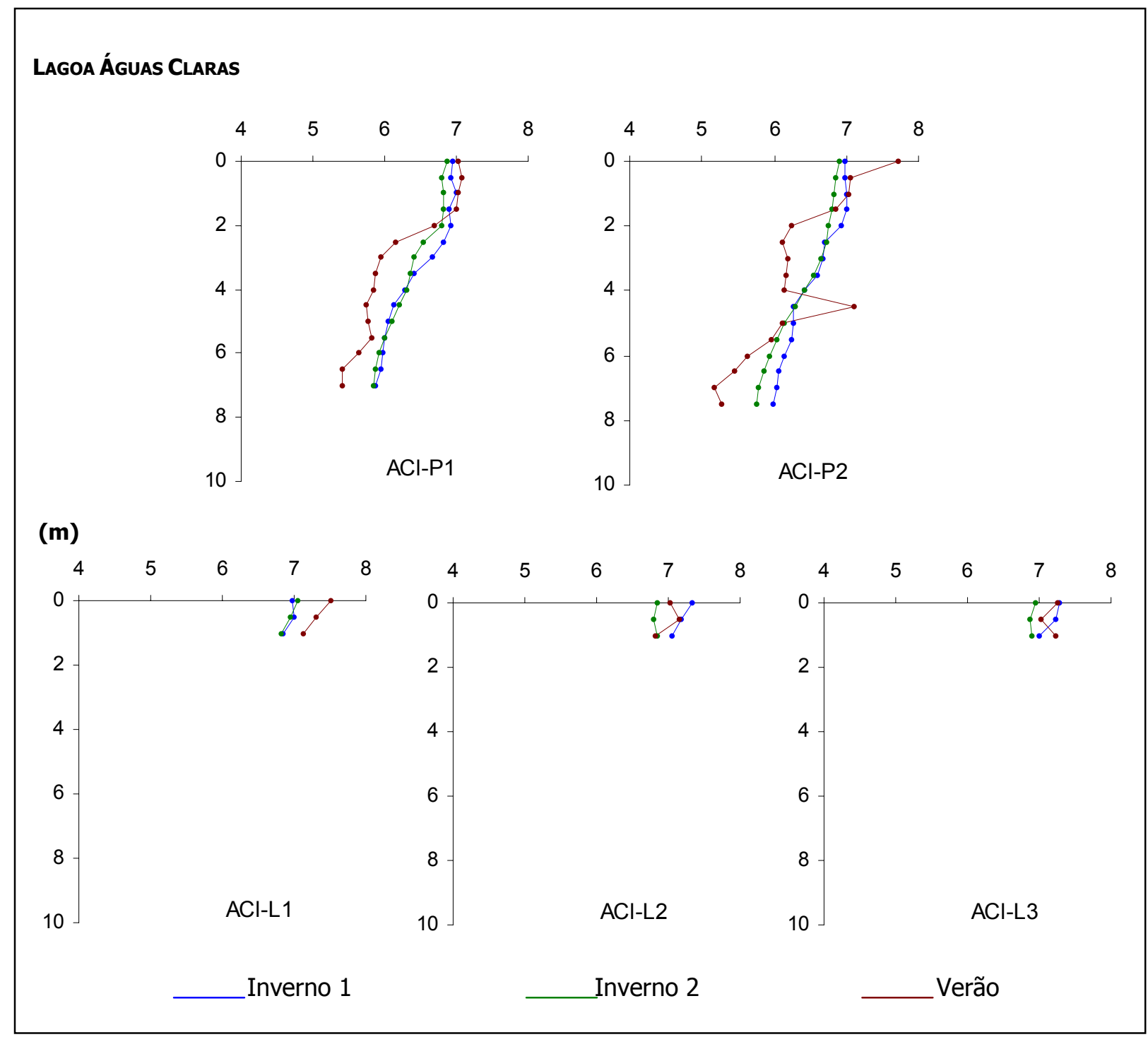

Continuação da Figura 24. Perfis de pH da água dos pontos de amostragem das cinco lagoas, para os três períodos estudados. 


\section{LAGOA ARIRANHA}

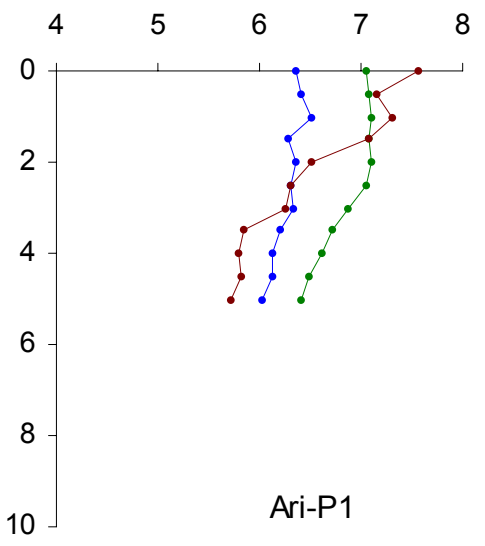

(m)

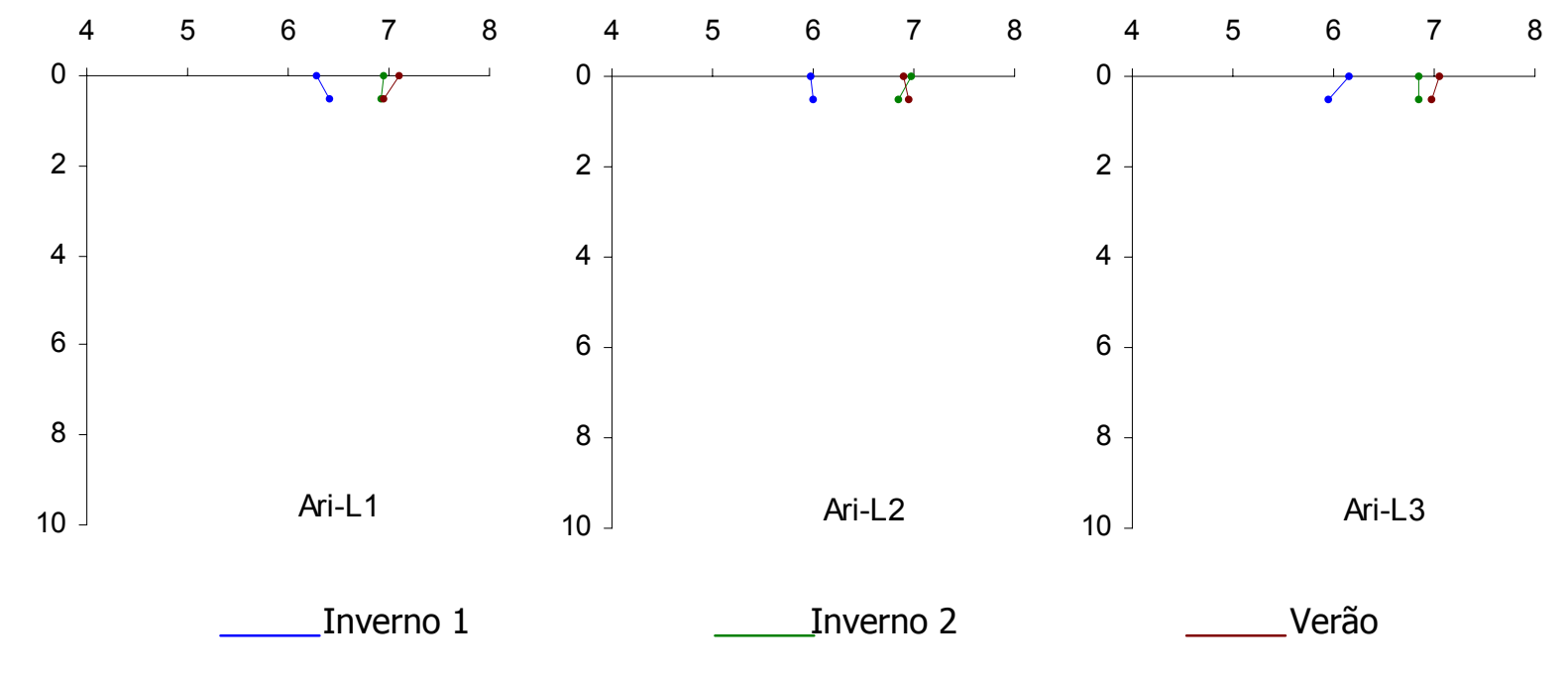

Continuação da Figura 24. Perfis de pH da água dos pontos de amostragem das cinco lagoas, para os três períodos estudados. 
LAgoa Amarela

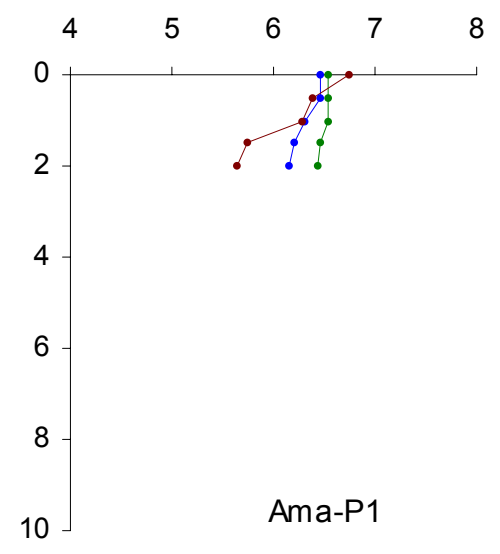

(m)

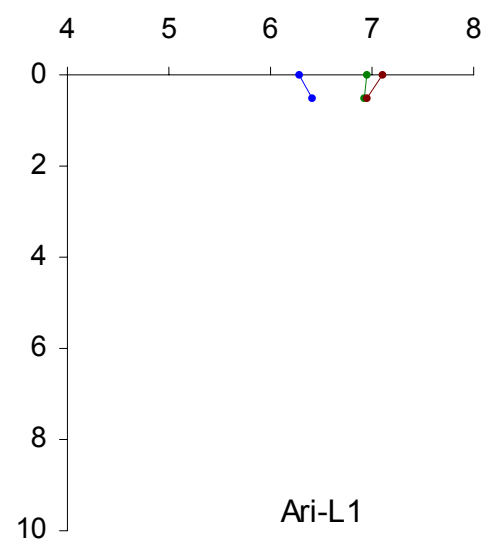

Inverno 1

Inverno 2

Verão

Continuação da Figura 24. Perfis de pH da água dos pontos de amostragem das cinco lagoas, para os três períodos estudados. 


\subsubsection{CONDUTIVIDADE ELÉTRICA}

Na Figura 25 estão apresentados os perfis de condutividade elétrica dos compartimentos litorâneos e limnéticos das lagoas estudadas nos três períodos amostrados.

De maneira geral, puderam-se verificar valores semelhantes de condutividade elétrica da água entre as profundidades e entre os compartimento limnético e litorâneos dentro de cada lagoa, para os três períodos de amostragem. A exceção a este padrão foi feita pelas maiores profundidades dos pontos limnéticos das lagoas Carioca e Amarela no período de verão, quando os valores aumentaram significativamente em relação à superfície.

Nos dois períodos de inverno, na lagoa Carioca, os valores desta variável mantiveram-se em torno de $28 \mu \mathrm{S} / \mathrm{cm}$ em todas as profundidades dos pontos amostrados. Já no verão, os valores encontrados foram menores ( $23 \mu \mathrm{S} / \mathrm{cm})$. No ponto limético desta lagoa, os valores de condutividade chegaram a atingir $21 \mu \mathrm{S} / \mathrm{cm}$ nas profundidades de 5,0 e 5,5 metros, sendo os menores encontrados para todo o estudo. A partir dos 6,0 metros, no ponto limnético, os valores aumentaram de forma expressiva até atingir um máximo de $104 \mu \mathrm{S} / \mathrm{cm}$ no fundo.

A lagoa Aguapé caracterizou-se por apresentar valores de condutividade próximos a $39 \mu \mathrm{S} / \mathrm{cm}$ em todas as profundidades dos pontos de amostragem, não havendo diferenças expressivas entre os períodos analisados.

Já na lagoa Águas Claras, observou-se uma diferença de cerca de $6 \mu \mathrm{S} / \mathrm{cm}$ entre os períodos de inverno e o de verão. Nos invernos 1 e 2, os valores estiveram em torno de 40 e $41 \mu \mathrm{S} / \mathrm{cm}$, respectivamente. No verão, os valores encontrados foram menores, estando próximos dos $34 \mu \mathrm{S} / \mathrm{cm}$, excluindo-se as profundidades finais dos pontos limnéticos, quando os valores aumentaram.

Para ambos os compartimentos limnéticos e litorâneos da lagoa Ariranha observaram-se valores semelhantes de condutividade dentro de cada período. Nos períodos de inverno 1 e 2, esta lagoa ficou caracterizada com valores de condutividade entre 26 e $27 \mu \mathrm{S} / \mathrm{cm}$. Já no Verão, os valores diminuíram para cerca de $23 \mu \mathrm{S} / \mathrm{cm}$ em todos os pontos amostrados.

A caracterização geral da lagoa Amarela, revelou ser esta a lagoa na qual foram registrados os maiores valores para a condutividade elétrica, em torno de $67 \mu \mathrm{S} / \mathrm{cm}$ nos períodos de inverno 1 e 2 , e $61 \mu \mathrm{S} / \mathrm{cm}$ no verão. Na última profundidade do ponto limnético desta lagoa, no verão, o valor da condutividade aumentou para $109 \mu \mathrm{S} / \mathrm{cm}$, 
sendo o maior encontrado, nos três períodos amostrados e comparando-se as cinco lagoas.

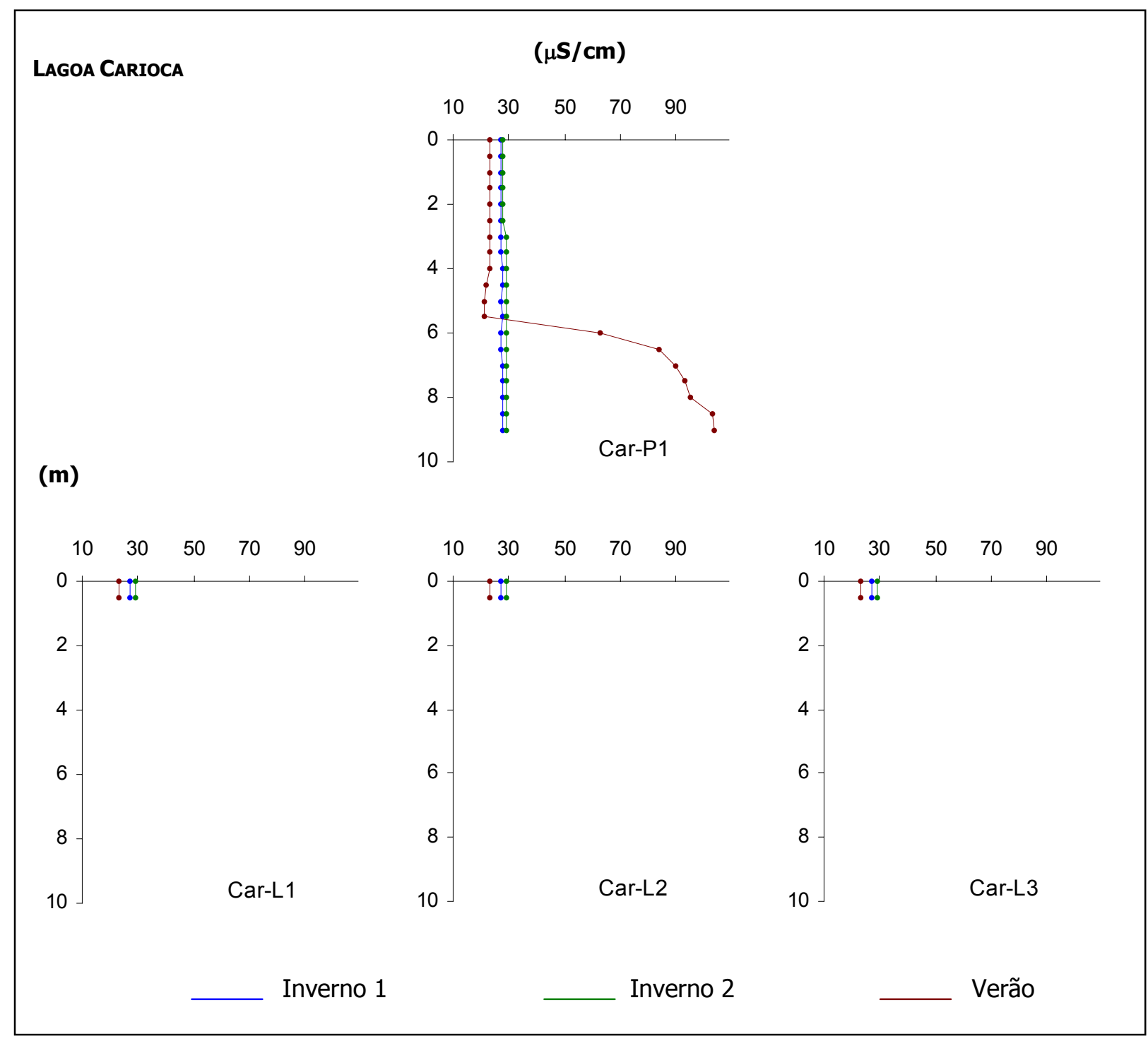

Figura 25. Perfis da condutividade elétrica da água dos pontos de amostragem das cinco lagoas, para os três períodos estudados. 


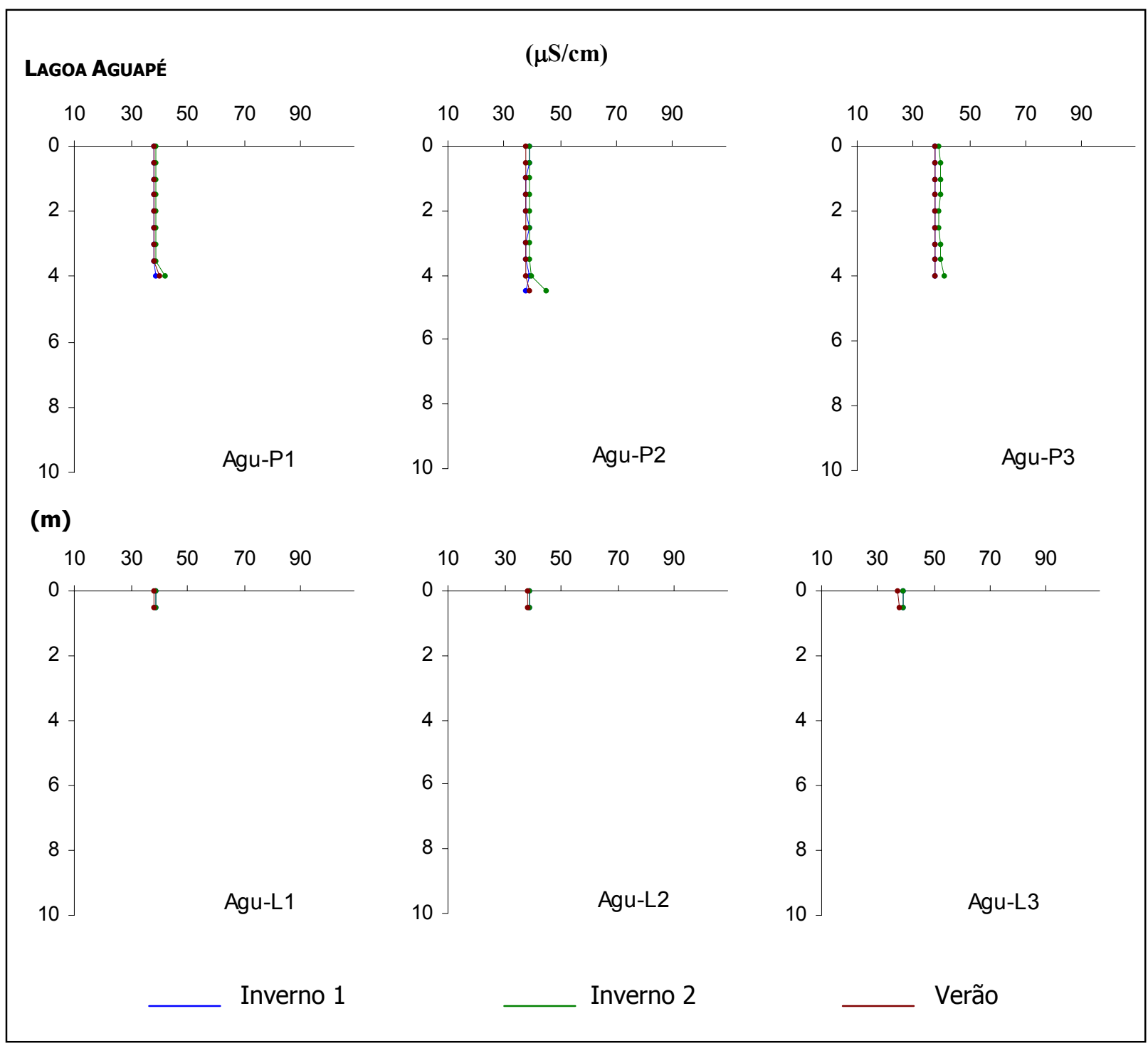

Continuação da Figura 25. Perfis da condutividade elétrica da água dos pontos de amostragem das cinco lagoas, para os três períodos estudados. 


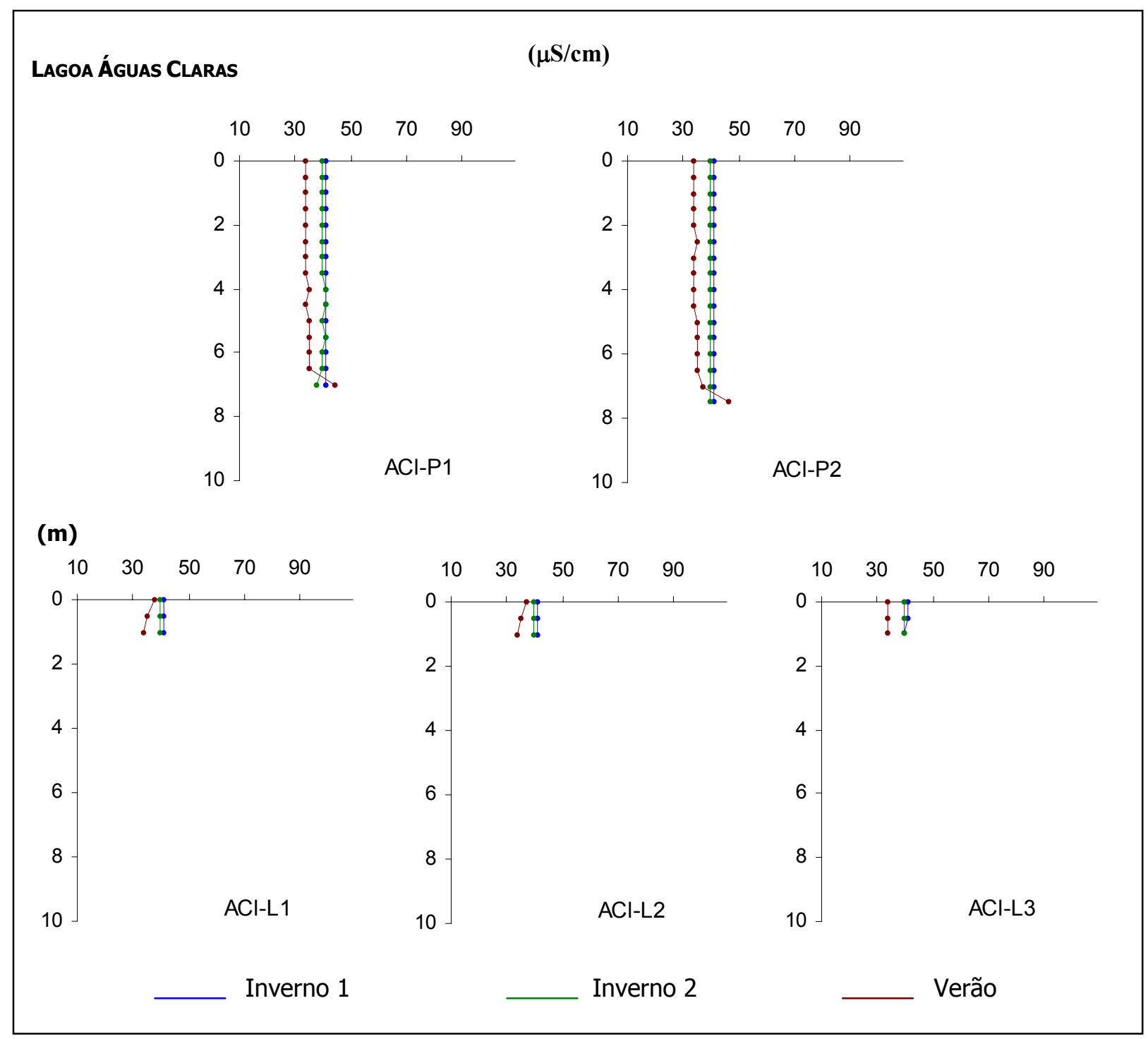

Continuação da Figura 25. Perfis da condutividade elétrica da água dos pontos de amostragem das cinco lagoas, para os três períodos estudados. 


\section{Lagoa Ariranha}

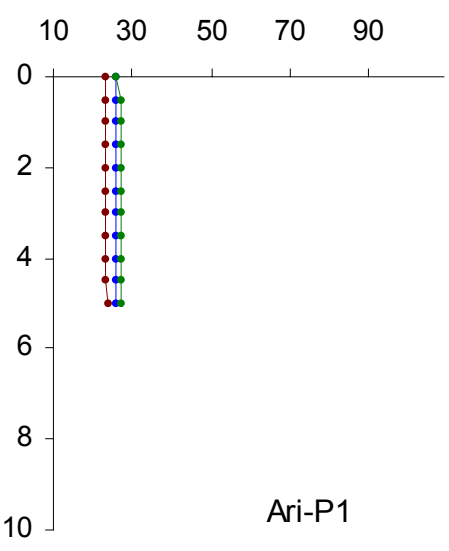

(m)

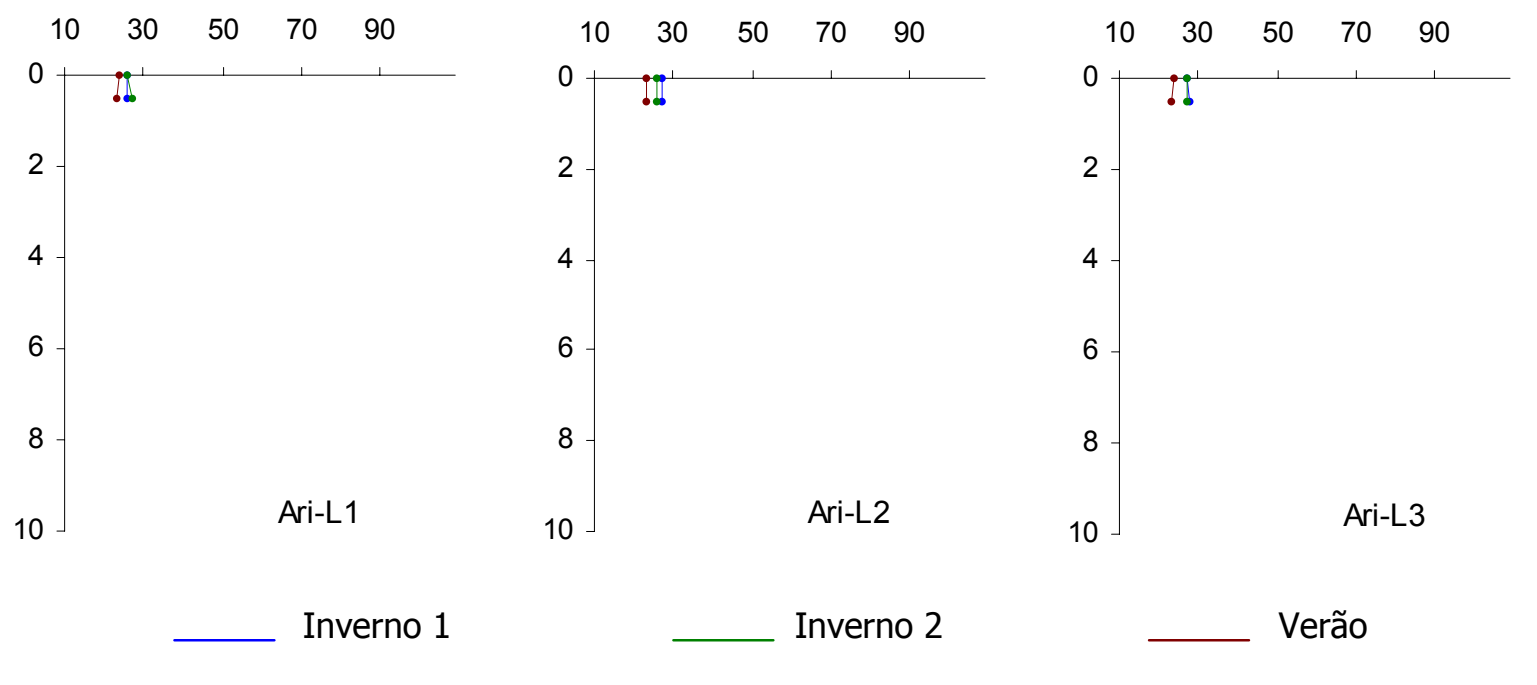

Continuação da Figura 25. Perfis da condutividade elétrica da água dos pontos de amostragem das cinco lagoas, para os três períodos estudados. 


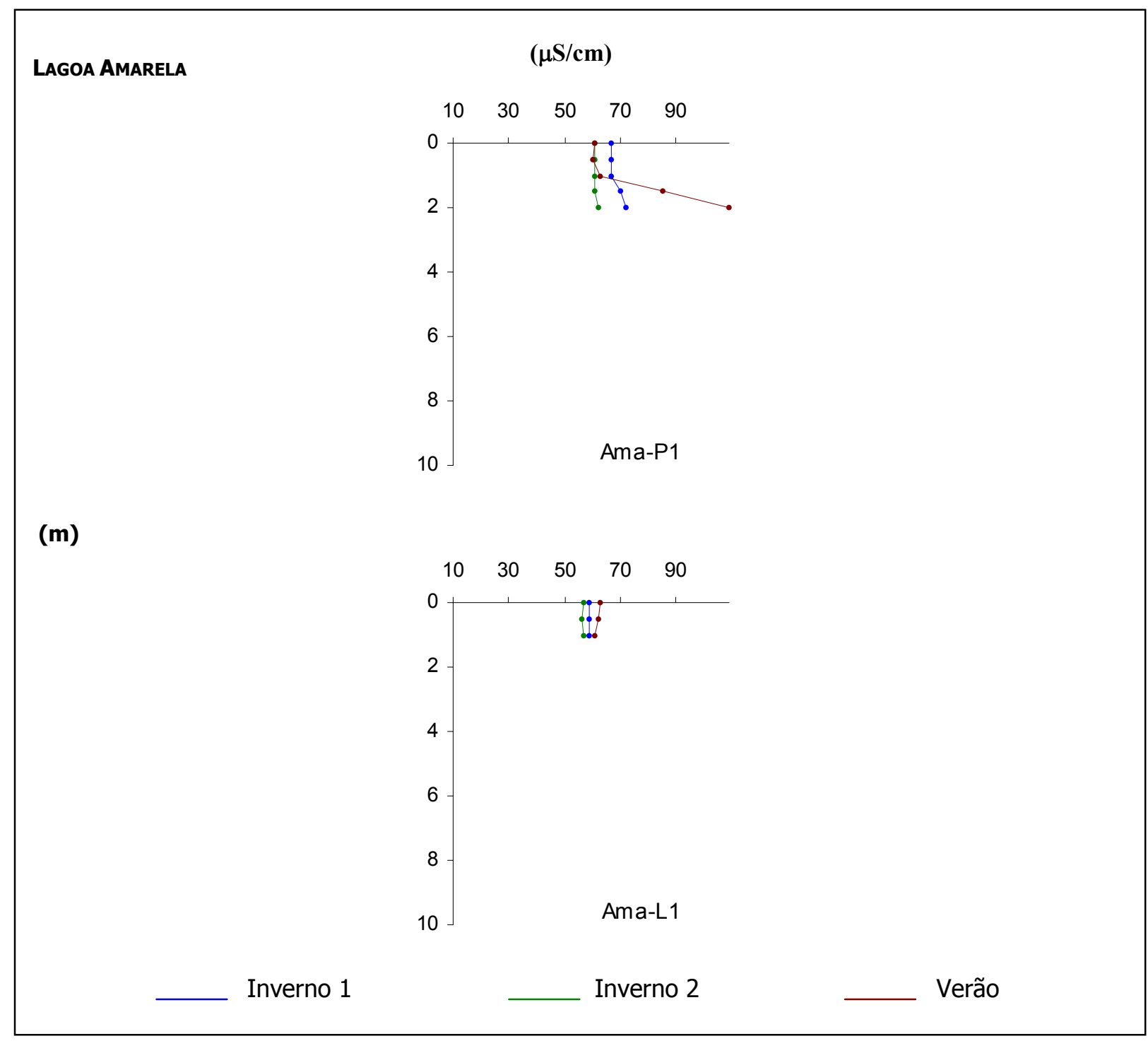

Continuação da Figura 25. Perfis da condutividade elétrica da água dos pontos de amostragem das cinco lagoas, para os três períodos estudados. 


\subsubsection{NUTRIENTES DISSOLVIDOS}

- NITRITO

Na Figura 26 estão apresentados os valores das concentrações de nitrito para os pontos de amostragem das lagoas, nos três períodos estudados.

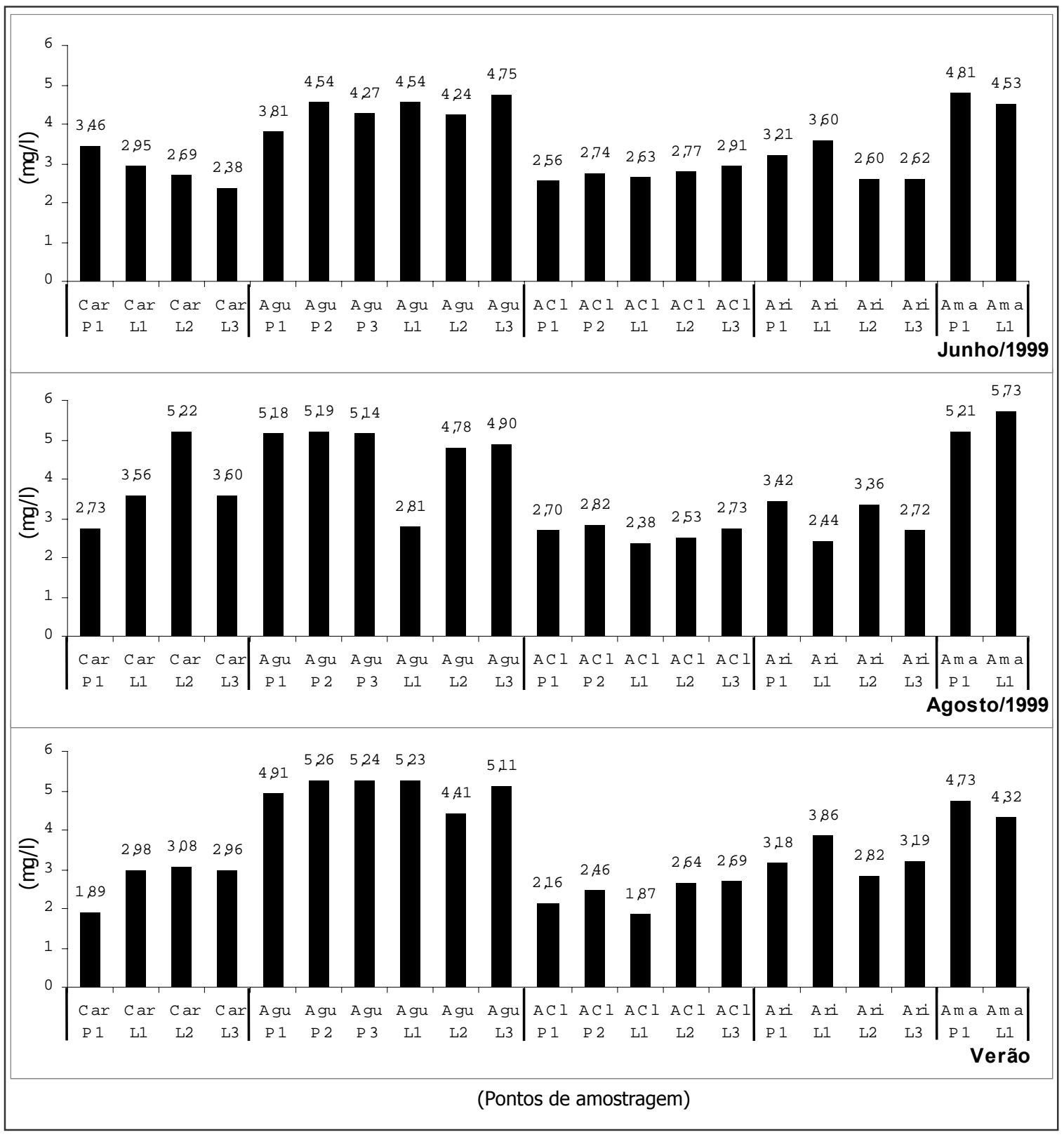

Figura 26. Concentração de nitrito nos pontos de amostragem das cinco lagoas, para os três períodos estudados.

De maneira geral, não foi possível verificar diferenças entre os valores da concentração de nitrito nos compartimentos limnéticos e litorâneos, e nos grupos de 
lagoas estudadas, nos três períodos de análise. As concentrações de nitrito, no geral, foram sempre baixas, não ultrapassando $3 \mathrm{mg} / \mathrm{l}$.

No ponto limnético da lagoa Carioca, observou-se um decréscimo nos valores de nitrito entre os períodos de inverno para o verão. Os valores encontrados para os pontos litorâneos desta lagoa mantiveram-se próximos entre os períodos amostrados. O maior valor para a concentração de nitrito foi de $2,80 \mathrm{mg} / \mathrm{L}$ (no ponto Car-L2, no inverno 1 , e o menor foi de $0,70 \mathrm{mg} / \mathrm{L}$ no ponto Car-L1, no verão.

$\mathrm{Na}$ lagoa Aguapé, em geral, puderam-se verificar valores mais altos na concentração de nitrito no verão e menores no inverno 2 , em todos os pontos de amostragem. No período de inverno 1 , os valores variaram entre 1,66 e 0,75 mg/L no compartimento limnético, e entre 0,93 e 0,98 mg/L no litorâneo. No inverno 2, quando foram encontrados os menores valores para esta variável dentre todos os pontos de amostragem, de todas as lagoas, os pontos limnéticos da lagoa Aguapé ficaram caracterizados com valores entre 0,24 e 0,41 mg/L, e os valores obtidos para os pontos litorâneos variaram entre 0,24 e 0,87 mg/L. Os valores encontrados para o compartimento limnético, no verão, estiveram entre 1,58 e $2,57 \mathrm{mg} / \mathrm{L}$, sendo este último o maior encontrado nesta lagoa, entre todos os períodos. O compartimento litorâneo caracterizou-se por valores da concentração de nitrito entre 2,46 e 1,66 mg/L no verão.

Na lagoa Águas Claras, pôde-se verificar um aumento nos valores desta variável entre os períodos de inverno e verão. O menor valor encontrado, entre os períodos de inverno, foi de $0,41 \mathrm{mg} / \mathrm{L}$ no ponto $\mathrm{ACl}-\mathrm{P} 1$ no inverno 2 , e o maior foi de $1,44 \mathrm{mg} / \mathrm{L}$ nos pontos litorâneos ACl-L1 e ACl-L3 no inverno 1 . No verão, os valores variaram entre $1,86 \mathrm{mg} / \mathrm{L}$ (maior valor encontrado para a lagoa) no ponto limnético ACl-P1 e 1,01 mg/L no ponto ACl-P2, também limnético.

O maior valor da concentração de nitrito encontrado na lagoa Ariranha foi de 2,80 mg/L, no ponto litorâneo Ari-L1 no inverno 2, que juntamente com o encontrado no ponto Car-L2 da lagoa Carioca no inverno 1 , consistem nos maiores valores encontrados para todo o estudo. Já o menor valor para esta variável foi encontrado nos pontos litorâneos Ari-L2 e Ari-L3, no período de inverno 2, com 0,58 mg/L.

No período de inverno 2 e Verão foram encontrados valores altos da concentração de nitrito, em comparação com os do inverno 1. Nesta lagoa, os valores variaram de um máximo de 2,63 mg/L no ponto litorâneo Ama-L1 no inverno 2, para 0 mínimo de 0,61 mg/L no ponto limnético Ama-P1, no período de inverno 1. 
- Nitrato

Os valores das concentrações de nitrato nos pontos de amostragem estão apresentados na Figura 27.

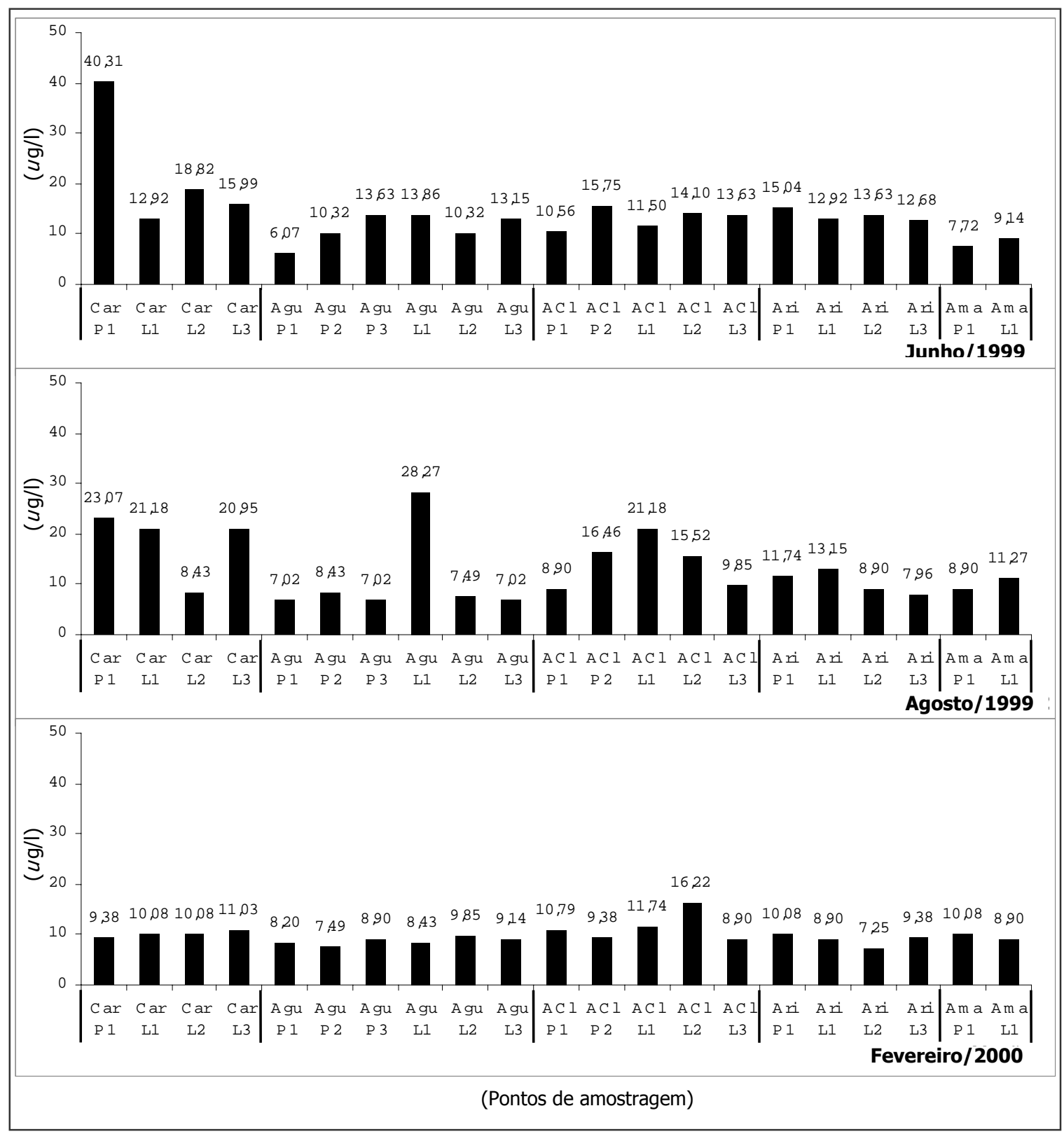

Figura 27. Concentrações de nitrato nos pontos de amostragem das cinco lagoas, para os três períodos estudados.

De maneira geral, não foi possível identificar diferenças nos valores de nitrato entre os compartimentos limnéticos e litorâneos das lagoas estudadas, em todos os períodos amostrados. Em relação à sazonalidade, verificou-se uma maior 
homogeneidade nestes resultados entre os pontos de amostragens de todas as lagoas dentro do período de verão.

No inverno 1, no compartimento limnético da lagoa Carioca, representado pelo ponto Car-P1, foi encontrado o maior valor para a concentração desta variável em todo o estudo, com 40,31 $\mu \mathrm{g} / \mathrm{L}$. Este valor foi bem superior aqueles observados para os pontos litorâneos da mesma lagoa, no mesmo período, sendo o ponto litorâneo Car-L1 o que apresentou o menor valor, de $12,92 \mu \mathrm{g} / \mathrm{L}$.

No inverno 2, os valores de nitrato estiveram próximos entre os pontos da lagoa Carioca, com exceção feita ao ponto Car-L2, onde foi encontrado o menor valor de $8,43 \mu \mathrm{g} / \mathrm{L}$. O maior valor neste período foi de $23,07 \mu \mathrm{g} / \mathrm{L}$, verificado no ponto limnético Car-P1.

Os valores da concentração deste nutriente estiveram bastante próximos no período de verão, entre os pontos da lagoa Carioca, e variaram de um máximo de $11,03 \mu \mathrm{g} / \mathrm{L}$ no ponto litorâneo Car-L3, e um mínimo de 9,38 $\mu \mathrm{g} / \mathrm{L}$ no ponto limnético Car-P1.

Em cada período de amostragem, os valores estiveram próximos entre os compartimentos limnéticos e litorâneos da lagoa Aguapé. No inverno 1 foi encontrado o menor valor para todo o período de estudo, com 6,07 $\mu \mathrm{g} / \mathrm{L}$ no ponto limnético AguP1. Neste mesmo período o maior valor encontrado foi de $13,86 \mu \mathrm{g} / \mathrm{L}$, no ponto litorâneo Agu-L1.

Ainda em relação à lagoa Aguapé, pode-se verificar um aumento considerável na concentração de nitrato no ponto litorâneo Agu-L1 no inverno 2, com o valor de $28,27 \mu \mathrm{g} / \mathrm{L}$. Para os demais pontos neste período foram observados valores bastante próximos, com um mínimo de 7,02 $\mu \mathrm{g} / \mathrm{L}$, encontrado em três pontos de amostragem: Agu-P1, Agu-P3 e Agu-L3.

No verão, o espectro de variação nos valores desta variável foi o menor verificado dentre todos os períodos de amostragem, o qual variou de um máximo de $9,85 \mu \mathrm{g} / \mathrm{L}$ no ponto litorâneo Agu-L2, até o mínimo de $7,49 \mu \mathrm{g} / \mathrm{L}$ no ponto limnético Agu-P2.

Na lagoa Águas Claras os valores encontrados para as concentrações de nitrato estiveram próximos entre os pontos de amostragem, e entre os períodos analisados. 0 maior valor encontrado foi de $21,18 \mu \mathrm{g} / \mathrm{L}$ no ponto litorâneo $\mathrm{ACl}-\mathrm{L} 1$ no inverno 2 , e o menor foi de $8,90 \mu \mathrm{g} / \mathrm{L}$ no ponto limnético $\mathrm{ACl}-\mathrm{P} 1$, no mesmo período.

Nos três períodos de amostragem, foi possível verificar uma grande homogeneidade nos valores desta variável entre os pontos de amostragem da lagoa 
Ariranha. O espectro de variação destes valores, entre os três períodos, variou de $15,04 \mu \mathrm{g} / \mathrm{L}$ encontrado no ponto limnético Ari-P1 no inverno 1 , para $7,25 \mu \mathrm{g} / \mathrm{L}$ no ponto litorâneo Ari-L2 no verão.

Da mesma maneira que o observado para a lagoa Ariranha, na lagoa Amarela a variação dos resultados referentes às concentrações de nitrato foram pequenas, com um máximo de $11,27 \mu \mathrm{g} / \mathrm{L}$ no ponto litorâneo Ama-L1 no período de inverno 2, e um mínimo de 7,72 $\mu \mathrm{g} / \mathrm{L}$ no ponto limnético Ama-P1, no inverno 1. 
- AMÔNIO

A Figura 28 apresenta os valores das concentrações do íon amônio encontradas nos pontos de amostragem das lagoas estudadas, para os três períodos analisados.

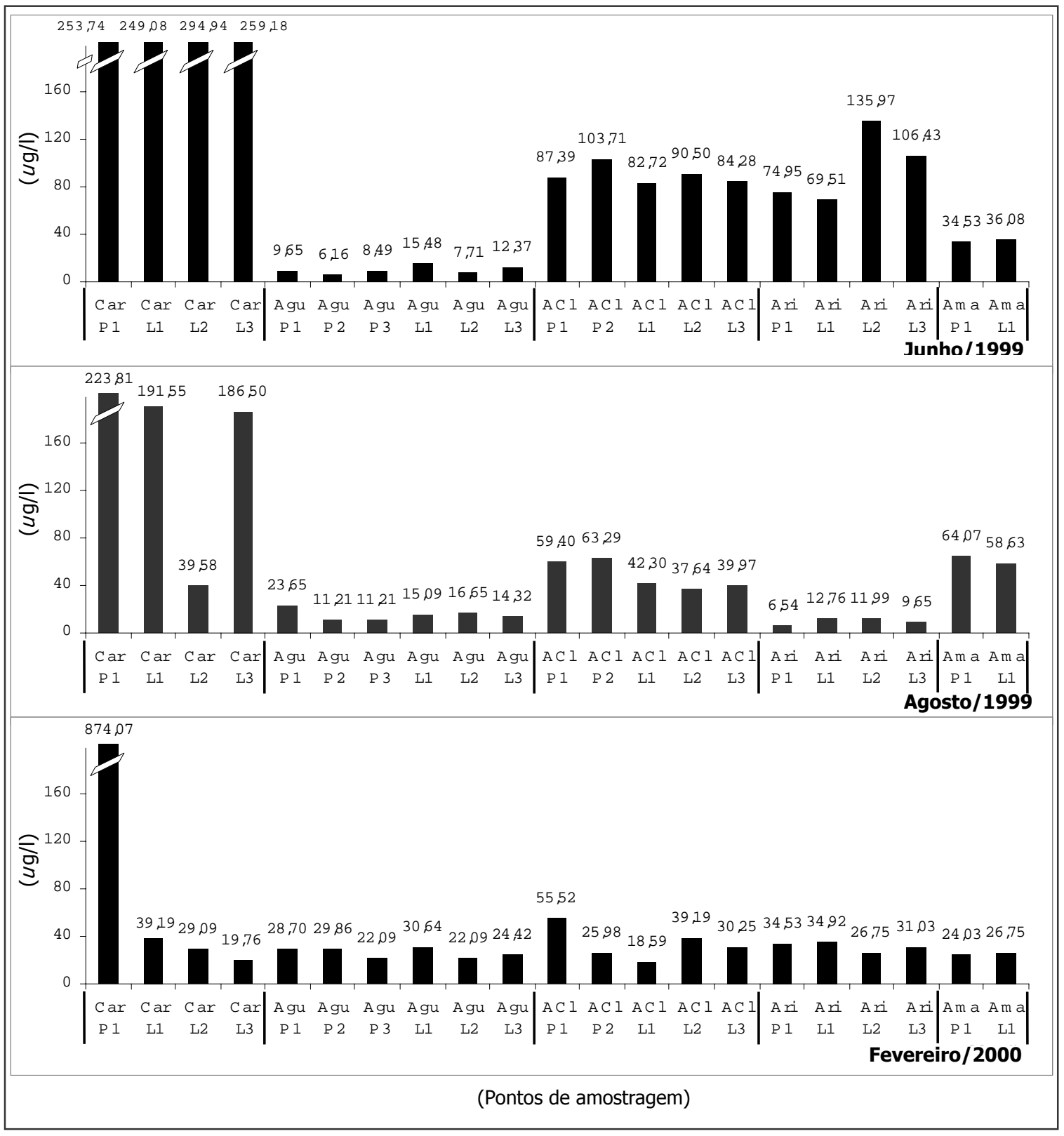

Figura 28. Concentração de amônio nos pontos de amostragens das cinco lagoas, para os três períodos estudados.

De maneira geral, pôde-se verificar maiores concentrações de amônio nos pontos da lagoa Carioca em relação aos demais pontos de amostragem. No período de inverno 1 , em todos os pontos da lagoa Carioca foram observados valores bastante 
acima daqueles das demais lagoas, sendo verificado um máximo de 294,94 $\mu \mathrm{g} / \mathrm{L}$ no

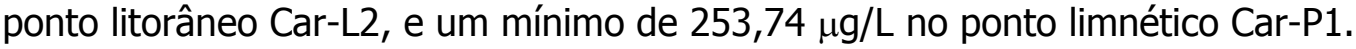

No inverno 2, este padrão também foi observado, com exceção ao ponto Car$\mathrm{L} 2$, onde foi encontrado o valor de $39,58 \mu \mathrm{g} / \mathrm{L}$, semelhante aos encontrados nas demais lagoas. O maior valor encontrado neste período foi de $223,81 \mu \mathrm{g} / \mathrm{L}$, no ponto limnético Car-P1. Vale ressaltar que nos períodos de inverno, em ambos os compartimentos litorâneos e limnéticos da lagoa Carioca foram observados valores muito superiores aos das demais lagoas, com apenas uma exceção já reportada acima.

Já no verão, apenas o ponto limnético Car-L1 da lagoa Carioca ficou caracterizado com um valor desta variável acima dos demais pontos amostrados. Neste ponto, foi encontrado o maior valor da concentração de amônio para todo o estudo, com $874,07 \mu \mathrm{g} / \mathrm{L}$. Nos pontos litorâneos da lagoa Carioca foram encontrados valores próximos aqueles das demais lagoas, com um mínimo de 19,76 $\mu \mathrm{g} / \mathrm{L}$ no ponto Car-L3. Vale ressaltar, que em todos os demais pontos amostrados das demais lagoas foram encontrados valores muito menores que este encontrado no ponto limnético da lagoa Carioca.

Na lagoa Aguapé foram encontrados os menores valores para a concentração de amônio dentre todas as lagoas no período de inverno 1 , variando de um máximo de $15,48 \mu \mathrm{g} / \mathrm{L}$ no ponto litorâneo Agu-L1, para um mínimo de $6,16 \mu \mathrm{g} / \mathrm{L}$ no ponto limnético Agu-P2. Este último valor foi o menor encontrado para todo o estudo.

Esta tendência também foi observada no período de inverno 2 na lagoa Aguapé, assim como na Ariranha. Neste período, os valores na lagoa Aguapé variaram de $23,65 \mu \mathrm{g} / \mathrm{L}$ no ponto limnético Agu-P1 para 11,21 $\mu \mathrm{g} / \mathrm{L}$ nos pontos Agu-P2 e AguP3, também limnéticos.

No período de verão, os valores verificados nos pontos da lagoa Aguapé foram próximos aos das demais lagoas, com exceção já feita ao ponto limnético Car-P1 da lagoa Carioca. Neste período, os valores variaram de $30,64 \mu \mathrm{g} / \mathrm{L}$ no ponto litorâneo Agu-L1, para 22,09 $\mu \mathrm{g} / \mathrm{L}$ no ponto limnético Agu-P3 e litotrâneo Agu-L2.

De maneira geral, os valores desta variável encontrados para os pontos da lagoa Águas Claras mostraram um decréscimo nas concentrações de amônio do período de inverno 1 para o verão. Não foi observada uma diferença entre os compartimentos litorâneo e limnético em cada período amostrado. No primeiro período de amostragem, inverno 1 , estes valores variaram de $103,71 \mu \mathrm{g} / \mathrm{L}$ no ponto limnético ACl-P2 para $82,72 \mu \mathrm{g} / \mathrm{L}$ no ponto litorâneo ACl-L1. No segundo período de inverno, a variação entre os valores foi menor, estando entre $63,29 \mu \mathrm{g} / \mathrm{L}$ no ponto limnético ACl- 
P2 e 37,64 $\mu \mathrm{g} / \mathrm{L}$ no ponto litorâneo $\mathrm{ACl}-\mathrm{L} 2$. Já no verão, quando foram encontrados os menores valores entre os três períodos, os valores variaram de $55,52 \mu \mathrm{g} / \mathrm{L}$ no ponto limnético ACl-P1 para 18,59 $\mu \mathrm{g} / \mathrm{L}$ no ponto litorâneo ACl-L1.

Os valores desta variável encontrados na lagoa Ariranha, mostraram maiores concentrações de amônio no período de inverno 1 , e menores no inverno 2, sendo intermediários a estes os valores encontrados no verão. A maior variação entre os pontos amostrados ocorreu no período de inverno, quando os valores estiveram entre um máximo de 135,97 $\mu \mathrm{g} / \mathrm{L}$ no ponto litorâneo Ari-L2, e um mínimo de 69,51 $\mu \mathrm{g} / \mathrm{L}$ no ponto Ari-L1, também litorâneo. No inverno 2, quando foram encontrados os menores valores dentre os três períodos, a variação foi de $6,54 \mu \mathrm{g} / \mathrm{L}$ no ponto limnético Ari-P1, para $12,76 \mu \mathrm{g} / \mathrm{L}$ no ponto litorâneo Ari-L1. Já no período de verão os valores variaram de $34,53 \mu \mathrm{g} / \mathrm{L}$ no ponto limnético Ari-P1 para $26,75 \mu \mathrm{g} / \mathrm{L}$ no ponto litorâneo Ari-L2.

Pode-se dizer que os valores encontrados para os compartimentos limnético e litorâneo da lagoa Amarela em cada período de amostragem, estiveram bastante próximos. Nesta lagoa, foram observados valores maiores no período de inverno 2, atingindo $64,07 \mu \mathrm{g} / \mathrm{L}$ no ponto limnético Ama-P1; e menores valores no período de verão, sendo o menor de $24,03 \mu \mathrm{g} / \mathrm{L}$ encontrado no ponto limnético Ama-P1. 
- FOSFATO DISSOLVIDO TOTAL

Os valores das concentrações de fosfato dissolvido total das lagoas para os três períodos de amostragem estão apresentados na Figura 29.

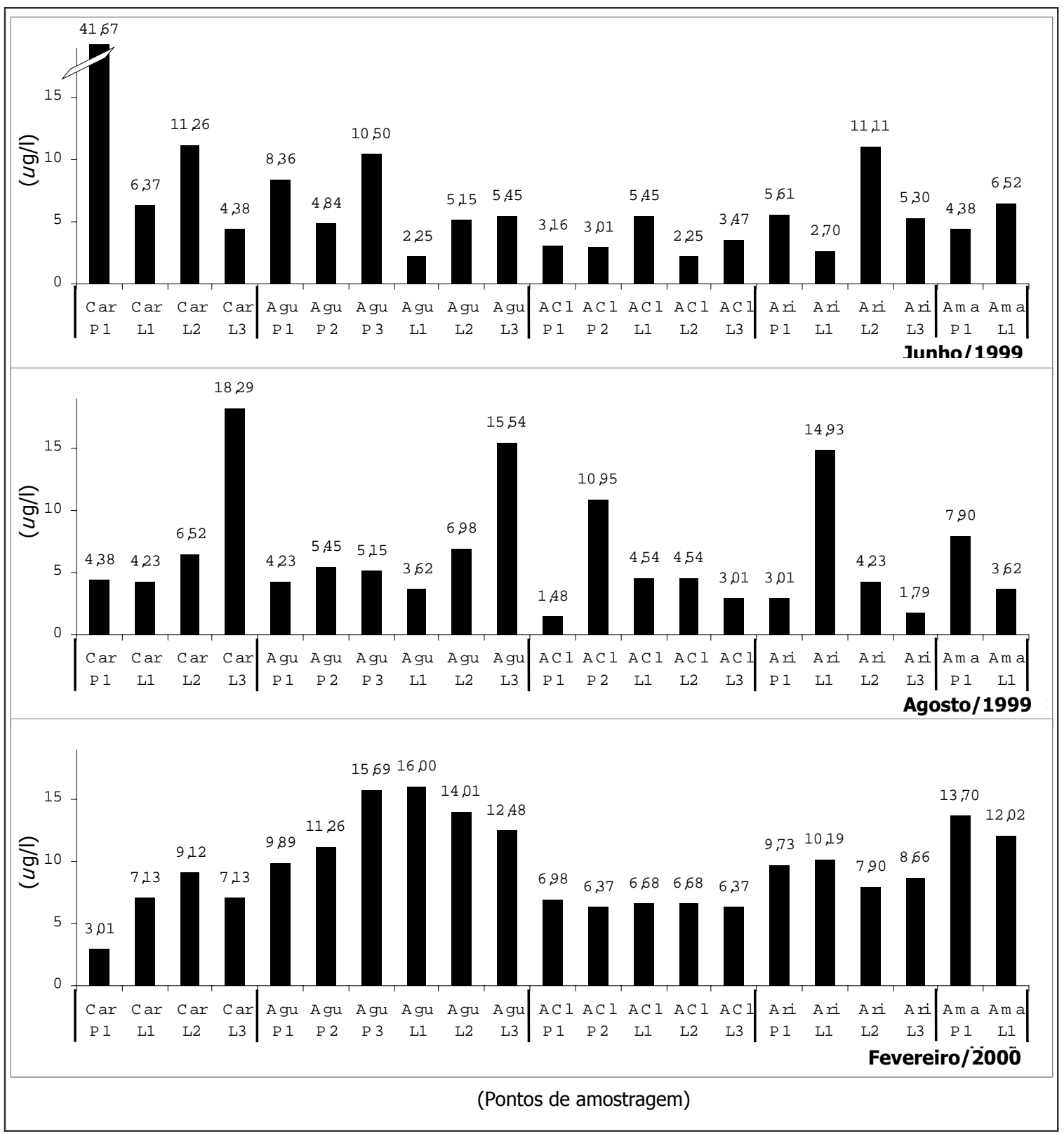

Figura 29. Concentrações de fosfato dissolvido total nos pontos de amostragem das cinco lagoas, para os três períodos estudados.

De maneira geral, não foi possível a verificação de diferenças nas concentrações de fosfato dissolvido total entre os compartimentos limnéticos e litorâneos e entre as lagoas estudadas. 
No período de inverno 1, no ponto limnético Car-P1 da lagoa Carioca foi observado o valor de $41,67 \mu \mathrm{g} / \mathrm{L}$, sendo considerado o maior para todo o estudo. $\mathrm{O}$ menor valor encontrado neste período foi de $2,25 \mu \mathrm{g} / \mathrm{L}$ no ponto litorâneo $\mathrm{ACl}-\mathrm{L} 1$ da lagoa Águas Claras. Neste período os valores encontrados para todos os pontos das cinco lagoas estudadas estiveram próximos, com exceção ao ponto Car-P1, já citado. Não houve portanto, diferenças expressivas entre as lagoas no período de inverno 1 , em função das concentrações de fosfato dissolvido total.

No inverno 2, foram encontrados valores relativamente altos nas concentrações deste nutriente no ponto litorâneo Car-L3 da lagoa Carioca $(18,29 \mu \mathrm{g} / \mathrm{L})$, no ponto litorâneo Agu-L3 da lagoa Aguapé $(15,54 \mu \mathrm{g} / \mathrm{L})$ e no ponto litorâneo Ari-L1 da lagoa Ariranha $(14,93)$. Os demais pontos de amostragem neste período apresentaram valores próximos, sendo os menores encontrados no ponto limnético ACl-P1 da lagoa Águas Claras $(1,48 \mu \mathrm{g} / \mathrm{L})$ e litorâneo Ari-L3 da lagoa Ariranha $(1,79 \mu \mathrm{g} / \mathrm{L})$.

No geral, os valores na concentração de fosfato dissolvido total foram próximos nos períodos de inverno 1 e 2, e aumentaram de forma expressiva no período de Verão. Neste período, os maiores valores foram observados nos ponto pelágico Agu-P3 $(15,69 \mu \mathrm{g} / \mathrm{L})$ e litorâneos Agu-L1 $(16,00 \mu \mathrm{g} / \mathrm{L})$, Agu-L2 (14,01 $\mu \mathrm{g} / \mathrm{L})$ e Agu-L3 (12,48 $\mu \mathrm{g} / \mathrm{L})$ da lagoa Aguapé; e nos dois pontos da lagoa Amarela: Ama-P1 (13,70 $\mu \mathrm{g} / \mathrm{L})$ e Ama-L1 $(12,02 \mu \mathrm{g} / \mathrm{L})$. O menor valor neste período foi verificado no ponto limnético Car-P1 da lagoa Carioca. 
- FOSFATO INORGÂNICO

A Figura 30 apresenta os valores da concentração de fosfato inorgânico nos pontos de amostragem das lagoas, nos três períodos de estudo.

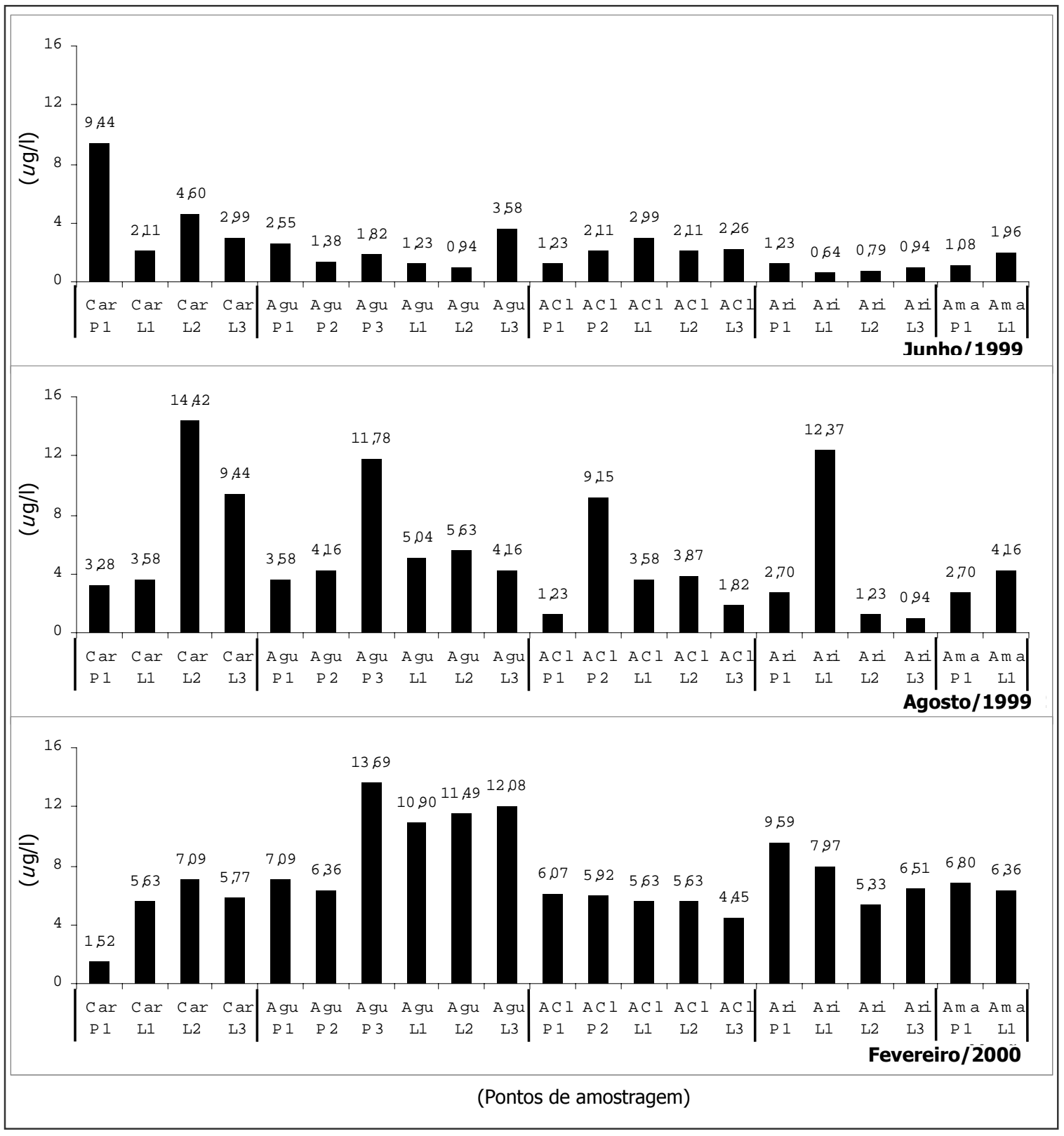

Figura 30. Concentrações de fostafo inorgânico nos pontos de amostragem das cinco lagoas, para os três períodos estudados. 
De maneira geral, foi possível observar um aumento nos valores de fosfato inorgânico do período de inverno 1 para o verão.

No período de inverno 1, com exceção ao ponto limnético Car-P1 da lagoa Carioca no qual foi encontrado o maior valor de período $(9,44 \mu \mathrm{g} / \mathrm{L})$, nos demais pontos de amostragem da lagoas estudadas foi verificada uma certa homogeneidade em relação às concentrações de fosfato inorgânico, os quais variaram de $0,64 \mu \mathrm{g} / \mathrm{L}$ no ponto litorâneo Ari-L1 da lagoa Ariranha para 4,60 $\mu \mathrm{g} / \mathrm{L}$ no ponto litorâneo Car-L2 da lagoa Carioca, com exceção já feita ao ponto limnético da lagoa Carioca.

No inverno 2, observaram-se ao longo dos pontos de amostragens das lagoas valores mais heterogêneos para as concentrações de fosfato inorgânico. Foram observados valores relativamente altos nos pontos Car-L2 (14,42 $\mu \mathrm{g} / \mathrm{L})$, Agu-P3 (11,78 $\mu \mathrm{g} / \mathrm{L})$, ACl-P2 $(9,15 \mu \mathrm{g} / \mathrm{L})$ e Ari-L1 (12,37 $\mu \mathrm{g} / \mathrm{L})$. Neste período o menor valor encontrado foi de $0,94 \mu \mathrm{g} / \mathrm{L}$ no ponto litorâneo da lagoa Ariranha Ari-L3.

Já no verão, os valores encontrados para os pontos de amostragem das lagoas também estiveram próximos, com exceção aos pontos Agu-P3, Agu-L1, Agu-L2, AguL3, Ari-P1 e Ari-L1 onde foram encontrados valores relativamente altos, e ao ponto Car-P1 onde foi verificado o menor valor $(1,52 \mu \mathrm{g} / \mathrm{L})$ dentre todos os pontos no período de verão. O maior valor encontrado foi de $13,69 \mu \mathrm{g} / \mathrm{L}$ no ponto limnético AguP3, da lagoa Aguapé. 
- Silicato ReATIVO

Os valores da concentração de silicato nos pontos de amostragem estão apresentados na Figura 31.

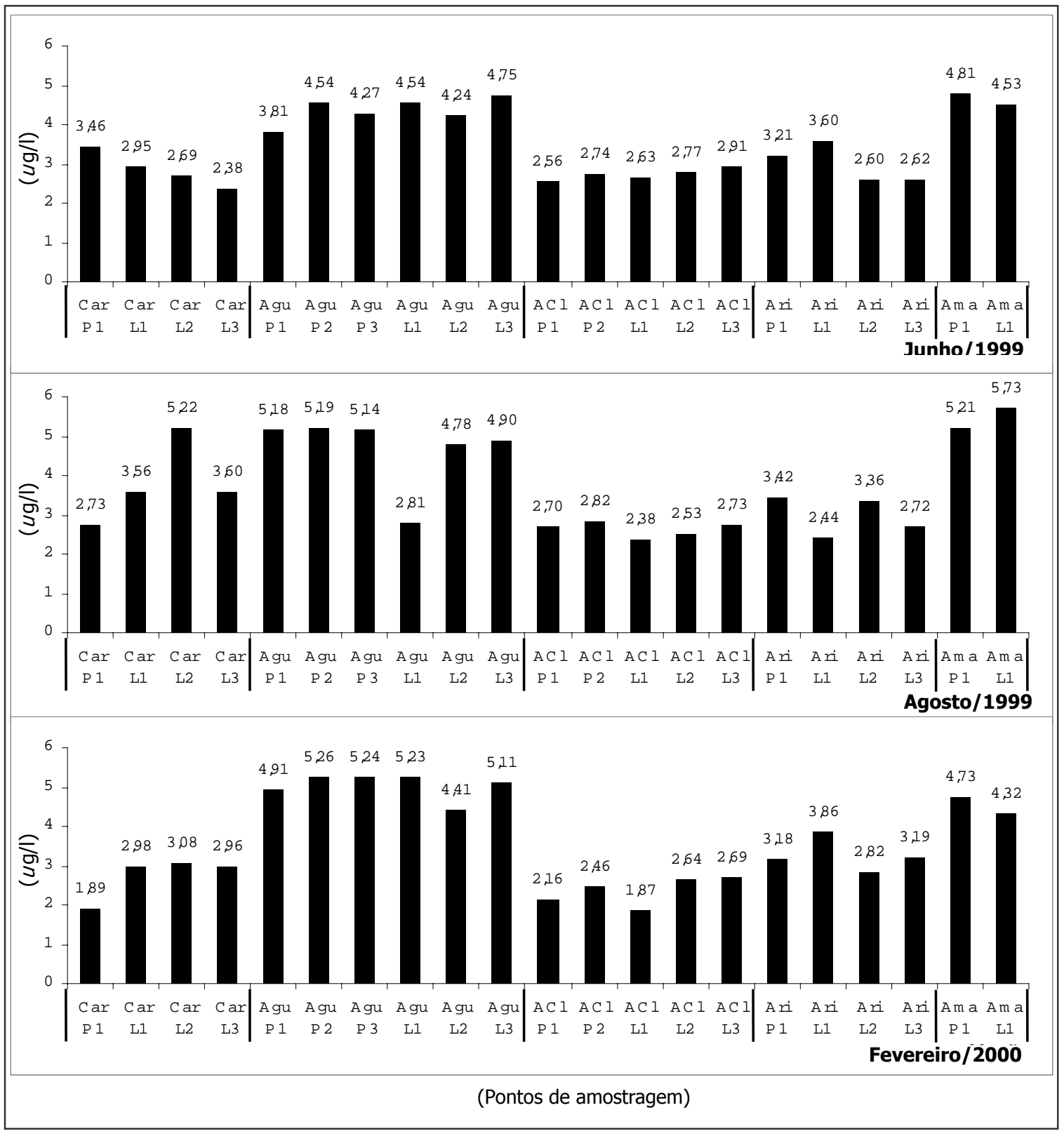

Figura 31. Concentrações de silicato reativo nos pontos de amostragem das cinco lagoas, para os três períodos estudados. 
Os valores da concentração de silicato na lagoa Carioca estiveram entre o mínimo de $1,89 \mu \mathrm{g} / \mathrm{L}$ no ponto limnético Car-P1 no verão, e máximo de $5,22 \mu \mathrm{g} / \mathrm{L}$ no ponto litorâneo Car-L2 no inverno 2. Vale ressaltar que foram observados valores menores no compartimento litorâneo em relação ao limnético no inverno 1. Porém, nos períodos de inverno 2 e verão, os valores encontrados para o compartimento litorâneo foram maiores do que aqueles do limnético.

$\mathrm{Na}$ lagoa Aguapé não foram verificadas diferenças expressivas dos valores desta variável entre os compartimentos limnético e litorâneo, nos períodos de estudo. Nos três períodos, os valores encontrados para esta lagoa e para a lagoa Amarela foram relativamente maiores do que aqueles das lagoas Carioca, Águas Claras e Ariranha. De maneira geral, os valores na lagoa Aguapé variaram de um mínimo de 2,81 $\mu \mathrm{g} / \mathrm{L}$ no ponto litorâneo Agu-L1, para um máximo de $5,26 \mu \mathrm{g} / \mathrm{L}$ no ponto limnético Agu-P2.

Os valores da concentração de silicato dos compartimentos da lagoa Águas Claras, Ariranha e Amarela mantiveram-se próximos nos três períodos de estudo. Na lagoa Águas Claras os valores variaram de $1,87 \mu \mathrm{g} / \mathrm{L}$ no ponto litorâneo ACl-L1 no verão, até $2,91 \mu \mathrm{g} / \mathrm{L}$ no ponto litorâneo $\mathrm{ACl}-\mathrm{L} 3$ no inverno 1.

A variação nas concentrações de silicato na lagoa Ariranha foi de um mínimo de $2,44 \mu \mathrm{g} / \mathrm{L}$ no ponto Ari-L1 no inverno 2 até um máximo de $3,86 \mu \mathrm{g} / \mathrm{L}$ no mesmo ponto de amostragem no verão.

Os valores estiveram bastante próximos dentro de cada período de estudo, sendo observados valores maiores no período de inverno 2 para ambos os compartimentos. A variação nesta lagoa foi de $4,32 \mu \mathrm{g} / \mathrm{L}$ no ponto litorâneo no verão a 5,73 no mesmo ponto no inverno 2 . Vale ressaltar que nos períodos de inverno $1 \mathrm{e}$ Verão o valor encontrado no ponto litorâneo foi menor do que aquele verificado no limnético. Já no inverno 2 esta relação inverteu-se, sendo encontrado o maior valor no ponto litorâneo. 


\subsubsection{NUTRIENTES TOTAIS}

- NITROGÊNIO ORGÂNICO TOTAL

A Figura 32 apresenta os valores das concentrações de nitrogênio orgânico total dos pontos de amostragem, nos três períodos de amostragem.

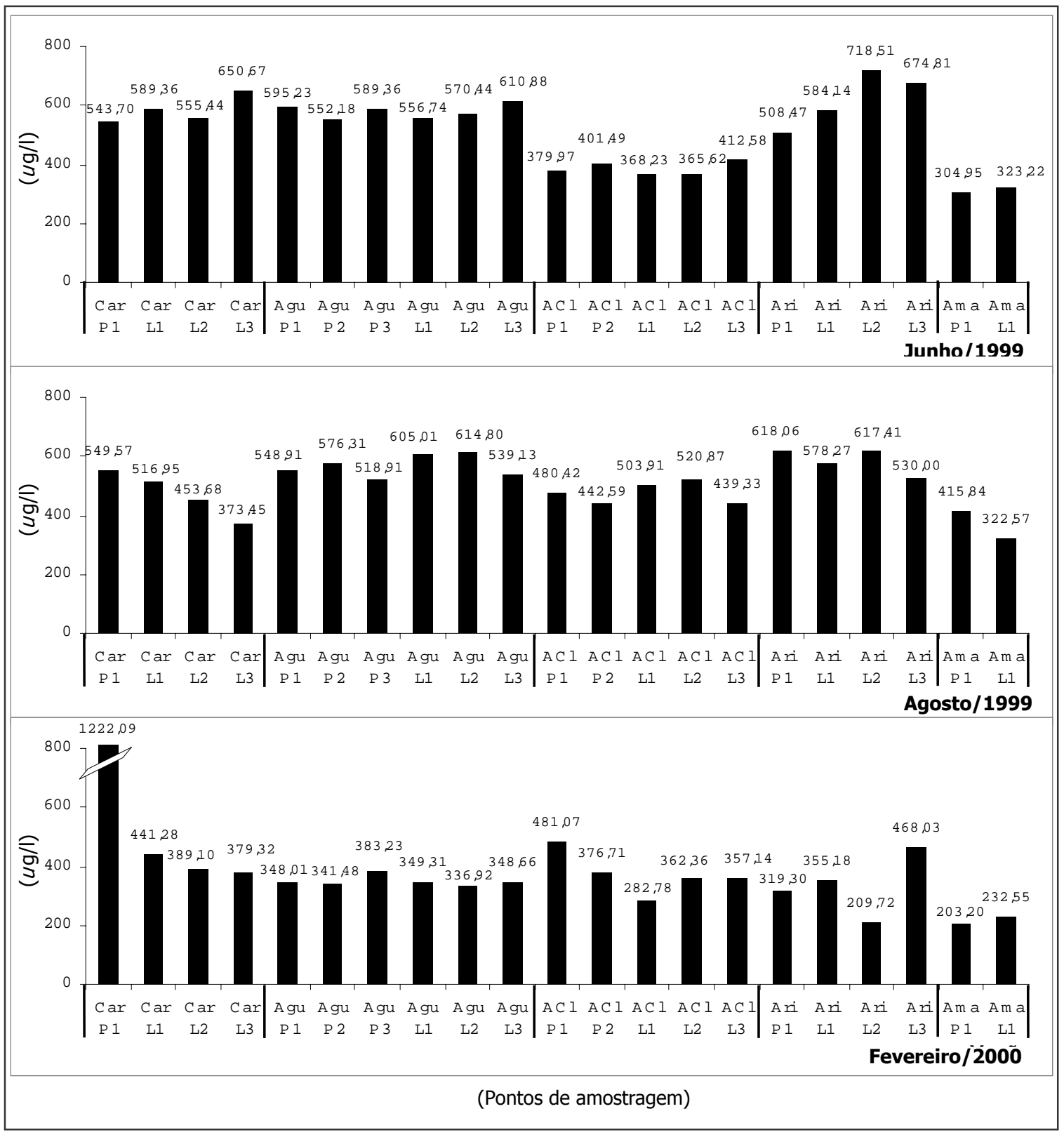

Figura 32. Concentrações de nitrogênio orgânico total nos pontos de amostragem das cinco lagoas, para os três períodos estudados.

No período de inverno 1 os valores de nitrogênio orgânico total estiveram próximos entre os pontos de amostragem das lagoas Carioca, Aguapé e Ariranha, com 
uma variação entre 508,47 $\mu \mathrm{g} / \mathrm{L}$ no ponto limnético Ari-P1 da lagoa Ariranha e 718,51 $\mu \mathrm{g} / \mathrm{L}$ no ponto litorâneo Ari-L2 da mesma lagoa. Nos pontos das lagoas Águas Claras e Amarela neste período, também foram encontrados valores próximos, os quais estiveram entre 304,95 $\mu \mathrm{g} / \mathrm{L}$ no ponto limnético da lagoa Amarela e 401,49 $\mu \mathrm{g} / \mathrm{L}$ no ponto limnético ACl-P2 da lagoa Águas Claras.

Em relação às concentrações de nitrogênio orgânico total entre os compartimentos, foram verificadas diferenças apenas na lagoa Ariranha no inverno 1, com valores menores desta variável no compartimento limnético, em relação ao litorâneo.

No inverno 2, os valores dos pontos de amostragem não mostraram diferenças expressivas entre as lagoas e entre os compartimentos. Neste período os valores encontrados estiveram entre $322,57 \mu \mathrm{g} / \mathrm{L}$ no ponto litorâneo da lagoa Amarela e $618,06 \mu \mathrm{g} / \mathrm{L}$ no ponto pelágico Ari-P1 da lagoa Ariranha.

No ponto limnético Car-P1 da lagoa Carioca no verão foi verificado o maior valor $(1222,09 \mu \mathrm{g} / \mathrm{L})$ desta variável para todo o estudo. Nos demais pontos de amostragem no período de verão, os valores estiveram relativamente próximos, entre $203,20 \mu \mathrm{g} / \mathrm{L}$ no ponto limnético da lagoa Amarela e 481,07 $\mu \mathrm{g} / \mathrm{L}$ no ponto limnético ACl-P1 da lagoa Águas Claras. 
- FÓSFORO TOTAL

A Figura 33 apresenta os valores das concentrações de fósforo total nos pontos de amostragem das lagoas, nos três períodos de estudo.

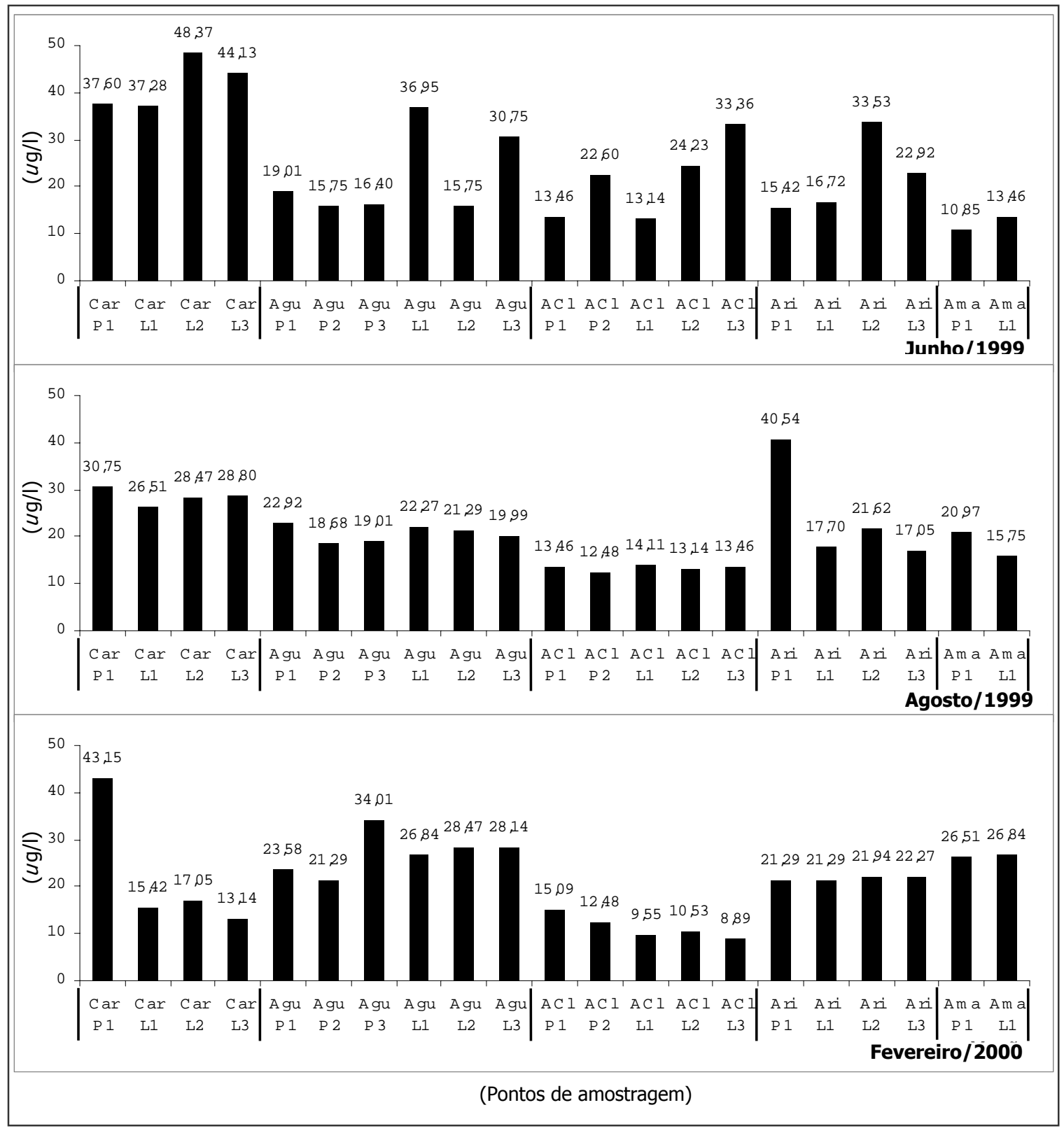

Figura 33. Concentrações de fósforo total nos pontos de amostragem das cinco lagoas, para os três períodos estudados. 
No período de inverno 1 os valores encontrados para os pontos de amostragem das lagoas não mostraram diferenças entre os compartimentos limnético e litorâneo. Neste período, os maiores valores foram observados na lagoa Carioca, sendo o maior de 48,37 $\mu \mathrm{g} / \mathrm{L}$ no ponto litorâneo Car-L2 da lagoa Carioca; e nos pontos Agu-L1, AguL3, ACl-L3 e Ari-L2. O menor valor $(10,85 \mu \mathrm{g} / \mathrm{L})$ foi verificado no ponto limnético da lagoa Amarela.

No inverno 2, dentro de cada lagoa, os valores dos pontos de amostragem estiveram próximos, com exceção ao ponto Ari-P1 da lagoa Ariranha onde foi encontrado o maior valor $(40,54 \mu \mathrm{g} / \mathrm{L})$ para o período. De maneira geral, foram observados maiores valores na lagoa Carioca, seguida das lagoas Aguapé, Ariranha (pontos litorâneos) e Amarela. Na lagoa Águas Claras no inverno 2 foram observados os menores valores desta variável, com um mínimo de $12,48 \mu \mathrm{g} / \mathrm{L}$ no ponto limnético ACl-P2.

No período de verão, nos pontos limnéticos das lagoas Carioca e Águas Claras foram registrados valores maiores do que aqueles verificados nos pontos litorâneos, dentro de cada lagoa. Já os valores observados para os pontos das lagoas Ariranha e Amarela, estiveram bastante próximos, também dentro de cada respectiva lagoa. 
4.2.10. MATERIAL EM SUSPENSÃO

- FRAÇÕES ORGÂNICA E INORGÂNICA

As relações percentuais entre fração orgânica e inorgânica do material em suspensão para cada ponto de amostragem, nos três períodos de estudo, estão apresentadas na Figura 34.

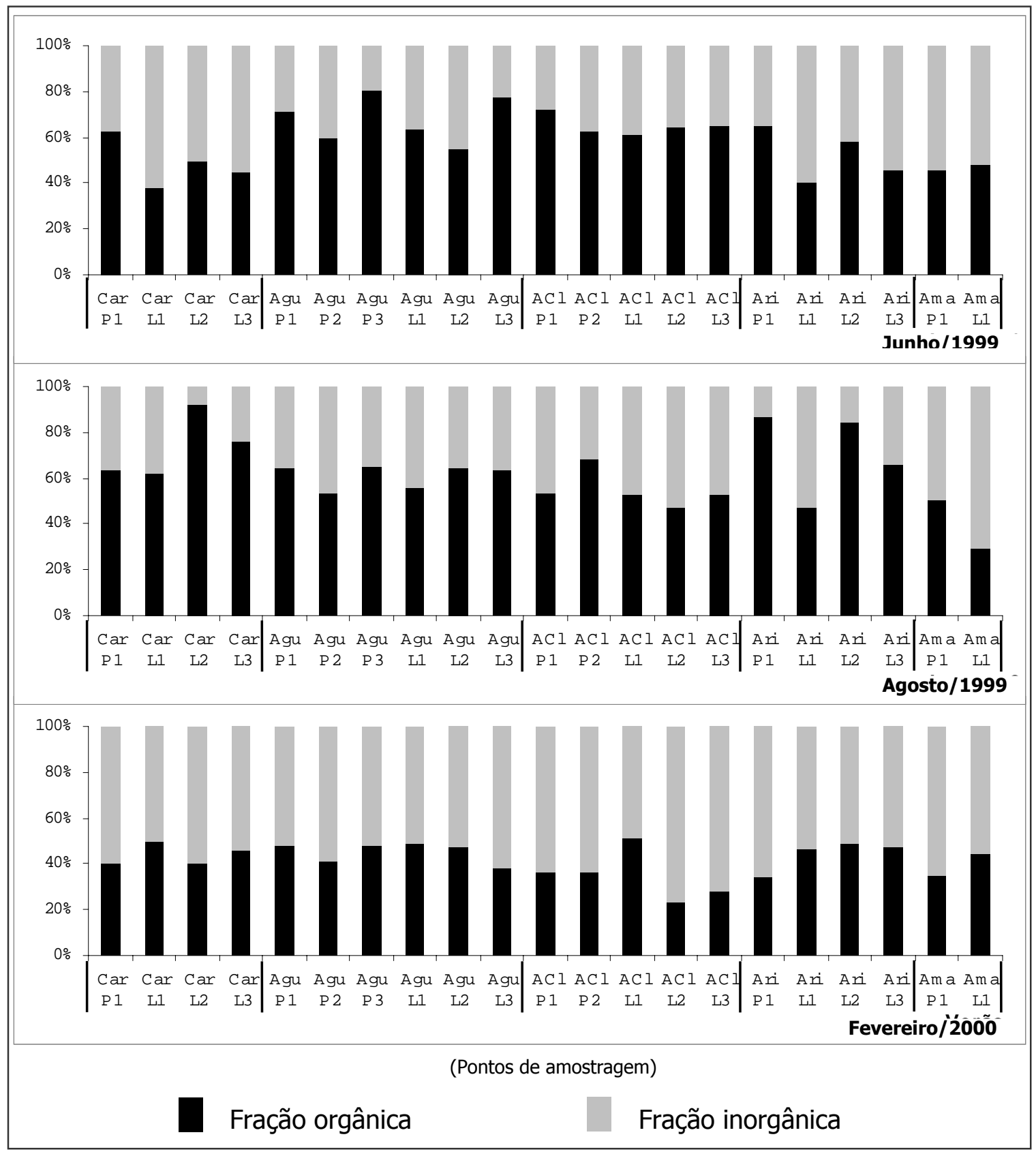

Figura 34. Valores do material em suspensão total nos pontos de amostragem das cinco lagoas, para os três períodos estudados. 
De maneira geral, o percentagem da fração orgânica nos pontos de amostragem nos períodos de inverno 1 e 2 foi maior do que a fração inorgânica, com exceção dos pontos Car-L1, Car-L2, Ari-L1, Ari-L2, Ama-P1 e Ama-L1 no período de inverno 1, e ACl-L2, Ari-L1, Ama-P1 e Ama-L1 no Inverno 2.

Já no verão, em todos os pontos de amostragem foi verificada uma maior proporção, em torno de $60 \%$, da fração inorgânica do material em suspensão em relação à orgânica. 
- MATERial EM SUSPENSÃO TOTAL

A Figura 35 apresenta os valores das concentrações de fósforo total nos pontos de amostragem das lagoas, nos três períodos de estudo.

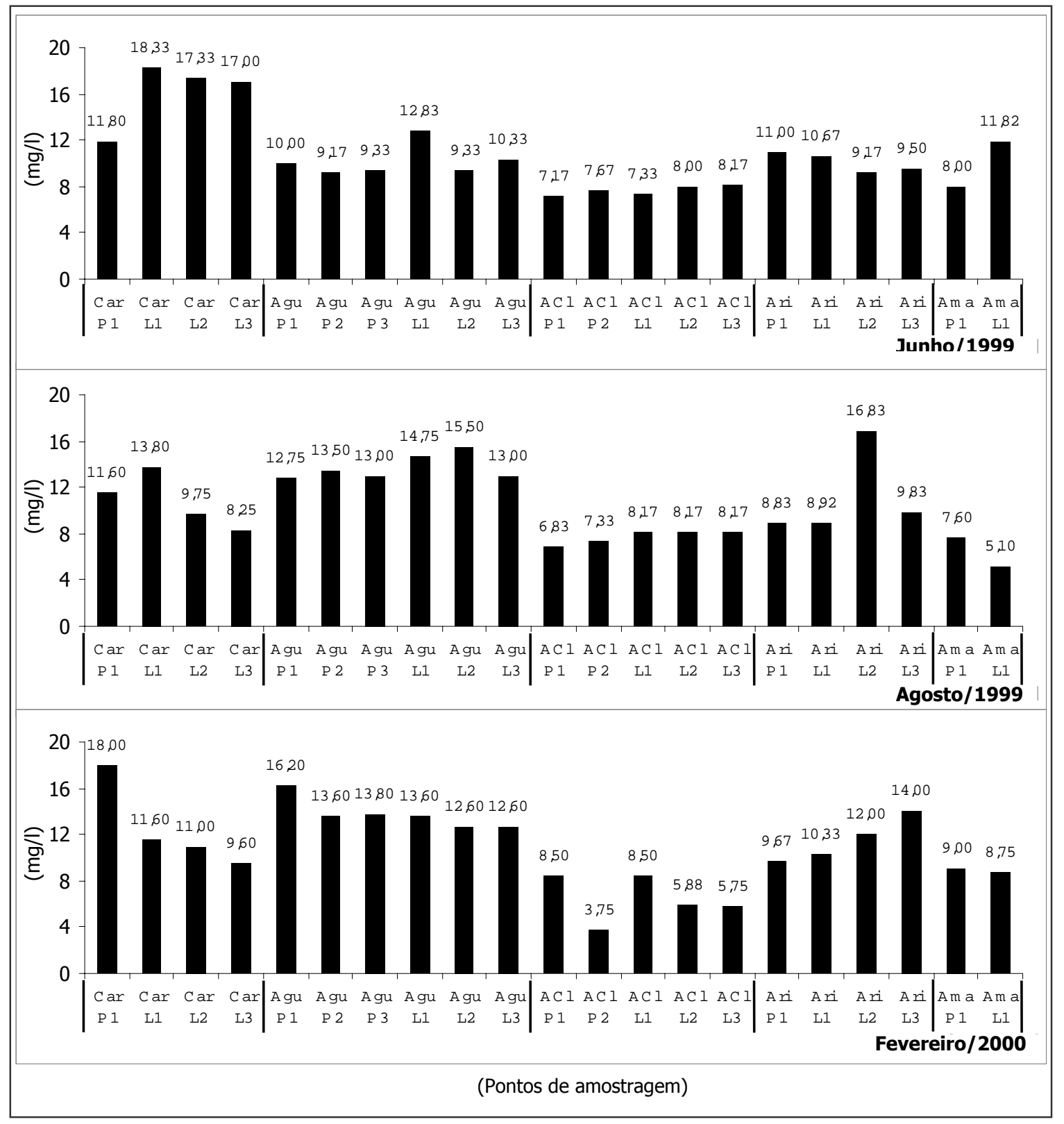

Figura 35. Valores do material em suspensão nos pontos de amostragem das cinco lagoas, para os três períodos estudados. 
De maneira geral, os maiores valores para o material em suspensão total ocorreram nos pontos litorâneos da lagoa Carioca no inverno 1, com um máximo de $18,33 \mathrm{mg} / \mathrm{l}$ no ponto Car-L1. Neste mesmo período, verificaram-se valores mais altos no compartimento litorâneo em relação ao limnético desta lagoa. Porém, nas demais lagoas esta relação não foi verificada no mesmo período de inverno.

No período de inverno 2, não houve diferenças expressivas nos valores de material em suspensão total entre os compartimentos limnético e litorâneo das lagoas estudadas, sendo que as concentrações variaram de um mínimo de $5,10 \mathrm{mg} / \mathrm{l}$ no ponto litorâneo Ama-L1 da lagoa Amarela, para 16,83 mg/l no ponto litorâneo Ari-L2 da lagoa Ariranha.

No verão, no ponto limnético Car-P1 da lagoa Carioca ocorreu o maior valor desta variável para todo o período, com 18,00 mg/l. Também neste período não foram verificadas diferenças expressivas entre os compartimentos limnético e litorâneo para todas as lagoas estudadas, sendo que o menor valor foi verificado no ponto limnético ACl-P2 da lagoa Águas Claras, com 3,75 mg/l.

No conjunto dos três períodos de amostragem não foi possível verificar diferenças sazonais expressivas para o conjunto de dados dos valores de material em suspensão total. 


\subsubsection{CONCENTRAÇÃO DE CLOROFILA}

De acordo com os valores da concentração de clorofila, apresentados na Tabela 6, pode-se verificar que nos períodos de inverno 1 e 2 , os valores de clorofila encontrados foram muito baixos em relação ao Verão, não sendo possível evidenciar diferenças entre os compartimentos limnético e litorâneo e entre as lagoas estudadas.

A única exceção a este padrão descrito anteriormente, ocorreu nos pontos CarL1 e Car-P1 da lagoa Carioca no período de inverno 1, onde os valores da concentração de clorofila foram próximos aqueles encontrados no verão.

Tabela 6. Concentrações de clorofila (ug/I) nos diferentes pontos de amostragem, nas cinco lagoas para os três períodos estudados.

\begin{tabular}{cccc}
\hline \hline Pontos de & \multicolumn{3}{c}{ Períodos } \\
\cline { 2 - 4 } amostragem & Junho/1999 & Agosto/1999 & Fevereiro/2000 \\
\hline Car-P1 & 2.93 & 0.10 & 5.87 \\
Car-L1 & 2.51 & 0.09 & 2.51 \\
Car-L2 & 0.05 & 0.12 & 3.15 \\
Car-L3 & 0.13 & 0.06 & 2.53 \\
Agu-P1 & 0.10 & 0.12 & 2.98 \\
Agu-P2 & 0.07 & 0.11 & 2.91 \\
Agu-P3 & 0.08 & 0.10 & 2.90 \\
Agu-L1 & 0.06 & 0.09 & 2.69 \\
Agu-L2 & 0.09 & 0.12 & 2.75 \\
Agu-L3 & 0.08 & 0.10 & 2.81 \\
ACl-P1 & 0.05 & 0.12 & 2.93 \\
ACl-P2 & 0.12 & 0.12 & 4.21 \\
ACl-L1 & 0.07 & 0.10 & 2.90 \\
ACl-L2 & 0.08 & 0.08 & 2.51 \\
ACl-L3 & 0.21 & 0.12 & 2.53 \\
Ari-P1 & 0.09 & 0.09 & 2.75 \\
Ari-L1 & 0.09 & 0.07 & 2.98 \\
Ari-L2 & 0.06 & 0.04 & 2.91 \\
Ari-L3 & 0.05 & 0.05 & 3.74 \\
Ama-P1 & 0.04 & 0.03 & 2.63 \\
Ama-L1 & 0.05 & 0.04 & 2.31 \\
\hline \hline
\end{tabular}

No período de verão, foram observados maiores valores desta variável no compartimento limnético em relação ao litorâneo, nas lagoas Carioca, Aguapé, Águas Claras e Amarela. O maior valor deste período foi de $5,87 \mathrm{mg} / \mathrm{l}$, verificado no ponto limnético Car-P1 da lagoa Carioca, e o menor foi de 2,31, no ponto litorâneo da lagoa Amarela. 


\subsection{ZOOPLÂNCTON}

\subsubsection{ANÁLISE QUALITATIVA}

- INVENTÁRIO TAXONÔMICO

O inventário taxonômico realizado revelou um total de 58 táxons, apresentados na classificação abaixo:

Filo: ROTIFERA

Classe: MONOGONONTA

Ordem: FLOSCULARIACEAE

Família: Hexarthridae

Hexarthra intermedia

Família: CONOCHILIDAE

Conochiloide coenobasis

Conochilus sp.

Família: FLOSCULARIIDAE

Ptygura libera

Família: TESTUDINELLIDAE

Testudinella patina

Ordem: PLOIMIDA

Família: BRACHIONIDAE

Anuraeopsis navicula

Brachionus angularis

Brachionus calyciflorus

Brachionus caudatus

Brachionus falcatus

Brachionus patulus

Brachionus quadridentatus

Keratella americana

Keratella lenzi

Keratella quadrata

Família: EUCHLANIDAE

Euchlanis sp.

Família: GASTROPODIDAE

Ascomorpha ovalis

Gastropus sp.

Família: PROALIDAE

Cephalodella sp.

Itura aurita

Proales giganthea

Família: SYNCHAETIDAE

Ploesoma truncatum

Polyarthra sp.

Synchaeta stylata

Família: COLURELIIDAE

Lepadella patella 
Família: EPIPHANIDAE

Epiphanes clavatula

Família: LECANIDAE

Lecane (Monostyla) bulla

Lecane (Monostyla) gillardi armata

Lecane (Monostyla) lunaris

Lecane (Monostyla) quadridentata

Lecane hornemanni

Lecane inermis

Lecane leontina

Lecane luna

Lecane stichaea

Família: THRICHOCERCIDAE

Trichocerca bidens

Trichocerca sp.

Família: TRICHOTRIIDAE

Macrochaetus collinsi

Ordem: ColLOTHECACEA

Família: COLLOTHECIDAE

Collotheca sp.

Filo: ARTHROPODA

Classe: CRUSTACEA

Ordem: ANOMOPODA

Família: BOSMINIDAE

Bosmina hagmani

Bosmina tubicen

Família: CHYDORIDAE

Alona quadrata

Biapertura affinis

Chydorus pubescens

Chydorus sphaericus

Disparalona sp.

Família: DAPHNIDAE

Ceriodaphnia silvestrii

Daphnia laevis

Simocephalus serrulatus

Família: MACROTHRICIDAE

Macrotrix laticornis

Ordem: CTENOPODA

Família: SIDIDAE

Diaphanosoma birgei

Diaphanosoma fluviatile 


\section{Ordem: COPEPODA \\ Sub-ordem: CALANOIDA \\ Família: DIAPTOMIDAE \\ Notodiaptomus isabelae \\ Sub-ordem: CYCLOPOIDA \\ Família: CYCLOPIDAE \\ Mesocyclops brasilianus \\ Thermocyclops minutus \\ Tropocyclops prasinus}

Ordem: OSTRACODA

Physocypria sp.

Classe: INSECTA

Família: CHAOBORIDAE

Chaoborus

Filo: ANNELIDA

Família: CHIRONOMIDAE

Classe: OligochaEtA

Filo: NEMATHELMINTHES

Ordem: NEMATODA

Foram encontrados representantes de 4 filos: Rotifera, Arthropoda, Annelida e Nemathelminthes.

Foram encontrados 39 táxons pertencentes oa filo Rotifera, das quais 5 foram identificados apenas até o nível genérico. As espécies neste filo estiveram divididas em 3 diferentes ordens: Flosculariaceae, Ploimida e Collothecacea.

A ordem Flosculariaceae foi formada por um total de 4 famílias: Hexarthridae (1 espécie), Conochilidae (2 espécies), Floscularidae (1 espécie) e Testudinellidae (1 espécie).

Já a ordem Ploimida foi aquela representada pelo maior número de famílias, com um total de 10, classificadas como Brachionidae (10 espécies), Euchlanidae (1 espécie), Gastropodidae (2 espécies), Proalidae (2 espécies), Synchaetidae (2 espécies) Colureliidae (1 espécie), Epiphanidae (1 espécie), Lecanidae (9 espécies), Thrichocercidae (2 espécies) e Trichotridae (1 espécie).

A ordem Collothecacea foi composta apenas pela família Collothecidae, com uma espécie, apenas.

As famílias de Rotifera que foram compostas por maior número de espécies foram Brachionidae e Lecanidae, pertencentes à ordem Ploimida. 
O filo Arthropoda foi composto pelas classes Crustacea e Insecta, sendo que nesta última apareceram somente as fases larvais das espécies.

A classe Crustacea foi formada pelas ordens Anomopoda, Ctenopoda, Copepoda e Ostracoda. Dentre estas, as ordens Anomopoda e Ctenopoda formam o grupo (filogeneticamente artificial) chamado de Cladocera.

A ordem Anomopoda foi representada pelo maior número de famílias, dentre 0 filo Arthropoda, sendo elas: Bosminidae (2 espécies), Chydoridae (5 espécies), Daphnidae (3 espécies) e Macrothricidae (1 espécie). Vale ressaltar que a família Chydoridae foi representada pelo maior número de espécies dentro deste filo.

A ordem Ctenopoda foi composta apenas pela família Sididae, com 2 espécies representantes.

Os copépodos, representados pela ordem Copepoda, foram formados pelas sub-ordens Calanoida e Cyclopoida.

A sub-ordem Calanoida esteve representada por apenas uma espécie pertencente à família Diaptomidae. Já para a sub-ordem Cyclopoida ocorreram 3 espécies, todas pertencentes à família Cyclopidae.

Ainda pertencente ao Filo Arthropoda, a classe Insecta foi composta por fases larvais de espécies das famílias Chaoboridae (1 gênero) e Chironomidae.

Foram ainda encontrados representantes dos filos Annelida (classe Oligochaeta) e Nemathelminthes (ordem Nematoda). 
- COMPOSIÇÃO DE ESPÉCIES ZOOPLANCTÔNICAS NAS LAGOAS

A seguir é apresentada a composição de espécies encontrada em cada lagoa no conjunto dos três períodos de estudo, separadas por compartimento limnético e litorâneo.

$\mathrm{Na}$ Tabela 7 está apresentada a lista das espécies encontradas na lagoa Carioca.

Tabela 7. Lista dos táxons presentes nas zonas limnética e litorânea da lagoa Carioca.

\begin{tabular}{|c|c|c|}
\hline Táxon & Limnética & Litorânea \\
\hline \multicolumn{3}{|l|}{ Rotifera } \\
\hline Hexarthra intermedia & $\mathrm{x}$ & $\mathrm{x}$ \\
\hline Anuraeopsis navicula & $\mathrm{x}$ & $\mathrm{x}$ \\
\hline Brachionus angularis & $\mathrm{x}$ & $\mathrm{X}$ \\
\hline Brachionus caudatus & $\mathrm{x}$ & $\mathrm{x}$ \\
\hline Keratella americana & $\mathrm{x}$ & $\mathrm{x}$ \\
\hline Collotheca sp. & $\mathrm{x}$ & $\mathrm{x}$ \\
\hline Conochiloide coenobasis & - & $\mathrm{x}$ \\
\hline Ptygura libera & $\mathrm{x}$ & $\mathrm{x}$ \\
\hline Lecane (Monostyla) bulla & $\mathrm{X}$ & - \\
\hline Lecane (Monostyla) lunaris & - & $\mathrm{X}$ \\
\hline Lecane leontina & - & $\mathrm{x}$ \\
\hline Lecane luna & - & $\mathrm{x}$ \\
\hline Cephalodella sp. & - & $\mathrm{x}$ \\
\hline Proales giganthea & - & $\mathrm{X}$ \\
\hline Ploesoma truncatum & $\mathrm{x}$ & - \\
\hline Polyarthra sp. & $\mathrm{x}$ & $\mathrm{X}$ \\
\hline Synchaeta stylata & - & $\mathrm{x}$ \\
\hline Trichocerca sp. & $\mathrm{X}$ & $\mathrm{x}$ \\
\hline Macrochaetus collinsi & - & $\mathrm{x}$ \\
\hline \multicolumn{3}{|l|}{ Cladocera } \\
\hline Alona quadrata & - & $x$ \\
\hline Biapertura affinis & - & $\mathrm{X}$ \\
\hline Chydorus pubescens & - & $\mathrm{x}$ \\
\hline Macrotrix laticornis & - & $\mathrm{x}$ \\
\hline Diaphanosoma birgei & $\mathrm{x}$ & $\mathrm{x}$ \\
\hline \multicolumn{3}{|l|}{ Copepoda } \\
\hline Mesocyclops brasilianus & $\mathrm{x}$ & $\mathrm{x}$ \\
\hline Thermocyclops minutus & $\mathrm{X}$ & $\mathrm{X}$ \\
\hline Tropocyclops prasinus & $\mathrm{x}$ & $\mathrm{X}$ \\
\hline \multicolumn{3}{|l|}{ Insecta } \\
\hline \multicolumn{3}{|l|}{ Ostracoda } \\
\hline Physocypria sp. & - & $x$ \\
\hline $\begin{array}{l}\text { Total de espécies por zona } \\
\text { Total de espécies comuns às zonas } \\
\text { Total de espécies na lagoa }\end{array}$ & 16 & 27 \\
\hline
\end{tabular}

- : ausência do táxon

$\mathbf{x}$ : presença do táxon

No conjunto dos três períodos de estudo, foram encontradas um total de 29 táxons na lagoa Carioca, sendo considerado o menor número total de espécies encontradas entre as cinco lagoas estudadas. 
No compartimento limnético foram identificadas 16 táxons e no litorâneo 27, sendo 14 comuns aos dois compartimentos.

Na lagoa Aguapé (Tabela 8), nos três períodos de estudo, foi encontrado um total de 37 táxons, sendo 26 no compartimento limnético e 35 no litorâneo, com 24 táxons pertencentes aos dois compartimentos.

Tabela 8. Lista dos táxons presentes nas zonas limnética e litorânea da lagoa Aguapé.

\begin{tabular}{|c|c|c|}
\hline Táxon & Limnética & Litorânea \\
\hline \multicolumn{3}{|l|}{ Rotifera } \\
\hline Hexarthra intermedia & $\mathrm{X}$ & $\mathrm{X}$ \\
\hline Anuraeopsis navicula & $\mathrm{x}$ & $\mathrm{x}$ \\
\hline Brachionus angularis & $\mathrm{X}$ & $\mathrm{X}$ \\
\hline Brachionus caudatus & $\mathrm{x}$ & $\mathrm{x}$ \\
\hline Brachionus falcatus & $\mathrm{X}$ & - \\
\hline Keratella americana & $\mathrm{x}$ & $\mathrm{x}$ \\
\hline Collotheca sp. & $\mathrm{x}$ & $\mathrm{X}$ \\
\hline Conochiloide coenobasis & $\mathrm{x}$ & $\mathrm{x}$ \\
\hline Conochilus sp. & $\mathrm{x}$ & $\mathrm{X}$ \\
\hline Epiphanes clavatula & $\mathrm{x}$ & $\mathrm{x}$ \\
\hline Euchlanis sp. & - & $\mathrm{X}$ \\
\hline Ptygura libera & $\mathrm{x}$ & $\mathrm{X}$ \\
\hline Ascomorpha ovalis & $\mathrm{x}$ & $\mathrm{x}$ \\
\hline Lecane (Monostyla) bulla & - & $\mathrm{X}$ \\
\hline Lecane (Monostyla) lunaris & - & $x$ \\
\hline Lecane inermis & $\mathrm{x}$ & - \\
\hline Lecane leontina & $\mathrm{x}$ & $\mathrm{x}$ \\
\hline Lecane luna & - & $\mathrm{X}$ \\
\hline Lecane stichaea & - & $\mathrm{x}$ \\
\hline Polyarthra sp. & - & $\mathrm{X}$ \\
\hline Synchaeta stylata & - & $\mathrm{X}$ \\
\hline Testudinella patina & $x$ & $\mathrm{x}$ \\
\hline Trichocerca sp. & $\mathrm{x}$ & $\mathrm{x}$ \\
\hline \multicolumn{3}{|l|}{ Cladocera } \\
\hline Bosmina hagmani & $\mathrm{x}$ & $\mathrm{X}$ \\
\hline Bosmina tubicen & $\mathrm{x}$ & $\mathrm{x}$ \\
\hline Alona quadrata & - & $\mathrm{X}$ \\
\hline Biapertura affinis & $\mathrm{x}$ & $\mathrm{X}$ \\
\hline Chydorus pubescens & - & $\mathrm{X}$ \\
\hline Disparalona sp. & - & $\mathrm{X}$ \\
\hline Simocephalus serrulatus & - & $\mathrm{x}$ \\
\hline Macrotrix laticornis & $\mathrm{x}$ & $\mathrm{x}$ \\
\hline Diaphanosoma birgei & $\mathrm{x}$ & $\mathrm{X}$ \\
\hline \multicolumn{3}{|l|}{ Copepoda } \\
\hline Mesocyclops brasilianus & $\mathrm{x}$ & $\mathrm{X}$ \\
\hline Thermocyclops minutus & $\mathrm{x}$ & $\mathrm{X}$ \\
\hline Tropocyclops prasinus & $\mathrm{X}$ & $\mathrm{x}$ \\
\hline \multicolumn{3}{|l|}{ 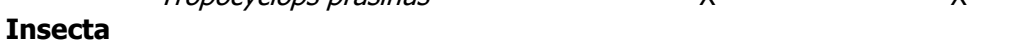 } \\
\hline \multirow{2}{*}{\multicolumn{3}{|c|}{ Ostracoda }} \\
\hline & & \\
\hline Physocypria sp. & $\mathrm{X}$ & $\mathrm{X}$ \\
\hline $\begin{array}{l}\text { Total de espécies por zona } \\
\text { Total de espécies comuns às zonas } \\
\text { Total de espécies na lagoa }\end{array}$ & \multicolumn{2}{|c|}{$\begin{array}{l}24 \\
37\end{array}$} \\
\hline
\end{tabular}

De acordo com os resultados apresentados na Tabela 9, foram encontrados 43 táxons na lagoa Águas Claras, dentre os três períodos de estudo, com 22 no 
compartimento limnético e 42 no litorâneo. Pode-se dizer que apenas um dos táxons do total encontrado nesta lagoa não ocorreu nos pontos litorâneos.

Tabela 9. Lista dos táxons presentes nas zonas limnética e litorânea da lagoa Águas Claras.

\begin{tabular}{|c|c|c|}
\hline Táxon & Limnética & Litorânea \\
\hline \multicolumn{3}{|l|}{ Rotifera } \\
\hline Hexarthra intermedia & $\mathrm{x}$ & $\mathrm{x}$ \\
\hline Anuraeopsis navicula & $\mathrm{x}$ & $\mathrm{x}$ \\
\hline Brachionus angularis & $\mathrm{x}$ & $\mathrm{x}$ \\
\hline Brachionus calyciflorus & - & $\mathrm{x}$ \\
\hline Brachionus caudatus & $\mathrm{x}$ & $\mathrm{x}$ \\
\hline Brachionus falcatus & $\mathrm{x}$ & $\mathrm{x}$ \\
\hline Brachionus patulus & - & $\mathrm{x}$ \\
\hline Keratella americana & $\mathrm{x}$ & $\mathrm{x}$ \\
\hline Collotheca sp. & $\mathrm{X}$ & $\mathrm{x}$ \\
\hline Lepadella patella & - & $\mathrm{x}$ \\
\hline Conochiloide coenobasis & - & $\mathrm{x}$ \\
\hline Conochilus sp. & - & $x$ \\
\hline Epiphanes clavatula & - & $\mathrm{x}$ \\
\hline Ptygura libera & $\mathrm{X}$ & $\mathrm{x}$ \\
\hline Ascomorpha ovalis & $\mathrm{x}$ & $\mathrm{x}$ \\
\hline Lecane (Monostyla) bulla & - & $\mathrm{x}$ \\
\hline Lecane (Monostyla) gillardi armata & - & $\mathrm{x}$ \\
\hline Lecane (Monostyla) Iunaris & - & $\mathrm{x}$ \\
\hline Lecane (Monostyla) quadridentata & - & $\mathrm{x}$ \\
\hline Lecane inermis & - & $\mathrm{x}$ \\
\hline Lecane leontina & - & $\mathrm{x}$ \\
\hline Lecane stichaea & - & $\mathrm{x}$ \\
\hline Proales giganthea & $\mathrm{x}$ & $\mathrm{x}$ \\
\hline Polyarthra sp. & $\mathrm{X}$ & $\mathrm{x}$ \\
\hline Testudinella patina & $\mathrm{x}$ & $\mathrm{x}$ \\
\hline Trichocerca sp. & $\mathrm{x}$ & $\mathrm{x}$ \\
\hline Macrochaetus collinsi & - & $\mathrm{x}$ \\
\hline \multicolumn{3}{|l|}{ Cladocera } \\
\hline Bosmina hagmani & $\mathrm{x}$ & $\mathrm{x}$ \\
\hline Bosmina tubicen & $\mathrm{X}$ & $\mathrm{X}$ \\
\hline Alona quadrata & - & $\mathrm{x}$ \\
\hline Biapertura affinis & - & $\mathrm{x}$ \\
\hline Chydorus pubescens & - & $\mathrm{x}$ \\
\hline Chydorus sphaericus & - & $\mathrm{x}$ \\
\hline Ceriodaphnia silvestrii & - & $\mathrm{X}$ \\
\hline Daphnia laevis & $\mathrm{x}$ & - \\
\hline Simocephalus serrulatus & - & $\mathrm{x}$ \\
\hline Macrotrix laticornis & - & $\mathrm{x}$ \\
\hline Diaphanosoma birgei & $\mathrm{x}$ & $\mathrm{x}$ \\
\hline \multicolumn{3}{|l|}{ Copepoda } \\
\hline Mesocyclops brasilianus & $\mathrm{X}$ & $\mathrm{X}$ \\
\hline Thermocyclops minutus & $\mathrm{X}$ & $\mathrm{x}$ \\
\hline Tropocyclops prasinus & $\mathrm{x}$ & $\mathrm{x}$ \\
\hline \multicolumn{3}{|l|}{ Insecta } \\
\hline \multirow{2}{*}{\multicolumn{3}{|c|}{ Ostracoda }} \\
\hline & & \\
\hline Physocypria sp. & $\mathrm{x}$ & $\mathrm{X}$ \\
\hline $\begin{array}{l}\text { Total de espécies por zona } \\
\text { Total de espécies comuns às zonas } \\
\text { Total de espécies na lagoa }\end{array}$ & \multicolumn{2}{|c|}{$\begin{array}{l}21 \\
43\end{array}$} \\
\hline
\end{tabular}

- : ausência do táxon

$\mathbf{x}$ : presença do táxon 
Na lagoa Ariranha (Tabela 10) foi encontrado um total de 43 táxons, sendo que todas ocorreram no compartimento litorâneo. No limnético ocorreram apenas 24 táxons.

Tabela 10. Lista dos táxons presentes nas zonas limnética e litorânea da lagoa Ariranha.

\begin{tabular}{|c|c|c|}
\hline Táxon & Limnética & Litorânea \\
\hline \multicolumn{3}{|l|}{ Rotifera } \\
\hline Hexarthra intermedia & $\mathrm{X}$ & $\mathrm{X}$ \\
\hline Anuraeopsis navicula & $\mathrm{x}$ & $\mathrm{x}$ \\
\hline Brachionus angularis & $\mathrm{x}$ & $\mathrm{X}$ \\
\hline Brachionus caudatus & $\mathrm{x}$ & $\mathrm{X}$ \\
\hline Brachionus falcatus & $\mathrm{x}$ & $\mathrm{X}$ \\
\hline Brachionus patulus & - & $\mathrm{x}$ \\
\hline Keratella americana & - & $\mathrm{X}$ \\
\hline Collotheca sp. & $\mathrm{x}$ & $\mathrm{x}$ \\
\hline Lepadella patella & - & $\mathrm{x}$ \\
\hline Conochiloide coenobasis & - & $\mathrm{x}$ \\
\hline Conochilus sp. & $\mathrm{x}$ & $\mathrm{X}$ \\
\hline Epiphanes clavatula & $\mathrm{x}$ & $\mathrm{X}$ \\
\hline Ptygura libera & $x$ & $\mathrm{x}$ \\
\hline Ascomorpha ovalis & $\mathrm{x}$ & $\mathrm{x}$ \\
\hline Lecane (Monostyla) bulla & - & $\mathrm{x}$ \\
\hline Lecane (Monostyla) Iunaris & $\mathrm{x}$ & $\mathrm{X}$ \\
\hline Lecane inermis & - & $\mathrm{X}$ \\
\hline Lecane leontina & - & $\mathrm{x}$ \\
\hline Lecane luna & - & $\mathrm{X}$ \\
\hline Lecane stichaea & - & $\mathrm{x}$ \\
\hline Proales giganthea & - & $\mathrm{x}$ \\
\hline Polyarthra sp. & $\mathrm{x}$ & $\mathrm{X}$ \\
\hline Testudinella patina & - & $\mathrm{X}$ \\
\hline Trichocerca sp. & $\mathrm{x}$ & $\mathrm{x}$ \\
\hline Macrochaetus collinsi & - & $\mathrm{X}$ \\
\hline \multicolumn{3}{|l|}{ Cladocera } \\
\hline Bosmina hagmani & $\mathrm{x}$ & $\mathrm{X}$ \\
\hline Bosmina tubicen & $\mathrm{x}$ & $\mathrm{X}$ \\
\hline Alona quadrata & - & $\mathrm{X}$ \\
\hline Biapertura affinis & - & $\mathrm{x}$ \\
\hline Chydorus pubescens & $\mathrm{x}$ & $\mathrm{X}$ \\
\hline Chydorus sphaericus & - & $\mathrm{X}$ \\
\hline Disparalona sp. & - & $\mathrm{x}$ \\
\hline Ceriodaphnia silvestrii & - & $\mathrm{X}$ \\
\hline Simocephalus serrulatus & - & $\mathrm{x}$ \\
\hline Macrotrix laticornis & - & $\mathrm{x}$ \\
\hline Diaphanosoma birgei & $\mathrm{x}$ & $\mathrm{x}$ \\
\hline Diaphanosoma fluviatile & $\mathrm{x}$ & $\mathrm{X}$ \\
\hline \multicolumn{3}{|l|}{ Copepoda } \\
\hline Notodiaptomus isabelae & $\mathrm{X}$ & $\mathrm{X}$ \\
\hline Mesocyclops brasilianus & $\mathrm{X}$ & $\mathrm{X}$ \\
\hline Thermocyclops minutus & $\mathrm{x}$ & $\mathrm{X}$ \\
\hline \multirow{2}{*}{\multicolumn{3}{|c|}{ торосусторь prasirius }} \\
\hline & & \\
\hline \multicolumn{3}{|l|}{ Ostracoda } \\
\hline Physocypria sp. & $\mathrm{X}$ & $\mathrm{X}$ \\
\hline Total de espécies por zona & 24 & 43 \\
\hline $\begin{array}{c}\text { Total de espécies comuns às zonas } \\
\text { Total de espécies na lagoa }\end{array}$ & & \\
\hline
\end{tabular}

- : ausência do táxon

$\mathbf{x}$ : presença do táxon 
A composição de táxons da lagoa Amarela (Tabela 11) revelou um total de 44 táxons, com 29 espécies no compartimento limnético e 37 no litorâneo. Dos 44 táxons, 23 ocorreram em ambos os compartimentos.

Tabela 11. Lista dos táxons presentes nas zonas limnética e litorânea da lagoa Amarela.

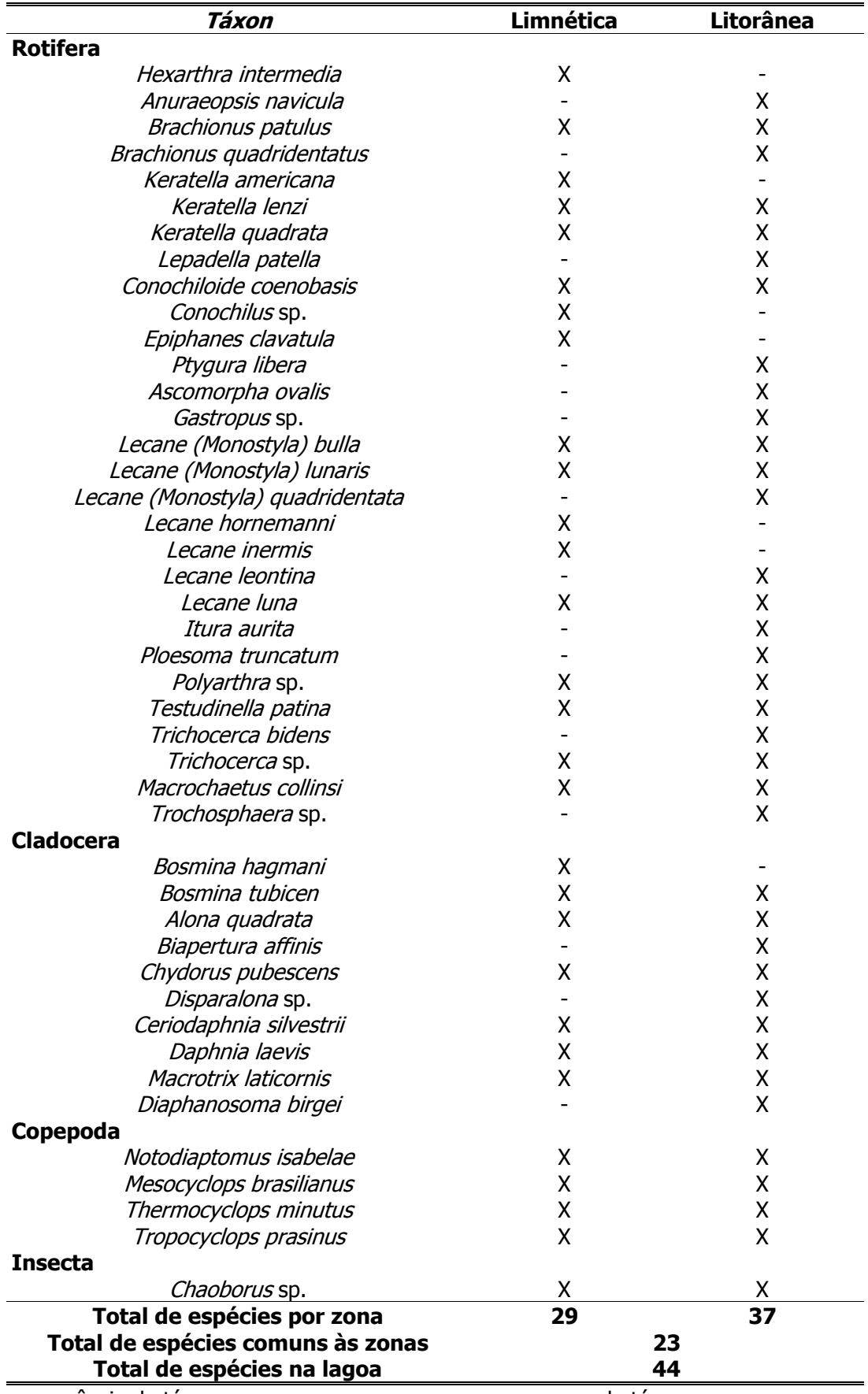

- : ausência do táxon

$\mathbf{x}$ : presença do táxon 
Vale ressaltar que, de maneira geral, as espécies pertencentes às famílias Lecanidae (Rotifera) e Chydoridae (Cladocera) ocorreram de forma mais marcante no compartimento litorâneo.

Pelos resultados apresentados, pode-se afirmar que a lagoa onde foi registrado o maior número de táxons foi a Amarela, em constraste com a Carioca, onde se observou o menor. A ordem crescente das lagoas em função do número de táxons foi: Carioca $<$ Aguapé $<$ Águas Claras = Ariranha $<$ Amarela.

Apenas nas lagoas Ariranha e Amarela foi encontrada a espécie de Copepoda Calanoida Notodiaptomus isabelae. 


\subsubsection{ANÁLISE QUANTITATIVA}

- DensidAde NUMÉRICA

As Tabelas 12 e 13 apresentam a densidade numérica dos táxons e dos grupos zooplanctônicos da lagoa Carioca.

Tabela 12. Densidade numérica (org. $/ \mathrm{m}^{3}$ ) dos táxons encontrados na lagoa Carioca, nos três períodos estudados.

\begin{tabular}{|c|c|c|c|c|c|c|}
\hline \multirow{2}{*}{ Táxon \ Densidade (org./m3) } & \multicolumn{2}{|c|}{ Junho/1999 } & \multicolumn{2}{|c|}{ Agosto/1999 } & \multicolumn{2}{|c|}{ Fevereiro/2000 } \\
\hline & Limnética & Litorânea & Limnética & Litorânea & Limnética & Litorânea \\
\hline Hexarthra intermedia & 1200 & 0 & 15520 & 4960 & 0 & 223 \\
\hline Anuraeopsis navicula & 363000 & 629947 & 67900 & 150080 & 0 & 0 \\
\hline Brachionus angularis & 1200 & 0 & 0 & 0 & 0 & 6208 \\
\hline Brachionus caudatus & 171000 & 14900 & 13580 & 6640 & 17880 & 12173 \\
\hline Keratella americana & 1200 & 0 & 9700 & 400 & 0 & 0 \\
\hline Collotheca sp. & 2400 & 290 & 0 & 0 & 2235 & 3272 \\
\hline Conochiloide coenobasis & 0 & 0 & 0 & 0 & 0 & 248 \\
\hline Ptygura libera & 4800 & 1330 & 0 & 0 & 0 & 698 \\
\hline Lecane (Monostyla) bulla & 0 & 0 & 0 & 0 & 1530 & 0 \\
\hline Lecane (Monostyla) lunaris & 0 & 580 & 0 & 0 & 0 & 0 \\
\hline Lecane leontina & 0 & 377 & 0 & 0 & 0 & 0 \\
\hline Lecane luna & 0 & 0 & 0 & 960 & 0 & 0 \\
\hline Cephalodella sp. & 0 & 750 & 0 & 0 & 0 & 0 \\
\hline Proales giganthea & 0 & 1267 & 0 & 0 & 0 & 2383 \\
\hline Ploesoma truncatum & 0 & 0 & 1940 & 0 & 0 & 0 \\
\hline Polyarthra sp. & 0 & 3693 & 3880 & 16320 & 750 & 227 \\
\hline Synchaeta stylata & 0 & 0 & 0 & 400 & 0 & 0 \\
\hline Trichocerca sp. & 3600 & 4073 & 42680 & 25920 & 1490 & 972 \\
\hline Macrochaetus collinsi & 0 & 0 & 0 & 0 & 0 & 248 \\
\hline Alona quadrata & 0 & 103 & 0 & 182 & 0 & 50 \\
\hline Biapertura affinis & 0 & 223 & 0 & 128 & 0 & 75 \\
\hline Chydorus pubescens & 0 & 900 & 0 & 0 & 0 & 0 \\
\hline Macrotrix laticornis & 0 & 520 & 0 & 0 & 0 & 0 \\
\hline Diaphanosoma birgei & 0 & 30 & 0 & 0 & 800 & 181 \\
\hline Mesocyclops brasilianus & 960 & 673 & 0 & 3268 & 267 & 1418 \\
\hline Thermocyclops minutus & 11880 & 3627 & 17460 & 11097 & 20800 & 26988 \\
\hline Tropocyclops prasinus & 6000 & 136 & 5240 & 1478 & 1067 & 867 \\
\hline Chaoborus sp. & 660 & 300 & 840 & 605 & 1333 & 104 \\
\hline Physocypria sp. & 0 & 123 & 0 & 160 & 0 & 0 \\
\hline
\end{tabular}

Tabela 13. Densidade numérica (org. $/ \mathrm{m}^{3}$ ) para os principais grupos taxonômicos e fases de desenvolvimento de Copepoda encontrados na lagoa Carioca, nos três períodos estudados.

\begin{tabular}{|c|c|c|c|c|c|c|}
\hline \multirow{2}{*}{ Grupos \Densidade (org./m3) } & \multicolumn{2}{|c|}{ "Junho/1999 } & \multicolumn{2}{|c|}{ Agosto/1999 } & \multicolumn{2}{|c|}{ Fevereiro/2000 } \\
\hline & Pelágica & Litorânea & Pelágica & Litorânea & Pelágica & Litorânea \\
\hline ROTIFERA & 548400 & 657207 & 155200 & 205680 & 23885 & 26653 \\
\hline CLADOCERA & 0 & 1777 & 0 & 310 & 800 & 306 \\
\hline Náuplios de COPEPODA CYCLOPOIDA & 132000 & 71447 & 199820 & 81103 & 98340 & 104917 \\
\hline Copepodito de COPEPODA CYCLOPOIDA & 11040 & 2757 & 25030 & 19265 & 9867 & 4590 \\
\hline Adultos de COPEPODA CYCLOPOIDA & 18840 & 4436 & 22700 & 15842 & 22134 & 29273 \\
\hline COPEPODA CYCLOPOIDA & 161880 & 78639 & 247550 & 116210 & 130341 & 138779 \\
\hline COPEPODA & 161880 & 78639 & 247550 & 116210 & 130341 & 138779 \\
\hline CHAOBORIDAE & 660 & 300 & 840 & 605 & 1333 & 104 \\
\hline OSTRACODA & 0 & 123 & 0 & 160 & 0 & 0 \\
\hline CHIRONOMIDAE & 120 & 9333 & 0 & 928 & 667 & 715 \\
\hline OLIGOCHAETA & 0 & 0 & 0 & 198 & 0 & 169 \\
\hline NEMATODA & 240 & 1167 & 0 & 164 & 0 & 0 \\
\hline Total de outros grupos & 1020 & 10923 & 840 & 2054 & 2000 & 988 \\
\hline Total de organismos & 711300 & 748546 & 403590 & 324254 & 157026 & 166727 \\
\hline
\end{tabular}


De acordo com os resultados encontrados, a espécie com maior densidade numérica nos períodos de inverno (1 e 2), em ambos os compartimentos limnético e litorâneo, foi o Rotifera Anuraeropsis navicula. A maior densidade encontrada para esta espécie na lagoa Carioca foi de 629947 ind. $/ \mathrm{m}^{3}$, na região litorânea no período de Junho de 1999 (inverno 1).

No período de verão, a espécie dominante foi o Copepoda Cyclopoida Mesocyclops brasilianus.

O grupo dos Rotifera ocorreu em maior densidade nos compartimentos limnético e litorâneo no período de inverno 1, e no compartimento litorâneo no Inverno 2 (Agosto de 1999).

No compartimento limnético no inverno 2 , e em ambos os compartimentos no Verão (Fevereiro de 2000), o grupo presente em maior densidade numérica foi Copepoda Cyclopoida.

O grupo dos Cladocera ocorreu em maior densidade numérica no compartimento litorâneo nos períodos de inverno 1 e 2, sendo que no compartimento limnético, nos mesmos períodos, não ocorreu nenhum exemplar deste grupo, no zooplâncton. No verão, a densidade no compartimento limnético foi maior do que no litorâneo.

Nos períodos de inverno 1 e 2 a densidade de náuplios, copepoditos e de adultos de Cyclopoida foi maior no compartimento limnético. Já no verão, os náuplios ocorreram com maior densidade no compartimento litorâneo e os copepoditos e adultos no limnético.

No geral, os Copepoda Cyclopoida ocorreram com maior densidade no compartimento limnético nos período de inverno 1 e 2, e no compartimento litorâneo no Verão.

Os organismos representantes da família Chaoboridae ocorreram em maior densidade numérica sempre no compartimento limnético, em todos os períodos estudados.

Os Ostracoda ocorreram apenas no compartimento litorâneo nos períodos de inverno 1 e 2 . No verão, esta ordem não ocorreu em nenhum compartimento.

Os organismos da família Chironomidae ocorreram em maior densidade na região litorânea em todos os períodos de amostragem, não ocorrendo apenas na região limnética no período de inverno 2. Já os Nematoda ocorreram apenas no inverno 1 , e no compartimento litorâneo no inverno 2. 
Nos períodos de inverno 1 e verão a densidade total zooplanctônica foi maior no compartimento litorâneo. No inverno 2, a densidade maior de organismos foi registrada no compartimento limnético.

De uma forma geral, observou-se um descréscimo na densidade numérica do zooplâncton do período de inverno 1 para o Verão.

O maior número de organismos zooplanctônicos da lagoa Carioca foi de 748546 ind./ $\mathrm{m}^{3}$ no compartimento litorâneo no inverno 1, e o menor foi de 157026 ind./ $\mathrm{m}^{3}$ no compartimento limnético no verão.

Nas Tabelas 14 e 15 estão apresentados os valores da densidade das espécies e dos grupos encontrados na lagoa Aguapé.

Tabela 14. Densidade numérica (org. $/ \mathrm{m}^{3}$ ) dos táxons encontrados na lagoa Aguapé, nos três períodos estudados.

\begin{tabular}{|c|c|c|c|c|c|c|}
\hline \multirow{2}{*}{ Táxon \Densidade (org./m3) } & \multicolumn{2}{|c|}{ Junho/1999 } & \multicolumn{2}{|c|}{ Agosto/1999 } & \multicolumn{2}{|c|}{ Fevereiro/2000 } \\
\hline & Limnética & Litorânea & Limnética & Litorânea & Limnética & Litorânea \\
\hline Hexarthra intermedia & 0 & 0 & 0 & 0 & 1203 & 1277 \\
\hline Anuraeopsis navicula & 8527 & 12650 & 1513 & 650 & 680 & 255 \\
\hline Brachionus angularis & 30343 & 10837 & 2683 & 0 & 10185 & 17077 \\
\hline Brachionus caudatus & 8893 & 647 & 4417 & 11763 & 15055 & 2305 \\
\hline Brachionus falcatus & 0 & 0 & 0 & 0 & 1188 & 0 \\
\hline Keratella americana & 743 & 980 & 0 & 737 & 4477 & 5440 \\
\hline Collotheca sp. & 1027 & 3333 & 0 & 0 & 227 & 0 \\
\hline Conochiloide coenobasis & 0 & 0 & 0 & 0 & 7075 & 3093 \\
\hline Conochilus sp. & 5793 & 4850 & 3293 & 17717 & 0 & 0 \\
\hline Epiphanes clavatula & 0 & 0 & 0 & 0 & 282 & 255 \\
\hline Euchlanis sp. & 0 & 0 & 0 & 0 & 0 & 287 \\
\hline Ptygura libera & 3120 & 1960 & 6967 & 16337 & 11708 & 17480 \\
\hline Ascomorpha ovalis & 26923 & 30653 & 0 & 5173 & 0 & 287 \\
\hline Lecane (Monostyla) bulla & 0 & 800 & 0 & 1300 & 0 & 0 \\
\hline Lecane (Monostyla) Iunaris & 0 & 0 & 0 & 637 & 0 & 0 \\
\hline Lecane inermis & 0 & 0 & 633 & 0 & 0 & 0 \\
\hline Lecane leontina & 0 & 0 & 0 & 0 & 283 & 287 \\
\hline Lecane luna & 0 & 0 & 0 & 1910 & 0 & 255 \\
\hline Lecane stichaea & 0 & 653 & 0 & 0 & 0 & 0 \\
\hline Polyarthra sp. & 0 & 800 & 0 & 0 & 0 & 0 \\
\hline Synchaeta stylata & 0 & 0 & 0 & 1273 & 0 & 0 \\
\hline Testudinella patina & 0 & 0 & 0 & 1300 & 282 & 0 \\
\hline Trichocerca sp. & 102050 & 68697 & 17333 & 17150 & 2148 & 1127 \\
\hline Bosmina hagmani & 135 & 184 & 317 & 157 & 140 & 64 \\
\hline Bosmina tubicen & 149 & 67 & 803 & 263 & 366 & 0 \\
\hline Alona quadrata & 0 & 101 & 0 & 0 & 0 & 360 \\
\hline Biapertura affinis & 83 & 32 & 63 & 334 & 0 & 199 \\
\hline Chydorus pubescens & 0 & 0 & 0 & 368 & 0 & 244 \\
\hline Chydorus sphaericus & 0 & 0 & 0 & 0 & 0 & 0 \\
\hline Disparalona sp. & 0 & 130 & 0 & 135 & 0 & 0 \\
\hline Ceriodaphnia silvestrii & 0 & 82 & 0 & 0 & 0 & 0 \\
\hline Simocephalus serrulatus & 0 & 0 & 0 & 417 & 0 & 64 \\
\hline Macrotrix laticornis & 34 & 110 & 0 & 65 & 0 & 58 \\
\hline Diaphanosoma birgei & 20 & 0 & 215 & 126 & 3036 & 440 \\
\hline Mesocyclops brasilianus & 277 & 695 & 30 & 3203 & 88 & 1193 \\
\hline Thermocyclops minutus & 30905 & 1126 & 31223 & 5662 & 76880 & 583 \\
\hline Tropocyclops prasinus & 3722 & 388 & 1322 & 1226 & 1543 & 790 \\
\hline Chaoborus sp. & 83 & 34 & 487 & 1113 & 1944 & 436 \\
\hline Physocypria sp. & 0 & 0 & 220 & 2738 & 135 & 0 \\
\hline
\end{tabular}


Tabela 15. Densidade numérica (org. $/ \mathrm{m}^{3}$ ) dos principais grupos taxonômicos e fase de desenvolvimento de Copepoda encontrados na lagoa Aguapé, nos três períodos estudados.

\begin{tabular}{lcccccc}
\hline \multirow{2}{*}{ Grupos \ Densidade (org./m3) } & \multicolumn{2}{c}{ Junho/1999 } & \multicolumn{2}{c}{ Agosto/1999 } & \multicolumn{2}{c}{ Fevereiro/2000 } \\
\cline { 2 - 7 } & Limnética & Litorânea & Limnética & Litorânea & Limnética & Litorânea \\
\hline ROTIFERA & $\mathbf{1 8 7 4 2 0}$ & $\mathbf{1 3 6 8 6 0}$ & $\mathbf{3 6 8 4 0}$ & $\mathbf{7 5 9 4 7}$ & $\mathbf{5 4 7 9 3}$ & $\mathbf{4 9 4 2 3}$ \\
CLADOCERA & $\mathbf{4 2 1}$ & $\mathbf{7 0 5}$ & $\mathbf{1 3 9 8}$ & $\mathbf{1 8 6 5}$ & $\mathbf{3 5 4 1}$ & $\mathbf{1 4 2 8}$ \\
Náulplios de COPEPODA CYCLOPOIDA & 307990 & 89537 & 311023 & 576057 & 184588 & 196902 \\
Copepodito de COPEPODA CYCLOPOIDA & 17440 & 638 & 27055 & 7015 & 145670 & 20031 \\
Adultos de COPEPODA CYCLOPOIDA & 34903 & 2210 & 32575 & 10091 & 78511 & 2565 \\
COPEPODA CYCLOPOIDA & $\mathbf{3 6 0 3 3 3}$ & $\mathbf{9 2 3 8 5}$ & $\mathbf{3 7 0 6 5 3}$ & $\mathbf{5 9 3 1 6 3}$ & $\mathbf{4 0 8 7 6 9}$ & $\mathbf{2 1 9 4 9 8}$ \\
COPEPODA & $\mathbf{3 6 0 3 3 3}$ & $\mathbf{9 2 3 8 5}$ & $\mathbf{3 7 0 6 5 3}$ & $\mathbf{5 9 3 1 6 3}$ & $\mathbf{4 0 8 7 6 9}$ & $\mathbf{2 1 9 4 9 8}$ \\
CHAOBORIDAE & 83 & 34 & 487 & 1113 & 1944 & 436 \\
OSTRACODA & 0 & 0 & 220 & 2738 & 135 & 0 \\
CHIRONOMIDAE & 146 & 900 & 157 & 763 & 0 & 698 \\
OLIGOCHAETA & 0 & 33 & 0 & 247 & 65 & 208 \\
NEMATODA & 0 & 282 & 0 & 20 & 0 & 341 \\
Total de outros grupos & $\mathbf{2 2 9}$ & $\mathbf{1 2 4 8}$ & $\mathbf{8 6 3}$ & $\mathbf{4 8 8 1}$ & $\mathbf{2 1 4 4}$ & $\mathbf{1 6 8 2}$ \\
Total de organismos & $\mathbf{5 4 8 4 0 4}$ & $\mathbf{2 3 1 1 9 8}$ & $\mathbf{4 0 9 7 5 4}$ & $\mathbf{6 7 5 8 5 5}$ & $\mathbf{4 6 9 2 4 7}$ & $\mathbf{2 7 2 0 3 1}$ \\
\hline \hline
\end{tabular}

No período de inverno 1 o táxon que ocorreu em maior densidade numérica em ambos os compartimentos foi Trichocerca sp. No período de inverno 2, a espécie de Copepoda Cyclopoida Thermocyclops minutus foi registrada em maior densidade no compartimento limnético, e o Rotifera Conochilus sp. foi o mais numeroso no litorâneo. No verão, Thermocyclops minutus também ocorreu em maior densidade no compartimento limnético, e o Rotifera Ptigura libera no litorâneo.

Nos períodos de inverno 1 e verão o grupo dos Rotifera ocorreu em maior densidade no compartimento litorâneo do que no limnético. Já no inverno 2, a maior densidade foi observada no litorâneo.

Os Cladocera foram mais numerosos na região litorânea nos períodos de inverno 1 e 2, principalmente pela ocorrência de espécies da família Chydoridae. No verão, foi encontrada maior densidade no compartimento limnético.

Os náuplios de copepoditos de Cyclopoida ocorreram em maior densidade no compartimento limnético nos períodos de inverno 1 e 2. Já no verão, os náuplios foram mais numerosos na região litorânea, e os copepoditos continuaram mais numerosos em região limnética.

Vale ressaltar que os Copepoda na lagoa Aguapé foram representados apenas por espécies da sub-ordem Cyclopoida.

A família Chaoboridae (Insecta) ocorreu em maior densidade nos períodos de inverno 2 e verão. No inverno 1 e verão, a maior densidade foi observada no compartimento limnético, e no inverno 2 no litorâneo.

Os Ostracoda ocorreram apenas no período de inverno 2 em ambos os compartimentos, com maior densidade no litorâneo, e no compartimento limnético no verão. 
Sempre foi observada uma maior densidade da família Chironomidae no compartimento litorâneo, valendo lembrar que no verão este grupo não ocorreu na região limnética.

Os Oligochaeta não ocorreram na região limnética nos períodos de inverno 1 e 2, e foi observada maior densidade na região litorânea no verão.

Os organismos do grupo Nematoda ocorreram apenas na região litorânea.

De maneira geral, os organismos zooplanctônicos ocorreram em maior número na região limnética nos períodos de inverno 1 e verão, e na litorânea no inverno 2.

A densidade numérica das espécies e dos grupos encontrados na lagoa Águas Claras está apresentada nas Tabelas 16 e 17.

Tabela 16. Densidade numérica (org. $/ \mathrm{m}^{3}$ ) dos táxons encontrados na lagoa Águas Claras, nos três períodos estudados.

\begin{tabular}{|c|c|c|c|c|c|c|}
\hline \multirow{2}{*}{ Táxon \Densidade (org./m3) } & \multicolumn{2}{|c|}{ Junho/1999 } & \multicolumn{2}{|c|}{ Agosto/1999 } & \multicolumn{2}{|c|}{ Fevereiro/2000 } \\
\hline & Limnética & Litorânea & Limnética & Litorânea & Limnética & Litorânea \\
\hline Hexarthra intermedia & 21225 & 46890 & 12880 & 5375 & 763 & 0 \\
\hline Anuraeopsis navicula & 148515 & 84590 & 514440 & 25735 & 0 & 0 \\
\hline Brachionus angularis & 0 & 0 & 1428 & 635 & 1020 & 287 \\
\hline Brachionus calyciflorus & 0 & 0 & 0 & 623 & 0 & 0 \\
\hline Brachionus caudatus & 12030 & 780 & 16920 & 1452 & 19898 & 0 \\
\hline Brachionus falcatus & 0 & 0 & 353 & 3147 & 0 & 0 \\
\hline Brachionus patulus & 0 & 0 & 0 & 0 & 0 & 297 \\
\hline Keratella americana & 0 & 0 & 2670 & 7168 & 763 & 2940 \\
\hline Collotheca sp. & 7500 & 5923 & 12680 & 5505 & 423 & 660 \\
\hline Lepadella patella & 0 & 0 & 0 & 1258 & 0 & 287 \\
\hline Conochiloide coenobasis & 0 & 2440 & 0 & 0 & 0 & 1277 \\
\hline Conochilus sp. & 0 & 0 & 0 & 312 & 0 & 0 \\
\hline Epiphanes clavatula & 0 & 0 & 0 & 323 & 0 & 0 \\
\hline Ptygura libera & 3060 & 2173 & 11570 & 47812 & 14085 & 29460 \\
\hline Ascomorpha ovalis & 38490 & 6107 & 353 & 312 & 0 & 0 \\
\hline Lecane (Monostyla) bulla & 0 & 1270 & 0 & 703 & 0 & 4163 \\
\hline Lecane (Monostyla) gillardi armata & 0 & 423 & 0 & 0 & 0 & 0 \\
\hline Lecane (Monostyla) Iunaris & 0 & 1800 & 0 & 0 & 0 & 287 \\
\hline Lecane (Monostyla) quadridentata & 0 & 0 & 0 & 0 & 0 & 287 \\
\hline Lecane inermis & 0 & 1270 & 0 & 0 & 0 & 0 \\
\hline Lecane leontina & 0 & 847 & 0 & 0 & 0 & 573 \\
\hline Lecane luna & 0 & 0 & 0 & 0 & 0 & 330 \\
\hline Lecane stichaea & 0 & 423 & 0 & 312 & 0 & 947 \\
\hline Proales giganthea & 0 & 0 & 0 & 0 & 423 & 1277 \\
\hline Polyarthra sp. & 510 & 10960 & 0 & 5298 & 845 & 29773 \\
\hline Testudinella patina & 0 & 0 & 1075 & 623 & 0 & 330 \\
\hline Trichocerca sp. & 0 & 1693 & 81703 & 17383 & 680 & 330 \\
\hline Macrochaetus collinsi & 0 & 340 & 0 & 688 & 0 & 1817 \\
\hline Bosmina hagmani & 0 & 410 & 162 & 5464 & 0 & 426 \\
\hline Bosmina tubicen & 0 & 788 & 212 & 7341 & 212 & 1901 \\
\hline Alona quadrata & 0 & 307 & 0 & 31 & 0 & 2281 \\
\hline Biapertura affinis & 0 & 410 & 0 & 252 & 0 & 0 \\
\hline Chydorus pubescens & 0 & 33 & 0 & 126 & 0 & 3019 \\
\hline Chydorus sphaericus & 0 & 68 & 0 & 129 & 0 & 0 \\
\hline Ceriodaphnia silvestrii & 0 & 210 & 0 & 97 & 0 & 0 \\
\hline Daphnia laevis & 0 & 0 & 1097 & 0 & 0 & 0 \\
\hline Simocephalus serrulatus & 0 & 0 & 0 & 37 & 0 & 0 \\
\hline Macrotrix laticornis & 0 & 1863 & 0 & 575 & 0 & 239 \\
\hline Diaphanosoma birgei & 0 & 0 & 0 & 38 & 11350 & 9908 \\
\hline Mesocyclops brasilianus & 105 & 5557 & 0 & 3966 & 910 & 7275 \\
\hline Thermocyclops minutus & 20383 & 2713 & 6923 & 4196 & 27970 & 3905 \\
\hline Tropocyclops prasinus & 1675 & 238 & 980 & 1106 & 2870 & 1461 \\
\hline Chaoborus sp. & 21590 & 623 & 1017 & 229 & 741 & 38 \\
\hline Physocypria sp. & 5860 & 952 & 2251 & 129 & 4985 & 0 \\
\hline
\end{tabular}


Tabela 17. Densidade numérica (org./ $\mathrm{m}^{3}$ ) dos principais grupos taxonômicos e fase de desenvolvimento de Copepoda encontrados na lagoa Águas Claras, nos três períodos de estudo.

\begin{tabular}{lcccccc}
\hline \hline \multirow{2}{*}{ Grupos \ Densidade (org./m3) } & \multicolumn{2}{c}{ Junho/1999 } & \multicolumn{2}{c}{ Agosto/1999 } & \multicolumn{2}{c}{ Fevereiro/2000 } \\
\cline { 2 - 7 } & Limnética & Litorânea & Limnética & Litorânea & Limnética & Litorânea \\
\hline ROTIFERA & $\mathbf{2 3 1 3 3 0}$ & $\mathbf{1 6 7 9 3 0}$ & $\mathbf{6 5 6 0 7 0}$ & $\mathbf{1 2 4 6 6 5}$ & $\mathbf{3 8 8 9 8}$ & $\mathbf{7 5 3 2 0}$ \\
CLADOCERA & $\mathbf{0}$ & $\mathbf{4 0 9 0}$ & $\mathbf{1 4 7 0}$ & $\mathbf{1 4 0 9 2}$ & $\mathbf{1 1 5 6 2}$ & $\mathbf{1 7 7 7 5}$ \\
Náulplios de COPEPODA CYCLOPOIDA & 246465 & 82473 & 157560 & 211037 & 115755 & 28107 \\
Copepodito de COPEPODA CYCLOPOIDA & 99073 & 10413 & 14680 & 14896 & 59590 & 12958 \\
Adultos de COPEPODA CYCLOPOIDA & 22163 & 8508 & 7903 & 9268 & 31750 & 12641 \\
COPEPODA CYCLOPOIDA & $\mathbf{3 6 7 7 0 0}$ & $\mathbf{1 0 1 3 9 5}$ & $\mathbf{1 8 0 1 4 2}$ & $\mathbf{2 3 5 2 0 0}$ & $\mathbf{2 0 7 0 9 5}$ & $\mathbf{5 3 7 0 6}$ \\
COPEPODA & $\mathbf{3 6 7 7 0 0}$ & $\mathbf{1 0 1 3 9 5}$ & $\mathbf{1 8 0 1 4 2}$ & $\mathbf{2 3 5 2 0 0}$ & $\mathbf{2 0 7 0 9 5}$ & $\mathbf{5 3 7 0 6}$ \\
CHAOBORIDAE & 21590 & 623 & 1017 & 229 & 741 & 38 \\
OSTRACODA & 5860 & 952 & 2251 & 129 & 4985 & 0 \\
CHIRONOMIDAE & 0 & 1252 & 0 & 604 & 0 & 124 \\
OLIGOCHAETA & 0 & 160 & 0 & 179 & 0 & 63 \\
NEMATODA & 0 & 278 & 84 & 601 & 0 \\
Total de outros grupos & $\mathbf{2 7 4 5 0}$ & $\mathbf{3 2 6 5}$ & $\mathbf{3 3 5 1}$ & $\mathbf{1 7 4 2}$ & $\mathbf{5 7 2 6}$ & $\mathbf{4 5 1}$ \\
Total de organismos & $\mathbf{6 2 6 4 8 0}$ & $\mathbf{2 7 6 6 8 0}$ & $\mathbf{8 4 1 0 3 3}$ & $\mathbf{3 7 5 6 9 9}$ & $\mathbf{2 6 3 2 8 1}$ & $\mathbf{1 4 7 2 5 7}$ \\
\hline \hline
\end{tabular}

Na lagoa Águas Claras, a espécie de Rotifera Anuraeopsis navicula foi a que ocorreu em maior densidade numérica em ambos os compartimentos no período de inverno 1 e no limnético no inverno 2. Na região litorânea no inverno 2 e verão a espécie mais numerosa foi o Rotifera Ptygura libera. Já na região limnética no inverno 2, a maior densidade foi encontrada para a espécie de Copepoda Cyclopoida Thermocyclops minutus.

O grupo dos Rotifera foi mais numeroso na região limnética nos períodos de inverno 1 e 2. No verão, quando foi observada menor densidade numérica de Rotifera, o compartimento em que estes ocorreram em maior densidade foi o litorâneo.

Na região limnética no período de inverno 1 não foram observados organismos do grupo Cladocera. No demais períodos, este grupo foi mais numeroso na região litorânea.

Nos períodos de inverno 1 e verão, os náuplios e copepoditos de Cyclopoida foram mais numerosos no compartimento limnético. No inverno 2, os náuplios apresentaram maior densidade no compartimento litorâneo, e os copepoditos ocorreram em densidades numéricas próximas em ambos os compartimentos.

Os Chaoboridae e Ostracoda, foram mais numerosos sempre no compartimento limnético, em todos os períodos de amostragem. Vale ressaltar, que não foram observados organismos representantes do grupo Ostracoda no compartimento litorâneo no verão.

Os organismos pertencentes aos grupos Chironomidae, Oligochaeta e Nematoda ocorreram apenas no compartimento litorâneo em todos os períodos analisados, com exceção à região pelágica no inverno 2 onde foram encontrados organismos pertencentes ao grupo dos Nematoda. 
De maneira geral, na lagoa Águas Claras, os organismos zooplanctônicos ocorreram com maior densidade numérica no compartimento limnético de todos os períodos amostrados.

As Tabelas 18 e 19 apresentam a densidade numérica das espécies e dos grupos de organismos que ocorreram na lagoa Ariranha.

Tabela 18. Densidade numérica (org. $/ \mathrm{m}^{3}$ ) dos táxons encontrados na lagoa Ariranha, nos três períodos estudados.

\begin{tabular}{|c|c|c|c|c|c|c|}
\hline \multirow{2}{*}{ Táxon \Densidade (org./m3) } & \multicolumn{2}{|c|}{ Junho/1999 } & \multicolumn{2}{|c|}{ Agosto/1999 } & \multicolumn{2}{|c|}{ Fevereiro/2000 } \\
\hline & Limnética & Litorânea & Limnética & Litorânea & Limnética & Litorânea \\
\hline Hexarthra intermedia & 12480 & 71307 & 2970 & 6073 & 1570 & 333 \\
\hline Anuraeopsis navicula & 161200 & 264477 & 0 & 1373 & 0 & 1275 \\
\hline Brachionus angularis & 15600 & 14470 & 3960 & 4958 & 1570 & 600 \\
\hline Brachionus caudatus & 346320 & 118560 & 1980 & 332 & 12560 & 300 \\
\hline Brachionus falcatus & 0 & 0 & 7920 & 8402 & 47885 & 11108 \\
\hline Brachionus patulus & 0 & 0 & 0 & 663 & 0 & 0 \\
\hline Keratella americana & 0 & 727 & 0 & 650 & 0 & 2242 \\
\hline Collotheca sp. & 1040 & 1100 & 2970 & 4577 & 3925 & 1558 \\
\hline Lepadella patella & 0 & 0 & 0 & 1645 & 0 & 325 \\
\hline Conochiloide coenobasis & 0 & 0 & 0 & 0 & 0 & 900 \\
\hline Conochilus sp. & 2080 & 1453 & 0 & 0 & 0 & 300 \\
\hline Epiphanes clavatula & 0 & 0 & 1980 & 0 & 0 & 1225 \\
\hline Ptygura libera & 1040 & 2567 & 275 & 243235 & 8635 & 74542 \\
\hline Ascomorpha ovalis & 0 & 9057 & 0 & 2932 & 1570 & 1250 \\
\hline Lecane (Monostyla) bulla & 0 & 1443 & 0 & 332 & 0 & 1267 \\
\hline Lecane (Monostyla) Iunaris & 0 & 373 & 990 & 2613 & 0 & 0 \\
\hline Lecane inermis & 0 & 747 & 0 & 0 & 0 & 0 \\
\hline Lecane leontina & 0 & 0 & 0 & 0 & 0 & 333 \\
\hline Lecane Iuna & 0 & 4333 & 0 & 663 & 0 & 0 \\
\hline Lecane stichaea & 0 & 350 & 0 & 1313 & 0 & 600 \\
\hline Proales giganthea & 0 & 0 & 0 & 0 & 0 & 325 \\
\hline Polyarthra sp. & 0 & 4317 & 990 & 0 & 0 & 0 \\
\hline Testudinella patina & 0 & 0 & 0 & 1300 & 0 & 1867 \\
\hline Trichocerca sp. & 9360 & 38203 & 18810 & 11947 & 785 & 3767 \\
\hline Macrochaetus collinsi & 0 & 363 & 0 & 3900 & 0 & 900 \\
\hline Bosmina hagmani & 105 & 1467 & 0 & 0 & 0 & 66 \\
\hline Bosmina tubicen & 625 & 3670 & 0 & 0 & 79 & 2612 \\
\hline Alona quadrata & 0 & 37 & 0 & 65 & 0 & 303 \\
\hline Biapertura affinis & 0 & 290 & 0 & 134 & 0 & 123 \\
\hline Chydorus pubescens & 0 & 145 & 102 & 24 & 0 & 368 \\
\hline Chydorus sphaericus & 0 & 182 & 0 & 0 & 0 & 0 \\
\hline Disparalona sp. & 0 & 145 & 0 & 18 & 0 & 180 \\
\hline Ceriodaphnia silvestrii & 0 & 140 & 0 & 33 & 0 & 0 \\
\hline Simocephalus serrulatus & 0 & 0 & 0 & 129 & 0 & 138 \\
\hline Macrotrix laticornis & 0 & 330 & 0 & 650 & 0 & 151 \\
\hline Diaphanosoma birgei & 0 & 0 & 0 & 0 & 393 & 73 \\
\hline Diaphanosoma fluviatile & 415 & 1002 & 0 & 31 & 156 & 62 \\
\hline Notodiaptomus isabelae & 6865 & 0 & 6188 & 0 & 400 & 0 \\
\hline Mesocyclops brasilianus & 830 & 2827 & 198 & 1243 & 314 & 1514 \\
\hline Thermocyclops minutus & 19970 & 2478 & 66528 & 33 & 24335 & 1102 \\
\hline Tropocyclops prasinus & 1250 & 793 & 1287 & 195 & 4553 & 0 \\
\hline Chaoborus sp. & 275 & 67 & 285 & 239 & 235 & 263 \\
\hline Physocypria sp. & 415 & 0 & 0 & 0 & 150 & 27 \\
\hline
\end{tabular}


Tabela 19. Densidade numérica (org./ $\mathrm{m}^{3}$ ) dos principais grupos taxonômicos e fases de desenvolvimento de Copepoda encontrados na lagoa Ariranha, nos três períodos estudados.

\begin{tabular}{|c|c|c|c|c|c|c|}
\hline \multirow{2}{*}{ Grupos \Densidade (org./m3) } & \multicolumn{2}{|c|}{ Junho/1999 } & \multicolumn{2}{|c|}{ Agosto/1999 } & \multicolumn{2}{|c|}{ Fevereiro/2000 } \\
\hline & Limnética & Litorânea & Limnética & Litorânea & Limnética & Litorânea \\
\hline ROTIFERA & 549120 & 533847 & 42845 & 296908 & 78500 & 105017 \\
\hline CLADOCERA & 1145 & 7407 & 102 & 1083 & 628 & 4077 \\
\hline Náuplios de COPEPODA CALANOIDA & 23920 & 15537 & 55440 & 59845 & 49455 & 32633 \\
\hline Copepodito de COPEPODA CALANOIDA & 730 & 360 & 11880 & 490 & 80 & 267 \\
\hline Adultos de COPEPODA CALANOIDA & 6865 & 253 & 6188 & 0 & 400 & 0 \\
\hline COPEPODA CALANOIDA & 31515 & 16150 & 73508 & 60335 & 49935 & 32900 \\
\hline Náulplios de COPEPODA CYCLOPOIDA & 96720 & 62347 & 374220 & 240485 & 166420 & 65783 \\
\hline Copepodito de COPEPODA CYCLOPOIDA & 39935 & 5298 & 81972 & 2123 & 6594 & 6083 \\
\hline Adultos de COPEPODA CYCLOPOIDA & 22050 & 6098 & 68013 & 1471 & 29202 & 2616 \\
\hline COPEPODA CYCLOPOIDA & 158705 & 73743 & 524205 & 244079 & 202216 & 74482 \\
\hline COPEPODA & 190220 & 89893 & 597713 & 304414 & 252151 & 107382 \\
\hline CHAOBORIDAE & 275 & 67 & 285 & 239 & 235 & 263 \\
\hline OSTRACODA & 415 & 0 & 0 & 0 & 150 & 27 \\
\hline CHIRONOMIDAE & 0 & 4078 & 0 & 3695 & 160 & 439 \\
\hline OLIGOCHAETA & 0 & 327 & 0 & 924 & 0 & 0 \\
\hline NEMATODA & 0 & 248 & 0 & 265 & 0 & 488 \\
\hline Total de outros grupos & 690 & 4720 & 285 & 5122 & 545 & 1217 \\
\hline Total de organismos & 741175 & 635867 & 640945 & 607528 & 331824 & 217693 \\
\hline
\end{tabular}

No compartimento limnético no inverno 1 e verão, a espécie que ocorreu em maior densidade de organismos foi o Rotifera Brachionus caudatus. A espécie de Rotifera Anuraeopsis navicula foi registrada em maior densidade na região litorânea no período de inverno 1 . No inverno 2, as espécies mais numerosas foram o Copepoda Cyclopoida Mesocyclops brasilianus na região limnética e o Rotifera Ptygura libera na litorânea. Esta última espécie também foi a mais numerosa no compartimento litorâneo no verão.

No período de inverno 1 , foram observadas densidades numéricas próximas para o grupo dos Rotifera entre os compartimentos litorâneo e limnético, sendo um pouco mais numeroso neste último. Já nos períodos de inverno 2 e verão, a densidade encontrada no compartimento litorâneo foi maior.

Em relação ao grupo dos Cladocera, em todos os períodos amostrados, foi encontrada maior densidade no compartimento litorâneo.

Tanto para os náuplios de Calanoida como os de Cyclopoida foi observada maior densidade no compartimento pelágico no inverno 1 e verão. No inverno 2, os náuplios de Cyclopoida foram mais numerosos também no compartimento pelágico, diferentemente dos náuplios de Calanoida cuja densidade foi maior no litorâneo.

Nos períodos de inverno 1 e 2 as densidades de copepoditos de Calanoida e de Cyclopoida foram maiores nos compartimentos limnéticos. Para os copepoditos de Cyclopoida esta tendência também foi observada no verão. Porém, para os de Calanoida, a maior densidade neste período foi verificada no compartimento litorâneo. 
Tanto para o grupo dos Copepoda Calanoida como o dos Cyclopoida, as maiores densidades foram observadas no compartimento limnético, nos três períodos de estudo.

Os Chaoboridae ocorreram em maior densidade no compartimento limnético nos períodos de inverno 1 e 2 . Já no verão, embora as densidades tenham sido próximas, foi observado maior número de organismos no compartimento litorâneo.

Os organismos pertencentes ao grupo dos Ostracoda ocorreram apenas no compartimento limnético no inverno 1 e em ambos os compartimentos no verão, sendo que neste último período foi observada maior densidade no limnético.

No períodos de inverno 1 e 2, foram encontrados organismos dos grupos de Chironomidae, Oligochaeta e Nematoda apenas no compartimento litorâneo. No verão, os Chironomidae ocorreram em ambos os compartimentos, mas com maior densidade no limnético. Os Oligochaeta não ocorreram no período de verão, e os Nematoda ocorreram apenas na região litorânea neste período.

De maneira geral, a densidade total zooplanctônica foi maior na região limnética nos três períodos de amostragem.

As Tabelas 20 e 21 apresentam a densidade das espécies e dos grupos encontrados na lagoa Amarela.

O táxon cuja densidade foi maior no compartimento limnético no inverno 1 , foi o Rotifera Trichocerca sp. No compartimento litorâneo no inverno 1, foi observada uma maior densidade para a espécie de Cladocera Ceriodaphnia silvestrii. Em ambos os compartimentos no inverno 2, a espécie mais numerosa foi o Cladocera Daphnia laevis, com maior densidade no compartimento limnético. Esta mesma espécie foi mais numerosa também no compartimento limnético no verão. Neste período, a maior densidade no compartimento litorâneo foi encontrada para a espécie de Rotifera Keratella quadrata.

Os Rotifera ocorreram em maior densidade no compartimento limnético no inverno 1. Já nos períodos de inverno 2 e verão, a maior densidade de Rotifera foi observada no litorâneo.

No inverno 1, foi observada maior densidade de Cladocera na região litorânea, enquanto que nos períodos de inverno 2 e verão, a maior densidade deste grupo foi verificada na região limnética. 
Tabela 20. Densidade numérica (org. $/ \mathrm{m}^{3}$ ) dos táxons encontrados na lagoa Amarela, nos três períodos estudados.

\begin{tabular}{|c|c|c|c|c|c|c|}
\hline \multirow{2}{*}{ Táxon \ Densidade (org./m3) } & \multicolumn{2}{|c|}{ Junho/1999 } & \multicolumn{2}{|c|}{ Agosto/1999 } & \multicolumn{2}{|c|}{ Fevereiro/2000 } \\
\hline & Limnética & Litorânea & Limnética & Litorânea & Limnética & Litorânea \\
\hline Hexarthra intermedia & 0 & 0 & 4480 & 0 & 0 & 0 \\
\hline Anuraeopsis navicula & 0 & 0 & 0 & 3460 & 0 & 0 \\
\hline Brachionus patulus & 0 & 0 & 0 & 865 & 1840 & 1520 \\
\hline Brachionus quadridentatus & 0 & 0 & 0 & 0 & 0 & 1520 \\
\hline Keratella americana & 1270 & 0 & 0 & 0 & 0 & 0 \\
\hline Keratella lenzi & 1130 & 1160 & 0 & 0 & 0 & 0 \\
\hline Keratella quadrata & 0 & 0 & 0 & 0 & 35880 & 53200 \\
\hline Lepadella patella & 0 & 0 & 0 & 865 & 0 & 0 \\
\hline Conochiloide coenobasis & 0 & 0 & 0 & 0 & 23920 & 7600 \\
\hline Conochilus sp. & 0 & 0 & 1012 & 0 & 0 & 0 \\
\hline Epiphanes clavatula & 0 & 0 & 0 & 0 & 920 & 0 \\
\hline Ptygura libera & 0 & 4640 & 0 & 2595 & 0 & 0 \\
\hline Ascomorpha ovalis & 0 & 3480 & 0 & 1730 & 0 & 0 \\
\hline Gastropus sp. & 0 & 1160 & 0 & 0 & 0 & 0 \\
\hline Lecane (Monostyla) bulla & 0 & 3480 & 3325 & 4325 & 8280 & 6080 \\
\hline Lecane (Monostyla) lunaris & 3390 & 0 & 0 & 2595 & 0 & 1520 \\
\hline Lecane (Monostyla) quadridentata & 0 & 0 & 0 & 0 & 0 & 1520 \\
\hline Lecane hornemanni & 0 & 0 & 0 & 0 & 920 & 0 \\
\hline Lecane inermis & 2260 & 0 & 0 & 0 & 0 & 0 \\
\hline Lecane leontina & 0 & 1160 & 0 & 0 & 0 & 0 \\
\hline Lecane luna & 0 & 3480 & 0 & 865 & 1840 & 0 \\
\hline Itura aurita & 0 & 1160 & 0 & 0 & 0 & 0 \\
\hline Ploesoma truncatum & 0 & 2320 & 0 & 0 & 0 & 0 \\
\hline Polyarthra sp. & 3390 & 10440 & 0 & 0 & 0 & 0 \\
\hline Testudinella patina & 45200 & 0 & 0 & 865 & 0 & 10640 \\
\hline Trichocerca bidens & 0 & 5800 & 0 & 0 & 0 & 0 \\
\hline Trichocerca sp. & 71190 & 31320 & 0 & 865 & 0 & 0 \\
\hline Macrochaetus collinsi & 0 & 0 & 0 & 0 & 920 & 1520 \\
\hline Trochosphaera sp. & 0 & 0 & 0 & 0 & 0 & 1520 \\
\hline Bosmina hagmani & 905 & 0 & 0 & 0 & 210 & 0 \\
\hline Bosmina tubicen & 1245 & 4175 & 896 & 0 & 920 & 720 \\
\hline Alona quadrata & 115 & 930 & 0 & 0 & 0 & 1480 \\
\hline Biapertura affinis & 0 & 465 & 0 & 0 & 0 & 0 \\
\hline Chydorus pubescens & 0 & 0 & 224 & 80 & 350 & 120 \\
\hline Chydorus sphaericus & 0 & 0 & 0 & 0 & 0 & 0 \\
\hline Disparalona sp. & 0 & 0 & 0 & 87 & 0 & 0 \\
\hline Ceriodaphnia silvestrii & 790 & 77950 & 672 & 278 & 905 & 120 \\
\hline Daphnia laevis & 4070 & 0 & 61824 & 12456 & 72050 & 14252 \\
\hline Macrotrix laticornis & 0 & 420 & 448 & 91 & 1050 & 142 \\
\hline Diaphanosoma birgei & 0 & 478 & 0 & 0 & 0 & 0 \\
\hline Notodiaptomus isabelae & 225 & 1855 & 232 & 1211 & 360 & 2400 \\
\hline Mesocyclops brasilianus & 565 & 1390 & 825 & 175 & 1240 & 250 \\
\hline Thermocyclops minutus & 7910 & 6030 & 11088 & 6142 & 15250 & 4350 \\
\hline Tropocyclops prasinus & 115 & 1855 & 0 & 0 & 0 & 0 \\
\hline Chaoborus sp. & 680 & 1395 & 461 & 844 & 320 & 540 \\
\hline Physocypria sp. & 0 & 0 & 0 & 0 & 0 & 0 \\
\hline
\end{tabular}

Os náuplios de Copepoda Calanoida foram mais numerosos no compartimento limnético no inverno 1. Já os náuplios de Cyclopoida, ocorreram em maior densidade no compartimento litorâneo neste mesmo período. No período de inverno 2, a maior densidade de náuplios de Calanoida e de Cyclopoida foi observada no compartimento limnético, enquanto no verão maior densidade foi registrada no litorâneo.

Os copepoditos de Calanoida ocorreram em maior densidade numérica sempre no compartimento litorâneo, nos três períodos de estudo. Já os copepoditos de Cyclopoida foram mais numerosos no compartimento litorâneo no inverno 1, e no compartimento limnético nos períodos de inverno 2 e verão. 
Tabela 21. Densidade numérica (org./ $\mathrm{m}^{3}$ ) dos principais grupos taxonômicos e fases de desenvolvimento de Copepoda encontrados na lagoa Amarela, nos três períodos estudados.

\begin{tabular}{lcccccc}
\hline \hline \multirow{2}{*}{ Grupos \ Densidade (org./m3) } & \multicolumn{2}{c}{ Junho/1999 } & \multicolumn{2}{c}{ Agosto/1999 } & \multicolumn{2}{c}{ Fevereiro/2000 } \\
\cline { 2 - 7 } & Limnética & Litorânea & Limnética & Litorânea & Limnética & Litorânea \\
\hline ROTIFERA & $\mathbf{1 2 7 8 3 0}$ & $\mathbf{6 9 6 0 0}$ & $\mathbf{8 8 1 7}$ & $\mathbf{1 9 0 3 0}$ & $\mathbf{7 4 5 2 0}$ & $\mathbf{8 6 6 4 0}$ \\
CLADOCERA & $\mathbf{7 1 2 5}$ & $\mathbf{8 4 4 1 8}$ & $\mathbf{6 4 0 6 4}$ & $\mathbf{1 2 9 9 2}$ & $\mathbf{7 5 4 8 5}$ & $\mathbf{1 6 8 3 4}$ \\
Náuplios de COPEPODA CALANOIDA & 15820 & 15080 & 10380 & 5600 & 7230 & 15680 \\
Copepodito de COPEPODA CALANOIDA & 138 & 530 & 560 & 606 & 260 & 452 \\
Adultos de COPEPODA CALANOIDA & 225 & 1855 & 232 & 1211 & 360 & 2400 \\
COPEPODA CALANOIDA & $\mathbf{1 6 1 8 3}$ & $\mathbf{1 7 4 6 5}$ & $\mathbf{1 1 1 7 2}$ & $\mathbf{7 4 1 7}$ & $\mathbf{7 8 5 0}$ & $\mathbf{1 8 5 3 2}$ \\
Náulplios de COPEPODA CYCLOPOIDA & 27120 & 55680 & 57090 & 33500 & 15020 & 62700 \\
Copepodito de COPEPODA CYCLOPOIDA & 6215 & 6495 & 6048 & 4152 & 7830 & 5360 \\
AdultoS de COPEPODA CYCLOPOIDA & 8590 & 9275 & 11913 & 6317 & 16490 & 4600 \\
COPEPODA CYCLOPOIDA & $\mathbf{4 1 9 2 5}$ & $\mathbf{7 1 4 5 0}$ & $\mathbf{7 5 0 5 1}$ & $\mathbf{4 3 9 6 9}$ & $\mathbf{3 9 3 4 0}$ & $\mathbf{7 2 6 6 0}$ \\
COPEPODA & $\mathbf{5 8 1 0 8}$ & $\mathbf{8 8 9 1 5}$ & $\mathbf{8 6 2 2 3}$ & $\mathbf{5 1 3 8 6}$ & $\mathbf{4 7 1 9 0}$ & $\mathbf{9 1 1 9 2}$ \\
CHAOBORIDAE & 680 & 1395 & 461 & 844 & 320 & 540 \\
OSTRACODA & 0 & 0 & 0 & 0 & 0 & 0 \\
CHIRONOMIDAE & 0 & 1855 & 1008 & 0 & 562 & 260 \\
OLIGOCHAETA & 0 & 0 & 112 & 0 & 0 \\
NEMATODA & 0 & 0 & 784 & 260 & 852 & 0 \\
Total de outros grupos & $\mathbf{6 8 0}$ & $\mathbf{3 2 5 0}$ & $\mathbf{2 3 6 5}$ & $\mathbf{1 1 0 4}$ & $\mathbf{1 7 3 4}$ \\
Total de organismos & $\mathbf{1 9 3 7 4 3}$ & $\mathbf{2 4 6 1 8 3}$ & $\mathbf{1 6 1 4 6 9}$ & $\mathbf{8 4 5 1 2}$ & $\mathbf{1 9 8 9 2 9}$ & $\mathbf{1 9 5 4 6 6}$ \\
\hline \hline
\end{tabular}

No geral, os Copepoda foram mais numerosos no compartimento litorâneo nos períodos de inverno 1 e verão, e no compartimento limnético no inverno 2.

Os Chaoboridae ocorreram em maior densidade de organismos no compartimento litorâneo em todos os períodos de amostragem. Já os Ostracoda não ocorreram na lagoa Amarela em nenhum período.

Os organismos pertencentes ao grupo dos Chironomidae não ocorreram nos compartimentos limnético no inverno 1 e no litorâneo no inverno 2 . No verão, foi verificada maior densidade deste grupo na região limnética.

Os Oligochaeta foram observados apenas no compartimento limnético do inverno 2.

Já os Nematoda não ocorreram em ambos os compartimentos no inverno 1, e no compartimento litorâneo no verão. No período de inverno 2, foi observada maior densidade de Nematoda no compartimento limnético.

De forma geral, no período de inverno 1 , foi observada maior densidade do zooplâncton no compartimento litorâneo. Já nos períodos de inverno 2 e verão, a maior densidade zooplanctônica foi verificada na região limnética. 
- ABUndânCia RELATIVA

\section{- Abundância relativa dos principais grupos zooplanctônicos}

Na Figura 36 estão apresentadas, graficamente, as relações percentuais entre os grupos zooplanctônicos para cada compartimento amostrado, nos três períodos de estudo.

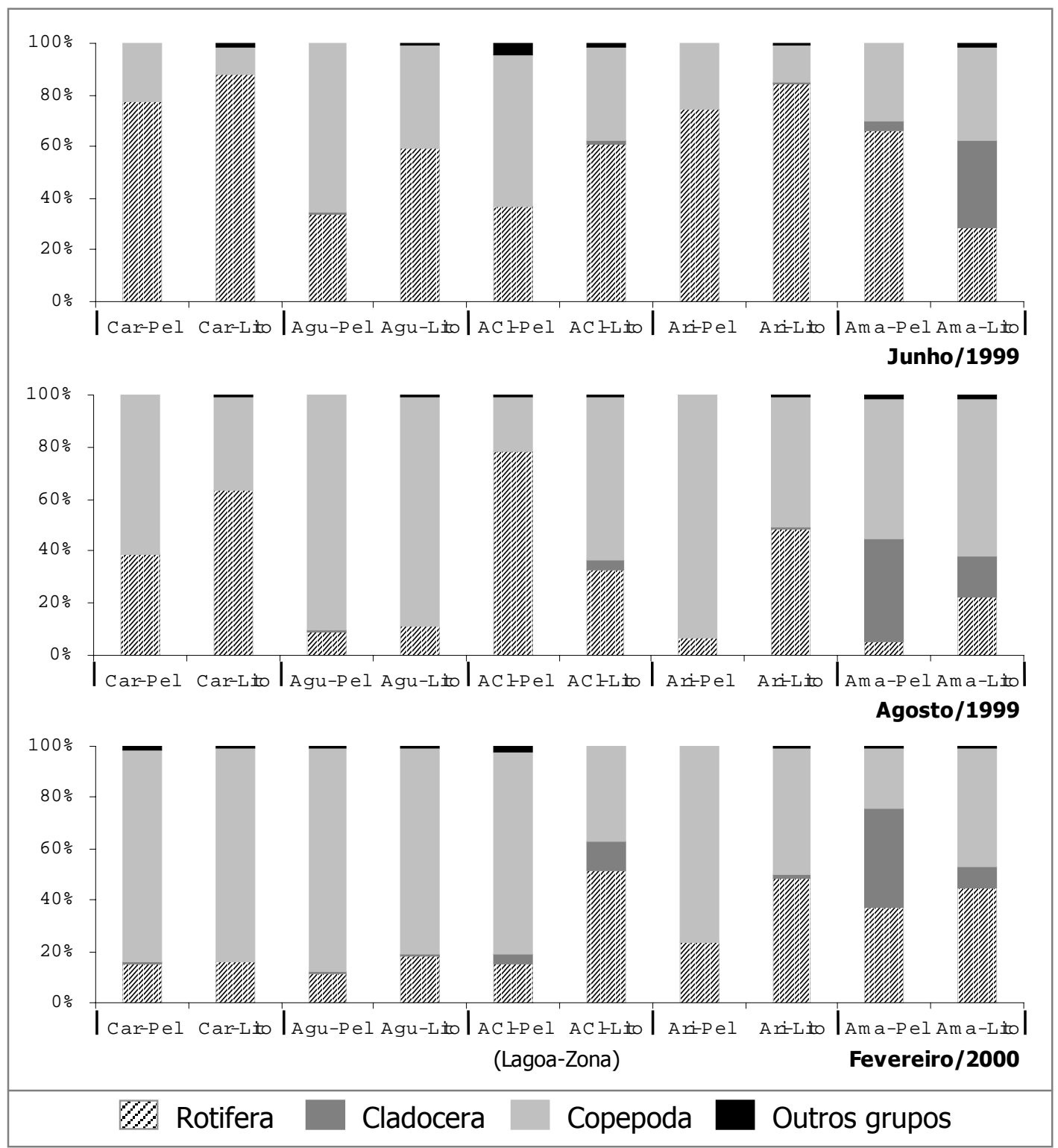

Figura 36. Abundância relativa entre os principais grupos zooplanctônicos, nas zonas limnéticas e litorâneas das lagoas estudadas, nos três períodos de estudo.

Os valores percentuais de cada grupo podem ser verificados no Anexo. 
No período de inverno 1, o grupo dos Rotifera foi o mais abundante em todas as lagoas, com exceção feita ao compartimento limnético da lagoa Águas Claras, onde os Copepoda dominaram, e ao litorâneo da lagoa Amarela, onde dominaram os Cladocera.

No inverno 2, os Rotifera dominaram apenas no compartimento litorâneo da lagoa Carioca e pelágico da lagoa Águas Claras. Neste mesmo período, em ambos os compartimentos das lagoas Aguapé, Ariranha e Amarela, e nos compartimentos limnético da lagoa Carioca e litorâneo da lagoa Águas Claras, o grupo dominante foi o dos Copepoda.

No último período de amostragem (verão) o grupo dos Rotifera foi observado em maior abundância relativa apenas no compartimento litorâneo da lagoa Águas Claras. No limnético da lagoa Amarela os Cladocera dominaram. Em ambos os compartimentos das lagoas Carioca, Aguapé e Ariranha, neste período, e nos compartimentos limnético da lagoa Águas Claras e litorâneo da lagoa Amarela o grupo dominante foi o dos Copepoda. Vale ressaltar, que nos compartimentos litorâneos das lagoas Ariranha e Amarela, as abundâncias relativas entre Copepoda e Rotifera foram próximas.

Os outros grupos zooplanctônicos ocorreram em baixa abundância relativa em todos os compartimentos de todas as lagoas, não sendo dominantes em nenhum período de amostragem. 
- Abundância relativa dos Lecanidae, Brachionidae e as demais famílias de Rotifera

A Figura 37 apresenta as relações de abundância entre as famílias Lecanidae, Brachionidae e todas as demais famílias de Rotifera.

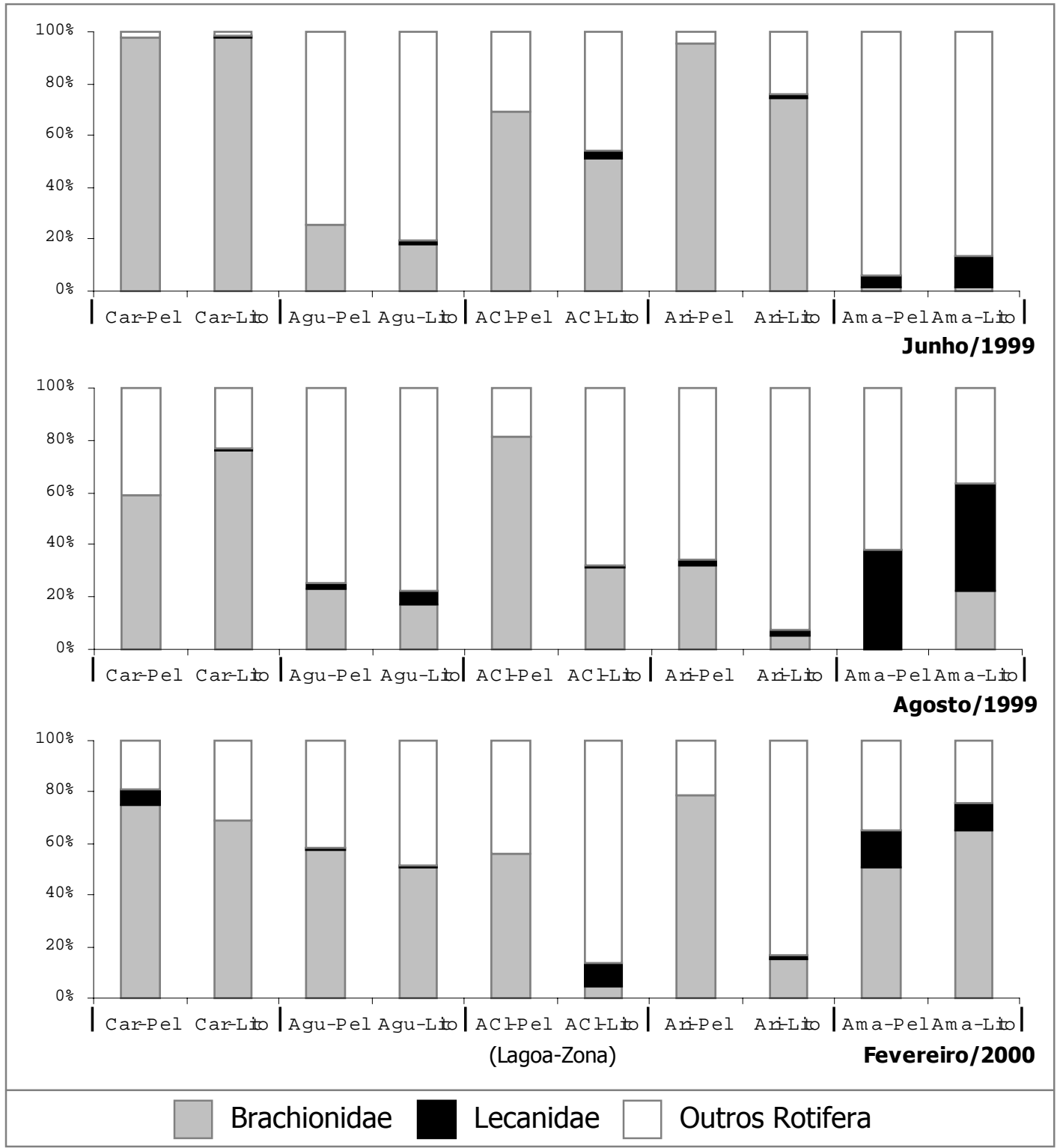

Figura 37. Abundância relativa entre os Lecanidae, Brachionidae e as demais famílias de Rotifera, nas zonas limnética e litorânea das lagoas estudadas, nos três períodos estudados. 
No inverno 1 os Rotifera Brachionidae ocorreram em maior abundância dentre todos os Rotifera, em ambos os compartimentos das lagoas Carioca, Águas Claras e Ariranha. Vale ressaltar que nos compartimentos limnético e litorâneo da lagoa Carioca, o grupo dos Rotifera foi quase totalmente composto pela família Brachionidae. Já no inverno 2, os Brachionidae foram mais abundantes apenas na lagoa Carioca, em ambos os compartimentos, e no compartimento pelágico da lagoa Águas Claras. Neste período, ocorreu a única dominância da família Lecanidae dentre todos os períodos estudados, no compartimento litorâneo da lagoa Amarela.

No período de verão, a família Brachionidae dominou, em função da abundância relativa, quase todos os compartimentos de todas as lagoas, com exceção dos litorâneos da lagoas Águas Claras e Ariranha. 


\section{- Abundância relativa das famílias de Cladocera}

A Figura 38 apresenta as relações de abundância entre as famílias de Cladocera, nas diferentes lagoas, nos compartimentos limnético e litorâneo, nos três períodos amostrados.

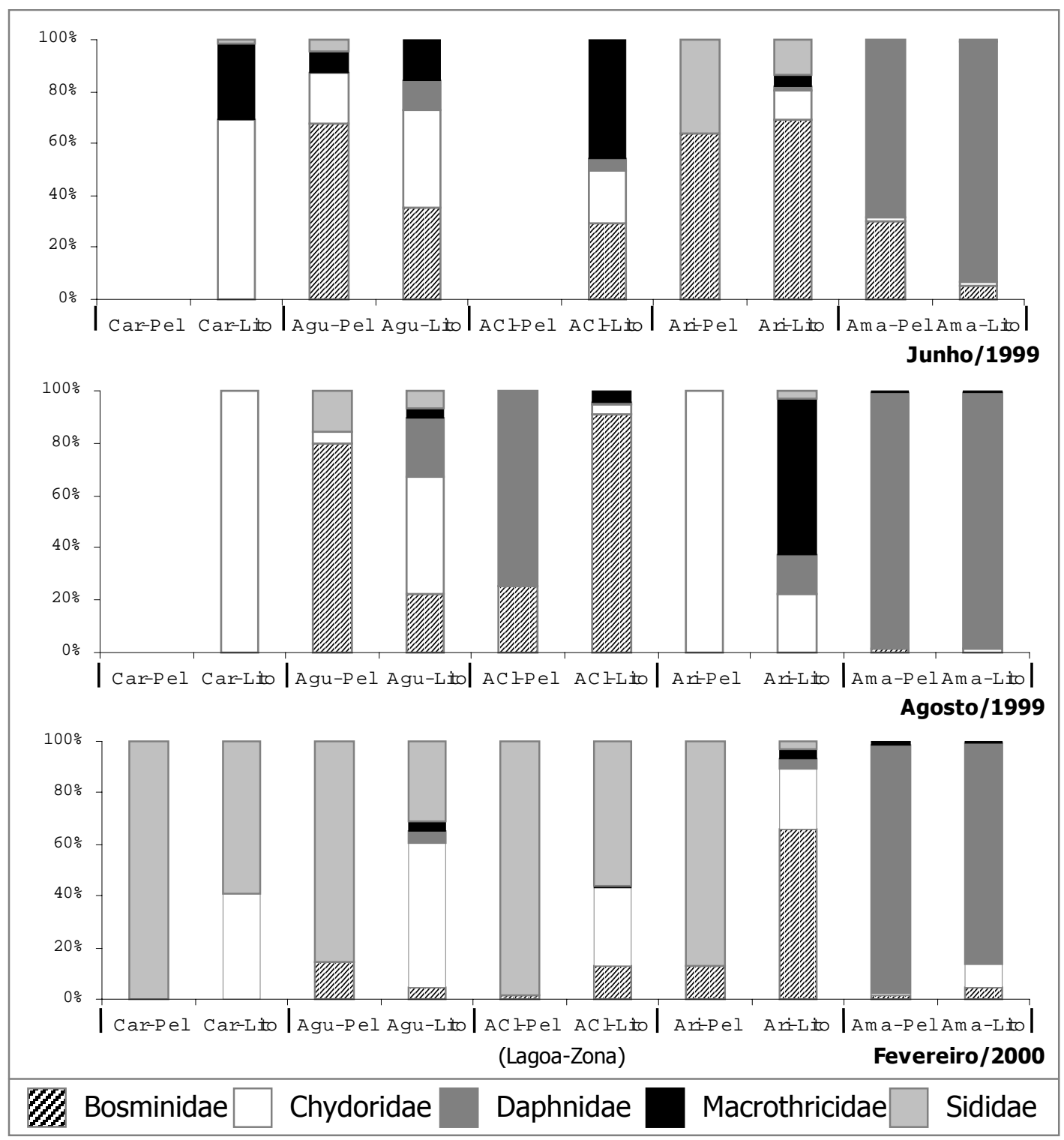

Figura 38. Abundância relativa entre as famílias de Cladocera, nas zonas pelágica e litorânea das lagoas estudadas, nos três períodos estudados.

Inicialmente, é importante destacar que nos compartimentos pelágicos da lagoa Carioca no inverno 1 e 2 e no da lagoa Águas Claras no inverno 1, não foi encontrada nenhuma espécie de Cladocera. 
No período de inverno 1, a família Chydoridae foi mais abundante nos compartimentos litorâneos das lagoas Carioca e Aguapé. A família Bosminidae ocorreu em maior abundância no compartimento pelágico da lagoa Aguapé e em ambos os compartimentos da lagoa Ariranha. Os Macrothricidae dominaram apenas no compartimento litorâneo da lagoa Águas Claras, e os Daphnidae foram mais abundantes em ambos os compartimentos da lagoa Amarela.

Nos compartimentos litorâneo da lagoa Carioca e pelágico da Ariranha, no inverno 2, só ocorreram espécies pertencentes à família Chydoridae. Este grupo também foi o mais abundante dentre os Cladocera no compartimento litorâneo da lagoa Aguapé, no mesmo período. Ainda no inverno 2, foi encontrada maior abundância da família Bosminidae nos compartimentos limnético da lagoa Aguapé e litorâneo da lagoa Águas Claras. A família Daphnidae ocorreu em maior abundância no compartimento limnético da lagoa Águas Claras e em ambos os compartimentos da lagoa Amarela, no período de inverno 2. No compartimento litorâneo da lagoa Ariranha, a família mais abundante dentre os Cladocera foi a Macrothricidae.

No verão, a família Sididae apresentou maior abundância em ambos os compartimentos da lagoa Carioca e Águas Claras, e nos compartimentos limnéticos das lagoas Aguapé e Ariranha. Os Chydoridae foram mais abundantes dentre os Cladocera no compartimento litorâneo da lagoa Águas Claras e os Bosminidae no compartimento litorâneo da lagoa Ariranha. A família Daphnidae teve maior abundância dentre os Cladocera, em ambos os compartimentos da lagoa Amarela, no verão. 


\section{- Abundância relativa dos Copepoda Calanoida e Cyclopoida}

A Figura 39 apresenta as relações de abundância entre os Copepoda Calanoida e Cyclopoida apenas nas lagoas Ariranha e Amarela, pois nas demais lagoas não ocorrem espécies de Copepoda Calanoida.

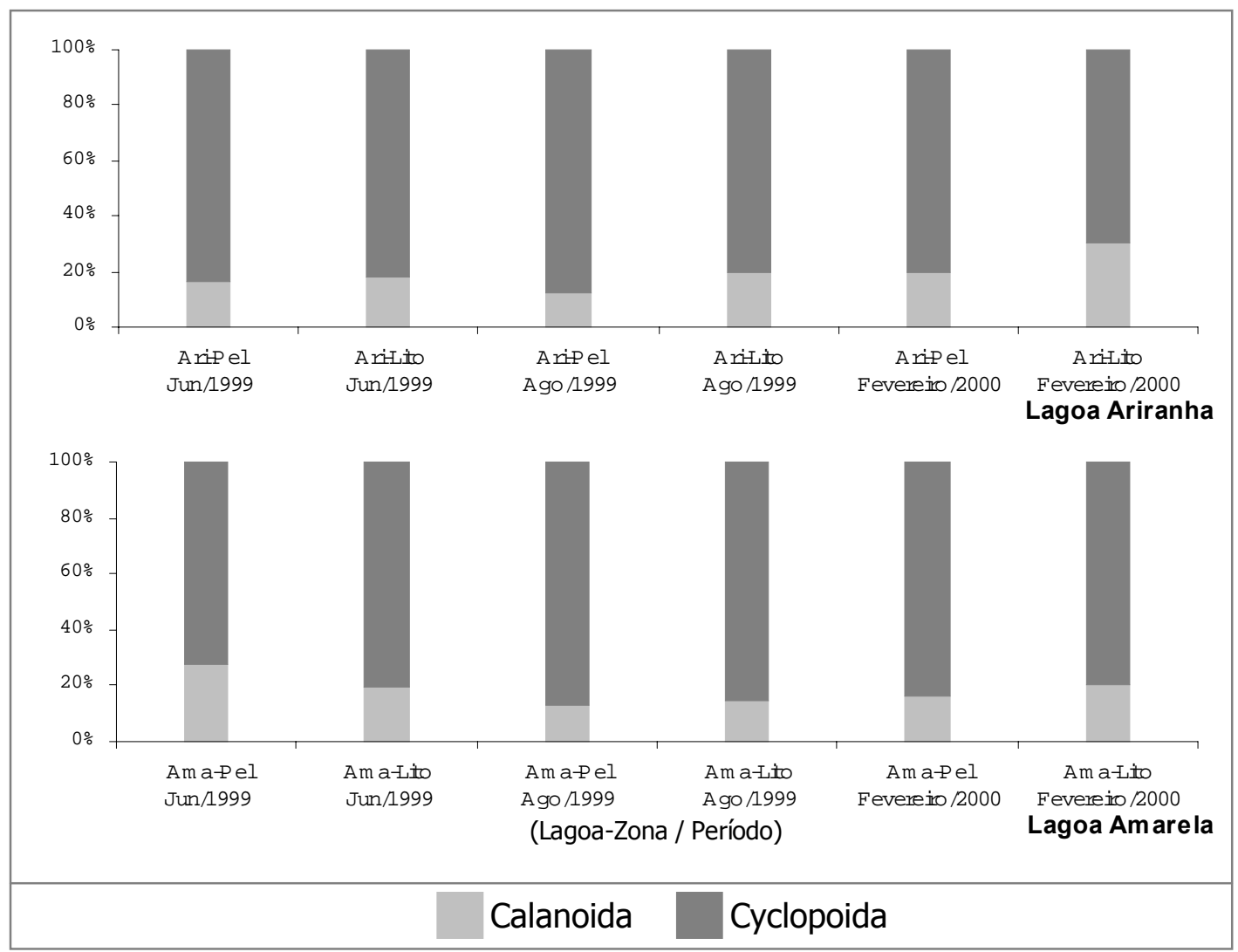

Figura 39. Abundância relativa entre os Copepoda Calanoida e Cyclopoida, nas zonas pelágicas e litorâneas das lagoas Ariranha e Amarela, nos três períodos estudados.

Em todos os períodos de amostragem, foi observada maior abundância relativa dos Copepoda Cyclopoida em relação as Calanoida, em todos os compartimentos das lagoas Amarela e Ariranha. 
- Abundância relativa de Notodiaptomus isabelae entre zonas limnéticas e litorâneas das lagoas Ariranha e Amarela

A Figura 40 apresenta as relações de abundância do Copepoda Calanoida Notodiaptomus isabelae, entre os compartimentos limnético e litorâneo das lagoas Amarela e Ariranha, nos três períodos de amostragem.

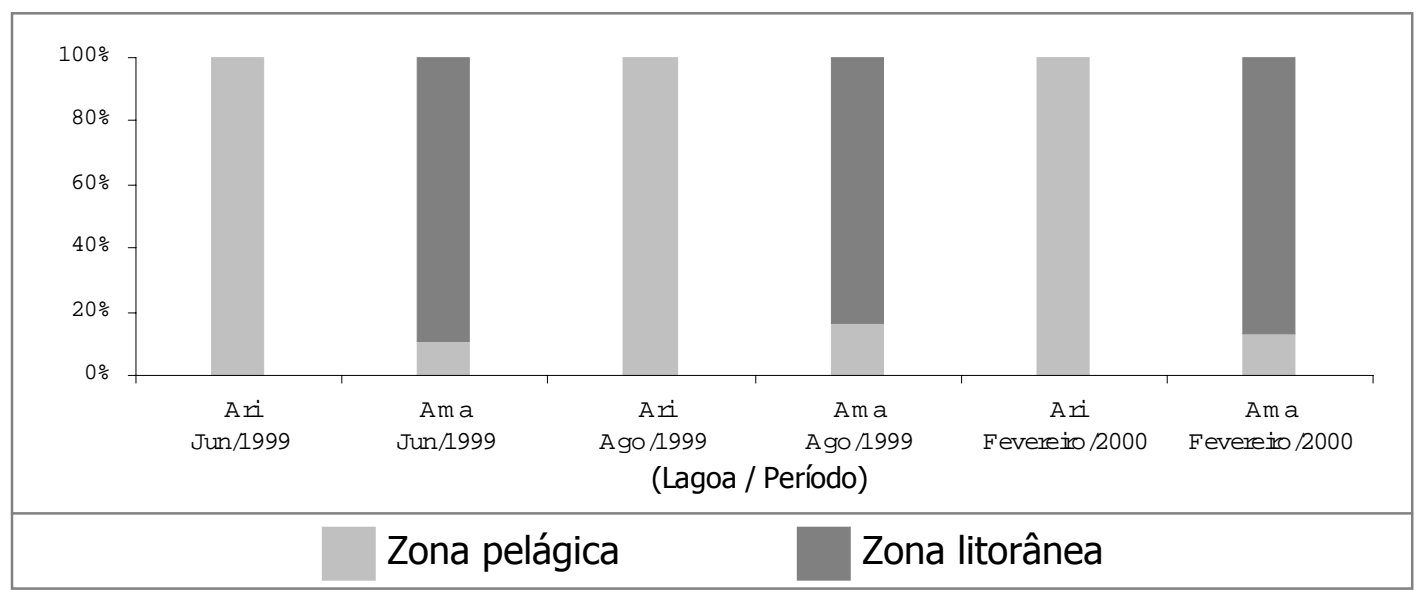

Figura 40. Abundância relativa de Notodiaptomus isabelae, entre as zonas limnética e litorânea das lagoas Ariranha e Amarela, nos três períodos estudados.

Nos três períodos de amostragem a única espécie de Copepoda Calanoida, Notodiaptus isabelae, ocorreu apenas no compartimento limnético da lagoa Ariranha.

Na lagoa Amarela esta relação se inverteu, e foi observada maior abundância desta espécie no compartimento litorâneo, nos três períodos de amostragem, embora ela tenha ocorrido no limnético também. 
- Abundância relativa Thermocyclops minutus entre zonas limnética e litorânea

A Figura 41 mostra as relações de abundância do Copepoda Cyclopoida Thermocyclops minutus entre os compartimentos limnético e litorâneo das lagoas estudadas, nos três períodos de amostragem.

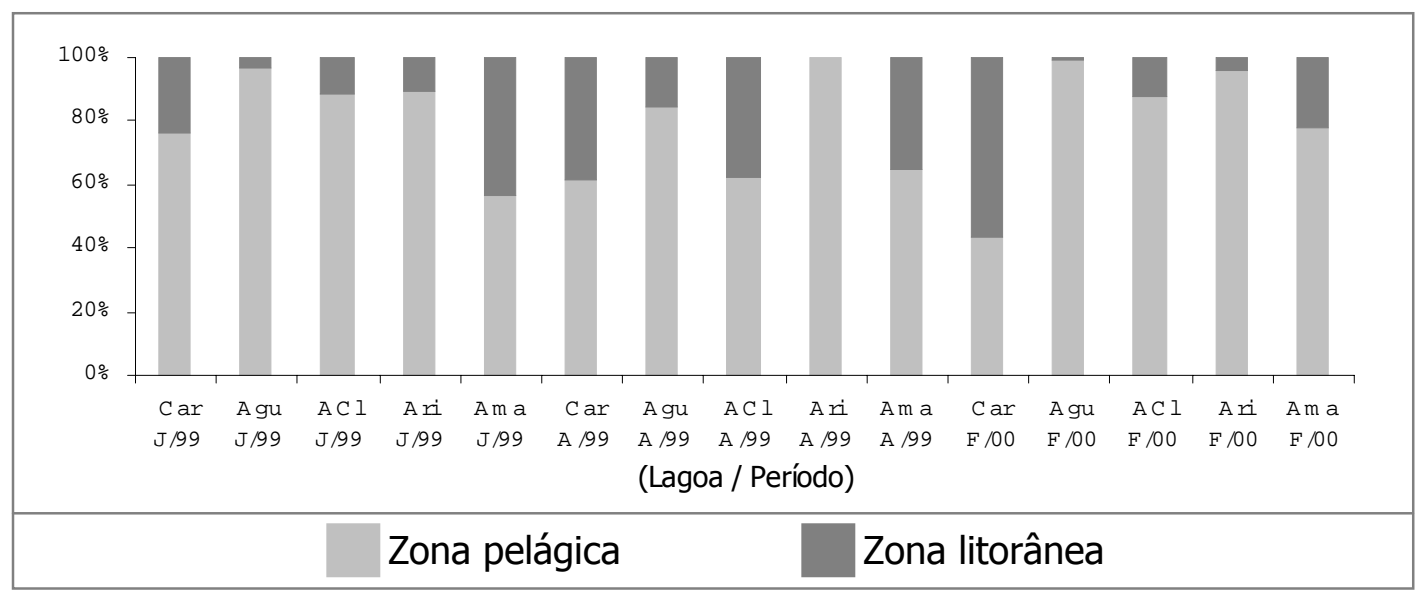

Figura 41. Abundância relativa de Thermocyclops minutus, entre as zonas limnética e litorânea das cinco lagoas, nos três períodos estudados.

No geral, a abundância de Thermocyclops minutus foi maior nos compartimentos limnéticos de todas as lagoas estudadas e nos três períodos de amostragem, com exceção à lagoa Carioca no verão, quando a abundância desta espécie foi maior no compartimento litorâneo. 
- Abundância relativa de Mesocyclops brasilianus entre zonas limnética e litorânea

De acordo com a Figura 42, no geral, a espécie de Copepoda Cyclopoida Mesocyclops brasilianus foi mais abundante nos compartimentos litorâneos de todas as lagoas em todos os períodos amostrados, com exceção à lagoa Carioca no inverno 1, à lagoa Amarela no inverno 2 e verão, onde a abundância relativa desta espécie no compartimento limnético foi maior.

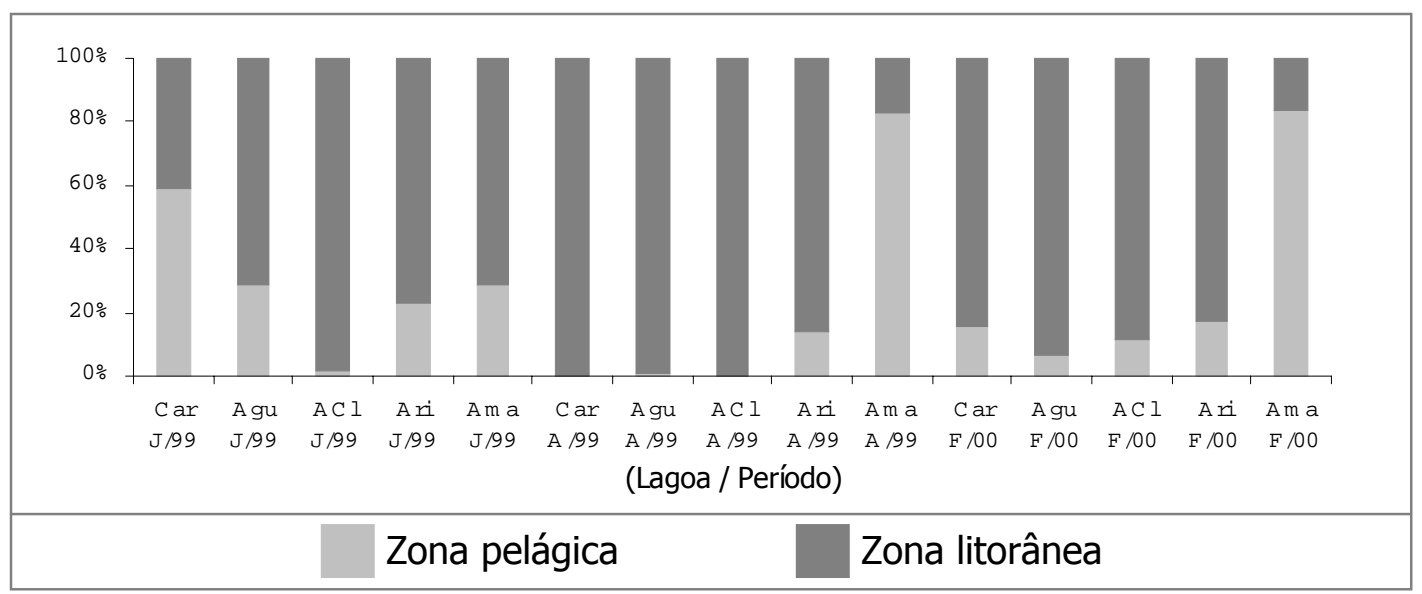

Figura 42. Abundância relativa de Mesocyclops brasilianus, entre as zonas limnética e litorânea nas cinco lagoas, nos três períodos estudados. 


\section{- Abundância relativa de náuplios de Calanoida e Cyclopoida}

A Figura 43 apresenta as relações de abundância entre os náuplios de Copepoda Calanoida e Cyclopoida apenas nas lagoas Ariranha e Amarela, pois nas demais lagoas não ocorrem espécies de Copepoda Calanoida.

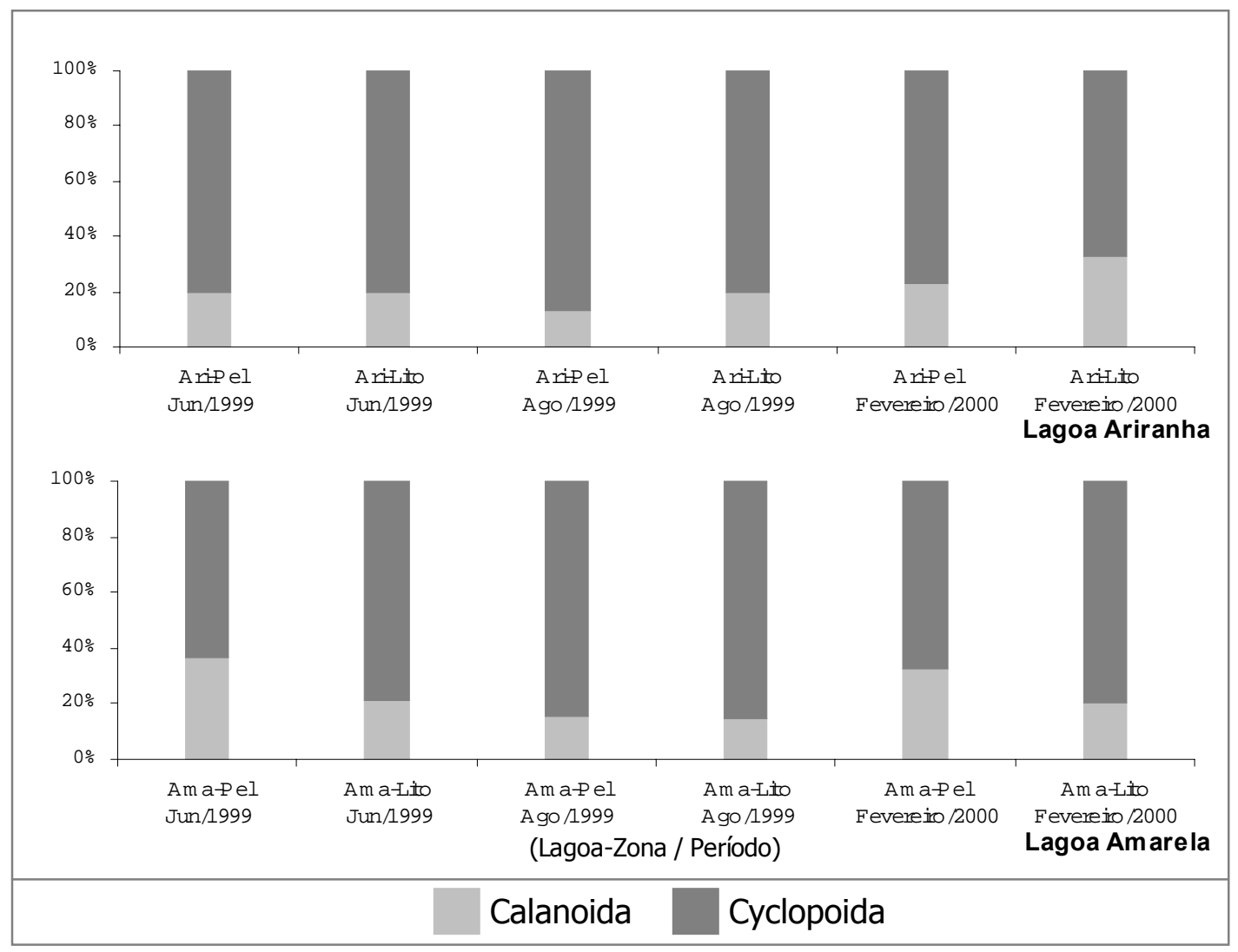

Figura 43. Abundância relativa entre náuplios de Calanoida e Cyclopoida, nas zonas limnética e litorânea das lagoas Ariranha e Amarela, nos três períodos estudados.

Em todos os períodos estudados, foi observada uma maior abundância relativa de náuplios de Copepoda Cyclopoida em todos os compartimentos das lagoas Amarela e Ariranha. 


\section{- Abundância relativa de copepoditos de Calanoida e de Cyclopoida}

A Figura 44 apresenta as relações de abundância entre os copepoditos de Copepoda Calanoida e Cyclopoida apenas nas lagoas Ariranha e Amarela, pois nas demais lagoas não ocorrem espécies de Copepoda Calanoida.

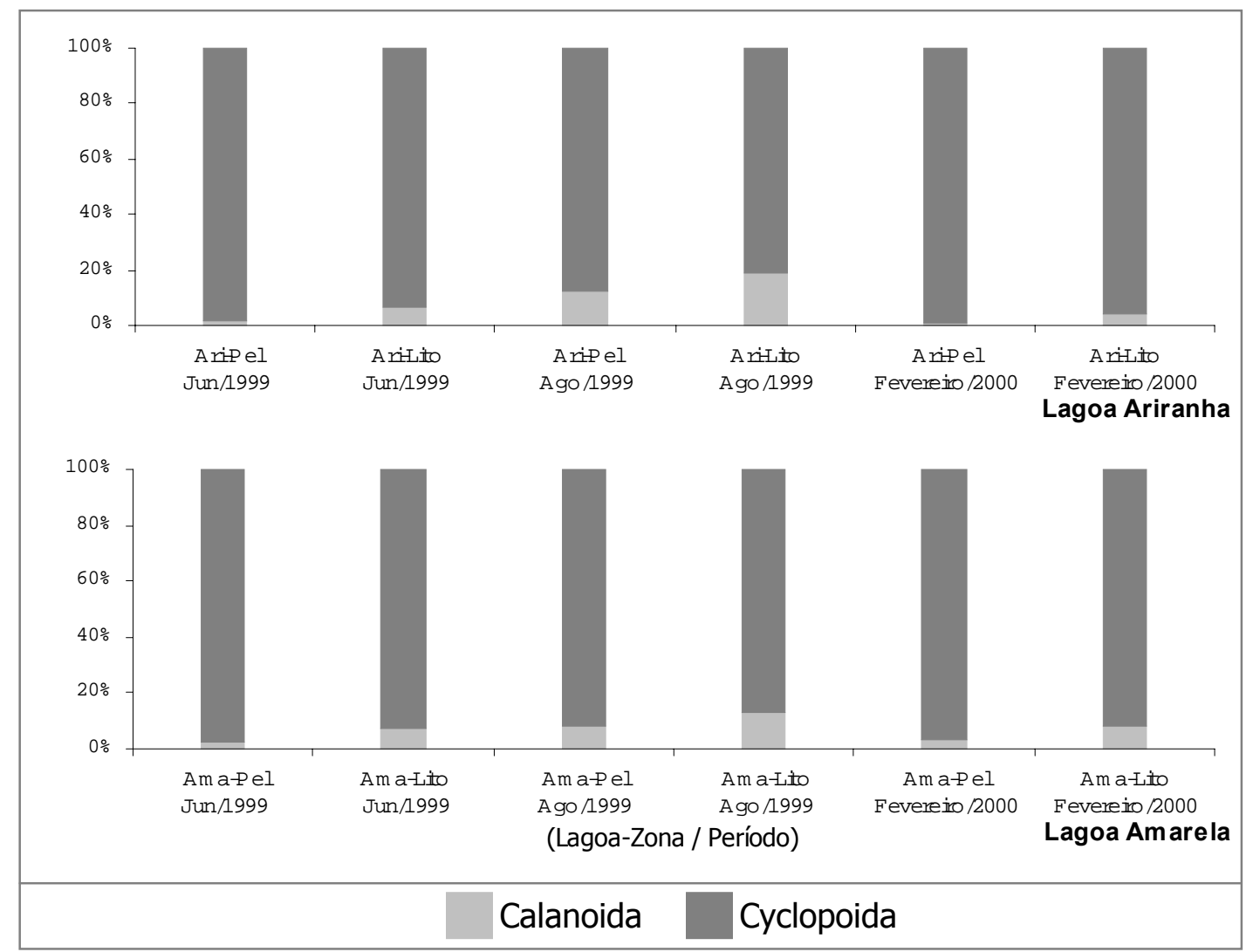

Figura 44. Abundância relativa dos copepoditos de Copepoda Calanoida e Cyclopoida, entre as zonas limnética e litorânea das lagoas Ariranha e Amarela, nos três períodos estudados.

Assim como verificado para náuplios, os copepoditos de Cyclopoida ocorreram em maior abundância relativa em todos os compartimentos das lagoas Amarela e Ariranha, nos três períodos amostrados. 
- Abundância relativa das forma jovens de Copepoda (náuplios e copepodito) entre as zonas limnética e litorânea

De acordo com os resultados apresentados na Figura 45 observou-se maior abundância relativa de jovens de Copepoda (náuplios e copepodito) na zona limnética nas lagoas Carioca, Aguapé, Águas Claras e Ariranha no inverno 1; Carioca, Ariranha e Amarela no inverno 2; e Aguapé, Águas Claras e Ariranha no verão.

Nas lagoas Amarela no inverno 1, Aguapé e Águas Claras no inverno 2 e Amarela no verão, foi verificada maior abundância de jovens de Copepoda no compartimento litorâneo.

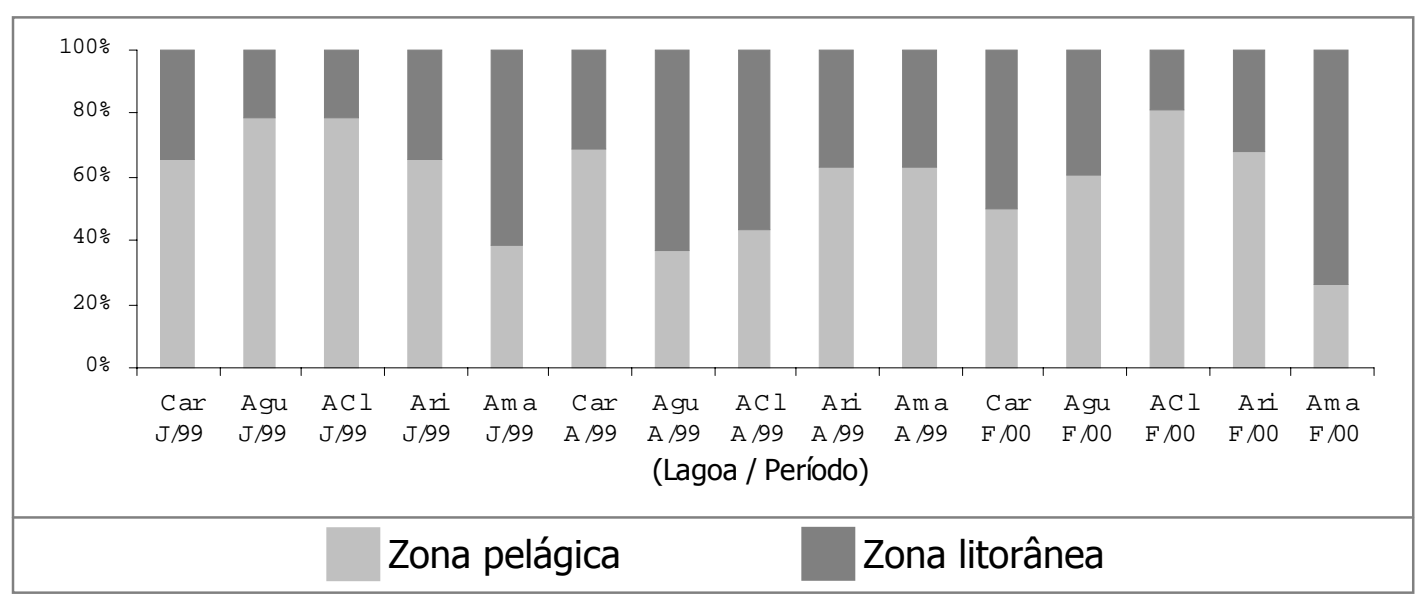

Figura 45. Abundância relativa das formas jovens de Copepoda, entre as zonas limnética e litorânea nas cinco lagoas, nos três períodos estudados. 


\section{- Abundância relativa dos outros grupos zooplanctônicos}

As relações de abundância entre os demais grupos zooplanctônicos encontrados, estão apresentadas na Figura 46.

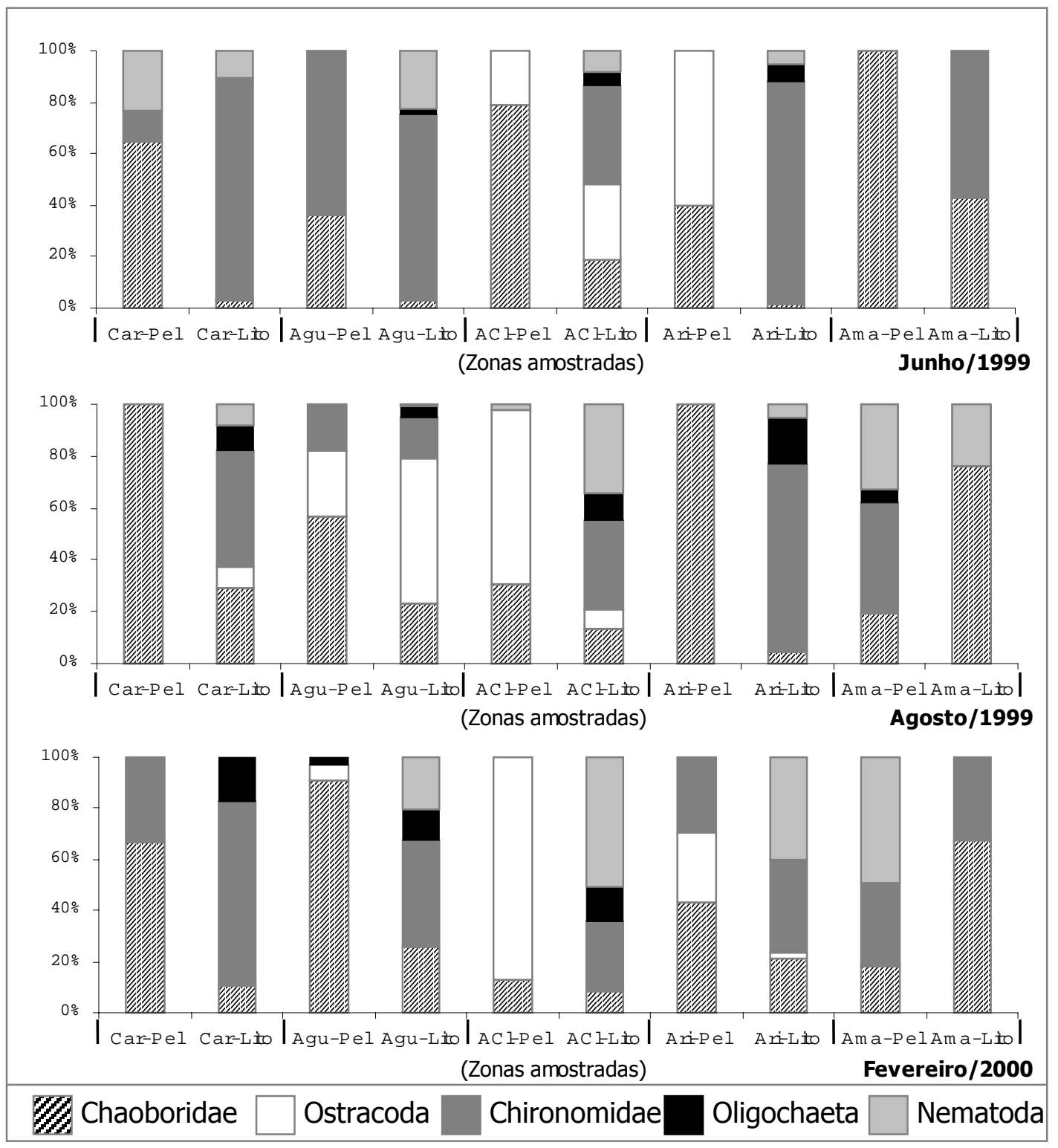

Figura 46. Abundância relativa entre os outros grupos zooplanctônicos, nas zonas limnética e litorânea, das cinco lagoas nos três períodos estudados.

Os Chaoboridae ocorreram em maior abundância relativa no compartimento limnético da lagoa Carioca nos três períodos de estudo, no compartimento limnético da lagoa Aguapé nos períodos de inverno 2 e verão, no compartimento limnético da lagoa 
Águas Claras no inverno 1, no compartimento limnético da lagoa Ariranha no inverno 2 e verão, no compartimento limnético da lagoa Amarela no inverno 1 , e no compartimento litorâneo desta última lagoa no inverno 2 e verão.

No compartimento litorâneo da lagoa Carioca nos três períodos de estudo a maior abundância foi dos Chironomidae, assim como no compartimento pelágico da lagoa Aguapé no inverno 1, no compartimento litorâneo desta mesma lagoa no inverno 1 e verão, no compartimento litorâneo da lagoa Águas Claras no inverno 1 e 2, no compartimento litorâneo da lagoa Ariranha nos três períodos de amostragem, e nos compartimentos litorâneo no inverno 1 e limnético no inverno 2 da lagoa Amarela.

Os Ostracoda ocorreram em maior abundância no compartimento litorâneo da lagoa Aguapé no inverno 2, no compartimento limnético da lagoa Águas claras no inverno 2 e verão, e no compartimento limnético da lagoa Ariranha no inverno 1.

Os Nematoda foram mais abundantes apenas no compartimento litorâneo da lagoa Águas Claras e no limnético da lagoa Amarela, ambos no período de verão.

Já o grupo dos Oligochaeta não chegaram a dominar nenhum compartimento em nenhuma lagoa estudada. 


\subsection{AVAliaÇão das lagoas QUANTO AO GRAU de tROFIA}

4.4.1. MOdelo de CARLSON MOdificAdo POR TOLEDO JR.

Na Tabela 22 estão apresentados os valores do índice de Carlson, bem como a classificação dos pontos de amostragem.

\section{Tabela 22. Valores do índice e classificação do estado trófico, segundo modelo proposto por CARLSON (1977) e modificado por TOLEDO Jr. et al. (1983).}

\begin{tabular}{ccc|cc|cc}
\hline \hline Pontos de & \multicolumn{2}{c}{ Junho/1999 } & \multicolumn{2}{c}{ Agosto/1999 } & \multicolumn{2}{c}{ Fevereiro/2000 } \\
amostragem & Índice & Classificação & Índice & Classificação & Índice & Classificação \\
\hline Car-P1 & 53,28 & Mesotrófico & 30,19 & Oligotrófico & 43,62 & Oligotrófico \\
Car-L1 & 43,69 & Oligotrófico & 28,95 & Oligotrófico & 39,98 & Oligotrófico \\
Car-L2 & 34,59 & Oligotrófico & 32,34 & Oligotrófico & 42,41 & Oligotrófico \\
Car-L3 & 32,80 & Oligotrófico & 35,04 & Oligotrófico & 39,24 & Oligotrófico \\
Agu-P1 & 30,98 & Oligotrófico & 29,09 & Oligotrófico & 44,17 & Mesotrófico \\
Agu-P2 & 26,26 & Oligotrófico & 29,16 & Oligotrófico & 44,22 & Mesotrófico \\
Agu-P3 & 30,62 & Oligotrófico & 28,52 & Oligotrófico & 48,06 & Mesotrófico \\
Agu-L1 & 26,07 & Oligotrófico & 27,18 & Oligotrófico & 46,76 & Mesotrófico \\
Agu-L2 & 27,39 & Oligotrófico & 31,30 & Oligotrófico & 46,49 & Mesotrófico \\
Agu-L3 & 30,50 & Oligotrófico & 34,17 & Oligotrófico & 45,94 & Mesotrófico \\
ACl-P1 & 22,33 & Oligotrófico & 21,61 & Oligotrófico & 40,29 & Oligotrófico \\
ACl-P2 & 27,51 & Oligotrófico & 30,87 & Oligotrófico & 40,15 & Oligotrófico \\
ACl-L1 & 25,96 & Oligotrófico & 26,61 & Oligotrófico & 37,85 & Oligotrófico \\
ACl-L2 & 25,09 & Oligotrófico & 25,53 & Oligotrófico & 37,84 & Oligotrófico \\
ACl-L3 & 31,94 & Oligotrófico & 25,02 & Oligotrófico & 36,82 & Oligotrófico \\
Ari-P1 & 27,76 & Oligotrófico & 29,32 & Oligotrófico & 43,34 & Oligotrófico \\
Ari-L1 & 24,50 & Oligotrófico & 32,22 & Oligotrófico & 43,83 & Oligotrófico \\
Ari-L2 & 33,29 & Oligotrófico & 25,58 & Oligotrófico & 42,66 & Oligotrófico \\
Ari-L3 & 27,58 & Oligotrófico & 20,93 & Oligotrófico & 44,02 & Mesotrófico \\
Ama-P1 & 22,43 & Oligotrófico & 27,47 & Oligotrófico & 45,88 & Mesotrófico \\
Ama-L1 & 25,90 & Oligotrófico & 22,61 & Oligotrófico & 44,89 & Mesotrófico \\
\hline \hline
\end{tabular}

Segundo este índice, a maioria dos pontos de amostragem das cinco lagoas e nos três períodos de estudo puderam ser classificados como oligotrófico. Ficaram classificados como mesotrófico o ponto limnético Car-P1 da lagoa Carioca, no inverno 1, todos os pontos da lagoa Aguapé no verão, o ponto litorâneo Ari-L3 da lagoa Ariranha no verão e os pontos de amostragem da lagoa Amarela no verão.

Vale ressaltar que todos os pontos de amostragem de todas as lagoas no período de inverno 2 ficaram classificados como oligotróficos. 


\subsubsection{MOdELO DE SALAS \& MARTINO}

A Tabela 23 apresenta os valores dos índices de SALAS \& MARTINO e as classificações quanto ao grau de trofia dos pontos de amostragem das cinco lagoas, para os três períodos estudados.

\section{Tabela 23. Valores do índice e classificação do estado trófico, segundo modelo proposto por SALAS \& MARTINO (1990).}

\begin{tabular}{ccc|cc|cc}
\hline \hline Pontos de & \multicolumn{2}{c}{ Junho/1999 } & \multicolumn{2}{c}{ Agosto/1999 } & \multicolumn{2}{c}{ Fevereiro/2000 } \\
amostragem & Índice & Classificação & Índice & Classificação & Índice & Classificação \\
\hline Car-P1 & 56,48 & Eutrófico & 53,58 & Eutrófico & 58,46 & Eutrófico \\
Car-L1 & 56,35 & Eutrófico & 51,44 & Eutrófico & 43,62 & Mesotrófico \\
Car-L2 & 60,11 & Hiper-eutrófico & 52,46 & Eutrófico & 45,07 & Mesotrófico \\
Car-L3 & 58,79 & Eutrófico & 52,63 & Eutrófico & 41,31 & Mesotrófico \\
Agu-P1 & 46,64 & Mesotrófico & 49,34 & Mesotrófico & 49,74 & Mesotrófico \\
Agu-P2 & 43,92 & Mesotrófico & 46,39 & Mesotrófico & 48,27 & Mesotrófico \\
Agu-P3 & 44,50 & Mesotrófico & 46,64 & Mesotrófico & 55,03 & Eutrófico \\
Agu-L1 & 56,23 & Eutrófico & 48,92 & Mesotrófico & 51,61 & Eutrófico \\
Agu-L2 & 43,92 & Mesotrófico & 48,27 & Mesotrófico & 52,46 & Eutrófico \\
Agu-L3 & 53,58 & Eutrófico & 47,36 & Mesotrófico & 52,30 & Eutrófico \\
ACl-P1 & 41,66 & Mesotrófico & 41,66 & Mesotrófico & 43,31 & Mesotrófico \\
ACl-P2 & 49,13 & Mesotrófico & 40,57 & Mesotrófico & 40,57 & Mesotrófico \\
ACl-L1 & 41,31 & Mesotrófico & 42,34 & Mesotrófico & 36,71 & Oligotrófico \\
ACl-L2 & 50,14 & Eutrófico & 41,31 & Mesotrófico & 38,11 & Oligotrófico \\
ACl-L3 & 54,75 & Eutrófico & 41,66 & Mesotrófico & 35,67 & Oligotrófico \\
Ari-P1 & 43,62 & Mesotrófico & 57,56 & Eutrófico & 48,27 & Mesotrófico \\
Ari-L1 & 44,79 & Mesotrófico & 45,61 & Mesotrófico & 48,27 & Mesotrófico \\
Ari-L2 & 54,82 & Eutrófico & 48,49 & Mesotrófico & 48,71 & Mesotrófico \\
Ari-L3 & 49,34 & Mesotrófico & 45,07 & Mesotrófico & 48,92 & Mesotrófico \\
Ama-P1 & 38,55 & Oligotrófico & 48,05 & Mesotrófico & 51,44 & Eutrófico \\
Ama-L1 & 41,66 & Mesotrófico & 43,92 & Mesotrófico & 51,61 & Eutrófico \\
\hline \hline
\end{tabular}

Segundo este índice, apenas o ponto limnético Ama-P1 da lagoa Amarela no período de inverno 1 ficou classificado como oligotrófico. Os demais pontos foram classificados de mesotróficos a eutróficos, com exceção do ponto litorâneo Ca-L2 da lagoa Amarela que ficou classificado como hirper-eutrófico.

No inverno 2 nenhum ponto de amostragem ficou classificado como oligotrófico. Neste período, a maioria dos pontos de amostragem ficaram classificados como mesotróficos, com exceção de todos os pontos da lagoa Carioca e do ponto pelágico Ari-P1 da lagoa Ariranha, que foram considerados eutróficos.

Já no verão, os três pontos litorâneos da lagoa Águas Claras foram os únicos classificados como oligotróficos. Foram considerados eutróficos o ponto pelágico CarP1 da lagoa Carioca, os pontos limnético Agu-P3 e litorâneos (Agu-L1, Agu-L2 e Agu- 
L3) da lagoa Aguapé e todos os pontos da lagoa Amarela (Ama-P1 e Ama-L1). Os demais pontos de amostragem neste período ficaram classificados como mesotróficos. 


\subsection{AVALIAÇÃo DA DiVERSIDADE ZOOPLANCTÔNICA}

\subsubsection{DIVERSIDADE ALFA}

A seguir está apresentada a caracterização da diversidade alfa dos pontos de amostragem nos três períodos estudados, segundo as seguintes medidas de diversidade: riqueza de espécies, índice de Margalef, índice de Shannon, índice de Simpson, inverso do índice de Simpson e índice de Pielou.

- RIQUEZA DE ESPÉCIES

Os valores da diversidade alfa em função da riqueza de espécies dos pontos de amostragem das cinco lagoas, nos três períodos estudados, estão apresentados na Tabela 24.

Tabela 24. Valores da riqueza de espécies para o zooplâncton dos pontos de amostragem das cinco lagoas, nos três períodos estudados.

\begin{tabular}{cccc}
\hline \hline Lagoa-Ponto & Junho/1999 & Agosto/1999 & Fevereiro/2000 \\
\hline Car-P1 & 12 & 10 & 10 \\
Car-L1 & 15 & 10 & 10 \\
Car-L2 & 11 & 11 & 12 \\
Car-L3 & 12 & 12 & 12 \\
Agu-P1 & 16 & 12 & 18 \\
Agu-P2 & 12 & 10 & 17 \\
Agu-P3 & 13 & 11 & 13 \\
Agu-L1 & 16 & 16 & 19 \\
Agu-L2 & 14 & 16 & 15 \\
Agu-L3 & 12 & 13 & 13 \\
ACl-P1 & 12 & 16 & 13 \\
ACl-P2 & 10 & 14 & 14 \\
ACl-L1 & 21 & 28 & 21 \\
ACl-L2 & 20 & 17 & 15 \\
ACl-L3 & 20 & 20 & 21 \\
Ari-P1 & 17 & 16 & 17 \\
Ari-L1 & 21 & 10 & 27 \\
Ari-L2 & 26 & 18 & 14 \\
Ari-L3 & 21 & 22 & 19 \\
Ama-P1 & 17 & 12 & 18 \\
Ama-P1 & 23 & 19 & 20 \\
\hline \hline
\end{tabular}

De maneira geral, a riqueza de espécies de todos os pontos de amostragem entre todos os períodos de estudo, variou de 28 táxons no ponto litorâneo ACl-L1 da lagoa Ariranha, no período de inverno 2, até um mínimo de 10 táxons encontrado em 
vários pontos de amostragem e em vários períodos: ACl-P2 no inverno 1, Car-P1, CarL1 e Agu-P2 no inverno 2, Car-P1 e Car-L1 no verão.

Pode-se considerar que a lagoa Carioca foi aquela em que se registrou o menor número de táxons, dentre todas as lagoas estudadas, nos três períodos analisados. 0 maior número de táxons encontrado nesta lagoa, ocorreu no ponto litorâneo Car-L1 no período de inverno 1.

Para a lagoa Aguapé foram obtidos valores de riqueza de espécies que variaram de 19 táxons no ponto litorâneo Agu-L1 no verão, para 10 táxons no ponto limnético Agu-P2 no inverno 2. Nesta lagoa observou-se um aumento na riqueza de espécies nos pontos limnéticos no período de verão. Pode-se dizer também, que, no geral, nos pontos litorâneos ocorreram valores de riqueza de táxons maiores que nos limnéticos nos períodos de inverno 1 e 2.

Na lagoa Águas Claras observou-se uma maior riqueza de espécies nos pontos litorâneos, com um máximo de 28 táxons encontrado no ponto $\mathrm{ACl}-\mathrm{L} 1$ no período de inverno 2. A menor riqueza de táxons nesta lagoa foi de 10 táxons encontrada no ponto limnético $\mathrm{ACl}-\mathrm{P} 2$ no período de inverno 1.

De maneira geral, também foi observada uma maior riqueza de espécies nos pontos litorâneos da lagoa Ariranha em relação aos limnéticos, com exceção dos pontos Ari-L2 no verão e Ari-L1 no inverno onde foram obtidos valores menores do que para os pontos limnéticos. Neste último ponto de amostragem foi encontrado o menor valor, de 10 táxons, dentre todos os pontos de amostragem da lagoa Ariranha e dentre todos os períodos estudados. A maior riqueza de espécies encontrada nesta lagoa foi de 26 táxons, no ponto litorâneo Ari-L2 no período de inverno 1.

$\mathrm{Na}$ lagoa Amarela também foi observada uma maior riqueza de espécies no ponto litorâneo em relação ao limnético. Nesta lagoa o índice de riqueza variou de um máximo de 23 táxons no ponto litorâneo Ama-L1 no inverno 1, para 12 táxons no ponto limnético Ama-P1 no inverno 2.

No geral, as lagoas com maior riqueza de táxons foram a Ariranha, a Águas Claras e a Amarela.

- ÍNDice de MARgalef (DIVERSidAde)

Na Tabela 25 estão apresentados os valores do índice de Margalef calculados por ponto de amostragem nas cinco lagoas, para os três períodos de estudo. 
De maneira geral, verifica-se que, em todos os períodos, os menores valores deste índice foram encontrados em todos os pontos da lagoa Carioca, e nos pontos limnéticos das demais lagoas.

Na lagoa Carioca, os valores variaram de um mínimo de 0,70 no ponto litorâneo Car-L1 no inverno 2, para um máximo de 1,08 no mesmo ponto no período de inverno 1. Nesta lagoa, não foi possível verificar diferenças nos valores deste índice entre os pontos limnético e litorâneos.

Tabela 25. Valores do índice de diversidade de Margalef para o zooplâncton dos pontos de amostragem das cinco lagoas, nos três períodos estudados.

\begin{tabular}{cccc}
\hline \hline Lagoa-Ponto & Junho/1999 & Agosto/1999 & Fevereiro/2000 \\
\hline Car-P1 & 0,83 & 0,74 & 0,83 \\
Car-L1 & 1,08 & 0,70 & 0,80 \\
Car-L2 & 0,75 & 0,83 & 1,02 \\
Car-L3 & 0,80 & 0,98 & 1,04 \\
Agu-P1 & 1,22 & 1,04 & 1,42 \\
Agu-P2 & 0,88 & 0,82 & 1,49 \\
Agu-P3 & 0,99 & 0,85 & 0,98 \\
Agu-L1 & 1,23 & 1,35 & 1,69 \\
Agu-L2 & 1,08 & 1,29 & 1,28 \\
Agu-L3 & 1,02 & 1,04 & 1,09 \\
ACl-P1 & 0,87 & 1,11 & 1,06 \\
ACl-P2 & 0,72 & 0,97 & 1,14 \\
ACl-L1 & 1,75 & 2,17 & 1,73 \\
ACl-L2 & 1,56 & 1,42 & 1,19 \\
ACl-L3 & 1,53 & 1,63 & 1,77 \\
Ari-P1 & 1,21 & 1,28 & 1,38 \\
Ari-L1 & 1,49 & 0,76 & 2,23 \\
Ari-L2 & 1,92 & 1,33 & 1,14 \\
Ari-L3 & 1,53 & 1,63 & 1,52 \\
Ama-P1 & 1,35 & 0,97 & 1,41 \\
Ama-P1 & 1,83 & 1,70 & 1,64 \\
\hline \hline
\end{tabular}

Já na lagoa Aguapé, houve uma distinção entre os compartimentos limnético e litorâneo em função deste índice. No limnético, os valores variaram de um mínimo de 0,82 no ponto Agu-P2 no inverno 2, para 1,49 no mesmo ponto no verão. Os pontos representantes do compartimento litorâneo apresentaram valores maiores, os quais variaram de 1,02 no ponto Agu-L3 no inverno 1, para 1,69 no ponto Agu-L1 no verão.

Da mesma forma como observado para a lagoa Aguapé, na lagoa Águas Claras houve uma diferença clara entre a diversidade pelo índice de Margalef entre os compartimentos. Entre os pontos limnéticos, a variação deste índice esteve entre 0,72 
no ponto ACl-P2 no inverno 1 e 1,14 no mesmo ponto no verão. Entre os litorâneos, 0 menor valor encontrado foi de 1,19 no ponto ACl-L2 no verão, e o maior foi de 2,17 no ponto $\mathrm{ACl}-\mathrm{L} 1$ no inverno 2.

Para o ponto limnético da lagoa Ariranha foram obtidos valores próximos deste índice entre os três períodos de estudo, variando de 1,21 no inverno 1 para 1,38 no verão. Assim, pode-se dizer que houve um aumento dos valores deste índice neste ponto do período de inverno 1 para o verão. Nos pontos litorâneos foram encontrados os maiores valores do índice de Margalef para esta lagoa, atingindo um máximo de 2,23 no ponto Ari-L1 no verão, sendo o maior valor encontrado para todos os períodos de estudo entre todas as lagoas. No ponto litorâneo Ari-L1 foi observado um valor relativamente baixo de 0,76 .

Na lagoa Amarela, em cada período de amostragem, os valores encontrados para o ponto litorâneo sempre foram maiores do que aqueles observados no limnético. Nesta lagoa, os valores deste índice variaram de 0,97 no ponto limnético no inverno 2 , para 1,83 no ponto litorâneo no inverno 1 .

\section{- ÍNDICE DE SHANNON-WienER (DIVERSidADE)}

Os valores do índice de Shannon-Wiener encontrados para os diferentes pontos de amostragem das cinco lagoas, nos três períodos de estudo, estão apresentados na Tabela 26.

No período de inverno 1 , nos pontos litorâneos da lagoa Carioca, foram encontrados os menores valores deste índice obtidos em todo o estudo, com um mínimo de 0,18 no ponto Car-L3. Para os demais pontos nos três períodos estudados foram obtidos valores próximos, de forma que não foi possível estabelecer diferenças entre os compartimentos limnético e litorâneo nesta lagoa. O maior valor encontrado nesta lagoa foi de 1,76 nos pontos Car-P1 no inverno 2 e Car-L3 no verão.

Na lagoa Aguapé os valores variaram de um mínimo de 1,14 no ponto limnético Agu-P3 no verão, para 2,26 no ponto litorâneo Agu-L1 no inverno 2. Também nesta lagoa não foi possível verificar diferenças entre compartimento limnético e litorâneo.

De maneira geral, no compartimento litorâneo da lagoa Águas Claras foram obtidos valores maiores para o índice de Shannon, quando comparado aqueles da região limnética. Nesta lagoa, os valores variaram de um mínimo de 0,71 no ponto limnético ACl-P1 no inverno 2 para 2,45 no ponto ACl-L2 no mesmo período de estudo. Vale ressaltar que este último valor foi o maior encontrado para todo o estudo. 
Tabela 26. Valores do índice de diversidade de Shannon-Wiener para para o zooplâncton os pontos de amostragem das cinco lagoas, nos três períodos estudados.

\begin{tabular}{cccc}
\hline \hline Lagoa-Ponto & Junho/1999 & Agosto/1999 & Fevereiro/2000 \\
\hline Car-P1 & 0,93 & 1,76 & 1,44 \\
Car-L1 & 0,33 & 1,03 & 1,03 \\
Car-L2 & 0,38 & 1,33 & 1,34 \\
Car-L3 & 0,18 & 1,49 & 1,76 \\
Agu-P1 & 1,76 & 1,78 & 1,85 \\
Agu-P2 & 1,57 & 1,33 & 2,13 \\
Agu-P3 & 1,60 & 1,46 & 1,14 \\
Agu-L1 & 1,48 & 2,26 & 2,14 \\
Agu-L2 & 1,43 & 1,79 & 1,91 \\
Agu-L3 & 1,23 & 1,65 & 1,52 \\
ACl-P1 & 1,53 & 0,71 & 1,87 \\
ACl-P2 & 1,58 & 1,07 & 1,83 \\
ACl-L1 & 2,34 & 2,20 & 2,28 \\
ACl-L2 & 1,50 & 2,45 & 1,73 \\
ACl-L3 & 1,46 & 1,36 & 2,38 \\
Ari-P1 & 1,17 & 1,57 & 1,71 \\
Ari-L1 & 1,53 & 0,70 & 1,60 \\
Ari-L2 & 1,52 & 1,14 & 1,69 \\
Ari-L3 & 1,57 & 0,79 & 0,89 \\
Ama-P1 & 1,46 & 1,05 & 1,70 \\
Ama-P1 & 1,97 & 2,28 & 1,90 \\
\hline \hline
\end{tabular}

$\mathrm{Na}$ lagoa Ariranha, também não foi possível a verificação de padrões diferenciados entre os compartimentos litorâneo e limnético nos três períodos de estudo, em função do índice de Shannon. O menor valor encontrado foi de 0,70 no ponto litorâneo Ari-L1 no inverno 2, e o maior foi de 1,71 no ponto pelágico Ari-P1 no verão.

Em cada período de amostragem, verificaram-se valores maiores no ponto litorâneo do que no limnético na lagoa Amarela. Assim, os valores variaram de 1,05 no ponto limnético no inverno 2 para 2,28 no ponto litorâneo no mesmo período de estudo.

- INVERSO do ÍNDICE DE SimPSON (DIVERSIDADE)

A Tabela 27 apresenta os valores do inverso do índice de Simpson para os pontos de amostragem das cinco lagoas, nos três período de estudo. 
Tabela 27. Valores do índice de diversidade de Simpson para o zooplâncton dos pontos de amostragem das cinco lagoas, nos três períodos estudados.

\begin{tabular}{cccc}
\hline \hline Lagoa-Ponto & Junho/1999 & Agosto/1999 & Fevereiro/2000 \\
\hline Car-P1 & 2,00 & 4,37 & 3,03 \\
Car-L1 & 1,11 & 1,86 & 2,17 \\
Car-L2 & 1,18 & 2,37 & 2,64 \\
Car-L3 & 1,06 & 2,82 & 3,78 \\
Agu-P1 & 3,78 & 4,73 & 4,08 \\
Agu-P2 & 3,51 & 2,83 & 6,56 \\
Agu-P3 & 3,64 & 3,27 & 1,80 \\
Agu-L1 & 3,16 & 8,14 & 5,91 \\
Agu-L2 & 2,90 & 4,48 & 4,82 \\
Agu-L3 & 2,05 & 3,49 & 3,21 \\
ACl-P1 & 3,05 & 1,39 & 5,13 \\
ACl-P2 & 3,17 & 1,96 & 4,48 \\
ACl-L1 & 6,94 & 6,22 & 6,13 \\
ACl-L2 & 2,40 & 9,88 & 3,96 \\
ACl-L3 & 2,93 & 2,07 & 6,34 \\
Ari-P1 & 2,29 & 2,80 & 3,77 \\
Ari-L1 & 3,52 & 1,41 & 2,21 \\
Ari-L2 & 2,70 & 1,72 & 3,56 \\
Ari-L3 & 3,10 & 1,38 & 1,47 \\
Ama-P1 & 2,89 & 1,84 & 3,79 \\
Ama-P1 & 3,78 & 6,63 & 3,75 \\
\hline
\end{tabular}

Na lagoa Carioca, nos dois períodos de inverno, os maiores valores para este índice foram encontrados no ponto limnético Car-P1. Já no verão, o maior valor foi verificado no ponto litorâneo Car-L3. Nos pontos litorâneos, no período de inverno 1, foram encontrados os menores valores para este índice em todo o período de estudo, atingindo um mínimo de 1,06 no ponto Car-L3. O ponto Car-P1, no inverno 2, apresentou o maior valor de 4,37 dentre todos os valores da lagoa Carioca.

Na lagoa Aguapé não foi possível se verificar diferenças entre região limnética e litorânea. Os valores variaram de 1,80 no ponto limnético Agu-P3 no verão, para 8,14 no ponto litorâneo Agu-L1 no inverno 2.

No geral, os valores encontrados nos pontos litorâneos da lagoa Águas Claras, nos três períodos de estudo, foram maiores do que aqueles dos pontos limnéticos. Os valores no compartimento limnético variaram de 1,39 no ponto ACl-P1 no inverno 2 para 5,13 no verão, no mesmo ponto. Já no compartimento litorâneo, a variação foi a partir de 2,07 no ponto $\mathrm{ACl}-\mathrm{L} 3$ no inverno 2 para 9,88 no ponto $\mathrm{ACl}-\mathrm{L} 2$ no mesmo 
período. Vale ressaltar, que este último valor foi o maior encontrado para todo o período de estudo.

No período de inverno 1, o valor encontrado para o compartimento limnético da lagoa Ariranha, foi maior que o do litorâneo. Nos períodos de inverno 2 e verão esta relação se inverteu, e foram observados valores maiores nos pontos litorâneos do que no limnético. Os valores variaram de 1,41 no ponto litorâneo Ari-L1 no inverno 2, para 3,77 no ponto limnético Ari-P1 no verão.

Na lagoa Amarela, nos períodos de inverno, observou-se para o ponto limnético valores para este índice, menores do que aqueles encontrados nos litorâneos. Já no verão, o maior valor foi verificado no ponto limnético. Nesta lagoa, os valores variaram de 1,84 no ponto limnético no inverno 2 para 6,63 no ponto litorâneo no mesmo período de amostragem.

- ÍNDICE DE SimPSON (DOMINÂNCIA)

Na Tabela 28 estão apresentados os valores do índice de Simpson para os pontos de amostragem das cinco lagoas, nos três períodos de amostragem.

Tabela 28. Valores do índice de dominância de Simpson para o zooplâncton dos pontos de amostragem das cinco lagoas, nos três períodos estudados.

\begin{tabular}{cccc}
\hline \hline Lagoa-Ponto & Junho/1999 & Agosto/1999 & Fevereiro/2000 \\
\hline Car-P1 & 0,50 & 0,23 & 0,33 \\
Car-L1 & 0,90 & 0,54 & 0,46 \\
Car-L2 & 0,85 & 0,42 & 0,38 \\
Car-L3 & 0,95 & 0,35 & 0,26 \\
Agu-P1 & 0,26 & 0,21 & 0,24 \\
Agu-P2 & 0,28 & 0,35 & 0,15 \\
Agu-P3 & 0,27 & 0,31 & 0,56 \\
Agu-L1 & 0,32 & 0,12 & 0,17 \\
Agu-L2 & 0,35 & 0,22 & 0,21 \\
Agu-L3 & 0,49 & 0,29 & 0,31 \\
ACl-P1 & 0,33 & 0,72 & 0,19 \\
ACl-P2 & 0,32 & 0,51 & 0,22 \\
ACl-L1 & 0,14 & 0,16 & 0,16 \\
ACl-L2 & 0,42 & 0,10 & 0,25 \\
ACl-L3 & 0,34 & 0,48 & 0,16 \\
Ari-P1 & 0,44 & 0,36 & 0,27 \\
Ari-L1 & 0,28 & 0,71 & 0,45 \\
Ari-L2 & 0,37 & 0,58 & 0,28 \\
Ari-L3 & 0,32 & 0,73 & 0,68 \\
Ama-P1 & 0,35 & 0,54 & 0,26 \\
Ama-P1 & 0,26 & 0,15 & 0,27 \\
\hline \hline
\end{tabular}


$\mathrm{Na}$ lagoa Carioca, os pontos de amostragem onde se observou maior dominância de espécies foram aqueles limnéticos no período de inverno 1, com um máximo de 0,90 para o índice de Simpson no ponto Car-L1. O menor valor deste índice foi de 0,23, observado no ponto pelágico Car-P1 no período de inverno 2.

Nas lagoas Aguapé e Águas Claras não foram verificadas diferenças entre os compartimentos pelágico e litorâneo em função do índice de Simspon.

Na lagoa Aguapé, os valores variaram de 0,12 no ponto litorâneo Agu-L1 no inverno 2, para 0,56 no ponto limnético Agu-P3 no verão. Já na Águas Claras, a variação nos valores deste índice foi de um mínimo de 0,10 no ponto litorâneo $\mathrm{ACl}-\mathrm{L} 2$ no inverno 2, para 0,72 no ponto pelágico Agu-P1, no mesmo período de amostragem.

$\mathrm{Na}$ lagoa Ariranha, observou-se uma maior dominância de espécies no compartimento limnético no inverno 1 , e no compartimento litorâneo nos períodos de inverno 2 e verão. A variação nos valores foi de 0,27 no ponto pelágico Ari-P1 no verão para 0,73 no ponto litorâneo no inverno 2 .

Nos períodos de inverno, observou-se maior dominância de espécies no compartimento limnético, e no verão a maior dominância foi verificada no compartimento litorâneo da lagoa Amarela. O espectro de variação dos valores nesta lagoa foi de 0,15 no ponto litorâneo no inverno 2, para 0,54 no ponto limnético no mesmo período de amostragem.

- Í́NDice de Pielou (EQUidade)

Os valores do índice de Pielou, que representam a equidade ou uniformidade entre as abundâncias das espécies, estão apresentados na Tabela 29.

Os menores valores para o índice de equidade foram registrados nos pontos litorâneos da lagoa Carioca no período de inverno 1, sendo o menor valor de 0,07 do ponto Car-L1. Nesta lagoa, o maior valor encontrado foi de 0,76 no ponto limnético Car-P1 no inverno 2.

Na lagoa Aguapé os valores deste índice variaram de 0,44 no ponto limnético Agu-P3 no verão, até 0,82 no ponto litorâneo Agu-L1 no inverno 2.

A variação nos valores do índice de equidade na lagoa Águas Claras estive entre 0,26 no ponto limnético ACl-P1 no inverno 2 e 0,78 no ponto litorâneo ACl-L3 no verão. 
Tabela 29. Valores do índice de equidade de Pielou para o zooplâncton dos pontos de amostragem das cinco lagoas, nos três períodos estudados.

\begin{tabular}{cccc}
\hline \hline Lagoa-Ponto & Junho/1999 & Agosto/1999 & Fevereiro/2000 \\
\hline Car-P1 & 0,37 & 0,76 & 0,63 \\
Car-L1 & 0,12 & 0,45 & 0,45 \\
Car-L2 & 0,16 & 0,55 & 0,54 \\
Car-L3 & 0,07 & 0,60 & 0,71 \\
Agu-P1 & 0,63 & 0,72 & 0,64 \\
Agu-P2 & 0,63 & 0,58 & 0,75 \\
Agu-P3 & 0,62 & 0,61 & 0,44 \\
Agu-L1 & 0,53 & 0,82 & 0,73 \\
Agu-L2 & 0,54 & 0,65 & 0,71 \\
Agu-L3 & 0,49 & 0,64 & 0,59 \\
ACl-P1 & 0,62 & 0,26 & 0,73 \\
ACl-P2 & 0,69 & 0,41 & 0,69 \\
ACl-L1 & 0,77 & 0,66 & 0,75 \\
ACl-L2 & 0,50 & 0,86 & 0,64 \\
ACl-L3 & 0,49 & 0,45 & 0,78 \\
Ari-P1 & 0,41 & 0,57 & 0,60 \\
Ari-L1 & 0,50 & 0,30 & 0,49 \\
Ari-L2 & 0,47 & 0,39 & 0,64 \\
Ari-L3 & 0,52 & 0,26 & 0,30 \\
Ama-P1 & 0,52 & 0,42 & 0,59 \\
Ama-P1 & 0,63 & 0,77 & 0,63 \\
\hline
\end{tabular}

O valor de 0,26 também foi o menor encontrado na lagoa Ariranha, no ponto litorâneo Ari-L3 no inverno 2. Nesta lagoa o maior valor encontrado para este índice foi de 0,64 no ponto litorâneo Ari-L2 no verão.

A lagoa Amarela foi a única que apresentou um padrão entre os compartimentos litorâneo e limnético em função do índice de equidade, sendo encontrados valores maiores no ponto litorâneo, nos três períodos de estudo. Os valores variaram de um mínimo de 0,42 no ponto limnético no inverno 2 , e um máximo de 0,77 no ponto litorâneo no mesmo período de estudos. 


\subsubsection{DIVERSIDADE BETA}

A Figuras 47, 48 e 49 apresentam os dendrogramas para diversidade beta resultantes das análises de agrupamento entre as cinco lagos estudadas, respectivamente, nos período de inverno 1 (junho de 1999), inverno 2 (agosto de 1999) e verão (fevereiro de 2000), utilizando como coeficiente de ligação o índice de Sorensen.

Valor do coeficiente de correlação cofenética: 0,8932

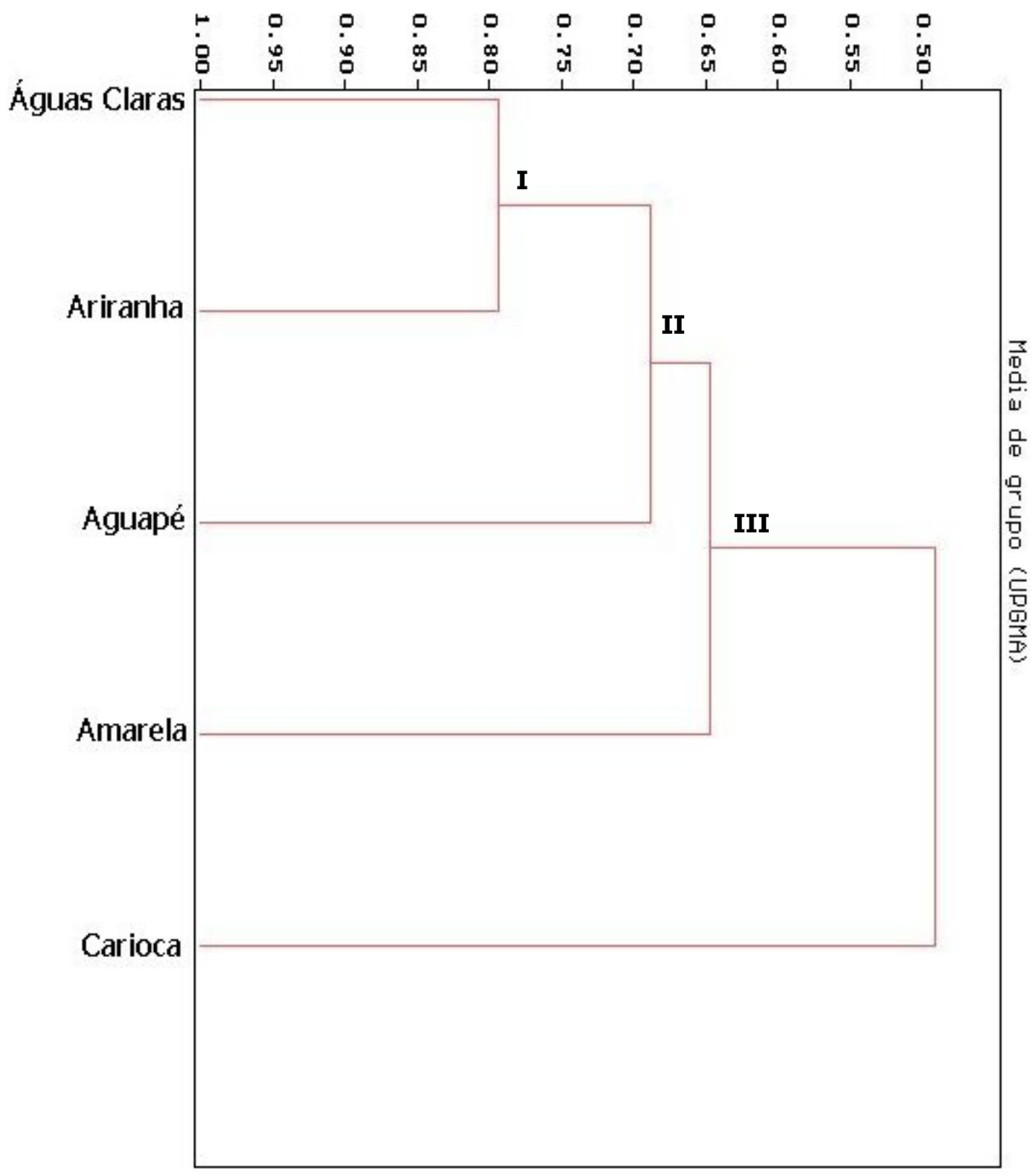

Figura 47. Dendrograma representando a diversidade beta entre as cinco lagoas no período de inverno 1 (junho de 1999). 
Valor do coeficiente de correlação cofenética: 0,9116

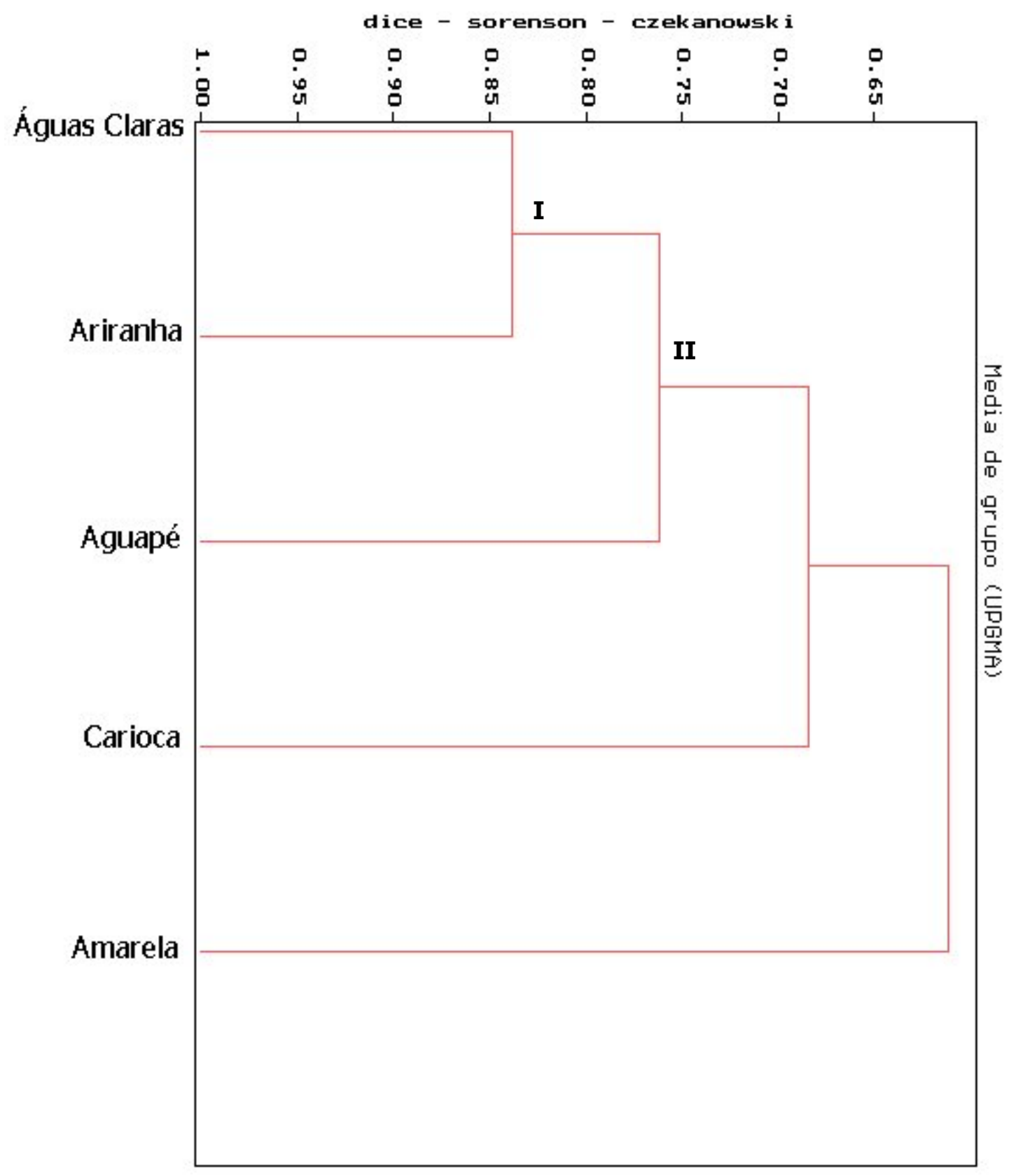

Figura 48. Dendrograma representando a diversidade beta entre as cinco lagoas no período de inverno 2 (agosto de 1999). 
Valor do coeficiente de correlação cofenética: 0,9131

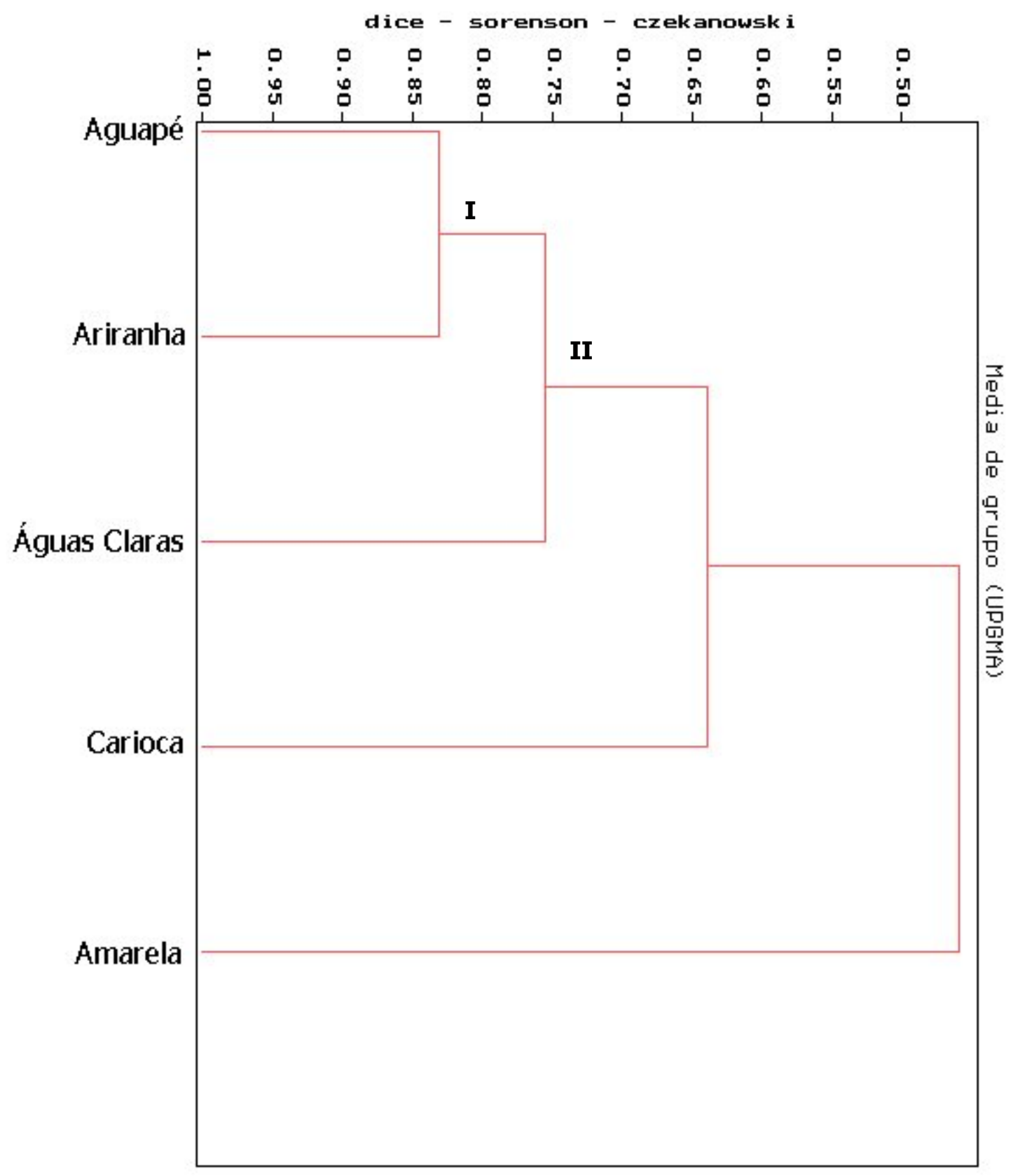

Figura 49. Dendrograma representando a diversidade beta entre as cinco lagoas no período de verão (fevereiro de 2000).

Pelos resultados apresentados nos períodos de inverno de 1999, pôde-se verificar a ocorrência dos mesmos agrupamentos I e II formado pelas mesmas lagoas: lagoa Águas Claras com a lagoa Ariranha, e estas com a lagoa Aguapé. 
Já no período de verão (fevereiro de 2000) o agrupamento I foi formado pelas lagoas Ariranha e Aguapé, e o II foi formado por estas em conjunto com a Águas Claras. Assim, o agrupamento II no período de inverno manteve as mesma lagoas, porém com manteve as mesmas lagoas, mas com organização diferente.

Apenas no período de inverno 1 a lagoa Carioca apresentou valores de diversidade beta diferente de todas as outras lagoas em estudo. Nos períodos de inverno 2 e verão, a lagoa que mostrou-se mais distante das demais, segundo o índice de Sorensen, foi a Amarela. 


\subsection{ANÁLISE ESTATÍSTICA}

O tratamento estatístico realizado está apresentado a seguir, em duas classes de dados distintas (características limnológicas, e medidas de diversidade).

No Anexo estão apresentadas as matrizes que alimentaram as análises e todos os dados (escores, matrizes, coeficientes de variação, porcentagem explicada etc.) gerados pelos programas estatísticos.

\subsubsection{CARACTERÍSTICAS LIMNOLÓGICAS}

- ANÁLISE de VARIÂNCIA MULTIVARIADA (MANOVA)

Os resultados obtidos pela análise de variância multivariada, no nível de decisão de $5 \%(\alpha=0,05)$, revelaram haver efeito da sazonalidade na distribuição dos dados referentes às características gerais dos pontos de amostragem e aos dados limnológicos obtidos nestes, sendo encontrado um valor altamente significante de $\rho$ igual a 0,000, ou seja, menor que o nível de decisão.

Dessa forma, para as análises seguintes previstas no planejamento estatístico, a matriz inicial foi dividida em três outras matrizes, segundo o período de amostragem.

A seguir são apresentados os resultados das análises de componentes principais e de agrupamento (cluster) para os períodos de inverno 1 (junho de 1999), inverno 2 (agosto de 1999) e verão (fevereiro de 2000), separadamente.

\section{- CARACTERÍSTICAS LIMNOLÓGICAS - INVERNO 1}

- Análise de componentes principais

Por uma análise de componentes principais preliminar, foi possível descartar as variáveis que apresentaram valores baixos de correlação, ou seja, temperatura da água, oxigênio dissolvido, pH e silicato.

As variáveis que se mostraram relevantes na distribuição dos dados, após a análise final, e seus valores de correlação com os componentes 1 e 2, estão apresentados na Tabela 31.

A porcentagem total explicada de $63,139 \%$ pelos dois componentes, mostrouse acima do limite mínimo estipulado pelo planejamento estatístico, ou seja, a análise 
de componentes principais com os dados das características gerais e limnológicas no período de inverno 1 , foi satisfatoriamente representativa do conjunto de dados iniciais.

Tabela 31. Correlação (coeficiente de correlação>0.700) das variáveis limnológicas com os componentes principais 1 e 2, "Eigenvalue" e variância explicada, no período de inverno 1 (junho de 1999).

\begin{tabular}{ccc}
\hline \hline & \multicolumn{2}{c}{ CoMPONENTES } \\
Variáveis limnológicas & $\mathbf{1}$ & $\mathbf{2}$ \\
\hline IET Carlson (FT, FDT, Clor.) & 0.882 & \\
Fósforo total & 0.857 & \\
IET Salas (FT) & 0.848 & \\
Material em suspensão total & 0.759 & \\
Nitrato & 0.729 & \\
Condutividade elétrica & -0.716 & 0.866 \\
Transparência da água & & 0.770 \\
$\quad$ Tipo de habitat & & -0.903 \\
Profundidade & \multirow{2}{*}{21.762} \\
Percentagem da variância & 41.377 & \\
explicada & \multicolumn{2}{c}{63.139} \\
Percentagem total da variância \\
explicada
\end{tabular}

De acordo com a natureza das variáveis que se correlacionaram com os componentes, o fator 1 relacionou-se com o grau de trofia das lagoas, e o fator com a estrutura física dos pontos de amostragem.

A Figura 50 mostra a ordenação dos pontos de amostragem em função dos eixos ou fatores.

Em relação ao fator 1, destacaram-se os pontos da lagoa Carioca, que se associaram positivamente no sentido de um aumento do grau de trofia. Os demais pontos não apresentaram um padrão de distribuição bem definido em relação a este fator, valendo destacar que o ponto limnético da lagoa Amarela, Ama-P1, foi o que se associou mais negativamente ao eixo que representa o grau de trofia. 


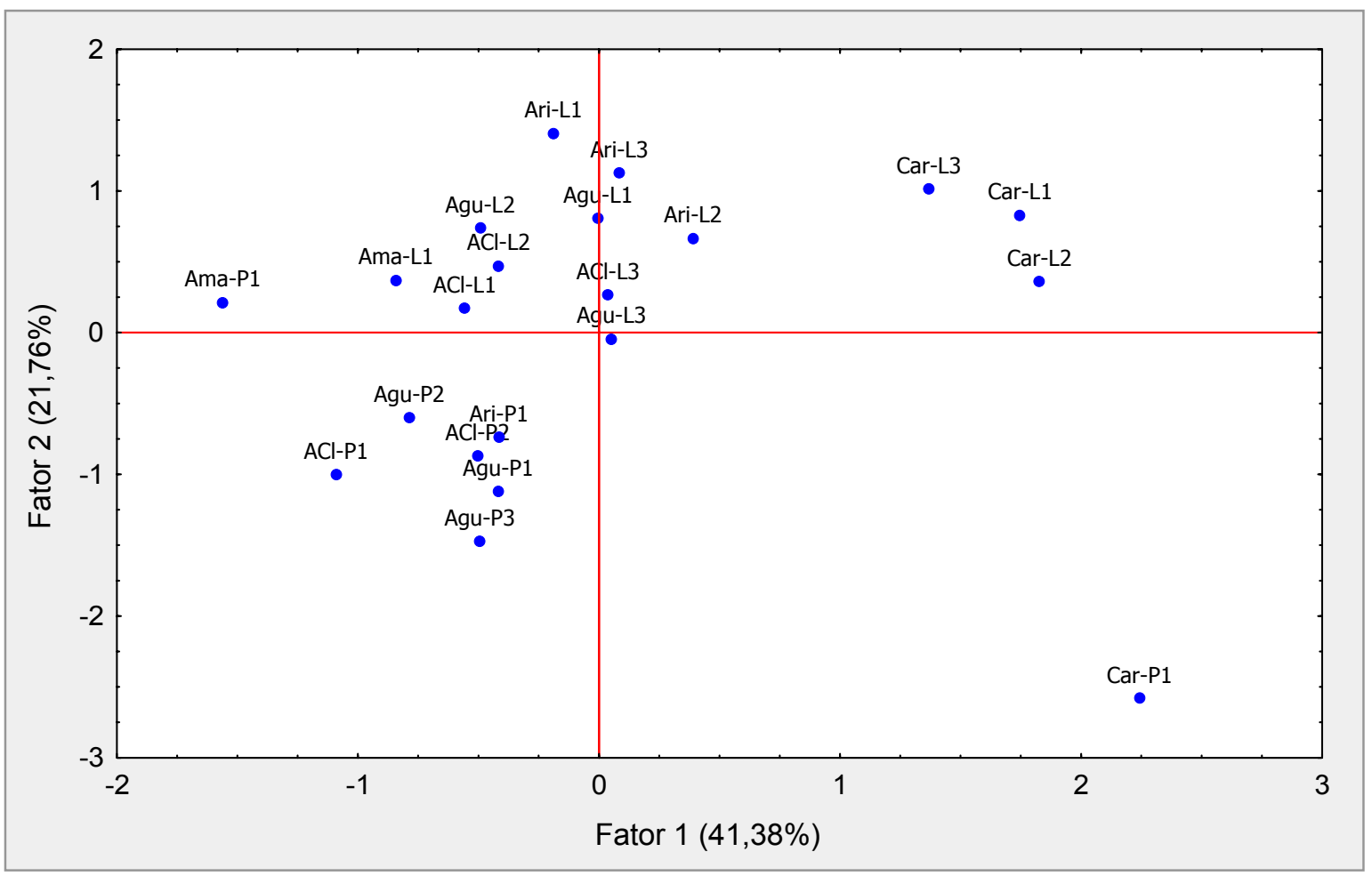

Figura 50. Ordenação dos pontos de amostragem no período de inverno 1, pela análise de componentes principais para as varáveis limnológicas, segundo os fatores 1 e 2.

O fator 2 separou claramente os compartimentos limnéticos e litorâneos das lagoas estudadas no período de inverno 1 . Segundo este eixo, os pontos limnéticos de todas as lagoas associaram-se negativamente com a transparência da água, e positivamente com a profundidade da coluna. Os pontos representantes dos compartimentos litorâneos de todas as lagoas associaram-se positivamente a este eixo, com exceção ao ponto litorâneo da lagoa Aguapé, Agu-P3, que apresentou uma associação negativa próxima à origem do eixo.

Vale destacar que o ponto limnético da lagoa Carioca foi o que se apresentou mais distante dos demais pontos de amostragens de todas as lagoas estudadas, no período de inverno 1 , sendo caracterizado com alto grau de trofia pelo fator 1 , e baixa transparência da água e alta profundidade pelo fator 2 .

- Análise de agrupamento

A partir dos escores obtidos pela análise anterior, foi possível realizar uma análise de agrupamento do tipo cluster, que culminou no dendrograma apresentado na Figura 51. 
Esta segunda análise revelou-se satisfatoriamente significativa, representando $89,24 \%$ dos dados originais, já que o coeficiente de correlação cofenética encontrado foi 0,8924 .

Primeiramente, pode-se afirmar que o ponto limnético da lagoa Carioca Car-P1, distingue-se de todos os demais pontos no período de inverno 1 , em relação às características gerais e limnológicas analisadas.

Verificou-se a formação de três agrupamentos de pontos de amostragens, no período de inverno 1 , em relação às caracterísiticas gerais e limnológicas.

O primeiro agrupamento (I) ficou caracterizado por todos os pontos litorâneos de todas as lagoas que se encontram na área da CAF, juntamente com o ponto limnético da lagoa Amarela (Ama-P1).

O agrupamento II foi formado por todos os pontos limnéticos das lagoas que se encontram na área da CAF, excluindo-se o ponto limnético da lagoa Amarela que compôs o agrupamento I.

Vale ressaltar, que os agrupamentos I e II estiveram mais próximos entre si do que o terceiro agrupamento (III), que foi composto pelos pontos litorâneos da lagoa Carioca.

Dessa forma, a presente análise revelou a seguinte distribuição dos pontos de amostragem no período de inverno 1 , em função das características gerais e limnológicas: compartimentos litorâneos (agrupamento I) e limnéticos (agrupamentos I e II) das lagoas que se encontram na área da CAF distintos dos pontos litorâneos (agrupamento III) e do limnético da lagoa Carioca, que se encontra no Parque Estadual do Rio Doce. 
Valor do coeficiente de correlação cofenética: 0.8924

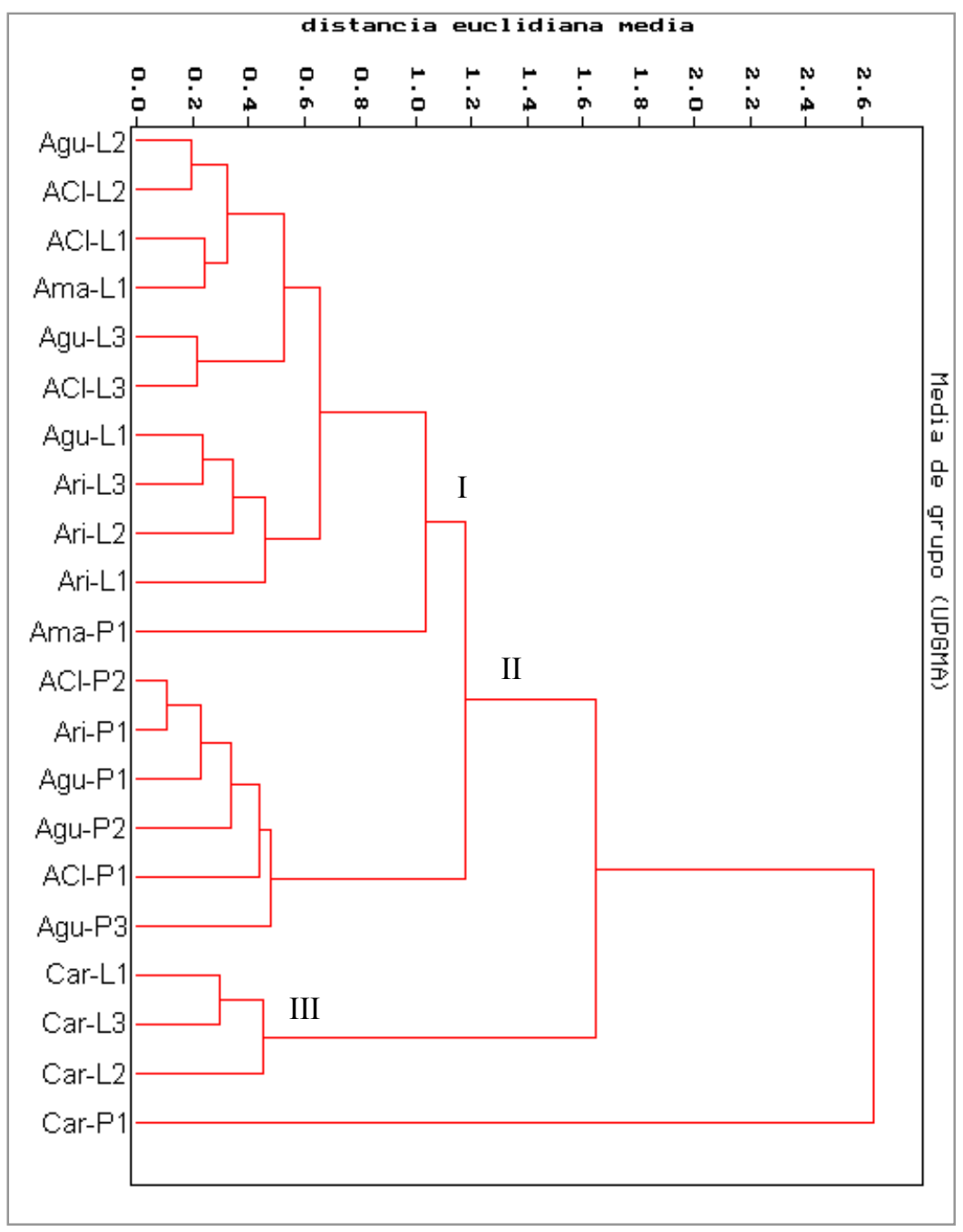

Figura 51. Dendrograma dos pontos de amostragem a partir da análise de agrupamento do tipo Cluster para valores dos coeficientes dos fatores da ACP para valores das variáveis limnológicas no período de inverno 1 , com distância euclidiana média e método de ligação do tipo UPGMA. 
- CARACTERÍSTICAS LIMNOLÓGICAS - INVERNO 2

- Análise de componentes principais

A partir de uma análise preliminar de componentes principais foram descartadas as seguintes variáveis: tipo de habitat, profundidade da coluna da água, transparência, fosfato dissolvido total, fósforo total, nitrato, silicato reativo e clorofila.

As variáveis cujos valores foram utilizados para a presente análise, estão apresentadas na Tabela 32, juntamente com seus coeficientes de correlação com os componentes 1 e 2 .

Tabela 32. Correlação (coeficiente de correlação>0.700) das variáveis limnológicas com os componentes principais 1 e 2, "Eigenvalue" e variância explicada, no período de inverno 2 (agosto de 1999).

\begin{tabular}{ccc}
\hline \hline & \multicolumn{2}{c}{ CoMPONENTES } \\
Variáveis limnológicas & $\mathbf{1}$ & $\mathbf{2}$ \\
\hline Mat. susp. fração orgânica & 0.827 & \\
IET Salas (FT) & 0.811 & \\
Fósforo total & 0.809 & \\
Condutividade elétrica & -0.726 & \\
Mat. susp. fração inorgânica & -0.859 & 0.834 \\
Amônio & & -0.804 \\
pH & & -0.810 \\
Temperatura da água & & -0.862 \\
Oxigênio dissolvido & \multirow{2}{*}{35.662} & 30.792 \\
Percentagem da variância & \multicolumn{2}{c}{66.454} \\
explicada & \multicolumn{2}{c}{} \\
Percentagem total da variância & & \\
explicada & & \\
\hline
\end{tabular}

A variância total explicada pelos dois componentes totalizou uma porcentagem de 66,454 , aceita como satisfatória pelo presente estudo.

Segundo as variáveis que se associaram aos componentes da análise, o fator 1 representou o grau de trofia das lagoas, e o fator 2 os perfis térmicos, de oxigênio dissolvido e pH, além da concentração de amônio. 
Na Figura 52 está apresentada a ordenação dos pontos de amostragem em função dos fatores.

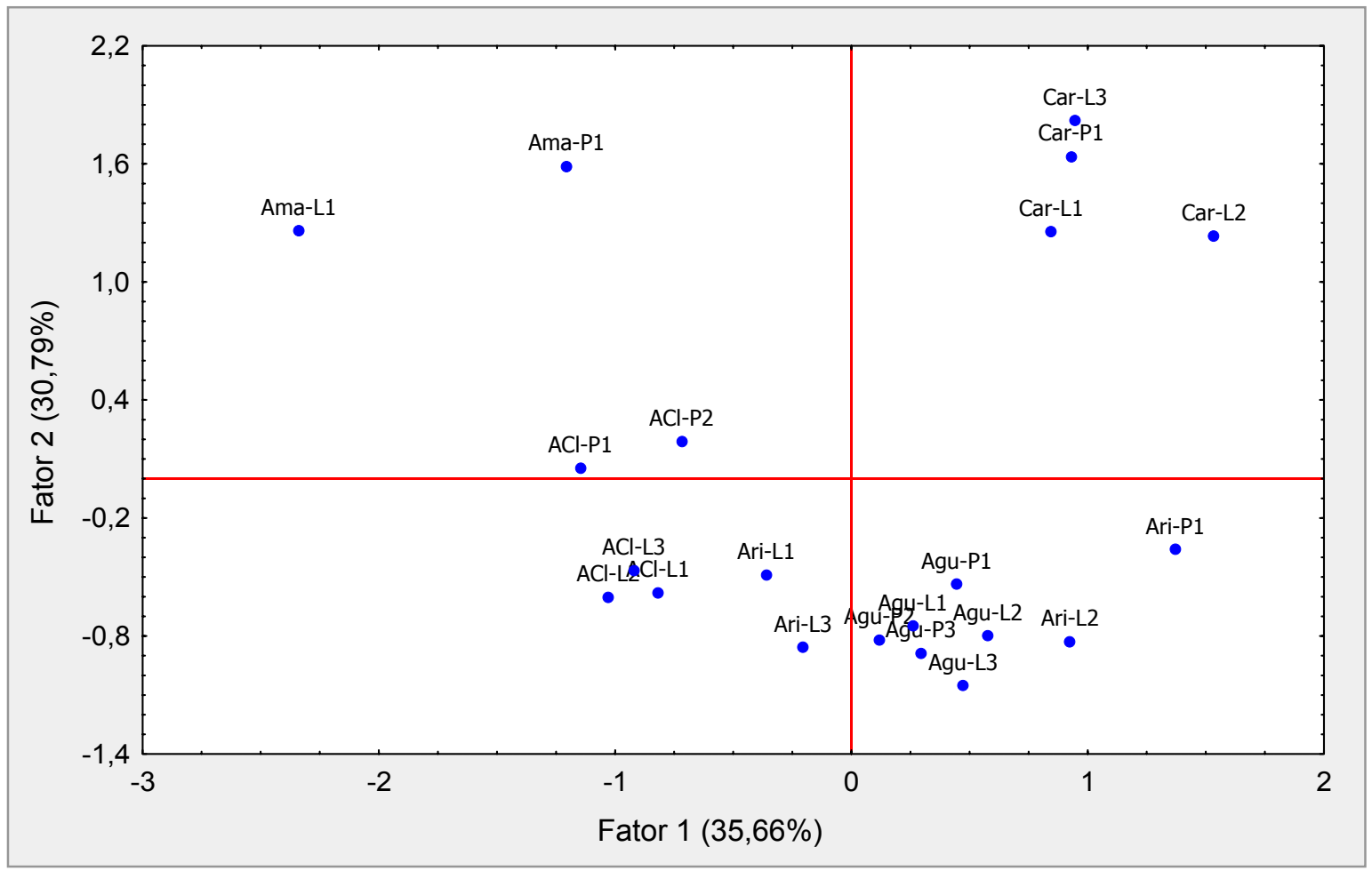

Figura 52. Ordenação dos pontos de amostragem no período de inverno 2 , pela análise de componentes principais para as varáveis limnológicas, segundo os fatores 1 e 2.

Pode-se verificar que os pontos limnético e litorâneos da lagoa Carioca associaram-se positivamente aos dois fatores, formando um grupo de pontos de amostragem separado dos demais, neste período de análise.

Também estiveram associados positivamente ao fator 1 , todos os pontos de amostragem da lagoa Aguapé, além de dois pontos da lagoa Ariranha (Ari-P1 e Ari-L2). Os demais pontos associaram-se negativamente com o fator 1 , ou seja, os pontos litorâneos Ari-L1 e Ari-L3 da lagoa Ariranha, e todos os pontos das lagoas Amarela e Águas Claras.

Vale ressaltar, que os pontos litorâneos da lagoa Águas Claras formaram um grupo bastante próximo, em função dos dois fatores.

Ocorreram associações positivas em relação ao fator 2 dos pontos da lagoa Carioca, já citados, dos pontos da lagoa Amarela e daqueles limnéticos da lagoa Águas Claras. Os demais pontos de amostragem ficaram associados negativamente a este 
eixo, ou seja, os pontos litorâneos da lagoa Águas Claras, e todos os pontos das lagoas Aguapé e Ariranha.

- Análise de agrupamento

O dendrograma apresentado na Figura 53 mostra os agrupamentos obtidos a partir dos escores gerados pela análise de componentes principais.

Esta análise revelou em coeficiente de correlação cofenético de 0,8943 satisfatoriamente significativo, mostrando que a análise representa $89,43 \%$ dos dados originais.

De maneira geral não foi possível verificar agrupamentos distintos em função dos compartimentos limnéticos e litorâneos das lagoas.

Porém, em função das lagoas formaram-se quatro agrupamentos distintos. 0 agrupamento I foi formado pelos pontos da lagoa Aguapé, juntamente com dois pontos da lagoa Ariranha (Ari-P1 e Ari-L2). Os demais pontos da lagoa Ariranha (Ari-L1 e Ari-L3) agruparam-se com os pontos da lagoa Águas Claras, em II.

Vale ressaltar que os agrupamentos I e II compreendem as lagoas que se encontram na área da CAF, com exceção feita para a lagoa Amarela, cujos pontos de amostragem formaram o agrupamento IV, e foram distintos de todos os demais pontos de amostragem, segundo a análise de agrupamento empregada.

O agrupamento III foi formado pelos pontos da lagoa Carioca, pertencente ao Parque Estadual do Rio Doce. Este agrupamento esteve mais próximo ao conjunto dos agrupamentos I e II, do que ao agrupamento IV. 
Valor do coeficiente de correlação cofenética: 0.8943

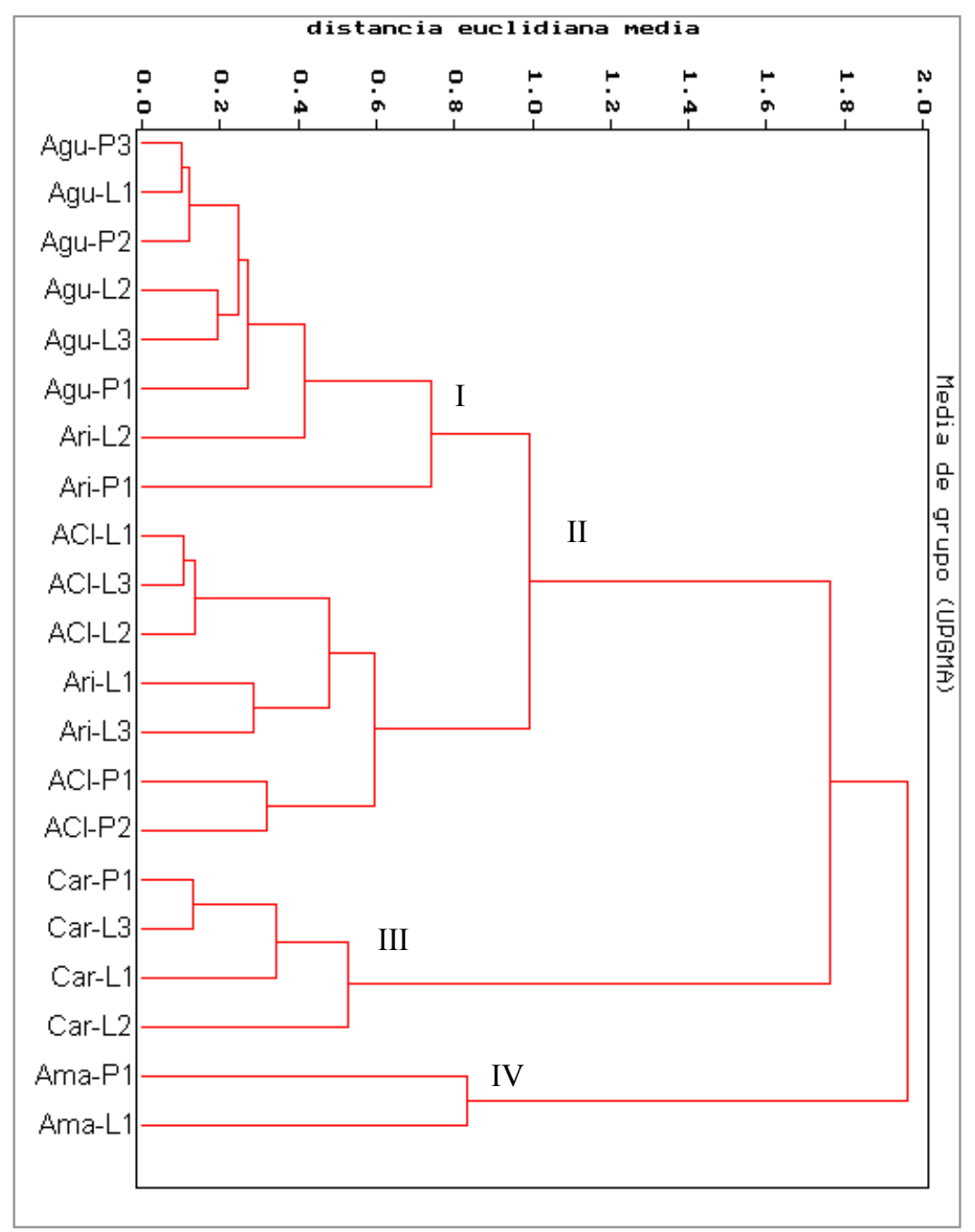

Figura 53. Dendrograma dos pontos de amostragem a partir da análise de agrupamento do tipo Cluster para valores dos coeficientes dos fatores da ACP para valores das variáveis limnológicas no período de inverno 2 , com distância euclidiana média e método de ligação do tipo UPGMA. 
- CARACterísticas LimNológicAs - VerÃo

- Análise de componentes principais

As variáveis que foram descartadas a partir da análise de componentes principais preliminar, foram: vegetação, lagoa, temperatura da água, condutividade elétrica, oxigênio dissolvido, nitrito, fração orgânica e fração inorgânica do material em suspensão.

A variância total explicada pelos dois componentes no período de verão foi de $70,881 \%$. Os valores dos coeficientes de correlação das variáveis que se mostraram importantes na ordenação dos pontos de amostragem estão apresentados na Tabela 33.

Tabela 33. Correlação (coeficiente de correlação>0.700) das variáveis limnológicas com os componentes principais 1 e 2, "Eigenvalue" e variância explicada, no período de verão (fevereiro de 2000).

\begin{tabular}{ccc}
\hline \hline & \multicolumn{2}{c}{ CoMPONENTES } \\
Variáveis limnológicas & $\mathbf{1}$ & $\mathbf{2}$ \\
\hline Fósforo total & 0.797 & \\
IET Salas (FT) & 0.785 & \\
Profundidade & 0.703 & \\
Tipo de habitat & -0.729 & \\
Transparência da água & -0.765 & \\
pH & -0.841 & 0.961 \\
Fosfato dissolvido total & & 0.905 \\
Silicato & & 0.834 \\
Fosfato inorgânico & & 0.750 \\
IET Car (FT, FDT, Clor.) & & 5.060 \\
Eigenvalue & 5.572 & 33.732 \\
Percentagem da variância & 37.149 & \\
explicada & \multicolumn{2}{c}{70.881} \\
Percentagem total da variância \\
explicada & \multicolumn{2}{c}{} \\
\hline \hline
\end{tabular}

Segundo as variáveis que melhor explicaram a análise, ambos os fatores representaram o grau de trofia das lagoas.

A ordenação dos pontos de amostragem segundo as variáveis gerais e limnológicas das lagoas está apresentada na Figura 54. 


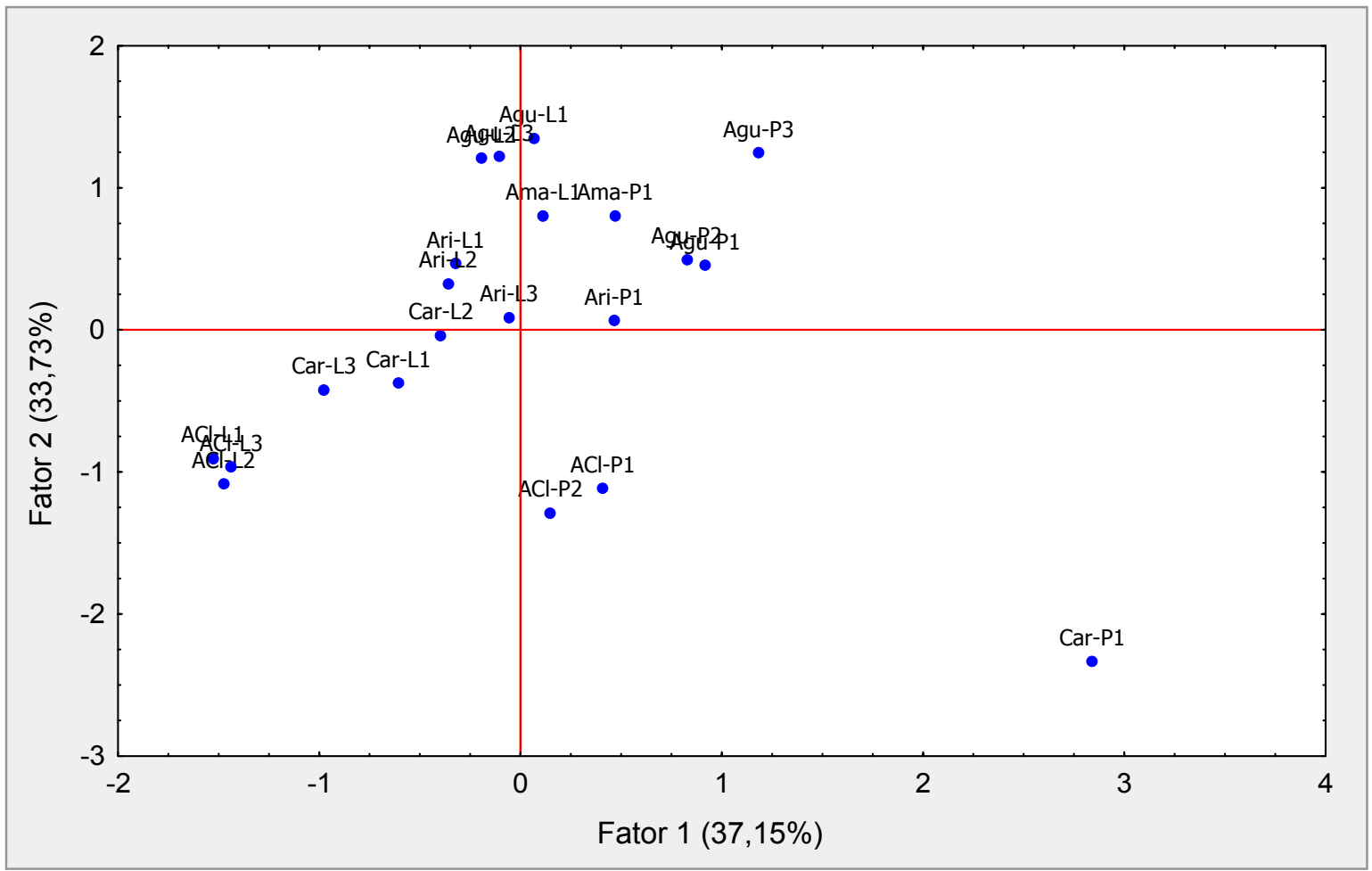

Figura 54. Ordenação dos pontos de amostragem no período de verão, pela análise de componentes principais para as varáveis limnológicas, segundo os fatores 1 e 2 .

O ponto limnético da lagoa Carioca Car-P1 não se apresentou próximo a nenhum outro ponto de amostragem, associando-se positivamente com o Fator 1, e negativamente com o 2 .

Os pontos limnéticos da lagoa Águas Claras (ACl-P1 e ACl-P2) apresentaram-se próximos entre si, e mostraram uma associação positiva, embora próximos à origem, ao Fator 1, e negativa ao 2. Já os pontos litorâneos desta mesma lagoa (ACl-L1, ACl-L2 e ACl-L3) ordenaram-se próximos entre si, com associações negativas a ambos os fatores.

Os demais pontos apresentaram-se dispersos, e não mostraram tendência evidentes de ordenação.

Vale ressaltar que, de maneira geral, o fator 1 foi responsável por separar os pontos das lagoas Carioca e Águas Claras (associados negativamente) dos pontos das lagoas Aguapé, Ariranha e Amarela (associados positivamente).

Já o fator 2, separou os pontos limnéticos (associados positivamente) dos litorâneos (associados negativamente) de todas as lagoas, com exceções aos pontos 
litorâneos Agu-L1 (lagoa Aguapé) e Ama-L1 (lagoa Amarela), que associaram-se positivamente ao fator 2 .

- Análise de agrupamento

A análise de agrupamento do tipo cluster para as características gerais e limnológica no período de verão mostrou-se significativo, com o coeficiente de correlação cofenético igual a 0,8791. O dendrograma resultante desta análise está apresentado na Figura 55.

Igualmente como verificado no período de inverno 1 , no verão o ponto limnético Car-P1 da lagoa Carioca apresentou-se distinto de todos os demais pontos de amostragem de todas as lagoas.

Foi possível verificar a existência de seis agrupamentos de pontos de amostragem no período de verão.

O agrupamento I foi formado pelos pontos litorâneos (Agu-L1, Agu-L2 e AguL3) da lagoa Aguapé. Os pontos limnético (Ama-P1) e litorâneo (Ama-L1) da lagoa Amarela formaram o agrupamento II. O agrupamento III foi formado pelos pontos pelágicos das lagoa Ariranha (Ari-P1) e Aguapé (Agu-P1, Agu-P2 e Agu-P3). Vale ressaltar, que os agrupamentos I e II juntos estiveram mais próximos ao agrupamento III, do que a qualquer outro agrupamento, representando todos os pontos das lagoas Aguapé, Amarela e também o ponto limnético Ari-P1 da lagoa Ariranha.

Os pontos litorâneos das lagoas Carioca (Car-L1, Car-L2 e Car-L3) e Ariranha (Ari-L1, Ari-L2 e Ari-L3) formaram o agrupamento IV. Este agrupamento esteve mais próximo dos agrupamentos I, II e III do que de qualquer outro agrupamento. Assim, os agrupamentos I, II, III, e IV representaram todos os pontos de amostragem das lagoas Aguapé, Amarela e Ariranha.

O agrupamento $\mathrm{V}$ representou os pontos litorâneos (ACl-L1, ACl-L2 e ACl-L3) da lagoa Águas Claras, e o VI os pontos limnéticos (ACl-P1 e ACl-P2) da mesma lagoa. $\mathrm{O}$ conjunto dos agrupamentos $\mathrm{V}$ e IV representaram todos os pontos de amostragem da lagoa Águas Claras. 
Valor do coeficiente de correlação cofenética: 0.8791

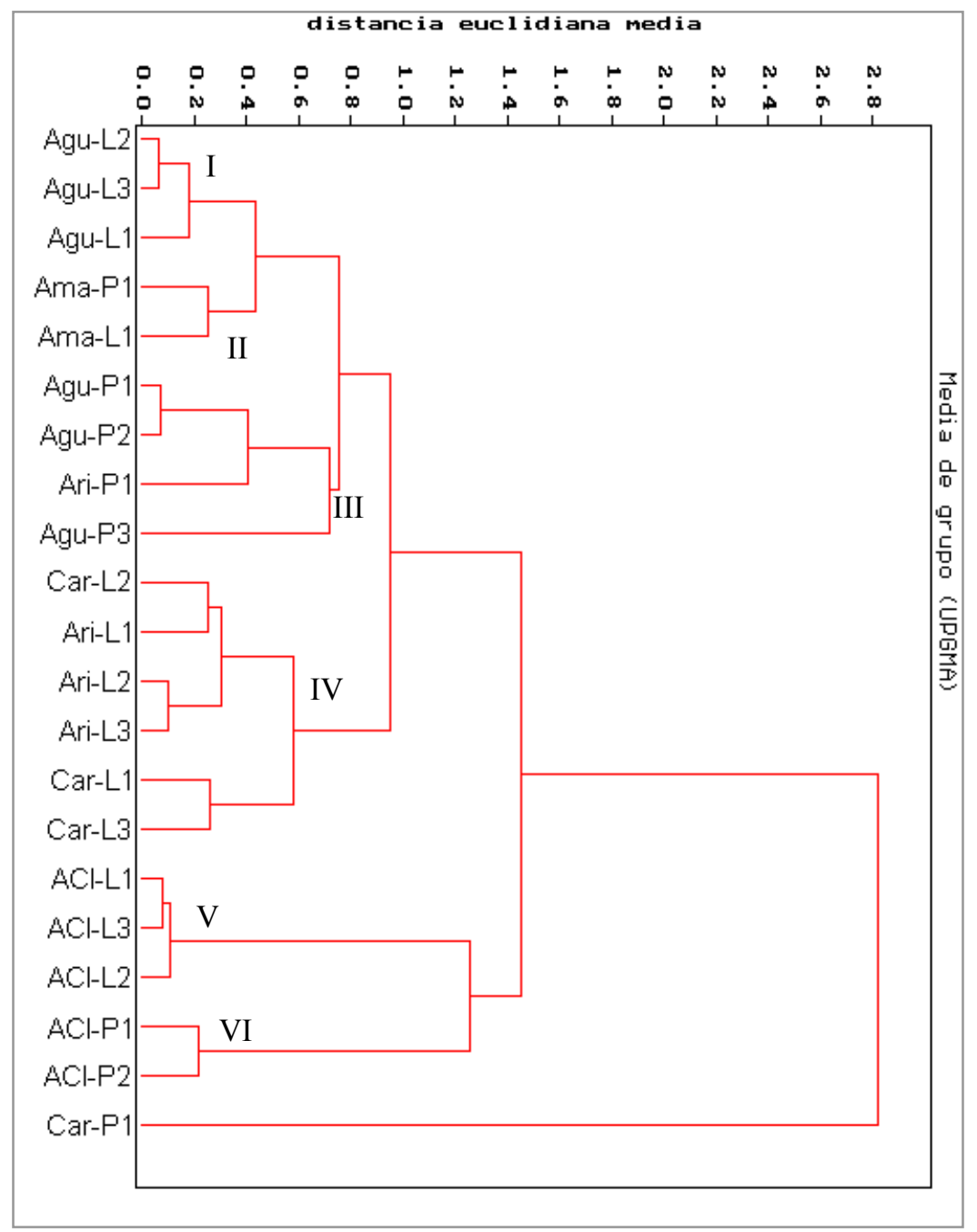

Figura 55. Dendrograma dos pontos de amostragem a partir da análise de agrupamento do tipo Cluster para valores dos coeficientes dos fatores da ACP para valores das variáveis limnológicas no período de verão, com distância euclidiana média e método de ligação do tipo UPGMA. 


\subsubsection{MEDIDAS DE DIVERSIDADE}

- ANÁLiSE DE VARIÂNCIA MULTIVARIAdA (MANOVA)

Os resultados obtidos pela análise de variância multivariada, no nível de decisão de $5 \%(\alpha=0,05)$, revelaram haver efeito da sazonalidade na distribuição dos dados referentes às medidas de diversidade dos pontos de amostragem, sendo encontrado um valor altamente significante de $\rho$ igual a 0,000 , ou seja, menor que o nível de decisão.

Dessa forma, para as análises seguintes previstas no planejamento estatístico, a matriz inicial foi dividida em três outras matrizes, segundo o período de amostragem.

A seguir são apresentados os resultados das análises de componentes principais e de agrupamento (cluster) para os períodos de inverno 1, inverno 2 e verão, separadamente.

A partir das análises preliminares de componentes principais para todos os períodos de estudo, não foi necessário o descarte de nenhuma medida de diversidade, já que todas apresentaram valores de correlação acima de 0,700 com os componentes 1 e/ou 2.

- MedidAS DE DIVERSIDADE - INVERNO 1

- Análise de componentes principais

A Tabela 34 apresenta os resultados obtidos pela análise de componentes principais para medidas de diversidade no período de inverno 1. De acordo com estes, a variância total explicada foi de $96,781 \%$, porém, considerou-se apenas o componente 1 , já que todas as medidas de diversidade associaram-se apenas a este, com uma variância explicada de 76,311 \%, altamente representativa do conjunto de dados originais. 
Tabela 34. Correlação (coeficiente de correlação $\mathbf{0 . 7 0 0 )}$ das medidas de diversidade com os componentes principais 1 e 2, "Eigenvalue" e variância explicada, no período de inverno 1 (junho de 1999).

\begin{tabular}{ccc}
\hline & \multicolumn{2}{c}{ CoMPONENTES } \\
Medidas de diversidade & $\mathbf{1}$ & $\mathbf{2}$ \\
\hline Índice de equidade de Pielou & 0.958 & \\
Índice de diversidade de Shannon-Weaner & 0.938 & \\
Índice de diversidade de Simpson & 0.891 & \\
Índice de diversidade de Margalef & 0.792 & \\
Riqueza de espécies & 0.726 & \\
Índice de dominância de Simpson & -0.913 & \\
Eigenvalue & 4.579 & 1.228 \\
Percentagem da variância explicada & 76.311 & 20.470 \\
Percentagem total da variância explicada & \multicolumn{2}{c}{96.781} \\
\hline
\end{tabular}

Assim, a classificação do fator 1 , segundo as medidas de diversidade, foi a seguinte:

- Associação positiva: diversidade

- Associação negativa: dominância

Na Figura 56 está apresentada a ordenação dos pontos de amostragem no período de inverno 1 , segundo os valores das medidas de diversidade.

De acordo com os resultados, apresentaram associações positivas com o fator 1, todos os pontos litorâneos da lagoas Amarela (Ama-L1), Águas Claras (ACl-L1, AClL2 e ACl-L3) e Ariranha (Ari-L1, Ari-L2 e Ari-L3), dois pontos litorâneos (Agu-L1 e AguL3) e todos os limnéticos (Agu-P1, Agu-P2 e Agu-P3) da lagoa Aguapé. Estes pontos representaram uma menor dominância de espécies e maior diversidade na estrutura zooplanctônica.

Os pontos pelágicos das lagoas Águas Claras (ACl-P1 e ACl-P2) e Ariranha (AriP1), e todos os pontos limnéticos e litorâneos da lagoa Carioca associaram-se negativamente ao fator 1 , mostrando haver maior dominância de espécies e menor diversidade na estrutura zooplanctônica.

Os pontos que estiveram mais associados à maior diversidade de táxons foram o ponto litorâneo ACl-L2 da lagoa Águas Claras, e o ponto litorâneo Ama-L1 da lagoa Amarela.

Aqueles que se mostraram mais fortemente associados à dominância de espécies foram todos os pontos litorâneos da lagoa Carioca. 


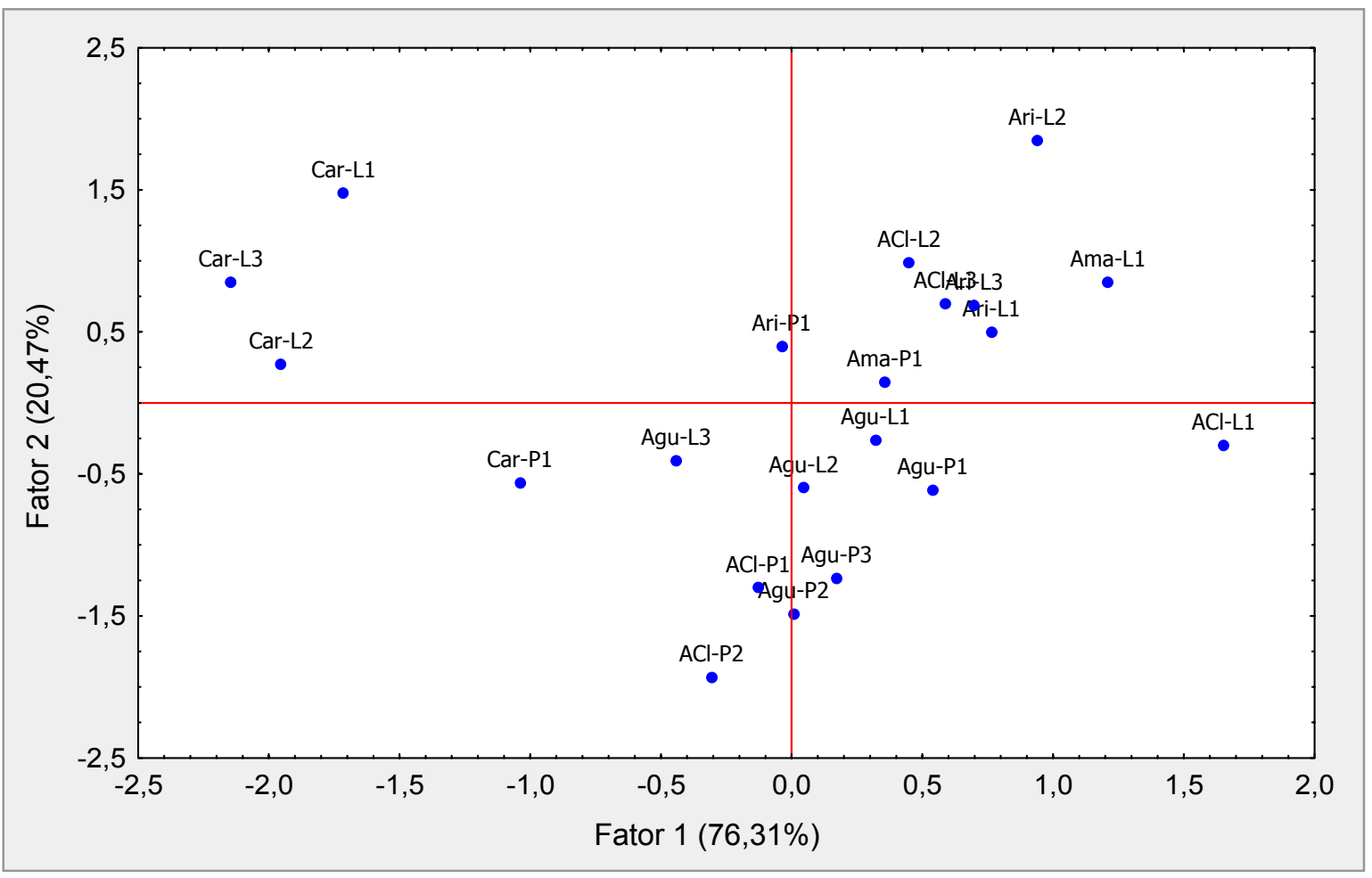

Figura 56. Ordenação dos pontos de amostragem no período de inverno 1, pela análise de componentes principais para as medidas de diversidade, segundo os fatores 1 e 2.

- Análise de agrupamento

O dendrograma resultante da análise de agrupamento dos pontos de amostragem no período de inverno 1 , segundo as medidas de diversidade, está apresentado na Figura 57.

O coeficiente de correlação cofenética encontrado, 0,7857 , mostrou-se significativo dos dados originais.

A análise de agrupamento revelou a existência de dois grupos distintos de pontos de amostragem. O agrupamento I foi formado por todos os pontos limnéticos e litorâneos das lagoas que se encontram na área da CAF, juntamente com o ponto limnético Car-P1 da lagoa Carioca.

Por outro lado, os pontos litorâneos da lagoa Carioca formaram o agrupamento II. 
Valor do coeficiente de correlação cofenética: 0.7857

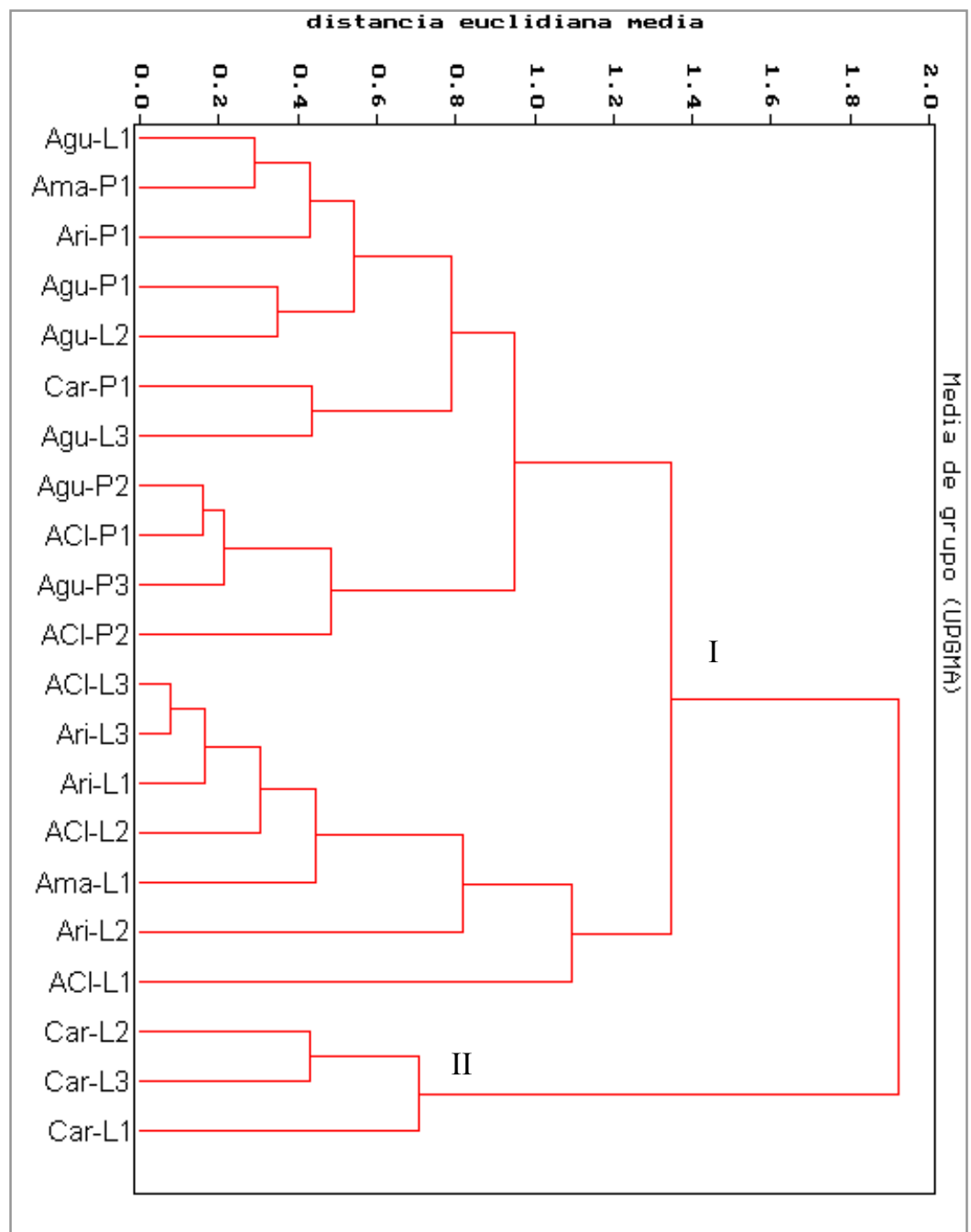

Figura 57. Dendrograma dos pontos de amostragem a partir da análise de agrupamento do tipo Cluster para valores dos coeficientes dos fatores da ACP para valores das medidas de diversidade no período de inverno 1 , com distância euclidiana média e método de ligação do tipo UPGMA. 
- MEDIDAS DE DIVERSIDADE - INVERNO 2

- Análise de componentes principais

Da mesma forma como ocorrido para o período de inverno 1, no inverno 2 apenas o componente 1 está analisado, uma vez que só a este associaram-se as medidas de diversidade.

A variância explicada pelo primeiro componente da análise foi de $61,657 \%$, sendo considerada satisfatória.

Os valores dos coeficientes de correlação das medidas de diversidade com o componente 1 estão apresentados na Tabela 35.

Tabela 35. Correlação (coeficiente de correlação>0.700) das medidas de diversidade com os componentes principais 1 e 2, "Eigenvalue" e variância explicada, no período de inverno 2 (agosto de 1999).

\begin{tabular}{ccc}
\hline & \multicolumn{2}{c}{ CoMPONENTES } \\
Medidas de diversidade & $\mathbf{1}$ & $\mathbf{2}$ \\
\hline Índice de diversidade de Shannon-Weaner & 0.853 & \\
Índice de diversidade de Simpson & 0.840 & \\
Índice de diversidade de Margalef & 0.812 & \\
Riqueza de espécies & 0.707 & \\
Índice de equidade de Pielou & 0.701 & \\
Índice de dominância de Simpson & -0.784 & \\
\hline Eigenvalue & 3.699 & 2.013 \\
Percentagem da variância explicada & 61.657 & 33.557 \\
Percentagem total da variância explicada & \multicolumn{2}{c}{95.214} \\
\hline
\end{tabular}

Segundo estes resultados, o componente 1 ficou classificado pela diversidade associada positivamente ao eixo, e dominância de espécies associada negativamente.

A ordenação dos pontos de amostragem, segundo as medidas de diversidade no período de inverno 2, está apresentada na Figura 58.

Os pontos de amostragem que se associaram positivamente ao fator 1 foram todos os litorâneos das lagoas Águas Claras (ACl-L1, ACl-L2 e ACl-L3), Aguapé (AguL1, Agu-L2 e Agu-L3) e Amarela (Ama-L1), além dos pontos pelágicos das lagoas Ariranha (Ari-P1) e Aguapé (Agu-P1). 


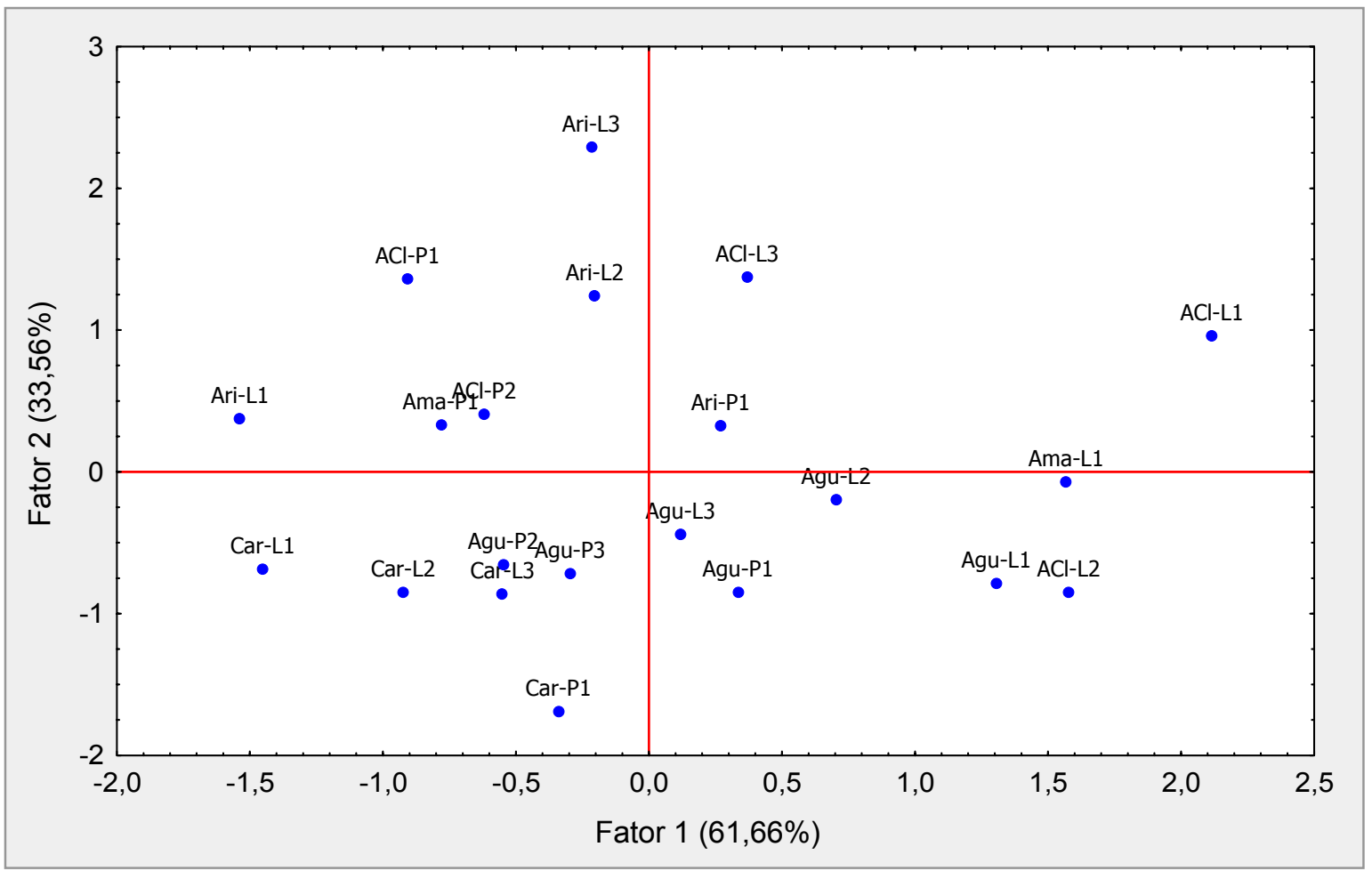

Figura 58. Ordenação dos pontos de amostragem no período de inverno 2 , pela análise de componentes principais para as medidas de diversidade, segundo os fatores 1 e 2.

Os demais pontos associaram-se negativamente ao fator 1 , ou seja, todos os pontos litorâneos da lagoa Ariranha (Ari-L1, Ari-L2 e Ari-L3), os pontos pelágicos das lagoas Amarela (Ama-P1), Águas Claras (ACl-P1 e ACl-P2), dois pontos pelágicos da lagoa Aguapé (Agu-P2 e Agu-P3) e todos os pontos limnético e litorâneos da lagoa Carioca.

- Análise de agrupamento

A análise de agrupamento revelou um coeficiente de correlação cofenético satisfatório, 0,7076, porém não apresentou agrupamentos condizentes com a formação de compartimentos limnéticos e litorâneos (Figura 59), ou segundo a localização das lagoas em questão (CAF ou Parque Estadual do Rio Doce). 
Valor do coeficiente de correlação cofenética: 0.7076

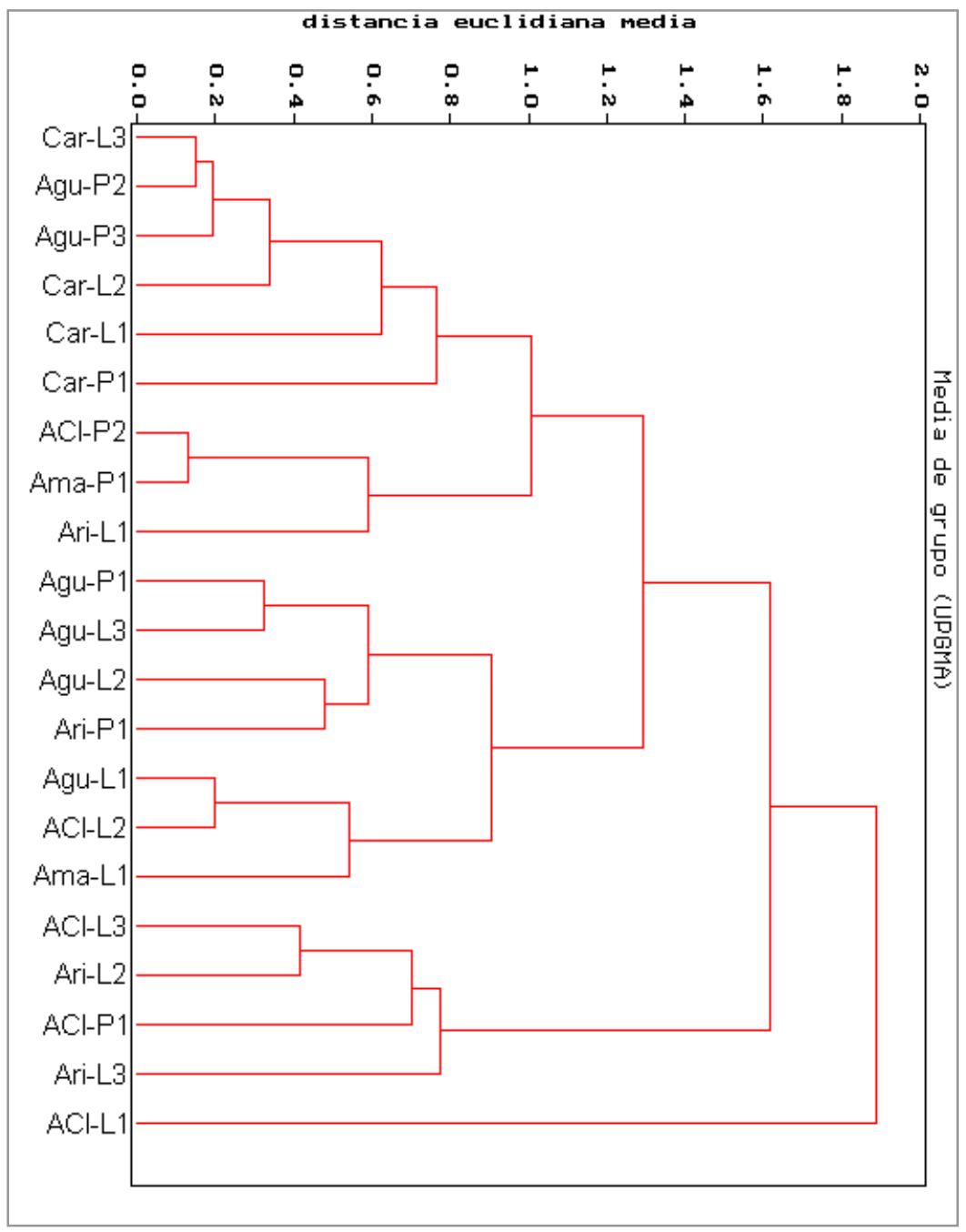

Figura 59. Dendrograma dos pontos de amostragem a partir da análise de agrupamento do tipo Cluster para valores dos coeficientes dos fatores da ACP para valores das medidas de diversidade no período de inverno 2 , com distância euclidiana média e método de ligação do tipo UPGMA. 
- MEDIDAS DE DIVERSIDADE - VERÃO

- Análise de componentes principais

Os resultados da análise de componentes principais, Tabela 36, revelou uma variância total explicada pelos componentes 1 e 2 de 99,020\%, considerada altamente representante dos dados originais.

Tabela 36. Correlação (coeficiente de correlação $\mathbf{0 . 7 0 0}$ ) das medidas de diversidade com os componentes principais 1 e 2, "Eigenvalue" e variância explicada, no período de verão (fevereiro de 2000).

\begin{tabular}{ccc}
\hline & \multicolumn{2}{c}{ CoMPONENTES } \\
Medidas de diversidade & $\mathbf{1}$ & $\mathbf{2}$ \\
\hline Índice de diversidade de Shannon-Weaner & 0.876 & \\
Índice de equidade de Pielou & 0.846 & \\
Índice de diversidade de Margalef & 0.840 & \\
Riqueza de espécies & 0.793 & \\
Índice de diversidade de Simpson & 0.760 & \\
Índice de dominância de Simpson & -0.702 & 0.706 \\
\hline Eigenvalue & 3.887 & 2.054 \\
Percentagem da variância explicada & 64.782 & 34.238 \\
Percentagem total da variância explicada & \multicolumn{2}{c}{99.020} \\
\hline \hline
\end{tabular}

Em função das medidas de diversidade, o fator 1 representou a diversidade (associação positiva) e dominância (associação negativa), e o fator 2 a dominância (associação negativa).

Na Figura 60 está apresentada a ordenação dos pontos de amostragem segundo as medidas de diversidade no período de Verão.

Não foi possível a verificação de ordenações dos pontos de amostragem, representantes dos compartimentos limnéticos e litorâneos, e da localização das lagoas estudadas. 


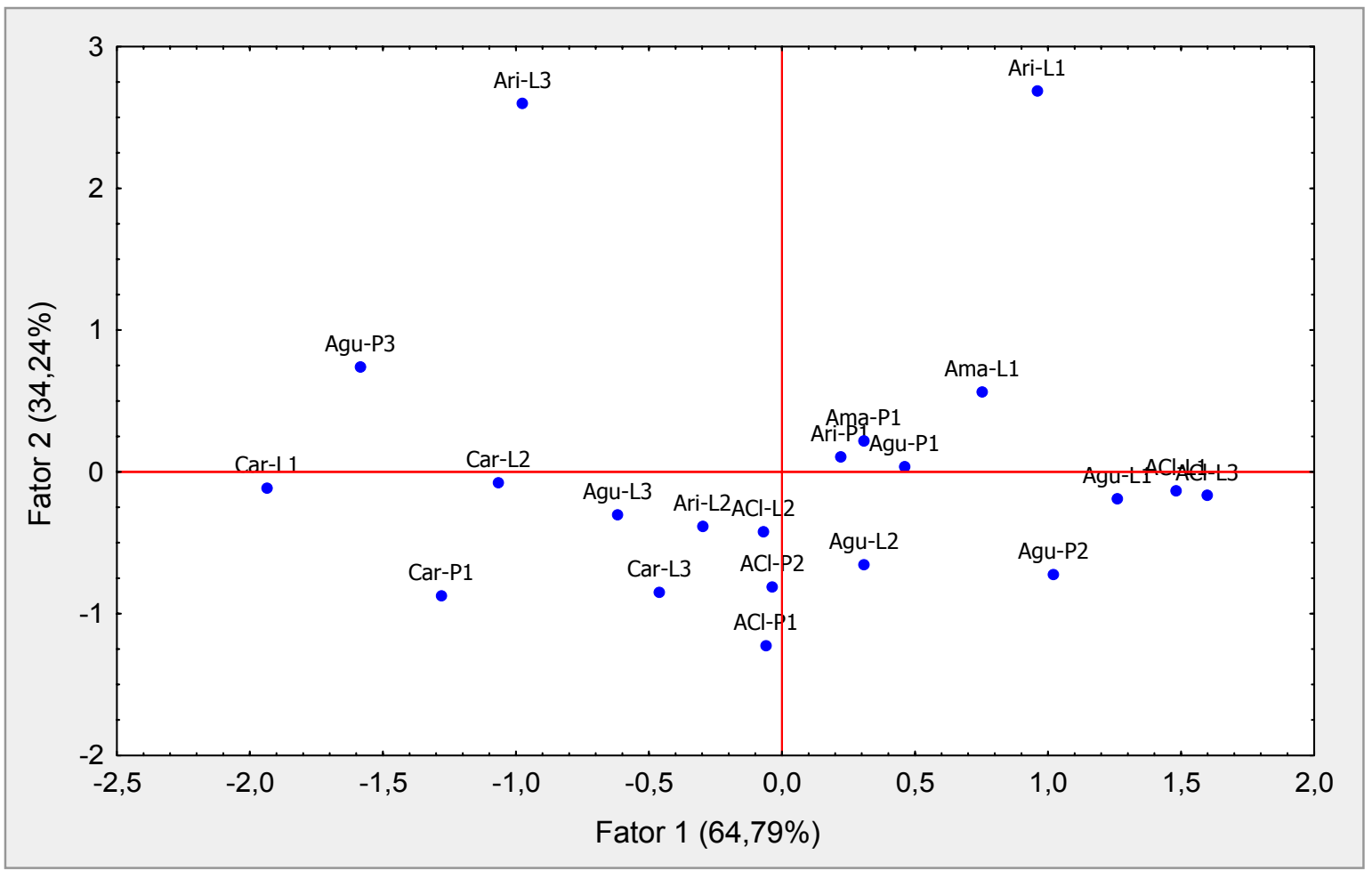

Figura 60. Ordenação dos pontos de amostragem no período de verão, pela análise de componentes principais para as medidas de diversidade, segundo os fatores 1 e 2 .

- Análise de agrupamento

Esta análise revelou um coeficiente de correlação cofenético de 0,8623 , considerado representativo dos dados originais.

Assim como a análise de componentes principais, no verão, não ocorreram agrupamentos de pontos de amostragem em função dos compartimentos limnético e litorâneo, ou em função da localização das lagoas estudadas.

Vale destacar apenas um agrupamento formado pelos pontos litorâneos Ari-L1 e Ari-L3 da lagoa Ariranha, que apresentaram-se distantes de todos os demais pontos de amostragem, segundo o dendograma apresentado na Figura 61. 
Valor do coeficiente de correlação cofenética: 0.8623

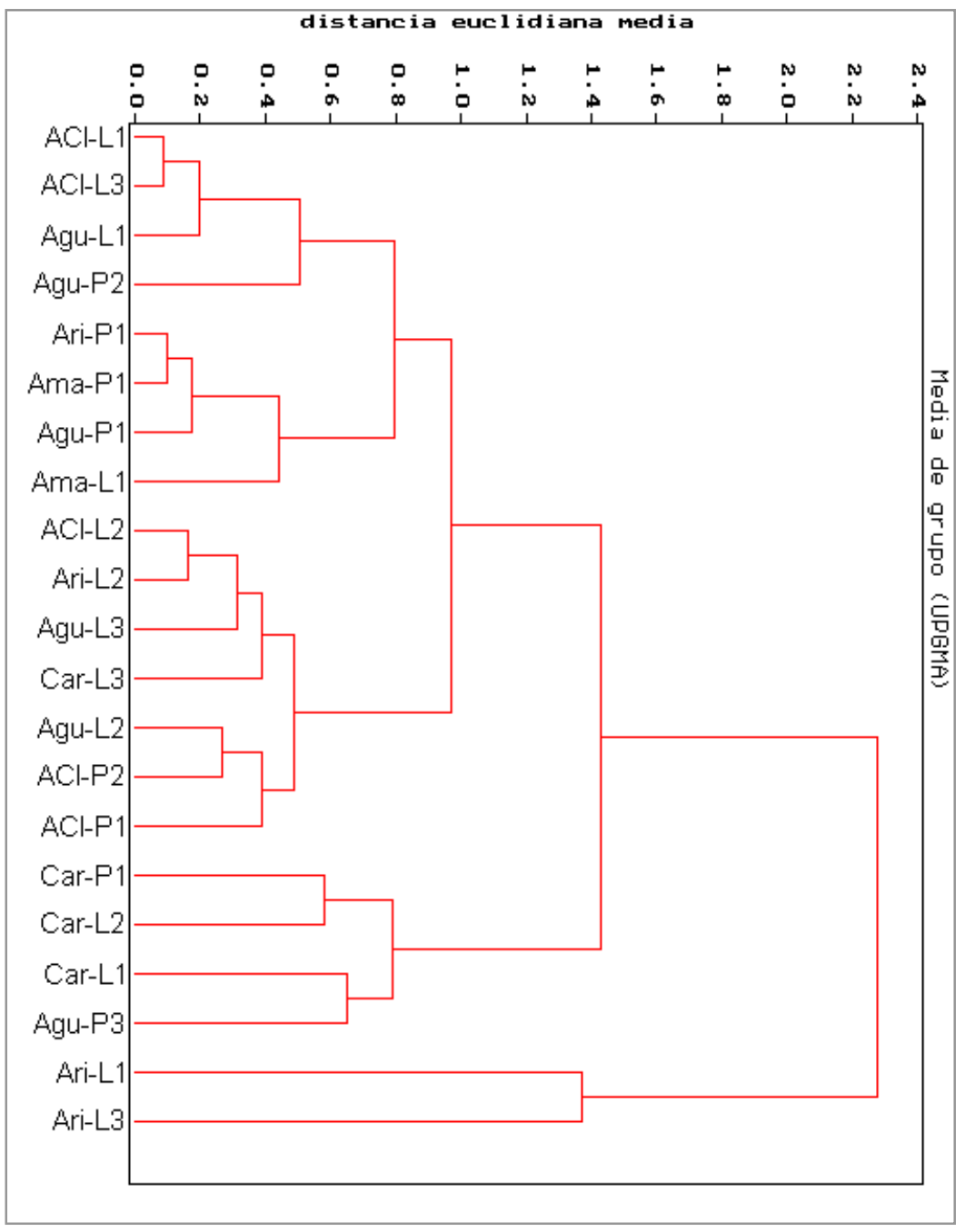

Figura 61. Dendrograma dos pontos de amostragem a partir da análise de agrupamento do tipo Cluster para valores dos coeficientes dos fatores da ACP para valores das medidas de diversidade no período de verão, com distância euclidiana média e método de ligação do tipo UPGMA. 


\section{DISCUSSÃo}

\section{- VARIÁVEIS LIMNOLÓGICAS E MORFOMÉTRICAS}

No presente trabalho foram observadas características morfométricas, como profundidade, comprimento máximo, perímetro, área e índice de desenvolvimento de margem, bastante variáveis entre as cinco lagoas investigadas.

No sistema de lagos do Vale do Rio Doce, os aspectos morfológicos, como as características do contorno do fundo e da superfície lacustres, representam a intensidade da energia ambiental, nos sentidos da erosão ou deposição que atuaram na sua formação geológica (MEIS \& TUNDISI, 1997).

Segundo os mesmos autores, a origem geológica dos lagos deste sistema é o principal fator responsável pelas variações morfológicas que ocorrem entre as lagoas, uma vez que, na maioria delas, não ocorrem tributários que poderiam acarretar variações temporais expressivas no volume da água e, consequentemente, em características como área e profundidade. Embora no período das chuvas (verão), geralmente, ocorram comunicações de pequenos riachos com algumas lagoas, como é o caso da lagoa Ariranha, estes não chegam a assumir o papel de verdadeiros tributários no aporte de água. Por esta ligação temporária, podem ocorrer fluxos de matéria e transferência de algumas populações aquáticas.

Em conseqüência da origem geológica, os lagos do Vale do Rio Doce possuem um contorno batimétrico na forma de "V", uma vez que estão localizados, na maioria dos casos, nos vales do relevo montanhoso da região (HENRY et al., 1997a). 
MEIS \& TUNDISI (1997) caracterizaram os lagos deste sistema de acordo com a forma da superfície, a profundidade e o tipo de circulação, classificando-os da seguinte forma:

- Lagoas Carioca e Ariranha: forma circular, rasas e com circulação completa;

- Lagoas Águas Claras e Aguapé: forma dendrítica, rasas e com circulação rápida e completa;

- Lagoa Amarela: tipo de área alagada, em fase final de evolução sucessional.

Pelos resultados das variáveis morfométricas obtidos, pode-se dizer que houve grande variação das características morfométricas verticais (profundidade) e horizontais (comprimento máximo, perímetro, área e índice de desenvolvimento de margem) entre as cinco lagoas estudadas. Como exemplo desta variabilidade pode-se destacar a lagoa Carioca, que possui a maior profundidade e os menores valores de perímetro, área e índice de desenvolvimento de margem.

Os maiores valores para as variáveis morfométricas horizontais foram encontrados para a lagoa Aguapé e Águas Claras. Já a lagoa Amarela ficou caracterizada pelos menores valores de profundidade e das variáveis morfométricas horizontais (comprimento, perímetro e área). Mesmo assim, na lagoa Carioca é que foi encontrado o menor valor para o índice de desenvolvimento de margem, devido ao fato desta apresentar uma forma bastante circular na superfície da água, como caracterizado por MEIS \& TUNDISI (1997).

Ainda em relação ao índice de desenvolvimento de margem, os maiores valores foram verificados para as lagoas Aguapé e Águas Claras, o que indica um alto grau de sinuosidade da margem lacustre, ou seja, contornos mais dendríticos em relação as demais lagoas, o que está de acordo com a classificação de MEIS \& TUNDISI (1997). Pelo fato deste índice representar o grau de reentrâncias na margem do lago, pode-se dizer que estas lagoas são as que têm a maior probabilidade de apresentar uma grande heterogeneidade de habitats litorâneos.

Pode-se dizer também que o balanço hídrico das lagoas, composto principalmente pela entrada de água pluviométrica e perdas pelo lençol freático, por evaporação e pela transpiração das formas vegetais, manteve o volume de água das lagoas aparentemente constante entre as estações de seca (inverno de 1999) e chuva (verão de 2000), uma vez que os valores da profundidade, nos pontos amostrados entre os períodos de estudo, não se alteraram. Vale ressaltar que o regime climático da região é determinado por chuvas concentradas num período de seis meses que atingem até 1250 mm/ano, sendo mais intensas no verão, e um período de estiagem 
representado, principalmente, pela estação climática de inverno (NAKAMOTO et al., 1997). Os resultados obtidos sugerem que o período 1999-2000 foi de relativa estabilidade climática.

De forma geral, foram verificados baixos valores de profundidade para a coluna da água dos pontos litorâneos em todas as lagoas estudadas. Nestas regiões, a extensão da zona eufótica foi sempre máxima, ou seja, sempre houve luminosidade em todos os estratos da coluna da água.

Por estas características e pelo fato de ter havido uma maior homogeneidade térmica e nas concentrações de oxigênio dissolvido, $\mathrm{pH}$ e de condutividade elétrica da água nas regiões litorâneas das lagoas, em todos os períodos climáticos amostrados, pode-se inferir que houve uma maior instabilidade das características limnológicas nestas regiões quando comparadas aos pontos limnéticos. HORNE \& GOLDMAN (1994), afirmam que em zonas litorâneas rasas, como é o caso destas regiões litorâneas, tende-se a encontrar uma maior turbulência da água pela ação dos ventos, o que poderia gerar alterações nas condições verticais destes compartimentos.

Por outro lado, para as regiões limnéticas, que apresentam maior profundidade, um importante fator determinante da estabilidade das características limnológicas é a presença da vegetação terrestre do entorno dos lagos, seja nativa ou cultivada, que impede a ação dos ventos.

HENRY et al. (1997) atribuem a reduzida ação dos ventos na mistura da coluna da água de três lagoas do Vale do Rio Doce, incluindo a Carioca, ao grande porte da vegetação secundária de Floresta Tropical de Mata Atlântica ali existente. Da mesma forma, o cultivo de eucalipto (homogêneo ou misto com sub-bosque de espécies nativas) de grande porte que ocorre no entorno das lagoas Aguapé, Águas Claras, Ariranha e Amarela, também deve amortizar o efeito da ação dos ventos sobre a mistura da coluna da água.

Nas regiões litorâneas onde a zona eufótica estendeu-se até o fundo da coluna da água, não foram verificados valores maiores nas concentrações de oxigênio dissolvido e clorofila do que nas regiões limnéticas. Assim, mesmo tendo havido uma grande disponibilidade da energia luminosa (fótons) no compartimento litorâneo em todas as profundidades da coluna da água, não ocorreu um aumento da produção primária de organismos fitoplanctônicos ou perifíticos, como sugerido pelo indicador de biomassa fitoplanctônica, que é a concentração de clorofila ou a supersaturação de oxigênio. 
HENRY (1990) realizou experimentos sobre a utilização de nitrogênio e fósforo pelos organismos produtores primários no Reservatório de Jurumirim (SP) e revelou que a extensão da zona eufótica deste sistema esteve relacionada somente às variações sazonais de penetração de luz decorrentes, principalmente da presença de nebulosidade e não da pequena variação sazonal da insolação. Comportamento semelhante parece ocorrer nas lagoas estudadas.

Os valores da transparência da água dos pontos limnéticos de todas as lagoas variaram de um período de amostragem para o outro, de forma que, no geral, os maiores valores foram encontrados no período de verão de 2000 (fevereiro) e os menores no inverno de 1999, principalmente no mês de agosto. Vale lembrar que esta variação não se relacionou com a da concentração de material suspenso na água nestes períodos. NogueIRA et al. (1999), também encontraram valores de transparência da água maiores no período de verão nos pontos lacustres do reservarório de Jurumirim (Rio Paranapanema - SP).

CALIJURI et al. (1997), estudando a atenuação luminosa em 15 lagos do sistema do Vale do Rio Doce, encontraram valores de transparência da água maiores no período de verão para as lagoas Aguapé e Ariranha, associados a um aumento na penetração de luz nas mesmas lagoas em relação ao período de inverno. Os mesmos autores discutem que as características espectrais e a energia da luminosidade incidente na coluna da água são dependentes das propriedades ópticas da radiação solar (intensidade, ângulo de incidência e reflectância) e físicas da água (substâncias suspensas, absorbância da água e organismos presentes), além de outros fatores regionais, como latitude, elevação do terreno, estação climática, período de incidência luminosa e condições meteorológicas.

Os valores para a transparência da água (leituras realizadas em pontos limnéticos) encontrados pelos mesmos autores citados acima para a lagoa Carioca, foram os mesmos entre os períodos de inverno e verão. Já no presente trabalho, houve uma variação entre os períodos de inverno de 1999 (junho e agosto) e verão de 2000 (fevereiro), período onde foram registrados os maiores valores para esta variável.

Na lagoa Aguapé, foi verificado um valor baixo para a extensão da zona eufótica no verão em relação ao maior valor observado no inverno. Excluindo-se o mês de agosto de 1999, quando a transparência da água foi a menor encontrada para a lagoa Aguapé, os valores observados no presente trabalho, para esta lagoa, estiveram próximos aqueles verificados por CALIJURI et al. (1997) e TUNDISI et al. (1997b). 
Foi encontrada uma correspondência entre os valores de transparência da água observados no presente trabalho com os de CALIJURI et al (1997) e TUNDISI et al. (1997b) para a lagoa Águas Claras nos períodos de inverno de 1999 e verão de 2000, para a lagoa Ariranha no período de inverno (junho de 1999) e para a lagoa Amarela em ambos os períodos de inverno de 1999.

IKUSIMA \& GENTIL (1997) observaram valores baixos de transparência da água na lagoa Amarela e consideraram a água desta lagoa como negra, por suas características espectrais. Os autores atribuíram esta análise à coloração da água em função da grande quantidade de ácidos húmicos oriundos da decomposição das macrófitas que ocorrem na lagoa, como a espécie Nymphaea elegans.

Por outro lado, a variação sazonal nos valores da extensão da zona eufótica dos compartimentos limnético e litorâneo amostrados tiveram reflexo nos valores encontrados para a concentração de clorofila nos períodos de inverno de 1999 e verão de 2000, quando neste último foram encontrados os valores mais altos para a concentração de clorofila e para a extensão da zona eufótica. Porém, BARBOSA \& TUNDISI (1980), estudando os mesmos sistemas, evidenciaram maior produtividade primária fitoplanctônica no período de inverno em relação ao de verão, para a lagoa Carioca.

Vale lembrar, que a relação direta entre extensão da zona eufótica e concentração de clorofila, comparando-se as regiões limnética e litorânea de cada lagoa, foi observada apenas para a lagoa Carioca em ambos os períodos amostrados e para a lagoa Águas Claras no de verão de 2000, onde os maiores valores da extensão da zona eufótica das regiões limnéticas estiveram diretamente associados aos maiores valores da concentração de clorofila, em relação aos valores destas variáveis nas regiões litorâneas.

O aumento na incidência da luminosidade é também o fator que explica 0 aumento nos valores da temperatura da água de todos as regiões amostradas no período de verão de 2000. HeNRY (1995) atribui as variações na estrutura térmica em ambientes aquáticos diretamente às alterações nas características da radiação solar ao longo do ano e à penetração de luz na coluna da água em relação à profundidade; e indiretamente à ação do vento, à umidade relativa e à temperatura do ar.

De forma geral, a estrutura térmica da coluna da água dos pontos limnéticos seguiu um padrão de isotermia no inverno e estratificação no verão, como também verificado por HENRY \& BARBOSA (1989), HENRY et al. (1997), MATSUMURA-TUNDISI et al. (1997) e TUNDISI (1997). A estratificação térmica foi melhor evidenciada na região 
limnética da lagoa Carioca, provavelmente pelo fato desta ser a mais profunda e com pequena área superficial dentre as regiões amostradas.

Ficou claro, pelo presente trabalho, que há ocorrência de estratificação térmica na lagoa Carioca no período de verão, com o estabelecimento da termoclina entre as profundidades de 4,5 a 8 metros e isotermia no período de inverno, similarmente ao padrão também descrito por HENRY et al. (1997), para esta mesma lagoa, que verificou a presença da termoclina entre as profundidades de 2 e 8 metros.

Segundo TUNDISI (1997), os padrões térmicos e químicos sazonais das lagoas do Vale do Rio Doce já são bem conhecidos e descritos, caracterizados por um período de nove a dez meses de estratificação térmica, com padrão monomítico, e isotermia no inverno. O mesmo autor caracteriza o fim do inverno nos meses de agosto e setembro, a partir dos quais se inicia a estratificação térmica nas lagoas da região. Porém, de acordo com HENRY \& BARBOSA (1989), a circulação na coluna da água que ocorre durante o inverno, quando é atingida a isotermia, é incompleta.

Após o início das chuvas na região, ocorre um rápido aumento da estratificação térmica e da estabilidade das lagoas deste sistema, como discutido por HENRY et al. (1997), que se inicia em outubro e finaliza entre março e abril, sendo este último o período de maior estabilidade da coluna da água das lagoas do Vale do Rio Doce, segundo TUNDISI (1997).

De maneira geral, os valores da temperatura ao longo do perfil da coluna da água encontrados no presente trabalho foram maiores do que aqueles observados por TUNDISI et al. (1997b), tanto nos períodos de inverno como no verão. Da mesma forma, os padrões térmicos de cada lagoa, observado pelos mesmos autores no períodos de inverno e verão, também ocorreram no presente trabalho, com exceção à lagoa Aguapé no verão de 2000, onde não foi verificada a ocorrência de estratificações térmicas bem definidas quanto aquelas observadas por TUNDISI et al. (1997b) em 1985. Vale ressaltar, ainda, que no trabalho dos autores já citados não foi verificada estratificação térmica na lagoa Amarela no período de verão de 1985, em oposição ao presente estudo que registrou uma tendência à estratificação no verão de 2000 , o que evidencia ligeiras variações interanuais.

Segundo HUTCHINSON (1959), os padrões térmicos da coluna da água de lagos são regulados por fatores ativos, como o clima regional e a proteção contra a ação dos ventos, e passivos que seriam representados pelas características morfométricas.

Da mesma forma como observado para a estrutura térmica, no presente trabalho foram encontrados padrões e valores semelhantes para as concentrações de 
oxigênio dissolvido nas regiões limnéticas das lagoas, nos períodos de inverno de 1999 e verão de 2000, semelhantes àqueles observados por TUNDISI et al. (1997b) no inverno de 1987 e verão de 1985. Porém, no presente trabalho foi verificada anoxia nas maiores profundidades das regiões limnéticas das lagoas Águas Claras e Amarela no período de verão de 2000 , o que não ocorreu no referido trabalho para o mesmo período climático. Provavelmente, os diferentes meses de amostragem do período climático de verão adotados nos dois trabalhos deva ser o fator que gerou esta diferença entre os resultados obtidos nas Águas Claras e Amarela, uma vez que em fevereiro, mês adotado no presente trabalho, a estratificação térmica e química da coluna da água encontra-se mais avançada no verão, do que no mês de novembro, amostrado por TUNDISI et al. (1997b), que corresponde ao início do verão naquela latitude próxima ao limite inferior da região tropical.

No presente trabalho, assim como no de TUNDISI et al. (1997b), foram observados condições similares de estratificação térmica e de estratificação química relativa à distribuição de oxigênio dissolvido. Porém, no presente, a formação da oxiclina no período de verão de 2000 foi mais acentuada do que a termoclina observada no mesmo período. Esta estratificação, em função das concentrações de oxigênio dissolvido, foi observada em todas as lagoas, chegando até a uma anoxia quase total nas camadas mais profundas das regiões limnéticas das lagoas Carioca, Águas Claras e Amarela.

Nas lagoas Carioca e Águas Claras, a anoxia observada no fundo da coluna da água, provavelmente está relacionada, em parte, às maiores profundidades das regiões limnéticas destas lagoas, o que dificulta a difusão do oxigênio até as camadas mais profundas. Já para a lagoa Amarela, este fato deve estar relacionado à presença de bancos de macrófitas emergentes, que bloqueiam a passagem da luminosidade, impossibilitando a ocorrência do processo fotossintético nas maiores profundidades, além do acúmulo de grande quantidade de matéria orgânica oriunda das macrófitas, as quais demandam oxigênio para a degradação.

TUNDISI et al. (1997b) associou a anoxia próxima do fundo das lagoas do sistema do vale do Rio Doce, à entrada de serrapilheira de origem na floresta de Mata Atlântica, a qual aumenta a concentração de matéria orgânica no fundo das lagoas, especialmente visível na lagoa Carioca, como evidenciado por BARBOSA et al. (1981), levando a uma depleção do oxigênio dissolvido pelo mesmo processo de degradação da matéria orgânica, citado anteriormente. 
Entre os períodos climáticos amostrados, não ocorreram variações sazonais claras em relação às concentrações de oxigênio dissolvido, evidenciando que a maior concentração de clorofila no período de verão de 2000 não foi determinante para que ocorressem maiores concentrações deste gás oxigênio dissolvido na água.

De maneira geral, nas lagoas estudadas foi observado valores de $\mathrm{pH}$ próximos à neutralidade, mas com um caráter ligeiramente ácido.

Os valores de $\mathrm{pH}$ encontrados no presente trabalho na superfície das regiões limnéticas de todas as lagoas, estiveram próximos ou ligeiramente acima daqueles observados por TUNDISI et al. (1997b), nos períodos de inverno de 1987 e verão de 1985.

A partir dos valores da condutividade elétrica, estabeleceu-se que a lagoa que apresentou maior concentração de íons dissolvidos foi a Amarela, embora não tenham sido encontrados maiores valores nas concentrações de nutrientes químicos e material em suspensão total em relação às demais lagoas. Este fato deve estar, provavelmente, relacionado à presença de grande quantidade de íons originados da rápida decomposição das macrófitas (mineralização), uma vez que este tipo de vegetação aquática ocupa praticamente toda a superfície da água da lagoa Amarela. Nesta lagoa também foi observado o maior valor para esta variável no período de inverno de 1987, por TUNDISI et al. (1997b).

Nas demais lagoas estudadas também foram observados valores de condutividade elétrica semelhantes aqueles observados pelos autores supracitados. Vale ressaltar que, no presente trabalho, foi observada uma diminuição nos valores da condutividade elétrica entre o período de seca (inverno de 1999) e o das chuvas (verão de 2000) nas lagoas Carioca, Aguapé, Águas Claras e Ariranha. O mesmo padrão também foi verificado por TUNDISI et al. (1997b) para as lagoas Aguapé, Águas Claras, Ariranha e Amarela. Esta diminuição nos valores de condutividade está relacionada à entrada de água de origem alóctone no período das chuvas, que atua como um fator diluidor da concentração de íons dissolvidos nas lagoas.

Os menores valores para a condutividade elétrica da água foram registrados nas lagoas Ariranha e Carioca, tanto no compartimento limnético quanto no litorâneo.

No verão, foi observado um aumento expressivo nos valores desta variável a partir dos 5,50 $\mathrm{m}$ de profundidade da região limnética da lagoa Carioca. Esta profundidade coincide com o final do epilímnio ou do metalímnio da lagoa Carioca no verão. A camada do metalímnio pode ser considerada como um "pseudo" fundo do lago, onde se acumulam substâncias, como nutrientes, por diferenças no gradiente de 
densidade da água (PAYNE, 1986). É também possível que tenha ocorrido recirculação da água neste estrato hipolimnético da coluna da água e disponibilização das formas iônicas a partir do sedimento.

No Grupo II de lagoas, estabelecido no presente trabalho e constituído pelas lagoas Aguapé e Águas Claras, foram observados valores de condutividade elétrica próximos. No entorno destas lagoas, o manejo empregado na atividade do cultivo de eucalipto ocorre de forma semelhante, por exemplo, com a constante retirada do subbosque de espécies nativas, que torna o solo mais exposto à ação da água das chuvas. Dessa forma, o material alóctone carreado das respectivas bacias de drenagem para dentro destas lagoas, devem ser de quantidade e qualidade diferentes daqueles transportados para dentro das demais lagoas estudadas.

Já os valores observados para as lagoas Ariranha, Carioca e Amarela, não as agruparam de acordo com os grupos estabelecidos no delineamento deste trabalho, ou seja, em função das características da vegetação do entorno.

Em relação aos nutrientes químicos, praticamente não foram evidenciadas diferenças entre os compartimentos limnético e litorâneo e entre os grupos de lagoas, nos três períodos de estudo. No geral, também não foram verificadas variações sazonais expressivas nas concentrações dos nutrientes químicos entre inverno e verão, embora se considere que, no geral, a concentração da maior parte dos nutrientes em lagos, como por exemplo as formas nitrogenadas, seja dependente de fatores sazonais, como precipitação e estrutura térmica da coluna da água (HORNE \& GOLDMAN, 1994). Por outro lado, foi observada uma tendência a valores um pouco maiores em junho de 1999 em relação a agosto de 1999, principalmente em função de nitrito, amônio, silicato, nitrogênio total e fósforo total.

Os valores das concentrações de nitrito em todos os compartimentos amostrados de todas as lagoas, nos três períodos climáticos, estiveram sempre abaixo de $3 \mu \mathrm{g} / \mathrm{l}$. Em outros trabalhos realizados em lagoas do Vale do Rio Doce, como os de MITAMURA \& Hino (1997) e TUNDISI et al. (1997b), os valores das concentrações de nitrito não ultrapassaram $5 \mu \mathrm{g} / \mathrm{l}$.

O nitrito é uma forma nitrogenada que pode sofrer oxidação e originar nitrato na presença de oxigênio em sistemas aquáticos. Segundo HORNE \& GOLDMAN (1994), normalmente, o nitrito ocorre em baixas concentrações em lagos naturais. De acordo com os mesmos autores, concentrações mais altas de nitrito podem ser observadas, ocasionalmente, nas camadas próximas à termoclina de lagos. 
Já para as concentrações de nitrato, os valores encontrados no presente trabalho diferiram daqueles observados por TUNDISI et al. (1997b), em ambos os períodos climáticos de amostragem. Em relação aos resultados obtidos por estes autores, os valores de nitrato encontrados no presente trabalho variaram de 2 vezes menos até 10 vezes mais, para todas as lagoas. No período de inverno de 1999, os valores encontrados em ambas as regiões limnética e litorânea da lagoa Ariranha estiveram próximos.

MITAMURA \& HiNo (1997) verificaram que os valores de nitrato e nitrito nas lagoas Amarela e Carioca foram menores do que aqueles geralmente observados em lagos temperados. Além disso, a partir dos resultados obtidos pelos autores, foi possível verificar que estas formas nitrogenadas estiveram uniformemente distribuídas ao longo da coluna da água nos períodos de inverno e verão, para as mesmas lagoas. Foi verificada, também, uma diminuição da concentração de nitrato do período de inverno para o verão. No presente trabalho, o mesmo foi verificado na lagoa Carioca e no ponto limnético da lagoa Amarela, porém sempre com valores superiores aqueles encontrados pelos autores citados, chegando a ser até a 7 vezes maiores.

De uma maneira geral, pôde-se observar um decréscimo nos valores de nitrato dos períodos de inverno de 1999 para o verão de 2000, sendo encontrados, neste último período, uma maior homogeneidade, com valores próximos entre as regiões limnética e litorânea de todas as lagoas. Durante os períodos de inverno de 1999, os maiores valores de nitrato podem ter sido conseqüência do processo de circulação na coluna da água que disponibilizou este nutriente a partir do sedimento. Já no verão de 2000, devido aos processos biológicos de absorção por algas na região limnética e macrófitas na litorânea, as concentrações de nitrato foram menores. Estes processos de redução e disponibilização de nitrato são apresentados por HORNE \& GOLDMAN (1994). Além disso, segundo os mesmos autores, em regiões alagadas com a presença de bancos de macrófitas e ocorrência de anoxia, pode haver diminuição na concentração de nitrato por denitrificação. Este processo é muito importante para a diminuição do estoque de nitrogênio em lagos e outros corpos de água, acumulados nas estruturas vegetais de macrófitas e do fitoplâncton.

Outro fator que pode explicar a ocorrência de valores maiores de nitrato nos períodos de inverno de 1999 seria a sua menor absorção tanto pelas algas como pelas macrófitas. Além disso, a mistura completa da coluna da água no período de inverno, pode ter ocasionado uma maior disponibilização desta forma nitrogenada do sedimento para a água. Porém, em alguns casos, o processo de sedimentação pode ser de tal 
intensidade, de forma a enterrar a matéria orgânica no sedimento, inviabilizando a disponibilização dos nutrientes para a coluna da água (KURATA e KIRA, 1995).

HORNE \& GOLDMAN (1994) evidenciam que, em lagos eutróficos tropicais, é comum encontrar concentrações de nitrato na zona eufótica aproximadamente constantes ao longo do ano, como por exemplo o caso do lago George (Uganda). No presente trabalho também foram verificados valores próximos, entre os períodos de inverno de 1999 e verão de 2000, nas zonas litorâneas, nas quais a extensão da zona eufótica sempre abrangeu toda a coluna da água.

De forma geral, as concentrações de nitrato encontradas no presente trabalho foram bastante inferiores àquelas consideradas tóxicas para as comunidades aquáticas e para o uso humano. STRASKRABA \& TUNDISI (1999) reportam que concentrações excessivas de nitrato, em alguns países, são consideradas tóxicas entre 20 e 50 mg/l. Já HORNE \& GOLDMAN (1994), consideram tóxicas concentrações acima de 10 mg/l, em lagos. Acima destes níveis, o nitrato pode causar doenças fatais, principalmente em crianças.

O limite estabelecido pela Resolução $n^{0 .} 20$ do CONAMA (1986) para a Classe 1, que contempla o destino da água para o abastecimento doméstico após tratamento simplificado, à proteção das comunidades aquáticas e à recreação de contato primário (natação e mergulho), é de $10 \mathrm{mg} / \mathrm{l}$ de nitrato, dentre outras variáveis estabelecidas. No presente trabalho, os valores das concentrações de nitrato estiveram por volta de $10 \mu \mathrm{g} / \mathrm{l}$, ou seja, muito abaixo deste limite.

Em regiões litorâneas, com a presença de vegetação de macrófitas emergentes e submersas, é comum a ocorrência de uma alta produtividade primária e consequente remoção de quantidades significativas de nitrato da água pela incorporação deste na cadeia trófica, já que, segundo HORNE \& GOLDMAN (1994), o nitrato é uma forma nitrogenada bastante assimilável pelos organismos produtores.

Porém, KURATA \& KIRA (1995) descrevem que a assimilação de nitrato por estas plantas aquáticas não significa necessariamente a remoção deste nutriente da coluna da água, uma vez que pode retornar pela degradação dos tecidos das macrófitas, que apresentam uma alta taxa de decomposição.

DoNk et al. (1993), estudando o lago Zwenlust (Holanda) também associam a diminuição na concentração das formas nitrogenadas e fosfatadas na região litorânea à absorção realizada pelas macrófitas, e conseqüente introdução destes compostos na cadeia trófica. 
MitAMURA et al. (1995), a partir de experimentos realizados na região limnética da lagoa Carioca do Vale do Rio Doce, concluiram que as baixas concentrações de nitrato neste lago eutrófico são reflexo do processo de denitrificação, da entrada de água pobre em nitrato pelo aporte superficial e em decorrência do consumo pelo fitoplâncton. O autor afirma, ainda, que as formas regeneráveis de nitrogênio, como o nitrato, são as mais essenciais para os processos biogeoquímicos do ciclo do nitrogênio em lagos eutróficos tropicais, assim como em temperados.

HENRY (1990), em experimentos realizados na Represa de Jurumirim (SP), verificou que a deficiência na resposta do fitoplâncton ao enriquecimento por nitrogênio demostra que algumas algas utilizam preferencialmente o nitrato, disponível na coluna da água ou já fixado biologicamente, para a produção. Já PRÉSING et al. (2001), estudando o lago Balaton (Hungria) - um sistema raso e eutrófico - verificaram que a forma nitrogenada mais importante para a produção fitoplanctônica foi o íon amônio.

Além da comunidade fitoplânctonica com importante papel na absorção de nutrientes na região limnética, um outro grupo de organismos que vem sendo investigado na última década, sob o mesmo enfoque, são as bactérias e o picoplâncton. Estes organismos tem a capacidade de remover formas nitrogenadas e fosfatadas dissolvidas, mesmo em quantidades muito baixas, e introduzí-las na cadeia trófica por processos autotróficos e heterotróficos (CAPBLANCQ, 1990). Este recente enfoque vem confrontando a visão tradicional da Limnologia e da Oceanografia de que a máxima produção possível a ser atingida pelas comunidades pelágicas é determinada pela disponibilidade mínima de um ou de alguns nutrientes. Para isso, o autor acima declara que estes pequenos organismos são capazes de remover nutrientes da água, mesmo em condições consideradas limitantes, pela visão tradicional.

Clymo (1995) afirma que o conceito de fator limitante para nutrientes é incompleto, uma vez que todos os nutrientes podem atuar como limitantes dos processos produtivos do sistema. Dessa forma, pelas considerações dos autores citados anteriormente, fica clara a distinção entre os processos de absorção do nitrato (e dos demais nutrientes discutidos a seguir) nas regiões litorâneas (determinada pelas macrófitas) e na limnética (determinada pelo ação do fitoplâncton e de bactérias).

Em relação às concentrações de amônio, foi possível verificar uma diferença bastante expressiva da lagoa Carioca em relação às demais lagoas. No presente trabalho, os maiores valores para a concentração de amônio foram verificados na lagoa Carioca, em todos os períodos de amostragem. Já os menores valores da concentração 
deste nutriente foram verificados nas regiões limnética e litorânea da lagoa Aguapé, tanto pelo presente trabalho como por aquele de TUNDISI et al. (1997b).

MITAMURA \& HiNo (1997) observaram valores altos na concentração de amônio nas camadas mais profundas da coluna da água da lagoa Carioca no período das chuvas, associados às concentrações extremamente baixas de oxigênio dissolvido, 0 que deve ter levado à formação do íon amônio no fundo da lagoa pelo processo de amonificação (mineralização), a partir de compostos nitrogenados orgânicos particulados e dissolvidos, ou pela disponibilização a partir do sedimento. Este processo deve ter ocorrido também no presente trabalho, e originado o alto valor na concentração deste nutriente na mesma região da lagoa Carioca.

TUNDISI et al. (1997b) afirmam que a acumulação de matéria orgânica no sedimento das lagoas do Vale do Rio Doce colabora para a depleção de oxigênio abaixo da termoclina no período de verão e, consequentemente, para a alta concentração de amônio.

Sazonalmente, pôde-se verificar uma diminuição das concentrações de amônio do inverno de 1999 para o verão de 2000 nas lagoas Carioca (com exceção à região limnética), Águas Claras e Amarela. TUNDISI et al. (1997b) verificaram valores menores nas concentrações de amônio no período de inverno de 1987, em relação aos do verão de 1985 nas lagoas Amarela, Ariranha, Aguapé e Águas Claras.

De maneira geral, o íon amônio é derivado da excreção animal, da mineralização de detritos orgânicos e da disponibilização do sedimento em estado de anoxia, sendo rapidamente utilizado para o crescimento vegetal ou transformado em nitrito (HORNE \& GOLDMAN, 1994). Assim como o fosfato, o íon amônio é facilmente retido do sedimento.

MITAMURA et al. (1995) verificaram a importância do íon amônio como suporte para o crescimento do fitoplâncton em experimentos realizados em três lagoas do Vale do Rio Doce, incluindo a Carioca.

Da mesma forma, Présing et al. (2001), observaram uma rápida ciclagem de amônio no lago Balaton no período de verão, o que favoreceu o crescimento fitoplanctônico. No presente trabalho foi observado um aumento na concentração de clorofila no período de verão de 2000, evidenciando um aumento da biomassa fitoplanctônica neste período, o que deve estar relacionado com o processo descrito pelo autores acima citados. Vale ressaltar que a maior concentração de clorofila no período de verão de 2000 foi observada na região limnética da lagoa Carioca, o que deve estar associado ao alto valor na concentração de amônio neste mesmo período. 
HENRY (1990) verificou que o fosfato é um agente estimulador da produção fitoplanctônica, mais eficiente do que amônio, em experimentos realizados na Represa de Jurumirim - SP, devido ao fato dos organismos vegetais preferirem o nitrato como forma nitrogenada. O mesmo foi observado por HENRY \& TUNDISI (1985), HENRY et al. (1987) e HenRY et al. (1989b) em lagoas do vale do Rio Doce.

A partir dos valores da concentração de nitrogênio orgânico total foi possível evidenciar uma maior homogeneidade de valores em todos os pontos de amostragem no período de verão de 2000 , com exceção feita à região limnética da lagoa Carioca, em relação aos valores encontrados para os dois períodos de inverno de 1999. Neste período, merece destaque o maior valor encontrado para a região limnética da lagoa Carioca, onde também foi verificado um alto valor da concentração de clorofila, indicando que as formas nitrogenadas estiveram disponíveis em teores adequados para um maior crescimento da biomassa fitoplanctônica nesta região.

Por outro lado, os menores valores verificados na região litorânea da lagoa Carioca, e em ambas as regiões limnética e litorânea das demais lagoas estudadas, podem ter sido responsáveis pela limitação do crescimento fitoplanctônico, expresso por valores da concentração de clorofila menores do que na região limnética da lagoa Carioca.

MitAMURA \& Hino (1997), estudando as lagoas Carioca e Amarela do Vale do Rio Doce, verificaram que as baixas concentrações de nitrogênio encontradas no período de verão foram responsáveis pela limitação do crescimento fitoplanctônico.

Como apresentado para as formas nitrogenadas, os compostos fosfatados também são importantes para o crescimento fitoplanctônico e para a produção, em geral, de corpos aquáticos.

HORNE \& GOLDMAN (1994) afirmam que o fósforo é, geralmente, o fator limitante mais importante na produção fitoplanctônica devido ao fato de ocorrer em baixas concentrações. A quantidade de fósforo que as plantas e animais necessitam para a manutenção do seu ciclo biológico é muito menor do que a de nitrogênio, sendo encontrada, geralmente, uma razão entre N:P de 10:1 nos sistemas aquáticos naturais de água doce não poluídos - dentro dos sistemas orgânicos a relação é geralmente de 16:1, conhecida como proporção de Redfield (ODUM, 1988). O aumento desta relação pode indicar uma deficiência em fósforo para o crescimento fitoplanctônico, que é proporcional à quantidade de fósforo total (dissolvido + particulado). 
Segundo BRETT et al. (2000), o conteúdo de fósforo tem efeito indireto na produção secundária pela regulação da qualidade alimentar de algas para os organismos zooplanctônicos herbívoros.

Assim como para o ciclo do nitrogênio, existem diferenças importantes para o ciclo do fósforo entre zonas pelágicas e litorâneas.

Nas zonas limnéticas ou pelágicas a dinâmica e estrutura do ciclo do fósforo são determinadas pelas relações entre fitoplâncton, zooplâncton, bactérias, peixes e sedimentos profundos (GRANÉLI \& SOLANDER, 1988). Além disso, processos físicos da coluna da água, como a circulação no período de inverno que proporciona a mistura entre as massas de água do hipolímnio e epilímnio, podem disponibilizar quantidades de fósforo do sedimento (HORNE \& GOLDMAN, 1994).

Durante muito tempo, um papel secundário foi atribuído aos animais aquáticos na dinâmica do ciclo do fósforo. Porém, segundo ANDERSSON et al. (1988), existem evidências crescentes de que estes animais (predadores e herbívoros) apresentam um papel central no controle da dinâmica deste nutriente, regulando diretamente e indiretamente a biomassa de produtores primários, e em consequência, a ciclagem do fósforo em regiões pelágicas.

Outro importante mecanismo regulador da quantidade de fósforo disponível em regiões limnéticas é a atividade da enzima fosfatase alcalina liberada por alguns tipos de algas fitoplanctônicas, bactérias e organismos zooplanctônicos. Esta enzima forma um amálgama com o fosfato e outras moléculas ogânicas fosfatadas, catalizando a liberação de ortofosfato para a produção primária (HORNE \& GOLDMAN, 1994; JANSON et al., 1988; KALINOWSKA, 1997).

HORNE \& GOLDMAN (1994) afirmam que nos períodos em que o fosfato ocorre em grandes concentrações, como no início da primavera em regiões temperadas, algumas algas fitoplanctônicas podem armazenar o excesso deste nutriente em grânulos celulares denominados polifosfatos, constituindo um estoque de fosfato em regiões pelágicas. Assim, quando a concentração de fosfato torna-se muito baixa estas algas utilizam tais grânulos para se dividirem.

Já em regiões litorâneas de lagos, um dos principais elementos que atua no ciclo do fósforo é a comunidade de macrófitas, que captam quantidades de fósforo diretamente do sedimento ou da água, e alteram as condições químicas da água, como o teor de oxigênio e o pH. As macrófitas funcionam como um estoque de fósforo, e aquelas enraizadas formam um rede de transporte de nutrientes entre sedimento e água (GRANÉLI \& SOLANDER, 1988; HORNE \& GOLDMAN, 1994). 
Além disso, regiões litorâneas geralmente apresentam baixas profundidades, 0 que propicia um grande acúmulo de fósforo no sedimento e uma intensa movimentação de nutrientes deste compartimento para a água (HORNE \& GOLDMAN, 1994). GRANÉLI \& SOLANDER (1988) afirmam que o papel das macrófitas no ciclo dos nutrientes ainda é pouco entendido em relação ao efeito do sedimento.

De uma maneira geral, pelos resultados encontrados no presente trabalho não foram verificados padrões diferenciados para as concentrações de fosfato dissolvido total e inorgânico entre os compartimentos limnético e litorâneo, nos três períodos amostrados.

No ponto limnético da lagoa Carioca foi encontrado o maior valor para as concentrações de fosfato dissolvido orgânico e inorgânico no período de inverno de 1999 (junho). Isto, provavelmente, está relacionado com a circulação na coluna da água que ocorre neste período, e que deve ter disponibilizado este nutriente a partir do sedimento. Este processo também pode ser o responsável pelos altos valores encontrados de fosfato orgânico dissolvido nos pontos limnéticos Agu-P3 da lagoa Aguapé, no mesmo período, e ACl-P2 da lagoa Águas Claras no período inverno de 1999 (agosto).

No período de verão de 2000, os valores das concentrações de fosfato dissolvido orgânico e inorgânico encontrados na região limnética da lagoa Carioca foram menores do que aqueles observados em todos os demais pontos de amostragem desta lagoa, e das outras quatro lagoas estudadas. Neste caso, o padrão de estratificação que ocorreu na região limnética da lagoa Carioca, no período de verão de 2000, que é o mais bem marcado dos observados neste estudo, deve ter levado a estes baixos valores.

No geral, observou-se um aumento nas concentrações das formas de fosfato no período de verão de 2000, ao contrário do verificado por TUNDISI et al. (1997b), para as lagoas Amarela, Águas Claras e Aguapé. Estes altos valores de fosfato podem ter estimulado o crescimento da biomassa fitoplânctonica neste período, como verificado pelas concentrações de clorofila em todos os pontos de amostragem de todas as lagoas. Porém, vale lembrar que essa correspondência não ocorreu para o ponto limnético da lagoa Carioca onde, embora tenha ocorrido a maior concentração de clorofila, as concentrações de fosfato foram muito baixas.

Pelos valores da concentração de silicato ficou claro não haver diferenças expressivas entre os compartimentos limnético e litorâneos da lagoas e entre os períodos de amostragem. Entre as lagoas estudadas, os valores de silicato também 
estiveram próximos, valendo destacar a ocorrência de valores mais altos na lagoa Aguapé, o que pode ser um reflexo do tipo de manejo empregado no cultivo intensivo de eucalipto que ocorre no entorno desta lagoa.

Em relação ao material em suspensão, vale ressaltar que nos períodos de inverno de 1999 a fração orgânica foi geralmente maior do que a inorgânica na maioria dos pontos de amostragem de todas as lagoas. No período de verão de 2000 , esta proporção inverteu-se devido, provavelmente, à entrada de material alóctone de natureza inorgânica pelas chuvas que ocorrem nesta época do ano. Porém, em relação ao material em suspensão total, não houve aumento expressivo nos valores deste parâmetro dos períodos de inverno para o verão. Os maiores percentuais da fração inorgânica do material em suspensão no verão de 2000, evidenciam que neste período houve um maior aporte de matéria inorgânica das bacias de drenagens para as lagoas, devido, principalmente, às chuvas típicas do período de verão.

O aumento nos valores da concentração de clorofila nas datas amostradas no período de verão de 2000, em relação aos de inverno, deve ter sido reflexo das maiores concentrações de fosfato total dissolvido e inorgânico que ocorreram neste período, representando, talvez, uma maior produtividade fitoplanctônica, embora esta variável não tenha sido medida no presente trabalho. Como nas amostragens de verão foram verificados valores menores de nitrato e amônio do que naquelas de inverno, pode-se dizer que o fator regulador do crescimento fitoplanctônico verificado no presente trabalho foram as formas de fosfato.

A avaliação do grau de trofia feita pelo índice de CARLSON modificado por TOLEDO JR. et al. (1983) para lagos e reservatórios tropicais revelou baixo grau de trofia nos períodos de inverno de 1999 para todos os pontos de amostragem de todas as lagoas estudadas, com classificação oligotrófica. No período de verão de 2000, pôde-se observar a formação de dois grupos de lagoas segundo este índice: o primeiro formado pelas lagoas Aguapé e Amarela, e o segundo formado pelas lagoas Ariranha (excluindo-se o ponto Ari-L3 que foi classificado como mesotrófico), Carioca e Águas Claras com classificação oligotrófica. As diferenças nos resultados obtidos pelos dois índices de estado trófico aplicados devem-se, provavelmente, à sensibilidade destes e aos tipos de fatores que consideram nos cálculos.

Vale ressaltar que, como para as concentrações de fósforo total não ocorreram com diferenças expressivas entre os períodos climáticos de amostragem, as variáveis que mais influenciaram, nesta diferença sazonal do grau de trofia, foram fosfato dissolvido orgânico e clorofila. 
Já em relação ao período de verão de 2000 , o fosfato dissolvido orgânico foi responsável pela separação dos pontos de amostragem em oligotrófico e mesotrófico.

Porém, pelo índice de SALAS \& MARTINO, baseado apenas nas concentrações de fósforo total, foi possível verificar uma classificação de mesotrófica a hiper-eutrófica na lagoa Carioca nos três períodos de amostragem. Nos períodos de inverno de 1999 para todas as demais lagoas, foi verificada uma classificação de oligotrófico a eutrófico, e para a Carioca de eutrófico a hiper-eutrófico. No verão de 2000, os pontos das lagoas Carioca, Aguapé e Amarela ficaram classificados de mesotrófico a eutrófico, e os das lagoas Águas Claras e Ariranha de oligotrófico a mesotrófico.

A lagoa Carioca parece ser aquela que se encontra em um estágio mais avançado de evolução geológica, por apresentar um maior grau de trofia em relação à maioria das lagoas do Vale do Rio Doce, evidenciado principalmente no período de inverno de 1999 pelo índice de SALAS \& MARTINO. Outro fator que deve acarretar alto grau de trofia na água da lagoa Carioca, é o fato desta apresentar-se morfometricamente como uma bacia de sedimentação, com pequena área superficial e grande profundidade, em relação às demais lagoas em estudo.

Em relação ao tratamento estatístico realizado no presente trabalho, a partir das variáveis limnológicas e características gerais das lagoas, como as variáveis morfométricas, foi possível verificar o efeito significativo da sazonalidade na distribuição dos valores destas variáveis pela análise de variância multivariada. Ou seja, a análise de MANOVA revelou que estas variáveis ocorrem com valores e padrões significativamente diferentes para cada período de amostragem (junho e agosto de 1999, e fevereiro de 2000).

Como já discutido anteriormente, na região do Vale do Rio Doce predominam períodos de inverno com temperaturas mais baixas e estiagem, e de verão com chuvas freqüentes e valores mais altos de temperatura. Assim, as variáveis que, provavelmente, foram responsáveis pelas diferenças entre os períodos climáticos, reveladas pela análise de variância multivariada, foram temperatura (padrões térmicos de isotermia nos períodos de inverno e estratificação no verão), extensão da zona eufótica (valores maiores no período de verão), oxigênio dissolvido (padrões de homogeneidade no inverno e estratificação no verão), valores de algumas formas nitrogenadas (como os de nitrato menores no verão), proporção entre as frações do material em suspensão (com a fração inorgânica maior no verão) e valores de clorofila (maiores no período de verão). 
A partir desta primeira análise foram realizadas análises de componentes principais para cada período de amostragem, segundo as variáveis limnológicas e características morfométricas das lagoas, sendo que, em todas estas análises, a porcentagem total da variância explicada pelo conjunto dos fatores 1 e 2 foi maior do que $60 \%$.

Por esta segunda análise, no período de inverno 1 (junho de 1999) ficaram claras as diferenças entre os pontos de amostragem da lagoa Carioca e os das demais lagoas, principalmente em função da condição mais eutrófica da água da lagoa Carioca, representada pelo fator 1 . Outro aspecto relevante é a separação entre pontos de amostragem limnéticos (associados negativamente) e os litorâneos (associados positivamente) de todas as lagoas, em função do fator 2. Apenas o ponto limnético da lagoa Amarela ficou associada positivamente ao fator 2, juntamente com os pontos litorâneos, provavelmente, em função da menor profundidade que ocorrem na região limnética desta lagoa, e aos menores valores de transparência da água, semelhantes aqueles verificados nas regiões litorâneas.

Estas relações ficaram também evidentes pelo dendrograma feito a partir da análise de componentes principais para o inverno 1. Além disto, o dendrograma revelou que a lagoa Carioca, principalmente a região limnética, difere de todas as demais lagoas conjuntamente em função das variáveis limnológicas e das características morfométricas.

No período de inverno 2 (agosto de 1999), a análise de componentes principais revelou a separação da lagoa Carioca das demais lagoas, em função de sua maior condição trófica e de maiores valores de amônio, principalmente. Porém, pelo dendrograma, ficou claro que a lagoa Carioca esteve com características mais próximas às das lagoas Aguapé, Águas Claras e Ariranha, do que da Amarela. Neste período climático não ficaram evidentes associações formadas por pontos limnéticos ou litorâneos.

Da mesmo forma que o observado no período de inverno 2, no verão (fevereiro de 2000) não ficaram claros as tendências de associações de pontos pertencentes às regiões limnéticas e litorâneas. Neste período, ficou destacada apenas a diferença das maiores condições tróficas da região limnética da lagoa Carioca em relação aos demais pontos de amostragem de todas as lagoas, incluindo aqueles litorâneos da lagoa Carioca.

Dessa forma, apenas no período de inverno 1, representado pelo mês de junho de 1999, a hipótese alternativa proposta no delineamento experimental do presente 
trabalho para as diferenças entre as regiões limnéticas e litorâneas, não foi rejeitada. Ou seja, apenas neste período assume-se que ocorreram diferenças expressivas nas condições limnológicas e características morfométricas entre as regiões limnéticas e litorâneas das cinco lagoas.

Por outro lado, a hipótese alternativa que propunha diferenças entre os três grupos de lagoas separados em função do tipo de vegetação do entorno, foi rejeitada pelos resultados obtidos no presente trabalho, referentes às condições limnnológicas em todos os períodos de estudo.

Apenas nos períodos de inverno (junho e agosto de 1999), a lagoa Carioca ficou destacada das demais em função, principalmente, das condições mais eutróficas da água, o que não contempla a hipótese proposta, uma vez que as demais lagoas distribuíram-se, pelas análises estatísticas, indistintamente do tipo de vegetação que ocorre no entorno, seja apenas de eucalipto, ou desta com a presença de sub-bosque de espécies próprias da mata atlântica.

Como o principal fator que separou a lagoa Carioca das demais foi o maior grau de trofia de sua água, relacionado principalmente à tipologia morfométrica desta lagoa que a caracteriza como uma bacia de sedimentação (pequena área e grande profundidade), não foi possível inferir relações dos resultados estatísticos com o uso e ocupação das bacias de drenagem das lagoas estudadas, como proposto no delineamento experimental.

- Comparação das características limnológicas das lagoas do Vale do Rio doce com Lagos natURAis do Pantanal E da AMAZÔNia

É interessante comparar as características limnológicas das lagoas do Vale do Médio Rio Doce com aquelas de outros sistemas de lagos naturais. Assim, uma comparação é feita sobre os cinco lagos estudados no presente trabalho, dois lagos do Pantanal Matogrossense (lagos Buritizal e Recreio) investigados por SILVA (1980) e três lagos da Bacia Amazônica (lagos Castanho, Redondo e Jacaretinga) estudados por HARDY (1978). Os valores de algumas variáveis limnológicas para esta análise estão apresentados na Tabela 37, e correspondem sempre à superfície e ao período de inverno, pois eram o período e a camada de água para os quais se encontraram dados disponíveis nos referidos trabalhos. 
Tabela 37. Comparação entre os valores de algumas variáveis limnológicas de lagos naturais do Vale do Rio Doce, do Pantanal matogrossense e da Bacia Amazônica.

\begin{tabular}{|c|c|c|c|c|c|c|c|c|c|c|}
\hline & \multicolumn{2}{|c|}{ Pantanal } & \multicolumn{3}{|c|}{ Bacia Amazônica } & \multicolumn{5}{|c|}{ Vale do Rio Doce } \\
\hline & Recreio & Buritizal & $\begin{array}{c}\text { Castanh } \\
0\end{array}$ & Redondo & Jacaretinga & Carioca & Aguapé & $\begin{array}{l}\text { Águas } \\
\text { Claras }\end{array}$ & Ariranha & Amarela \\
\hline Transparência (m) & 0,50 & 0,30 & - & - & - & 1,20 & 1,40 & 2,30 & 1,60 & 1,30 \\
\hline Temperatura $\left({ }^{\circ} \mathrm{C}\right)$ & 25,60 & 26,00 & - & - & - & 22,25 & 22,64 & 23,59 & 22,91 & 20,80 \\
\hline $\begin{array}{l}\text { Oxigênio } \\
\text { dissolvido } \\
\text { (mg/l) }\end{array}$ & 8,83 & 7,70 & 3,40 & 2,80 & 4,90 & 5,72 & 6,85 & 7,78 & 6,15 & 2,25 \\
\hline $\begin{array}{l}\text { Condutividade } \\
\text { elétrica }(\mu \mathrm{S} / \mathrm{cm})\end{array}$ & 5,05 & 7,79 & 32,70 & 59,60 & 42,80 & 27,25 & 38,40 & 41,00 & 26,00 & 67,00 \\
\hline $\mathrm{pH}$ & 7,00 & 6,60 & 6,60 & 6,60 & 6,50 & 5,98 & 6,32 & 6,52 & 6,28 & 6,32 \\
\hline Amônio $(\mu \mathrm{g} / \mathrm{l})$ & 30,70 & 2,70 & - & - & - & 253,74 & 6,16 & 103,71 & 74,95 & 34,53 \\
\hline Nitrito $(\mu \mathrm{g} / \mathrm{l})$ & 8,00 & 5,00 & - & - & - & 2,63 & 0,75 & 1,07 & 1,21 & 0,61 \\
\hline Nitrato $(\mu \mathrm{g} / \mathrm{l})$ & 0,00 & 77,90 & 0,19 & 1,10 & 0,45 & 40,31 & 10,32 & 15,75 & 15,04 & 7,72 \\
\hline $\begin{array}{c}\text { Fósforo } \\
\text { total }(\mu \mathrm{g} / \mathrm{l})\end{array}$ & 125,40 & 66,00 & 47,80 & 43,00 & 64,00 & 37,60 & 15,75 & 22,60 & 15,42 & 10,85 \\
\hline $\begin{array}{c}\text { Fosfato } \\
\text { inorgânico }(\mu \mathrm{g} / \mathrm{l})\end{array}$ & 63,00 & 60,30 & - & - & - & 9,44 & 1,38 & 2,11 & 1,23 & 1,08 \\
\hline $\begin{array}{l}\text { Fosfato } \\
\text { Orgânico }(\mu \mathrm{g} / \mathrm{l})\end{array}$ & 62,30 & 5,70 & - & - & - & 41,67 & 4,84 & 3,01 & 5,61 & 4,38 \\
\hline Silicato $(\mu \mathrm{g} / \mathrm{l})$ & 3,50 & 3,90 & 3,00 & 3,50 & 1,5 & 3,46 & 4,54 & 2,74 & 3,21 & 4,81 \\
\hline $\begin{array}{c}\text { Material em } \\
\text { suspensão }(\mu \mathrm{g} / \mathrm{l})\end{array}$ & 19,20 & 17,40 & - & - & - & 11,80 & 9,17 & 7,67 & 11,00 & 8,00 \\
\hline Clorofila $(\mu \mathrm{g} / \mathrm{l})$ & 256,40 & 20,10 & - & - & - & 2,93 & 0,07 & 0,12 & 0,09 & 0,04 \\
\hline
\end{tabular}

Nas lagoas do Vale do Rio Doce os valores de transparência da água foram maiores do que os observados pelos referidos autores nos lagos do Pantanal, revelando uma maior penetração de luz na coluna da água devido, provavelmente, aos menores valores de material em suspensão também verificados nas lagoas abordadas no presente estudo.

Mesmo com maiores valores de transparência da água e, em conseqüência, maior extensão da zona eufótica, nas lagoas do Vale do Rio Doce parecem ter ocorrido menores quantidades de biomassas fitoplanctônicas, reveladas indiretamente pelas baixas concentrações de clorofila. Esta menor biomassa fitoplanctônica para as lagoas do Vale do Rio Doce está, provavelmente, relacionada às menores concentrações de nutrientes químicos, especialmente fósforo total, em relação aos lagos do Pantanal.

Nos lagos do Pantanal Matogrossense e nos lagos amazônicos, os maiores valores de nutrientes químicos (fósforo total) e de material em suspensão devem ser resultado do aporte de água de tributários naturais que ocorrem nestes sistemas, diferentemente das lagoas do Vale do Rio Doce, estudadas no presente trabalho, que não apresentam rios em suas bacias de drenagem. 
Os valores da temperatura da água nas lagoas do Vale do Rio Doce no período de inverno foram sempre menores do que os observados nos lagos do Pantanal e naqueles amazônicos, o que indica a ocorrência de um inverno mais rigoroso na região abordada pelo presente estudo, em relação à região do Pantanal Matogrossense e ao Norte do país. Excluindo-se a lagoa Amarela, nas demais lagoas do Vale do Rio Doce parece ocorrer uma melhor oxigenação, com maiores valores de oxigênio dissolvido na água, do que nos lagos do Pantanal e da bacia amazônica.

De forma geral, as águas das lagoas estudadas no presente trabalho apresentaram um caráter ligeiramente mais ácido em relação aos lagos do Pantanal e aos da bacia amazônica. Já os valores de silicato foram semelhantes em todos os corpos lacustres comparados. 
- COMUNIDADE ZOOPLANCTÔNICA

Com relação à composição de espécies das cinco lagoas estudadas, foi realizado um inventário taxonômico que revelou a ocorrência de pelos menos 58 táxons zooplanctônicos no conjunto de todas as cinco lagoas, e nos três períodos de estudo, envolvendo os grupos Rotifera, Cladocera, Copepoda, Ostracoda, Nematoda, Oligochaeta e fases larvais de Insecta, o que revela uma complexa cadeia de consumidores primários e secundários em termos de níveis tróficos.

Para cada lagoa estudada, foi sempre verificada maior número de espécies zooplanctônicas nas regiões litorâneas, em relação às limnéticas. Esta maior riqueza na composição de espécies deve estar relacionada com a maior disponibilidade de alimento nestas regiões costeiras (LEMLY \& DIMMICK, 1982; MARGALEF, 1983), além da presença de bancos de macrófitas que naturalmente abrigam um maior número de espécies oferecendo maior refúgio contra predadores (KURATA \& KIRA, 1995) e maior estabilidade nas características físicas e químicas da água (metabolismo mais intenso e dinâmico).

Outro fator relevante em relação à riqueza de espécies nas lagoas amostradas é uma menor ocorrência de espécies na lagoa Carioca em relação às demais lagoas, nos três períodos de amostragem. A inadequação do alimento para espécies herbívoras, revelado pelo alto grau de trofia, uma pressão de predação e competição em função da ocorrência de grande densidade da espécie de Copepoda Thermocyclops minutus e o menor índice de desenvolvimento de margem (menor disponibilidade de habitats) podem ser os fatores que justificam a menor riqueza de espécies zooplanctônicas nesta lagoa.

Vale ressaltar que, levando-se em consideração cada lagoa isoladamente, em praticamente todos os períodos de estudo, os táxons zooplanctônicos observados na regiões limnéticas ocorreram também nas regiões litorâneas. Assim, o incremento no número de táxons observado nas regiões litorâneas é resultado da ocorrência de organismos típicos destes ambientes, como alguns representantes de Rotifera (Macrochaetus collinsı) e de Cladocera, como espécies das famílias Chydoridae, Macrothricidae (Macrotrix laticornis) e Daphnidae (Simocephalus serrulatus).

De acordo com Dumont (1993), a maioria das espécies de Rotifera é estritamente litorânea, sendo ocasionalmente encontrada em regiões limnéticas. 0 mesmo autor afirma que do total de espécies descritas de Rotifera (cerca de 2000) apenas uma minoria de 200 a 250 espécies são pelágicas. 
KURATA \& KIRA (1995) afirmam que, em regiões litorâneas de sistemas lacustres, ocorre um grande número de espécies de invertebrados relacionado com os bancos de macrófitas, o sedimento e outros substratos sólidos.

Em relação à composição zooplanctônica observada para cada lagoa, no conjunto dos três períodos de estudo, pôde-se verificar a formação de três grupos distintos: o primeiro, com menor número de táxons (29) formado pela lagoa Carioca; o segundo, com número total de táxons intermediário (37), formado pela lagoa Aguapé, e o terceiro com maior número formado pelo conjunto das lagoas Amarela (44), Ariranha e Águas Claras, ambas com um total de 43 táxons.

Dos grupos zooplanctônicos encontrados, aquele que apresentou maior riqueza em relação aos demais foi o dos Rotifera, sendo também mais rico dentro dos compartimentos estudados de cada lagoa. RocHA et al. (1995), analisando a composição e estrutura da comunidade zooplanctônica de lagos, reservatórios e rios brasileiros das Bacias Amazônica, do Paraná, do Paraguai e do Nordeste, Oeste e Sudeste brasileiros, verificaram maiores números de espécies pertencentes ao grupo dos Rotifera em todos os ecossistemas aquáticos estudados.

Em geral, os organismos pertencentes ao grupo dos Rotifera são caracterizados, em relação ao hábito alimentar, como detritívoros e consumidores de bactérias (SEGERS, 1995-1996). Devido a estes hábitos, os Rotifera são comumente encontrados com maior riqueza e densidade em relação aos Cladocera e Copepoda, em ambientes eutróficos (GANNON \& STEMBERGER, 1978, ORCUTt \& PACE, 1984), onde predomina a cadeia trófica de detritivoria. Porém, outros autores, como INFANTE et al. (1982), ARCIFA et al. (1992) e NogUeIRA (1996) encontraram maior riqueza e densidade deste grupo zooplanctônico também nos ambientes oligotróficos, com baixa produtividade.

MATSUMURA-TUNDISI et al. (1990) sugerem que não é apenas o grau de trofia de um sistema que determina a maior ocorrência dos organismos pertencentes ao grupo dos Rotifera, mas também outros fatores como os aspectos morfométricos, a origem geológica dos lagos e as interações biológicas, como a predação e a competição por recursos tróficos.

No presente trabalho não foram evidenciadas relações definidas entre o grau de trofia das lagoas e a riqueza de espécies do grupo dos Rotifera, de acordo com a tendência esperada de maior número de espécies deste grupo em ambientes eutróficos. Assim, na lagoa Carioca, ambiente eutrófico, foi verificado um menor número de espécies de Rotifera, em relação às demais lagoas. Da mesma forma, na 
lagoa Águas Claras, que apresentou baixo grau de trofia, foi encontrada uma grande riqueza de espécies deste grupo zooplanctônico.

De forma geral, não foi observada uma correspondência entre a riqueza do zooplâncton com as características morfológicas das lagoas estudadas, como o índice de desenvolvimento de margem. Assim, em lagoas com baixo grau de sinuosidade da margem, como a Ariranha e a Amarela, foi encontrado um grande número de táxons, em contraste com a lagoa Aguapé que apresenta o maior índice de desenvolvimento de margem e foi composta por uma riqueza zooplanctônica menor.

A grande biomassa de macrófitas aquáticas que ocorre em toda a área superficial da lagoa Amarela, proporcionando maior disponibilidade de hábitats, e a comunicação temporária, no período das chuvas, de um pequeno riacho com a lagoa Ariranha, que deve proporcionar um fluxo de organismos planctônicos, como por exemplo da espécie de Cladocera Diaphanosoma fluviatile; devem ser os fatores responsáveis pelo maior número de táxons observados nestas lagoas.

RoCHA et al. (1997) comparando a estrutura zooplanctônica com o grau de trofia de diversos ecossistemas lacustres, como lagos naturais e reservatórios, verificaram que há uma maior taxa de transferência de energia do primeiro para o segundo nível trófico em lagos mesotróficos, onde foram verificadas maiores densidades para o zooplâncton, do que nos eutróficos. Nos lagos com menor grau de trofia estudados pelos autores, como os reservatórios do Broa e Lagoa Dourada (Itirapina/Brotas - SP) foram verificadas dominâncias dos mesmos grupos zooplanctônicos, tendo como destaque o dos Rotifera. Os mesmos autores inferem ainda, que em lagos onde está instaurado o processo de eutrofização, há uma tendência a uma diminuição da produção zooplanctônica, evidenciada pela diminuição da densidade numérica.

Segundo DUMONT (1993) e PEJLER (1995) é comum a ocorrência de uma fauna de Rotifera mais rica em número de espécies em regiões litorâneas com presença de bancos de macrófitas.

Dentro do grupo dos Rotifera, observou-se maior ocorrência de espécies pertencentes às famílias Lecanidae (10 táxons) e Brachionidae (9 táxons), principalmente nas regiões litorâneas das lagoas estudadas.

A maior riqueza da família Brachionidae em regiões litorâneas da cinco lagoas deve estar relacionada ao fato da maior parte das espécies do grupo dos Rotifera ocorrer nas regiões costeiras dos lagos, assim como descreve DUMONT (1993). 
Embora, segundo RUTTNER-KOLISKO (1974), as espécies do gênero Brachionus sejam termófilas, no presente trabalho não foram observadas relações entre a maior ocorrência, densidade ou abundância das espécies deste gênero e maiores valores de temperatura, como no período de verão de 2000.

SENDACZ et al. (1985) afirmam que espécies pertencentes à família Brachionidae de Rotifera ocorrrem em maior número em águas eutróficas, como por exemplo a espécie Brachionus angularis, segundo BERZINS \& PEJLER (1987). No presente trabalho, a ocorrência e a densidade dos exemplares desta família não se relacionaram claramente com os diferentes graus de trofia das lagoas estudadas. Assim, foram observados baixos graus de trofia e grandes densidades de espécies de Brachionidae nas lagoas Ariranha e Aguapé. Porém, na lagoa Amarela, caracterizada pelo presente trabalho com um alto grau de trofia, os exemplares desta família ocorreram em grande número.

Já em relação às espécies da família Lecanidae, com maior número de táxons e densidade nas regiões litorâneas no presente trabalho, RUTTNER-KOLISKO (1974) relata que a sua ocorrência no plâncton de regiões limnéticas é eventual e deve-se a migrações ocasionais, estando sua ocorrência relacionada essencialmente aos litorais lacustres.

RocHA et al. (1995) afirmam que é comum a ocorrência de maior dominância das famílias Lecanidae, Brachionidae e de espécies do gênero Anuraeopsis em ecossistemas aquáticos da América do Sul. Vale ressaltar que foram encontradas, no presente trabalho, altas densidades da espécie de Rotifera Anuraeopsis navicula em todas as lagoas, assim como também das espécies das famílias Lecanidae e Brachionidae de Rotifera.

A espécie Anuraeopsis navicula foi registrada com grande densidade principalmente nos períodos de inverno de 1999, com exceção à lagoa Amarela. ESPARCIA et al. (1991) relacionam a ocorrência de espécies do gênero Anuraeopsis a ambientes onde há muita matéria orgânica em suspensão, predominando a decomposição sobre a produção. Esta relação pode explicar as grandes densidades observadas para esta espécie de Rotifera em ambos os períodos de inverno, especialmente nas lagoas Carioca e Águas Claras, uma vez que nestes períodos também foram verificadas grandes porcentagens da fração orgânica do material em suspensão.

Por outro lado, na lagoa Amarela, onde também foram observadas grandes porcentagens de matéria orgânica, a espécie Anuraeopsis navicula não ocorreu, 
provavelmente, devido a outros fatores ecológicos como predação e competição por recurso trófico.

Embora, segundo PeJLER \& BERZINS (1993), as espécies do gênero Trichocerca ocorram preferencialmente associadas a comunidades perifíticas, no presente trabalho não foi observado maior número de espécies e maiores densidades em regiões litorâneas, onde predominam estes tipos de comunidades associadas a macrófitas aquáticas e outros substratos.

Em relação à espécie de Rotifera, Ptygura libera, OLIVEIRA-Neto (1993) afirma que sua ocorrência, em especial, está ligada a lagos naturais e ecossistemas lacustres com águas oligotróficas. Da mesma forma, no presente trabalho esta espécie foi verificada com maiores densidades em lagoas com graus de trofia relativamente menores, como as lagoas Aguapé, Águas Claras e Ariranha.

Esta mesma relação de ocorrência em maior densidade em ambientes com menores graus de trofia, também é feita para as espécies do gênero Collotheca por SENDACZ et al. (1985) e GüNTZEL (2000). No presente trabalho esta relação foi verificada nas lagoas Águas Claras e Ariranha, ambas com menores graus de trofia, onde foram observadas maiores densidades da espécie do gênero Collotheca.

Já a ocorrência, tipicamente no plâncton de regiões limnéticas, de espécies dos gêneros Collotheca e Conochilus, como relatado por DE MANUEL \& ARMENGOL (1993), não foi verificada no presente trabalho, uma vez que os exemplares destes gêneros encontrados distribuíram-se indistintamente, em termos de densidade, nas regiões limnética e litorâneas, das lagoas investigadas no presente trabalho.

De maneira geral a densidade total dos Rotifera na lagoa Amarela foi menor do que nas demais lagoas estudadas, chegando a representar uma densidade até 8 vezes mais baixa.

Na lagoa Carioca, a densidade dos Rotifera foi sempre maior nas amostragens realizadas na região litorânea e foi observado também um decréscimo de densidade no verão de 2000 (fevereiro), quando comparada com a densidade obtida nas amostragens de inverno de 1999 (junho).

Assim como foi verificado para o grupo dos Rotifera, a composição dos Cladocera variou bastante entre os compartimentos e entre as lagoas, no conjunto dos três períodos de estudo. Observou-se que nas regiões litorâneas de todas as lagoas estudadas o número de táxons de Cladocera foi sempre maior do que nas limnéticas, e que, no geral, as espécies que ocorreram nas regiões limnéticas também estiveram presentes nas litorâneas, dentro de cada lagoa. 
Dos 13 táxons verificados para o grupo dos Cladocera em todas as lagoas estudadas, 5 foram representantes da família Chydoridae que ocorreu com maior frequência nas regiões litorâneas.

Dessa forma, o maior número de táxons pertencentes ao grupo dos Cladocera que foi observado nas regiões litorâneas de todas as lagoas, deveu-se à ocorrência de espécies típicas do litoral lacustre, como as da família Chydoridae e Macrothricidae, além da espécie Simocephalus serrulatus da família Daphnidae.

ELMOR-LOUREIRO (1997) afirma que a grande maioria das espécies de Cladocera, principalmente as pertencentes às famílias Chydoridae e Macrothricidae, podem ser encontradas nas regiões litorâneas, associadas, principalmente, à vegetação e a outros substratos como o próprio sedimento.

Os exemplares destas famílias de Cladocera apresentam grande sucesso na exploração dos litorais lacustres devido, principalmente, à capacidade que possuem de coletar partículas suspensas na água, aderidas ao fundo, à vegetação de macrófitas e ao sedimento litorâneo (FRYER, 1968; 1974).

Por outro lado, as espécies das famílias Sididae, Daphnidae e Bosminidae (filtradoras e herbívoras) não apresentam a mesma eficiência na exploração do ambiente litorâneo, sendo comumente encontradas em regiões limnéticas, por apresentarem o mecanismo de filtração passiva para a alimentação (HUTCHINSON, 1967).

Pelo número de táxons encontrados para o grupo dos Cladocera, foi possível verificar a formação de dois grupos distintos de lagoas: o primeiro formado pela lagoa Carioca com menor número de táxons, e o segundo composto pelas demais lagoas (Aguapé, Águas Claras, Ariranha e Amarela).

Não foi observado nenhum exemplar do grupo dos Cladocera na região limnética da lagoa Carioca nas amostragens realizadas nos períodos de inverno (junho de 1999 e agosto de 1999) e da lagoa Águas Claras em junho de 1999. Também na lagoa Carioca, a densidade do grupo dos Cladocera foi sempre menor do que nas demais lagoas. A inadequação do alimento ou uma alta pressão de predação poderiam ser fatores determinantes da ausência ou baixa densidade dos Cladocera na região limnética destas lagoas.

A única espécie filtradora que ocorreu na lagoa Carioca foi Diaphanosoma birgei. Assim como verificado por GüNTZEL (2000) nos reservatórios do Rio Tietê, o que pode explicar a ausência de outras espécies de hábito herbívoro é o elevado grau de trofia, como ocorre na lagoa Carioca, que é uma condição característica de sistemas 
onde há o predomínio da cadeia de detritívoria. Assim, deve ter ocorrido uma seleção alimentar nesta lagoa, favorecendo apenas a espécie Diaphanosoma birgei que apresenta maior eficiência na coleta de partículas suspensas na água. SENDACZ et al. (1979), estudando os reservatórios da Bacia do Rio Tietê, verificaram uma maior abundância de Diaphanosoma birgei em águas eutróficas.

As maiores densidades das espécies Bosmina hagmani e Diaphanosoma birgei foram verificadas nas lagoas Aguapé e Águas Claras, onde foram observados baixos graus de trofia e baixos valores de material em suspensão. GüNTZEL (2000), estudando os reservatórios em cascata do Rio Tietê, também verificou a ocorrência destas espécies de Cladocera em águas mais oligotróficas e com menor quantidade de material em suspensão.

Na lagoa Amarela a densidade dos Cladocera foi determinada, principalmente, pela maior abundância da família Daphnidae, representada principalmente pela espécie Daphnia laevis, em ambos os compartimentos. Além de sua ocorrência na lagoa Amarela, esta espécie ocorreu também na lagoa Águas Claras.

Assim como a família Chydoridae, dentro do grupo dos Cladocera, a família Macrothricidae também ocorreu em grande densidade nas regiões litorâneas, principalmente na da lagoa Ariranha, no período de inverno de 1999.

A família Sididae ocorreu em maior abundância, dentro do grupo dos Cladocera, principalmente no período de verão de 2000 , em ambas as regiões da lagoa Carioca e Águas Claras, e nas regiões limnéticas da Aguapé e Ariranha. Na lagoa Carioca, esta família foi representada apenas pela espécie Diaphanosoma birgei.

A espécie de Cladocera Diaphanosona fluviatile, típica de sistemas lóticos, foi encontrada apenas na lagoa Ariranha, o que deve estar associada à comunicação temporária desta lagoa, no período das chuvas, com um pequeno tributário do Rio Doce, corroborando assim à relação desta espécie com ambientes lóticos, como já observado anteriormente por outros autores (Paggi, 1978).

Dentre os principais grupos zooplanctônicos, o dos Copepoda foi aquele representado pelo menor número de táxons dentre todas as lagoas estudadas, tendo sido encontradas 3 espécies de Cyclopoida e apenas uma de Calanoida. Vale ressaltar que a espécie representante da sub-ordem Calanoida, Notodiaptomus isabelae, ocorreu apenas nas lagoas Ariranha e Amarela.

De maneira geral, as espécies de Copepoda Cyclopoida foram observadas em grande densidade e abundância em todos os compartimentos de todas as lagoas estudadas. Esta ocorrência deve estar relacionada aos graus de trofia das lagoas, que 
na maioria dos casos, varia de mesotrófico a eutrófico, segundo a aplicação do índice de estado trófico de SALAS \& MARTINO.

De maneira geral, em ambientes eutrofizados, como é o caso da lagoa Carioca, a comunidade fitoplanctônica é composta por microalgas com grande produtividade primária, o que favorece o desenvolvimento de espécies de Copepoda Cyclopoida, como Thermocyclops minutus (GANNON \& STEMBERGER, 1978). Neste ambientes, a cadeia trófica predominante é de detritivoria e herbivoria. MATSUMURA-TUNDISI et al. (1997b) verificaram uma maior preferência alimentar da espécie Thermocyclops minutus, de hábito raptorial, por microalgas coloniais, como Microcystis aeruginosa e Botryococcus braunii no lago Dom Helvécio também, pertencente ao sistema de lagos do Vale do Rio Doce. Esta última espécie de microalga compõe o fitoplâncton da lagoa Carioca com grande abundância, segundo TUNDISI et al. (1997b), o que deve explicar a ocorrência em grande densidade da espécie Thermocyclops minutus nesta lagoa.

Dentro da sub-ordem Cyclopoida, foi observada maior densidade de Mesocyclops brasilianus, principalmente nas regiões litorâneas de todas as lagoas.

Para as espécies de Copepoda Cyclopoida, Thermocyclops minutus e Tropocyclops prasinus, foram observadas maior abundância e densidade dentre todos os Copepoda, principalmente nas regiões limnéticas.

ADRIAN \& FROST (1992), estudando o hábito alimentar da espécie Tropocyclops prasinus mexicanus, verificaram que há uma maior preferência por algas fitoplanctônicas, embora o hábito da espécie seja onívoro. Isto pode ser o fator que explica a maior ocorrência desta espécie nas regiões limnéticas das lagoas, no presente trabalho, uma vez que nestes compartimentos a presença de algas fitoplanctônicas é maior do que nas litorâneas, onde predominam o perifíton e as macrófitas.

A espécie Thermocyclops minutus foi observada em maior abundância sempre nas regiões limnéticas, em relação às litorâneas, em praticamente todas as lagoas estudadas, assim como também como todo o grupo dos Copepoda, principalmente nas lagoas Aguapé e Águas Claras em junho de 1999, nas lagoas Carioca, Aguapé, Ariranha e Amarela em agosto de 1999, e nas lagoas Carioca, Aguapé, Águas Claras e Amarela no verão, provavelmente, devido a uma preferência à qualidade alimentar presente nestas regiões.

A única espécie representante dos Copepoda Calanoida foi Notodiaptomus isabelae, encontrado apenas nas lagoas Amarela e Ariranha, em todos os compartimentos e nos três períodos de estudo, mas com maior densidade nas regiões limnéticas. Estas lagoas encontram-se próximas e devem ter sido originadas, 
temporalmente, em períodos próximos na evolução do sistema de lagos do Vale do Rio. Dessa forma, a presença desta espécie apenas nas lagoas Amarela e Ariranha pode revelar um possível isolamento geográfico decorrente da história de gênese dos lagos. Outro fator que poderia explicar estas ocorrências isoladas é o transporte pela fauna aquática.

Ainda em relação às lagoas Amarela e Ariranha, foi observada uma maior abundância do grupo dos Copepoda Cyclopoida, incluindo suas formas jovens (copepodito e náuplios) e adultas, em relação ao grupo dos Calanoida. Muitos autores, como Gannon \& Stemberger (1978), Pinto-Coelho (1987), EsteVes \& Sendacz (1988), TUNDISI \& MATSUMURA-TUNDISI (1990), entre outros, associam o predomínio das espécies de Cyclopoida a condições eutróficas.

De maneira geral, as formas jovens de Copepoda foram observadas com maior abundância sempre nas regiões limnéticas em relação às litorâneas. O principal fator que deve justificar esta evidência é a maior ocorrência do nanofitoplâncton na região limnética, que constitui o principal recurso trófico para as fases juvenis de Copepoda, embora regiões litorâneas possam ser adotados como sítios reprodutivos.

Em relação à abundância dos grupos zooplanctônicos, foi observada uma maior proporção para os Rotifera em relação aos demais grupos nas lagoas Carioca, Ariranha e Amarela nos períodos de inverno 1999, e nas lagoas Águas Claras, Ariranha e Amarela no verão de 2000, principalmente nas regiões litorâneas, o que indica a ocorrência predominante da cadeia de detritívoria nestas lagoas, já que as espécies representantes do grupo dos Rotifera são descritas como consumidores de detrítos e de bactérias (SEGERS, 1995-1996).

O único táxon representante da ordem Ostracoda foi uma espécie de Phisiocypria, a qual ocorreu em todas as lagoas, com exceção à lagoa Amarela. Esta espécie também foi registrada no lago Dom Helvécio, pertencente ao mesmo sistema de lagos, por MATSUMURA-TUNDISI (1997) e TUNDISI et al. (1997b).

As formas larvais do gênero Chaoborus ocorreram com maior densidade principalmente nas regiões limnéticas. FUKUHARA et al. (1997a,b) verificaram a ocorrência de quatro espécies deste gênero, tendo sido idenficada apenas uma (Chaoborus magnificus). JAMES (1957) e PUCAT (1965), apud PAREJKO (1991) descrevem estes organismos como habitantes das regiões pelágicas, onde são eficientes predadores.

Já os representantes dos grupos Chironomidae, Nematoda e Oligochaeta foram observados com maior densidade principalmente nas regiões litorâneas, sendo 
eventualmente encontrados nas regiões limnéticas, devido ao fato das espécies destes grupos apresentarem, geralmente, hábitos bentônicos e associados a comunidade de macrófitas e outros tipos de substrato.

No geral, foram observadas maiores densidades, para todo o zooplanctôn, nos períodos de inverno de 1999 , e as menores densidades foram verificadas na lagoa Amarela, em todos os períodos.

Comparando-se o presente trabalho com o realizado por TUNDISI et al. (1997), que apresenta a composição de espécies das lagoas Aguapé, Águas Claras e Ariranha em novembro de 1985, pode-se dizer que a composição zooplanctônica alterou-se bastante ao longo de 13 anos nestas lagoas. TUNDISI et al. (1997) verificaram a ocorrência de apenas 11 táxons na lagoa Aguapé, 10 na lagoa Águas Claras e 3 na lagoa Ariranha naquele período. No presente estudo foram verificados, respectivamente, 37, 43 e 43 táxons nestas lagoas. A diferença entre os números de táxons verificados pelos trabalhos em comparação, deu-se pela ocorrência, no presente, de espécies das famílias Lecanidae e Brachionidae de Rotifera e das famílias Chydoridae e Macrothricidae de Cladocera, todas típicas de regiões litorâneas, as quais não foram abordadas no trabalho realizado por TUNDISI et al. (1997).

Além disso, TUNDISI et al. (1997) verificaram a ocorrência da espécie Notodiaptomus isabelae também na lagoa Águas Claras, o que não ocorreu no presente trabalho. Outras espécies também foram verificadas por TUNDISI et al. (1997) e não foram encontradas nas amostras do presente trabalho, como Bosminopsis deitersi e Brachionus forficula na lagoa Aguapé, Conochiloides coenobasis na lagoa Águas Claras e Filinia longiseta nas lagoas Aguapé e Águas Claras.

Em relação à diversidade alfa calculada para todos os pontos de amostragem de todas as lagoas, ficou clara a diferença entre os pontos da lagoa Carioca em relação às demais, principalmente, em função da riqueza de espécies, a partir da qual também foi possível evidenciar diferenças entre os pontos de amostragem limnéticos e litorâneos.

GüNTZEL (2000), estudando os reservatórios em cascata da Bacia do Rio Tietê/Paraná, também verificou maiores valores para a riqueza de espécies de alguns pontos litorâneos, em relação aos limnéticos, nos reservatórios de Bariri, Ibitinga, Promissão, Nova Avanhandava e Três Irmãos.

Pelos valores obtidos dos demais índices de diversidade, no presente trabalho, não ficaram claras as diferenças entre os pontos de amostragens das lagoas e entre os compartimentos limnético e litorâneo dentro de cada lagoa. Assim, as diferenças entre as comunidades zooplanctônicas dos pontos de amostragem limnéticos e litorâneos das 
diferentes lagoas abordadas neste trabalho, estão relacionados, principalmente, ao número de espécies. Quando foram utilizados índices que contemplam a densidade numérica específica ou total da comunidade, as diferenças não ficaram claras.

Também não foram observadas relações entre as condições de trofia das lagoas com os valores dos índices de diversidade, como verificadas por GüNTZEL (2000), que encontrou maiores valores do índice de SHANNON nos reservatórios de Barra Bonita e Bariri, da Bacia do Rio Tietê, cujas águas apresentavam condições mais eutróficas. Os menores valores do índice de SHANNON, observadas pela mesma autora, foram de 2,72 e 2,74, respectivamente, nos reservatórios de Promissão e Nova Avanhandava, cujas condições de trofia foram menores. No presente trabalho, o maior valor do índice de SHANNON foi de 2,38 na região litorânea da lagoa Águas Claras no período de verão de 2000.

Pela análise da diversidade beta, baseada no índice de SORENSEN (qualitativo), foi possível verificar uma maior similaridade, em função da riqueza de espécies, para as lagoas Ariranha, Aguapé e Águas Claras, em todos os períodos amostrados. No período de inverno 1 (junho de 1999), a lagoa Carioca foi a que mais se distanciou das demais lagoas em função deste índice, provavelmente em função de baixa riqueza de espécies representada, como por exemplo, pela ausência de espécies de Cladocera, principalmente nas amostras da região limnética. Já nos períodos de inverno 2 (agosto de 1999) e verão de 2000, a lagoa Amarela apresentou-se mais distante das demais lagoas estudadas. $\mathrm{O}$ que deve que explicar este distanciamento da lagoa Amarela, em função do índice de Sorensen, é alta riqueza de espécies, com uma composição bastante característica de ambientes com predomínio de macrófitas.

Pelas análises de componentes principais, aplicadas segundo os valores dos índices de diversidade, também não foi possível evidenciar conjuntos de pontos pertencentes a uma lagoa, ou a um compartimento lacustre, embora todos os índices de diversidade tenham apresentado valores de correlação satisfatórios nesta análise, em todos os períodos climáticos.

Dessa forma, pelos resultados referentes à diversidade zooplanctônica, as hipóteses alternativas estipuladas no delineamento experimental deste trabalho, referentes a diferenças entre região limnética e litorânea e a diferenças entre os três grupos de lagoas, foram rejeitadas. Ou seja, a associação de índices de diversidade proposta não revelou diferenças expressivas entre os compartimentos limnético e litorâneos das lagoas, e nem agrupou as lagoas segundo a tipologia de vegetação do entorno. 
Ficou evidente, apenas, que as lagoas que se encontram na área de propriedade da Companhia Agrícola Florestal, com cultivo de eucalipto no entorno (uniforme ou com sub-bosque de espécies nativas), apresentaram maior riqueza de espécies em relação à lagoa Carioca, que apresenta vegetação de Mata Atlântica no seu entorno. Ainda assim, esta menor riqueza observada na lagoa Carioca não deve ser decorrência do tipo de vegetação do entorno, mas sim em função da condição eutrófica de sua água e da menor disponibilidade de habitats (baixo índice de desenvolvimento de margem).

Os fatores que devem determinar os padrões estruturais e a dinâmica da comunidade zooplanctônica nas lagoas estudadas, devem ser aqueles relativos à morfometria (profundidade, índice de desenvolvimento de margem, comprimento, área superficial) e ao estágio sucessional das lagoas, e não ao tipo de vegetação que ocorre no entorno. 


\section{CONCLUSÕES}

- O volume das lagoas, investigadas no presente estudo, manteve-se praticamente 0 mesmo entre os períodos de inverno de 1999 e verão de 2000, em função da constância nos valores da profundidade dos pontos de amostragem entre os períodos climáticos;

- Em relação às características morfométricas horizontais (comprimento máximo, área superficial e perímetro), as lagoas puderam ser agrupadas da seguinte forma: lagoas Aguapé e Águas Claras, com maiores valores; lagoas Carioca e Ariranha, com valores intermediários; e lagoa Amarela, com os menores valores para estas variáveis;

- A lagoa Carioca é aquela que possui o menor valor para o índice de desenvolvimento de margem, com menor grau de sinuosidade de sua região costeira e, consequentemente, com menor disponibilidade de hábitats litorâneos;

- Pelas profundidades das regiões limnéticas, as lagoas podem ser agrupadas da seguinte forma, em ordem decrescente de grandeza: lagoas Carioca e Águas Claras; lagoas Aguapé e Ariranha; e lagoa Amarela;

- Ocorreram diferenças significativas nos valores das variáveis limnológicas das lagoas entre os períodos climáticos amostrados (inverno de 1999 e verão de 2000), 
principalmente em função dos perfis térmicos e químicos (valores de oxigênio dissolvido) da coluna da água, da extensão da zona eufótica e das proporções entre as frações orgânica e inorgânica do material em suspensão;

- Há uma maior homogeneidade das condições físicas e químicas nas regiões litorâneas em relação às limnéticas, das lagoas estudadas, revelada por valores relativamente próximos de temperatura, oxigênio dissolvido, $\mathrm{pH}$ e condutividade elétrica ao longo da coluna da água. Esta homogeneização foi decorrente, provavelmente, pela menor ação dos ventos nestas regiões devido à presença de bancos de macrófitas nestes e pela ocorrência de vegetação de grande porte no entorno das lagoas, seja nativa (floresta de Mata Atlântica) ou artificial (eucalipto);

- Ocorreram diferenças entre as regiões limnéticas e litorâneas das lagoas estudadas no período de inverno de 1999 (junho) em função de características físicas da água representadas, principalmente pela profundidade, transparência da água e extensão da zona eufótica;

- Não foram observadas diferenças entre os grupos de lagoas, de acordo com o tipo de vegetação do entorno, em função das variáveis limnológicas;

- A lagoa Carioca é, dentre as lagoas estudadas, aquela com condições mais eutróficas, em ambos os períodos de inverno (junho e agosto de 1999), em função dos valores de fósforo total, fosfato dissolvido orgânico e concentração de clorofila. O que, provavelmente, acarreta esta situação na lagoa Carioca são seus aspectos morfométricos que a caracterizam como uma bacia de sedimentação, com pequena área superficial e grande profundidade, quando comparada com as outras lagoas estudadas;

- Nas cinco lagoas estudadas ocorreram 58 táxons zooplanctônicos pertencentes aos grupos dos Rotifera, Cladocera, Copepoda, Nematoda, Ostracoda, Oligochaeta e Insecta, revelando uma complexa cadeia alimentar de consumidores primários e secundários;

- Em todas as lagoas estudadas existe maior número de táxons nas regiões litorâneas devido à maior disponibilidade de alimentos, à presença de bancos de 
macrófitas que oferecem refúgios contra a predação por vertebrados e outros invertebrados, e à maior homogeneidade das condições físicas e químicas destes compartimentos;

- O maior número de táxons zooplanctônicos observados nas regiões litorâneas devese à presença de espécies de hábitos tipicamente costeiros, associados a banco de macrófitas, como as representantes da família Lecanidae, do gênero Trichocerca, e das famílias Chydoridae e Macrothricidae;

- Não se observaram relações entre as densidades totais do zooplâncton e as condições de entorno das lagoas ou o grau de trofia das mesmas;

- A lagoa Carioca diferencia-se das demais lagoas por apresentar menor riqueza de táxons zooplanctônicos, devido às condições mais eutróficas de sua água (menor qualidade alimentar para espécies herbívoras), pela forte pressão de predação e competição da espécie Thermocyclops minutus (ocorrência em grande densidade), e também pela menor disponibilidade de habitats litorâneos, evidenciada pelo menor índice de desenvolvimento de margem;

- As espécies de Cladocera de hábitos herbívoro e filtrador não ocorrem no compartimento limnético da lagoa Carioca devido à baixa qualidade alimentar desta lagoa, com exceção da espécie Diaphanosoma birgei, configurando uma cadeia alimentar predominantemente detrítica;

- A espécie de Cladocera Diaphanosoma fluviatile, típica de ambientes lóticos, ocorreu apenas na lagoa Ariranha, possivelmente devido ao fato desta lagoa comunicar-se temporariamente, no período das chuvas, com um pequeno tributário do Rio Doce;

- Existem diferenças entre a composição de espécies de copepoda nos compartimentos limnético e litorâneo das lagoas, evidenciadas pelas espécies de Cyclopoida Thermocyclops minutus e Tropocyclops prasinus que habitam preferencialmente as regiões limnéticas das lagoas, e pela espécie Mesocyclops brasilianus nas litorâneas; 
- A espécie de Copepoda Calanoida Notodiaptomus isabelae ocorreu apenas nas lagoas Ariranha e Amarela, provavelmente devido ao isolamento que estas lagoas sofreram ao longo de sua formação geológica; evidenciando um possível efeito da fragmentação natural do Rio Doce;

- Apenas em relação à riqueza de espécies ocorreram diferenças entre a lagoa Carioca e as demais lagoas estudadas, fato relacionado à qualidade alimentar que ocorre nesta lagoa, cuja água apresenta as condições mais eutróficas dentre todas as lagoas analisadas, e em função do menor desenvolvimento de margem que representa uma menor quantidade de habitats litorâneos. Esta evidência refutou a proposta inicial de agrupamento segundo as alterações na qualidade da água dos lagos em decorrência das características da vegetação do entorno (nativa ou de cultivo de eucalipto), que configurariam alterações na diversidade do zooplâncton em função de impactos antrópicos.

- Os diferentes tipos de vegetação que ocorrem no entorno das lagoas estudadas não acarretam diferenças entre as condições limnológicas, a estrutura e a dinâmica da comunidade zooplanctônica. O fator responsável pelas diferenças observadas, tanto em relação às características limnológicas quanto à estrutura e dinâmica do zooplâncton, entre a lagoa Carioca e as demais lagoas estudadas, é a condição de eutrofia dessa lagoa em relação às demais, que como já caracterizado anteriormente por outros autores, é resultado da sucessão hidrárquica natural, neste sistema de lagos. 


\section{REFERÊNCIAS BIBLIOGRÁFICAS}

AB'SABER, A. N. (1972). Os domínios morfoclimáticos da América do Sul: primeira aproximação. Geomorfologia. São Paulo. Instituto de Geografia Universal de São Paulo.

AbelHo, M.; GRAÇA, M. A. S. (1996). Effects of eucalliptus afforestation on leaf litter dynamics and macroinvertebrate community structure of streams in Central Portugal. Hydrobiologia, vol. 324, p. 195-204.

ACIESP. (1997). Glossário de Ecologia. SÃO PAULO. ACIESP.

ADRIAN, R.; FROST, T. M. (1992). Comparative feeding ecology of Tropocyclops prasinus mexicanus (Copepoda, Cyclopoida). Journal of Plankton Research, vol. 14, n. 10, p. $1369-1382$.

AnDERSSON, G.; GRANÉli, W.; STENSON, J. (1988). The influence of animals on phosphorus cycling in lake ecosystems. Hydrobiologia, vol. 170, p. 267-284.

Andrade, P. M.; Pereira, M. C. A.; Costa e Silva, L. V. (1997). The vegetation of Rio Doce State Park. In: TUNDISI, J. G.; SAIJO, Y., eds. Limnological Studies on the Rio Doce Valley Lakes, Brazil. Brazilian Academy of Sciences. University of São Paulo. School of Engineering at São Carlos. Center for Water Resources and Applied Ecology, p. 15-21. 
Arcifa, M. S.; Gomes, E. A. T.; MeschiAtTi, A. J. (1992). Composition and fluctuations of the zooplankton of a tropical Brazilian reservoir. Arch. Hydrobiol., vol. 123, n. 4, p. 479-495.

Barbieri, A. F.; Guerra, C. B.; Torres, H. G.; Simões, R. F.; Reis, A. V.; Scliar, C.; Abdo, R. O. O.; LINS, S. E. B. (1997). Atividades Antrópicas e Impactos Ambientais. In: PAULA, J. A. Biodiversidade, população e economia de uma região de mata atlântica. Belo Horizonte. UFMG/Cedeplar, p. 273-343.

BARBOSA, F. A. R.; TUNDISI, J. G. (1980). Primary production of phytoplankton and environmental characteristics of a shallow quaternary lake at Eastern Brazil. Arch. Hydrobiol., vol. 90, n. 2, p. 131-161.

BARBOSA, F. A. R. (1981). Variações diurnas (24 horas) de parâmetros limnológicos básicos e da produtividade primária de fitoplâncton na Lagoa Carioca, Parque Florestal do Rio Doce, MG. São Carlos, SP. Tese de Doutoramento. Universidade Federal de São Carlos.

Barbosa, F. A. R.; EsteVes, F. A.; TUndisi, J. G. (1981). Limnological Studies at Eastern Brazil (Rio Doce Valley). Chemical composition and nutritional quality of the forest litter. Tropical Ecology, vol. 23, n. 1, p. 155-163.

BARBOSA, F. A. R.; TUNDISI, J. G. (1988). Diel variations in a shallow tropical Brazilian lake, 1: the influence of temperature variation on the distribution of dissolved oxygen and nutrients. Arch. Hydrobiol., vol. 116, p. 333-344.

Bertilsson, J.; BËRzins, B.; PeJler, B. (1995). Occurrence of limnic micro-crustaceans in relation to temperature and oxygen. Hydrobiologia, vol. 299, p. 163-167.

BËRZINS, B.; BERTILSSON, J. (1988). On limnic micro-crustaceans and trophic degree. Hydrobiologia, vol. 185, p. 95-100.

Brandlova, J.; BRANDL, Z.; FERnANDO, C. H. (1972). The Cladocera of Ontario with remarks on some species and distribution. Can. J. Zool., vol. 50, p. 1373-1403. 
BRASIL. (1998). Primeiro relatório nacional para a Convenção sobre Diversidade

Biológica. Ministério do Meio Ambiente, dos Recursos Hídricos e da Amazônia Legal. Brasil, Brasília.

Berzins, B.; PejLeR, B. (1987). Rotifer occurrence in relation to pH. Hydrobiologia, v. 147 , p. $107-116$.

BRETT, M. T.; Müller-Navarra, D. C.; Park, S. (2000). Empirical analysis of the effect of phosphorus limitation on algal food quality for freshwater zooplankton. Limnol. Oceanogr., vol. 45, n. 7, p. 1564-1575.

Calijuri, M. C.; TUndisi, J. G.; HenRy, R.; IBAÑEZ, M. S. R.; MATSUMURA-Tundisi, T.; Rocha, O. (1997). Changes in Light Attenuation in Fifteen Lakes and their Relationship with Chlorophyll and Particulate Material During Summer and Winter. In: TUNDISI, J. G.; SAIJO, Y., eds. Limnological Studies on the Rio Doce Valley Lakes, Brazil. Brazilian Academy of Sciences. University of São Paulo. School of Engineering at São Carlos. Center for Water Resources and Applied Ecology, p. 83-93.

CARLSON, R. E. (1977). A trophic state index for lakes. Limnol. and Oceanogr., vol. 22, n. 2, p. 361-369.

CAPBLANCQ, J. (1990). Nutrient dynamics and pelagic food web interactions in oligotrophic and eutrophic enviroments: an overview. Hydrobiologia, vol. 207, p. 1-14.

Carvalho, I. R.; Gentilini, E.; Teixeira, M. C. B. (1983). Levantamento da vegetação do Parque Estadual o Rio Doce. Rev. SOM, vol. 27.

CEmig. (1989). Levantamento Aerofotométrico, Coronel Fabriciano - 4. Folhas 36-22-03, 36-22-07 e 36-22-10.

CeteC. (1981). Programa de Pesquisas Ecológicas no Parque Estadual do Rio Doce. Fundação Centro Tecnológico de Minas Gerais. $1^{\circ}$ Vol. Relatório Final não publicado. 
CeteC. (1994). Mapa Geopolítico de Minas Gerais - IGA. Digitalização: Assessoria da Secretaria Geral do Governador.

Chapman, M. A.; Green, J. D.; Jolly, V. H. (1985). Relationships between zooplankton abundance and trophic state in seven New Zealand lakes. Hydrobiologia, vol. 123, p. $119-136$.

ClYMO, R. S. (1995). Nutrients and limiting factors. Hydrobiologia, vol. 315, p. 15-24.

COLE, G. A. (1979). Textbook of Limnology. The C. V. Mosby Company.

DE MANUEL, J.; ARMENGOL, J. (1993). Rotifer assemblages: a contribution to the tipology of Spanish reservoirs. Hydrobiologia, v. 255-256, p. 421-428.

Donk, E. V.; Gulati, R. D.; Iedema, A.; Meulemans, J. T. (1993). Macrophyte-related shifts in the nitrogen and phosphorus contents of different levels in a biomanipulated shallow lake. Hydrobiologia, vol. 251, p. 19-26.

DumONT, H. J. F. (1993). Rotifera. Biology, Ecology and Systematics. Hague, Netherlands, SPB Academic Publishing, vol. 1.

EDMONDSON, W. T. (1959). Fresh Water Biology. 2nd Edition. JOHn WiLEY \& SONS, Inc.

ElmoOR-Loureiro, L. M. A. (1988). O gênero Bosmina (Crustacea, Cladocera) na Região do Distrito Federal. Acta Limnol. Brasil., vol. 2, p. 501-512.

ELMOOR-LOUREIRO, L. M. A. (1997). Manual de identificação de cladóceros límnicos do Brasil. Brasília, Editora Universa, Universidade Católica de Brasília.

Esparcia, A.; Armengol, J.; Vicente, E.; Miracle, M. R. (1991). Vertical distribution of Anuraeopsis species as related to oxygen depletion in two stratified lakes. Verh. Internat. Verein. Limnol., v. 24, p. 2745-2749.

EsteVeS, F. A. (1988). Fundamentos de Limnologia. Rio de Janeiro. InterciênciaFINEP. 
Feio, R. N.; Braga, U. M. L.; Wiederhecker, H.; Patrícia, S. S. (1998). Anfíbios do Parque Estadual do Rio Doce (Minas Gerais) - Viçosa, UFV, IEF.

FOnSECA, G. A. B. (1997). Impactos Antrópicos e Biodiversidade Terrestre. In: PAULA, J. A. Biodiversidade, população e economia de uma região de mata atlântica. Belo Horizonte. UFMG/Cedeplar, p. 455-466.

FRYER, G. (1968). Evolution and adaptative radiation in the Chydoridae (Crustacea: Cladocera): a study in comparative function morphology and ecology. Phylosophical Transactions of the Royal Society of London, v. 254, p. 221-385.

FRYER, G. (1974). Evolution and adaptative radiation in the Macrothricidae (Crustacea: Cladocera): a study in comparative function morphology and ecology. Phylosophical Transactions of the Royal Society of London, v. 269, p. 137-274.

FUKUHARA, H. (1989). Emergence of Chaoborids in Lake Dom Helvécio. In: SAIJO, Y.; TUNDISI, J. G. Limnological studies in Rio Doce Valley Lakes, Brazil. $3^{\text {rd }}$ Report. Water Research Institute, Nagoya University, Japan.

FukUhARA, H.; TORRES, G. E.; MONTEIRO, S. M. C.; SUnAGA, T. (1997a). Migratory and nonmigratory Chaoborus species in lake Dom Helvécio. In: TUNDISI, J. G.; SAIJO, Y., eds. Limnological Studies on the Rio Doce Valley Lakes, Brazil. Brazilian Academy of Sciences. University of São Paulo. School of Engineering at São Carlos. Center for Water Resources and Applied Ecology, p. 345-352.

FuKUHARA, H.; TORRES, G. E.; MONTEIRO, S. M. C. (1997b). Emergengy ecology of Chaoborids in lake Dom Helvécio. In: TUNDISI, J. G.; SAIJO, Y., eds. Limnological Studies on the Rio Doce Valley Lakes, Brazil. Brazilian Academy of Sciences. University of São Paulo. School of Engineering at São Carlos. Center for Water Resources and Applied Ecology, p. 353-358.

GANNON, J. E.; STEMBERGER, R. S. (1978). Zooplankton (specially microcrustaceans and rotifers) as indicators of water quality. Trans. Am. Micros. Soc., vol. 97, n. 1, p. 1635. 
GILHUIS, L. P. (1986). Vegetation survey of the Parque Florestal Estadual do Rio Doce, MG, Brazil. Dissertação (Mestrado), Viçosa/ IEF/ Agricultural University of Wageningen, Wageningen/ Netherlands.

GodinHO, A. L.; Formagio, P. S. (1992). Efeitos da introdução de Cichla ocellaris e Pygocentrus sp. sobre a comunidade de peixes da lagoa Dom Helvécio, MG. Encontro da Associação Mineira de Aquicultura.

Godinho, A. L.; FonseCA, M. T.; ARaúJo, L. M. (1994). "The ecology of predator fish introductions: the case of Rio Doce valley lakes." In: CoelHo, R. M. P.; GiAni, A.; SPERLING, E. V. eds. Ecology and human impact on lakes and reservoirs in Minas Gerais with special reference to future development and management strategies. Belo Horizonte, Segrac., p 77-83.

Godinho, A. L. 1996. Peixes do Parque Estadual do Rio Doce - Belo Horizonte, Instituto Estadual de Florestas / Universidade Federal de Minas Gerais.

Golterman, H. L.; Clymo, R. S.; Ohnstad, M. A. 1978. Methods for physical \& chemical analysis of Fresh Waters. 2nd. Edition. Blackwell Scientific Publications. IBP, n. 8.

GRANÁLI, W.; SOLANDER, D. (1988). Influence of aquatic macrophytes on phosphorus cycling in lakes. Hydrobiologia, vol. 170, p. 245-266.

GÜNTZEL, A. M. (2000). Variações espaço-temporais da comunidade zooplanctônica nos Reservatórios do Médio e Baixo Rio Tietê/Paraná, SP. Tese de Doutorado. Universidade Federal de São Carlos.

HARDY, E. R. (1978). Composição do zooplâncton em cinco lagos da Amazônia Central. Dissertação de Mestrado, Universidade Federal de São Carlos, São Carlos - SP.

HENRY, R.; TUNDISI, J. G. (1985). Enrichment experiments and their effects on phytoplankton (biomass and primary productivity). In: SAIJO, Y.; TUNDISI, J. G. eds. Limnological studies in Central Brazil. Rio Doce Valley Lakes and Pantanal 
wetland, Brazil (1 ${ }^{\text {st }}$ Report). Water Research Institute, Nagoya University, Japan, p. $63-80$.

HenRY, R.; IBAÑES, M. S. R.; TUNDiSI, J. G.; CALIJURI, M. C. (1987). Addition of phosphate and ammonia and its effects on the surface phytoplankton in two lakes of Rio Doce Valley Park. In: SAIJO, Y.; TUNDISI, J. G. eds. Limnological studies in Central Brazil. Rio Doce Valley Lakes and Pantanal wetland, Brazil (2 ${ }^{\text {nd }}$ Report). Water Research Institute, Nagoya University, Japan, p. 61-67.

HENRY, R. e BARBOSA, F. A. R. (1989). Thermal structure, heat content and stability of two lakes in the National Park of Rio Doce Valley (Minas Gerais, Brazil). Hydrobiologia, vol.171, p. 1989-199.

HenRY, R.; Pontes, M. C. F.; TUndisi, J. G. (1989a). O déficit de oxigênio no Lago Dom Helvécio (Parque Florestal do Rio Doce, Minas Gerais). Rev. Brasil. Biol., vol. 49, p. 251-260.

Henry, R.; Tundisi, J. G.; Calijuri, M. C.; Ibañes, M. S. R.; Mitamura, O.; MatsumuraTUNDISI, T.; ROCHA. O.; EsPÍNDOLA, E. L. G.; GUILLEN, S. M. (1989b). Addition of phosphate and ammonia and its effects on primary productivity by phytoplankton in Lake D. Helvécio using large enclosures. In: SAIJO, Y.; TUNDISI, J. G. eds. Limnological studies in Central Brazil. Rio Doce Valley Lakes and Pantanal wetland, Brazil ( $3^{\text {rd }}$ Report). Water Research Institute, Nagoya University, Japan, p. 53-59.

HENRY, R. (1990). Amônia ou fosfato como agente estimulador do crescimento do fitoplâncton na Represa de Jurumirim (Rio Paranapanema, SP)? Rev. Bras. Biol., vol. 50 , n. 4 , p. $883-892$.

HENRY, R. (1995). The Thermal Structure of Some Lakes and Reservoirs in Brazil. In. TUNDISI, J. G.; BICUDO, C. E. M.; MATSUMURA-TUNDISI, T., eds. Limnology in Brazil. Rio de Janeiro. ABC/SLB, p. 351-363. 
HenRY, R.; TUndisi, J. G.; CaliJuRi, M. C.; IBAÑEZ, M. S. R. (1997). A Comparative Study of Thermal Structure, Heat Content and Stability of Stratification in Tree Lakes. In: TUndisi, J. G.; SAIJO, Y., eds. Limnological Studies on the Rio Doce Valley Lakes, Brazil. Brazilian Academy of Sciences. University of São Paulo. School of Engineering at São Carlos. Center for Water Resources and Applied Ecology, p. 69-77.

Hino, K.; TUNDISI, J. G.; ReYNOLDS, C. (1986). Vertical distribuition of phytoplankton in a stratified lake (Lago Dom Helvécio, southeastern Brazil) with special reference to the metalimnion. Japan J. Limnol., vol. 47, n. 3, p. 239-246.

HoRne, A. J.; GoldMAn, C. R. (1994). Limnology. New York, McGraw-Hill, Inc. $2^{\text {nd }}$ edition.

HUTCHINSON, G.E. (1959). A treatise on limnology. Volume I: Lake origins, physics, and chemistry. New York, John Wiley \& Sons.

HUTCHINSON, G. E. (1967). A treatise on limnology. Volume II: Introduction to lake biology and the limnoplankton. New York, John Wiley \& Sons.

IKUSUMA, I.; GENTIL, J. G. (1987). Studies od vegetative growth and productivity of Eichhornia azurea in the Rio Doce valley lakes. In: SAIJO, Y.; TUNDISI, J. G. Limnological studies in Central Brazil: Rio Doce Valley lakes and Pantanal wetland, Brazil. $2^{\text {rd }}$ Report. Water Research Institute, Nagoya University, Japan, p. 89-101.

INFANTE, A. (1982). Annual variations in abundance of zooplankton in Lake Valencia (Venezuela). Arch. Hydrobiol., vol. 93, n. 2, p. 194-208.

IKUSIMA, I; GENTIL, J. G. (1997). Ecological Studies of Aquatic Macrophytes in Four Lakes. In: TUNDISI, J. G.; SAIJO, Y., eds. Limnological Studies on the Rio Doce Valley Lakes, Brazil. Brazilian Academy of Sciences. University of São Paulo. School of Engineering at São Carlos. Center for Water Resources and Applied Ecology, p. 309326.

JAnsson, M.; OlsSON, H.; PetTeRsson, K. (1988). Phosphatases: origin, characteristics and function in lakes. Hydrobiologia, vol. 170, p. 157-175. 
JØRGENSEN, S. E. (1995). Introducción. In: JØrgensen, S. E; Löffler, H. Directrizes para la gestion de lagos. Volumen 3. La Gestion de la Costa del Lago. ILECPNUMA, p. 1-3.

KirA, T.; SAZANAmI, H. (1995). Utilização de recursos hídricos e problemas de gerenciamento de lagos. In: HASHIMOTO, M.; BARRET, B. F. D. Diretrizes para o Gerenciamento de Lagos. ILEC - UNEP, vol. 2, p. 1-5.

KolASA, J.; ZALEWSKI, M. (1995). Notes on ecotone attributes and functions. Hydrobiologia, vol. 303, p. 1-7.

KALINOWSKA, K. (1997). Eutrophication processes in a shallow, macrophyte dominated lake - alkaline phosphatase activity in Lake Luknajno (Poland). Hydrobiologia, vol. 342343 , p. 395-399.

KORINEK, V. (1981). Diaphanosoma birgei n. sp. (Crustacea, Cladocera). A new species from America and its widely distributed subspecies Diaphanosoma birgei spp. lacustris n. spp. Can. J. Zool. vol. 59, n. 6, p. 1115-1121.

KorolefF, F. (1976). Determination of nutrients. In: GrASSHOFF, K., ed., Methods of seawater analysis. Weinhein, Verlag.

KOSTE, W. (1978a). Rotatoria - Die Radertiere Mitt leuropas - I Text band.

KOSTE, W. (1978b). Rotatoria - Die Radertiere Mitt leuropas - II Text band.

KuRATA, A.; KiRA, T. (1995). Aspectos de calidad del agua. In: JØRGENSEN, S. E; LÖFFLER, H. eds. Directrizes para la gestion de lagos. Volumen 3. La Gestion de la Costa del Lago. ILEC-PNUMA, p. 17-33.

LANNA, A. E. L. (1995). Gerenciamento de bacia hidrográfica: aspectos conceituais e metodológicos. Brasília. IBAMA. 
LegendRE, L.; Demmers, S. (1984). Towards dynamic Oceanography and Limnology. Can.

J. Fish Aquat. Sci. vol. 41, p 2-19.

LEMLY, A. D.; DiMMICK, J. F. (1982). Structure and dynamics of zooplankton communities in the littoral zone of some North Carolina lakes. Hydrobiologia, vol. 88, p. 299-307.

lemos, R. C.; Mello Marques, A. F.; Quadros, A. C.; Bellinaso, I. F. (1981). Levantamento Pedológico do Parque Florestal do Rio Doce. In: Programa de pesquisas Ecológicas do Parque Florestas do Rio Doce. Fundação Centro Tecnológico de Minas Gerais. CETEC. Relatório Final, Belo Horizonte, MG.

LIKENS, G. E. (1992). The ecosystem approach: its use and abuse. Ecology Institute. Oldenhorf/Lehe, Germany.

MACKReth, F. J. H.; Heron, J.; TAlling, F. J. (1978). Water analysis: Some revised methods for limnologists. Freshwater Biological Association Scientific Publication. Kendall, Titus Wilson \& Sons LTD, n. 36.

MCNAUGHT, D. C. (1975). A hypotesis to explain the succession from calanoids to cladocerans during eutrophication. Verh. Int. Ver. Limnol., vol. 19, p. 724-731.

MAgurRAN, A. E. (1989). Diversidad Ecológica y su Medición. Barcelona. Ediciones Vedrá.

MANLY, B. F. J. (1986). Multivariate statistical methods. London, CHAPMAN e HALL.

MARGALEF, R. (1983). Limnologia. Barcelona, Ediciones Omega.

MARgalef, R. (1993). Teoria de los sistemas ecológicos. $2^{a}$ ed. Barcelona. Universitat de Barcelona.

MARTENS, K. (1997). Speciation in ancient lakes. Tree, vol. 12, n. 5, p. 177-182.

MATSUMURA-TUNDISI, T. (1984). Ocurence of species of the genus Daphnia in Brazil. Hydrobiologia, vol. 112, p. 161-165. 
MATSUMURA-TUNDISI, T. (1986). Latitudinal distribuition of Calanoida copepods in Freshwater aquatic systems of Brazil. Rev. Brasil. Biol., vol. 46, n. 3, p. 527-553.

MATSUMURA-TUNDISI, T.; TUNDISI., J. G. (1986). Biomass and Zooplankton Community Structure of Three Lakes of River Doce Valley (Minas Gerais-Brasil). The Fifth Japan-Brazil Simposium on Science and Tecnology. Tokyo, Japan.

Matsumura-Tundisi, T.; LeitÃo, S. N.; AguenA, L. S.; MiYAhARA, J. (1990). Eutrofização da Represa de Barra Bonita: estrutura e organização da comunidade de Rotifera. Rev. Brasil. Biol., vol. 50, n. 4, p. 923-935.

MATSUMURA-TUNDISI, T. (1997). Composition and vertical distribution of zooplankton in Lake Helvécio. In: TUNDISI, J. G.; SAIJO, Y., eds. Limnological Studies on the Rio Doce Valley Lakes, Brazil. Brazilian Academy of Sciences. University of São Paulo. School of Engineering at São Carlos. Center for Water Resources and Applied Ecology, p. 265-274.

Matsumura-Tundisi, T.; TUndisi, J. G.; RoCha, O.; Calijuri, M. C. (1997a). The Ecological Significance of the Metalimnion in Lakes of Middle Rio Doce Valley. In: TUNDISI, J. G.; SAIJO, Y., eds. Limnological Studies on the Rio Doce Valley Lakes, Brazil. Brazilian Academy of Sciences. University of São Paulo. School of Engineering at São Carlos. Center for Water Resources and Applied Ecology, p. 373-390.

MATSUMURA-TUNDISI, T.; ROCHA. O.; TUNDISI, J. G. (1997b). Carbon uptake by Scolodiaptomus corderoi and Thermocyclops minutus feeding on different size fractions of phytoplankton from Lake Dom Helvécio. In: TUNDISI, J. G.; SAIJO, Y., eds. Limnological Studies on the Rio Doce Valley Lakes, Brazil. Brazilian Academy of Sciences. University of São Paulo. School of Engineering at São Carlos. Center for Water Resources and Applied Ecology, p. 275-284.

Matsumura-Tundisi, T.; Silva, W. M. (1999). Crustáceos Copépodos Planctônicos. In: Joly, C. A.; BiCUDO, C. E. M. org. Biodiversidade do Estado de São Paulo, Brasil: síntese do conhecimento do final do século $X X, 4$ : invertebrados de água 
doce / Ismael, D.; Valenti, W. C.; Matsumura-Tundisi, T.; Rocha, O. - São Paulo: FAPESP, p. 93-100.

MEIS, M. R. M. (1977). As unidades morfoestratigráficas neoquaternárias do Médio Rio Doce. An. Acad. Brasil. Ciênc., vol. 49, n. 3, p. 443-459.

Meis, M. R. M.; MonTEIRo, A. M. F. (1979). Upper quaternary "rampas": Doce River Valley, southeastern Brazilian plateau. Z. Geomorph, N. F., vol. 23, n. 2, p. 132-151.

MEIS, M. R. M.; TUNDISI, J. G. (1986). Geomorphological and limnological processes as a basin for lake typology: The Middle Rio Doce Lake System; An. Acad. Bras. Ci., vol. 58 , n. 1 , p. $103-120$.

MEIS, M. R. M.; TUNDISI, J. G. (1997). Geomorphological and Limnological Processes as a Basis for Lake Typology. The Middle Rio Doce Lake System. In: TUnDISI, J. G.; SAIJO, Y., eds. Limnological Studies on the Rio Doce Valley Lakes, Brazil. Brazilian Academy of Sciences. University of São Paulo. School of Engineering at São Carlos. Center for Water Resources and Applied Ecology, p. 25-48.

MelLo, C. L. (1997). Sedimentação e tectônica cenozóicas no médio Vale do Rio Doce (MG, sudeste do Brasil) e suas implicações na evolução de um sistema de lagos. São Paulo, SP. Tese de doutoramento. Instituto de Geociências Universidade de São Paulo.

Mitamura, O.; Saijo, Y.; Hino, K.; BarbosA, F. A. R. (1995). The significance of regenerated nitrogen for phytoplankton in the Rio Doce Valley Lakes, Brazil. Arch. Hydrobiol., vol. 134, n. 2, p. 179-194.

MitamuRA, O.; HinO, K. (1997). Distribuition of Biogeochemical Constituents in the Waters. In: TUNDISI, J. G.; SAIJO, Y., eds. Limnological Studies on the Rio Doce Valley Lakes, Brazil. Brazilian Academy of Sciences. University of São Paulo. School of Engineering at São Carlos. Center for Water Resources and Applied Ecology, p. 97108. 
Montú, M.; Goeden, I. M. (1986). Atlas dos Cladocera e Copepoda (Crustacea) do Estuário da Lagoa dos Patos (Rio Grande, Brasil). Nerítica, Pontal do Sul, PR, vol. 1, n. 2, p. 1-34.

NAKAMOto, N.; SAIJO, Y.; TUNDISI, J. G. (1997). Meteolorogical Environment in the Rio Doce Valley. In: TUndisI, J. G.; SAIJO, Y., eds. Limnological Studies on the Rio Doce Valley Lakes, Brazil. Brazilian Academy of Sciences. University of São Paulo. School of Engineering at São Carlos. Center for Water Resources and Applied Ecology, p. 51-66.

NoGUEIRA, M. G. (1996). Composição, abundância e distribuição espaço-temporal das populações planctônicas e das variáveis físico-químicas na Represa de Jurumirim, Rio Paranapanema, SP. Tese de Doutorado. Escola de Engenharia de São Carlos, Universidade de São Paulo.

Nogueira, M. G.; Henry, R.; Maricatto, F. E. (1999). Spatial and temporal heterogeneity in the Jurumirim Reservoir, São Paulo, Brazil. Lakes \& Reservoir: Research and Management, vol. 4, p. 107-120.

NUSCH, E. A. (1980). Comparison of different methods for chlorophyll and phaeopigment determination. Arch. Hydrobiol. Beih. Ergebn. Limnol, vol. 14, p. 14-36.

Odum, E. P. (1988). Ecologia. Rio de Janeiro, Editora Guanabara Koogan S. A.

OKANO, W. Y. (1980). Padrão de migração vertical e flutuação sazonal das principais espécies de Copepoda (Crustacea) do Lago Dom Helvécio, Parque Florestal do Rio Doce, MG. São Carlos, SP. Dissertação de Mestrado. Universidade Federal de São Carlos.

Oliveira-Neto, A. (1993). Estudo da variação da comunidade zooplanctônica, com ênfase na comunidade de rotíferos, em curtos intervalos de tempo (variações diárias e nictemerais) na Represa do Lobo (Broa) - Itirapina, SP. Dissertação de mestrado, Escola de Engenharia de São Carlos, USP - São Carlos. 
Oliveira-Neto, A. L.; Moreno, I. H. (1999). Rotíferos. In: Joly, C. A.; Bicudo, C. E. M. org. Biodiversidade de Estado de São Paulo, Brasil: síntese do conhecimento do final do século XX, 4: invertebrados de água doce / ISMAEL, D.; VAlenti, W. C.; MATSUMURA-TUndisi, T.; RoCHA, O. - São Paulo: FAPESP, p. 41-52.

ORCUTT, J. D.; PACE, M. L. (1984). Seasonal dynamics of rotifer and crustacean zooplankton populations in a eutrophic, monomitic lake with a note on rotifer sampling tecniques. Hydrobiologia, vol. 119, p. 73-80.

PAGGI, J. C. (1978). Revision de las especies argentinas del genero Diaphanosoma Fischer (Crustacea, Cladocera), Acta Zoologica Lilloana, vol. XXXIII, n. 1, p. 43-65.

PAREJKO, K. (1991). Predation by chaoborids on typical and spined Daphnia pulex. Freshwater biology, v. 25, p. 211-217.

PAULA, J. A. 1997. Biodiversidade, população e economia de uma região de mata atlântica. Belo Horizonte. UFMG/Cedeplar.

PAYNE, A. I. (1986). The ecology of tropical rivers and lakes. New York, John Wiley.

PEJLER, B. (1983). Zooplankton indicators of trophy and their food. Hydrobiologia, vol. 101, p. $111-114$.

Pejler, B.; Berzins, B. (1993). On the ecology of Trichocercidae (Rotifera). Hydrobiologia, v. 263, p. 55-59.

PeJLER, B. (1995). Relation to habitat in rotifers. Hydrobiologia, vol. 313-314, p. 267278.

PENNAK, R. W. (1991). Fresh-water invertebrates of the United States - Protozoa to Mollusca. $3^{\text {rd }}$ edition, Wiley-Interscience Publication.

PfLUGG, R. (1969). Quaternaty lakes of eastern Brazil. Photogrametria, vol. 24, p. 2535. 
PIECZYNSKA, E. (1995). Comunidades Y Hábitats del litoral. In: JØrgensen, S. E; Löffler, H. Directrizes para la gestion de lagos. Volumen 3. La Gestion de la Costa del Lago. ILEC-PNUMA, p. 34-63.

POMPEU, P. S. (1995). Efeito da introdução de espécies exóticas na estrutura trófica dos lagos do médio Rio Doce. Belo Horizonte, MG. Relatório. Universidade Federal de Minas Gerais.

Présing, M.; Herodek, S.; Preston, T.; VÖRÖS, L. (2001). Nitrogen uptake and the importance of internal nitrogen loading in Lake Balaton. Freshwater biology, vol. 46 , p. $125-139$.

RebouçAS, A. C. (1999). Água Doce no Mundo e no Brasil. In: RebouçAS, A. C.; Braga, B.; TUndisI, J. G. eds. Águas Doces no Brasil. São Paulo. Escrituras Editora.

REID, J. W. (1985). Chave de identificação e lista de referências bibliográficas para as espécies continentais sulamericanas de vida livre da ordem Cyclopoida (Crustacea, Copepoda). Bol. Zool., vol. 9, p. 17-143.

REID, J. W. (1988). Thermocyclops decipiens (Copepoda Cyclopoida). Exemplo de confusão taxonômica. Acta Limnol. Brasil. vol. 1, p. 479-499.

RESOLUÇÃO N. 20 DO CONAMA (1986). Legislação Federal Brasileira

RiCKLEFS, R. E. (1993). A Economia da Natureza. Rio de Janeiro, Guanabara Koogan S. A.

ROCHA, O.; MATSUMURA-TUNDISI, T. (1976). Atlas do zooplâncton (Represa do Broa, São Carlos) Vol. I - Copepoda. Universidade Federal de São Carlos, Centro de Ciências e Tecnologia. Departamento de Ciências Biológicas.

Rocha, O.; Matsumura-Tundisi, T.; Tundisi, J. G.; Henry, R.; Calijuri, M. C. (1989). Respiration rates of epilimnetic and metalimnetic zooplankton of Lake D. Helvécio during circulation. In: SAIJO, Y.; J. G. TUNDISI. eds. Limnological studies in Rio 
Doce Valley Lakes, Brazil. $2^{\text {nd }}$ Report. Water Research Institute Nagoya University, p. $99-103$.

RochA, O.; MATSUMURA-TUNDISI, T.; TUNDISI, J. G. (1994). Latitudinal Trends of Zooplankton Diversity in the Neotropical Region: Present Knowledge and Future Needs. An. Acad. Brasi. Ci., vol. 66, p. 41-47.

Rocha, O.; Sendacz, S.; Matsumura-Tundisi, T. (1995). Composition, Biomass and Productivity of Zooplankton in Natural Lakes and Reservoirs of Brazil. In: TUNDISI, J. G.; Bicudo, C. E. M.; MATSUmuRA-Tundisi, T. eds. Limnology in Brazil. Rio de Janeiro, $A B C / S B L$.

RoCha, O.; MATSUMURA-TUndisi; T.; SAMPaIO, E. V. (1997). Phytoplankton and zooplankton community structure and production as related to trophic state in some Brazilian lakes and reservoirs. Verh. Internat. Verein. Limnol., vol. 39, p. 1-6.

RoChA, O.; GüntZel, A. (1999). Crustáceos Branquiópodos. In: Joly, C. A.; BiCudo, C. E. M. org. Biodiversidade de Estado de São Paulo, Brasil: síntese do conhecimento do final do século $\mathrm{XX}$, 4: invertebrados de água doce / ISMAEL, D.; VAlenti, W. C.; Matsumura-Tundisi, T.; RochA, O. - São Paulo: FAPESP, p. 109120.

RUTTNER-KolinSKo (1974), A. (1974). Plakton rotifers: biology and taxonomy. Stuttgart, E. Schweizerbart'sche Verlagsbuchhandlung.

SAIJO, Y.; TUNDISI, J. G. (1983). Limnological studies in Central Brazil: Rio Doce Valley lakes and Pantanal wetland, Brazil. $1^{\text {st }}$ Report. Water Research Institute, Nagoya University, Japan.

SAIJO, Y.; TUNDISI, J. G. (1985). Limnological studies in Central Brazil: Rio Doce Valley lakes and Pantanal wetland, Brazil. $2^{\text {nd }}$ Report. Water Research Institute, Nagoya University, Japan. 
SAIJO, Y. \& TUNDISI, J. G. (1987). Limnological studies in Central Brazil: Rio Doce Valley lakes and Pantanal wetland, Brazil. $3^{\text {rd }}$ Report. Water Research Institute, Nagoya University, Japan.

SAlAS, H. J.; MATINO, P. (1988). Memoria del IV Encuentro del Projecto Regional "Desarrollo de Metodologías Simplificadas para la Evaluación de Eutroficación en Lagos Cálidos Tropicales". OPS-CEPIS.

Segers, H.; Dumont, H. J. (1994). 102+ Rotifer species (Rotifera: Monogononta) in Broa reservoir (SP., Brazil) on 26 August 1994, with the description of three new species. Hydrobiologia, vol. 316, p. 183-197.

SEGERS, H. (1995-1996). Introduction to the practice of identifying - Rotifera. Universiteit Gent.

Sendacz, S.; Kubo, E.; Cestarolli, M. A. (1985). Limnologia de reservatórios do sudeste do estado de São Paulo, Brasil. VIII. Zooplâncton. Bol. Inst. Pesca, v. 12, n. 1, p. 187-207.

SETTI, A. A. (1996). A necessidade do uso sustentável dos recursos hídricos. Brasília, IBAMA.

SILVA, V. P. (1980). Variações diurnas de fatores ecológicos em quatro lagos naturais do "Pantanal Matogrossense" e seu estudo comparativo com dois lagos da Amazônia Central e um lago artificial (Represa do Lobo, "Broa", São Carlos, SP). Dissertação de Mestrado. Universidade Federal de São Carlos.

SLADECEK, V. (1983). Rotifers as indicators of water quality. Hydrobiologia, vol. 100, p. 169-201.

STRASKRABA, M.; TUNDISI, J. G. (1999). Reservoir water quality management. Guidelines for lake management. ILEC, vol. 9.

StRickland, J. D.; PARSOnS, T. R. (1960). A manual of sea water analysis. Bull. Fish. Res. Bel. Can., vol. 125, p. 1-185. 
Sunaga, T.; Verani, J. R. (1991). The fish communities of the lakes in Rio Doce Valley, Northeast Brazil. Verh. Internat. Verein. Limnol., vol. 24, p. 2563-2566.

Toledo JR., A. P.; Talarico, M.; Chinez, S. J.; Agudo, E. G. (1983). A aplicação de modelos simplificados para a avaliação do processo da eutrofização em lagos e reservatórios tropicais. $\mathbf{1 2}^{\circ}$ Congresso Brasileiro de Engenharia Sanitária e Ambiental, Camboriú, DENG.

TRINDADE, M. (1984). Lagos: origem, classificação e distribuição geográfica. Departamento de Ciências Biológicas. São Carlos, Universidade Federal de São Carlos.

TUNDISI, J. G.; MATSUMURA-TUNDISI, T. (1981). Estudos Limnológicos no Sistema de Lagos do Médio Rio Doce, MG - Brazil. Anais do II Sem. Regional de Ecologia, p. 133258.

TUNDISI, J. G. (1990). Distribuição espacial, seqüência temporal e ciclo sazonal do fitoplâncton em represas: fatores limitantes e controladores. Rev. Brasil. Biol., vol. 50 , n. 4, p. 937-955.

Tundisi, J. G.; MAtsumura-Tundisi, T.; Pontes, M. C. F.; Gentil, G. (1981). Limnological studies at quaternary lakes in eastern Brazil, I. Primary production of phytoplankton and ecological factors at the lake Dom Helvecio. Rev. Bras. Bot., vol. 4, p. 5-14.

TUNDISI, J. G. (1983). A review of basic ecological processes interacting with production and standig stock of phytoplankton in lakes and reservoirs in Brazil. Hydrobiologia, vol. 100 , p. $223-243$.

TUNDISI, J. G. (1987). A note on the effect of rainfall in the process of stratification and stability in the Rio Doce lakes. In: SAIJO, Y. \& TUNDISI, J. G. Limnological studies in Central Brazil: Rio Doce Valley lakes and Pantanal wetland, Brazil. $2^{\text {rd }}$ Report. Water Research Institute, Nagoya University, Japan, p 21-23. 
TUNDISI, J. G.; BARBOSA, F. A. R. (1995). Conservation of Aquatic Ecosystems: Present Status and Perspectives. In: TUndisI, J. G.; BICUDO, C. E. M.; MATSUMURA-TUndisI, T. eds. Limnology in Brazil. Rio de Janeiro, ABC/SBL.

TUNDISI, J. G. (1997). A Note on the Effect of Rainfall in the Process of Stratification and Stability in the Rio Doce Lakes. In: TUNDISI, J. G.; SAIJO, Y., eds. Limnological Studies on the Rio Doce Valley Lakes, Brazil. Brazilian Academy of Sciences. University of São Paulo. School of Engineering at São Carlos. Center for Water Resources and Applied Ecology, p. 79-81.

TUNDISI, J. G.; SAIJO, Y. (1997). Limnological Studies on the Rio Doce Valley Lakes, Brazil. Brazilian Academy of Sciences. University of São Paulo. School of Engineering at São Carlos. Center for Water Resources and Applied Ecology.

Tundisi, J. G.; SAIJO, Y.; HenRY, R.; NAKAmoto, N. (1997a). Primary Productivity, Phytoplankton Biomass and Light Photosyntesis Responses in Four Lakes. In: TUNDISI, J. G.; SAIJO, Y., eds. Limnological Studies on the Rio Doce Valley Lakes, Brazil. Brazilian Academy of Sciences. University of São Paulo. School of Engineering at São Carlos. Center for Water Resources and Applied Ecology, p. 199-225.

Tundisi, J. G.; MATSUMURA-Tundisi, T.; FukUhara, O.; MitAmura, O.; Rocha, O.; Guillén, S. M.; HenRY, R.; CAliJuRI, M. C.; IBAÑez, M. S. R.; EsPÍndola, E. L. G.; Gonovi, S. (1997b). Limnology on Fifteen Lakes. In: TUNDISI, J. G.; SAIJO, Y., eds. Limnological Studies on the Rio Doce Valley Lakes, Brazil. Brazilian Academy of Sciences. University of São Paulo. School of Engineering at São Carlos. Center for Water Resources and Applied Ecology, p. 409-439.

TUNDISI, J. G.; SAIJO, Y.; SUNAGA, T. (1997c). Ecological Effects of Human Activities in the Middle Rio Doce Lakes. In: TUNDISI, J. G.; SAIJO, Y., eds. Limnological Studies on the Rio Doce Valley Lakes, Brazil. Brazilian Academy of Sciences. University of São Paulo. School of Engineering at São Carlos. Center for Water Resources and Applied Ecology, p. 477-482.

TUNDISI, J. G. (1999). Limnologia no século XXI: perspectivas e desafios. São Carlos, SP. IIE. 
VALDERRAMA, J. G. (1981). The simultaneous analysis of total nitrogen and phosphorus in natural waters. Marine Chemistry, vol. 10, p. 109-122.

VAN DE VeLDE, I. (1984). Revision of the African species of the genus Mesocyclops Sars, 1914 (Copepoda: Cyclopidae). Hydrobiologia, vol. 109, p. 3-66.

VIEIRA, F. (1994). Estrutura da comunidade e aspectos da alimentação e reprodução dos peixes em dois lagos do médio Rio Doce, MG. Belo Horizonte, Universidade Federal de Minas Gerais.

Welcomme, $R$. L. (1988). International introductions of inland aquatic species. FAO Fish. Tec. Pap., vol. 294.

WetZeL, R. G.; LikenS, G. E. (1991). Limnological Analyses. $2^{\text {nd }}$ ed. Springer-Verlag, New York.

Young, P. S. (1999). Catalogue of Crustacea of Brazil. Rio de Janeiro, Museu Nacional, n. 6. 
Anexo 
DADOS LIMNOLÓGICOS

\begin{tabular}{|c|c|c|c|c|c|}
\hline \multicolumn{6}{|c|}{ VALORES DE PROFundidAdE E TRANSPARÊNCIA (m) } \\
\hline \multirow[b]{2}{*}{ Lagoa } & \multirow[b]{2}{*}{ Ponto } & \multirow{2}{*}{$\begin{array}{l}\text { Profundidade } \\
\text { máxima }\end{array}$} & \multicolumn{3}{|c|}{ Transparência } \\
\hline & & & Inverno 1 & Inverno 2 & Verão \\
\hline \multirow{4}{*}{ CARIOCA } & Car-P1 & 9,50 & 1,20 & 0,90 & 1,80 \\
\hline & Car-L1 & 0,75 & 0,75 & 0,75 & 0,75 \\
\hline & Car-L2 & 0,75 & 0,75 & 0,75 & 0,75 \\
\hline & Car-L3 & 0,75 & 0,75 & 0,75 & 0,75 \\
\hline \multirow{6}{*}{ AGUAPÉ } & Agu-P1 & 4,50 & 1,40 & 1,00 & 1,10 \\
\hline & Agu-P2 & 5,00 & 1,40 & 0,80 & 1,50 \\
\hline & Agu-P3 & 4,50 & 1,40 & 1,00 & 1,10 \\
\hline & Agu-L1 & 0,75 & 0,75 & 0,75 & 0,75 \\
\hline & Agu-L2 & 0,75 & 0,75 & 0,75 & 0,75 \\
\hline & Agu-L3 & 0,75 & 0,75 & 0,75 & 0,75 \\
\hline \multirow{5}{*}{ ÁGUAS CLARAS } & $\mathrm{ACl}-\mathrm{P} 1$ & 7,50 & 2,10 & 1,80 & 3,10 \\
\hline & $\mathrm{ACl}-\mathrm{P} 2$ & 8,00 & 2,30 & 1,90 & 3,10 \\
\hline & ACl-L1 & 1,25 & 1,25 & 1,25 & 1,25 \\
\hline & ACl-L2 & 1,25 & 1,25 & 1,25 & 1,25 \\
\hline & $\mathrm{ACl}-\mathrm{L} 3$ & 1,25 & 1,25 & 1,25 & 1,25 \\
\hline \multirow{4}{*}{ ARIRANHA } & Ari-P1 & 5,50 & 1,60 & 1,20 & 1,60 \\
\hline & Ari-L1 & 0,75 & 0,75 & 0,75 & 0,75 \\
\hline & Ari-L2 & 0,75 & 0,75 & 0,75 & 0,75 \\
\hline & Ari-L3 & 0,75 & 0,75 & 0,75 & 0,75 \\
\hline \multirow{2}{*}{ AMARELA } & Ama-P1 & 2,25 & 1,30 & 1,20 & 1,30 \\
\hline & Ama-L1 & 1,25 & 1,25 & 1,25 & 1,25 \\
\hline
\end{tabular}


PERFIS DA TEMPERATURA DA ÁGUA, OXIGÊNIO DISSOLVIDO, PH E CONDUTIVIDADE ELÉTRICA, DA LAGOA CARIOCA

\begin{tabular}{|c|c|c|c|c|c|c|c|c|c|c|c|c|c|}
\hline \multirow[b]{2}{*}{ Ponto } & \multirow{2}{*}{$\begin{array}{l}\text { Prof. } \\
\text { (m) }\end{array}$} & \multicolumn{4}{|c|}{ Inverno 1} & \multicolumn{4}{|c|}{ Inverno 2} & \multicolumn{4}{|c|}{ Verão } \\
\hline & & $\begin{array}{c}\text { Temp. } \\
\left({ }^{\circ} \mathrm{C}\right)\end{array}$ & $\begin{array}{c}\text { O.D. } \\
(\mathrm{mg} / \mathrm{l})\end{array}$ & $\mathrm{pH}$ & $\begin{array}{l}\text { Cond. } \\
(\mu \mathrm{S} / \mathrm{cm})\end{array}$ & $\begin{array}{c}\text { Temp. } \\
\left({ }^{\circ} \mathrm{C}\right)\end{array}$ & $\begin{array}{c}\text { O.D. } \\
(\mathrm{mg} / \mathrm{l})\end{array}$ & $\mathrm{pH}$ & $\begin{array}{l}\text { Cond. } \\
(\mu \mathrm{s} / \mathrm{cm})\end{array}$ & $\begin{array}{c}\text { Temp. } \\
\left({ }^{\circ} \mathrm{C}\right)\end{array}$ & $\begin{array}{c}\text { O.D. } \\
(\mathrm{mg} / \mathrm{l})\end{array}$ & $\mathrm{pH}$ & $\begin{array}{l}\text { Cond. } \\
(\mu \mathrm{S} / \mathrm{cm})\end{array}$ \\
\hline \multirow{19}{*}{ Car-P1 } & 0,00 & 23,40 & 7,43 & 6,48 & 27 & 21,80 & 6,94 & 6,72 & 28 & 30,40 & 7,42 & 6,79 & 23 \\
\hline & 0,50 & 23,30 & 7,37 & 6,58 & 27 & 21,80 & 6,64 & 6,76 & 28 & 30,10 & 6,95 & 6,78 & 23 \\
\hline & 1,00 & 22,80 & 6,51 & 6,45 & 27 & 21,80 & 6,76 & 6,73 & 28 & 29,80 & 6,99 & 6,73 & 23 \\
\hline & 1,50 & 22,30 & 7,07 & 6,53 & 27 & 21,70 & 6,67 & 6,69 & 28 & 29,60 & 7,00 & 6,34 & 23 \\
\hline & 2,00 & 22,20 & 7,07 & 6,44 & 27 & 21,70 & 6,39 & 6,63 & 28 & 29,50 & 6,85 & 5,80 & 23 \\
\hline & 2,50 & 22,20 & 6,71 & 6,37 & 27 & 21,70 & 6,33 & 6,55 & 28 & 29,30 & 6,89 & 5,70 & 23 \\
\hline & 3,00 & 22,20 & 6,40 & 6,09 & 27 & 21,70 & 6,10 & 6,43 & 29 & 28,70 & 6,35 & 5,19 & 23 \\
\hline & 3,50 & 22,10 & 5,63 & 6,06 & 27 & 21,70 & 6,07 & 6,32 & 29 & 28,80 & 6,83 & 5,47 & 23 \\
\hline & 4,00 & 22,10 & 5,36 & 5,88 & 28 & 21,70 & 5,85 & 6,20 & 29 & 28,70 & 6,12 & 5,53 & 23 \\
\hline & 4,50 & 22,10 & 5,45 & 5,93 & 28 & 21,70 & 6,63 & 6,02 & 29 & 28,20 & 3,84 & 5,24 & 22 \\
\hline & 5,00 & 22,00 & 5,56 & 5,83 & 27 & 21,70 & 5,49 & 5,91 & 29 & 27,80 & 3,13 & 5,14 & 21 \\
\hline & 5,50 & 22,00 & 5,29 & 5,80 & 28 & 21,60 & 5,43 & 5,78 & 29 & 26,80 & 0,50 & 4,99 & 21 \\
\hline & 6,00 & 22,00 & 5,72 & 5,77 & 27 & 21,60 & 4,90 & 5,65 & 29 & 25,30 & 0,05 & 5,42 & 63 \\
\hline & 6,50 & 22,00 & 5,25 & 5,72 & 27 & 21,60 & 4,55 & 5,55 & 29 & 24,20 & 0,01 & 5,62 & 84 \\
\hline & 7,00 & 22,00 & 4,89 & 5,67 & 28 & 21,60 & 4,44 & 5,48 & 29 & 23,80 & 0,00 & 5,71 & 90 \\
\hline & 7,50 & 22,00 & 4,17 & 5,59 & 28 & 21,60 & 4,27 & 5,40 & 29 & 23,20 & 0,00 & 5,74 & 93 \\
\hline & 8,00 & 22,00 & 4,26 & 5,54 & 28 & 21,60 & 4,42 & 5,36 & 29 & 23,50 & 0,23 & 5,43 & 95 \\
\hline & 8,50 & 22,00 & 4,14 & 5,51 & 28 & 21,60 & 4,23 & 5,34 & 29 & 23,00 & 0,07 & 5,54 & 103 \\
\hline & 9,00 & 22,00 & 4,31 & 5,47 & 28 & 21,60 & 4,41 & 5,31 & 29 & 22,90 & 0,04 & 5,72 & 104 \\
\hline \multirow{2}{*}{ Car-L1 } & 0,00 & 23,50 & 7,54 & 6,48 & 27 & 21,70 & 5,19 & 6,58 & 29 & 30,80 & 7,25 & 6,77 & 23 \\
\hline & 0,50 & 23,30 & 7,55 & 6,47 & 27 & 21,70 & 5,35 & 6,58 & 29 & 30,70 & 6,93 & 6,67 & 23 \\
\hline \multirow{2}{*}{ Car-L2 } & 0,00 & 23,10 & 6,11 & 6,10 & 27 & 21,30 & 6,09 & 6,48 & 29 & 30,50 & 6,36 & 6,68 & 23 \\
\hline & 0,50 & 22,80 & 5,79 & 6,24 & 27 & 21,60 & 5,51 & 6,51 & 29 & 30,20 & 6,63 & 6,51 & 23 \\
\hline \multirow{2}{*}{ Car-L3 } & 0,00 & 23,30 & 6,47 & 6,42 & 27 & 21,40 & 5,54 & 6,63 & 29 & 30,70 & 6,50 & 6,69 & 23 \\
\hline & 0,50 & 23,10 & 6,31 & 6,42 & 27 & 21,20 & 5,83 & 6,59 & 28 & 30,70 & 6,33 & 6,78 & 23 \\
\hline
\end{tabular}


PeRFIS DA TEMPERATURA DA ÁGUA, OXIGÊNIO DISSOLVIDO, PH E CONDUTIVIDADE ELÉTRICA, DA LAGOA AGUAPÉ

\begin{tabular}{|c|c|c|c|c|c|c|c|c|c|c|c|c|c|}
\hline \multirow[b]{2}{*}{ Ponto } & \multirow[b]{2}{*}{$\begin{array}{l}\text { Prof. } \\
(\mathrm{m})\end{array}$} & \multicolumn{4}{|c|}{ Inverno 1} & \multicolumn{4}{|c|}{ Inverno 2} & \multicolumn{4}{|c|}{ Verão } \\
\hline & & $\begin{array}{l}\text { Temp. } \\
\left({ }^{\circ} \mathrm{C}\right)\end{array}$ & $\begin{array}{c}\text { O.D. } \\
(\mathrm{mg} / \mathrm{l})\end{array}$ & $\mathrm{pH}$ & $\begin{array}{l}\text { Cond. } \\
(\mu \mathrm{S} / \mathrm{cm})\end{array}$ & $\begin{array}{c}\text { Temp. } \\
\left({ }^{\circ} \mathrm{C}\right)\end{array}$ & $\begin{array}{l}\text { O.D. } \\
(\mathrm{mg} / \mathrm{l})\end{array}$ & $\mathrm{pH}$ & $\begin{array}{l}\text { Cond. } \\
(\mu \mathrm{s} / \mathrm{cm})\end{array}$ & \begin{tabular}{|c|} 
Temp. \\
$\left({ }^{\circ} \mathrm{C}\right)$
\end{tabular} & $\begin{array}{c}\text { O.D. } \\
(\mathrm{mg} / \mathrm{l})\end{array}$ & $\mathrm{pH}$ & $\begin{array}{l}\text { Cond. } \\
(\mu \mathrm{S} / \mathrm{cm})\end{array}$ \\
\hline \multirow{9}{*}{ Agu-P1 } & 0,00 & 23,00 & 7,42 & 6,65 & 38 & 24,00 & 7,39 & 7,23 & 39 & 29,40 & 7,68 & 7,02 & 38 \\
\hline & 0,50 & 23,00 & 7,30 & 6,64 & 38 & 23,90 & 7,72 & 7,20 & 39 & 29,40 & 7,34 & 7,04 & 38 \\
\hline & 1,00 & 23,00 & 7,25 & 6,61 & 38 & 23,60 & 7,11 & 7,26 & 39 & 29,50 & 7,49 & 6,99 & 38 \\
\hline & 1,50 & 22,90 & 6,87 & 6,68 & 38 & 23,50 & 7,39 & 7,26 & 39 & 29,40 & 7,41 & 6,97 & 38 \\
\hline & 2,00 & 22,80 & 6,89 & 6,53 & 38 & 23,20 & 7,21 & 7,24 & 39 & 29,40 & 7,51 & 6,75 & 38 \\
\hline & 2,50 & 22,80 & 5,98 & 6,37 & 38 & 22,90 & 7,96 & 7,10 & 39 & 29,10 & 6,69 & 6,03 & 38 \\
\hline & 3,00 & 22,80 & 6,08 & 6,22 & 38 & 22,80 & 6,86 & 6,95 & 39 & 28,80 & 6,46 & 5,73 & 38 \\
\hline & 3,50 & 22,70 & 5,76 & 6,11 & 38 & 22,60 & 6,56 & 6,81 & 39 & 28,50 & 5,44 & 5,61 & 38 \\
\hline & 4,00 & 22,70 & 4,84 & 5,91 & 39 & 22,60 & 6,04 & 6,57 & 42 & 28,30 & 1,94 & 5,43 & 40 \\
\hline \multirow{10}{*}{ Agu-P2 } & 0,00 & 22,60 & 7,37 & 6,53 & 39 & 23,50 & 7,75 & 7,37 & 39 & 29,40 & 7,96 & 7,20 & 38 \\
\hline & 0,50 & 22,70 & 7,07 & 6,54 & 39 & 23,50 & 7,94 & 7,37 & 39 & 29,40 & 7,86 & 7,17 & 38 \\
\hline & 1,00 & 22,70 & 7,35 & 6,60 & 38 & 23,10 & 7,51 & 7,39 & 39 & 29,40 & 7,57 & 7,14 & 38 \\
\hline & 1,50 & 22,70 & 7,13 & 6,50 & 38 & 22,70 & 7,72 & 7,40 & 39 & 29,40 & 7,70 & 7,16 & 38 \\
\hline & 2,00 & 22,70 & 7,04 & 6,44 & 38 & 22,60 & 7,78 & 7,28 & 39 & 29,30 & 7,79 & 7,04 & 38 \\
\hline & 2,50 & 22,60 & 7,12 & 6,33 & 39 & 22,50 & 7,83 & 7,19 & 39 & 29,30 & 7,64 & 6,44 & 38 \\
\hline & 3,00 & 22,60 & 7,05 & 6,19 & 38 & 22,50 & 7,26 & 7,02 & 39 & 28,70 & 6,22 & 6,01 & 38 \\
\hline & 3,50 & 22,60 & 6,20 & 6,11 & 38 & 22,50 & 7,07 & 6,85 & 39 & 28,40 & 5,11 & 5,71 & 38 \\
\hline & 4,00 & 22,60 & 6,15 & 6,00 & 39 & 22,40 & 7,18 & 6,70 & 40 & 28,30 & 3,30 & 5,54 & 38 \\
\hline & 4,50 & 22,60 & 6,00 & 5,91 & 38 & 22,40 & 6,56 & 6,35 & 45 & 28,20 & 0,95 & 5,23 & 39 \\
\hline \multirow{9}{*}{ Agu-P3 } & 0,00 & 23,00 & 7,91 & 6,95 & 38 & 23,60 & 8,20 & 7,60 & 39 & 29,10 & 7,53 & 6,74 & 38 \\
\hline & 0,50 & 23,00 & 7,73 & 6,89 & 38 & 23,40 & 7,69 & 7,66 & 40 & 29,10 & 7,71 & 6,78 & 38 \\
\hline & 1,00 & 22,80 & 7,57 & 6,79 & 38 & 23,00 & 7,71 & 7,71 & 40 & 29,10 & 7,86 & 6,50 & 38 \\
\hline & 1,50 & 22,70 & 7,89 & 6,71 & 38 & 22,80 & 8,04 & 7,82 & 40 & 29,20 & 7,59 & 6,19 & 38 \\
\hline & 2,00 & 22,70 & 7,70 & 6,77 & 38 & 22,80 & 7,83 & 7,81 & 39 & 29,20 & 7,66 & 6,13 & 38 \\
\hline & 2,50 & 22,60 & 7,34 & 6,55 & 38 & 22,60 & 7,53 & 7,67 & 39 & 29,20 & 7,62 & 6,09 & 38 \\
\hline & 3,00 & 22,60 & 7,07 & 6,48 & 38 & 22,50 & 7,43 & 7,48 & 40 & 28,70 & 6,93 & 6,01 & 38 \\
\hline & 3,50 & 22,50 & 6,70 & 6,28 & 38 & 22,50 & 7,54 & 7,29 & 40 & 28,50 & 5,73 & 5,85 & 38 \\
\hline & 4,00 & 22,50 & 6,12 & 6,19 & 38 & 22,50 & 7,30 & 6,70 & 41 & 28,30 & 4,53 & 5,68 & 38 \\
\hline \multirow[b]{2}{*}{ Agu-L1 } & 0,00 & 22,70 & 5,20 & 6,45 & 39 & 23,50 & 7,49 & 7,27 & 39 & 29,20 & 6,07 & 6,79 & 38 \\
\hline & 0,50 & 22,70 & 4,92 & 6,33 & 39 & 23,30 & 7,13 & 7,29 & 39 & 29,20 & 5,87 & 6,61 & 38 \\
\hline \multirow{2}{*}{ Agu-L2 } & 0,00 & 23,10 & 7,36 & 6,71 & 38 & 23,50 & 7,62 & 7,14 & 39 & 29,40 & 7,43 & 7,07 & 38 \\
\hline & 0,50 & 23,10 & 7,14 & 6,70 & 38 & 23,40 & 7,04 & 7,15 & 39 & 29,40 & 6,78 & 7,08 & 38 \\
\hline \multirow{2}{*}{ Agu-L3 } & 0,00 & 22,70 & 6,85 & 6,79 & 38 & 25,10 & 7,68 & 7,41 & 39 & 29,20 & 7,08 & 6,97 & 37 \\
\hline & 0,50 & 22,60 & 6,06 & 6,55 & 38 & 24,20 & 7,98 & 7,47 & 39 & 29,20 & 6,89 & 7,00 & 38 \\
\hline
\end{tabular}


Perfis da temperatura da ÁGUA, OXIGÊNIO DISSOLVIDO, PH E CONDUTIVIDADE ELÉTRICA, DA LAGOA ÁGUAS CLARAS

\begin{tabular}{|c|c|c|c|c|c|c|c|c|c|c|c|c|c|}
\hline \multirow[b]{2}{*}{ Ponto } & \multirow{2}{*}{$\begin{array}{l}\text { Prof. } \\
\text { (m) }\end{array}$} & \multicolumn{4}{|c|}{ Inverno 1} & \multicolumn{4}{|c|}{ Inverno 2} & \multicolumn{4}{|c|}{ Verão } \\
\hline & & $\begin{array}{c}\text { Temp. } \\
\left({ }^{\circ} \mathrm{C}\right)\end{array}$ & $\begin{array}{l}\text { O.D. } \\
(\mathrm{mg} / \mathrm{l})\end{array}$ & $\mathrm{pH}$ & $\begin{array}{l}\text { Cond. } \\
(\mu \mathrm{s} / \mathrm{cm})\end{array}$ & $\begin{array}{l}\text { Temp. } \\
\left({ }^{\circ} \mathrm{C}\right)\end{array}$ & $\begin{array}{c}\text { O.D. } \\
(\mathrm{mg} / \mathrm{l})\end{array}$ & $\mathrm{pH}$ & $\begin{array}{l}\text { Cond. } \\
(\mu \mathrm{S} / \mathrm{cm})\end{array}$ & $\begin{array}{c}\text { Temp. } \\
\left({ }^{\circ} \mathrm{C}\right)\end{array}$ & $\begin{array}{l}\text { O.D. } \\
(\mathrm{mg} / \mathrm{l})\end{array}$ & $\mathrm{pH}$ & $\begin{array}{l}\text { Cond. } \\
(\mu \mathrm{s} / \mathrm{cm})\end{array}$ \\
\hline \multirow{15}{*}{ ACl-P1 } & 0,00 & 24,10 & 8,55 & 6,94 & 41 & 24,80 & 7,38 & 6,86 & 40 & 29,50 & 7,56 & 7,03 & 34 \\
\hline & 0,50 & 24,10 & 8,45 & 6,93 & 41 & 24,70 & 7,58 & 6,80 & 40 & 29,50 & 7,41 & 7,07 & 34 \\
\hline & 1,00 & 24,10 & 8,52 & 7,01 & 41 & 24,40 & 7,44 & 6,81 & 40 & 29,50 & 7,63 & 7,03 & 34 \\
\hline & 1,50 & 24,00 & 8,58 & 6,91 & 41 & 23,70 & 7,30 & 6,81 & 40 & 29,40 & 7,41 & 7,01 & 34 \\
\hline & 2,00 & 23,80 & 8,56 & 6,93 & 41 & 23,40 & 7,18 & 6,79 & 40 & 29,40 & 7,51 & 6,70 & 34 \\
\hline & 2,50 & 23,60 & 8,44 & 6,83 & 41 & 23,20 & 5,57 & 6,53 & 40 & 29,30 & 7,40 & 6,15 & 34 \\
\hline & 3,00 & 23,60 & 7,98 & 6,67 & 41 & 23,10 & 5,31 & 6,41 & 40 & 29,30 & 7,25 & 5,94 & 34 \\
\hline & 3,50 & 23,50 & 7,34 & 6,40 & 41 & 23,10 & 5,28 & 6,37 & 40 & 29,30 & 6,85 & 5,88 & 34 \\
\hline & 4,00 & 23,50 & 7,09 & 6,27 & 41 & 23,00 & 4,69 & 6,31 & 41 & 29,10 & 6,59 & 5,84 & 35 \\
\hline & 4,50 & 23,40 & 7,06 & 6,13 & 41 & 23,00 & 4,73 & 6,20 & 41 & 29,10 & 6,13 & 5,75 & 34 \\
\hline & 5,00 & 23,40 & 6,96 & 6,04 & 41 & 23,00 & 4,79 & 6,11 & 40 & 29,00 & 6,30 & 5,76 & 35 \\
\hline & 5,50 & 23,40 & 7,19 & 6,00 & 41 & 23,00 & 4,38 & 6,01 & 41 & 28,90 & 5,69 & 5,82 & 35 \\
\hline & 6,00 & 23,40 & 7,18 & 5,98 & 41 & 22,90 & 5,06 & 5,93 & 40 & 28,70 & 4,14 & 5,64 & 35 \\
\hline & 6,50 & 23,40 & 6,99 & 5,95 & 41 & 22,90 & 5,43 & 5,88 & 40 & 28,50 & 1,97 & 5,42 & 35 \\
\hline & 7,00 & 23,30 & 6,55 & 5,87 & 41 & 22,90 & 4,96 & 5,85 & 38 & 28,00 & 0,26 & 5,40 & 44 \\
\hline \multirow{16}{*}{ ACl-P2 } & 0,00 & 24,30 & 8,51 & 6,99 & 41 & 24,80 & 7,44 & 6,90 & 40 & 29,40 & 7,13 & 7,73 & 34 \\
\hline & 0,50 & 24,30 & 8,43 & 6,99 & 41 & 24,70 & 7,34 & 6,85 & 40 & 29,40 & 7,09 & 7,06 & 34 \\
\hline & 1,00 & 24,20 & 8,52 & 7,01 & 41 & 24,40 & 7,37 & 6,82 & 40 & 29,40 & 6,98 & 7,04 & 34 \\
\hline & 1,50 & 23,70 & 8,47 & 7,01 & 41 & 23,50 & 7,35 & 6,81 & 40 & 29,30 & 6,98 & 6,85 & 34 \\
\hline & 2,00 & 23,50 & 8,21 & 6,94 & 41 & 23,40 & 7,08 & 6,76 & 40 & 29,30 & 6,95 & 6,23 & 34 \\
\hline & 2,50 & 23,50 & 8,37 & 6,70 & 41 & 23,20 & 7,63 & 6,73 & 40 & 29,20 & 7,38 & 6,11 & 35 \\
\hline & 3,00 & 23,50 & 7,78 & 6,68 & 41 & 23,10 & 7,14 & 6,65 & 40 & 29,20 & 7,19 & 6,20 & 34 \\
\hline & 3,50 & 23,40 & 7,52 & 6,61 & 41 & 23,10 & 7,14 & 6,55 & 40 & 29,50 & 7,33 & 6,16 & 34 \\
\hline & 4,00 & 23,40 & 7,20 & 6,42 & 41 & 23,10 & 7,15 & 6,43 & 40 & 29,20 & 7,03 & 6,14 & 34 \\
\hline & 4,50 & 23,40 & 7,37 & 6,27 & 41 & 23,10 & 6,97 & 6,30 & 40 & 29,20 & 6,96 & 7,12 & 34 \\
\hline & 5,00 & 23,40 & 8,06 & 6,27 & 41 & 23,00 & 6,98 & 6,15 & 40 & 29,00 & 6,37 & 6,12 & 35 \\
\hline & 5,50 & 23,40 & 7,70 & 6,25 & 41 & 23,00 & 6,86 & 6,03 & 40 & 28,80 & 5,56 & 5,96 & 35 \\
\hline & 6,00 & 23,40 & 7,32 & 6,14 & 41 & 23,00 & 6,65 & 5,93 & 40 & 28,70 & 4,73 & 5,62 & 35 \\
\hline & 6,50 & 23,40 & 7,21 & 6,06 & 41 & 22,90 & 6,64 & 5,85 & 40 & 28,60 & 3,34 & 5,46 & 35 \\
\hline & 7,00 & 23,30 & 7,03 & 6,03 & 41 & 23,00 & 6,33 & 5,79 & 40 & 27,90 & 0,11 & 5,16 & 37 \\
\hline & 7,50 & 23,30 & 6,72 & 5,98 & 41 & 22,90 & 6,40 & 5,75 & 40 & 27,40 & 0,05 & 5,27 & 46 \\
\hline \multirow{3}{*}{ ACl-L1 } & 0,00 & 24,40 & 8,41 & 6,98 & 41 & 25,90 & 7,48 & 7,04 & 40 & 29,60 & 6,71 & 7,50 & 38 \\
\hline & 0,50 & 24,20 & 8,32 & 7,00 & 41 & 25,70 & 7,14 & 6,96 & 40 & 29,60 & 7,24 & 7,32 & 35 \\
\hline & 1,00 & 23,90 & 7,75 & 6,84 & 41 & 24,70 & 6,48 & 6,81 & 40 & 29,20 & 5,63 & 7,13 & 34 \\
\hline \multirow{3}{*}{ ACl-L2 } & 0,00 & 24,80 & 8,14 & 7,33 & 41 & 25,30 & 7,30 & 6,84 & 40 & 29,20 & 6,73 & 7,03 & 37 \\
\hline & 0,50 & 24,10 & 8,55 & 7,17 & 41 & 25,30 & 6,74 & 6,80 & 40 & 29,50 & 7,04 & 7,16 & 35 \\
\hline & 1,00 & 23,90 & 8,29 & 7,05 & 41 & 24,30 & 7,85 & 6,85 & 40 & 29,50 & 6,84 & 6,82 & 34 \\
\hline \multirow{3}{*}{ ACl-L3 } & 0,00 & 24,30 & 8,69 & 7,27 & 41 & 24,50 & 7,55 & 6,95 & 40 & 29,40 & 7,13 & 7,26 & 34 \\
\hline & 0,50 & 24,00 & 8,39 & 7,23 & 41 & 23,80 & 7,35 & 6,87 & 40 & 29,50 & 7,07 & 7,03 & 34 \\
\hline & 1,00 & 23,70 & 8,22 & 7,00 & 40 & 23,50 & 7,47 & 6,90 & 40 & 29,50 & 6,93 & 7,23 & 34 \\
\hline
\end{tabular}


PeRFIS DA TEMPERATURA DA ÁGUA, OXIGÊNIO DISSOLVIDO, PH E CONDUTIVIDADE ELÉTRICA, DA LAGOA ARIRANHA

\begin{tabular}{|c|c|c|c|c|c|c|c|c|c|c|c|c|c|}
\hline \multirow[b]{2}{*}{ Ponto } & \multirow[b]{2}{*}{$\begin{array}{l}\text { Prof. } \\
\text { (m) }\end{array}$} & \multicolumn{4}{|c|}{ Inverno 1} & \multicolumn{4}{|c|}{ Inverno 2} & \multicolumn{4}{|c|}{ Verão } \\
\hline & & $\begin{array}{c}\text { Temp. } \\
\left({ }^{\circ} \mathrm{C}\right)\end{array}$ & $\begin{array}{l}\text { O.D. } \\
(\mathrm{mg} / \mathrm{l})\end{array}$ & $\mathrm{pH}$ & $\begin{array}{l}\text { Cond. } \\
(\mu \mathrm{s} / \mathrm{cm})\end{array}$ & $\begin{array}{c}\text { Temp. } \\
\left({ }^{\circ} \mathrm{C}\right)\end{array}$ & $\begin{array}{c}\text { O.D. } \\
(\mathrm{mg} / \mathrm{l})\end{array}$ & $\mathrm{pH}$ & $\begin{array}{l}\text { Cond. } \\
(\mu \mathrm{s} / \mathrm{cm})\end{array}$ & $\begin{array}{c}\text { Temp. } \\
\left({ }^{\circ} \mathrm{C}\right)\end{array}$ & $\begin{array}{l}\text { O.D. } \\
(\mathrm{mg} / \mathrm{l})\end{array}$ & $\mathrm{pH}$ & $\begin{array}{l}\text { Cond. } \\
(\mu \mathrm{s} / \mathrm{cm})\end{array}$ \\
\hline \multirow{11}{*}{ Ari-P1 } & 0,00 & 22,90 & 6,89 & 6,37 & 26 & 23,50 & 8,34 & 7,06 & 26 & 28,90 & 7,77 & 7,57 & 23 \\
\hline & 0,50 & 22,90 & 6,40 & 6,40 & 26 & 23,40 & 8,24 & 7,08 & 27 & 28,90 & 7,75 & 7,16 & 23 \\
\hline & 1,00 & 22,90 & 6,76 & 6,50 & 26 & 23,30 & 8,23 & 7,09 & 27 & 29,00 & 7,41 & 7,32 & 23 \\
\hline & 1,50 & 22,90 & 6,68 & 6,29 & 26 & 23,10 & 8,36 & 7,08 & 27 & 29,00 & 7,66 & 7,08 & 23 \\
\hline & 2,00 & 22,90 & 6,64 & 6,35 & 26 & 22,90 & 8,36 & 7,10 & 27 & 29,00 & 7,64 & 6,52 & 23 \\
\hline & 2,50 & 23,00 & 6,21 & 6,32 & 26 & 22,80 & 7,69 & 7,06 & 27 & 29,00 & 7,47 & 6,31 & 23 \\
\hline & 3,00 & 22,90 & 5,97 & 6,33 & 26 & 22,70 & 7,17 & 6,88 & 27 & 29,00 & 7,48 & 6,25 & 23 \\
\hline & 3,50 & 22,90 & 5,34 & 6,20 & 26 & 22,70 & 6,98 & 6,72 & 27 & 28,90 & 7,29 & 5,84 & 23 \\
\hline & 4,00 & 22,90 & 5,80 & 6,12 & 26 & 22,60 & 7,04 & 6,61 & 27 & 28,70 & 6,67 & 5,80 & 23 \\
\hline & 4,50 & 22,90 & 5,55 & 6,13 & 26 & 22,60 & 7,23 & 6,48 & 27 & 28,50 & 5,60 & 5,81 & 23 \\
\hline & 5,00 & 22,90 & 5,36 & 6,02 & 26 & 22,60 & 6,98 & 6,42 & 27 & 28,30 & 3,49 & 5,72 & 24 \\
\hline \multirow{2}{*}{ Ari-L1 } & 0,00 & 22,90 & 6,52 & 6,27 & 26 & 24,40 & 7,69 & 6,95 & 26 & 28,90 & 6,47 & 7,09 & 24 \\
\hline & 0,50 & 22,90 & 6,12 & 6,41 & 26 & 24,00 & 7,64 & 6,92 & 27 & 29,00 & 6,69 & 6,95 & 23 \\
\hline \multirow{2}{*}{ Ari-L2 } & 0,00 & 22,30 & 4,92 & 5,97 & 27 & 23,00 & 7,28 & 6,97 & 26 & 28,80 & 7,18 & 6,90 & 23 \\
\hline & 0,50 & 22,30 & 4,58 & 6,00 & 27 & 22,90 & 7,57 & 6,84 & 26 & 28,80 & 7,14 & 6,95 & 23 \\
\hline \multirow{2}{*}{ Ari-L3 } & 0,00 & 22,80 & 2,69 & 6,16 & 27 & 24,00 & 7,54 & 6,85 & 27 & 28,60 & 7,31 & 7,06 & 24 \\
\hline & 0,50 & 22,90 & 1,97 & 5,96 & 28 & 23,60 & 7,62 & 6,84 & 27 & 28,60 & 6,85 & 6,98 & 23 \\
\hline
\end{tabular}

PeRFIS DA TEMPERATURA DA ÁGUA, OXIGÊNIO DISSOLVIDO, PH E CONDUTIVIDADE ELÉTRICA, DA LAGOA AMARELA

\begin{tabular}{|c|c|c|c|c|c|c|c|c|c|c|c|c|c|}
\hline \multirow[b]{2}{*}{ Ponto } & \multirow[b]{2}{*}{$\begin{array}{l}\text { Prof. } \\
\text { (m) }\end{array}$} & \multicolumn{4}{|c|}{ Inverno 1} & \multicolumn{4}{|c|}{ Inverno 2} & \multicolumn{4}{|c|}{ Verão } \\
\hline & & $\begin{array}{l}\text { Temp. } \\
\left({ }^{\circ} \mathrm{C}\right)\end{array}$ & $\begin{array}{l}\text { O.D. } \\
(\mathrm{mg} / \mathrm{l}\end{array}$ & $\mathrm{pH}$ & $\begin{array}{l}\text { Cond. } \\
(\mu \mathrm{S} / \mathrm{cm})\end{array}$ & $\begin{array}{c}\text { Temp. } \\
\left({ }^{\circ} \mathrm{C}\right)\end{array}$ & $\begin{array}{l}\text { O.D. } \\
(\mathrm{mg} / \mathrm{l})\end{array}$ & $\mathrm{pH}$ & $\begin{array}{l}\text { Cond. } \\
(\mu \mathrm{S} / \mathrm{cm})\end{array}$ & $\begin{array}{c}\text { Temp. } \\
\left({ }^{\circ} \mathrm{C}\right)\end{array}$ & $\begin{array}{c}\text { O.D. } \\
(\mathrm{mg} / \mathrm{l})\end{array}$ & $\mathrm{pH}$ & $\begin{array}{l}\text { Cond. } \\
(\mu \mathrm{s} / \mathrm{cm}\end{array}$ \\
\hline \multirow{5}{*}{ Ama-P1 } & 0,00 & 22,30 & 5,04 & 6,47 & 67 & 19,70 & 4,26 & 6,55 & 61 & 26,80 & 4,54 & 6,74 & 61 \\
\hline & 0,50 & 20,90 & 3,92 & 6,46 & 67 & 19,70 & 4,17 & 6,55 & 61 & 26,80 & 4,52 & 6,38 & 60 \\
\hline & 1,00 & 20,50 & 1,82 & 6,31 & 67 & 19,60 & 3,91 & 6,53 & 61 & 26,70 & 3,94 & 6,29 & 63 \\
\hline & 1,50 & 20,20 & 0,31 & 6,21 & 70 & 19,40 & 2,71 & 6,47 & 61 & 25,90 & 0,28 & 5,74 & 85 \\
\hline & 2,00 & 20,10 & 0,16 & 6,16 & 72 & 19,30 & 2,68 & 6,43 & 62 & 25,40 & 0,08 & 5,64 & 109 \\
\hline \multirow{3}{*}{ Ama-L1 } & 0,00 & 26,80 & 3,47 & 6,85 & 59 & 22,30 & 5,69 & 6,31 & 57 & 19,00 & 3,25 & 6,35 & 63 \\
\hline & 0,50 & 26,90 & 6,55 & 6,80 & 59 & 21,20 & 5,02 & 6,23 & 56 & 19,00 & 3,24 & 6,37 & 62 \\
\hline & 1,00 & 26,90 & 6,40 & 6,52 & 59 & 20,90 & 4,67 & 6,30 & 57 & 18,90 & 3,57 & 6,39 & 61 \\
\hline
\end{tabular}




\begin{tabular}{|c|c|c|c|c|}
\hline \multicolumn{5}{|c|}{ VALORES DE NITRITO ( $\mathrm{ug} / \mathrm{L})$} \\
\hline \multirow[b]{2}{*}{ Lagoa } & \multirow[b]{2}{*}{ Ponto } & \multicolumn{3}{|c|}{ Período de amostragem } \\
\hline & & Inverno 1 & Inverno 2 & Verão \\
\hline \multirow{4}{*}{ CARIOCA } & Car-P1 & 2,63 & 1,32 & 1,01 \\
\hline & Car-L1 & 1,29 & 0,93 & 0,70 \\
\hline & Car-L2 & 2,80 & 0,84 & 1,10 \\
\hline & Car-L3 & 0,98 & 1,44 & 1,27 \\
\hline \multirow{6}{*}{ AGUAPÉ } & Agu-P1 & 1,66 & 0,24 & 1,58 \\
\hline & Agu-P2 & 0,75 & 0,24 & 1,10 \\
\hline & Agu-P3 & 1,15 & 0,41 & 2,57 \\
\hline & Agu-L1 & 0,98 & 0,87 & 2,46 \\
\hline & Agu-L2 & 0,93 & 0,41 & 1,66 \\
\hline & Agu-L3 & 0,93 & 0,24 & 2,46 \\
\hline \multirow{5}{*}{ Águas Claras } & $\mathrm{ACl}-\mathrm{P} 1$ & 1,38 & 0,41 & 1,86 \\
\hline & $\mathrm{ACl}-\mathrm{P} 2$ & 1,07 & 1,32 & 1,01 \\
\hline & ACl-L1 & 1,44 & 0,87 & 1,61 \\
\hline & $\mathrm{ACl}-\mathrm{L} 2$ & 1,01 & 0,93 & 1,38 \\
\hline & $\mathrm{ACl}-\mathrm{L3}$ & 1,44 & 0,53 & 1,21 \\
\hline \multirow{4}{*}{ ARIRANHA } & Ari-P1 & 1,21 & 0,87 & 2,23 \\
\hline & Ari-L1 & 1,49 & 2,80 & 1,63 \\
\hline & Ari-L2 & 1,41 & 0,58 & 0,73 \\
\hline & Ari-L3 & 1,46 & 0,58 & 1,15 \\
\hline \multirow{2}{*}{ AMARELA } & Ama-P1 & 0,61 & 2,06 & 2,03 \\
\hline & Ama-L1 & 1,27 & 2,63 & 1,27 \\
\hline
\end{tabular}

\begin{tabular}{|c|c|c|c|c|}
\hline \multicolumn{5}{|c|}{ VALORES DE NITRATO ( $\mathrm{ug} / \mathrm{L})$} \\
\hline \multirow[b]{2}{*}{ Lagoa } & \multirow[b]{2}{*}{ Ponto } & \multicolumn{3}{|c|}{ Período de amostragem } \\
\hline & & Inverno 1 & Inverno 2 & Verão \\
\hline \multirow{4}{*}{ CARIOCA } & Car-P1 & 40,31 & 23,07 & 9,38 \\
\hline & Car-L1 & 12,92 & 21,18 & 10,08 \\
\hline & Car-L2 & 18,82 & 8,43 & 10,08 \\
\hline & Car-L3 & 15,99 & 20,95 & 11,03 \\
\hline \multirow{6}{*}{ AGUAPÉ } & Agu-P1 & 6,07 & 7,02 & 8,20 \\
\hline & Agu-P2 & 10,32 & 8,43 & 7,49 \\
\hline & Agu-P3 & 13,63 & 7,02 & 8,90 \\
\hline & Agu-L1 & 13,86 & 28,27 & 8,43 \\
\hline & Agu-L2 & 10,32 & 7,49 & 9,85 \\
\hline & Agu-L3 & 13,15 & 7,02 & 9,14 \\
\hline \multirow{5}{*}{ ÁGUAS CLARAS } & $\mathrm{ACl}-\mathrm{P} 1$ & 10,56 & 8,90 & 10,79 \\
\hline & $\mathrm{ACl}-\mathrm{P} 2$ & 15,75 & 16,46 & 9,38 \\
\hline & ACl-L1 & 11,50 & 21,18 & 11,74 \\
\hline & $\mathrm{ACl}-\mathrm{L} 2$ & 14,10 & 15,52 & 16,22 \\
\hline & $\mathrm{ACl}-\mathrm{L} 3$ & 13,63 & 9,85 & 8,90 \\
\hline \multirow{4}{*}{ ARIRANHA } & Ari-P1 & 15,04 & 11,74 & 10,08 \\
\hline & Ari-L1 & 12,92 & 13,15 & 8,90 \\
\hline & Ari-L2 & 13,63 & 8,90 & 7,25 \\
\hline & Ari-L3 & 12,68 & 7,96 & 9,38 \\
\hline \multirow{2}{*}{ AMARELA } & Ama-P1 & 7,72 & 8,90 & 10,08 \\
\hline & Ama-L1 & 9,14 & 11,27 & 8,90 \\
\hline
\end{tabular}




\begin{tabular}{|c|c|c|c|c|}
\hline \multicolumn{5}{|c|}{ VALORES DE AMÔNIO (ug/L) } \\
\hline \multirow[b]{2}{*}{ Lagoa } & \multirow[b]{2}{*}{ Ponto } & \multicolumn{3}{|c|}{ Período de amostragem } \\
\hline & & Inverno 1 & Inverno 2 & Verão \\
\hline \multirow{4}{*}{ CARIOCA } & Car-P1 & 253,74 & 223,81 & 874,07 \\
\hline & Car-L1 & 249,08 & 191,55 & 39,19 \\
\hline & Car-L2 & 294,94 & 39,58 & 29,09 \\
\hline & Car-L3 & 259,18 & 186,50 & 19,76 \\
\hline \multirow{6}{*}{ AGUAPÉ } & Agu-P1 & 9,65 & 23,65 & 28,70 \\
\hline & Agu-P2 & 6,16 & 11,21 & 29,86 \\
\hline & Agu-P3 & 8,49 & 11,21 & 22,09 \\
\hline & Agu-L1 & 15,48 & 15,09 & 30,64 \\
\hline & Agu-L2 & 7,71 & 16,65 & 22,09 \\
\hline & Agu-L3 & 12,37 & 14,32 & 24,42 \\
\hline \multirow{5}{*}{ ÁGUAS CLARAS } & $\mathrm{ACl}-\mathrm{P} 1$ & 87,39 & 59,40 & 55,52 \\
\hline & $\mathrm{ACl}-\mathrm{P} 2$ & 103,71 & 63,29 & 25,98 \\
\hline & ACl-L1 & 82,72 & 42,30 & 18,59 \\
\hline & ACl-L2 & 90,50 & 37,64 & 39,19 \\
\hline & $\mathrm{ACl}-\mathrm{L} 3$ & 84,28 & 39,97 & 30,25 \\
\hline \multirow{4}{*}{ ARIRANHA } & Ari-P1 & 74,95 & 6,54 & 34,53 \\
\hline & Ari-L1 & 69,51 & 12,76 & 34,92 \\
\hline & Ari-L2 & 135,97 & 11,99 & 26,75 \\
\hline & Ari-L3 & 106,43 & 9,65 & 31,03 \\
\hline \multirow{2}{*}{ AMARELA } & Ama-P1 & 34,53 & 64,07 & 24,03 \\
\hline & Ama-L1 & 36,08 & 58,63 & 26,75 \\
\hline
\end{tabular}

\begin{tabular}{|c|c|c|c|c|}
\hline \multicolumn{5}{|c|}{ VALORES DE NITROGÊNIO TOTAL ( ug/L) } \\
\hline \multirow[b]{2}{*}{ Lagoa } & \multirow[b]{2}{*}{ Ponto } & \multicolumn{3}{|c|}{ Período de amostragem } \\
\hline & & Inverno 1 & Inverno 2 & Verão \\
\hline \multirow{4}{*}{ CARIOCA } & Car-P1 & 543,70 & 549,57 & 1222,09 \\
\hline & Car-L1 & 589,36 & 516,95 & 441,28 \\
\hline & Car-L2 & 555,44 & 453,68 & 389,10 \\
\hline & Car-L3 & 650,67 & 373,45 & 379,32 \\
\hline \multirow{6}{*}{ AGUAPÉ } & Agu-P1 & 595,23 & 548,91 & 348,01 \\
\hline & Agu-P2 & 552,18 & 576,31 & 341,48 \\
\hline & Agu-P3 & 589,36 & 518,91 & 383,23 \\
\hline & Agu-L1 & 556,74 & 605,01 & 349,31 \\
\hline & Agu-L2 & 570,44 & 614,80 & 336,92 \\
\hline & Agu-L3 & 610,88 & 539,13 & 348,66 \\
\hline \multirow{5}{*}{ ÁGUAS CLARAS } & $\mathrm{ACl}-\mathrm{P} 1$ & 379,97 & 480,42 & 481,07 \\
\hline & $\mathrm{ACl}-\mathrm{P} 2$ & 401,49 & 442,59 & 376,71 \\
\hline & ACl-L1 & 368,23 & 503,91 & 282,78 \\
\hline & ACl-L2 & 365,62 & 520,87 & 362,36 \\
\hline & ACl-L3 & 412,58 & 439,33 & 357,14 \\
\hline \multirow{4}{*}{ ARIRANHA } & Ari-P1 & 508,47 & 618,06 & 319,30 \\
\hline & Ari-L1 & 584,14 & 578,27 & 355,18 \\
\hline & Ari-L2 & 718,51 & 617,41 & 209,72 \\
\hline & Ari-L3 & 674,81 & 530,00 & 468,03 \\
\hline \multirow{2}{*}{ AMARELA } & Ama-P1 & 304,95 & 415,84 & 203,20 \\
\hline & Ama-L1 & 323,22 & 322,57 & 232,55 \\
\hline
\end{tabular}




\begin{tabular}{|c|c|c|c|c|}
\hline \multicolumn{5}{|c|}{ VALORES DE FOSFATO INORGÂNICO (ug/L) } \\
\hline \multirow[b]{2}{*}{ Lagoa } & \multirow[b]{2}{*}{ Ponto } & \multicolumn{3}{|c|}{ Período de amostragem } \\
\hline & & Inverno 1 & Inverno 2 & Verão \\
\hline \multirow{4}{*}{ CARIOCA } & Car-P1 & 9,44 & 3,28 & 1,52 \\
\hline & Car-L1 & 2,11 & 3,58 & 5,63 \\
\hline & Car-L2 & 4,60 & 14,42 & 7,09 \\
\hline & Car-L3 & 2,99 & 9,44 & 5,77 \\
\hline \multirow{6}{*}{ AGUAPÉ } & Agu-P1 & 2,55 & 3,58 & 7,09 \\
\hline & Agu-P2 & 1,38 & 4,16 & 6,36 \\
\hline & Agu-P3 & 1,82 & 11,78 & 13,69 \\
\hline & Agu-L1 & 1,23 & 5,04 & 10,90 \\
\hline & Agu-L2 & 0,94 & 5,63 & 11,49 \\
\hline & Agu-L3 & 3,58 & 4,16 & 12,08 \\
\hline \multirow{5}{*}{ Águas Claras } & $\mathrm{ACl}-\mathrm{P} 1$ & 1,23 & 1,23 & 6,07 \\
\hline & $\mathrm{ACl}-\mathrm{P} 2$ & 2,11 & 9,15 & 5,92 \\
\hline & ACl-L1 & 2,99 & 3,58 & 5,63 \\
\hline & $\mathrm{ACl}-\mathrm{L} 2$ & 2,11 & 3,87 & 5,63 \\
\hline & $\mathrm{ACl}-\mathrm{L3}$ & 2,26 & 1,82 & 4,45 \\
\hline \multirow{4}{*}{ ARIRANHA } & Ari-P1 & 0,64 & 12,37 & 7,97 \\
\hline & Ari-L1 & 1,23 & 2,70 & 9,59 \\
\hline & Ari-L2 & 0,79 & 1,23 & 5,33 \\
\hline & Ari-L3 & 0,94 & 0,94 & 6,51 \\
\hline \multirow{2}{*}{ AMARELA } & Ama-P1 & 1,08 & 2,70 & 6,80 \\
\hline & Ama-L1 & 1,96 & 4,16 & 6,36 \\
\hline
\end{tabular}

\begin{tabular}{|c|c|c|c|c|}
\hline \multicolumn{5}{|c|}{ VALORES DE FOSFATO TOTAL DISSOLVIDO ( $\mathrm{ug} / \mathrm{L})$} \\
\hline \multirow[b]{2}{*}{ Lagoa } & \multirow[b]{2}{*}{ Ponto } & \multicolumn{3}{|c|}{ Período de amostragem } \\
\hline & & Inverno 1 & Inverno 2 & Verão \\
\hline \multirow{4}{*}{ CARIOCA } & Car-P1 & 41,67 & 4,38 & 3,01 \\
\hline & Car-L1 & 6,37 & 4,23 & 7,13 \\
\hline & Car-L2 & 11,26 & 6,52 & 9,12 \\
\hline & Car-L3 & 4,38 & 18,29 & 7,13 \\
\hline \multirow{6}{*}{ AGUAPÉ } & Agu-P1 & 8,36 & 4,23 & 9,89 \\
\hline & Agu-P2 & 4,84 & 5,45 & 11,26 \\
\hline & Agu-P3 & 10,50 & 5,15 & 15,69 \\
\hline & Agu-L1 & 2,25 & 3,62 & 16,00 \\
\hline & Agu-L2 & 5,15 & 6,98 & 14,01 \\
\hline & Agu-L3 & 5,45 & 15,54 & 12,48 \\
\hline \multirow{5}{*}{ ÁGUAS CLARAS } & $\mathrm{ACl}-\mathrm{P} 1$ & 3,16 & 1,48 & 6,98 \\
\hline & $\mathrm{ACl}-\mathrm{P} 2$ & 3,01 & 10,95 & 6,37 \\
\hline & ACl-L1 & 5,45 & 4,54 & 6,68 \\
\hline & $\mathrm{ACl}-\mathrm{L} 2$ & 2,25 & 4,54 & 6,68 \\
\hline & $\mathrm{ACl}-\mathrm{L} 3$ & 3,47 & 3,01 & 6,37 \\
\hline \multirow{4}{*}{ ARIRANHA } & Ari-P1 & 5,61 & 3,01 & 9,73 \\
\hline & Ari-L1 & 2,70 & 14,93 & 10,19 \\
\hline & Ari-L2 & 11,11 & 4,23 & 7,90 \\
\hline & Ari-L3 & 5,30 & 1,79 & 8,66 \\
\hline \multirow{2}{*}{ AMARELA } & Ama-P1 & 4,38 & 7,90 & 13,70 \\
\hline & Ama-L1 & 6,52 & 3,62 & 12,02 \\
\hline
\end{tabular}




\begin{tabular}{|c|c|c|c|c|}
\hline \multicolumn{5}{|c|}{ VALORES DE FÓSFORO TOTAL (ug/L) } \\
\hline \multirow[b]{2}{*}{ Lagoa } & \multirow[b]{2}{*}{ Ponto } & \multicolumn{3}{|c|}{ Período de amostragem } \\
\hline & & Inverno 1 & Inverno 2 & Verão \\
\hline \multirow{4}{*}{ CARIOCA } & Car-P1 & 37,60 & 30,75 & 43,15 \\
\hline & Car-L1 & 37,28 & 26,51 & 15,42 \\
\hline & Car-L2 & 48,37 & 28,47 & 17,05 \\
\hline & Car-L3 & 44,13 & 28,80 & 13,14 \\
\hline \multirow{6}{*}{ AGUAPÉ } & Agu-P1 & 19,01 & 22,92 & 23,58 \\
\hline & Agu-P2 & 15,75 & 18,68 & 21,29 \\
\hline & Agu-P3 & 16,40 & 19,01 & 34,01 \\
\hline & Agu-L1 & 36,95 & 22,27 & 26,84 \\
\hline & Agu-L2 & 15,75 & 21,29 & 28,47 \\
\hline & Agu-L3 & 30,75 & 19,99 & 28,14 \\
\hline \multirow{5}{*}{ Águas Claras } & $\mathrm{ACl}-\mathrm{P} 1$ & 13,46 & 13,46 & 15,09 \\
\hline & $\mathrm{ACl}-\mathrm{P} 2$ & 22,60 & 12,48 & 12,48 \\
\hline & ACl-L1 & 13,14 & 14,11 & 9,55 \\
\hline & ACl-L2 & 24,23 & 13,14 & 10,53 \\
\hline & $\mathrm{ACl}-\mathrm{L3}$ & 33,36 & 13,46 & 8,89 \\
\hline \multirow{4}{*}{ ARIRANHA } & Ari-P1 & 15,42 & 40,54 & 21,29 \\
\hline & Ari-L1 & 16,72 & 17,70 & 21,29 \\
\hline & Ari-L2 & 33,53 & 21,62 & 21,94 \\
\hline & Ari-L3 & 22,92 & 17,05 & 22,27 \\
\hline \multirow{2}{*}{ AMARELA } & Ama-P1 & 10,85 & 20,97 & 26,51 \\
\hline & Ama-L1 & 13,46 & 15,75 & 26,84 \\
\hline
\end{tabular}

\begin{tabular}{|c|c|c|c|c|}
\hline \multicolumn{5}{|c|}{ VALORES DE SiliCATO (mg/L) } \\
\hline \multirow[b]{2}{*}{ Lagoa } & \multirow[b]{2}{*}{ Ponto } & \multicolumn{3}{|c|}{ Período de amostragem } \\
\hline & & Inverno 1 & Inverno 2 & Verão \\
\hline \multirow{4}{*}{ CARIOCA } & Car-P1 & 3,46 & 2,73 & 1,89 \\
\hline & Car-L1 & 2,95 & 3,56 & 2,98 \\
\hline & Car-L2 & 2,69 & 5,22 & 3,08 \\
\hline & Car-L3 & 2,38 & 3,60 & 2,96 \\
\hline \multirow{6}{*}{ AGUAPÉ } & Agu-P1 & 3,81 & 5,18 & 4,91 \\
\hline & Agu-P2 & 4,54 & 5,19 & 5,26 \\
\hline & Agu-P3 & 4,27 & 5,14 & 5,24 \\
\hline & Agu-L1 & 4,54 & 2,81 & 5,23 \\
\hline & Agu-L2 & 4,24 & 4,78 & 4,41 \\
\hline & Agu-L3 & 4,75 & 4,90 & 5,11 \\
\hline \multirow{5}{*}{ ÁGUAS CLARAS } & $\mathrm{ACl}-\mathrm{P} 1$ & 2,56 & 2,70 & 2,16 \\
\hline & $\mathrm{ACl}-\mathrm{P} 2$ & 2,74 & 2,82 & 2,46 \\
\hline & ACl-L1 & 2,63 & 2,38 & 1,87 \\
\hline & ACl-L2 & 2,77 & 2,53 & 2,64 \\
\hline & ACl-L3 & 2,91 & 2,73 & 2,69 \\
\hline \multirow{4}{*}{ ARIRANHA } & Ari-P1 & 3,21 & 3,42 & 3,18 \\
\hline & Ari-L1 & 3,60 & 2,44 & 3,86 \\
\hline & Ari-L2 & 2,60 & 3,36 & 2,82 \\
\hline & Ari-L3 & 2,62 & 2,72 & 3,19 \\
\hline \multirow{2}{*}{ AMARELA } & Ama-P1 & 4,81 & 5,21 & 4,73 \\
\hline & Ama-L1 & 4,53 & 5,73 & 4,32 \\
\hline
\end{tabular}




\begin{tabular}{|c|c|c|c|c|}
\hline \multicolumn{5}{|c|}{ VALORES DE MATÉRIA ORGÂNICA (mg/L) } \\
\hline \multirow[b]{2}{*}{ Lagoa } & \multirow[b]{2}{*}{ Ponto } & \multicolumn{3}{|c|}{ Período de amostragem } \\
\hline & & Inverno 1 & Inverno 2 & Verão \\
\hline \multirow{4}{*}{ CARIOCA } & Car-P1 & 7,40 & 7,40 & 7,25 \\
\hline & Car-L1 & 7,00 & 8,60 & 5,80 \\
\hline & Car-L2 & 8,67 & 9,00 & 4,40 \\
\hline & Car-L3 & 7,67 & 6,25 & 4,40 \\
\hline \multirow{6}{*}{ AGUAPÉ } & Agu-P1 & 7,17 & 8,25 & 7,80 \\
\hline & Agu-P2 & 5,50 & 7,25 & 5,60 \\
\hline & Agu-P3 & 7,50 & 8,50 & 6,60 \\
\hline & Agu-L1 & 8,17 & 8,25 & 6,60 \\
\hline & Agu-L2 & 5,17 & 10,00 & 6,00 \\
\hline & Agu-L3 & 8,00 & 8,25 & 4,80 \\
\hline \multirow{5}{*}{ ÁGUAS CLARAS } & $\mathrm{ACl}-\mathrm{P} 1$ & 5,17 & 3,67 & 3,13 \\
\hline & $\mathrm{ACl}-\mathrm{P} 2$ & 4,83 & 5,00 & 1,38 \\
\hline & $\mathrm{ACl}-\mathrm{L} 1$ & 4,50 & 4,33 & 4,38 \\
\hline & $\mathrm{ACl}-\mathrm{L} 2$ & 5,17 & 3,83 & 1,38 \\
\hline & ACl-L3 & 5,33 & 4,33 & 1,62 \\
\hline \multirow{4}{*}{ ARIRANHA } & Ari-P1 & 7,17 & 7,67 & 3,33 \\
\hline & Ari-L1 & 4,33 & 4,25 & 4,83 \\
\hline & Ari-L2 & 5,33 & 14,17 & 5,83 \\
\hline & Ari-L3 & 4,33 & 6,50 & 6,67 \\
\hline \multirow{2}{*}{ AMARELA } & Ama-P1 & 3,67 & 3,80 & 3,12 \\
\hline & Ama-L1 & 5,67 & 1,50 & 3,88 \\
\hline
\end{tabular}

\begin{tabular}{|c|c|c|c|c|}
\hline \multicolumn{5}{|c|}{ VALORES DE MATÉRIA INORGÂNICA (mg/L) } \\
\hline \multirow[b]{2}{*}{ Lagoa } & \multirow[b]{2}{*}{ Ponto } & \multicolumn{3}{|c|}{ Período de amostragem } \\
\hline & & Inverno 1 & Inverno 2 & Verão \\
\hline \multirow{4}{*}{ CARIOCA } & Car-P1 & 4,40 & 4,20 & 10,75 \\
\hline & Car-L1 & 11,33 & 5,20 & 5,80 \\
\hline & Car-L2 & 8,67 & 0,75 & 6,60 \\
\hline & Car-L3 & 9,33 & 2,00 & 5,20 \\
\hline \multirow{6}{*}{ AGUAPÉ } & Agu-P1 & 2,83 & 4,50 & 8,40 \\
\hline & Agu-P2 & 3,67 & 6,25 & 8,00 \\
\hline & Agu-P3 & 1,83 & 4,50 & 7,20 \\
\hline & Agu-L1 & 4,67 & 6,50 & 7,00 \\
\hline & Agu-L2 & 4,17 & 5,50 & 6,60 \\
\hline & Agu-L3 & 2,33 & 4,75 & 7,80 \\
\hline \multirow{5}{*}{ ÁGUAS CLARAS } & ACl-P1 & 2,00 & 3,17 & 5,38 \\
\hline & $\mathrm{ACl}-\mathrm{P} 2$ & 2,83 & 2,33 & 2,38 \\
\hline & ACl-L1 & 2,83 & 3,83 & 4,13 \\
\hline & ACl-L2 & 2,83 & 4,33 & 4,50 \\
\hline & ACl-L3 & 2,83 & 3,83 & 4,13 \\
\hline \multirow{4}{*}{ ARIRANHA } & Ari-P1 & 3,83 & 1,17 & 6,33 \\
\hline & Ari-L1 & 6,33 & 4,67 & 5,50 \\
\hline & Ari-L2 & 3,83 & 2,67 & 6,17 \\
\hline & Ari-L3 & 5,17 & 3,33 & 7,33 \\
\hline \multirow{2}{*}{ AMARELA } & Ama-P1 & 4,33 & 3,80 & 5,87 \\
\hline & Ama-L1 & 6,15 & 3,60 & 4,87 \\
\hline
\end{tabular}




\begin{tabular}{|c|c|c|c|c|}
\hline \multicolumn{5}{|c|}{ VALORES DE MATERIAL EM SUSPENSÃO TOTAL (mg/L) } \\
\hline \multirow[b]{2}{*}{ Lagoa } & \multirow[b]{2}{*}{ Ponto } & \multicolumn{3}{|c|}{ Período de amostragem } \\
\hline & & Inverno 1 & Inverno 2 & Verão \\
\hline \multirow{4}{*}{ CARIOCA } & Car-P1 & 11,80 & 11,60 & 18,00 \\
\hline & Car-L1 & 18,33 & 13,80 & 11,60 \\
\hline & Car-L2 & 17,33 & 9,75 & 11,00 \\
\hline & Car-L3 & 17,00 & 8,25 & 9,60 \\
\hline \multirow{6}{*}{ AGUAPÉ } & Agu-P1 & 10,00 & 12,75 & 16,20 \\
\hline & Agu-P2 & 9,17 & 13,50 & 13,60 \\
\hline & Agu-P3 & 9,33 & 13,00 & 13,80 \\
\hline & Agu-L1 & 12,83 & 14,75 & 13,60 \\
\hline & Agu-L2 & 9,33 & 15,50 & 12,60 \\
\hline & Agu-L3 & 10,33 & 13,00 & 12,60 \\
\hline \multirow{5}{*}{ ÁGuAs CLARAS } & $\mathrm{ACl}-\mathrm{P} 1$ & 7,17 & 6,83 & 8,50 \\
\hline & $\mathrm{ACl}-\mathrm{P} 2$ & 7,67 & 7,33 & 3,75 \\
\hline & ACl-L1 & 7,33 & 8,17 & 8,50 \\
\hline & $\mathrm{ACl}-\mathrm{L} 2$ & 8,00 & 8,17 & 5,88 \\
\hline & $\mathrm{ACl}-\mathrm{L} 3$ & 8,17 & 8,17 & 5,75 \\
\hline \multirow{4}{*}{ ARIRANHA } & Ari-P1 & 11,00 & 8,83 & 9,67 \\
\hline & Ari-L1 & 10,67 & 8,92 & 10,33 \\
\hline & Ari-L2 & 9,17 & 16,83 & 12,00 \\
\hline & Ari-L3 & 9,50 & 9,83 & 14,00 \\
\hline \multirow{2}{*}{ AMARELA } & Ama-P1 & 8,00 & 7,60 & 9,00 \\
\hline & Ama-L1 & 11,82 & 5,10 & 8,75 \\
\hline
\end{tabular}

\begin{tabular}{|c|c|c|c|c|}
\hline \multicolumn{5}{|c|}{ VALORES DE CLOROFILA (ug/L) } \\
\hline \multirow[b]{2}{*}{ Lagoa } & \multirow[b]{2}{*}{ Ponto } & \multicolumn{3}{|c|}{ Período de amostragem } \\
\hline & & Inverno 1 & Inverno 2 & Verão \\
\hline \multirow{4}{*}{ CARIOCA } & Car-P1 & 2,93 & 0,10 & 5,87 \\
\hline & Car-L1 & 2,51 & 0,09 & 2,51 \\
\hline & Car-L2 & 0,05 & 0,12 & 3,15 \\
\hline & Car-L3 & 0,13 & 0,06 & 2,53 \\
\hline \multirow{6}{*}{ AguAPÉ } & Agu-P1 & 0,10 & 0,12 & 2,98 \\
\hline & Agu-P2 & 0,07 & 0,11 & 2,91 \\
\hline & Agu-P3 & 0,08 & 0,10 & 2,90 \\
\hline & Agu-L1 & 0,06 & 0,09 & 2,69 \\
\hline & Agu-L2 & 0,09 & 0,12 & 2,75 \\
\hline & Agu-L3 & 0,08 & 0,10 & 2,81 \\
\hline \multirow{5}{*}{ ÁGUAs CLARAS } & $\mathrm{ACl}-\mathrm{P} 1$ & 0,05 & 0,12 & 2,93 \\
\hline & $\mathrm{ACl}-\mathrm{P} 2$ & 0,12 & 0,12 & 4,21 \\
\hline & $\mathrm{ACl}-\mathrm{L} 1$ & 0,07 & 0,10 & 2,90 \\
\hline & $\mathrm{ACl}-\mathrm{L} 2$ & 0,08 & 0,08 & 2,51 \\
\hline & $\mathrm{ACl}-\mathrm{L3}$ & 0,21 & 0,12 & 2,53 \\
\hline \multirow{4}{*}{ ARIRANHA } & Ari-P1 & 0,09 & 0,09 & 2,75 \\
\hline & Ari-L1 & 0,09 & 0,07 & 2,98 \\
\hline & Ari-L2 & 0,06 & 0,04 & 2,91 \\
\hline & Ari-L3 & 0,05 & 0,05 & 3,74 \\
\hline \multirow{2}{*}{ AMARELA } & Ama-P1 & 0,04 & 0,03 & 2,63 \\
\hline & Ama-L1 & 0,05 & 0,04 & 2,31 \\
\hline
\end{tabular}




\section{ANÁLISE DE COMPONTENTES PRINCIPAIS}

COEFICIENTES (ESCORES) DOS FATORES RESULTANTES DA ANÁLISE DE COMPONENTES PRINCIPAIS PARA VALORES DAS VARIÁVEIS LIMNOLÓGICAS DOS PONTOS DE AMOSTRAGEM NO PERÍODO DE INVERNO 1 (JUNHO DE 1999).

\begin{tabular}{ccc}
\hline \hline Ponto & Fator 1 & Fator 2 \\
\hline Car - P1 & 2.66 & 2.81 \\
Car - L1 & 1.35 & -1.12 \\
Car - L2 & 1.90 & -0.68 \\
Car - L3 & 1.18 & -1.37 \\
Agu - P1 & -0.25 & 0.24 \\
Agu - P2 & -0.67 & 0.14 \\
Agu - P3 & -0.39 & 0.46 \\
Agu - L1 & 0.03 & -1.03 \\
Agu - L2 & -0.65 & -0.57 \\
Agu - L3 & -0.11 & -0.47 \\
ACl - P1 & -0.81 & 1.30 \\
ACl - P2 & -0.62 & 1.44 \\
ACl - L1 & -0.72 & 0.56 \\
ACl - L2 & -0.73 & 0.31 \\
ACl - L3 & -0.47 & 0.30 \\
Ari - P1 & -0.07 & 0.33 \\
Ari - L1 & -0.10 & -0.82 \\
Ari - L2 & 0.46 & -0.79 \\
Ari - L3 & 0.18 & -0.97 \\
Ama - P1 & -1.28 & -0.04 \\
Ama - L1 & -0.89 & -0.02 \\
\hline \hline
\end{tabular}

COEFICIENTES (ESCORES) DOS FATORES RESULTANTES DA ANÁLISE DE COMPONENTES PRINCIPAIS PARA VALORES DAS VARIÁVEIS LIMNOLÓGICAS DOS PONTOS DE AMOSTRAGEM NO PERÍODO DE INVERNO 2 (AGOSTO DE 1999).

\begin{tabular}{ccc}
\hline \hline Ponto & Fator 1 & Fator 2 \\
\hline Car - P1 & 0.68 & 1.39 \\
Car - L1 & 0.09 & 1.50 \\
Car - L2 & 0.26 & 1.30 \\
Car - L3 & 1.12 & 1.88 \\
Agu - P1 & -0.74 & -0.24 \\
Agu - P2 & -0.91 & -0.27 \\
Agu - P3 & -0.85 & -0.20 \\
Agu - L1 & -1.02 & 0.20 \\
Agu - L2 & -1.31 & 0.16 \\
Agu - L3 & -1.14 & -0.18 \\
ACl - P1 & 0.82 & -1.61 \\
ACl - P2 & 1.00 & -1.14 \\
ACl - L1 & 0.03 & -1.22 \\
ACl - L2 & 0.06 & -1.24 \\
ACl - L3 & 0.05 & -1.38 \\
Ari - P1 & -0.39 & 0.42 \\
Ari - L1 & -0.09 & 0.10 \\
Ari - L2 & -1.27 & 0.92 \\
Ari - L3 & -0.48 & -0.37 \\
Ama - P1 & 1.94 & 0.41 \\
Ama - L1 & 2.15 & -0.41 \\
\hline \hline
\end{tabular}


COEFICIENTES (ESCORES) DOS FATORES RESULTANTES DA ANÁLISE DE COMPONENTES PRINCIPAIS PARA VALORES DAS VARIÁVEIS LIMNOLÓGICAS DOS PONTOS DE AMOSTRAGEM NO PERÍOdO DE VERÃO (FEVEREIRO DE 2000).

\begin{tabular}{ccc}
\hline \hline Ponto & Fator 1 & Fator 2 \\
\hline Car - P1 & -4.03 & 0.53 \\
Car - L1 & 0.18 & 0.48 \\
Car - L2 & 0.13 & 0.25 \\
Car - L3 & 0.46 & 0.64 \\
Agu - P1 & -0.49 & -0.95 \\
Agu - P2 & -0.32 & -0.59 \\
Agu - P3 & -0.10 & -1.73 \\
Agu - L1 & 0.27 & -1.58 \\
Agu - L2 & 0.46 & -1.04 \\
Agu - L3 & 0.42 & -1.29 \\
ACl - P1 & -0.32 & 1.11 \\
ACl - P2 & -0.12 & 1.80 \\
ACl - L1 & 0.76 & 0.99 \\
ACl - L2 & 0.97 & 1.42 \\
ACl - L3 & 0.86 & 1.18 \\
Ari - P1 & 0.15 & 0.06 \\
Ari - L1 & 0.39 & -0.17 \\
Ari - L2 & 0.15 & 0.13 \\
Ari - L3 & -0.25 & -0.12 \\
Ama - P1 & 0.21 & -0.63 \\
Ama - L1 & 0.22 & -0.48 \\
\hline \hline
\end{tabular}

COEFICIENTES (ESCORES) DOS FATORES RESULTANTES DA ANÁLISE DE COMPONENTES PRINCIPAIS PARA MEDIDAS DE DIVERSIDADE DOS PONTOS DE AMOSTRAGEM NO PERÍODO DE INVERNO 1 (JUNHO DE 1999).

\begin{tabular}{ccc}
\hline \hline Ponto & Fator 1 & Fator 2 \\
\hline Car - P1 & -1.07 & -0.49 \\
Car - L1 & -1.58 & 1.38 \\
Car - L2 & -1.82 & 0.42 \\
Car - L3 & -1.96 & 0.89 \\
Agu - P1 & 0.47 & -0.74 \\
Agu - P2 & -0.11 & -1.44 \\
Agu - P3 & 0.06 & -1.25 \\
Agu - L1 & 0.22 & -0.28 \\
Agu - L2 & -0.07 & -0.57 \\
Agu - L3 & -0.52 & -0.28 \\
ACl - P1 & -0.25 & -1.22 \\
ACl - P2 & -0.41 & -1.73 \\
ACl - L1 & 1.92 & -0.87 \\
ACl - L2 & 0.47 & 1.00 \\
ACl - L3 & 0.58 & 0.70 \\
Ari - P1 & -0.11 & 0.43 \\
Ari - L1 & 0.75 & 0.45 \\
Ari - L2 & 1.11 & 2.00 \\
Ari - L3 & 0.70 & 0.67 \\
Ama - P1 & 0.29 & 0.14 \\
Ama - L1 & 1.35 & 0.79 \\
\hline \hline
\end{tabular}


COEFICIENTES (ESCORES) DOS FATORES RESULTANTES DA ANÁLISE DE COMPONENTES PRINCIPAIS PARA MEDIDAS DE DIVERSIDADE DOS PONTOS DE AMOSTRAGEM NO PERÍODO DE INVERNO 2 (AGOSTO DE 1999).

\begin{tabular}{ccc}
\hline Ponto & Fator 1 & Fator 2 \\
\hline Car - P1 & -0.42 & -1.53 \\
Car - L1 & -1.33 & -0.43 \\
Car - L2 & -0.91 & -0.67 \\
Car - L3 & -0.59 & -0.74 \\
Agu - P1 & 0.18 & -0.89 \\
Agu - P2 & -0.62 & -0.60 \\
Agu - P3 & -0.41 & -0.68 \\
Agu - L1 & 1.25 & -1.02 \\
Agu - L2 & 0.57 & -0.27 \\
Agu - L3 & -0.02 & -0.47 \\
ACl - P1 & -0.82 & 1.29 \\
ACl - P2 & -0.64 & 0.37 \\
ACl - L1 & 2.33 & 1.13 \\
ACl - L2 & 1.62 & -1.19 \\
ACl - L3 & 0.43 & 1.37 \\
Ari - P1 & 0.18 & 0.27 \\
Ari - L1 & -1.41 & 0.43 \\
Ari - L2 & -0.17 & 1.19 \\
Ari - L3 & -0.03 & 2.32 \\
Ama - P1 & -0.77 & 0.30 \\
Ama - L1 & 1.57 & -0.18 \\
\hline \hline
\end{tabular}

COEFICIENTES (ESCORES) DOS FATORES RESULTANTES DA ANÁLISE DE COMPONENTES PRINCIPAIS PARA MEDIDAS DE DIVERSIDADE DOS PONTOS DE AMOSTRAGEM NO PERÍODO DE VERÃO (FEVEREIRO DE 2000).

\begin{tabular}{ccc}
\hline \hline Ponto & Fator 1 & Fator 2 \\
\hline Car - P1 & -1.24 & -0.68 \\
Car - L1 & -1.79 & 0.04 \\
Car - L2 & -1.08 & -0.01 \\
Car - L3 & -0.51 & -0.78 \\
Agu - P1 & 0.39 & -0.01 \\
Agu - P2 & 1.03 & -0.88 \\
Agu - P3 & -1.52 & 0.76 \\
Agu - L1 & 1.27 & -0.29 \\
Agu - L2 & 0.23 & -0.67 \\
Agu - L3 & -0.67 & -0.25 \\
ACl - P1 & -0.11 & -1.21 \\
ACl - P2 & -0.10 & -0.80 \\
ACl - L1 & 1.55 & -0.26 \\
ACl - L2 & -0.15 & -0.42 \\
ACl - L3 & 1.68 & -0.30 \\
Ari - P1 & 0.13 & 0.10 \\
Ari - L1 & 1.21 & 2.82 \\
Ari - L2 & -0.38 & -0.36 \\
Ari - L3 & -0.87 & 2.47 \\
Ama - P1 & 0.23 & 0.18 \\
Ama - L1 & 0.71 & 0.55 \\
\hline \hline
\end{tabular}




\begin{tabular}{|c|c|c|c|c|c|c|}
\hline \multicolumn{7}{|c|}{ MATRIZ DAS MEDIDAS DE DIVERSIDADE PARA A ANÁLISE DE COMPONENTES PRINCIPAIS } \\
\multicolumn{7}{|c|}{ PERÍODO DE INVERNO 1 (JUNHO DE 1999) } \\
\hline Pontos & No. Espécies (n) & Margalef (DMG) & Shannon (H) & Simpson (1/D) & Simpson (D) & Equidade (E) \\
\hline Car-P1 & 12,00 & 0,83 & 0,93 & 2,00 & 0,50 & 0,37 \\
Car-L1 & 15,00 & 1,08 & 0,33 & 1,11 & 0,90 & 0,12 \\
Car-L2 & 11,00 & 0,75 & 0,38 & 1,18 & 0,85 & 0,16 \\
Car-L3 & 12,00 & 0,80 & 0,18 & 1,06 & 0,95 & 0,07 \\
\hline Agu-P1 & 16,00 & 1,22 & 1,76 & 3,78 & 0,26 & 2,81 \\
Agu-P2 & 12,00 & 0,88 & 1,57 & 3,51 & 0,28 & 2,03 \\
Agu-P3 & 13,00 & 0,99 & 1,60 & 3,64 & 0,27 & 2,27 \\
Agu-L1 & 16,00 & 1,23 & 1,48 & 3,16 & 0,32 & 2,83 \\
Agu-L2 & 14,00 & 1,08 & 1,43 & 2,90 & 0,35 & 2,48 \\
Agu-L3 & 12,00 & 1,02 & 1,23 & 2,05 & 0,49 & 2,34 \\
\hline ACl-P1 & 12,00 & 0,87 & 1,53 & 3,05 & 0,33 & 2,01 \\
ACl-P2 & 10,00 & 0,72 & 1,58 & 3,17 & 0,32 & 1,66 \\
ACl-L1 & 21,00 & 1,75 & 2,34 & 6,94 & 0,14 & 4,02 \\
ACl-L2 & 20,00 & 1,56 & 1,50 & 2,40 & 0,42 & 3,58 \\
ACl-L3 & 20,00 & 1,53 & 1,46 & 2,93 & 0,34 & 3,52 \\
\hline Ari-P1 & 17,00 & 1,21 & 1,17 & 2,29 & 0,44 & 2,78 \\
Ari-L1 & 21,00 & 1,49 & 1,53 & 3,52 & 0,28 & 3,43 \\
Ari-L2 & 26,00 & 1,92 & 1,52 & 2,70 & 0,37 & 4,41 \\
Ari-L3 & 21,00 & 1,53 & 1,57 & 3,10 & 0,32 & 3,51 \\
\hline Ama-P1 & 17,00 & 1,35 & 1,46 & 2,89 & 0,35 & 3,10 \\
Ama-L1 & 23,00 & 1,83 & 1,97 & 3,78 & 0,26 & 4,21 \\
\hline
\end{tabular}

\begin{tabular}{|c|c|c|c|c|c|c|}
\hline \multicolumn{7}{|c|}{$\begin{array}{c}\text { MATRIZ DAS MEDIDAS DE DIVERSIDADE PARA A ANÁLISE DE COMPONENTES PRINCIPAIS } \\
\text { PERÍODO DE INVERNO } 2 \text { (AGOSTO DE 1999) }\end{array}$} \\
\hline Pontos & No. Espécies (n) & Margalef (DMG) & Shannon $(\mathrm{H})$ & Simpson (1/D) & Simpson (D) & Equidade $(\mathrm{E})$ \\
\hline Car-P1 & 10,00 & 0,74 & 1,76 & 4,37 & 0,23 & 0,77 \\
\hline Car-L1 & 10,00 & 0,70 & 1,03 & 1,86 & 0,54 & 0,45 \\
\hline Car-L2 & 11,00 & 0,83 & 1,33 & 2,37 & 0,42 & 0,55 \\
\hline Car-L3 & 12,00 & 0,98 & 1,49 & 2,82 & 0,35 & 0,60 \\
\hline Agu-P1 & 12,00 & 1,04 & 1,78 & 4,73 & 0,21 & 2,40 \\
\hline Agu-P2 & 10,00 & 0,82 & 1,33 & 2,83 & 0,35 & 1,90 \\
\hline Agu-P3 & 11,00 & 0,85 & 1,46 & 3,27 & 0,31 & 1,97 \\
\hline Agu-L1 & 16,00 & 1,35 & 2,26 & 8,14 & 0,12 & 3,11 \\
\hline Agu-L2 & 16,00 & 1,29 & 1,79 & 4,48 & 0,22 & 2,97 \\
\hline Agu-L3 & 13,00 & 1,04 & 1,65 & 3,49 & 0,29 & 2,40 \\
\hline ACl-P1 & 16,00 & 1,11 & 0,71 & 1,39 & 0,72 & 2,56 \\
\hline $\mathrm{ACl}-\mathrm{P} 2$ & 14,00 & 0,97 & 1,07 & 1,96 & 0,51 & 2,24 \\
\hline ACl-L1 & 28,00 & 2,17 & 2,20 & 6,22 & 0,16 & 5,00 \\
\hline $\mathrm{ACl}-\mathrm{L} 2$ & 17,00 & 1,42 & 2,45 & 9,88 & 0,10 & 3,26 \\
\hline ACl-L3 & 20,00 & 1,63 & 1,36 & 2,07 & 0,48 & 3,76 \\
\hline Ari-P1 & 16,00 & 1,28 & 1,57 & 2,80 & 0,36 & 2,96 \\
\hline Ari-L1 & 10,00 & 0,76 & 0,70 & 1,41 & 0,71 & 1,75 \\
\hline Ari-L2 & 18,00 & 1,33 & 1,14 & 1,72 & 0,58 & 3,06 \\
\hline Ari-L3 & 22,00 & 1,63 & 0,79 & 1,38 & 0,73 & 3,75 \\
\hline Ama-P1 & 12,00 & 0,97 & 1,05 & 1,84 & 0,54 & 2,23 \\
\hline Ama-L1 & 19,00 & 1,70 & 2,28 & 6,63 & 0,15 & 3,91 \\
\hline
\end{tabular}




\begin{tabular}{|c|c|c|c|c|c|c|}
\hline \multicolumn{7}{|c|}{ MATRIZ DAS MEDIDAS DE DIVERSIDADE PARA A ANÁLISE DE COMPONENTES PRINCIPAIS } \\
PERÍODO DE VER̃O (FEVEREIRO DE 2000) & \multicolumn{1}{c|}{} \\
\hline Pontos & No. Espécies (n) & Margalef (DMG) & Shannon (H) & Simpson (1/D) & Simpson (D) & Equidade (E) \\
\hline Car-P1 & 10,00 & 0,83 & 1,44 & 3,03 & 0,33 & 1,92 \\
Car-L1 & 10,00 & 0,80 & 1,03 & 2,17 & 0,46 & 1,84 \\
Car-L2 & 12,00 & 1,02 & 1,34 & 2,64 & 0,38 & 2,34 \\
Car-L3 & 12,00 & 1,04 & 1,76 & 3,78 & 0,26 & 2,39 \\
\hline Agu-P1 & 18,00 & 1,42 & 1,85 & 4,08 & 0,24 & 3,27 \\
Agu-P2 & 17,00 & 1,49 & 2,13 & 6,56 & 0,15 & 3,43 \\
Agu-P3 & 13,00 & 0,98 & 1,14 & 1,80 & 0,56 & 2,25 \\
Agu-L1 & 19,00 & 1,69 & 2,14 & 5,91 & 0,17 & 3,90 \\
Agu-L2 & 15,00 & 1,28 & 1,91 & 4,82 & 0,21 & 2,94 \\
Agu-L3 & 13,00 & 1,09 & 1,52 & 3,21 & 0,31 & 2,50 \\
\hline ACl-P1 & 13,00 & 1,06 & 1,87 & 5,13 & 0,19 & 2,44 \\
ACl-P2 & 14,00 & 1,14 & 1,83 & 4,48 & 0,22 & 2,61 \\
ACl-L1 & 21,00 & 1,73 & 2,28 & 6,13 & 0,16 & 3,98 \\
ACl-L2 & 15,00 & 1,19 & 1,73 & 3,96 & 0,25 & 2,73 \\
ACl-L3 & 21,00 & 1,77 & 2,38 & 6,34 & 0,16 & 4,08 \\
\hline Ari-P1 & 17,00 & 1,38 & 1,71 & 3,77 & 0,27 & 3,18 \\
Ari-L1 & 27,00 & 2,23 & 1,60 & 2,21 & 0,45 & 5,14 \\
Ari-L2 & 14,00 & 1,14 & 1,69 & 3,56 & 0,28 & 2,63 \\
Ari-L3 & 19,00 & 1,52 & 0,89 & 1,47 & 0,68 & 3,51 \\
\hline Ama-P1 & 18,00 & 1,41 & 1,70 & 3,79 & 0,26 & 3,25 \\
Ama-L1 & 20,00 & 1,64 & 1,90 & 3,75 & 0,27 & 3,77 \\
\hline
\end{tabular}


MATRIZ DAS VARIÁVEIS LIMNOLÓGICAS PARA A ANÁLISE DE COMPONENTES PRINCIPAIS - PERÍODO DE INVERNO 1 (JUNHO DE 1999)

\begin{tabular}{|c|c|c|c|c|c|c|c|c|c|c|c|c|c|c|c|c|c|c|c|c|c|}
\hline \multicolumn{22}{|c|}{ MATRIZ DAS VARIÁVEIS } \\
\hline Pontos & Habitat & Prof & Transp & Temp & Cond & OxiDiss & $\mathrm{pH}$ & Nitrato & Nitrito & Amônio & Nitro Tot & FDT & FI & $\mathrm{FT}$ & Silicato & Mat Org & Mat Inorg & Mat Susp & Clorofila & ietCar & ietSalas \\
\hline Car-P1 & $\lim$ & 9,50 & 1,20 & 22,25 & 27,25 & 5,72 & 5,98 & 40,31 & 2,63 & 253,74 & 543,70 & 41,67 & 9,44 & 37,60 & 3,46 & 7,40 & 4,40 & 11,80 & 2,93 & 53,28 & 55,68 \\
\hline Car-L1 & lito & 0,75 & 0,75 & 23,40 & 27,00 & 7,55 & 6,48 & 12,92 & 1,29 & 249,08 & 589,36 & 6,37 & 2,11 & 37,28 & 2,95 & 7,00 & 11,33 & 18,33 & 2,51 & 43,69 & 46,10 \\
\hline Car-L2 & lito & 0,75 & 0,75 & 22,95 & 27,00 & 5,95 & 6,17 & 18,82 & 2,80 & 294,94 & 555,44 & 11,26 & 4,60 & 48,37 & 2,69 & 8,67 & 8,67 & 17,33 & 0,05 & 34,59 & 37,28 \\
\hline Car-L3 & lito & 0,75 & 0,75 & 23,20 & 27,00 & 6,39 & 6,42 & 15,99 & 0,98 & 259,18 & 650,67 & 4,38 & 2,99 & 44,13 & 2,38 & 7,67 & 9,33 & 17,00 & 0,13 & 32,80 & 35,42 \\
\hline Agu-P1 & $\lim$ & 4,50 & 1,40 & 22,86 & 38,11 & 6,49 & 6,41 & 6,07 & 1,66 & 9,65 & 595,23 & 8,36 & 2,55 & 19,01 & 3,81 & 7,17 & 2,83 & 10,00 & 0,10 & 30,98 & 33,62 \\
\hline Agu-P2 & $\lim$ & 5,00 & 1,40 & 22,64 & 38,40 & 6,85 & 6,32 & 10,32 & 0,75 & 6,16 & 552,18 & 4,84 & 1,38 & 15,75 & 4,54 & 5,50 & 3,67 & 9,17 & 0,07 & 26,26 & 28,93 \\
\hline Agu-P3 & $\lim$ & 4,50 & 1,40 & 22,71 & 38,00 & 7,34 & 6,62 & 13,63 & 1,15 & 8,49 & 589,36 & 10,50 & 1,82 & 16,40 & 4,27 & 7,50 & 1,83 & 9,33 & 0,08 & 30,62 & 33,28 \\
\hline Agu-L1 & lito & 0,75 & 0,75 & 22,70 & 39,00 & 5,06 & 6,39 & 13,86 & 0,98 & 15,48 & 556,74 & 2,25 & 1,23 & 36,95 & 4,54 & 8,17 & 4,67 & 12,83 & 0,06 & 26,07 & 28,75 \\
\hline Agu-L2 & lito & 0,75 & 0,75 & 23,10 & 38,00 & 7,25 & 6,71 & 10,32 & 0,93 & 7,71 & 570,44 & 5,15 & 0,94 & 15,75 & 4,24 & 5,17 & 4,17 & 9,33 & 0,09 & 27,39 & 30,04 \\
\hline Agu-L3 & lito & 0,75 & 0,75 & 22,65 & 38,00 & 6,46 & 6,67 & 13,15 & 0,93 & 12,37 & 610,88 & 5,45 & 3,58 & 30,75 & 4,75 & 8,00 & 2,33 & 10,33 & 0,08 & 30,50 & 33,15 \\
\hline $\mathrm{ACl}-\mathrm{P} 1$ & $\lim$ & 7,50 & 2,10 & 23,64 & 41,00 & 7,70 & 6,46 & 10,56 & 1,38 & 87,39 & 379,97 & 3,16 & 1,23 & 13,46 & 2,56 & 5,17 & 2,00 & 7,17 & 0,05 & 22,33 & 25,02 \\
\hline ACl-P2 & $\lim$ & 8,00 & 2,30 & 23,59 & 41,00 & 7,78 & 6,52 & 15,75 & 1,07 & 103,71 & 401,49 & 3,01 & 2,11 & 22,60 & 2,74 & 4,83 & 2,83 & 7,67 & 0,12 & 27,51 & 30,14 \\
\hline ACl-L1 & lito & 1,25 & 1,25 & 24,17 & 41,00 & 8,16 & 6,94 & 11,50 & 1,44 & 82,72 & 368,23 & 5,45 & 2,99 & 13,14 & 2,63 & 4,50 & 2,83 & 7,33 & 0,07 & 25,96 & 28,63 \\
\hline ACl-L2 & lito & 1,25 & 1,25 & 24,27 & 41,00 & 8,33 & 7,18 & 14,10 & 1,01 & 90,50 & & 2,25 & 2,11 & 24,23 & 2,7 & 5,17 & 2,83 & 8, & 0,0 & 25,09 & 27,75 \\
\hline $\mathrm{ACl}-\mathrm{L} 3$ & lito & 1,25 & 1,25 & 24,00 & 40,67 & 8,43 & 7,17 & 13,63 & 1,44 & 84,28 & 412,58 & 3,47 & 2,26 & 33,36 & 2,91 & 5,33 & 2,83 & 8,17 & 0,21 & 31,94 & 34,53 \\
\hline Ari-P1 & $\lim$ & 5,50 & 1,60 & 22,91 & 26,00 & 6,15 & 6,28 & 15,04 & 1,21 & 74,95 & 508,47 & 5,61 & 1,23 & 15,42 & 3,21 & 7,17 & 3,83 & 11,00 & 0,09 & 27,76 & 30,41 \\
\hline Ari-L1 & lito & 0,75 & 0,75 & 22,90 & 26,00 & 6,32 & 6,34 & 12,92 & 1,49 & 69,51 & 584,14 & 2,70 & 0,64 & 16,72 & 3,60 & 4,33 & 6,33 & 10,67 & 0,09 & 24,50 & 27,15 \\
\hline Ari-L2 & lito & 0,75 & 0,75 & 22,30 & 27,00 & 4,75 & 5,99 & 13,63 & 1,41 & 135,97 & 718,51 & 11,11 & 0,79 & 33,53 & 2,60 & 5,33 & 3,83 & 9,17 & 0,06 & 33,29 & 35,97 \\
\hline Ari-L3 & lito & 0,75 & 0,75 & 22,85 & 27,50 & 2,33 & 6,06 & 12,68 & 1,46 & 106,43 & 674,81 & 5,30 & 0,94 & 22,92 & 2,62 & 4,33 & 5,17 & 9,50 & 0,05 & 27,58 & 30,26 \\
\hline Ama-P1 & $\lim$ & 2,25 & 1,30 & 20,80 & 67,00 & 2,25 & 6,32 & 7,72 & 0,61 & 34,53 & 304,95 & 4,38 & 1,08 & 10,85 & 4,81 & 3,67 & 4,33 & 8,00 & 0,04 & 22,43 & 25,13 \\
\hline Ama-L1 & lito & 1,25 & 1,25 & 26,87 & 59,00 & 5,47 & 6,72 & 9,14 & 1,27 & 36,08 & 323,22 & 6,52 & 1,96 & 13,46 & 4,53 & 5,67 & 6,15 & 11,82 & 0,05 & 25,90 & 28,59 \\
\hline
\end{tabular}


MATRIZ DAS VARÍ́VEIS LIMNOLÓGICAS PARA A ANÁLISE DE COMPONENTES PRINCIPAIS - PERÍODO DE INVERNO 2 (AGOSTO DE 1999)

\begin{tabular}{|c|c|c|c|c|c|c|c|c|c|c|c|c|c|c|c|c|c|c|c|c|c|}
\hline Pontos & Habitat & Prof & Transp & Temp & Cond & OxiDiss & $\mathrm{pH}$ & Nitrato & Nitrito & Amônio & Nitro Tot & FDT & $\mathrm{FI}$ & FT & Silicato & Mat Org & Mat Inorg & Mat Susp & Clorofila & ietCar & ietSalas \\
\hline Car-P1 & $\lim$ & 9,50 & 0,90 & 21,67 & 28,50 & 5,61 & 6,04 & 23,07 & 1,32 & 223,81 & 549,57 & 4,38 & 3,28 & 30,75 & 2,73 & 7,40 & 4,20 & 11,60 & 0,10 & 30,19 & 32,83 \\
\hline Car-L1 & lito & 0,75 & 0,75 & 21,70 & 29,00 & 5,27 & 6,58 & 21,18 & 0,93 & 191,55 & 516,95 & 4,23 & 3,58 & 26,51 & 3,56 & 8,60 & 5,20 & 13,80 & 0,09 & 28,95 & 31,60 \\
\hline Car-L2 & lito & 0,75 & 0,75 & 21,45 & 29,00 & 5,80 & 6,50 & 8,43 & 0,84 & 39,58 & 453,68 & 6,52 & 14,42 & 28,47 & 5,22 & 9,00 & 0,75 & 9,75 & 0,12 & 32,34 & 34,97 \\
\hline Car-L3 & lito & 0,75 & 0,75 & 21,30 & 28,50 & 5,69 & 6,61 & 20,95 & 1,44 & 186,50 & 373,45 & 18,29 & 9,44 & 28,80 & 3,60 & 6,25 & 2,00 & 8,25 & 0,06 & 35,04 & 37,72 \\
\hline Agu-P1 & $\lim$ & 4,50 & 1,00 & 23,23 & 39,33 & 7,14 & 7,07 & 7,02 & 0,24 & 23,65 & 548,91 & 4,23 & 3,58 & 22,92 & 5,18 & 8,25 & 4,50 & 12,75 & 0,12 & 29,09 & 31,72 \\
\hline Agu-P2 & $\lim$ & 5,00 & 0,80 & 22,77 & 39,20 & 7,46 & 7,09 & 8,43 & 0,24 & 11,21 & 576,31 & 5,45 & 4,16 & 18,68 & 5,19 & 7,25 & 6,25 & 13,50 & 0,11 & 29,16 & 31,80 \\
\hline Agu-P3 & $\lim$ & 4,50 & 1,00 & 22,86 & 39,78 & 7,70 & 7,53 & 7,02 & 0,41 & 11,21 & 518,91 & 5,15 & 11,78 & 19,01 & 5,14 & 8,50 & 4,50 & 13,00 & 0,10 & 28,52 & 31,17 \\
\hline Agu-L1 & lito & 0,75 & 0,75 & 23,40 & 39,00 & 7,31 & 7,28 & 28,27 & 0,87 & 15,09 & 605,01 & 3,62 & 5,04 & 22,27 & 2,81 & 8,25 & 6,50 & 14,75 & 0,09 & 27,18 & 29,84 \\
\hline Agu-L2 & lito & 0,75 & 0,75 & 23,45 & 39,00 & 7,33 & 7,15 & 7,49 & 0,41 & 16,65 & 614,80 & 6,98 & 5,63 & 21,29 & 4,78 & 10,00 & 5,50 & 15,50 & 0,12 & 31,30 & 33,92 \\
\hline Agu-L3 & lito & 0,75 & 0,75 & 24,65 & 39,00 & 7,83 & 7,44 & 7,02 & 0,24 & 14,32 & 539,13 & 15,54 & 4,16 & 19,99 & 4,90 & 8,25 & 4,75 & 13,00 & 0,10 & 34,17 & 36,81 \\
\hline ACl-P1 & $\lim$ & 7,50 & 1,80 & 23,41 & 40,07 & 5,81 & 6,38 & 8,90 & 0,41 & 59,40 & 480,42 & 1,48 & 1,23 & 13,46 & 2,70 & 3,67 & 3,17 & 6,83 & 0,12 & 21,61 & 24,23 \\
\hline ACl-P2 & $\lim$ & 8,00 & 1,90 & 23,39 & 40,00 & 7,03 & 6,39 & 16,46 & 1,32 & 63,29 & 442,59 & 10,95 & 9,15 & 12,48 & 2,82 & 5,00 & 2,33 & 7,33 & 0,12 & 30,87 & 33,50 \\
\hline ACl-L1 & lito & 1,25 & 1,25 & 25,43 & 40,00 & 7,03 & 6,94 & 21,18 & 0,87 & 42,30 & 91 & 4,54 & 3,58 & 14,11 & 2,38 & 4,33 & 3,83 & 8,17 & 0,10 & 26,61 & 29,26 \\
\hline ACl-L2 & lito & 1,25 & 1,25 & 24,97 & 40,00 & 7,30 & 6,83 & 15,52 & 0,93 & 37,64 & 520,87 & 4,54 & 3,87 & 13,14 & 2,53 & 3,83 & 4,33 & 8,17 & 0,08 & 25,53 & 28,18 \\
\hline ACl-L3 & lito & 1,25 & 1,25 & 23,93 & 40,00 & 7,46 & 6,91 & 9,85 & 0,53 & 39,97 & 439,33 & 3,01 & 1,82 & 13,46 & 2,73 & 4,33 & 3,83 & 8,17 & 0,12 & 25,02 & 27,65 \\
\hline Ari-P1 & $\lim$ & 5,50 & 1,20 & 22,93 & 26,91 & 7,69 & 6,87 & 11,74 & 0,87 & 6,54 & 618,06 & 3,01 & 2,70 & 40,54 & 3,42 & 7,67 & 1,17 & 8,83 & 0,09 & 29,32 & 31,97 \\
\hline Ari-L1 & lito & 0,75 & 0,75 & 24,20 & 26,50 & 7,67 & 6,94 & 13,15 & 2,80 & 12,76 & 578,27 & 14,93 & 12,37 & 17,70 & 2,44 & 4,25 & 4,67 & 8,92 & 0,07 & 32,22 & 34,89 \\
\hline Ari-L2 & lito & 0,75 & 0,75 & 22,95 & 26,00 & 7,43 & 6,91 & 8,90 & 0,58 & 11,99 & 617,41 & 4,23 & 1,23 & 21,62 & 3,36 & 14,17 & 2,67 & 16,83 & 0,04 & 25,58 & 28,28 \\
\hline Ari-L3 & lito & 0,75 & 0,75 & 23,80 & 27,00 & 7,58 & 6,85 & 7,96 & 0,58 & 9,65 & 530,00 & 1,79 & 0,94 & 17,05 & 2,72 & 6,50 & 3,33 & 9,83 & 0,05 & 20,93 & 23,62 \\
\hline Ama-P1 & $\lim$ & 2,25 & 1,20 & 19,54 & 61,00 & 3,55 & 6,51 & 8,90 & 2,06 & 64,07 & 415,84 & 7,90 & 2,70 & 20,97 & 5,21 & 3,80 & 3,80 & 7,60 & 0,03 & 27,47 & 30,20 \\
\hline Ama-L1 & lito & 1,25 & 1,25 & 21,47 & 56,67 & 5,13 & 6,28 & 11,27 & 2,63 & 58,63 & 322,57 & 3,62 & 4,16 & 15,75 & 5,73 & 1,50 & 3,60 & 5,10 & 0,04 & 22,61 & 25,33 \\
\hline
\end{tabular}


MATRIZ DAS VARIÁVEIS LIMNOLÓGICAS PARA A ANÁLISE DE COMPONENTES PRINCIPAIS - PERÍODO DE VERÃO (FEVEREIRO DE 2000)

\begin{tabular}{|c|c|c|c|c|c|c|c|c|c|c|c|c|c|c|c|c|c|c|c|c|c|}
\hline \multicolumn{22}{|c|}{ MATRIZ DAS VARIÁVEIS LIMNOLÓGICAS PARA A ANÁLISE DE COMPONENTES PRINCIPAIS - PERÍODO DE VERÃO (FEVEREIRO DE 2000) } \\
\hline Pontos & Habitat & Prof & Transp & Temp & Cond & OxiDiss & $\mathrm{pH}$ & Nitrato & Nitrito & Amônio & Nitro Tot & FDT & FI & FT & Silicato & Mat Org & Mat Inorg & Mat Susp & Clorofila & ietCar & ietSalas \\
\hline Car-P1 & $\lim$ & 9,50 & 1,80 & 27,03 & 22,58 & 3,65 & 5,73 & 9,38 & 1,01 & 874,07 & 1222,09 & 3,01 & 1,52 & 43,15 & 1,89 & 7,25 & 10,75 & 18,00 & 5,87 & 43,62 & 45,97 \\
\hline Car-L1 & lito & 0,75 & 0,75 & 30,75 & 23,00 & 7,09 & 6,72 & 10,08 & 0,70 & 39,19 & 441,28 & 7,13 & 5,63 & 15,42 & 2,98 & 5,80 & 5,80 & 11,60 & 2,51 & 39,98 & 42,39 \\
\hline Car-L2 & lito & 0,75 & 0,75 & 30,35 & 23,00 & 6,50 & 6,60 & 10,08 & 1,10 & 9,09 & 389,10 & 9,12 & 7,09 & 17,05 & 3,08 & 4,40 & 6,60 & 11,00 & 3,15 & 42,41 & 44,80 \\
\hline Car-L3 & lito & 0,75 & 0,75 & 30,70 & 23,00 & 6,42 & 6,74 & 11,03 & 1,27 & 19,76 & 379,32 & 7,13 & 5,77 & 13,14 & 2,96 & 4,40 & 5,20 & 9,60 & 2,53 & 39,24 & 41,65 \\
\hline Agu-P1 & $\lim$ & 4,50 & 1,10 & 29,09 & 38,22 & 6,44 & 6,40 & 8,20 & 1,58 & 28,70 & 348,01 & 9,89 & 7,09 & 23,58 & 4,91 & 7,80 & 8,40 & 16,20 & 2,98 & 44,17 & 46,57 \\
\hline Agu-P2 & $\lim$ & 5,00 & 1,50 & 28,98 & 38,10 & 6,21 & 6,46 & 7,49 & 1,10 & 29,86 & 341,48 & 11,26 & 6,36 & 21,29 & 5,26 & 5,60 & 8,00 & 13,60 & 2,91 & 44,22 & 46,62 \\
\hline Agu-P3 & $\lim$ & 4,50 & 1,10 & 28,93 & 38,00 & 7,02 & 6,22 & 8,90 & 2,57 & 22,09 & 383,23 & 15,69 & 13,69 & 34,01 & 5,24 & 6,60 & 7,20 & 13,80 & 2,90 & 48,06 & 50,46 \\
\hline Agu-L1 & lito & 0,75 & 0,75 & 29,20 & 38,00 & 5,97 & 6,70 & 8,43 & 2,46 & 30,64 & 34 & 16,00 & 10,90 & 26,84 & 5,23 & 6,60 & 7,00 & 13,60 & 2,69 & 46,76 & 49,17 \\
\hline Agu-L2 & lito & 0,75 & 0,75 & 29,40 & 38,00 & 7,11 & 7,08 & 9,85 & 1,66 & 22,09 & & 14,01 & 11,49 & 28,47 & 4,41 & 6,00 & 6,60 & 12,60 & 2,75 & 46,49 & 48,89 \\
\hline Agu-L3 & lito & 0,75 & 0,75 & 29,20 & 37,50 & 6,99 & 6,99 & 9,14 & 2,46 & 24,42 & 348,66 & 12,48 & 12,08 & 28,14 & 5,11 & 4,80 & 7,80 & 12,60 & 2,81 & 45,94 & 48,35 \\
\hline ACl-P1 & $\lim$ & 7,50 & 3,10 & 29,10 & 34,36 & 6,01 & 6,16 & 10,79 & 1,86 & 55,52 & 481,07 & 6,98 & 6,07 & 15,09 & 2,16 & 3,1 & 5,38 & 8,50 & 2,93 & 40,29 & 42,69 \\
\hline ACl-P2 & $\lim$ & 8,00 & 3,10 & 28,97 & 34,36 & 5,70 & 6,26 & 9,38 & 1,01 & 25,98 & 376,71 & 6,37 & 5,92 & 12,48 & 2,46 & 1,38 & 2,38 & 3,75 & 4,21 & 40,15 & 42,52 \\
\hline ACl-L1 & lito & 1,25 & 1,25 & 29,47 & 35,67 & 6,53 & 7,32 & 11,74 & 1,61 & 18,59 & 282,78 & 6,68 & 5,63 & 9,55 & 1,87 & 4,38 & 4,13 & 8,50 & 2,90 & 37,85 & 40,25 \\
\hline ACl-L2 & lito & 1,25 & 1,25 & 29,40 & 35,33 & 6,87 & 7,00 & 16,22 & 1,38 & 39,19 & & 6,68 & 5,63 & 10,53 & 2,64 & 1,38 & 4,50 & 5,88 & 2,51 & 37,84 & 40,24 \\
\hline ACl-L3 & lito & 1,25 & 1,25 & 29,47 & 34,00 & 7,04 & 7,17 & & 1,21 & 30,25 & & 6,37 & 4,45 & 8,89 & 2,69 & 1,62 & 4,13 & 5,75 & 2,53 & 36,82 & 39,23 \\
\hline Ari-P1 & $\lim$ & 5,50 & 1,60 & 28,84 & 23,09 & & 6,49 & 10,08 & 2,23 & 34,53 & & 9,73 & 9,59 & 21,29 & 3,18 & 3,3 & 6,33 & 9,67 & 2,7 & 43,34 & 45,74 \\
\hline Ari-L1 & lito & 0,75 & 0,75 & 28,95 & 23,50 & 6,58 & 7,02 & & 1,63 & 34,92 & & 10,19 & 7,97 & 21,29 & 3,86 & 4,8 & 5,50 & 10,33 & 2,98 & 43,83 & 46,23 \\
\hline Ari-L2 & lito & 0,75 & 0,75 & 28,80 & 23,00 & 7,16 & 6,93 & 7,25 & 0,73 & 26,75 & 209,72 & 7,90 & 5,33 & 21,94 & 2,82 & 5,83 & 6,17 & 12,00 & 2,91 & 42,66 & 45,06 \\
\hline Ari-L3 & lito & 0,75 & 0,75 & 28,60 & 23,50 & 7,08 & 7,02 & 9,38 & 1,15 & 31,03 & 468,03 & 8,66 & 6,51 & 22,27 & 3,19 & 6,67 & 7,33 & 14,00 & 3,74 & 44,02 & 46,40 \\
\hline Ama-P1 & $\lim$ & 2,25 & 1,30 & 26,32 & 61,33 & 2,67 & 6,16 & 10,08 & 2,03 & 24,03 & 203,20 & 13,70 & 6,80 & 26,51 & 4,73 & 3,12 & 5,87 & 9,00 & 2,63 & 45,88 & 48,29 \\
\hline Ama-L1 & lito & 1,25 & 1,25 & 18,97 & 62,00 & 3,35 & 6,37 & 8,90 & 1,27 & 26,75 & 232,55 & 12,02 & 6,36 & 26,84 & 4,32 & 3,88 & 4,87 & 8,75 & 2,31 & 44,89 & 47,30 \\
\hline
\end{tabular}

